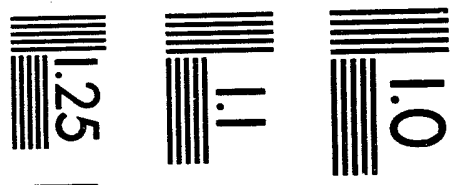

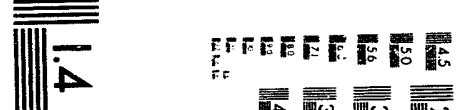

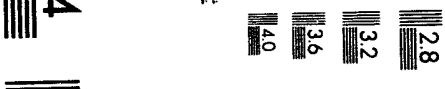

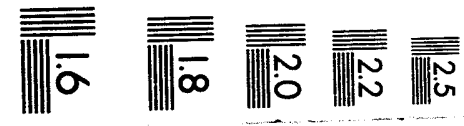



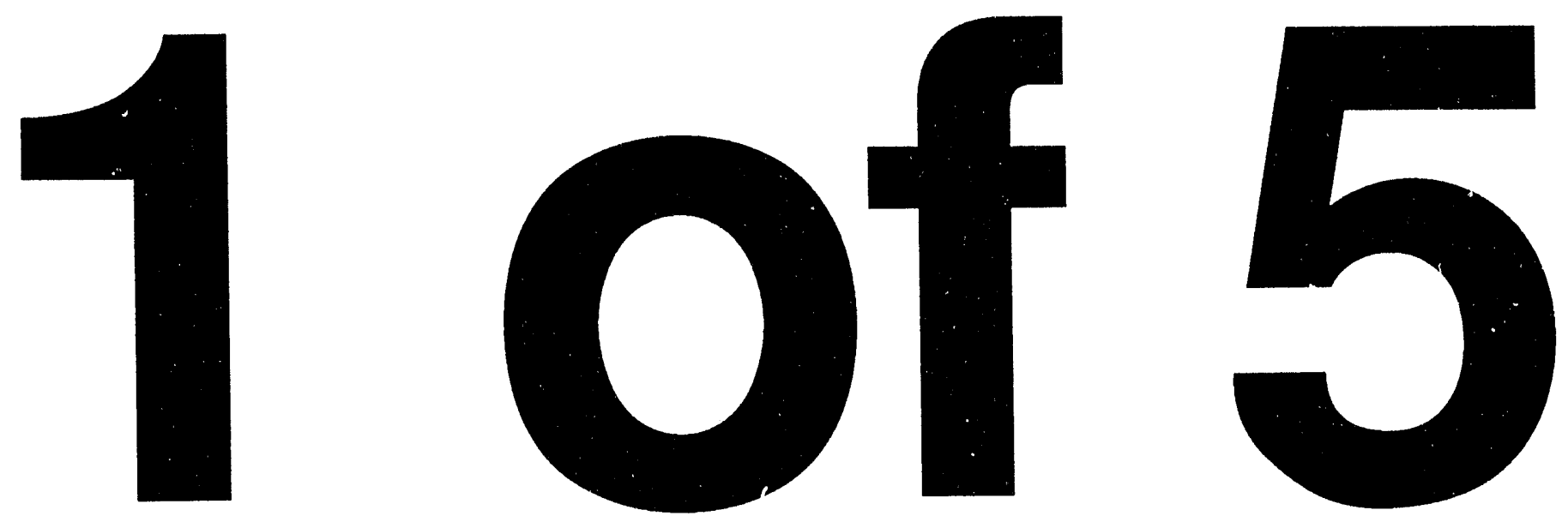


\section{Low-Rank Coal Research}

\section{Task 5.1}

\section{Topical Report \\ April 1986 - December 1992}

February 1993

Work Performed Under Contract No.: DE-FC21-86MC10637

For

U.S. Department of Energy

Office of Fossil Energy

Morgantown Energy Technology Center

Morgantown, West Virginia

By

University of North Dakota

Energy and Environmental Research Center

Grand Forks, North Dakota 


\section{DISCLAIMER}

This report was prepared as an account of work sponsored by an agency of the United States Government. Neither the United States Government nor any agency thereof, nor any of their employees, makes any warranty, express or implied, or assumes any legal liability or responsibility for the accuracy, completeness, or usefulness of any information, apparatus, product, or process disclosed, or represents that its use would not infringe privately owned rights. Reference herein to any specific commercial product, process, or service by trade name, trademark, manufacturer, or otherwise does not necessarily constitute or imply its endorsement, recommendation, or favoring by the United States Government or any agency thereof. The views and opinions of authors expressed herein do not necessarily state or reflect those of the United States Government or any agency thereof.

This report has been reproduced directly from the best available copy.

Available to DOE and DOE contractors from the Office of Scientific and Technical Information, 175 Oak Ridge Tumpike, Oak Ridge, TN 37831; prices available at (615) 576-8401.

Available to the public from the National Technical Information Service, U.S. Department of Commerce, 5285 Port Royal Road, Springfield, VA 22161; phone orders accepted at (703) 487-4650. 
TABLE OF CONTENTS

\subsection{TABLE OF CONTENTS}

2.0 CONTROL TECHNOLOGY AND COAL PREPARATION RESEARCH

2.1 Flue Gas Cleanup

2.2 Waste Management

2.3 Regional Energy Policy Program for the Northern Great Plains

2.4 Hot-Gas Cleanup

\subsection{ADVANCED RESEARCH AND TECHNOLOGY DEVELOPMENT}

3.1 Turbine Combustion Phenomena

3.2 Combustion Inorganic Transformation

3.3 (Combined with Section 3.2 in Year 4)

3.4 Liquefaction Reactivity of Low-Rank Coals

3.5 Gasification Ash and Slag Characterization

3.6 Coal Science

\subsection{COMBUSTION RESEARCH}

4.1 Atmospheric Fluidized-Bed Combustion

4.2 Beneficiation of Low-Rank Coals

4.3 Combustion Characterization of Low-Rank Fuels (COMPLETED 10-31-90)

4.4 Diesel Utilization of Low-Rank Coals (COMPLETED 12-31-90)

4.5 Produce and Characterize HWD Fuels for Heat Engine Applications (COMPLETED 10-31-90)

4.6 Nitrous Oxide Emissions

4.7 Pressurized Fluidized-Bed Combustion

\subsection{LIQUEFACTION RESEARCH}

5.1 Low-Rank Coal Direct Liquefaction

\subsection{GASIFICATION RESEARCH}

6.1 Production of Hydrogen and By-Products from Coals

6.2 Sulfur Forms in Coal 
2.0 CONTROL TECHNOLOGY AND COAL PREPARATION RESEARCH 
2.1 Flue Gas Cleanup 


\section{FLUE GAS CLEANUP}

Final Technical Progress Report

for the Period April 1, 1986, through December 31, 1992

by

Marlys K. Heidt, Research Engineer Stanley J. Miller, Research Supervisor

Greg F. Weber, Research Supervisor and Dennis L. Laudal, Research Engineer

Energy and Environmental Research Center University of North Dakota Box 8213, University Station Grand Forks, North Dakota 58202-8213

for

Task Contracting Officer's Representative: Dr. Perry D. Bergman

U.S. Department of Energy

Pittsburgh Energy Technology Center

P.0. Box 10940, MS 922-H

Pittsburgh, Pennsylvania 15236-0940

December 1992

Work Performed under Cooperative Agreement No. DE-FC21-86MC10637 


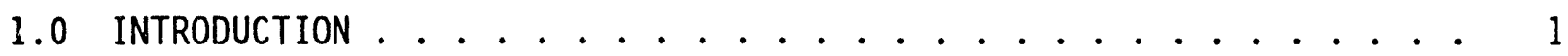

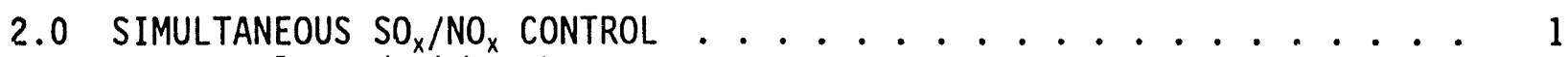

2.1 Goals and Objectives ................ 2

2.2 Accomplishments ............... 2

2.2.1 Task A. Sorbent Evaluation ......... 2

2.2.2 Task B. Enhanced Sorbent Reactivity/Utilization ... . 4

2.2 .3 Task C. Combustion System Operability....... 5

2.2 .4 Task $\mathrm{D}$. $\mathrm{NO} \rightarrow \mathrm{NO}_{2}$ Conversion ........... 6

2.2 .5 Task E. Process Economics ........... 7

3.0 CATALYTIC FABRIC FILTRATION FOR SIMULTANEOUS NO $0_{x}$ AND PARTICULATE

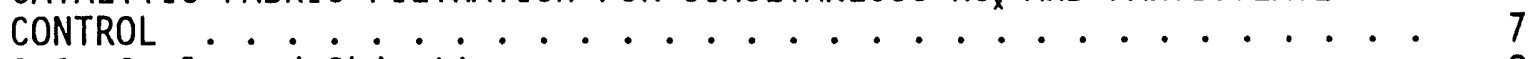
3.1 Goals and objectives ............... 8

3.2 Accomplishments ............... 9

3.2.1 Task A. Catalyst/Fabric Development . . . . . . . 9

3.2 .2 Task B. Fabric Screening Tests .......... 11

4.0 FINE PARTICULATE EMISSIONS/CONTROL . . . . . . . . . . . 12

4.1 Goals and objectives .................... 13

4.2 Accomplishments . . . . . . . . . . . . . . . 14

5.0 IMPACT OF COAL COMBUSTION ON ATMOSPHERIC VISIBILITY/SUMMARY

OF LITERATURE REVIEW ON ATMOSPHERIC VISIBILITY . . . . . . . . . 17

6.0 PUBLICATIONS AND PRESENTATIONS . . . . . . . . . . . 19

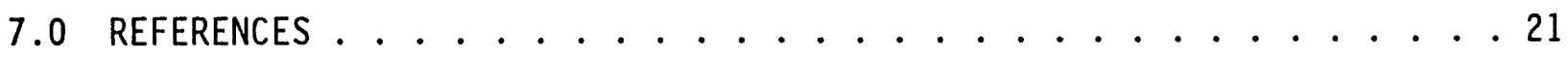




\section{FLUE GAS CLEANUP}

\subsection{INTRODUCTION}

The objective of the Department of Energy's (DOE) Flue Gas Cleanup Program, under the direction of the Pittsburgh Energy Technology Center (PETC), is to promote the widespread use of coal by providing the technology necessary for utilization of coal in an environmentally and economically acceptable manner. The program addresses the reduction of acid rain precursor emissions as well as developing technologies with the potential to meet more stringent emissions control requirements for $\mathrm{SO}_{2}, \mathrm{NO}_{x}$, and particulate matter. Activities within the Energy and Environmental Research Center's (EERC) Cooperative Agreement Flue Gas Cleanup project have addressed control of all three of these pollutants over the last six years.

Initially, the Cooperative Agreement included separate projects in fine particulate emissions and simultaneous $\mathrm{SO}_{2} / \mathrm{NO}_{x}$ control. The projects were later combined into a single project called Flue Gas Cleanup, which included work in $\mathrm{NO}_{\mathrm{x}}$ control and fine particulate control.

From April 1983 through March 1988, the focus of the Cooperative Agreement $\mathrm{SO}_{\mathrm{x}} / \mathrm{NO}_{\mathrm{x}}$ Control project was investigation of dry sorbent injection for $\mathrm{SO}_{\mathrm{x}}$ control and methods of enhancing $\mathrm{SO}_{\mathrm{x}}$ sorbent reactivity/utilization. The primary emphasis was furnace injection of calcium-based sorbents with some experiments evaluating back-end humidification $(1,2)$. In April 1988, the emphasis of the project was changed to advanced $\mathrm{NO}_{\mathrm{x}}$ control to evaluate the potential of a catalytic fabric filter for simultaneous $\mathrm{NO}_{\mathrm{x}}$ and particulate control.

In June 1989, the project name was changed to Flue Gas Cleanup, and the scope of project activities was expanded to include tasks supporting benchscale work in the fine particulate control area. Work in the fine particulate control area was included as a separate project within the Cooperative Agreement from April 1983 through March 1988 and was also funded as a result of a competitive DOE award during the period May 1988 through December 1989.

In March 1990, the EERC at the University of North Dakota was notified that a proposal entitled "Catalytic Fabric Filtration for Simultaneous $\mathrm{NO}_{\mathrm{x}}$ and Particulate Control," which was submitted to DOE/PETC, was selected for funding. Therefore, further catalytic fabric filter development activities were discontinued under the Cooperative Agreement Flue Gas Cleanup project in July 1991. A task was added in the last year of the Cooperative Agreement to assess the effect of coal combustion on visibility impairment in the

atmosphere. Therefore, in the last year of the Cooperative Agreement the Flue Gas Cleanup project focused on the visibility study and on bench-scale efforts to investigate the relationships between fine particle emissions from fabric filters and the cohesive properties of fly ash.

\subsection{SIMULTANEOUS $\mathrm{SO}_{\mathrm{x}} / \mathrm{NO}_{\mathrm{x}}$ CONTROL}

Earlier pilot and field tests demonstrated the potential to control $\mathrm{SO}_{2}$ by direct furnace injection of calcium-based sorbents (3-12). However, development of furnace injection of pressure-hydrated lime as a viable 
technique for $\mathrm{SO}_{2}$ control required evaluation of several issues, including optimization of sorbent reactivity and investigation of the potential for additives and sorbent recycle to increase sorbent reactivity/utilization. In addition, the effect of furnace sorbent injection and ash/sorbent interactions on sorbent reactivity, rate of ash deposition, deposit strength, particulate collection device performance, and boiler operability required further study.

\subsection{Goals and Objectives}

The overall objective of the $\mathrm{SO}_{x} / \mathrm{NO}_{x}$ Control project was to expand the scientific and engineering database necessary for the development of innovative processes for the control of $\mathrm{SO}_{x}$ emissions during coal combustion. Dry sorbent injection for $\mathrm{SO}_{\mathrm{x}}$ control and methods of enhancing $\mathrm{SO}_{\mathrm{x}}$ sorbent reactivity/utilization were investigated. The study addressed factors impacting both sorbent reactivity and operability of the combustion system for new and retrofit applications. Specific factors addressed included 1) sorbent properties, 2) sorbent processing conditions, 3) impact of sorbent injection on boiler performance, and 4) operability of the particulate control device.

The $\mathrm{SO}_{\mathrm{x}} / \mathrm{NO}_{\mathrm{x}}$ Control project was organized into the following tasks to meet the project objectives: Task A, Sorbent Evaluation; Task B, Enhanced Sorbent Reactivity/Utilization; Task $C$, Combustion System Operability; Task $D$, $\mathrm{NO} \rightarrow \mathrm{NO}_{2}$ Conversion; and Task E, Process Economics. Detailed summaries of the work completed under the $\mathrm{SO}_{\mathrm{x}} / \mathrm{NO}_{\mathrm{x}}$ Control project were presented in the Final Technical Reports for the periods April 1, 1986, through March 31, 1987 , and Apri1 1, 1987, through March 31, $1988(1,2)$.

\subsection{Accomplishments}

\subsubsection{Task A. Sorbent Evaluation}

The purpose of Task $A$ was to identify and quantify the effects of sorbent processing on the reactivity of commercial high-calcium sorbents. Sorbent processing includes the calcination and hydration conditions that result in a hydrated lime (calcium hydroxide) product. The sorbent reactivity of pressure hydrates has been shown to equal or surpass that of commercial slaked hydrates. Although processing conditions can lead to changes in the physical properties of a sorbent, the final criterion for determining improved reactivity is the actual performance of a sorbent in controlling $\mathrm{SO}_{2}$ emissions.

A literature review was conducted to address sorbent characteristics with respect to flue gas desulfurization (FGD) processes with emphasis on furnace injection technology. The literature review showed that limestone properties have been extensively characterized for fluid-bed combustion applications as well as for conventional FGD processes. Comprehensive information on lime and hydrated lime was limited with respect to furnace sorbent injection technology and FGD processes in general.

Based on the results of the literature review, four commercial limestones and their respective calcination and atmospheric hydration products were selected for pilot-scale furnace injection tests. The four materials were Marblehead limestone from the Marblehead Lime Company in Illinois; Longview limestone from the Dravo Lime Company in Alabama; Round Rock 
1imestone, from the Round Rock Division of the Dravo Lime Company in Titus County, Texas; and Mercer Timestone from the Mercer Lime Company in Michigan. Sufficient quantities of the commercial preparations of 1 imestone, lime, and atmospheric hydrate were acquired from each supplier to perform calcination, pressure-hydration, and sorbent-reactivity tests. Pilot-scale furnace injection tests and chemical and physical analyses were performed to establish baseline characteristics for the commercial sorbents. The commercial sorbents, experimental calcines, pressure-hydrated calcines, and pressure hydrates produced from the commercial limes were evaluated in the Particulate Test Combustor (PTC) fired on natural gas with anhydrous $\mathrm{SO}_{2}$ and ammonia injected to produce $\sim 1000-\mathrm{ppm} \mathrm{SO}$ and $700-\mathrm{ppm} \mathrm{NO}$ in the flue gas. The sorbents were pneumatically injected into the combustor at a point where the bulk gas temperature was $1825^{\circ} \mathrm{F}$. Sorbent reactivity was determined by $\mathrm{SO}_{2}$ reduction and sorbent utilization.

Experimental results from the furnace injection tests showed that the commercial hydrate resulted in better sorbent utilization than the limestone or lime for all the commercial sorbent materials. At $\mathrm{Ca} / \mathrm{SO}_{2}$ molar ratios of 1.0, utilization values for the Marblehead hydrate, limestone, and lime were $27 \%, 17 \%$, and $12 \%$, respectively. Pressure hydrates produced using the Marblehead lime resulted in utilization values of about $35 \%$ at a $\mathrm{Ca} / \mathrm{SO}_{2}$ molar ratio of 1.0. Results with the Longview materials were somewhat different. Uti?ization values for the commercial hydrate and pressure hydrate were similar, $27 \%$ at a $\mathrm{Ca} / \mathrm{SO}_{2}$ molar ratio of 1.0 . Limestone and lime also exhibited similar results with utilization values of $15 \%$ observed at a $\mathrm{Ca} / \mathrm{SO}_{2}$ molar ratio of 1.0 .

At a $\mathrm{Ca} / \mathrm{SO}_{2}$ molar ratio of 1.5 , utilization values for the Round Rock hydrate, 1 imestone, and 1 ime were $24 \%, 13 \%$, and $11 \%$, respectively. Pressure hydrates produced using the Round Rock lime resulted in utilization values of approximately $24 \%$ at a $\mathrm{Ca} / \mathrm{SO}_{2}$ molar ratio of 1.5 . Itilization values for the Mercer commercial hydrate, limestone, and 1 ime were $28 \%, 15 \%$, and $15 \%$, respectively, at a $\mathrm{Ca} / \mathrm{SO}_{2}$ molar ratio of about 1.5 . At a comparable $\mathrm{Ca} / \mathrm{SO}_{2}$ molar ratio, the utilization values for the pressure hydrate prepared with the Mercer lime ranged from $30 \%$ to $35 \%$.

Pressure-hydrated limes produced in the bench-scale pressure hydrator using Marblehead and Mercer 1 imes were better sorbents for $\mathrm{SO}_{2}$ reduction than the commercial Marblehead and Mercer hydrates, respectively, and far better than the corresponding limestones or limes. Utilization values for the Marblehead pressure hydrate, commercial hydrate, limestone, and 1 ime were $35 \%$, $27 \%, 17 \%$, and $12 \%$, respectively, when injected into a pilot-scale combustor at $1825^{\circ} \mathrm{F}$ and a $\mathrm{Ca} / \mathrm{SO}_{2}$ molar ratio of 1.0 . Utilization values for the Mercer pressure hydrate, commercial hydrate, limestone, and 1 ime were $33 \%, 28 \%, 15 \%$, and $15 \%$, respectively, in pilot-scale furnace injection tests at a $\mathrm{Ca} / \mathrm{SO}_{2}$ molar ratio of 1.5 .

Pressure-hydrated limes produced in a bench-scale pressure hydrator using Longview and Round Rock limes resulted in sorbent utilization values similar to those observed with commercial Longview and Round Rock hydrates, respectively. However, both the commercial and pressure-hydrated limes were better sorbents for $\mathrm{SO}_{2}$ reduction than the corresponding 1 imestones or 1 imes. Utilization values for the Longview hydrates, limestone, and 1 ime were $27 \%$, $14 \%$, and $11 \%$, respectively, in pilot-scale furnace injection tests at a $\mathrm{Ca} / \mathrm{SO}_{2}$ molar ratio of 1.0. Utilization values for the Round Rock hydrates, 
1 imestone, and 1 ime were $24 \%, 13 \%$, and $11 \%$, respectively, when injected into a pilot-scale combustor at $1825^{\circ} \mathrm{F}$ and a $\mathrm{Ca} / \mathrm{SO}_{2}$ molar ratio of 1.5 .

Pressure-hydration experiments were performed to evaluate the effect of pressure and water stoichiometry on the reactivity of Marblehead and Longview pressure hydrates. Hydration pressures ranging from $50 \mathrm{psig}$ to $180 \mathrm{psig}$ and water stoichiometries ranging from 1.0 to 1.6 were evaluated. Results from $2 \times 2$ factorial design experiments showed that hydration pressure and water stoichiometry were not statistically significant with respect to sorbent utilization for either the Marblehead or Longview pressure hydrates, as determined by pilot-scale furnace injection tests.

Marblehead and Longview limestones were calcined at $1850^{\circ}, 2000^{\circ}$, and $2150^{\circ} \mathrm{F}$ in a muffle furnace. The Round Rock and Mercer Timestones were calcined at $1800^{\circ}, 2000^{\circ}$, and $2150^{\circ} \mathrm{F}$. The resulting calcines showed decreasing surface area with increasing calcination temperature. Sorbent injection tests showed that utilization values for the calcines decreased with increasing temperature for all the limestones. Pressure hydrates prepared from Marblehead and Longview calcines produced at $2000^{\circ} \mathrm{F}$ demonstrated better utilization than pressure hydrates prepared from calcines produced at $1850^{\circ}$ and $2150^{\circ} \mathrm{F}$. Pressure hydrates prepared from Round Rock and Mercer calcines produced at $1800^{\circ} \mathrm{F}$ demonstrated better utilization than pressure hydrates prepared from calcines produced at $2000^{\circ}$ and $2150^{\circ} \mathrm{F}$.

\subsubsection{Task B. Enhanced Sorbent Reactivity/Utilization}

Increased sorbent reactivity decreases the amount of sorbent necessary to achieve a specific level of $\mathrm{SO}_{2}$ control. In addition, reduced sorbent requirements should result in reduced combustion system impacts and lower operating costs, thus improving the economics of furnace injection technology. The use of additives and sorbent recycle have the potential to increase overall sorbent utilization. The objective of Task B, Enhanced Sorbent Reactivity/Utilization, was to determine the effect of selected additives on sorbent reactivity.

Six additives to improve the sorbent reactivity/utilization of calciumbased sorbents were evaluated using commercial Marblehead lime as the base sorbent. The additives included $10 \%$ aqueous solutions (by weight) of $\mathrm{NaOH}$, $\mathrm{NaHCO}_{3}, \mathrm{NaSiO}_{3}, \mathrm{CaCl}_{2}$, and acetic acid, and a $25 \%$ solution of ethanol. The $\mathrm{NaSiO}_{3}$ solution was actually a saturated mixture of $\mathrm{NaSiO}_{2}$ in water that wa: weighed as $10 \%$ of the final mixture. The aqueous solutions were used to hydrate the Marblehead 1 ime using $40 \%$ excess water under both atmospheric and pressure-hydration conditions. Sodium-based additives were previously identified as improving the utilization of calcium-based hydrates and, therefore, they were included as a basis for comparison with previous work $(13-15)$.

Although the atmospheric hydrates appeared to result in slightly higher utilization than the pressure hydrates in furnace injection tests, the difference was not significant when the standard deviation for the data was considered. Overall, the additives had very little effect on sorbent utilization when compared to the utilization values typically observed for Marblehead pressure hydrate. 


\subsubsection{Task C. Combustion System Operability}

The application of dry scrubbing techniques and specifically furnace injection technology in a commercial boiler is contingent on the overall performance of the combustion system. Introducing a sorbent into the system increases the ash loading which affects ash deposition rate, and also places additional stress on particulate control devices. Pilot-scale combustion tests were performed to characterize the operability of various coal/sorbent combinations. The coals were selected on the basis of marketability, geographical location, rank, and previous use in other furnace injection programs. High-calcium pressure-rydrated 1 ime was prepared in the EERC benchscale pressure hydrator.

The impact of furnace sorbent injection on ash deposition, electrostatic precipitator (ESP) performance, and baghouse performance was evaluated in pilot-scale combustion tests using 111 inois No. 6 bituminous coal/Marblehead pressure-hydrate, Monticello, Texas, 1ignite/Round Rock pressure hydrate; and Pittsburgh No. 8 bituminous coal/Mercer pressure hydrate fuel/sorbent combinations. Each coal was fired in the ash-fouling combustor to evaluate fouling potential, sorbent utilization, and ESP efficiency. One test was conducted with each coal without sorbent injection to establish baseline characteristics. Two additional tests were performed with sorbent injection, with targeted $\mathrm{SO}_{2}$ reductions of $50 \%$ and $90 \%$, representing $\mathrm{SO}_{2}$ control levels (prior to the 1990 Clean Air Act Amendments) for retrofit and new installations, respectively. The same test matrix was also performed using the PTC, with emphasis placed on sorbent utilization, particulate characterization, and ESP or baghouse performance.

Ninety percent $\mathrm{SO}_{2}$ control was not achieved during tests with Illinois No. 6/Marblehead pressure hydrate due to sorbent feeder limitations. After the Illinois No. 6 tests, the sorbent feed syscem was modified to allow higher sorbent feed rates for tests with high-sulfur coal and/or inferior sorbent materials. $\mathrm{A} \mathrm{Ca} / \mathrm{SO}_{2}$ molar ratio of 1.2 was necessary to achieve $50 \% \mathrm{SO}_{2}$ control, and $75 \% \mathrm{SO}_{2}$ was achieved at a $\mathrm{Ca} / \mathrm{SO}_{2}$ molar ratio of 2.2 . ESP performance decreased substantially with increased sorbent addition. Particulate collection efficiency decreased from $96 \%$ to $67 \%$ as sorbent injection increased particulate loadings at the ESP inlet from 1.6 to 6.5 grains/scf. Correspondingly, bulk ash resistivity increased from $10^{12}$ to $10^{14} \mathrm{ohm}-\mathrm{cm}$. Although sorbent injection increased deposition rate during ash-fouling tests with the Illinois No. 6 coal and the Marblehead pressurehydrated lime, probe deposits continuously sloughed off the probes indicating that the deposits were weak and could be easily removed with conventional soot-blowing equipment.

For the Monticello lignite/Round Rock pressure hydrate fuel/sorbent combination, a $\mathrm{Ca} / \mathrm{SO}_{2}$ molar ratio of 2.1 to 2.3 was necessary to achieve $50 \%$ $\mathrm{SO}_{2}$ control, and a ratio of approximately 4.8 was required for $90 \% \mathrm{SO}_{2}$ control. The high ash loading due to fuel ash content and sorbent injection resulted in high convective pass deposition rates, but the deposits were friable and of the type that would be easily removable with frequent operation of conventional soot-blowing equipment. ESP performance decreased substantially with increased sorbent addition. Particulate collection efficiency decreased from $95 \%$ to $68 \%$ as sorbent injection increased particulate loadings at the ESP inlet from 2.6 to 4.5 grains $/ \mathrm{scf}$, and the bulk ash resistivity increased from $10^{12}$ to $10^{13} \mathrm{ohm}-\mathrm{cm}$. Particulate emissions from 
the baghouse during the PTC tests actually decreased with increasing sorbent injection, but at the expense of increased dust cake resistance and baghouse differential pressure.

For the Pittsburgh No. 8 bituminous coal/Mercer pressure hydrate fuel/sorbent combination, a $\mathrm{Ca} / \mathrm{SO}_{2}$ molar ratio of 1.0 to 1.7 was necessary to achieve $50 \% \mathrm{SO}_{2}$ control, and a $\mathrm{Ca} / \mathrm{SO}_{2}$ molar ratio of 3.0 to 4.0 was required for $90 \% \mathrm{SO}_{2}$ control. Furnace sorbent injection increased ash deposition rate to a moderate level, but the deposits were very friable, indicating that conventional soot-blowing equipment would easily control convective pass deposition. ESP performance decreased from $92 \%$ to $71 \%$ collection efficiency with increasing sorbent injection as mass loading at the ESP inlet increased from 1.9 to 9.1 grains/scf. Particulate emissions from the baghouse decreased with increasing sorbent injection, but again at the expense of increasing baghouse differential pressure. In this case, the specific dust-cake resistance decreased with increasing sorbent injection, indicating a more cohesive/porous dust cake.

Flue gas humidification experiments were performed using the pilot-scale combustion system fired using natural gas with steam as the humidification medium. In all pilot-scale combustion tests performed, flue gas humidification with steam increased sorbent utilization. Sorbent utilization increased from $30 \%$ to $50 \%$ with hydrate injection at $500^{\circ} \mathrm{F}$, and particulate collection in a baghouse operated at $190^{\circ} \mathrm{F}$ when flue gas moisture was increased from $15 \%$ to $24 \%$ by volume. Increasing sorbent residence time in the duct by injecting the hydrated 1 ime at $1250^{\circ} \mathrm{F}$ resulted in $55 \%$ sorbent utilization.

\subsubsection{Task D. $\quad \mathrm{NO} \rightarrow \mathrm{NO}_{2}$ Conversion}

Sodium-based sorbents, specifically soda ash, have been used for $\mathrm{SO}_{2}$ control in utility boiler systems using spray dryer technology. Demonstration projects have resulted in $70 \%$ to $80 \% \mathrm{SO}_{2}$ control using dry injection of nahcolite and trona upstream of a utility baghouse. However, concern developed with respect to the association of sodium-based sorbents and plume coloration due to the $\mathrm{NO}_{2}$ concentration in the stack gas. A western utility, which employed a soda ash spray dryer, experienced plume coloration due to high $\mathrm{NO}_{2}$ concentrations in the stack gas (16). A utility-scale demonstration of dry sorbent injection, using sodium-based sorbents, resulted in a brown coloration of the stack gas due to $\mathrm{NO}_{2}$ formation (17). A bench-scale fixedbed reactor study was undertaken in Task $D$ to identify the mechanisms responsible for the production of $\mathrm{NO}_{2}$ from $\mathrm{NO}$ as it pertains to gas stream cleanup processes and to develop methods to reduce/eliminate $\mathrm{NO}_{2}$ emissions.

Initially, screening tests were conducted to evaluate the effect of temperature, humidity, $\mathrm{SO}_{2}$ concentration, and $\mathrm{O}_{2}$ concentration on $\mathrm{NO}_{2}$ formation. A full factorial experimental design in four variables and two levels with 2 conditions repeated (for a total of 18 tests) was performed for each of four sorbent materials: sodium carbonate, sodium sulfite, calcium hydroxide, and calcium carbonate. The independent variables were $\mathrm{SO}_{2}$ concentration ( $0 \mathrm{ppm}$ and $3000 \mathrm{ppm}), \mathrm{O}_{2}$ concentration ( $0 \%$ and $6 \%$ by volume), $\mathrm{H}_{2} \mathrm{O}$ concentration ( $0 \%$ and $20 \%$ by volume), and temperature $\left(160^{\circ} \mathrm{F}\right.$ and $350^{\circ} \mathrm{F}$ ). Only sodiurn carbonate and calcium hydroxide produced measurable amounts of $\mathrm{NO}_{2}$. The amount of $\mathrm{NO}_{2}$ observed during the tests with calcium hydroxide was only slightly above the baseline $\mathrm{NO}_{2}$ concentration. Formation of $\mathrm{NO}_{2}$ was 
observed at 4 of the 16 test conditions using sodium carbonate. Analysis of the data showed that humidity was not statistically significant relative to the other three variables with respect to $\mathrm{NO}_{2}$ production.

A three-factorial experimental design in two levels was added to Task $D$ in order to 1) determine the most significant variable in $\mathrm{NO}_{2}$ formation, 2) replicate runs to provide additional data for analysis of variance, 3) screen additional sorbent materials, and 4) provide additional information for determining reaction mechanisms. The variables evaluated were $\mathrm{SO}_{2}$ concentration (1500 and $3000 \mathrm{ppm}$ ), $\mathrm{O}_{2}$ concentration ( $3 \%$ and $6 \%$ by volume), and temperature $\left(250^{\circ} \mathrm{F}\right.$ and $\left.350^{\circ} \mathrm{F}\right)$. Three new sorbent materials were evaluated in addition to sodium carbonate from the first experimental design: calcium sulfite, Muntana Dakota Utility (MDU) fly ash, and Colorado Power \& Light (CPL) fly ash.

Of the parameters evaluated, temperature, $\mathrm{O}_{2}$ concentration, $\mathrm{SO}_{2}$ concentration, and $\mathrm{H}_{2} \mathrm{O}$ concentration, only the effect of temperature was statistically significant at tne $90 \%$ confidence level. Oxidation of NO to $\mathrm{NO}_{2}$ increased dramatically as the reactor temperature increased from $250^{\circ} \mathrm{F}$ to $350^{\circ} \mathrm{F}$. The rate of $\mathrm{NO}_{2}$ formation increased with increased sulfation rate. Therefore, materials such as $\mathrm{Na}_{2} \mathrm{CO}_{3}$, which are highly reactive with respect to $\mathrm{SO}_{2}$ at the conditions evaluated, resulted in the formation of higher $\mathrm{NO}_{2}$ concentrations.

\subsubsection{Task E. Process Economics}

An engineering/economic evaluation comparing furnace sorbent injection with a calcium-based spray dryer system for both a retrofit ( $50 \% \mathrm{SO}_{2}$ control) and new facility $\left(90 \% \mathrm{SO}_{2}\right.$ control) was completed as part of the previous EERC/DOE Cooperative Agreement. A new economic evaluation was scheduled for completion in the third year of the Simultaneous $\mathrm{SO}_{x} / \mathrm{NO}_{x}$ Control project if substantial improvement in $\mathrm{SO}_{2}$ control or sorbent utilization was demonstrated in the first two years of the project. Improved sorbent utilization was not achieved, and it was concluded that further pilot-scale furnace injection work was unnecessary under the EERC/DOE Cooperative Agreement. Further work in the area of furnace sorbent injection would be useful only in support of sitespecific utility evaluations of the technology. Therefore, a new economic evaluation was not performed, and the focus of the $\mathrm{SO}_{\mathrm{x}} / \mathrm{NO}_{\mathrm{x}}$ Control project was redirected to advanced $\mathrm{NO}_{x}$ control.

\subsection{CATALYTIC FABRIC FILTRATION FOR SIMULTANEOUS NO AND PARTICULATE CONTROL}

In response to restrictive $\mathrm{NO}_{\mathrm{x}}$ regulations in Europe, selective catalytic reduction (SCR) technology has been installed on over 30,000 MW of full-scale utility boiler capacity as a postcombustion $\mathrm{NO}_{\mathrm{x}}$ control technique (18). Application of conventional SCR technology to coal-fired systems presents several potential problems, including plugging of the catalyst support structure by fly ash, deactivation of the catalyst by fly ash components and $\mathrm{SO}_{3}$, deposition of sulfur and ammonia by-products on air-heater surfaces, and waste product handling/reuse/disposal.

The primary difference between the catalytic filter bag developed by Owens-Corning Fiberglas Inc. (OCF) and conventional SCR technology is the catalyst support. Conventional SCR technology uses a honeycomb or plate 
support structure. The catalytic fabric is prepared by coating the surface of an S-glass (high-temperature) cloth, resulting in a catalyst bonded to the surface of the fabric. The catalytic coating consists of a combination of titanium isopropoxide and vanadium tri-n-propoxide oxide, sometimes called "sol-gel" materials. The sol-gels hydrolyze during air-drying of the coated fabric, resulting in a highly porous layer. The fabric is then cured at low temperature to drive off any residual organics and partially densify the coating. The final product is a highly porous catalytic coating strongly bonded to the surface of the glass fabric.

Initial development of the catalyst-coated woven fabrics was conducted in-house by OCF. Bench-scale evaluation of the catalytic fabrics using simulated flue gas resulted in $\mathrm{NO}_{\mathrm{x}}$ reduction as high as $90 \%$ at $660^{\circ} \mathrm{F}$ and a face velocity of $2 \mathrm{ft} / \mathrm{min}$. After several years of development, OCF contracted with the EERC to evaluate the NO reduction capability of fifteen catalytic fabrics using a slipstream of flue gas from the PTC fired with Velva North Dakota lignite. Based on the results of the initial tests, the catalytic fabric filter concept demonstrated over $90 \% \mathrm{NO}$, reduction in a flue gas stream, promising catalyst/fabric self-abrasion characteristics and the potential for substantially reduced cost when compared with conventional SCR/fabric filtration technology. Catalytic fabric filter development was discontinued in the fall of 1986 due to lack of funding.

Development of the catalytic fabric filter concept was resumed by OCF and the EERC in April 1988 under the DOE Cooperative Agreement. OCF activities were funded in-house and involved the preparation of catalytic fabric samples for testing at the EERC. The work focused on bench-scale experiments to show continuity with previous work and to screen samples of catalyst-coated fabric under both simulated and actual flue gas conditions.

\subsection{Goals and Objectives}

The overall objective of the catalytic fabric filter project was the development of a catalytic fabric filter for $\mathrm{NO}_{\mathrm{x}}$ and particulate control that will provide high removal efficiency of $\mathrm{NO}_{\mathrm{x}}$ and particulate matter, acceptably long bag and catalyst 1 ife, and an economic savings over a conventional SCR system and baghouse. The specific goal of the program was the development of a catalytic fabric filter that will provide:

- $90 \% \mathrm{NO}_{x}$ removal with <25-ppm ammonia slip.

- A particulate removal efficiency $>99.5 \%$.

- A bag/catalyst life of $>1$ year.

- A $20 \%$ cost savings over conventional baghouse and SCR control technology.

- Compatibility with $\mathrm{SO}_{2}$ removal systems.

- A nonhazardous waste material.

The Catalytic Fabric Filtration project was organized into the following tasks to meet the project objectives: Task A, Catalyst/Fabric Development; Task B, Fabric Screening Tests; Task C, Bag Evaluation and Parametric Tests; 
and Task D, Bag Durability and Process Assessment. Tasks A and B were completed as part of the Flue Gas Cleanup project under the Cooperative Agreement. Further development of the catalytic fabric filter concept with respect to bag evaluation and durability and process assessment continued with pilot-scale testing under a competitive award from DOE/PETC with commercial cost-share participants. Detailed summaries of the work completed in Tasks $A$ and $B$ were presented in the Final Technical Reports for the periods April 1 , 1988, through June 30, 1989, and July 1, 1989, through June 30, 1990, and in the Semiannual Technical Progress Report for the period January 1, 1991, through June $30,1991(19-21)$.

\subsection{Accomplishments}

\subsubsection{Task A. Catalyst/Fabric Development}

The purpose of Task $A$ was to demonstrate continuity with previous work conducted for OCF and to screen several samples of catalytic fabric in a bench-scale fabric filter system using simulated flue gas. Although promising results were obtained previously, continued bench-scale work was necessary to develop the product that would give the best combination of high $\mathrm{NO}_{\mathrm{x}}$ removal efficiency, low ammonia slip, high particulate removal efficiency, and long catalyst/bag life. The fabric weave, coating composition, and coating process were adjusted to develop fabrics for further testing. Two series of parametric experiments were completed along with screening tests to evaluate sixteen catalytic fabric samples.

A series of shakedown tests was completed with the bench-scale fabric filter system to determine system operability and repeat previous $\mathrm{NO}_{\mathrm{x}}$ reduction results. However, poor $\mathrm{NO}_{x}$ reduction was observed using three fabric samples which previously had produced good $\mathrm{NO}_{2}$ at reduction. After several more tests, catalyst aging, overheating of the catalytic fabric, and simulated versus actual flue gas were eliminated as causes of the poor $\mathrm{NO}_{\mathrm{x}}$ reduction results. Thermal decomposition products (silicon dioxide and siloxanes) from the silicone gasket material used in the fabric filter holder were eventually identified as the reason for the destruction of the $\mathrm{NO}_{\mathrm{x}}$ reduction capability of the fabrics.

After the bench-scale fabric filter holder was modified so that the silicone gasket material was no longer required to obtain a good seal, a full factorial parametric test matrix with four factors and two levels was completed using the same fabric sample for all sixteen tests. The independent variables included $\mathrm{NO}_{x}$ concentration, $\mathrm{SO}_{2}$ concentration, ammonia/ $/ \mathrm{NO}_{x}$ molar ratio, and air-to-cloth ratio. The dependent variables were $\mathrm{NO}_{\mathrm{x}}$ removal efficiency, ammonia slip, and $\mathrm{SO}_{3}$ production. The test matrix was later repeated with Fabric \#2, which had performed we 11 (94\% NO, removal and 35-ppm ammonia slip) in the fabric screening tests described later in this section. Fabric \#2 was not textured, and no undercoat was applied. It was prepared using seven coats of a $0.2-M$ solution of $V / T i$ catalyst. In addition, three center point experiments were performed to test for curvature, and one test condition was repeated four times to increase the number of degrees of freedom.

Statistical analysis of the results of the experiments showed that $\mathrm{NO}_{\mathrm{x}}$ concentration, air-to-cloth ratio, and the interaction between $\mathrm{NO}_{\mathrm{x}}$ concentration and air-to-cloth ratio had the greatest effect on $\mathrm{NO}_{\mathrm{x}}$ removal 
efficiency. At a low air-to-cloth ratio $(1.5 \mathrm{ft} / \mathrm{min})$, an increase in $\mathrm{NO}_{\mathrm{x}}$ concentration from 300 to $1000 \mathrm{ppm}$ resulted in an increase in $\mathrm{NO}_{\mathrm{x}}$ removal efficiency. When the air-to-cloth ratio was increased to $4 \mathrm{ft} / \mathrm{min}$, an increase in $\mathrm{NO}_{x}$ concentration had no effect on $\mathrm{NO}_{x}$ removal efficiency. Increasing the air-to-cloth ratio from 1.5 to $4.0 \mathrm{ft} / \mathrm{min}$ resulted in a decrease in the $\mathrm{NO}_{x}$ removal efficiency independent of $\mathrm{NO}_{\mathrm{x}}$ concentration.

The ammonia/ $\mathrm{NO}_{x}$ molar ratio, the $\mathrm{SO}_{2}$ concentration, and the interaction between the $\mathrm{NO}_{x}$ concentration and the $\mathrm{SO}_{2}$ concentration affected $\mathrm{NO}_{x}$ removal efficiency to a lesser degree. As expected, increasing the ammonia/ $\mathrm{NO}_{\mathrm{x}} \mathrm{molar}$ ratio from 0.8 to 1.1 increased the $N O_{x}$ removal. But due to the 1 imited range, the statistical significance of the effect was small. Although there was inconsistency in the data, increasing the $\mathrm{SO}_{2}$ concentration from $300 \mathrm{ppm}$ to $3000 \mathrm{ppm}$ appeared to decrease the $\mathrm{NO}_{x}$ removal efficiency.

Sixteen catalyst-coated fabric samples were evaluated at constant conditions in fabric screening experiments using the bench-scale fabric filter holder and simulated flue gas system. The tests were performed to evaluate the effect of cloth type (textured versus nontextured), fabric undercoat (none, silica/titanium, or silica/zirconium), catalyst quantity (one versus two coats of $1.0-M 25 \% \mathrm{~V}$ and $75 \% \mathrm{Ti}$ ), and catalyst composition ( $\mathrm{V} / \mathrm{Ti}, \mathrm{V} / \mathrm{Ti} / \mathrm{Al}$, $\mathrm{V} / \mathrm{Ti} / \mathrm{Zr}$, or CuO) on $\mathrm{NO}_{\mathrm{x}}$ removal and ammonia slip. Brunauer-Emmett-Teller (BET) surface area measurements were performed on all fabric samples both before and after exposure to flue gas.

Prior to initiating the fabric screening tests, the simulated flue gas system was modified to include dust injection. Fly ash was not injected continuously during the fabric screening tests. It was initiated at the beginning of each test to develop a differential pressure across the fabric sample of between 2 and 4 inches of water. Fly ash injection was discontinued when the differential pressure reached 4 inches of water to prevent problems with control of the flue gas flow rate.

Results from the fabric screening tests showed that modification of the catalyst composition by adding small amounts of alumina or zirconium refractory components to the original catalyst to expand the operating temperature range substantially reduced the catalytic reactivity of the fabrics tested. Application of a refractory undercoat to improve the abrasion resistance of the glass fabric and to possibly develop greater surface area had no effect on $\mathrm{NO}_{x}$ removal or ammonia slip.

The $\mathrm{NO}_{\mathrm{x}}$ removal efficiency and ammonia slip data did not indicate an advantage one way or another for fabric samples prepared using multiple coats of a low-concentration solution versus a single coat of a high-concentration solution. The reactivity of the catalyst-coated fabric was improved by increasing the amount of catalyst on the fabric. Increases in $\mathrm{NO}_{\mathrm{x}}$ removal efficiency and decreased ammonia slip were observed when the quantity of catalyst placed on the fabric was increased through the use of multiple coatings of the catalytic solution.

The use of a textured fabric improved the catalytic performance of the catalyst-coated fabrics tested. Fabric comparisons in one case showed an increase in $\mathrm{NO}_{\mathrm{x}}$ removal efficiency from $82 \%$ to $93 \%$ and a decrease in ammonia slip from 56 to $35 \mathrm{ppm}$. In a second case, comparison of two fabric samples that provided essentially identical $N_{x}$ removal values ( $84 \%$ versus $85 \%$ ), 
showed that ammonia slip was substantially less for the textured fabric (2 ppm versus $53 \mathrm{ppm}$ ).

\subsubsection{Task B. Fabric Screening Tests}

The purpose of Task $B$ was to evaluate eight of the best performing fabrics from Task $A$, while filtering fly ash from a pulverized coal-fired combustor. In an actual flue gas environment, the effect of submicron particles, volatile species, and trace elements which may affect catalyst activity could be evaluated. The 0.8- $\mathrm{ft}^{2}$ fabric filter holder and oven used with simulated flue gas in Task $A$ were used to filter a slipstream of flue gas from the PTC. The criteria for selection of the catalytic fabrics used in Task $B$ were high $\mathrm{NO}_{x}$ removal efficiency and/or low ammonia slip based on Task A results. Four coals were used in the fabric screening tests: a mediumsulfur, washed Illinois \#6 bituminous; a high-sulfur Pyro Kentucky bituminous; a Jacobs Ranch subbituminous; and a South Hallsville Texas lignite. Each of the eight fabrics was tested at air-to-cloth ratios of $2,3,4$, and $6 \mathrm{ft} / \mathrm{min}$ with the baseline coal (washed Illinois \#6). Ammonia slip and $\mathrm{SO}_{3}$ measurements were made at each air-to-cloth ratio, with the ammonia/ $\mathrm{NO}_{x} \mathrm{molar}$ ratio held constant at 0.9 .

There was a substantial decrease in catalyst-coated fabric performance with increased air-to-cloth ratio for all the fabrics tested. For the fabric samples tested, the maximum air-to-cloth ratio at which $85 \%-90 \%$ NO removal could be achieved was $3 \mathrm{ft} / \mathrm{min}$. Although there was some variability in the data, the $\mathrm{NO}_{\mathrm{x}}$ removal efficiency appeared constant with time for the shortterm (8-hour) tests completed. Fabric \#2 (7 coats of $0.2-\mathrm{M} 25 \% \mathrm{~V}$ and $75 \% \mathrm{Ti}$, no refractory undercoat, and a texturized weave) appeared to provide the best performance with respect to high $\mathrm{NO}_{x}$ removal efficiency and $10 \mathrm{w}$ ammonia slip. Fabric \#13 (1 coat of $1-\mathrm{M} \mathrm{25 \%} \mathrm{V}$ and $75 \% \mathrm{Ti}, 50 \% \mathrm{Si}$ and $50 \% \mathrm{Ti}$ undercoat, and texturized weave) also provided good performance.

Both the concentration of vanadium on the fabric and the BET surface area correlate strongly with $\mathrm{NO}_{x}$ removal efficiency. When the catalyst-coated fabric was exposed to flue gas, both the quantity of catalyst on the fabric and the total surface area decreased. However, the percentage decrease in surface area is greater, indicating that a high percentage of the total surface area is located at or near the surface of the catalyst coating. A minimum surface area of 4.5 to $5 \mathrm{~m}^{2} / \mathrm{g}$ and a vanadium concentration of $6.5-\mathrm{mg}$ to $7-\mathrm{mg}$ vanadium per gram of fabric are necessary to achieve $85 \%-90 \% \mathrm{NO}_{\mathrm{x}}$ reduction at an ammonia/ $\mathrm{NO}_{x}$ molar ratio of 0.9 .

Following the fabric screening tests, Fabrics \#2 and \#13 were selected to evaluate the effects of coal type on catalyst-coated fabric performance. Both fabrics were tested using each of the three remaining coals (South Hallsville Texas lignite; Jacobs Ranch subbituminous; and Pyro Kentucky bituminous) at an ammonia/NO molar ratio of 0.9 and a flue gas temperature of $650^{\circ} \mathrm{F}$. For the first 6 hours of the test, the air-to-cloth ratio was held constant at 3 $\mathrm{ft} / \mathrm{min}$. At the end of each test, the air-to-cloth ratio was adjusted to 2 $\mathrm{ft} / \mathrm{min}$ for 1 hour, and then to $4 \mathrm{ft} / \mathrm{min}$ for 1 hour.

Although three of the coals, the two bituminous coals and the subbituminous coal, did not appear to affect the performance of the catalystcoated fabric samples, the South Hallsville Texas lignite did result in lower 
NO removal and higher ammonia slip. This was probably caused by pinholes that formed in the dust cake, resulting in flue gas channeling through the fabric.

Two catalyst-coated fabric samples were evaluated in conjunction with the setup and testing of a nitrous oxide $\left(\mathrm{N}_{2} \mathrm{O}\right)$ analyzer. The catalytic fabrics were evaluated in a slipstream of flue gas from the PTC fired with washed Illinois \#6 bituminous coal. Nitrous oxide concentrations were measured at the inlet and outlet of the fabric filter holder to verify that $\mathrm{N}_{2} \mathrm{O}$ was not produced as a result of the $\mathrm{NO}_{x}$ reduction reactions occurring on the surface of the catalyst-coated fabric.

Fabric \#17 was similar to a previously tested fabric (\#2), except that a substantially less expensive vanadium source was used and a high molecular weight organic was added. The new catalyst coating was highly amorphous, reducing the potential for catalyst loss from the fabric surface. The other fabric (\#8) was iron on titania, which may increase the temperature window for catalytic activity or cost less than vanadium-based catalysts.

The fabric sample coated with a new and less expensive source of vanadium performed as well as a similar fabric sample coated with the original vanadium catalyst, which may result in substantial cost savings. The fabric sample coated with an iron-based catalyst showed potential. A NO removal efficiency of $64 \%$ at an air-to-cloth ratio of $2 \mathrm{ft} / \mathrm{min}$ was observed without optimizing the iron-based catalyst coating process. The $\mathrm{N}_{2} \mathrm{O}$ concentration ranged from 3.5 to $6.0 \mathrm{ppm}$, which is consistent with results obtained by other researchers for pulverized coal-fired boilers $(22,23)$. There was minimal conversion of $\mathrm{NO}_{x}$ to $\mathrm{N}_{2} \mathrm{O}(<1 \mathrm{ppm})$ across the catalyst-coated fabric.

\subsection{FINE PARTICULATE EMISSIONS/CONTROL}

Present New Source Performance Standards (NSPS) for utility coal-fired boilers limit particulate emissions to $0.031 \mathrm{~b} / \mathrm{million}$ Btu and $20 \%$ or 1 ower opacity. The control device removal efficiency required to meet this standard varies from about $99 \%$ to $99.9 \%$, depending on the heating value and ash content of the coal. Electrostatic precipitators and fabric filters are the technologies that have most often been employed to meet the current standard. Although the best proven control technology for fine particulate matter appears to be fabric filtration, if properly designed, both of these technologies have been successful, in most cases, in meeting the current standard. However, the removal efficiency of both electrostatic precipitators and baghouses is significantly reduced for fine particles less than $2 \mu m$. Furthermore, present emissions standards do not address fine particle emissions. Emissions of fine particles are of concern because these particles are likely to be deposited in the lower respiratory system through normal breathing. The problem is further compounded because hazardous trace elements such as selenium and arsenic are known to be concentrated on these fine particles. Control device removal efficiency is lowest for respirable particles, so a situation exists where the most hazardous particles from coal combustion are collected with the lowest removal efficiency. In addition to causing adverse health effects, fine particle emissions have an impact on atmospheric visibility. Particles which are the most efficient at scattering light are in the $0.1-$ to $2-\mu \mathrm{m}$ range. These particles do not readily settle out of the atmosphere and are subject to long-range transport. When present 
in sufficient concentrations, these fine particles will cause serious visibility impairment. Therefore, the emission of fine particles is an issue because of potential adverse health effects and visibility impairment in the atmosphere.

Early work involving fly ash characterization demonstrated the dependence of fly ash collectability in fabric filters on coal type $(24,25)$. Experiments were initiated to determine if fly ash characteristics could be modified using additives to enhance fly ash collectability. Results showed that fine particulate emissions and baghouse pressure drop could be reduced when small amounts of ammonia and $\mathrm{SO}_{3}$ were injected into the flue gas upstream of a baghouse $(26,27)$. An assessment report was prepared to compare the technical and economic merits of flue gas conditioning applied to fabric filtration with other existing or emerging methods of fine particulate control (28). From April 1987 through May 1988, the focus of the Fine Particulate Control project was on the completion of bench-scale experiments to study the mechanisms of the flue gas conditioning process. The results showed that flue gas conditioning reduces emissions by enhancing the ability of the fly ash to bridge large pores and pinholes and by inhibiting the reentrainment of ash from the dust cake/fabric interface (29). From May 1988 through December 1989, work continued under a competitive award from DOE/PETC. The objective of the project was to demonstrate the effectiveness of flue gas conditioning for improved fine particulate control in reverse-gas cleaned baghouses. The results showed that the benefits of reduced pressure drop due to flue gas conditioning were retained over multiple cleaning cycles, with no problems with dust cake buildup or bag cleaning (30). During the last three years of the Cooperative Agreement, work focused on bench-scale tests to predict fabric filter performance and to model the conditioning process $(20,21,31,32)$. The tests showed that conditioning increases the tensile stength of fly ash at constant porosity and also reduces the packing tendency. Porosity measurements showed that both aerated and packed porosities are significantly increased for conditioned ashes compared to baseline ashes without conditioning. Bench-scale reentrainment experiments were performed to measure the reentrainment potential of fly ash from the surface of a fly ash filter cake and relate it to the measured cohesive strength. A joint venture project funded by the DOE, the Electric Power Research Institute (EPRI), and the Canadian Electric Association (CEA), completed in October 1992, evaluated the effectiveness of flue gas conditioning for improving the performance of pulsejet baghouses.

\subsection{Goals and Objectives}

The objectives of the Fine Particulate Emissions project for the period April 1986 through March 1987 were to 1) make a technical and economic comparison between flue gas conditioning as a method of reducing fine particulate emissions from a fabric filter and other state-of-the-art or emerging technologies, and 2) determine the effectiveness of flue gas conditioning with ammonia and sulfur trioxide $\left(\mathrm{SO}_{3}\right)$ for reducing fine particulate emissions from a fabric filter for several coals. Work in the second year of the Cooperative Agreement focused on the fundamental ash properties that control fine particle penetration through a fabric filter including 1) construction and setup of a bench-scale fabric filtration system; 2) tests with reentrained ash at ambient conditions to relate penetration behavior to coal type, ash characteristics, and conditioning; and 3) tests with ammonia and $\mathrm{SO}_{3}$ injected upstream of the bench-scale filter to determine 
conditioning effects and the effect of conditioning agent concentrations and temperature. Work in the area of fine particulate emissions was not funded under the third year of the Cooperative Agreement. However, work cont inued under a competitive award from DOE/PETC to evaluate flue gas conditioning applied to reverse-gas baghouses. The general objective of the fine particulate control effort during the last three years of the Cooperative Agreement was to develop methods to help characterize, control, and model fine particulate emissions from a fabric filter. Characterization goals included the development of methods to measure the cohesive strength and reentrainment potential of fly ashes. Control and modeling goals involved work to relate measured ash characteristics to the level of fine particle emissions from fabric filters.

\subsection{Accomplishments}

The technical and economic assessment focused on a literature review in the following areas: 1) a review of the basis for fine particulate control, including discussion of the health effects of particulate matter in the atmosphere, the effect of fine particulate emissions on visibility, and current and possible future fine particulate control requirements; 2) a technical and economic evaluation of existing particulate control

technologies, including flue gas conditioning applied to fabric filters; and 3 ) evaluation of the fundamental collection and penetration mechanisms in fabric filtration, basic ash properties which affect fine particulate emissions, and previous results with flue gas conditioning. Pilot-scale experiments were performed to determine the effect of injection temperature and coal type on the overall effectiveness of conditioning.

Results from the pilot-scale tests showed that fine respirable particulate emissions could be reduced by up to 4 orders of magnitude by injecting small amounts of ammonia and $\mathrm{SO}_{3}$ upstream of a baghouse. This corresponded to an increase in particulate collection efficiency from $90 \%$ to $99.999 \%$ for some difficult-to-collect ashes. Tests with both lignite and higher-rank coals showed that conditioning is an effective method of greatly reducing fine particulate emissions from a fabric filter. Baghouse pressure drop was also reduced, making the process more economical. Conditioning would add approximately $9 \%$ to the cost of operating a conventional reverse-gas baghouse; however, this cost could be more than recovered if pressure drop and/or baghouse size are reduced. Possible applications of flue gas conditioning applied to fabric filtration include retrofit applications where emissions or pressure drop are higher than acceptable or retrofit or new plant applications to meet stricter control requirements.

Bench-scale experiments in the second year of the Cooperative Agreement confirmed previous pilot-scale results which showed that flue gas conditioning is an effective method of reducing fine particle emissions from a fabric filter. Pressure drop is reduced because of an increase in dust cake porosity which results in a reduced specific dust cake resistance coefficient $\left(K_{2}\right)$. Conditioning reduces emissions by enhancing the ability of the ash to bridge large pores and pinholes, by inhibiting the reentrainment of ash from the dust cake/fabric interface, and by reducing $K_{2}$, which results in lower pinhole velocity. The mechanisms of emissions reduction are a direct result of increasing the cohesive strength of the ash through the conditioning process. A review of penetration mechanisms showed that there is a theoretical basis for lower emissions with increased bulk cohesive strength. Pressure drop 
reduction as a result of conditioning occurs due to an increase in dust cake porosity as theoretical and empirical models predict.

Work during the last three years of the Cooperative Agreement focused on the development of methods to measure the cohesive properties of fly ash and relate those properties to filtration behavior. The tensile strength, porosity, pore-bridging ability, and reentrainment potential of baseline and conditioned fly ashes were measured to determine if they could be used as predictors of fabric filter performance.

Most of the available methods for measuring the shear or tensile strength of bulk powders were developed for soil mechanics studies, and, therefore, might not adequately describe the behavior of fine powders such as fly ash. After reviewing the available methods for measuring the cohesive properties of bulk powders, an instrument called a Cohetester, manufactured by Hosokawa Micron International, was selected based on successful trial tensile strength measurements of baseline and conditioned fly ashes. The Cohetester gives a direct measurement of the tensile strength of a bulk powder sample. The aerated and packed porosities of the fly ash samples were measured with a Powder Characteristics Tester, al so manufactured by Hosokawa Micron International. A description of the Powder Characteristics Tester and the Cohetester, along with test procedures, was given in the Annual Project Report for the period July 1, 1989, through June 30, 1990 (20).

Initial measurements conducted with the Cohetester showed that one of the effects of conditioning on fly ash characteristics is an increase in tensile strength at constant porosity or an increase in porosity at constant tensile strength. When tensile strength was plotted as a function of porosity, the primary effect of conditioning was a shift in the curve upward (higher tensile strength) and to the right (higher porosity). Initial results also showed that the tensile strength measurements may be affected by the ambient relative humidity.

Reentrainment and pore-bridging experiments were performed using precision electroformed nickel sieves with square openings in place of a fabric. Five different pore sizes were evaluated: $300 \mu \mathrm{m}, 150 \mu \mathrm{m}, 75 \mu \mathrm{m}, 40$ $\mu \mathrm{m}$, and $20 \mu \mathrm{m}$. Measurement of pore-bridging and reentrainment of conditioned and baseline fly ashes was conducted as a function of pore size and face velocity. Results of the pore-bridging tests showed that conditioning, face velocity, and pore size are critical parameters in determining whether complete pore bridging will occur without reentrainment or pinhole formation. The data were well-behaved in terms of establishing the maximum velocity at which bridging occurs for a given pore size. Pore-bridging and reentrainment tests showed that conditioned ash is more effective at bridging pores over the entire velocity range tested $(1,2,4$, and $8 \mathrm{ft} / \mathrm{min})$. Although the porosity of the conditioned ash is much greater than the porosity of the baseline ash, and the tensile strength at filtration porosities of the conditioned ash is lower than the tensile strength of the baseline ash, the pore-bridging ability of the conditioned ash is superior. An apparent explanation is that the particle-to-particle binding forces are greater with conditioning. Reentrainment tests performed subsequently with size-fractionated baseline and conditioned fly ashes suggested there may be a change in the pore-bridging mechanism when the particle size approaches the pore size. 
Additional experiments were performed to evaluate the effect of particle size and relative humidity on tensile strength and porosity. Measurements were conducted using samples stored under controlled conditions in a humidity chamber. The effect of particle size was evaluated using size-fractionated samples of baseline and conditioned Monticello fly ash and two pure powders, ammonium sulfate and calcium sulfate dihydrate.

Test results showed that conditioning, relative humidity, and particle size are important parameters in determining the tensile strength and porosity of bulk powders such as fly ash. Tests at several relative humidities showed that elevated humidity increased the tensile strength at constant porosity for some fly ashes, but that the increase was ash-specific. An increase in relative humidity from $10 \%$ to $50 \%$ had 1 ittle effect on the tensile strength and porosity of pure calcium sulfate dihydrate, but did produce a shift in the tensile strength vs. porosity curve for samples of ammonium sulfate. The increase in relative humidity had only a small effect on the baseline Monticello fly ash, but resulted in a major increase in tensile strength for the conditioned fly ash. Therefore, there is an interaction between conditioning and relative humidity.

The primary effect of a smaller particle size was a shift of the tensile strength vs. porosity curve toward higher porosities for the calcium sulfate and conditioned fly ash, and a shift toward both higher tensile strength and higher porosity for the ammonium sulfate. Tensile strength measurements on the size-fractionated Monticello fly ash also showed that a smaller particle size caused a higher tensile strength for either the baseline or the conditioned ash.

Reentrainment tests conducted at higher relative humidities showed that increasing the relative humidity from $15 \%$ to $50 \%$ did not significantly affect the pore-bridging ability of the baseline Monticello fly ash. However, increasing the relative humidity from $15 \%$ to $50 \%$ improved the pore-bridging ability of the conditioned fly ash, which was consistent with the tensile strength data. Increasing the relative humidity for the conditioned ash also significantly reduced $K_{2}$, which was consistent with the increased aerated and packed porosities at the higher humidities. Since these correlations are for dusts with similar particle-size distributions, they should be valid indicators of fabric filter performance in terms of collection efficiency and dust resistance. For dusts with similar particle-size distributions, the higher the tensile strength, the greater the pore-bridging ability, and the greater the aerated or packed porosity, the smaller the $K_{2}$.

Based on the results of the bench-scale experiments, the best predictor of pore-bridging ability is tensile strength, and the best predictor of $K_{2}$ is the porosity data. Both tensile strength and porosity measurements correlate with pore-bridging ability and $\mathrm{K}_{2}$, but for fly ashes with similar particle sizes, tensile strength correlates more strongly with the pore-bridging ability of the dust, and measured porosity correlates more strongly with the $\mathrm{K}_{2}$ of the dust. This implies that both measurements should be conducted for the best prediction of filter performance. The results indicate that any model for predicting fabric filter performance must include both face velocity and particle size.

Bag cleanability is another aspect of filter performance that depends on the cohesive properties of the ash. For dusts with similar particle-size 
distributions, the correlations imply that the dusts with the highest tensile strengths and porosities will form dust cakes with the lowest $k_{2}$ values. This translates to lower pressure drop only if the residual dust cake weight does not increase. If a dust has too high a tensile strength, it may not be cleaned easily from the bags, and high dust cake weights could result. Nevertheless, the measured tensile strength and porosity of a dust can be used to predict qualitatively pore-bridging ability and dust cake resistance, which are the main indicators of filter performance.

\subsection{IMPACT OF COAL COMBUSTION ON ATMOSPHERIC VISIBILITY/SUMMARY OF LITERATURE REVIEW ON ATMOSPHERIC VISIBILITY}

In 1977 Congress added Section 169A to the Clean Air Act (CAA), which established as a national goal "the prevention of any future, and the remedying of any existing, impairment of visibility in mandatory Class I Federal areas which impairment results from manmade air pollution." The Environmental Protection Agency (EPA) defines "visibility impairment" as "any humanly perceptible change in visibility (visual range, contrast, coloration) from that which would have existed under natural conditions." The EPA has identified two types of air pollution that impair or reduce visibility. The first is single-source impairment defined by the EPA as smoke, dust, colored gas plumes, or layered haze emitted from stacks that obscure the sky or horizon and are relatable in a single source or a small group of sources. The second type is regional haze which is widespread, regionally homogeneous haze from a multitude of sources, which impairs visibility in every direction over a large area. The EPA has used a phased approach to implement the visibility program. Phase I of the program requires control of impairment that can be traced to a single, existing stationary facility or small group of existing stationary facilities. Section 169B was added to the CAA in 1990 to determine the need for expansion of the visibility protection program. It provides funding for continued research on visibility in Class I Federal areas including 1) expansion of current visibility impairment monitoring, 2) assessments of current sources of visibility impairment using regional air quality models, and 3 ) studies on atmospheric chemistry and the physics of visibility. Section $169 \mathrm{~B}$ also calls for the creation of Visibility Transport Regions consisting of one or more states which, because of interstate pollution, contribute significantly to visibility impairment in Class I areas. After the creation of Visibility Transport Regions, Visibility Transport Commissions (VTCS) (whose members include the governors of the affected states) will be formed to address the establishment of clean air corridors, restrictions on new construction, and the development of long-range strategies for remedying regional haze.

Visibility has been the focus of a significant amount of research for over a decade. However, attempts to accurately identify the contributions of various sources to visibility impairment have been hampered by the limitations of air quality models and the lack of understanding of the complex physical and chemical processes that govern the formation of secondary aerosols in the atmosphere.

At the request of the U.S. DOE-PETC, a task assessing the impact of coal combustion on atmospheric visibility was added to the Flue Gas Cleanup project of the EERC/DOE Cooperative Agreement for the period July 1, 1991, through June 30,1992 . A literature review was conducted to evaluate the effect of 
fine particulate emissions from coal-fired combustion systems on atmospheric visibility. The following questions were addressed as part of the literature review:

1. What are the causes of visibility impairment in the atmosphere? (For example, what sizes and concentrations of fine particulates in the atmosphere will result in significant visibility impairment?)

2. What is the composition of the visibility-reducing fine particulate aerosol, and what are the major sources of these fine particles?

3. What is the contribution of coal combustion to visibility-reducing fine particles in the atmosphere?

4. How are pollutants removed from the atmosphere, and what is the role of atmospheric chemistry in the production of secondary aerosols?

5. How would reduction of $\mathrm{SO}_{2}, \mathrm{NO}_{x}$, and fine particulate emissions affect visibility?

Visibility impairment in the atmosphere is primarily caused by light attenuation by fine particles $(<2.5 \mu \mathrm{m})$. Secondary fine particulate matter formed in the atmosphere from $\mathrm{SO}_{2}$ and $\mathrm{NO}_{x}$ precursors is a major source of these fine particles. Other major constituents of fine atmospheric particles are organics, elemental carbon, ammonium ion, soil dust, and water vapor. Water vapor contributes to visibility impairment primarily when the relative humidity is high enough to cause growth in the size of hygroscopic aerosols such as ammonium sulfate. Since coal combustion is a major source of $\mathrm{SO}_{2}$ (and, subsequently, atmospheric sulfates), some visibility impairment must be attributed to coal combustion. Visibility impairment in the Grand Canyon by secondary sulfates and nitrates from the Navajo Generating Station is a case where the visibility impairment was specifically attributed to a coal-fired power plant. In response, the EPA has required that scrubbers be installed at the Navajo plant to mitigate this visibility impairment. However, the exact contribution of coal combustion to regional haze is generally not known, and the benefits that may be derived from much stricter emission controls on coalfired power plants are difficult to assess. It appears logical that if $\mathrm{SO}_{2}$ and $\mathrm{NO}_{\mathrm{x}}$ emissions from coal-fired power plants were reduced by $50 \%$, there would have to be an eventual reduction of $50 \%$ of the sulfates and nitrates in the atmosphere that originated from coal combustion. However, because of the variable contribution to visibility impairment from coal combustion that might occur in a given location, the overall effect on visual range for that location might be small.

Results from the literature review indicate that there is a complex relationship between emissions from coal combustion and visibility impairment, but that coal combustion may be a significant contributor in some cases. A more detailed summary of the visibility literature review was presented in the Semiannual Technical Project Report for the period January 1, 1992, through June $30,1992(32)$. 


\subsection{PUBLICATIONS AND PRESENTATIONS}

The following is a list of publications and presentations which resulted from work sponsored by DOE under the Flue Gas Cleanup project of the multiyear Cooperative Agreement (Contract No. DE-FC2]-86ilC10637).

Miller, S.J.; Heidt, M.K.; Laudal, D.L.; Weber, G.F. "Flue Gas Cleanup," Semiannual Technical Project Report for the Period January 1, 1992, through June 30, 1992; DE-FC21-86MC10637, Grand Forks, ND, July 1992.

Heidt, M.K.; Miller, S.J. "Effect of Cohesive Properties on Fine Particle Collection and Reentrainment," Presented at the Eighth Annual Coal Preparation, Utilization, and Environmental Control Contractors' Conference, Pittsburgh, PA, July 27-30, 1992.

Miller, S.J.; Lauda1, D.L. "Pulse-Jet Baghouse Performance Improvement With Flue Gas Conditioning," Presented at the Eighth Annual Coal Preparation, Utilization, and Environmental Control Contractors' Conference, Pittsburgh, PA, July 27-30, 1992.

Miller, S.J.; Laudal, D.L.; Heidt, M.K. "Fly Ash Characterization Methods For Prediction of Fabric Filter Performance," Presented at ihe Second European Symposium on Separation of Particles From Gases, Nürnberg, Germany, March 24-26, 1992.

Miller, S.J.; Heidt, M.K.; Weber, G.F.; Laudal, D.L. "Flue Gas Cleanup," Semiannual Technical Project Report for the Period July 1, 1991, through December 31, 1991; DE-FC21-86MC10637, Grand Forks, ND, January 1992 .

Lauda1, D.L.; Miller, S.J.; Chang, R. "Enhanced Fine Particulate Control For Reduced Air-Toxic Emissions, " Presented at the International Air Toxics Conference, Washington, DC, November 4-6, 1991.

Miller, S.J.; Laudal, D.L.; Chang, R.L. "Flue Gas Conditioning For Improving Pulse-Jet Baghouse Performance," Presented at the Ninth Particulate Control Symposium, Williamsburg, VA, October 15-18, 1991.

Weber, G.F.; Ness, S.R.; Laudal, D.L. "Simultaneous NO and Particulate Control Using a Catalyst-Coated Fabric Filter," Presented at the International Joint Power Generation Conference, San Diego, CA, October 6-10, 1991.

Weber, G.F.; Miller, S.J.; Laudal, D.L.; Heidt, M.K. "Flue Gas Cleanup," Semiannual Technical Progress Report for the Period January 1, 1991, through June 30, 1991; DOE Contract No. DE-FC21-86MC10637, Grand Forks, ND, August 1991 .

Miller, S.J.; Laudal, D.L.; Heidt, M.K. "Effect of Flue Gas Conditioning on Fine Particle Collection and Reentrainment, "Presented at the Seventh Annual Coal Preparation, Utilization, and Environmental Control Contractors' Conference, Pittsburgh, PA, July 15-18, 1991. 
Weber, G.F.; Laudal, D.L.; Ness, S.R. "Catalytic Fabric Filtration for Simultaneous $\mathrm{NO}_{\mathrm{x}}$ and Particulate Control," Presented at the Seventh Annual Coal Preparation, Utilization, and Environmental Control Contractors' Conference, Pittsburgh, PA, July 15-18, 1991.

Miller, S.J.; Laudal, D.L. "Recent Developments in Particulate Control With Low-Rank Fuels," Presented at the Sixteenth Biennial Low-Rank Fuels Symposium, Billings, MT, May 20-23, 1991.

Weber, G.F.; Laudal, D.L.; Aubourg, P.F.; Kalinowski, M. "Catalytic Fabric Filtration for Simultaneous $\mathrm{NO}_{x}$ and Particulate Control," In Proceedings of the 1991 Joint Symposium on Stationary Combustion NO Control - EPA/EPRI; Washington, DC, March 25-28, 1991.

Miller, S.J.; Laudal, D.L. "Enhancing Baghouse Performance with Conditioning Agents: Basis, Developments, and Economics," In Proceedings of the Eighth Particulate Control Symposium; EPRI GS7050, November 1990, Vo1. 2, p 23-1.

Weber, G.F.; Miller, S.J.; Laudal, D.L. "Flue Gas Cleanup," Annual Technical Project Report for the Period July 1, 1989, through June 30, 1990; DE-FC21-86MC10637, Grand Forks, ND, October 1990.

Miller, S.J.; Laudal, D.L. "Enhancing Baghouse Performance With Conditioning Agents: Basis, Developments, and Economics," Presented at the Eighth EPA/EPRI Symposium on the Transfer and Utilization of Particulate Control Technology, San Diego, CA, March 20-23, 1990.

Miller, S.J.; Laudal, D.L. "Flue Gas Conditioning Applied to Fabric Filtration," Presented at the Sixth Annual International Pittsburgh Coal Conference, Pittsburgh, PA, September 25-29, 1989.

Weber, G.F.; Laudal, D.L. "SO $/ \mathrm{NO}_{x}$ Control - Catalytic Fabric Filtration for Simultaneous $\mathrm{NO}_{\mathrm{x}}$ and Particulate Control," Final Technical Report for the Period April 1, 1988, through June 30, 1989; D0E Contract No. DE-FC21-86MC10637, Grand Forks, ND, August 1989.

Weber, G.F.; Laudal, D.L. "SO $/ \mathrm{NO}_{x}$ Control - Catalytic Fabric Filtration for Simultaneous NO and Particulate Control," Presented at the Fifth Annual Coal Preparation, Utilization, and Environmental Control Contractors' Conference, Pittsburgh, PA, July 31-August 3, 1989.

Miller, S.J.; Laudal, D.L. "Flue Gas Conditioning: A Method to Improve Collection Efficiency and Reduce Pressure Drop With Fabric Filters," Presented at the Fifteenth Biennial Low-Rank Fuels Symposium, St. Pau1, MN, May 22-25, 1989.

Miller, S.J.; Laudal, D.L. "Flue Gas Conditioning Applied to Fabric Filtration," Presented at the First European Symposium on the Separation of Particles From Gases, Nuremberg, West Germany, April 19-21, 1989. 
Miller, S.J.; Laudal, D.L.; Kim, S.S. "Mechanisms of Fabric Filter Performance Improvement with Flue Gas Conditioning," In Proceedings of the Seventh EPA/EPRI Symposium on the Transfer and Utilization of Particulate Control Technology; EPRI GS-6208, February 1989, Vol. 2, p 25-1.

Miller, S.J.; Laudal, D.L. "Fine Particulate Emissions: Flue Gas Conditioning for Improved Fine Particle Capture in Fabric Filters," Final Technical Report for the Period April 1, 1987, through March 31, 1988; DE-FC21-86MC10637, Grand Forks, ND, August 1988.

Weber, G.F.; Collings, M.E.; Schelkoph, G.L. "Simultaneous $\mathrm{SO}_{\mathrm{x}} / \mathrm{NO}_{\mathrm{x}}$ Control," Final Technical Report for the Period April 1, 1987, through March 31, 1988; DE-FC21-86MC10637, Grand Forks, ND, May 1988.

Laudal, D.L.; Miller, S.J. "Flue Gas Conditioning for Baghouse Performance Improvement with Low-Rank Coals, "In Proceedings of the Fourteenth Biennial Lignite Symposium on the Technology and Utilization of Low-Rank Coals; University of North Dakota Energy and Environmental Research Center, Grand Forks, ND, 1987.

Miller, S.J.; Laudal, D.L. "Flue Gas Conditioning for Improved Fine Particle Capture in Fabric Filters: Comparative Technical and Economic Assessment," In Low-Rank Coal Research Final Report, Vol. II Advanced Research and Technology Development, DOE/FC/10637-2414, Vol. ¿ (DE87006532), Apri1 1987.

Weber, G.F.; Collings, M.E.; Schelkoph, G.L.; Steadman, E.N. "Simultaneous $\mathrm{SO}_{x} / \mathrm{NO}_{x}$ Control," Final Technical Report for the Period Apri1 1, 1986, through March 31, 1987; DE-FC21-86MC10637, DOE/FC/10637-2414, Grand Forks, ND, Apri1 1987.

Laudal, D.L.; Miller, S.J. "Flue Gas Conditioning for Improved Baghouse Performance," In Proceedings of the Sixth Symposium on the Transfer and Utilization of Particulate Control Technology; EPRI CS-4918, November 1986, Vol. 3, p 14-1.

Bobman, M.H.; Weber, G.F.; Dorchak, T.P. "Comparative Costs of Flue Gas Desulfurization: Advantages of Pressure Hydrated Lime Injection," Presented at the 1986 Joint Symposium on Dry $\mathrm{SO}_{2}$ and Simultaneous $\mathrm{SO}_{2} / \mathrm{NO}_{x}$ Control Technologies, Raleigh, $\mathrm{NC}$, June 2-6, 1986.

Weber, G.F.; Collings, M.E.; Schelkoph, G.L. "Enhanced Utilization of Furnace Injected Calcium-Based Sorbents," Presented at the 1986 Joint Symposium on Dry $\mathrm{SO}_{2}$ and Simultaneous $\mathrm{SO}_{2} / \mathrm{NO}_{x}$ Control Technologies, Raleigh, NC, June 2-6, 1986.

\subsection{REFERENCES}

1. Weber, G.F.; Collings, M.E.; Schelkoph, G.L.; Steadman, E.N. "Simultaneous $\mathrm{SO}_{x} / \mathrm{NO}_{x}$ Control," Final Technical Report for the Period Apri1 1, 1986, through March 31, 1987; DE-FC21-86MC10637, D0E/FC/106372414, Grand Forks, ND, Apri1 1987. 
2. Weber, G.F.; Collings, M.E.; Schelkoph, G.L. "Simultaneous $\mathrm{SO}_{\mathrm{x}} / \mathrm{NO}_{\mathrm{x}}$ Control," Final Technical Report for the Period April 1, 1987, through March 31, 1988; DE-FC21-86MC10637, Grand Forks, ND, May 1988.

3. Ness, H.M. et al. "Pilot Plant Scrubbing of $\mathrm{SO}_{2}$ With Fly Ash Alkali From North Dakota Lignite," Presented at the Technology and Use of Lignite Symposium, Grand Forks, ND, May 18-19, 1977.

4. Ness, H.M.; Selle, S.J. "Control of Western Power Plant Sulfur Dioxide Emissions: Development of the Ash-Alkali FGD Process and Dry Adsorption Techniques at the Grand Forks Energy Technology Center," DOE Symposium on Environmental Control Activities, Washington, DC, November 1978.

5. Ness, H.M. et al. "Power Plant Flue Gas Desulfurization for Low-Rank Western Coals," Presented at the Technology and Use of Lignite Symposium, Grand Forks, ND, May 30-31, 1979.

6. Ness, H.M. et a1. "Combined Flue Gas Cleanup/Simultaneous $\mathrm{SO}_{\mathrm{x}} / \mathrm{NO}_{\mathrm{x}}$ Control Quarterly Technical Progress Report," U.S. Department of Energy, Grand Forks, ND:

DOE/GFETC/QTR-79/4, July-September 1979
DOE/GFETC/QTR-80/1, October-December 1979
DOE/GFETC/QTR-80/2, January-March 1980
DOE/GFETC/QTR-80/3, April-June 1980
DOE/GFETC/QTR-80/4, JuTy-September 1980
DOE/GFETC/QTR-81/1, October-December 1980
DOE/GFETC/QTR-81/2, January-March 1981
DOE/GFETC/QTR-81/3, April-June 1981
DOE/GFETC/QTR-81/4, JuTy-September 1981
DOE/GFETC/QTR-82/1, October-December 1981
DOE/GFETC/QTR-82/2, January-March 1982

7. Ness, H.M. et al. "Combined Flue Gas Cleanup/Simultaneous $\mathrm{SO}_{\mathrm{x}} / \mathrm{NO}_{\mathrm{x}}$ Control Quarterly Technical Progress Report, "U.S. Department of Energy, Grand Forks, ND:

\section{DOE/GFETC/QTR-82/3, Apri1-June 1982 DOE/GFETC/QTR-82/4, July-September 1982 DOE/GFETC/QTR-82/1, October-December 1982}

8. Blythe, G.M. "Dry Limestone Injection Test at a Low-Rank Coal-Fired Power Plant," DOE Control No. AC18-80 C10200, November 1982.

9. Weber, G.F.; Bobman, M.H.; Schelkoph, G.L. "Pilot-Scale Studies of InFurnace Hydrated Lime Injection For Flue Gas $\mathrm{SO}_{2}$ Emission Control," Presented at the First Joint Symposium on Dry $\mathrm{SO}_{2}$ and Simultaneous $\mathrm{SO}_{2} / \mathrm{NO}_{x}$ Control Technologies, San Diego, CA, November 13-16, 1984.

10. Dorchak, T.P.; Ness, H.M.; Weber, G.F. " $\mathrm{SO}_{2}$ Removal Using Pressure Hydrated Lime," Presented at the Thirteenth Biennial Lignite Symposium, Bismarck, ND, May 21-23, 1985. 
11. Weber, G.F.; Bobman, M.H.; Collings, M.E. "Enhanced Utilization of Furnace Injected Calcium-Based Sorbents," Presented at the 1986 Joint Symposium on Dry $\mathrm{SO}_{2}$ and Simultaneous $\mathrm{SO}_{2} / \mathrm{NO}_{x}$ Control Technologies, Raleigh, NC, June 2-6, 1986.

12. Offen, G. "Prospects For Lime Injection, State of the Research," Presented at the 83rd Annual Convention of the National Lime Association, April 23-24, 1985.

13. Bobman, M.H.; Weber, G.F.; Kenner, T.C. "Additive Enhancement of Pressure-Hydrated Lime for Control of $\mathrm{SO}_{2}-\mathrm{NO}_{x}$ Emissions, "Presented at the Spring National Meeting of the AIChE, Houston, TX, March 24-28, 1985.

14. Muzio, L.J. et al. "The Effectiveness of Additives for Enhancing $\mathrm{SO}_{2}$ Removal With Calcium Based Sorbents," Presented at the 1986 Joint Symposium on Dry $\mathrm{SO}_{2}$ and Simultaneous $\mathrm{SO}_{2} / \mathrm{NO}_{x}$ Control Technologies, Raleigh, NC, June 2-6, 1986.

15. Slaughter, D.M. et a1. "Enhanced Sulfur Capture by Promoted CalciumBased Sorbents," Presented at the 1986 Joint Symposium on Dry $\mathrm{SO}_{2}$ and Simultaneous $\mathrm{SO}_{2} / \mathrm{NO}_{x}$ Control Technologies, Raleigh, NC, June 2-6, 1986.

16. Miller, S.J.; Baltisberger, R.J. "Plume Coloration Study at Coyote Power Station," Confidential Contract Report Prepared For Montana-Dakota Utilities Co., May 1986.

17. Ablin, D.W. et al. "Full Scale Demonstration of Dry Sodium Injection Flue Gas Desulfurization at City of Colorado Springs Ray D. Nixon Power Plant," Presented at the 1986 Joint Symposium on Dry $\mathrm{SO}_{2}$ and Simultaneous $\mathrm{SO}_{2} / \mathrm{NO}_{x}$ Control Technologies, Raleigh, NC, June 2-6, 1986.

18. Lowe, P.A.; Ellison, W.; Perlsweig, M. "Understanding the German and Japanese Coal-Fired Experience," Presented at the 1991 EPRI/EPA Joint Symposium on Stationary Combustion NO Control, Washington, DC, 1991.

19. Weber, G.F.; Laudai, D.L. "SO $/ \mathrm{NO}_{x}$ Control - Catalytic Fabric Filtration for Simultaneous $\mathrm{NO}_{x}$ and Particulate Control, "Final Technical Report for the Period Apri1 1, 1988, through June 30, 1989; DE-FC21-86MC10637, Grand Forks, ND, August 1989.

20. Weber, G.F.; Miller, S.J.; Laudal, D.L. "Flue Gas Cleanup," Annual Technical Project Report for the Period July 1, 1989, through June 30, 1990; DE-FC21-86MC10637, Grand Forks, ND, October 1990.

21. Weber G.F.; Miller, S.J.; Lauda1, D.L.; Heidt, M.K. "Flue Gas Cleanup," Semiannual Technical Project Report for the Period January 1, 1991, through June 30, 1991; DE-FC21-86MC10637, Grand Forks, ND, August 1991.

22. Aho, J.J.; Rantanen, J.T.; Linna, V.L. "Formation and Destruction of Nitrous Oxide in Pulverized Fuel Combustion Environments Between $750^{\circ}$ and $970^{\circ} \mathrm{C}, "$ Fuel 1990, 29, 957-1005.

23. Kokkinos, A. "Measurement of Nitrous Oxide Emissions," EPRI Journal 1990, April/May, 36-39.4. 
24 Sears, D.R.; Miller, S.J. "Impact of Fly Ash Composition Upon Shaker Baghouse Efficiency," Paper 84-56.6, Presented at the 77th Annual Meeting of the Air Pollution Control Assn., San Francisco, CA, June 24-29, 1984.

25. Miller, S.J.; Sears, D.R. "The Influence of Coal-Specific Fly Ash Properties Upon Baghouse Performance: A Comparison of Two Extreme Examples," In Proceedings of the Fifth Symposium on the Transfer and Utilization of Particulate Control Technology, EPRI CS-4404 Vol. 3, p. 22-1, February 1986.

26. Miller, S.J.; Lauda1, D.L. "Particulate Removal Enhancement of a Fabric Filter Using Flue Gas Conditioning," Presented at the Third EPRI Conference on Fabric Filter Technology for Coal-Fired Power Plants, Scottsdale, AZ, November 19-21, 1985.

27. Lauda1, D.L.; Miller, S.J. "Flue Gas Conditioning for Improved Baghouse Performance," In Proceedings of the Sixth Symposium on the Transfer and Utilization of Particulate Control Technology, EPRI Cs-4918 Vol. 3, p. $14-1$.

28. Miller, S.J.; Lauda1, D.L. "Flue Gas Conditioning for Improved Fine Particle Capture in Fabric Filters: Comparative Technical and Economic Assessment," In Low-Rank Coal Research Final Report, Vol. II, Advanced Research and Technology Development; DOE/FC/10637-2414, (DE87006532), April 1987.

29. Miller, S.J.; Laudal, D.L. "Fine Particulate Emissions: Flue Gas Conditioning for Improved Fine Particle Capture in Fabric Filters," Final Technical Report for the Period Apri1 1, 1987, through March 31, 1988; DE-FC21-86MC10637, Grand Forks, ND, August 1988.

31. Miller, S.J.; Heidt, M.K.; Weber, G.F.; Laudal, D.L. "Flue Gas Cleanup," Semiannual Technical Project Report for the Period July 1, 1991, through December 31, 1991; DE-FC21-86MC10637, Grand Forks, ND, January 1992.

32. Miller, S.J.; Heidt, M.K.; Laudal, D.L.; Weber, G.F. "Flue Gas Cleanup," Semiannual Technical Project Report for the Period January 1, 1992, through June 30, 1992; DE-FC21-86MC10637, Grand Forks, ND, July 1992. 
2.2 Waste Management 


\section{WASTE MANAGEMENT}

Final Technical Progress Report

for the Period Apri1 1, 1986, through December 31, 1992

by

Daniel J. Stepan, Research Engineer

Charles J. Moretti, Research Associate

David J. Hassett, Director, Applied Chemistry and Analytical Research

Debra F. Pflughoeft-Hassett, Research Chemist

Gale G. Mayer, Research Scientist/Hydrogeologist

Tina M. Strobel, Research Associate

Rose H. Fraley, Laboratory Technician

Energy and Environmental Research Center

University of North Dakota

Box 8213, University Station

Grand Forks, North Dakota 58202-8213

Task Contracting Officer's Representative: Jerry Harness

for

U.S. Department of Energy

Office of Fossil Energy

Morgantown Energy Technology Center

3610 Collins Ferry Road

P.0. Box 880 , M.S. E02

Morgantown, WV 26507-0880

December 1992

Work Performed under Cooperative Agreement No. DE-FC21-86MC10637 


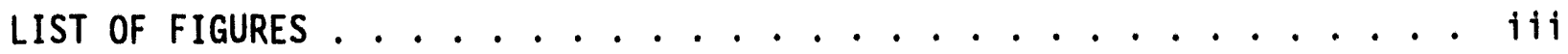

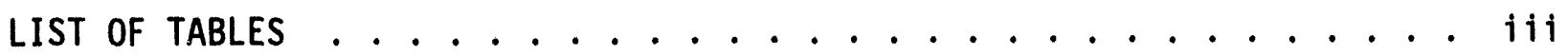

1.0 INTRODUCTION . . . . . . . . . . . . . . . . 1

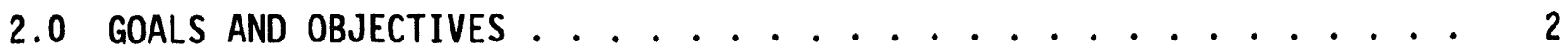

3.0 PROJECT TASK SUMMARIES .................... 2

3.1 Waste Characterization ............... 2

3.1 .1 Introduction ............... 2

3.1 .2 Goals and Objectives .............. 4

3.1.3 Results and Conclusions ............ 4

3.2 Fly Ash Liner Development Study . . . . . . . . . . . . 7

3.2 .1 Introduction ................. 7

3.2.2 Goals and Objectives .............. 9

3.2.3 Results and Conclusions ............ 9

3.3 Numerical Modeling of Disposal-Related Soil Properties . . . . 10

3.3 .1 Introduction ................... 10

3.3.2 Goals and objectives ............... 11

3.3.3 Results and Conclusions .............. 11

3.4 Leaching Test Evaluation .............. 12

3.4.1 Introduction ................ 12

3.4.2 Goals and objectives .............. 12

3.4.3 Results and Conclusions ........... 12

3.5 Electrostatic Separation of Unburned Carbon from Fiy Ash . . . 12

3.5.1 Introduction ............... 12

3.5.2 Goals and Objectives .............. . . 13

3.5.3 Results and Conclusions ........... 13

3.6 Bituminous Coal Fly Ash Data Collection and Evaluation .... 13

3.6 .1 Introduction ............... 13

3.6 .2 Goals and objectives . . . . . . . 14

3.6.3 Bituminous Coal Fly Ash Data Collection 15

3.6.4 Advanced Coal Process Residues Database Results : . 17

3.7 Activated Carbon Evaluation . . . . . . . . . . . . 17

3.7 .1 Introduction . . . . . . . . . . . . . 17

3.7 .2 Goals and Objectives............... 18

3.7 .3 Results and Conclusions ............. 18

3.8 Coal Ash Conditioning Study .............. 19

3.8.1 Introduction . . . . . . . . . . . . . . 19

3.8 .2 Goals and Objectives ............... 21

3.8.3 Results and Conclusions ............ 21

3.8.4 Bulk Chemical and Mineralogical Characterization .... 23

3.8.5 Results of Trace Element Mobility Investigations .... 23 


\section{TABLE OF CONTENTS (continued)}

Page

3.9 Characterization and Treatability of Coal-Water Fuel Process Waters .................. 25

3.9 .1 Introduction .............. 25

3.9.2 Goals and Objectives ............... 25

3.9.3 Results and Conclusions ............. . 25

3.10 Waste Depository Scavenger Study . . . . . . . . . . . . . . . 27

3.10 .1 Introduction ................ 27

3.10 .2 Research Scope . . . . . . . . . . . . . . . . 28

3.10 .3 Results and Conclusions ............ 28

4.0 REFERENCES . . . . . . . . . . . . . . . . . . . . 28 


\section{LIST OF FIGURES}

\section{Figure}

Page

1 Time line of tasks performed under the Waste Management project .................... 1

\section{LIST OF TABLES}

Table

1 Comparison of Lignite Char and Activated Carbon Characteristics

19 


\section{WASTE MANAGEMENT}

\subsection{INTRODUCTION}

The Waste Management project has involved a number of interrelated tasks relating to the characterization, handling and treatment of solid and liquid waste materials and by-products from advanced coal processing and utilization processes. Specific tasks within the Waste Management project have included:

- Waste Characterization

- Fly Ash Liner Development Study

- Numerical Modeling of Disposal-Related Soil Properties

- Leaching Test Evaluation

- Electrostatic Separation of Unburned Carbon from Fly Ash

- Bituminous Coal Fly Ash Data Collection and Evaluation

- Activated Carbon Evaluation

- Coal Ash Conditioning Study

- Characterization and Treatability of Coal-Water Fuel Process Waters

- Waste Depository Scavenger Study

Figure 1 illustrates the time frame in which individual studies were performed.

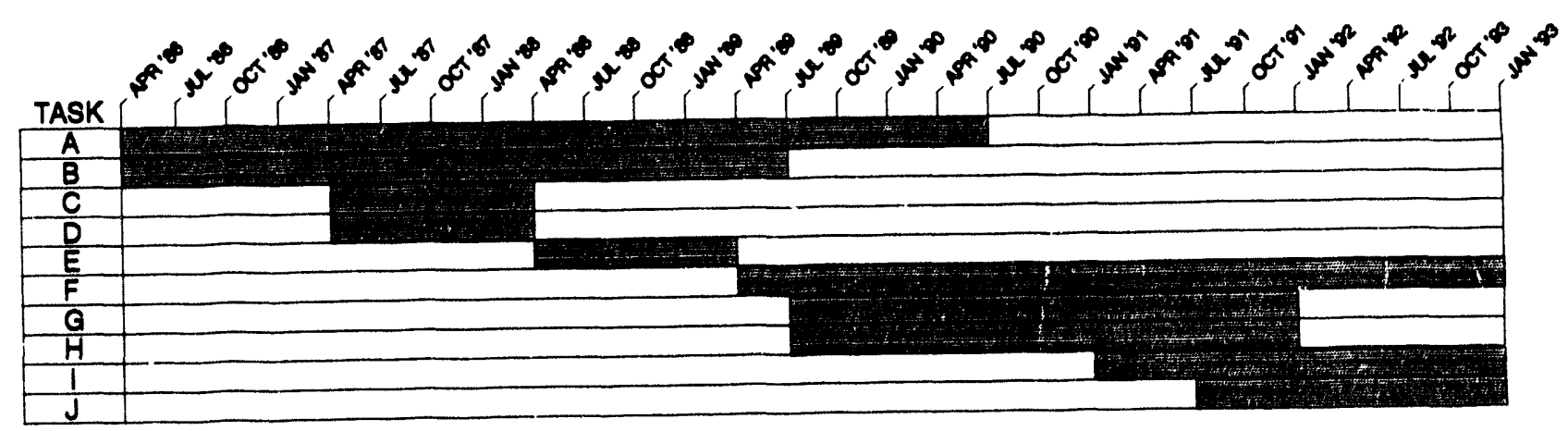

TASKA: WASTE CHARACTERIZATION

TASK B: FLY ASH LINER DEVELOPMENT STUDY

TASK C: NUMERICAL MODELING OF DISPOSAL-RELATED SOIL PROPERTIES

TASKD: LEACHING TEST EVALUATION

TASKE: ELECTROSTATIC SEPARATION OF UNBURNED CARBON FROM FLY ASH

TASKF: BITUMINOUS COAL FLY ASH DATA COLLECTION AND EVALUATION

TASK G: ACTIVATED CARBON EVALUATION

TASKH: COAL ASH CONDITIONING STUDY

TASK I: CHARACTERIZATION AND TREATABILITY OF COAL-WATER FUEL PROCESS WATERS

TASK J: WASTE DEPOSITORY SCAVENGER STUDY

Figure 1. Time line of tasks performed under the Waste Management project. 


\subsection{GOALS AND OBJECTIVES}

The overall objective of the Waste Management project is to characterize waters, waste materials, and by-products from advanced coal preparation and utilization processes; evaluate potential uses for these materials; and identify potentially adverse environmental impacts associated with their use and/or disposal. Research is also being done to develop innovative waste management techniques for conventional and advanced coal utilization processes to comply with existing and/or future environmental regulations.

\subsection{PROJECT TASK SUMMARIES}

\subsection{Waste Characterization}

\section{1 .1 Introduction}

Research in this task was conducted over a period of four years to characterize coal combustion solid wastes for evaluation of the waste disposal requirements for advanced combustion processes being developed at the Energy and Environmental Research Center (EERC).

The test protocol used for the characterization studies consisted of waste analyses for elemental, mineral, and trace organic matter content; waste leachate analyses for trace metals and trace organic compounds; and tests of physical properties relevant to waste disposal.

During the first year, characterization studies were conducted on fourteen waste streams. Ten waste samples generated from the atmospheric fluidized-bed combustion unit (AFBC) at the EERC were characterized. The types of waste samples studied included fly ashes, spent bed materials, primary and secondary cyclone ashes, and ash composites. These four samples represented all of the solid waste streams produced by the AFBC system. In addition, six composite waste samples prepared by blending primary cyclone ash, secondary cyclone ash, and baghouse fly ash were characterized.

The fuels used for the AFBC combustion runs were Sarpy Creek Montana subbituminous coal, Gibbons Creek Texas lignite, and Navajo New Mexico subbituminous coal. The combustion runs used either limestone addition for $\mathrm{SO}_{2}$ capture or ash reinjection for enhanced carbon burnout.

Two fly ash waste samples produced from combustion tests which used pressure-hydrated lime injection for $\mathrm{SO}_{2}$ control were also characterized during the first year. The fuel used for these runs was an Illinois \#6 bituminous coal. The lime injection fly ashes were collected from the electrostatic precipitator on a $500,000-B t u / h r$, pulverized coal combustion unit. One of the samples was produced from a baseline combustion test in which no lime was injected into the system, and the other sample was produced from a combustion test which used a 1.0 lime injection ratio $\left(\mathrm{Ca} / \mathrm{SO}_{2}\right)$.

Two fly ash waste samples produced from combustion tests which used ammonia-sulfite $\left(\mathrm{NH}_{3}-\mathrm{SO}_{3}\right)$ injection to increase baghouse efficiency were also characterized during the first year. The fuel used for these tests was a Monticello Texas lignite. The $\mathrm{NH}_{3}-\mathrm{SO}_{3}$ fly ashes were collected from a 
baghouse on a 500,000-Btu/hr, pulverized coal combustion unit. One of the samples was produced from a baseline combustion test in which no $\mathrm{NH}_{3}$ or $\mathrm{SO}_{3}$ was injected into the system, and the other sample was produced from a combustion test which used sufficient $\mathrm{NH}_{3}$ and $\mathrm{SO}_{3}$ injection to achieve concentrations of $25 \mathrm{ppm}$ and $12 \mathrm{ppm}$, respectively, in the flue gas.

During the second year, eleven different waste materials, all generated from coal utilization processes in development at the EERC, were characterized. The eleven materials included four wastes from low-temperature coal gasification runs performed for the Hydrogen Production project; six wastes from AFBC tests, which used a coal slurry fuel; and one waste from a coal preparation operation associated with the hot-water drying coal slurry process. The waste materials were tested for leachate trace metals and trace organics, elemental composition, mineral composition, and selected physical properties.

The four gasification waste samples included two gasifier bed materials from hydrogen production runs which used Martin Lake Texas 1ignite. Both runs were performed at a temperature of $800^{\circ} \mathrm{C}$ and a $3: 1$ steam-to-carbon molar ratio. One of the runs used a limestone bed material, and the other run used a silica sand bed material with a trona catalyst. The third gasifier bed material characterized was produced from a hydrogen production run with a Velva North Dakota 1 ignite. This run used a limestone bed, an $800^{\circ} \mathrm{C}$ gasification temperature, and a $2: 1$ steam-to-carbon ratio. The fourth gasifier bed material characterized was produced from a hydrogen production run with a Wyodak Wyoming subbituminous coal. This run used a limestone bed, an $800^{\circ} \mathrm{C}$ gasification temperature, and a $2: 1$ steam-to-carbon ratio.

The six AFBC waste samples were produced in tests performed at the EERC in a 1,000,000-Btu/hr, bubbling-bed combustion unit. The fuel used was a Sarpy Creek Montana subbituminous coal which was burned in the form of an aqueous slurry. The waste samples studied included a spent bed material (silica sand), a primary cyclone ash, a secondary cyclone ash, a baghouse fly ash, and a composite ash collected from the same combustion run. The sixth $A F B C$ waste characterized was a composite ash produced from a slurry combustion run that used limestone addition directly to the coal slurry to increase $\mathrm{SO}_{2}$ capture. The AFBC composite ash samples were prepared by blending the various process waste streams in direct proportion to the amounts of material produced during the combustion test. The proportions used were $90 \mathrm{wt} \%$ primary cyclone ash, 8 wt\% secondary cyclone ash, and 2 wt\% baghouse fly ash.

The coal slurry used for the AFBC tests was produced at the EERC with the hot-water-drying process. Wastes collected from slurry combustion runs may have different characteristics than wastes produced from pulverized, dry coal combustion runs because the slurry preparation process removes some watersoluble materials from the coal prior to combustion. To evaluate the differences in waste composition resulting from combustion of the coal in the form of a slurry, the waste characterization data presented in this report was compared to characterization data collected in previous studies from waste samples produced with the same coal burned in a dry form.

The waste sample from the hot-water-drying coal slurry process was produced from a float-sink run performed on a Beulah-Zap North Dakota lignite. 
The float-sink operation was part of the coal-cleaning procedure used for the slurry process.

Waste materials characterized during the third year included fly ashes produced from combustion tests performed at the EERC, in which pressurehydrated 1 ime was injected into the flue gas for $\mathrm{SO}_{2}$ control, and a solid waste from an EERC diesel engine burning a coal-derived liquid fuel. Three fly ash samples were obtained from combustion tests. The fuel used in the combustion tests was a Pittsburgh \#8 bituminous coal. The fly ash samples were collected in an electrostatic precipitator. The samples were obtained from baseline combustion runs during which no lime was injected, and from combustion runs with lime injection, which caused either a $50 \%$ or a $90 \% \mathrm{SO}_{2}$ content reduction in the flue gases.

The other waste material studied during the third year was a residual ash from a diesel engine, which was operated at the EERC and designed to burn coal-derived liquid fuels. The fuel used was a light coal tar fraction obtained from the Great Plains Coal Gasification Plant. The diesel waste was basically a high-carbon-content soot collected from the engine exhaust gas.

During the final year of this task, the remaining chemical characterization leaching procedures were completed, as were the analyses of the resulting leachates. Four unreacted limestone bed materials, generated from the Hydrogen Production project, were also chemically characterized.

\subsubsection{Goals and Objectives}

The overall goal of this task was to assess the impact of solid waste disposal requirements on the commercial viability of several coal utilization processes being developed at the EERC.

\subsubsection{Results and Conclusions}

The waste characterization test results for the first year are summarized as follows (1):

- None of the 14 materials tested would be classified as hazardous wastes based on their leachate trace metal contents, as determined by the USEPA EP Toxicity test.

- There were no trace organic compounds detected in leachates from any of the 14 waste materials. The trace organic analyses were performed by preparing acid and base/neutral solvent extracts from each waste leachate and then testing the extracts using gas chromatography/mass spectrometry (GC/MS). The minimum detection limit for the test procedure was $20 \mathrm{mg} / \mathrm{L}$ in the leachate (2).

- $\mathrm{pH}$ values of the ASTM leachates produced from the 14 waste materials ranged from 10.1 to 12.6. Selenium concentrations in three of the ASTM leachates exceeded the primary drinking water standard for selenium by more than a factor of 25 .

- The results of column leaching tests indicated that the principal water-soluble component in the wastes was calcium sulfate and that 
most of this material was extracted in the first ten pore volumes passed through the waste.

- Elemental analyses indicated that the 14 ash samples studied were principally composed of silicon, calcium, and aluminum with lesser amounts of sodium, sulfur, and iron also being present.

- The major mineral phases identified in the waste samples were quartz $\left(\mathrm{SiO}_{2}\right)$, anhydrite $\left(\mathrm{CaSO}_{4}\right)$, and lime $(\mathrm{CaO})$.

- The aqueous permeabilities of the waste samples ranged from $8.2 \times 10^{-3}$ to $1.9 \times 10^{-5} \mathrm{~cm} / \mathrm{sec}$, as measured by the falling head permeability test.

The characterization data generated for the 14 waste samples did not indicate that any major regulatory problems would be encountered relating to the disposal of these materials. Furthermore, two of the combustion-related processes developed by the EERC appeared to reduce the environmental impacts of the solid wastes being produced. The EPA-Extraction Procedure (EPA-EP) leaching test results showed that the 14 EERC wastes would not be classified as hazardous wastes based on their leachate trace metal content. Additionally, there were no trace organics found in the leachates from the wastes at the specified minimum detection limits.

Some state regulatory agencies may be concerned about the relatively high $\mathrm{pH}$ values of the ASTM leachates generated from many of the wastes. The selenium concentrations in the Gibbons Creek reinjection ash and the two Monticello fly ashes may also cause concern in some states, from a regulatory standpoint, since they exceed the primary drinking water standard by more than a factor of 25 .

The results of column leaching tests performed on the wastes indicated that calcium sulfate was the principal compound extracted. Generally, it appeared that the bulk of the leachable material was extracted from the waste in the first ten pore volumes passed. Barium $(15 \mathrm{mg} / \mathrm{L})$ and chromium $(2.9 \mathrm{mg} / \mathrm{L})$ were the only trace metals detected in any of the column leachates.

The presence of quartz as a major mineral phase in many of the wastes indicated that these materials are abrasive. Appropriate precautions would be taken with the design of waste-handling equipment to minimize equipment breakdown because of the abrasive nature.

The waste characterization data indicated that the use of limestone and $\mathrm{NH}_{3}-\mathrm{SO}_{3}$ as combustion-related additives tended to reduce the amounts of leachable selenium in the ash materials. Since high-selenium leachate concentration is a common problem in western low-rank coal waste, these types of results may be important factors which favor the continued development of these processes. 
The waste characterization test results for the second year are summarized as follows ( 3 ):

- EPA-EP leachates produced from all eleven of the coal utilization wastes contained trace metal concentrations well below the maximum allowable contaminant levels specified by Resource Conservation and Recovery Act (RCRA).

- No significant levels of trace organic compounds were detected in the leachates produced from the eleven wastes.

- The characterization studies indicated that no significant or unusual regulatory problems should be encountered for the disposal of the eleven coal utilization process wastes which were evaluated.

The characterization data generated for the eleven advanced process wastes did not indicate that any major regulatory problems should be encountered for the disposal of these materials on a commercial scale. The EPA-EP leaching test results clearly showed that the AFBC, hydrogen production, and coal slurry preparation wastes would not be classified as hazardous wastes based on their leachate trace metal contents under the existing RCRA regulations.

The column leaching tests performed on the composite ashes showed that significant reductions in the permeability coefficients of these materials occurred during the course of the tests, particularly for the AFBC ash produced with limestone addition. The permeability reductions were probably caused by pozzolanic reactions between the ash and the 1 imestone-derived reaction products. The observed behavior indicates that the permeabilities of the composite ashes may decrease by several orders of magnitude after the materials have been placed in a permanent disposal site.

The results for the third year are summarized as follows (4):

- With the exception of chromium, EPA-EP leachates produced from the combustion wastes ashes contained trace metal concentrations well below the maximum allowable contaminant levels specified by the regulations of the RCRA for hazardous waste classification.

- No significant trace organic compounds were detected in leachates produced from the hydrated lime injection wastes. It appeared that some organic material was extracted from diesel engine ash, but the materials could not be identified by routine GC/MS analysis.

- The aqueous permeabilities of the $50 \%$ and $90 \% \mathrm{SO}_{2}$ reduction fly ashes were both well below the $10^{-7}-\mathrm{cm} / \mathrm{sec}$ criteria generally required for clay liner materials.

- The fly ash obtained from the $90 \% \mathrm{SO}_{2}$ reduction test contained a significant amount of unhydrated calcium oxide that caused an extremely exothermal reaction when the material was wetted.

The characterization data generated for the lime injection fly ashes indicates that no major regulatory problems should be encountered for the 
disposal of these materials. The results of the EPA-EP leaching tests clearly showed that the waste would not be classified as hazardous based on trace metal content under the existing RCRA regulations.

Due to criticisms of the precision and field applications of the USEPA Extraction Procedure (EP) test, the Toxicity Characteristic Leaching Procedure (TCLP) was developed. The TCLP test officially replaced the EP test on September 25, 1990, and was mandated to evaluate wastes for additional contaminants, particularly organics.

The exothermal hydration behavior of the two fly ashes produced with lime injection could require implementation of special handling procedures if this $\mathrm{SO}_{2}$ control process were implemented on a commercial scale.

The diesel engine waste does not appear to pose any significant handling or disposal problems based on its inorganic trace element content. Although it was not possible to identify any specific trace organics, there did appear to be a significant amount of non-chromatographable material in the methylene chloride extract from the diesel engine waste.

The results for the final year are summarized as follows (5):

- Chemical characterization results show the 1 imestone bed materials to be nonhazardous according to the mandated regulatory leaching test, the toxicity characteristic leaching procedure (TCLP). Concentrations in the leachate for each bed material were determined to be below the hazardous limit as defined by RCRA.

- Results from the synthetic groundwater leaching procedures (SGLP) and the long-term leaching tests show these materials to be nonhazardous for the RCRA elements as well.

It is important to note that these procedures were included in the chemical characterization protocol to more closely approximate the leaching of these materials as a monofill in a natural setting as opposed to a landfill setting. The TCLP was designed specifically to approximate the leaching in a codisposal landfill setting. Materials such as these limestone bed materials are likely to be disposed of in a monofill rather than a sanitary landfill. Additional elements were determined in the various leachates generated. These results may be useful in the future as additional trace elements may be regulated or these materials may be investigated for potential utilization applications.

\subsection{Fly Ash Liner Development Study}

\subsubsection{Introduction}

A three-year research project was conducted at the EERC to develop fly ash-based liner materials for waste disposal sites. The research was conducted in three phases. Phase I of the project was a bench-scale laboratory study to formulate liner materials from mixtures of fly ash, hydrated 1ime, Type-1 portland cement, and water. 
In Phase I, six different fly ashes and mixtures of fly ash and scrubber waste from coal-burning power plants in five state were tested to evaluate their suitability as liner construction materials. The fly ash samples were supplied by the Northern States Power Cooperative (North Dakota), the Texas Utilities Generating Company (Texas), the Southwestern Electric Power Company (Texas), the Central Illinois Public Service Company (Illinois), and the Northern Indiana Public Service Company (Indiana).

Each of the six fly ashes was initially characterized for its elemental and mineral compositions, relevant physical properties, and leachate trace metal content. Experiments were then performed to develop a specific liner formula for each ash. The experiments determined the smallest amounts of lime, cement, or a mixture of lime and cement required for addition to each fly ash (at a specified water level) to produce a cemented liner material with a permeability coefficient less than $10^{-7} \mathrm{~cm} / \mathrm{sec}$ and an unconfined compressive strength greater than $400 \mathrm{psi}$.

During Phase II, liner slabs with dimensions of 4 square feet by 6 inches thick were prepared using the formulas developed in the Phase I work. The slabs were used to test the durability of the iiner materials and to verify the permeability and strength characteristics predicted by the formulation experiments. Each Phase II liner slab was placed in a leachate-compatibility test device and loaded with 6 inches of unconsolidated fly ash and 1.5 feet of water. Each slab was left in the test device for five months. An attempt was made to collect the leachate that passed through the slabs, but no measurable amounts of leachate appeared during the five-month test period. When the slabs were removed from the test device, permeability and strength tests were performed on cores cut from each slab.

Three of the six fly ashes studied in the laboratory were selected for field tests in Phase III. For the field tests, liner sections having dimensions of 40 feet by 40 feet by 2 feet thick were constructed at power plants located in Texas, Indiana, and Minnesota. The physical properties of the liner sections were monitored for approximately one year to evaluate their performance.

Three sets of samples were collected from each field site over a one-year period and sent to the EERC for testing. These samples were tested for permeability coefficient, unconfined compressive strength, textile strength, modulus of elasticity, Poisson's ratio, coefficient of thermal expansion, porosity, and dry density. In addition to the laboratory tests, a doublebarrel infiltrometer test was conducted at each of the sites to estimate the permeability of liner using an in-field method.

The Texas fly ash liner test was performed at the H.W. Pirkey Power Plant, owned by the Southwestern Electric Power Company (SWEPCO). The SWEPCO liner section was made with a Texas lignite fly ash. Approximately 5 wt\% portland cement, 1.5 wt\% hydrated 1 ime, and 18 wt\% (dry weight) water were added to the fly ash to produce the liner material.

The Indiana fly ash liner test was performed at the R.M. Schahfer Plant, owned by the Northern Indiana Public Service Company (NIPSCO). The NIPSCO liner section was made with approximately a 50:50 mixture of 111 inois \#6 fly ash and lime-based scrubber sludge. Approximately 5 wt\% portland cement, 
$3 \mathrm{wt} \%$ hydrated 1 ime, and $30 \mathrm{wt} \%$ (dry weight) water were added to the f1y ash scrubber sludge mix to produce the liner material.

The Minnesota fly ash liner test was performed at the Sherburne County Power Plant, owned by the Northern States Power Company (NSP). The NSP Iiner section was made with a dry-scrubber powder containing Sarpy Creek, Montana, subbituminous coal fly ash and a lime-based spray dryer residue. Approximately 23 wt\% (dry weight) water was added to the scrubber powder to produce the liner material. No lime or cement addition was required for the NSP liner.

\subsubsection{Goals and Objectives}

The purpose of the fly ash liner study was to develop cost-effective liner materials for utility waste disposal sites using mixtures of fly ash, water, hydrated lime, and/or portland cement.

\subsubsection{Results and Conclusions}

The results of the Phase I characterizations indicated that the six fly ashes generally exhibited acceptable physical properties for the liner application and that none of the materials could be classified as hazardous wastes based on their leachate trace metal contents. The results of the formulation experiments showed that liner materials with permeability coefficients less than $10^{-7} \mathrm{~cm} / \mathrm{sec}$ and unconfined compressive strengths close to or exceeding 400 psi could be made from each of the six fly ashes. The minimum lime, cement, or lime and cement addition rate required for the six fly ash liner materials ranged from $3 \%$ to $9.5 \%$ (of dry weight). The specific moisture addition level used to prepare the fly ash liner mixtures was found to be an extremely important factor in the development of proper permeability and strength characteristics. Generally, the moisture content had to be within plus or minus $2 \%$ of the specified value to achieve acceptable results (1).

The results from Phase II indicated that fly ash liner materials were quite stable during the five-month exposure period. The permeability coefficients and strengths measured for the liner cores were all less than $10^{-7} \mathrm{~cm} / \mathrm{sec}$ and greater than $400 \mathrm{psi}$, respectively. Additionally, none of the liner slabs developed any visible cracks, dimensional instability, or soft spots during the exposure periods (3).

The results of the SWEPCO field test generally indicated that the Texas lignite fly ash produced an acceptable liner material. Permeability coefficients measured in the laboratory for 12 liner samples varied from $1.4 \times 10^{-7} \mathrm{~cm} / \mathrm{sec}$ to $3.8 \times 10^{-9} \mathrm{~cm} / \mathrm{sec}$, and the permeability coefficient measured in the field was estimated to be less than $10^{-7} \mathrm{~cm} / \mathrm{sec}$. The liner material developed an unconfined compressive strength of approximately 1000 psi after curing in the field for one year. The only visible deterioration of the SWEPCO liner section during the field test was the development of some cracks on the liner surface. The cracks appeared to be limited to the top six inches of the liner (4).

The results of the NIPSCO field test indicated that the liner material did not meet the target permeability criteria. Permeability coefficients 
measured in the laboratory for 12 Indiana liner samples varied from $8.0 \times 10^{-5} \mathrm{~cm} / \mathrm{sec}$ to $2.0 \times 10^{-9} \mathrm{~cm} / \mathrm{sec}$, and the permeability coefficient measured in the field was estimated to be $7.8 \times 10^{-7} \mathrm{~cm} / \mathrm{sec}$. The 1 iner material developed an unconfined compressive strength of approximately 700 psi after curing in the field for one year. The only visible deterioration of the liner section during the field test was some crumbling at the liner surface. The crumbling extended about two inches below the surface. Although the permeability of the NIPSCO liner did not meet the target level of less than $10^{-7} \mathrm{~cm} / \mathrm{sec}$, it may still be usable for some liner applications since Indiana regulations only require that liners for coal combustion wastes have a permeability coefficient less than $10^{-6} \mathrm{~cm} / \mathrm{sec}(4)$.

A problem occurred with the NSP liner material used for the field test when shrinkage cracks developed in the initial stage of curing. The shrinkage was reduced by decreasing the amount of water added to the liner mix from $23 \mathrm{wt} \%$ to approximately $20 \mathrm{wt} \%$ (dry weight). Unfortunately, decreasing the water content of the liner mix caused its permeability to increase. The permeability coefficient estimated from the in-field test was $1.8 \times 10^{-5} \mathrm{~cm} / \mathrm{sec}$. The unconfined compressive strength of the NSP 1 iner ranged between 1000 and 2000 psi (4).

It was not possible to determine from the results of the field test whether the shrinkage cracks in the NSP liner were continuous. If the cracks were not continuous through the full depth of the liner, then the material may have been acceptable as a liner (4).

Mineralogical and microscopic characterization of the fly ash liner materials collected at the field-test sites produced valuable information about their composition and microstructure. For the SWEPCO liner, the fly ash particles appeared to be held together by fibrous bridges and surface-tosurface point adhesions. The fibrous bridges may have been composed of ettringite. For both the NSP and the NIPSCO liners, the fly ash particles appeared to be held together by a continuous, interparticle matrix composed primarily of consolidated scrubber material. Significant amounts of ettringite were also detected in these two liner materials (4).

A cost analysis of the liner materials indicated that the main factors which determined the unit cost of the materials were the amounts of $1 \mathrm{ime}$ and cement added and the cost credit allowed for avoided disposal cost for the fly ash. The analysis also indicated that the fly ash liner materials were generally in the same cost range as polymeric membrane liners (4).

An engineering analysis of the fly ash liners indicated that both temperature-induced and load-induced stresses could cause cracking. The results of the analyses suggested that it would be advisable to cover the fly ash liners with several feet of compacted ash as quickly as possible after construction to protect the liner (4).

\subsection{Numerical Modeling of Disposal-Related Soil Properties}

\subsubsection{Introduction}

This task was conducted to develop a procedure for identifying inconsistent permeability data obtained from laboratory tests on soil 
properties from candidate waste disposal sites. Such inconsistent data can result from improper sample collection, sample storage, or laboratory testing. Having the capability to check results for consistency is critical because a single permeability measurement that does not meet the specified regulatory criteria for soil liners may exclude a candidate disposal site from being permitted.

A soils data-screening procedure was developed by compiling a relatively large data set, containing information on the permeability coefficient, liquid limit, plasticity index, and percent passing a \#200 sieve, of soil samples collected at five power stations in east-central Texas. The screening procedure was based on a statistical model which predicted the permeability of a soil sample from its plasticity index and percent passing a \#200 sieve. To screen the data set, each of the measured permeability coefficients was compared to its predicted permeability coefficient, and the difference between the two values was used as a measure of consistency for the data. If it was found that there was less than a five percent chance that a measured permeability coefficient would have been predicted by the model, it was concluded that the permeability measurement was significantly different from the rest of the data set. This finding could then be used as a basis for removing the inconsistent measurement from the data set.

\subsubsection{Goals and Objectives}

The purpose of this task was to develop a statistical procedure for checking the consistency of permeability data from candidate waste disposal sites in the Texas lignite region. This procedure can then be used to screen newly acquired soils data to identify test results that appear to be inconsistent with other data collected in this region.

\subsubsection{Results and Conclusions}

The mean values for log permeability coefficient, liquid limit, plasticity index, and percent passing a \#200 sieve were a 11 we 11 within the acceptable ranges of the Texas Department of Water Resources (TDWR) Iiner criteria. All of the soil properties displayed relatively wide ranges of values, and all of the properties followed skewed distributions (3).

No strong correlations were found between permeability and the other soil properties. The best correlation was found between the liquid limit and the plasticity index (3).

The data regression analysis indicated that the plasticity index was the variable which had the largest effect on the permeability model. Percent passing the \#200 sieve had the next largest effect, and liquid limit had the smallest effect on the model (3).

The data-screening procedure was designed to identify permeability measurements that are inconsistent with the rest of the reference data set based on the interrelationships exhibited between the various soil properties. This inconsistency does not necessarily mean that a permeability measurement is erroneous; however, it does indicate a high probability that the measurement is in some way different from the other measurements. The screening procedure should be used along with any other available information 
about the sample to make the final decision whether or not to remove the sample from the data set (3).

\subsection{Leaching Test Evaluation}

\subsubsection{Introduction}

This task was conducted as a response to the proposed changes to the solid waste regulations under RCRA Subtitle $C$ amendments, which expanded the Toxicity Characteristic evaluation procedure to include additional chemicals and introduced a new extraction procedure to evaluate toxicity.

A study was performed to evaluate the use of follow-on TCLP tests. This was done by performing replicate leaching tests on two coal gasification tar samples using both Morgantown Energy Technology Center (METC) and TCL procedures. The METC leaching tests were used to identify the various classes of nonvolatile trace organics in the waste leachates, and the TCLP tests were used to quantitatively identify the organics which had specific regulatory criteria.

\subsubsection{Goals and Objectives}

The goal of this task was to evaluate the use of follow-on TCLP leaching tests in response to changes in the solid waste regulations under RCRA Subtitle $C$ Amendments.

\subsubsection{Results and Conclusions}

The results of the study indicated that the METC procedure was an effective means of screening the gasifier tar leachates for nonvolatile organic compounds (3).

All of the compounds detected during the METC leaching tests conducted on the "dry" and "oily" tar samples were aromatics, with phenolics present in the highest concentration. The analyses obtained using the METC leaching procedure for the two tars were similar except that the dimethylphenols and naphthalene were detected only in the dry tar leachate (3).

Some of the compounds identified with the METC leaching test were not detected in all of the replicates, but the two classes of regulated nonvolatile organics, phenol and cresols, were detected in all of the replicate leaching tests (3).

Six regulated organics were detected in each tar sample. The TCLP leaching method and the associated analyses appeared to do an excellent job of quantitatively identifying the phenolics which the METC method had indicated were present in the tar leachates (3).

\subsection{Electrostatic Separation of Unburned Carbon from Fly Ash}

\subsubsection{Introduction}

An "off-the-shelf" electrostatic separation process was modified for use to reduce the unburned carbon content of fly ash. A bench-scale separator 
apparatus was constructed at the EERC and a series of test runs were performed to optimize the process. After the process was optimized, a sufficient amount of low loss-on-ignition (LOI) fly ash was collected to determine its air entrainment characteristics.

The fly ash used for the separation tests was obtained from the Allen $S$. King Power Plant owned by the Northern States Power Company, Minnesota. The King plant burns a mixture of Wyoming and Montana subbituminous coals and Illinois bituminous coal.

The separator apparatus was operated by dispensing fly ash from a vibrating pan through a slit onto a grounded, rotating steel drum. The high LOI ash fraction falls off the drum due to gravity as it rotates. The low LOI ash fraction sticks to the wheel due to electrostatic forces and is scraped off at a separate collection point.

\subsubsection{Goals and Objectives}

The goal of this task was to reduce the unburned carbon content of fly ash using a modified electrostatic separation process. Specifically, the goal was to produce fly ash with an LOI of less than $3 \%$ using the electrostatic separation process.

\subsubsection{Results and Conclusions}

The results of the separator tests showed that the apparatus was capable of splitting the bulk fly ash, which had an LOI of $7.3 \%$, into two physically separate fractions. One fraction contained approximately 25 wt\% of the ash and had an LOI of $3.6 \%$ while the other fraction contained the other $75 \mathrm{wt} \%$ of the ash. Air entrainment tests performed on the two fly ash fractions indicated that the low LOI fraction required $13.2 \%$ less air entraining agent than the bulk fly ash to produce an equivalent entrained air level (4).

It was not possible to achieve the goal of producing a fly ash with a LOI of 1 ess than $3 \%$ in the test runs that were performed. However, the ASTM C618 fly ash specification for cement replacement only requires that fly ash have an LOI of less then $6 \%$, which the separation process easily achieved (4).

Based on the results of the bench-scale tests, it appears that the electrostatic carbon removal process has commercial development potential, since it is mechanically quite simple and produces significant carbon removal with a relatively low energy input. One drawback of the process is that only about $25 \%$ of the bulk fly ash is recovered in the low LOI fraction. However, it may be possible to increase this recovery with further development of the process. Furthermore, some power plants may not be able to sell more than $25 \%$ of their fly ash for cement replacement due to market limitations (4).

\subsection{Bituminous Coal Fly Ash Data Collection and Evaluation}

\subsubsection{Introduction}

The Western Fly Ash Research, Development, and Data Center (WFARDDC) is a research group funded by a consortium of sponsors interested in the utilization and safe economical disposal of coal by-products. A major research 
effort since the initiation of the WFARDDC has been the development of a database of information on the physical, chemical, and mineralogical properties of low-rank coal by-products, primarily fly ash. A database, such as the one generated by the WFARDDC, provides a valuable source of scientific and engineering information. The format is useful in identifying trends and specific information pertinent to current and potential utilization applications as well as disposal scenarios and research projects involving coal by-products. The current version of the Western Fly Ash Database contains entries representing more than 500 samples of low-rank coal by-products. WFARDDC researchers have begun a statistical evaluation of the information in this database. Information continues to be entered into the database, and the evaluation process is continuing. The initial evaluation of the database has provided valuable information regarding low-rank coal by-products and has initiated interest in researchers, electric power utilities, coal by-products marketers, and others to extend the database to include similar information on bituminous coal by-products. Bituminous coal fly ash is of particular interest due to the high volume of this material utilized and disposed, primarily in the Midwest and eastern United States. A database of information on bituminous coal fly ash has the potential to provide information valuable to the electric utility industry as it strives to meet regulatory mandates, such as the Clean Air Act, by blending coal and utilizing alternate coal combustion methods and by-product collection systems.

The effort to collect and evaluate physical, chemical, and mineralogical information on bituminous coal fly ash will result in a database that can be merged with the current Western Fly Ash Database or be utilized as a standalone database. As with the current database, the information will not identify the by-products by electric utility or company affiliation to guarantee anonymity to the participants in this effort.

Interaction with utilities, coal ash marketers and end users, as well as research groups in the areas of coal combustion technologies and environmental systems, has indicated a strong interest in the characteristics of solid byproducts or residues from advanced coal combustion technologies. In order to facilitate a scientific and engineering understanding of the characteristics of these materials, this task was expanded to include the development of a database of information on the physical, chemical, and mineralogical characteristics of advanced coal process residues. This preliminary investigation will pro'side information on which standard engineering and analytical tests are applicable and what new or innovative testing may provide more valuable and predictive information. It will also provide a basis for comparison of the residues generated by various technologies with each other and conventional solid by-products.

\subsubsection{Goals and Objectives}

The primary objective of this task is to collect and evaluate information on the physical, chemical, and mineralogical properties of bituminous coal fly ash and to generate a database of this information. 


\subsubsection{Bituminous Coal Fly Ash Data Collection and Evaluation Results}

The primary objective of this task--to collect and evaluate information on the physical, chemical, and mineralogical properties of bituminous coal fly ash--is a long-term objective that will continue for the EERC coal by-products research group well past the end of this task. During. the time frame of this specific task, the primary objective has been met to the expected level. The primary end result of this effort has been the construction of a database of information on bituminous coal fly ash. The construction of the database also provided opportunities to relate the by-product properties and production to the overall coal-fired electric power generation facility. As a result, several observations can be made that should significantly impact the overall understanding of the coal combustion by-product utilization industry, the by-product disposal practices, the functional relationships within a utility, and the impact of research in these areas. These observations, coupled with the technical expertise required to generate the characterization information for the database and the database itself, should provide useful insight for the research community to address important waste management issues (10).

The components of the database are the major and minor elemental constituents (expressed as oxides), mineral phases identified in the crystalline portion of the fly ash, selected physical properties and test results relevant to the utilization of fly ash as a mineral admixture in concrete, and information on the operating system and coal source (10).

The chemical characterization information consists of two groups. The first is the results as dictated by the ASTM C618 (1991). The chemical composition information required by the ASTM to classify fly ash is the total concentration of silicon, aluminum, iron, sulfur, and calcium. Magnesium, sodium, and potassium are included in the ASTM procedures as alternate information. These have also been included in the database for as many samples as possible. Test results from the ASTM designated procedures for moisture (mass of water lost at $105^{\circ}-110^{\circ} \mathrm{C}$ ), loss-on-ignition (LOI, mass lost at $750^{\circ} \mathrm{C}$ ), and available alkali (soluble sodium and potassium reported as equivalents of $\mathrm{Na}_{2} \mathrm{O}$ ) are also included in the database. The second portion of the chemical information in the database includes total concentrations of other minor elemental constituents. These elements were phosphorus, titanium, barium, manganese, and strontium. In keeping with the ASTM convention for reporting the concentrations of major elements in fly ash, all major and minor elemental concentrations were calculated and reported as the common oxides. ASTM also requires the sum of the $\mathrm{SiO}_{2}, \mathrm{Al}_{2} \mathrm{O}_{3}$, and $\mathrm{Fe}_{2} \mathrm{O}_{3}$ values for evaluation under $\mathrm{C618}(10)$.

In the physical portion of the database, the tests performed were fineness ( 325 sieve test), specific gravity, pozzolanic activity test with portland cement ( 28 day), pozzolanic activity with lime ( 7 day), water requirement, and autoclave expansion. These tests are also included in the ASTM C618 "Standard Specification for Fly Ash and Raw or Calcined Natural Pozzolan as a Mineral Admixture in Portland Cement Concrete." These procedures were performed in accordance with ASTM C311 (1990) (10).

Fly ash mineralogy was determined by a semiquantitative x-ray powder diffraction protocol developed by Dr. Gregory McCarthy at North Dakota State 
University. This method uses the Reference Intensity Ratio, where rutile $\left(\mathrm{TiO}_{2}\right)$ is the internal intensity standard. Fly ash is composed of crystalline and amorphous or glassy phases. X-ray diffraction only identifies the crystalline phases. Future research may include the use of scanning electron microscopy point count (SEMPC) to determine the chemistry of the amorphous phases (10).

Ash fusion was also performed on most samples represented in the database. The ash fusion procedure was performed according to ASTM D1857 (1968), and ash fusion temperatures in both an oxygen atmosphere $\left(\mathrm{O}_{2}\right)$ and a reducing atmosphere $\left(\mathrm{CO}_{2}\right)$ were generated $(10)$.

As noted earlier in this section, some important observations regarding the understanding of the coal combustion by-product utilization industry, the by-product disposal practices, the functional relationships within a utility, and the impact of research in these areas, were made over the duration of this task. These observations can be summarized as follows (10):

- Coal combustion fly ash is an underutilized resource in the United States. Government agencies, utilities, and research organizations need to coordinate efforts to promote ash use in current proven applications and extend ash use to new markets and applications.

- ASTM has set standards and specifications for the use of coal combustion fly ash in specific applications; however, these standards and specifications can be misleading and may be misapplied. Industry and research groups need to continue participation in ASTM committee work to maintain appropriate standards and to develop new and improved standards and specifications where needed.

- Regulatory agencies should encourage the use of coal combustion fly ash in proven applications. The use of coal combustion fly ash is consistent with the current emphasis on reuse and recycle. The use of this high-quality and lower-cost material can provide an economic advantage in rebuilding and expanding the U.S. infrastructure.

- Coal combustion fly ash should not be categorized as a waste material when it is utilized in engineering or other applications. Coal combustion fly ash should only be designated as a waste in the event the material requires disposal.

- Coal combustion fly ash must not be compared to, or confused with, fly ash resulting from the combustion of other materials, such as municipal solid waste or refuse. It is incorrect and inappropriate to regulate "ash" as a single type of material.

- Coal-fired electric generation facilities need to consider the production of coal combustion fly ash and other solid residues as an additional product resulting from their operations. This will become particularly advantageous as additional environmental restrictions are placed on air emissions and solid waste disposal. Production of a usable and salable solid residue will be highly advantageous. 
- Conventional coal fly ash will likely change in character as advanced coal combustion techniques, clean coal technologies, and new emissions control technologies become more prevalent. These new characteristics need to be investigated for utilization potential immediately to fit them into the current market and develop new markets for the future.

\subsubsection{Advanced Coal Process Residues Database Results}

A preliminary spreadsheet database of information on residues from various advanced coal processes has been generated. The effort required to complete this database is beyord the scope of this task; however, identifying and characterization information available at the EERC, through past and ongoing research projects involving these new coal conversion residues, has been collected and placed in a Lotus ${ }^{(1)} 1-2-3^{\oplus}$ spreadsheet as the initial step toward constructing a complete database similar in scope to the coal combustion fly ash database (which now includes the bituminous coal fly ash database) (10).

Part of the effort required to begin generating reliable and reproducible mineralogical characterization information on advanced coal process residues was to develop a semiquantitative $x$-ray powder diffraction technique. The protocol was developed by Dr. Gregory McCarthy at North Dakota State University under a subcontract to the EERC. The protocol uses the Reference Intensity Ratio, which requires mixing a fixed amount of an internal standard with each residue. Rutile $\left(\mathrm{TiO}_{2}\right)$, the internal standard used for coal combustion fly ash, produced peaks overlapping with analytical peaks of the new phases in the advanced coal process residues. An alternative internal standard, zinc oxide ( $\mathrm{ZnO})$, was identified (10).

Future work should include the expansion of the Advanced Coal Process Residues Database. It is crucial to develop a solid understanding of these materials and to be able to compare their properties in order to use and/or dispose of them safely and cost effectively (10).

\subsection{Activated Carbon Evaluation}

\section{7 .1 Introduction}

Activated carbons have many uses in industry. Most uses are associated with manufacturing and water purification, such as color removal and the removal of toxic or refractory compounds from waste streams. Additional uses are the removal of odorous compounds from industrial gas discharges and the adsorption of solvent vapor after air stripping of contaminated water.

Common materials utilized for the production of activated carbon include lignite and bituminous coals, wood, peat, heavy-petroleum fractions, and waste materials from pulping. In the process of activation, the carbon materials acquire a high surface area that provides a high efficiency of adsorption. Typical operations in the formation of activated carbon include devolatilization at about $590^{\circ} \mathrm{C}$, followed by activation with steam or carbon dioxide at approximately $900^{\circ}$ to $1010^{\circ} \mathrm{C}$. Activation results in weight loss in the range of $30 \%$ to $60 \%$. The loss of weight follows the enlargement of the pores during the oxidation that causes the increase in activation. Following 
activation, the carbon may be crushed, ground, grated, washed to reduce ash content, and dried.

A review of the literature pertaining to methods of characterizing and evaluating activated carbons was performed. Based on this review, methods were selected for laboratory evaluation. In addition, commercial vendors of activated carbons were contacted and several activated carbons were ordered for evaluation.

The analytical methods selected for characterizing and evaluating the chars and the activated carbons included surface area, sieve analysis, iodine number, molasses number, methylene glue number, bulk density, real density, apparent density, particle density, abrasion number, hardness number, and ash content.

Two mild gasification produced chars were collected. These included char samples from Red Harmon and Royal Oak lignites. Testing of these chars for characterization and evaluation was initiated. A mild gasification activated sludge effluent was used to evaluate the treatment efficiency of the lignite chars.

\subsubsection{Goals and Objectives}

The goal of this task was to characterize and evaluate chars produced from the mild gasification of lignite for use in the commercial activated carbon market or for cost-effective treatment of wastes generated by the mild gasification process.

\subsubsection{Results and Conclusions}

Preliminary testing of the Red Harmon and Royal Oak lignite chars indicated that they were not well suited for direct use as activated carbon. A comparison of lignite char and activated carbon characteristics is shown in Table 1. The values for effective size and uniformity coefficient for the lignite chars are approximately $60 \%$ less than those obtained using the commercial activated carbons. The mild gasification-produced lignite chars tended to be extremely friable and suffered from a high rate of attrition during handling (8).

The Red Harmon char-treated activated sludge effluent showed a chemical oxygen demand (COD) reduction of $17 \%$, from $808 \mathrm{mg} / \mathrm{L}$ to $670 \mathrm{mg} / \mathrm{L}$. Color was reduced from 3600 to 3300 APHA PtCo color units using the Red Harmon char, an $8.3 \%$ removal rate. Royal Oak char resulted in a COD reduction of $20 \%$, from $808 \mathrm{mg} / \mathrm{L}$ to $645 \mathrm{mg} / \mathrm{L}$. Royal 0a'. char reduced color from 3600 to $2700 \mathrm{APHA}$ PtCo units, a $25 \%$ reduction. An identical dosage of Calgon F-400 activated carbon resulted in $\mathrm{COD}$ and color removals of $90 \%$ and $98 \%$, respectively (8).

As-received mild gasification lignite chars are not well suited for direct use as an activated carbon. Surface area of these chars is less than desired for high-adsorption efficiency. Lignite chars exhibited a high degree of friability and suffered from elevated rates of attrition during handling. However, chars produced may be suitable for use following an activation step. Continuing research under this task will evaluate the effects of activation on mild gasification-produced lignite chars (8). 
TABLE 1

Comparison of Lignite Char and Activated Carbon Characteristics

\begin{tabular}{lcccc}
\hline & $\begin{array}{c}\text { Red Harmon } \\
\text { Char } \\
12 * 30\end{array}$ & $\begin{array}{c}\text { Royal Oak } \\
\text { Char } \\
12 * 30\end{array}$ & $\begin{array}{c}\text { Calgon } \\
\text { F-400 } \\
12 * 40\end{array}$ & $\begin{array}{c}\text { Norit } \\
\text { Hydrodarco } \\
12 * 40\end{array}$ \\
\hline Parameter & 211 & 183 & 404 & 271 \\
Surface Area (m $/ \mathrm{g})$ & & & & \\
Sieve Analysis (max \%) & 0 & 0 & 0.6 & 9.8 \\
Larger than No. 12 & 9.7 & 5.6 & 0 & 0 \\
Smaller than No. 30 & 0.4 & 0.2 & 0.4 & 0.4 \\
Smaller than No. 40 & 1.2 & 1.2 & 2.1 & 2.2 \\
Uniformity Coefficient & 0.7 & 0.7 & 1.1 & 1.2 \\
Mean Particle Diameter (mm) & 0.6 & 0.6 & 0.7 & 0.6 \\
Effective Size (mm) & 24 & 68 & 73 & 57 \\
Hardness Number (100 max) & 41 & 67 & 73 & 52 \\
Abrasion Number (\%) & 174 & 151 & 1150 & 640 \\
Iodine Number (mg/g) & 574 & 556 & 480 & 430 \\
Apparent Density (kg/m $\left.{ }^{3}\right)$ & 20.4 & 26.9 & 7.1 & 19.6 \\
Ash Content (\%) & & &
\end{tabular}

- Values obtained at EERC laboratories.

Samples of the Royal Oak and Red Harmon chars were subjected to activation by steam and by syngas $\left(\mathrm{H}_{2} \mathrm{CO}\right)$ activation methods. Neither of these methods resulted in a significant increase in surface area. Royal Oak char exhibited only a $4 \%$ increase in surface area when subjected to activation with syngas. Steam activation of the Royal 0ak char resulted in a decrease in surface area from the original char (8).

Continuing research of activated char should include the examination of the processing and handling of the char material as it is done in the mild gasification process because it is suspected that the char may be exposed to the atmosphere while still hot, resulting in the oxygen of the atmosphere "burning" out the pores of the char particles. Future research should also include examining the effect of altering the temperatures of the mild gas process. Higher temperatures during the carbonization of the material is said to produce a better carbon particle $(8)$.

\subsection{Coal Ash Conditioning Study}

\subsubsection{Introduction}

Dry coal utilization wastes are usually noncohesive materials which flow freely if not confined and are readily susceptible to dusting. Water is often mixed with these wastes prior to ultimate disposal to increase cohesion, 
reduce dusting, and lubricate the particles for better compaction. This operation is referred to as waste conditioning.

Conditioning of conventional fly ash usually requires the addition of between $10 \%$ to $15 \%$ water. For wastes from advanced processes such as AFBC with limestone addition, conditioning accomplishes an additional function because the water serves to hydrate the excess lime $(\mathrm{CaO})$ created during the combustion process. Thus for conditioning wastes that contain substantial amounts of unhydrated lime, a significantly higher water addition level may be required compared to conventional coal combustion wastes.

In addition to controlling dust and increasing compaction, the conditioning process can also affect the extent to which cementitious and pozzolanic reactions occur in the waste after it has been placed at the disposal site.

During the first year, four coal utilization wastes were characterized to provide baseline elemental composition, mineral composition, and physical property data for the conditioning process evaluation. The advanced process wastes that were studied included a composite cyclone ash and baghouse fly ash from the Tennessee Valley Authority (TVA) Shawnee AFBC unit, an electrostatic precipitator (ESP) fly ash from the NSP Black Dog AFBC unit, and a spent-bed material from the KRW fluidized-bed gasifier. All three wastes were produced from processes that used limestone addition to the bed for sulfur capture.

In addition to the three advanced process wastes, a fly ash from a Riverside conventional cyclone-fired boiler burning a western subbituminous coal (WSC) was included in the conditioning study. This ash was included because it exhibited some of the same types of problematic behavior as the advanced process wastes. Moisture-density tests were also completed on the Black Dog and Riverside fly ashes.

The wastes considered for characterization during the second year included EERC materials from the low-temperature coal gasifier and the circulating fluidized-bed combustor (CFBC). Emphasis for the waste characterization task during the second year was on limestone bed materials from the Hydrogen Production project.

Two sets of conditioned fly ash specimens were prepared for physical, chemical, and mineralogical analyses. The fly ash was obtained from a Black Dog AFBC. The specimens were prepared using two different conditioning moisture levels and four different curing times in order to track changes in the physical, chemical and mineralogical properties of the conditioned ash for the first 28 days of the curing process.

A conceptual design was developed during the last year of this task for an ash-handling process to condition 50 ton/hr of self-heating AFBC ash. In this process, the ash will be mixed as a slurry with $55 \%$ moisture added on a dry weight basis. This conditioning moisture le, 1 was selected to fully hydrate the AFBC ash and provide a 30\% residual moisture content, which previous studies have indicated will be the optimum moisture for producing the maximum compacted density. In this conceptual model, the conditioned ash would then be stored for a short period to allow the steam released by 
hydration reactions to dissipate and the ash to cool s?ightly before it would be transported to the ultimate disposal site.

The design of the conceptual ash-conditioning system was developed using certain assumptions. These included a 50-ton/hr conditioning rate, continuous operation, and a maximum transfer distance of $100 \mathrm{ft}$ from the main silo to the feed silo. These assumptions, in conjunction with the physical and chemical characteristics of the ash mixture, were the basis for the design of the system.

The proposed conceptual AFBC ash-conditioning system was broken down into four main operations: ash conveying, temporary ash feed storage, and mixer feed; mixer operation; temporary conditioned ash storage for hydration; and conditioned ash transport and ultimate disposal.

Chemical and mineralogical investigations of the original $A F B C$ residues and samples of conditioned AFBC residues will be included in this study to determine the chemical reactions and mineralogical-phase transformations that may occur during the conditioning process. Major, minor, and trace inorganic constituents of the original and conditioned residues will be studied, and experiments will be designed to investigate the mobility of trace inorganic constituents in the conditioned residues.

\subsubsection{Goals and Objectives}

The purpose of this task was to evaluate conditioning procedures for advanced coal utilization wastes and to evaluate trace element mobility within conditioned wastes.

\subsubsection{Results and Conclusions}

A dominant characteristic of all four wastes was a high calcium content. For the AFBC ashes, much of the calcium was present as free lime. For the KRW and Riverside wastes, however, only a small percentage of the calcium appeared to be in the form of free lime. The AFBC ashes liberated large amounts of heat when mixed with water and displayed a tendency to self-harden. The Riverside ash liberated a moderate amount of heat when mixed with water, but displayed a much greater tendency to self-harden. The KRW waste did not display significant self-heating or self-hardening behavior (5).

The three advanced process coal utilization wastes all had relatively high calcium and sulfur contents due to the fact that limestone was added to the AFBC and gasifier beds for sulfur capture. The Riverside fly ash also had a high calcium content due to the presence of calcium-bearing minerals in the coal rather than to an added sorbent.

Lime was found to be a major component of both the Black Dog and Tennessee Valley Authority (TVA) AFBC ashes. The lime was produced by calcination of limestone in the combustor bed.

The wastes were found to contain essentially no moisture, which was expected since the lime tended to bind any moisture in the waste through hydration reactions. The LOI measured for the Black Dog and TVA AFBC ashes were relatively high compared to conventional coal combustion ash. The 
extremely low LOI of the KRW gasifier bed material was probably caused by the oxidation of sulfide during the LOI test.

The advanced process wastes, particularly the AFBC ashes, appeared to contain significant amounts of free lime $(\mathrm{CaO})$ as indicated by their high initial $\mathrm{pH}$ values and large buffering capacities in the 11- to 12-pH range. In contrast to the advanced process wastes, the conventual Riverside fly ash contained only a small amount of free lime. The Riverside fly ash, however, displayed a large buffering capacity in the $\mathrm{pH}$ range of 5.5 to 2.0 .

Titration curves indicated that the advanced process wastes had a different gross chemical composition, at least in terms of acid-neutralizable components, compared to the Riverside fly ash. The titration of the KRW spent-bed material liberated a strong odor of hydrogen sulfide, indicating the presence of calcium sulfide in the waste. The results of the KRW titration indicated that the calcium sulfide content was in the range of 5 to $10 \mathrm{wt} \%$.

Moisture-density tests were completed on the Black Dog and Riverside fly ashes. Based on observation made during these tests, it appeared that selfhardening reactions occurred after the water was added and caused the Riverside ash to set up after about 15 minutes. As the ash set up, it changed from a fine powder to a coarse, granular material which was much less cohesive when compacted. The Black Dog ash also hardened after water was added, but to a much lesser extent than the Riverside ash.

It was found that if the amount of conditioning water was less than about $35 \%$, the $\mathrm{Black}$ Dog ash heated to $100^{\circ} \mathrm{C}$ (with an accompanying generation of steam). When the amount of water was greater than $35 \%$, the maximum ash temperature decreased. Apparently the additional water absorbed enough of the heat liberated from lime hydration to keep the temperature from reaching $100^{\circ} \mathrm{C}$. The Riverside ash showed a gradual increase in maximum temperature as the amount of conditioning water was increased to about $20 \%$. The difference between the two ashes is probably due to the fact that the heat released by the Black Dog ash was principally caused by lime hydration, while the heat released by the Riverside ash was principally caused by tricalcium aluminate hydration.

Both ashes consumed some of the water added during the conditioning tests. The difference between the water added and the water contained represents the water lost to either hydration reaction, evaporation, or steam generation. For the Black Dog ash, water loss (about 10\%) was independent of the amount of conditioning water initially added to the ash, but for the Riverside ash the water loss gradualiy increased to a maximum of about $10 \%$ as the amount of added water increased.

Although the self-heating and water-loss relationships indicated by the conditioning tests appear well defined, caution must be used when applying this type of information to field disposal. The chief difference between laboratory tests and field conditions is the bulk quantities of ash handled. The relatively small amounts of ash used for the laboratory tests will lose both heat and water more readily due to evaporation and steam generation than the large quantities of ash handled in the field. This means that ash handled in the field may get hotter, stay hot longer, and lose less water than the laboratory data indicates. 


\subsubsection{Bulk Chemical and Mineralogical Characterization}

In this study, proton-induced $x$-ray emission (PIXE) results were used to determine an initial list of trace elements for quantitation in the two residues. That list included all RCRA elements, even if they were not identified by the PIXE results. Other highly mobile elements were also included for completeness.

The chemical characterization protocol included the quantitative analysis of the trace elements and the major and minor inorganic constituents. Major/minor inorganic constituents, present in percentage amounts in the samples, were silicon, aluminum, iron, calcium, magnesium, sodium, potassium, titanium, phosphorous, strontium, and manganese. Moisture content, LOI, and carbonate were also determined in the original materials.

Mineralogical characterization by x-ray diffraction of the bulk samples was completed.

\subsubsection{Results of Trace Element Mobility Investigations}

These tasks involved the investigation of trace element mobility in test cylinders of the residues conditioned with different levels of moisture and at four curing times. Slices of these conditioned materials were submitted for the trace element mobility investigations. Two slices, approximately l-inch thick, were taken from the center of each cylinder. One slice was kept intact for the trace element mobility study, and the second was dried and crushed for potential use in a future leaching characterization study. A split of the material prepared for the leaching characterization was ground to -60 mesh for mineralogical investigations to be performed in conjunction with the leaching. All these samples have been retained and are being stored pending future funding for a leaching characterization study. The leaching characterization proposed was determined to be beyond the scope of this subtask. Additional sample preparation was required for the trace element mobility studies. The cylinder section that was reserved for this purpose had samples drilled out of specific regions of the slice using a carborundum drill bit. A sample was obtained from the center of the slice, from the edge or perimeter of each slice, and from a concentric ring between the two samples. This protocol resulted in three distinct samples for each conditioned sample that was submitted. A carborundum bit was chosen because any contamination of the samples by the drill bit would be readily recognized during the mineralogical characterization of these samples. Following this sample preparation procedure, forty-eight samples of conditioned residues were submitted for analysis of total trace elements and major/minor inorganic constituents analysis. These same samples were submitted for $x$-ray diffraction to identify mineralogical phases present and for comparison of the mineralogy of the conditioned versus nonconditioned material. Mineralogy was determined on the 1- and 28-day cured, conditioned materials at both moisture levels investigated in the engineering study under this task (10).

The chemical analyses results, in conjunction with the mineralogical results, indicate that the mobility of elemental constituents in conditioned $A F B C$ residues is virtually nondetectable. Results of the total chemical analysis are the same within the variability of the analytical method and the heterogeneous nature of these residues. Statistical analysis of these results 
was not performed, as general observations were adequate to conclude that the mobility of major, minor, and trace element constituents was very low even at the lowest curing times and moisture contents. Even the most mobile

constituents, such as chloride and sodium, showed no trend of mobility in this study. The only mineralogical changes that were noted between 1-day curing and 28 days of curing was the formation of gypsum, which is a hydrated form of $\mathrm{CaSO}_{4}$. Anhydrite, the nonhydrated form of $\mathrm{CaSO}_{4}$, was present in the sample at 1 -day curing time in all cases. Only one sample, the Black Dog AFBC at $37 \%$ moisture, showed the development of ettringite $\left(\mathrm{Ca}_{6} \mathrm{Al}_{2}\left[\mathrm{SO}_{4}\right]_{3}[\mathrm{OH}]_{12} \bullet 26 \mathrm{H}_{2} \mathrm{O}\right)$ in the sample that had cured for 28 days (10).

Leaching characterization of these conditioned materials is recommended for future work. The leaching characterization should include short- and long-term leaching procedures. This study will provide extremely beneficial supplemental information regarding trace element mobility in conditioned FBC ash.

The results and conclusions for the conceptual ash-conditioning system, developed during last year of this task are as follows (9):

- The optimum moisture content of the $65 / 35$ char/fly ash mixture was found to be $30 \%$ of dry weight (residual moisture). To achieve this moisture content, a water addition rate of $55 \%$ of dry sample weight must be used to compensate for moisture loss due to hydration reactions.

- The maximum compacted density of the ash mixture was found to be $77 \mathrm{lb} / \mathrm{ft}^{3}$ at a moisture content of $30 \%$ of dry weight. At this density, a maximum 28-day compressive strength of 366 psi was developed. A permeability of $1.5 \times 10^{-5} \mathrm{~cm} / \mathrm{sec}$ occurred at the optimum moisture content of $30 \%$ of dry weight.

- Since the AFBC ash began to stiffen shortly after the conditioning water was added, a limited amount of time was allowed for mixing. The time from the start of mixing until the ash begins to stiffen was approximately 2 minutes. Therefore, a mixer was selected with residence time less than 1 minute.

- The conditioned ash slurry developed an average short-term (15 minutes to 5 hours), unconfined compressive strength of $16.6 \mathrm{psi}$. Minimum and maximum short-term compressive strengths were found to be 13.6 and 19 psi, respectively. These data indicated that temporary storage of the conditioned ash would be possible, since these compressive strengths would not hinder the removal of the conditioned ash from the storage areas.

- The conditioning process was chosen to be continuous in order to meet the assumed 50 -ton/hr conditioning rate. A continuous process was al so required to meet the short mixer residence time required for conditioning.

- In the design, the AFBC ash would be stored in a 23,000- $\mathrm{ft}^{3}$ combination silo. The ash would be transported from the main silo the mixer silo with a screw conveyor. The mixer-feed silo would be used 
to temporarily store the ash mixture. Two $25-\mathrm{ft}$ by $25-\mathrm{ft}$ storage areas would then provide temporary storage for the conditioned ash slurry, allowing the hydration process to be completed, and the ash to cool. The temporary storage areas would be fully enclosed to capture the steam released during the hydration process. After approximately 30 minutes of steaming and cooling, the conditioned ash would be removed from the storage areas with a front-end loader equipped with a $2-y d^{3}$ bucket. The ash would then be placed in a 1 andfill.

- Major, minor, and trace constituents showed no trend of mobility within the conditioned AFBC ash. Hydrated mineral phases were identified in cured conditioned AFBC ash. Leaching characterization is recommended for future work.

\subsection{Characterization and Treatability of Coal-Water Fuel Process Waters}

\subsubsection{Introduction}

Coal beneficiation through hydrothermal dewatering has emerged as one of the most promising technologies for upgrading low-rank coals. Hydrothermal dewatering is a technique used to reduce the water content of high-moisture coals through heating a finely ground coal-water slurry under pressure. The drying temperature is high enough to decompose some carboxyl groups in the coal, forming carbon dioxide. The carbon dioxide then forces the water from the coal pores into the surrounding medium. Reabsorption of water is minimized due to coal surface modification and surface coating with evolved tars and waxes.

Conditions during hydrothermal dewatering, coal chemistry, and coal type have a major impact on the characteristics of coal-water fuel (CWF) process waters. Many of the contaminants are difficult to remove prior to discharge and may create operational problems if recycled back into the process. Wastewater treatment process selection for coal beneficiation processes is a difficult task. Great emphasis has not been placed on liquid waste management. The need exists for an improved treatability database and a clear methodology for treatment of CWF waters. Cost-effective production of CWFs can only take place if waste management technologies are developed prior to prototype plant construction.

\subsubsection{Goals and Objectives}

The purpose of this task was to characterize and investigate the treatability of hot-water dried (HWD) CWF at the bench scale.

\subsubsection{Results and Conclusions}

A survey of chemical characterization data for HWD coal process waters was conducted and relevant information was entered into a database management system (6). Several general trends were apparent when a comparison was performed on the chemical characteristics for process waters generated during hot-water drying of a variety of lignite and subbituminous coals. Increasing organic contaminant concentrations occurred with increasing process temperatures. A general increase in 4AAP phenolics, five-day biochemical oxygen demand $\left(\mathrm{BOO}_{5}\right)$, COD, and total organic carbon (TOC) occurred with all 
coal types. Increasing ammonia concentrations were observed with increasing process temperature. A general decrease in sulfate concentrations was seen in all process waters, with increasing temperature. Ash-producing ions, calcium and sodium, followed an increasing trend with increased process temperature. Magnesium concentrations decreased with the increasing operating temperatures. High $\mathrm{COD}: \mathrm{BOD}_{5}$ ratios indicated that high concentrations of biorefractory organics were present in the CWF process water (9).

Based on the results of this survey, several treatability issues were identified ( 9$)$ :

- Coal chemistry and coal type will have a major effect on process water characteristics, treatability, and reuse potential.

- Differences in processing temperature and pressure have a pronounced effect on process water characteristics within a temperature range between $270^{\circ}$ and $330^{\circ} \mathrm{C}$.

- Thorough characterization of process waters is necessary.

- Biological oxidation will be a key unit process.

- Future discharge and/or reuse criteria need to be defined so that treatment process limitations may be properly evaluated.

- Verification of treatment process stability, reliability, and the development or verification of kinetic parameters should be performed at the bench and pilot scale.

- High COD:five-day biochemical oxygen demand $\left(\mathrm{BOD}_{5}\right)$ ratios in HWD CWF process waters indicate high levels of biorefractory organics that will require further treatment of secondary effluent prior to discharge under most situations.

Process water used in treatability testing was collected during the hotwater drying of coal from the Usibelli coal mine near Anchorage, Alaska. A representative sample from the Usibelli HWD CWF process water was submitted to the EERC Analytical Research Laboratory (ARL) for chemical and physical characterization prior to treatability testing (9).

Two secondary treatment systems were selected for evaluation, an anaerobic treatment system and an aerobic treatment system. The anaerobic system combined anaerobic biodegradation with granular activated carbon adsorption in a two-stage expanded-bed reactor configuration. The aerobic system was a conventional activated sludge process (9).

An anaerobic bacterial culture was obtained from the Moorhead, Minnesota, sludge digester, and the aerobic culture was obtained from an activated sludge reactor treating mild gasification wastewater. Testing with these two systems was conducted to evaluate the removals of selected parameters, such as $\mathrm{BOD}_{5}$, COD, ammonia $\left(\mathrm{NH}_{3}\right)$, and color (9).

In the anaerobic system, breakthrough ( $C O D=400 \mathrm{mg} / \mathrm{L}$ ) in Column 1 was found to occur at approximately $34 \mathrm{~L}$ of throughput, corresponding to 34-bed 
volumes. Carbon exhaustion was estimated to occur after approximately $150 \mathrm{~L}$ of throughput, or 150-bed volumes. Exhaustion was assumed to occur at a column effluent COD of $3200 \mathrm{mg} / \mathrm{L}$, or $1200 \mathrm{mg} / \mathrm{L}$ less than the influent COD. The $1200 \mathrm{mg} / \mathrm{L}$ difference represents the biodegradable fraction of COD, as measured by $\mathrm{BOD}_{5}(10)$.

Operation of two columns in series significantly extended the time to system effluent COD breakthrough. Two-stage operation resulted in an increased utilization of adsorptive capacity that approximately tripled the throughput to breakthrough, while only doubling the amount of carbon (10).

The gas generated through anaerobic metabolism was analyzed for composition. The methane content of the gas generated averaged approximately over 70 mole percent. The relationship between COD loading and the gas generated is represented by the equation: $y=0.156 x+0.0139$. Thus for each 100 grams of COD applied to the system, approximately 16 liters of gas are generated (10).

The aerobic treatment system was based on the concept of activated sludge. $\mathrm{BOD}_{5}$ removals of $95 \%$ were achieved during activated sludge treatment of Usibelli process water. The average influent $B_{5} D_{5}$ of $1220 \mathrm{mg} / \mathrm{L}$ was reduced to as low as $31 \mathrm{mg} / \mathrm{L}$, but was not consistent. Treatability target discharge goals, based on the new source performance standard (NSPS), were $30 \mathrm{mg} / \mathrm{L}$. The average influent total COD during the operating was $4540 \mathrm{mg} / \mathrm{L}$. Average effluent soluble COD was $3730 \mathrm{mg} / \mathrm{L}$, an $18 \%$ removal rate. This concentration is much higher than the target effluent quality goal of $400 \mathrm{mg} / \mathrm{L}$. High concentrations of refractory $C O D$ in the activated sludge effluent will require further treatment. Average influent ammonia influent was $13 \mathrm{mg} / \mathrm{L}$. Effluent ammonia averaged $2 \mathrm{mg} / \mathrm{L}$, resulting in a removal efficiency of $83 \%$. Ammonia removals during activated sludge treatment are most likely the results of air stripping in the aeration basin, rather than biological nitrification. No increase in effluent nitrate was detected (10).

\subsection{Waste Depository Scavenger Study}

\subsection{0 .1 Introduction}

Constructing large depositories for municipal and industrial waste has become a standard waste management practice. Monitoring potentially hazardous leachate migrating from a waste depository is a critical responsibility to prevent groundwater and soil contamination. Current monitoring techniques, which consist of sampling and analysis of materials around the depository, are inadequate. This type of analysis can be inaccurate due to the heterogeneity of the materials and the virtually undetectable compositional changes with time.

Contaminants emanating from municipal waste can include lead, copper, zinc, and contaminants migrating from fly ash waste can include boron, molybdenum, arsenic, and selenium. Remediation of these types of contaminants is expensive and sometimes problematic. Inexpensive waste-cell 1 iners composed of abundant sorptive materials, such as zeolites, chars, and clays, could be an economical way to immobilize contaminants. 


\subsubsection{Research Scope}

A two-phase test plan was used to determine contaminant migration and sorptive capacity of the scavenger materials. The first phase involved the evaluation of chemical and mineral properties of the proposed scavenger materials. The second phase involved the use of batch testing and percolation experiments to determine the sorptive abilities of selected materials.

\subsubsection{Results and Conclusions}

Clinoptilolite, a zeolite mineral with the general formula of $(\mathrm{Na}, \mathrm{K})_{6}\left(\mathrm{Al}_{6} \mathrm{Si}_{30} \mathrm{O}_{72}\right) \cdot 2 \mathrm{OH}_{2} \mathrm{O}$, was tested for its ability to immobilize ions of selenium, molybdenum, copper, and lead. Ions of lead and copper were chosen for initial experiments because clinoptilolite has a strong affinity for both of these contaminants, and they are commonly found in municipal landfill leachate. Selenium and molybdenum were chosen for the first percolation experiment because they are common constituents in fly ash leachate (10).

Clinoptilolite obtained from East West Minerals Company, Denver, Colorado, was analyzed by $x$-ray diffraction (XRD) techniques to determine other phases present. The clinoptilolite was found to be nearly homogeneous and contained only a minor amount of quartz. Scanning electron microscope/ electron probe microanalysis (SEM/EPMA) revealed that the zeolite was more potassium-rich than sodium-rich (10).

Limited batch testing has indicated that clinoptilolite was effective at removing lead from solution, but not an effective scavenging material for $\mathrm{Se}^{+4}$ (selenium) or $\mathrm{Mo}^{+6}$ (molybdenum) (10).

Further research in this area will include the evaluation of other possible scavenging materials in more complex systems that model field behavior. The evaluation of other scavenging materials, such as chars and clays, and the development of optimum mixtures should also be pursued.

Future research should also focus on determining the quantities of contaminants that are permanently immobilized and quantities that are able to be remobilized from the scavenging agents. This will be an important factor in determining the environmental impact of these materials.

\subsection{REFERENCES}

1. Moretti, C.J., and Henke, K.R., 1987, Waste management, Final technical report to the U.S. Department of Energy for the period Apri1 1, 1986 March 31, 1987: University of North Dakota Energy Research Center, Grand Forks, North Dakota.

2. Wachter, J., U.S. Department of Energy, Morgantown Energy Technology Center, June 1986, Personal Communication.

3. Moretti, C.J., and Henke, K.R., 1988, Waste management, Final technical report to the U.S. Department of Energy for the period April 1, 1987 March 31, 1988: University of North Dakota Energy and Mineral Research Center, Grand Forks, North Dakota. 
4. Moretti, C.J., and Henke, K.R., 1989, Waste management, Final technical progress report to the U.S. Department of Energy for the period April 1, 1988 - June 30, 1989: University of North Dakota Energy and Mineral Research Center, Grand Forks, North Dakota.

5. Moretti, C.J., Hassett, D.J., Pflughoeft-Hassett, D.F., Mayer, G.G., and Stepan, D.J., 1990, Waste management, Final technical progress report to the U.S. Department of Energy for the period July 1, 1989 - June 30, 1990: University of North Dakota Energy and Environmental Research Center, Grand Forks, North Dakota.

6. Stepan, D.J., Moretti, C.J., and Pflughoeft-Hassett, D.F., 1990, Waste management, Quarterly technical progress report to the U.S. Department of Energy for the period July 1990 - September 1990: University of North Dakota Energy and Environmental Research Center, Grand Forks, North Dakota.

7. Stepan, D.J., Moretti, C.J., and Pflughoeft-Hassett, D.F., 1991, Waste management, Quarterly technical progress report to the U.S. Department of Energy for the period October 1990 - December 1990: University of North Dakota Energy and Environme!ltal Research Center, Grand Forks, North Dakota.

8. Stepan, D.J., Moretti, C.J., and Pflughoeft-Hassett, D.F., 1991, Waste management, Semiannual technical progress report to the U.S. Department of Energy for the period January 1, 1991 - June 30, 1991: University of North Dakota Energy and Environmental Research Center, Grand Forks, North Dakota.

9. Stepan, D.J., Moretti, C.J., Pflughoeft-Hassett, D.F., and Eylands, K.E., 1992, Waste management, Semiannual technical progress report to the U.S. Department of Energy for the period July 1, 1991 - December 30, 1991, University of North Dakota Energy and Environmental Research Center, Grand Forks, North Dakota.

10. Stepan, D.J., Pflughoeft-Hassett, D.F., Strobel, T.M., and Fraley, R.H., 1992, Waste management, Semiannual technical progress report to the U.S. Department of Energy for the period January 1, 1992 - June 30, 1992 , University of North Dakota Energy and Environmental Research Center, Grand Forks, North Dakota. 


\subsection{Regional Energy Policy Program for the Northern Great Plains}




\section{REgIONAL ENERGY POLICY PROGRAY FOR THE MORTHERN GREAT PLAINS}

Final Technical Progress Report

for the Period July 1, 1989, through December 31, 1992

by

Dantel J. Daly, Geologist

Energy and Environmental Research Center

University of North Dakota

Box 8213, University Station

Grand Forks, ND 58202-8213

Task Contracting Officer's Representative: Dr. Madhav R. Ghate

U.S. Department of Energy

Morgantown Energy Technology Center

3610 Coll ins Ferry Road

P.0. Box 880

Morgantown, WV 26507-0880

December 1992

Work Performed under Cooperative Agreement No. DE-FC21-86MC10637 


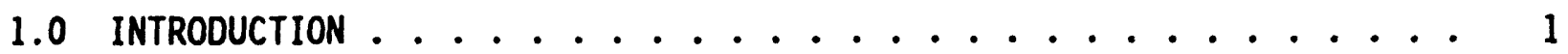

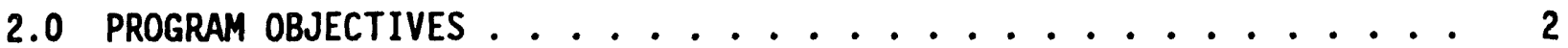

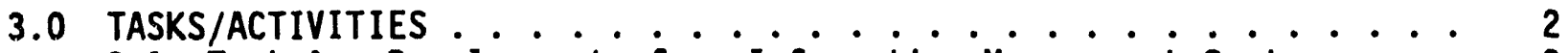

3.1 Task A. Development of an Information Management System . . 2

3.2 Task B. Information Acquisition .......... 6

3.2.1 Subtask B.1 Annotated Bibliography of Energy-Related Sources ................. 6

3.2.2 Subtask B.2 Organizations Database ........ 7

3.3 Task C. Energy Resource Database ............. 7

3.4 Task 0. Energy Production Database ............ 8

3.5 Task E. Energy Consumption Database .......... 8

3.6 Task F. Energy Technology Database ............ 9

3.7 Task G. Government Initiatives Database .......... 9

3.8 Task H. Environmental Issues Database . . . . . . . . 10

4.0 TRIPS/INFORMATION DISSEMINATION ............. 11

\section{LIST OF TABLES}

\section{Table}

1 Summary of Computerized Databases .............. 3

2 Summary of Report Products ................. 4 


\section{REGIONAL ENERGY POLICY PROGRAM FOR THE NORTHERN GREAT PLAINS}

\subsection{INTRODUCTION}

The United States is the world's leading consumer of energy. The production and consumption of energy vary over the country as a function of climate, the availability of natural resources, economics, and culture. The northern Great Plains region (Montana, Wyoming, North Dakota, and South Dakota) is an area characterized by many similarities in climate, culture, and physiography. With respect to energy, this region:

- Contains significant conventional fossil fuel resources as well as nonconventional energy resources such as oil shale and geothermal.

- Accounts for over 10 percent of domestic hydrocarbon production, a significant portion of domestic coal production by volume (low-rank, low-sulfur coal), and a significant amount of coal-fired electricity.

- Contains significant research capability, particularly with regard to coal-conversion and oil shale technologies, and with respect to the environmental effects of fossil fuel production, conversion, and utilization.

- Is a net exporter of energy and fossil fuel materials.

- Is a significant consumer of fuel and fossil fuel by-products in the agricultural sector.

- Receives significant revenues and economic support from fossil fuel exploration, production, conversion, and transportation industries, as well as from ancillary industries.

The fundamental intent of the federal Energy Policy is to provide enabling and restraining leverage on the market to protect the public interests that would not otherwise be well served. These interests include the protection of human health and the environment, ensuring an uninterrupted energy supply, resource stewardship, and providing for the national security. Since the first energy shock in 1973, response to uncertainty in energy supply, especially for oil, has varied between two extremes: strong government intervention, in response to energy supply crises, or reliance on market forces.

At the state level, responsibility for energy-related issues is typically divided among a number of agencies. Policy functions are divided among economic development, health and the environment, consumer price regulation, and revenue development (sources include severance, sales, and property taxes). Furthermore, state level activities must be coordinated with federal initiatives. The development and maintenance of well-founded energyrelated policy at the state or regional level requires basic knowledge in a number of subject areas, including energy resources, production and utilization technologies, markets, the environment, current and developing federal and state initiatives, and local, regional, national, and international trends. 


\subsection{PROGRAM OBJECTIVES}

The goal of this program has been to develop and manage a series of concise reports and databases intended to enhance the development and implementation of energy-related policies in the northern Great Plains region.

Computerized database products are summarized in Table 1, while project reports are summarized in Table 2 . The reports are being treated as open-file documents.

\subsection{TASKS/ACTIVITIES}

\subsection{Task A. Development of an Information Management System}

\section{Objective}

The objective of Task $A$ was to develop an integrated data management system for the storage, organization, and manipulation of data, as well as allowing for varied output including graphics, such as maps, tables, and reports.

Activities under this task included identifying data types and desired product formats; screening candidate software packages and selecting the appropriate software; and, following testing, develop the appropriate data packages. Given the need to foster ready distribution of the computerized data sets, the software selection criteria included:

- User-friendly, with wide usage in the marketplace

- Low cost

- Highly interactive with other software packages

- Personal-computer-based

Following the software selection, activities included tailoring the data management systems to meet the needs of the overall system and developing appropriate formats for data entry and management. In order to minimize costs to the project, software and hardware costs were shared with other projects when possible.

\section{Accomplishments}

\section{Computer Data Management System Software}

Three types of data were identified: those with a geographic tie, those which consisted of items in a list, and numerical data. The choice of database software was dictated by the character of the data as follows:

- Data sets with a strong geographic component included regulations, resource/reserve estimates, production, facilities, utilization data, 


\section{TABLE 1}

Summary of Computerized Databases

\begin{tabular}{|c|c|c|c|c|c|}
\hline Name & Task & Software & Description & Records & Remarks \\
\hline ENERBIB & B.1 & QQAA & 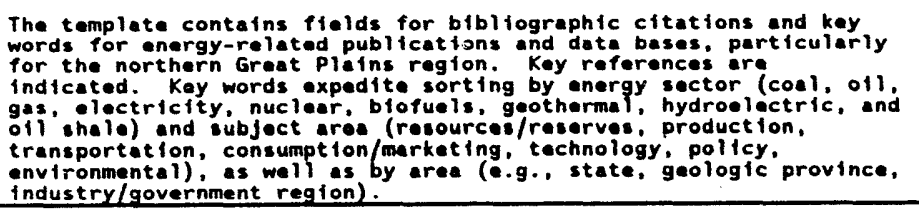 & 1500 records & $\begin{array}{l}\text { - Records can be sorted on any } \\
\text { field }\end{array}$ \\
\hline ENERCON & 8.2 & QSAC & $\begin{array}{l}\text { The template contalns flelds for names, addresses, key porsonnel, } \\
\text { and descriptions of energy-related organizat ions. Subsets include } \\
\text { stat end federal regulatory agencies. Iobbyists. energy compantes, } \\
\text { and select university departments. }\end{array}$ & 1160 records & $\begin{array}{l}\text { - Records can be sorted on } \\
\text { eny field }\end{array}$ \\
\hline PLANT & D & QRA० & 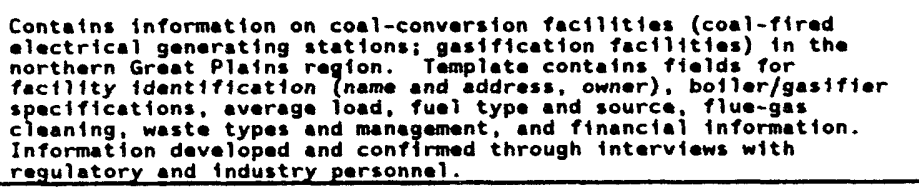 & 23 records & $\begin{array}{l}\text { - } 22 \text { electrical generating } \\
\text { plants } \\
\text { - } 1 \text { gesiffeation factifty }\end{array}$ \\
\hline MINE & D & QAA० & 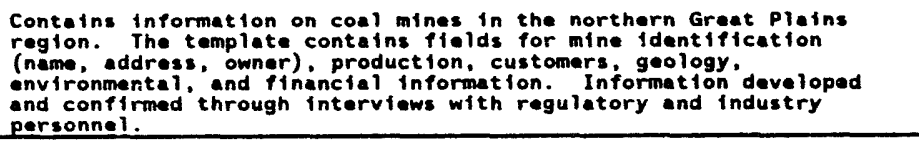 & 67 records & $\begin{array}{l}\text { - Records can be sorted on } \\
\text { eny field } \\
\text { - Unique combination of } \\
\text { Information fields }\end{array}$ \\
\hline NGPCOMP & A & Atles GIS" & 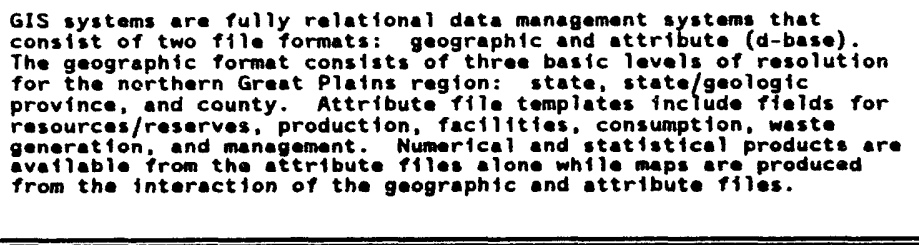 & & 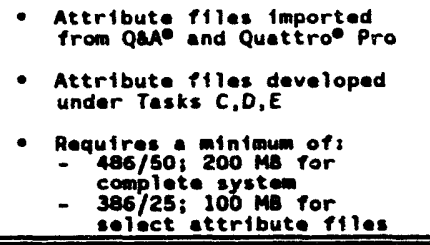 \\
\hline
\end{tabular}


TABLE 2

\section{Summary of Report Products}

\begin{tabular}{|c|c|c|}
\hline Title & Task & Description \\
\hline $\begin{array}{l}\text { Status of coal resource assessment in the } \\
\text { northern Great Plains }\end{array}$ & C & $\begin{array}{l}\text { Profiles the current state of knowledge and activities with respect to coal } \\
\text { resource/reserve information in the northern Great Plains. Focus is on the } \\
\text { Fort Union Lignite Region (coal-bearing area of the Williston Basin) and the } \\
\text { Powder River Region (coal-bearing strata of the Powder River Basin) which } \\
\text { together account for over } 95 \text { percent of the coal reserves in the region. }\end{array}$ \\
\hline Federal Energy Policy 1970-1990 & G & $\begin{array}{l}\text { Contains a summary of federal energy policy initiatives during the period } \\
1970-1990 \text { and provides concise profiles of the coal, oil, and gas sectors as } \\
\text { they were at the cormencement of the National Energy Strategy development } \\
\text { process. Includes a chronology of Energy Policy actions and world events. }\end{array}$ \\
\hline $\begin{array}{l}\text { Coal-conversion by-products management in the } \\
\text { North Dakota portion of the Fort Union Lignite } \\
\text { Region: A review of the literature }\end{array}$ & $H$ & $\begin{array}{l}\text { Contains a review of the waste types, management practices, and research } \\
\text { findings for coal-conversion by-products (fly ash, flue gas desulfurization } \\
\text { wastes, bottom ash). Includes maps of waste generation sites and tables } \\
\text { highlighting management practices, select research reports, and utilization } \\
\text { options. }\end{array}$ \\
\hline $\begin{array}{l}\text { Surface mining and reclamation in the North } \\
\text { Dakota portion of the Fort Union Lignite } \\
\text { Region: A review of the literature }\end{array}$ & H & $\begin{array}{l}\text { Contains a review of the environmental effects of mining and reclamation } \\
\text { activities. Includes maps of active mines, research sites, abandoned mined } \\
\text { lands (AML) and tables highlighting selected research activities and groups. }\end{array}$ \\
\hline $\begin{array}{l}011 \text { and gas exploration and production wastes } \\
\text { in the northern Great Plains: Occurrence, } \\
\text { character, and management }\end{array}$ & $H$ & $\begin{array}{l}\text { Contains an overview of exploration activity, wastes, management practices, } \\
\text { and research findings with respect to oil and gas exploration and production } \\
\text { wastes (drilling waste, produced water) in the northern Great Plains. Data } \\
\text { portrayed on Atlas GIS map products at the county level includes well } \\
\text { populations, production (oil, gas, and water) injection wells, and other } \\
\text { waste management sites. Tables show management practices and highl ight } \\
\text { research findings. }\end{array}$ \\
\hline
\end{tabular}


environmental data, and demographics. These data sets were assigned to the NGPCOMP (northern Great Plains comprehensive) database.

Geographic Information Systems $\left(G I S^{\circ}\right)$ which relate data within a consistent geographic framework are well suited for analysis of these types of data and have the ability to provide numerical and statistical reports as well as map output. GIS was considered to be the software of choice for NGPCOMP.

Following a screening phase, Atlas GIS ${ }^{\circ}$ was chosen as the software for NGPCOMP. The development of NGPCOMP was initially delayed, however, due to problems with the generation of the Atlas GIS ${ }^{\circ}$ software originally obtained for testing. In Year 2 of the project, plans were made to replace Atlas GIS ${ }^{\circ}$ with MapViewero, a themat ic mapping package from Golden Software. The acquisition of an Atlas GIS ${ }^{\circ}$ upgrade and the hiring of a full-time computer database manager, both in Year 3 of the project, cleared the way for the development of NGPCOMP using Atlas GISO. Since the formats and files can be readily revised and the program readily accepts information from other database formats, the choice of Atlas GIS for NGPCOMP resulted in the potential for a flexible, dynamic, portable, and expandable data management system.

GIS systems, fully relational data management systems, function with the interaction of two file formats--geographic (a standardized geographic reference structure) and attribute (d-base files, akin to spreadsheets, which are keyed to locations in the geographic structure)--where data are tied to a geographic location. Atlas GIS ${ }^{\circ}$ database construction was initiated with the development of an overall geographic structure for the northern Great Plains region. The geographic structure contained three layers, that of the state, geologic province/state, and county. The county, a geographic unit common among the diverse data sets (regulatory, geologic, production, consumption, environmental), was chosen as the fundamental geographic tie (level of resolution) for the GIS system and proved particularly useful for portraying the occurrence and distribution of elements of the larger attribute data sets such as $0 i 1$ and gas wells. In cases where populations were relatively small, such as the case for coal mines, the capability existed for individual facilities to be plotted while other types of data, including regulations, required plotting at the state or state/province level.

In the second half of Year 3, natural gas-related data were used as the basis for attribute files which were then used as sample data sets for the testing of Atlas GIS ${ }^{\circ}$ capabilities. With the successful demonstration of the system, subsequent activities included the development of data entry attribute formats, entry of selected data sets, and the production of select map products. Data entry was facilitated by creating attribute file templates in Atlas GIS ${ }^{\circ}$, exporting the iemplates to Quattro ${ }^{\circ}$ Pro for data entry, and then returning the completed files to the GIS system. Data intended to form the basis of attribute records in NGPCOMP were acquired under Tasks $C, D$, and $E$. The status of those activities is addressed under the individual tasks. 
- Enumerated items and supporting information, which included bibliographic citations, contacts, descriptions of technologies, and policy initiatives, were managed using Q\&A०, a flat file manager. Q\&A ${ }^{\odot}$ proved especially useful due to its powerful sorting capability.

- Most of the GIS databases were supported by data sets in a spreadsheet format, particularly quattro ${ }^{\circ}$ Pro. This was done for two reasons. The spreadsheet format allowed the rapid input of data and the program embodied powerful statistical and other analytical capabilities.

- Word processing was handled using WordPerfect ${ }^{\oplus}$.

\section{Computer Hardware}

The software packages selected for the project, particularly Atlas GIS ${ }^{\circ}$, required improved $P C$ capability. Ancillary capability was required to ensure appropriate products. Costs were shared with other contracts where appropriate. Hardware acquisitions included the following:

- IBM PC 386 SX; 40 MB hard disk; 8 MB RAM

- Upgrades of two IBM PC machines, including hard disk upgrades

- Purchase of a modem for access to on-line information sources

- Deskjet (ink jet printer) printer, produces map products for the Atlas GIS ${ }^{\circ}$ NGPCOMP database.

\subsection{Task B. Information Acquisition}

The overall objective of this task was to identify information sources with respect to the selected energy-related subject areas in the northern Great Plains and to characterize and assess these sources. Activities fell into two areas: compilation of an annotated bibliography of publications (B.1) and a compilation of background information on key energy-related contacts (B.2).

\subsubsection{Subtask B.1 Annotated Bibliography of Energy-Related Sources}

\section{Objective}

The objective of Subtask B.1 was to identify information materials, published sources, and databases; to acquire and review these materials; and, finally, to enter and manage these materials in a computerized annotated bibliography template developed using Q\&A ${ }^{\Phi}$ software. Sources of the materials included trade and lobbying groups, energy-related companies, and state and legislative agencies.

Although the initial intent of this task was to produce an annotated bibliography, the formal review and description of each reference was deemed inappropriate since 1) the activity was time-intensive, requiring an inordinate share of limited project resources; 2 ) the volume of materials was very large; and 3) annotations were already available in other formats in many 
cases (such as on-line databases). Instead, the original intent of the annotated bibliography, that is, the ranking and description of the information sources, was largely fulfilled through the identification of key data sources in select subject areas.

\section{Accomolishments}

- The identification and acquisition of energy-related sources for the northern Great Plains. Sources included computerized data bases, published materials, and on-line databases.

- Development of a computer-based annotated bibliography template, ENERBIB, in Q\&A ${ }^{\oplus}$. Fields include bibliographic information, key words, and descriptive information.

- Identification of key references by energy sector (coal, oil, gas, electricity, nuclear, biofuels, geothermal, hydropower, oil shale).

\subsubsection{Subtask B.2 Orqanizations Database}

\section{Objective}

The objective of Subtask B.2 was to identify key energy-related organizations for the northern Great Plains and to develop a computerized data system for the storage and manipulation of these data.

\section{Accompli shments}

- Selected energy-related groups at the national and regional levels were identified and contacted during Years 1 and 2 with respect to their activities in policy issues. The groups included environmental organizations, research organizations, government agencies, and industry trade groups.

- Development of the ENERCON database template in Q\&A ${ }^{\mathcal{O}}$ for the storage and management of these data.

\subsection{Task C. Energy Resource Database}

\section{Objective}

The objective of Task $C$ was to acquire data on the energy-related resources of the region and to determine the status of resource assessment.

\section{Accomplishments}

- Identifying and acquiring data sources, mainly published reports. These data were prepared for entry into the resource/reserve portion of the NGPCOMP database.

- Information was acquired for coal, oil, gas, nuclear, oil shale, and geothermal. Attribute sets were filled in for coal, oil, and gas. 
- Preparation of the report entitled "Status of Coal Resource Assessment in the Northern Great Plains." The report focuses on the status of resource and reserve assessment in the Williston and Powder River Basins which account for over 95 percent of the coal reserves of the northern Great Plains.

Information on the status of $0 i 1$, gas, and geothermal resource/reserve estimated were obtained but were not formalized in a report format.

\subsection{Task D. Energy Production Database}

\section{Objective}

The objective of Task $D$ is to develop a computerized database to provide information on current energy-related production. Related databases were planned to pertain to the storage, treatment, and conversion (i.e., mines, power facilities, refineries, gas processing facilities) of fossil fuels.

\section{Accomplishments}

- Identifying data sources and obtaining production information from the states and other appropriate groups.

- Development of format and entry of the data into the production portion of the NGPCOMP database.

- Development of databases on coal-related production and utilization facilities. These databases served as the source of data in these subject areas for the Atlas GIS ${ }^{\circ}$ NGPCOMP database.

\section{- Coar Mines (MINE)}

MINE is a Q\&A software template which contains information on coal mines within the northern Great Plains region. Each coal mine has an individual entry consisting of background information production figures and customer data as well as geologic, environmental, and financial information. Sixty-seven mines are listrd in the fourstate area, including twenty-one operations which are closed temporarily or permanently or have been absorbed into another mine or company.

\section{- Coal Conversion facilities (PLANT)}

PLANT is a Q\&A ${ }^{\Phi}$ software template which contains information on coal-conversion facilities (coal-fired generating stations, coal gasification facilities) in the northern Great Plains region. Each coal-conversion facility has entries consisting of background information, boiler/gasifier specifications, average load data, fuel, FGC, waste management, and financial information. Twentythree entries are included in the four-state region (22 electrical generating stations and 1 gasification facility).

- Information on other facilities, including gas processing plants and refineries, was not formalized in a database format since it 
exists in a number of commercially available formats as noted in the ENERBIB database. Further, waste and waste management information for these facilities was not readily available.

\subsection{Task E. Energy Consumption Database}

\section{Objective}

The objective is to develop a computerized database to provide information on energy consumption in the region.

\section{Accomplishments}

- Data source identification and data acquisition.

- Development of a database format for the NGPCOMP database.

- Consumption-related information was not reduced and entered into the NGPCOMP data, since it is already available in a number of formats, including state and federal publications, as noted in the ENERBIB database.

\subsection{Task F. Energy Technology Database}

\section{Objective}

The objective is to develop a computerized database to provide information on energy conversion and related technologies, focused on low-rank coal in the northern Great Plains.

\section{Accomplishments}

- Preparation of TECH, a database template in Q\&A which contains critiques of low-rank coal conversion technologies based on published and in-house sources.

\subsection{Task 6. Government Initiatives Database}

\section{Objective}

The objective was to develop computerized databases and supporting documentation dealing with energy-related policy initiatives at the federal and state levels.

\section{Accomplishments}

- The compilation of a concise history of energy-related events and policy initiatives during the period 1970 through 1990 at tiie international, national, and regional levels. Information regarding activities at the federal level is contained in the report "Federal Energy Policy 1970-1990."

- The identification and, where possible, assessment of past federal and state policy actions in a historical context. An assessment of 
federai actions for the period 1970-1990 were originally included in a Q\&A database format but this information has subsequently either been included in the report "Federal Energy Policy 1970-1990" or,

alternatively, was found to be readily avallable in more detailed form in on-line formats and publications as indicated in ENERBIB.

- Identification and tracking of current policy initiatives, and, where available, acquiring supporting documentation at the federal and state levels. Data sources included:

- Offices of federal and state legislators and agencies, including USDOE.

- Industry associations and environmental groups.

- Legislative tracking groups, notably the Environmental and Energy Study Institute (Weekly Bulletin, Legislation Briefing Books, Special Reports).

- Investigation of the use of on-line policy-related information sources. On-line services were available from the states as well as on the national level from such services as LEXIS/NEXIS and WESTLAW. However, the cost of the services was prohibitive, and it was decided that state sources would be sufficient for the needs of the program.

- Database products for legislation at the federal and state level were deemed inappropriate as originally envisioned. Needs in these areas are adequately met by published reports and on-line data services available as indicated in ENERBIB.

\subsection{Task H. Environmental Issues Database}

\section{Objective}

The objective was to prepare summary reports dealing with energy-related environmental issues in the northern Great Plains region.

\section{Accomplishments}

Reports were prepared to provide background information concerning the environmental aspects of the surface mining of coal, the management of coalconversion by-products, the management of oil and gas exploration and production wastes, and the ramifications of the 1990 Clean Air Act on coal in the region. The reports are summarized as follows:

- "Surface Mining and Reclamation in the Fort Union Lignite Region: A Review of the Literature"

- A review of the literature concerning mining and reclamation in the coal-bearing area of the Williston Basin. The paper contains information on abandoned mine 1 and sites, active mining and reclamation sites, and mine land research sites; a review of published reports and research programs; and a statement of research needs. 
- "Coal-Conversion By-Products Management in the Fort Union Lignite Region: A Review of the Literature"

- A review of the literature concerning the management of coalconversion wastes (fly ash, FGD waste, gasification waste) in the coal-bearing area of the Williston Basin. The paper contains information on waste types and their character, a review of published reports and research programs, management strategies for disposal and utilization, and a statement of research needs.

- "0il and Gas Exploration and Production Wastes in the Northern Great Plains: Occurrence, Character, and Management"

- A summary of the $0 i 1$ and gas exploration and production waste (produced water and drilling wastes) generation and management picture by county in the northern Great Plains. The paper contains information on waste character, generation sites, estimated volumes, management practices (allowed and actuai), and research projects.

- The decision was made not to prepare two planned documents, "The Clean Air Act in the Northern Great Plains" and "Leasing Federal Lands in the Northern Great Plains: Energy-related Issues," due to the fact that such reports would be premature. In the case of the Clean Air Act Amendments, for example, activities are ongoing in such key areas as the $\mathrm{NO}_{x}$ and air toxics standards.

\subsection{TRIPS/INFORMATION DISSEMINATION}

- October 1-4, 1989; Rocky Mountain Section Meeting of the American Association of Petroleum Geologists. Of particular interest were sessions on the outlook for the domestic uranium industry, reservoir heterogeneity and the potential for enhanced oil recovery, and oil and gas resources in the northern Great Plains.

- November 6-7, 1989; travel to Washington DC. Activities included a visit to the Energy Information Administration and attendance at a meeting of the DOE-sponsored Coal Awareness Steering Committee.

- January 22-24, 1990; travel to Washington DC. Activities included a visit to the DOE Office of Policy, Planning, and Analysis (OPPA) for discussions with Ms. Sandy Giatt and Mr. Henry Kelly on the form and status of the National Energy Strategy (NES) and examination of the draft NES and testimony from the NES public hearings.

- September 11, 1990; attendance at the Pittsburgh Coal Conference, Pittsburgh, Pennsyivania. Of particular interest were presentations by industry and government representatives in a formal session on the developing National Energy Strategy.

- September 12-13, 1990; attendance at the First International Symposium on $0 i 1$ and Gas Exploration and Production Waste Management Practices in New Orleans, Louisiana. The conference provided information on 
environmental issues for the oil and gas industry, including NORM, air quality, and general presentations on exploration and production wastes and waste management.

- September 30, 1991; attendance at a Geographic Information System (GIS) workshop at Argonne National Laboratory, Chicago, IIlinois.

Travel was typically undertaken in conjunction with other contracts, where possible, to minimize expenses. include:

Reports prepared using information developed through this project

Energy and Environmental Research Center Technical Staff, 1990, An analysis of energy policy and recommendations: Internal report, $22 \mathrm{p}$.

Groenewold, G.H., Beaver, F.W., Butler, R.D., Daly, D.J., and Schroeder, S.A., 1992, Overview of mine land reclamation research in the North Dakota portion of the Fort Union Lignite Region: in Finkelman, R.B., Tewalt, S.J., and Daly, D.J., eds., Geology and utilization of Fort Union lignites.

Pflughoeft-Hassett, D.F., Daly, D.J., Hassett, D.J., and Beaver, F.W., 1992, Coal conversion solid by-products management in the North Dakota portion of the Fort Union Lignite Region: in Finkelman, R.B., Tewalt, S.J., and Daly, D.J., eds., Geology and utilization of Fort Union lignites.

Sondreal, E.A., and Daly, D.J., 1991, Energy policy and technologies: Analysis and recommendations: Groenewold, G.H., ed., Beaver, F.W., Jones, M.L., Mathsen, D.V., and Willson, W.G., contributors, Energy and Environmental Research Center, Grand Forks, North Dakota, March 1991. 


\subsection{Hot-Gas Cleanup}

$+\ldots$ 


\section{HOT-GAS CLEANUP}

Final Technical Progress Report

for the Period April 1, 1986, through December 31, 1992

by

Michael L. Jones, Associate Director

Jay S. Haley, Research Engineer

John P. Hurley, Research Supervisor

Blażo Ljubičić, Restarch Engineer

Murali Ramanathan, Research Scientist

Energy and Environmental Research Center

University of North Dakota

Box 8213, University Station

Grand Forks, North Dakota 58202

Task Contracting Officer's Represe- $\quad \because$ Richard A Dennis

for

U.S. Department of Energy

Office of Fossil Energy

Morgantown Energy Technology Center

3610 Collins Ferry Road

P.O. Box 880, Mail Stop E02

Morgantown, West Virginia 26507

December 1992

Work Perfor:ned under Cooperative Agreement No. DE-FC21-86MC10637 


\section{TABLE OF CONTENTS}

\section{Page}

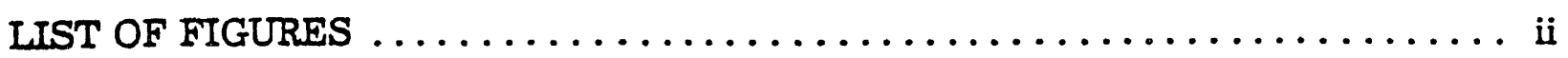

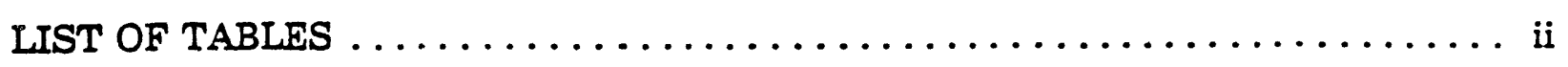

1.0 INTRODUCTION $\ldots \ldots \ldots \ldots \ldots \ldots \ldots \ldots \ldots \ldots \ldots \ldots \ldots \ldots \ldots \ldots \ldots \ldots$

2.0 GOALS AND OBJECTIVES $\ldots \ldots \ldots \ldots \ldots \ldots \ldots \ldots \ldots \ldots \ldots \ldots \ldots$

3.0 RESULTS AND CONCLUSIONS $\ldots \ldots \ldots \ldots \ldots \ldots \ldots \ldots \ldots \ldots \ldots \ldots \ldots \ldots \ldots$

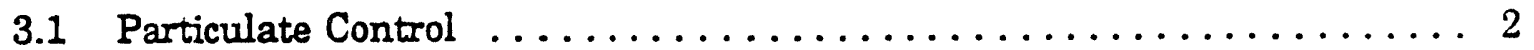

3.2 Alkali Getter Testing . . . . . . . . . . . . . . . . . . . . 6

3.3 Thermochemical Equilibrium Modeling: PHOEBE Database Modifications $\ldots \ldots \ldots \ldots \ldots \ldots \ldots \ldots \ldots \ldots \ldots \ldots \ldots \ldots \ldots \ldots$

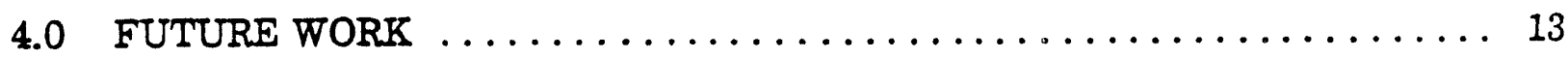

5.0 REFERENCES $\ldots \ldots \ldots \ldots \ldots \ldots \ldots \ldots \ldots \ldots \ldots \ldots \ldots \ldots \ldots \ldots \ldots \ldots \ldots \ldots$ 


\section{LIST OF FIGURES}

Figure

Page

1 Hot-gas cleanup test loop $\ldots \ldots \ldots \ldots \ldots \ldots \ldots \ldots \ldots \ldots \ldots \ldots \ldots$

2 Filter housing currently in use. $\ldots \ldots \ldots \ldots \ldots \ldots \ldots \ldots \ldots \ldots$

3 Test loop particulate sampling system $\ldots \ldots \ldots \ldots \ldots \ldots \ldots \ldots$

4 The percent of each element collected in each size fraction for the tests of kaolin as an alkali getter. . . . . . . . . . . . . . . . 10

5 A plot of the experimental vs. predicted phase diagram for a cross section

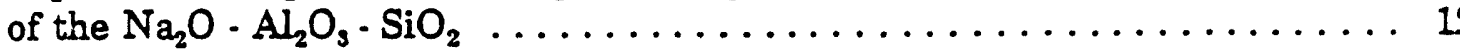

\section{LIST OF TABLES}

Table

1 Operating Parameters and Specifications for the Hot-Gas Cleanup Test Loop $\ldots \ldots \ldots \ldots \ldots \ldots \ldots \ldots \ldots \ldots \ldots \ldots \ldots \ldots \ldots \ldots \ldots \ldots \ldots \ldots$

2 Specifications for an Isokinetic Particulate Sampling System . . . . . . . . 6 


\section{HOT.GAS CLEANUP}

\subsection{INTRODUCTION}

The U.S. Department of Energy (DOE) is promoting the development of coal-based advanced power systems under the direction of Morgantown Energy Technology Center (METC). This activity covers a broad range of technologies involving combustion, gasification, and the integration of combustion and gasification technologies. The objective is to maximize cycle efficiencies to provide for a stable, secure, and environmentally sound energy future.

Specific combustion program areas include the development of heat engines, such as direct coal-fired turbines and diesels and pressurized fluidized-bed combustion (PFBC). Gasification technology development includes mild gasification for coproducts and hydrogen and methane production for fuel cell applications. Integrated gasification combined cycle (IGCC) technology promotes high cycle efficiencies by combining coal gasification with direct product-gas firing in turbines. In all of these cases, hot-gas cleanup systems are required to achieve acceptable process performance and to meet current and future environmental emission standards.

The Energy and Environmental Research Center (EERC) is currently involved in a number of research projects in both the combustion and gasification of coal and also in gas-stream cleanup. The fundamental gas-stream cleanup issues common to the various advanced concept systems are being investigated in this project. Emphasis is being placed on particulate control techniques and on ash/alkali interactions with the filter materials.

The Center has been involved in research related to ash/alkali interactions and slag behavior for many years. This expertise is being used in studying the effects of alkali interactions with filter media and possible mitigation options that may improve filter life. The global or overall objective in this phase of the project is the study of the thermodynamically equilibrated reaction mechanisms and mineral matter transformations in advanced coal combustion systems.

\subsection{GOALS AND OBJECTIVES}

The goals of the hot-gas cleanup project at the EERC are to build and operate a hotgas cleanup test loop in conjunction with various pilot-scale advanced systems currently in operation at the Center, to explore the various ash/alkali corrosion mechanisms for ceramic barrier filter materials, and to determine the effects of various mitigation options. The mitigation options will focus primarily on gettering techniques. Eventually these techniques will be verified at the pilot scale using the hot-gas test loop.

The Center is currently operating the following pilot-scale fluidized-bed reactors:

- Fluidized-bed mild gasification reactor

- Fluidized-bed catalytic reactor for the production of hydrogen

- Pressurized fluidized-bed combustor 
The Center is also planning to install and operate a transport reactor test unit (TRTU) to provide scaleup data for the hot-gas cleanup test facility in Wilsonville, Alabama. Table 1 shows the typical operating parameters of the various reactor systems.

\subsection{RESULTS AND CONCLUSIONS}

\subsection{Particulate Control}

In order to investigate particulate control methods, a test loop (Figure 1) was constructed and inserted into the exhaust piping of the advanced concept reactors at the Center. The test loop provides a means of exposing various hot-gas cleanup systems to actual product gases from coal gasification and combustion using fluidized-bed reactors. Long-term effects on hot-gas cleanup systems can be studied economically by passively participating in the various research gasification and combustion runs. Filter efficiency, strength degradation, changes in permeability, and corrosion resistance are being investigated, as well as other pertinent issues such as cleaning techniques and temperature/pressure effects.

The test loop was constructed using high-ailoy metals with no refractory in order to minimize maintenance and to avoid ash/alkali/refractory interactions that may occur due to the high surface-to-volume ratio present in smalle-scale systems. The alloys used in construction were Haynes alloys HR-160 and 556 and $316 \mathrm{H}$ stainless steel. The piping used in the highest-temperature regions was HR-160 and 556. It is expected that these alloys will demonstrate good high-temperature corrosion characteristics under both oxidizing and reducing conditions. The test loop is designed to operate at temperatures up to $1650^{\circ} \mathrm{F}$ and pressures up to $150 \mathrm{psig}$. The system was designed in accordance with B31.3 piping codes. The test loop consists of a single inlet pipe that branches into three different flow paths. Each path is controlled by a high-temperature valve located as far downstream as possible in order to minimize thermal stresses in the valves. Two of the flow paths are identical and are used as filter element test bays, and the third branch is used as a bypass line. Filter elements can be installed in either or both test bays simultaneously. The filter modules are flange-mounted so that they may be replaced as necessary for different filter types. The maximum filter housing dimensions are approximately 72 inches in length and 36 inches in diameter. Figure 2 shows the filter housing currently in use. The flanges used will permit operating conditions up to $1500^{\circ} \mathrm{F}$ and 150 psig. In order to achieve operating conditions up to $1650^{\circ} \mathrm{F}$ and 150 psig, further engineering is required to ensure that the flanged connection satisfies the criteria of the B31.3 piping code. The system will not be operated above $1500^{\circ} \mathrm{F}$ and 150 psig until this work has been completed. Gas flow rates through the various paths can be regulated by the downstream valves. The piping system is heated electrically using guard heaters. Pipe temperatures can be maintained at $1650^{\circ} \mathrm{F}$ continuously so that the process gas temperature can be raised or maintained as required in order to simulate the desired hotgas conditions. The system has a heated backpulse system capable of delivering pressurized, heated, inert gas to the filter modules for cleaning purposes. The inlet viping to the test loop can be connected to a $100-1 \mathrm{~b} / \mathrm{hr}$ fluidized-bed gasifier or to other reacturs being used for research at the Center. The TRTU is expected to be operational sometime in early 1993 and will be installed near the 100-lb/hr fluidized-bed reactor. The test loop will be connected to the TRTU when it is ready for operation. 


\section{TABLE 1}

Operating Parameters and Specifications for the Hot-Gas Cleanup Test Ioop

\begin{tabular}{|c|c|c|c|c|c|}
\hline Operating Mode & Mild Gasification & Hydrogen Production & PFBC & \multicolumn{2}{|c|}{ TRTU } \\
\hline $\begin{array}{l}\text { Gas Flow Rate (sch) } \\
\text { Gas Temperature }\left({ }^{\bullet} \mathrm{F}\right) \\
\text { Gas Pressure (atm) } \\
\text { Dust Loading (ppm) }\end{array}$ & $\begin{array}{c}2,000 \\
1,100-1,650 \\
1-10 \\
\text { TBD }\end{array}$ & $\begin{array}{c}1,800 \\
1,200-1,600 \\
1 \\
\text { TBD }\end{array}$ & $\begin{array}{l}30,000 \\
1,000-1,650 \\
1-10 \\
\text { TBD }\end{array}$ & \multicolumn{2}{|c|}{$\begin{array}{c}20,000 \\
1,400-1,650 \\
1-10 \\
\text { TBD }\end{array}$} \\
\hline $\begin{array}{l}\text { Gas Composition } \\
\text { (nominal) }\end{array}$ & $\begin{array}{c}86 \% \mathrm{~N}_{2,}, 10 \% \mathrm{CO}_{2,} \\
6 \% \mathrm{H}_{2} \mathrm{O} \\
\text { (see Note 1) } \\
120 \text { ppm } \mathrm{H}_{2} \mathrm{~S}\end{array}$ & $\begin{array}{c}67 \% \mathrm{H}_{2} \mathrm{O}, 18 \% \mathrm{HI}_{2} \\
14 \% \mathrm{CO}_{2}, 6 \% \mathrm{CO} \\
5 \% \mathrm{~N}_{2}, 1 \%-2 \% \mathrm{CH}_{4}\end{array}$ & $\begin{array}{l}69 \% \mathrm{~N}_{2,16 \% \mathrm{CO}_{2,}} \\
12 \% \mathrm{H}_{2} \mathrm{O}, 4 \% \mathrm{O}_{2}\end{array}$ & $\begin{array}{l}\text { Gusification } \\
63 \% \mathrm{~N}_{2,}, 16.6 \% \mathrm{CO}_{1} \\
11.6 \% \mathrm{I}_{2,}, 9.6 \% \mathrm{H}_{2} \mathrm{O} \\
8.6 \% \mathrm{CO}_{2} .6 \% \mathrm{CH}_{4}\end{array}$ & $\begin{array}{c}\text { Combustion } \\
75.5 \% \mathrm{~N}_{26} \\
16.6 \% \mathrm{CO}_{2,} \\
7 \% \mathrm{H}_{2} \mathrm{O}, 2 \% \mathrm{O}_{2}\end{array}$ \\
\hline $\begin{array}{l}\text { Backpulse Cleaning } \\
\text { Gas Compoaition } \\
\text { Gas Temperature (`F) } \\
\text { Gas Pressure (psia) } \\
\text { Pulse Duration (sec) }\end{array}$ & $\begin{array}{l}\text { Nitrogen } \\
1600 \\
300 \\
\text { Variable }\end{array}$ & & & & \\
\hline $\begin{array}{l}\text { Tube-Sheet Cooling } \\
\text { Steam Pressure (psia) } \\
\text { Steam Flow Rate }(\mathbf{b} / \mathbf{h}) \\
\text { Steam Inlet T'emp. }\left({ }^{\circ} \mathbf{F}\right)\end{array}$ & $\begin{array}{l}\text { Steam } \\
110 \\
600 \\
\mathbf{9 3 0}\end{array}$ & & & & \\
\hline Sampling Apparatus & TBD & & & & \\
\hline Analyticul Apparatus & 'Т(вI) & & & & \\
\hline
\end{tabular}

Note 1: There is no single set of operating parameters for the mild gas calciner oince it could vary considerably depending on the heating/laidizing gas. Ranges to consider should be $\mathrm{N}_{2}=65 \%$ to $85 \% ; \mathrm{CO}_{2}=10 \%$ to $30 \% ; \mathrm{H}_{2} \mathrm{O}=0 \%$ to $10 \% ; \mathrm{CO}=1 \%$ to $5 \% ; \mathrm{II}_{2}=1 \%$ to $\mathrm{E} \% ; \mathrm{CH}_{4}=1 \%$ to $2 \%$;
and $\mathrm{H}_{2} \mathrm{~S}=100$ to 2000 ppm. 


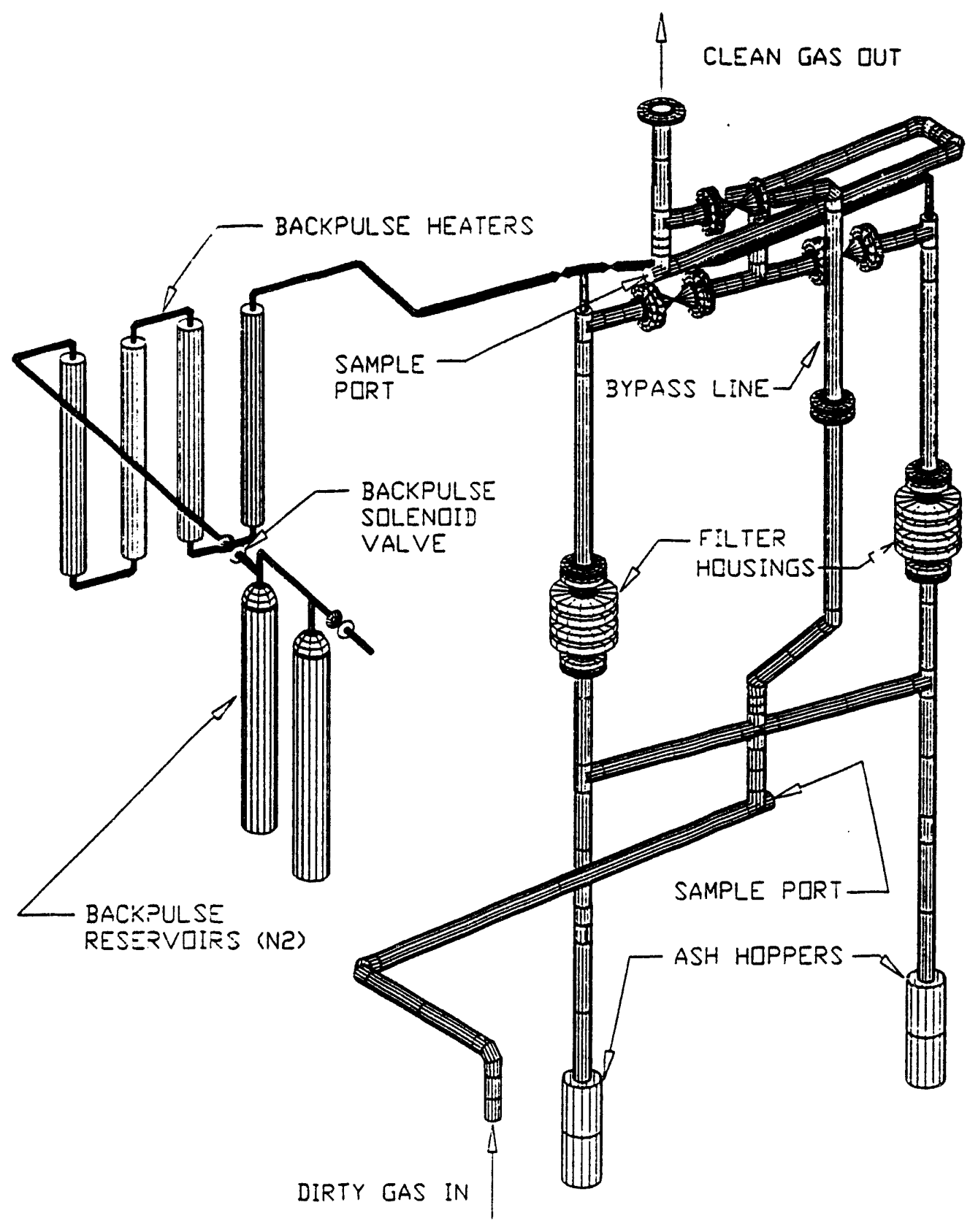

Figure 1. Hot-gas cleanup test loop. 


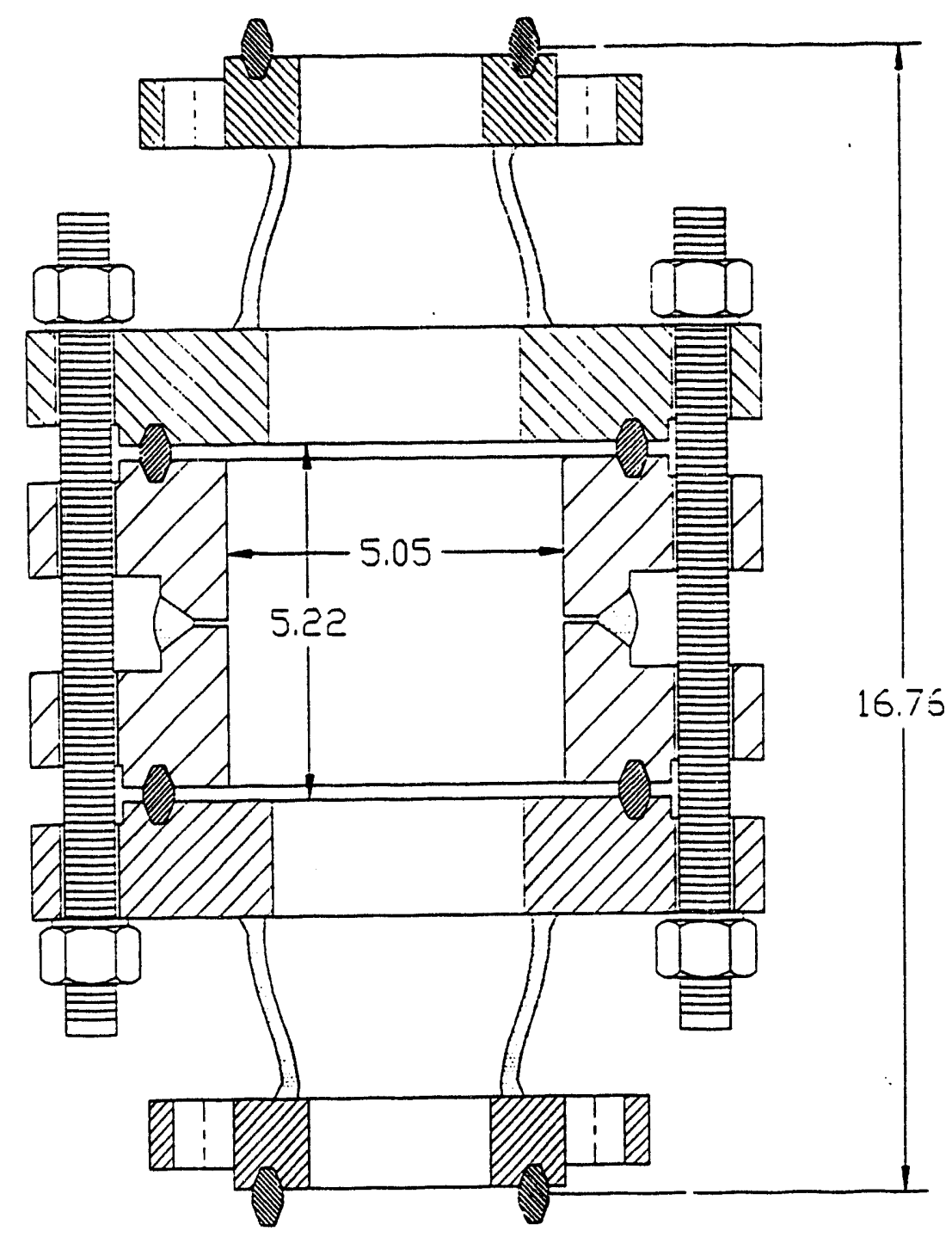

Figure 2. Filter housing currently in use.

The performance of the backpulse cleaning system was characterized to determine the available cleaning capabilities of the system. The actual cleaning requirements will be dependent upon the hot-gas cleanup system being evaluated. Modifications to the pulse cleaning system may be necessary as dictated by these requirements.

A high-temperature, high-pressure, particle sampling system is being developed for use with the hot-gas cleanup test loop. This sampling system must meet the National Electrical Code (NEC) and B31.3 piping requirements, as well as allowing sampling at the extreme operating conditions of the test loop. Aside from code-related issues, the particle sampling system currently in use is slow and cumbersome to use. A separate probe must be inserted to make flow measurements, then the particulate probe must be inserted to make dust-loading measurements. It takes approximately 45 to 60 minutes to collect one 
sample with the current configuration. While this system may be adequate for intermittent measurements on a temporary basis, it is inadequate for safe, reliable, long-term work. The particulate sampling system is being designed to sample at pressures up to $200 \mathrm{psi}$ at a temperature of $1800^{\circ} \mathrm{F}$ under both oxidizing and reducing conditions. Table 2 shows the performance specifications for the sample system, and Figure 3 shows the sampling system. A sampling probe is inserted into the test loop, and a particulate sample is withdrawn isokinetically. The sample probe is considered to be disposable (based on wear). Different materials will be used for different operating conditions. The gas sample will pass through a series of cyclones and a borosilicate filter to remove all particulate matter, then through a quench train to remove any condensables, then through gas meters to determine flow. The probe and cyclone assembly will be electrically heated to maintain the gas temperature until it reaches the quench train.

The test loop is scheduled to be operational by the time the transport reactor is ready for shakedown testing. Recommendations for future work include testing and calibrating the particulate sampling system and evaluating various filter candidates in the test loop in conjunction with other research activities.

\subsection{Alkali Getter Testing}

Tests of kaolin as an entrained alkali getter in atmospheric and pressurized coal combustion systems were performed with the EERC pressurized drop-tube furnace (PDTF) system. Kaolin is a clay composed primarily of the mineral kaolinite $\left(\mathrm{A}_{2} \mathrm{Si}_{2} \mathrm{O}_{5}[\mathrm{OH}]_{4}\right)$. In pressurized fluid-bed combustion tests using granular filter beds, clays have been shown to be good sorbents for removing alkali compounds from the gas stream (1). In laboratory studies, kaolin has been shown to be effective not only at removing sodium compounds from the gas phase, but also in irreversibly fixing the sodium (2). Other clays are also believed to absorb sodium compounds from the furnace gas when the clay is added to the coal feed. Emathlite has been shown to be especially good at gettering sodium (2).

\section{TABLE 2}

Specifications for an Isokinetic Particulate Sampling System

\begin{tabular}{ll}
\hline Maximum Inlet Gas Temperature & $1,800^{\circ} \mathrm{F}$ \\
Maximum Inlet Gas Pressure & $200 \mathrm{psig}$ \\
Gas Flow Range & $2,000 \cdot 30,000 \mathrm{scfh}$ \\
Maximum Gas Temp. @ Filter & $1,000^{\circ} \mathrm{F}$ \\
Typical Sample Rate & One Sample per Hour \\
Gases to be Sampled & Exhaust Gases from Coal Combustion and \\
& Gasification (reducing and oxidizing) \\
Electrical Classification (NFPA) & Class I, Div. 2, Group B \\
Applicable Codes & ASME B31.3 Piping Code \\
\hline
\end{tabular}




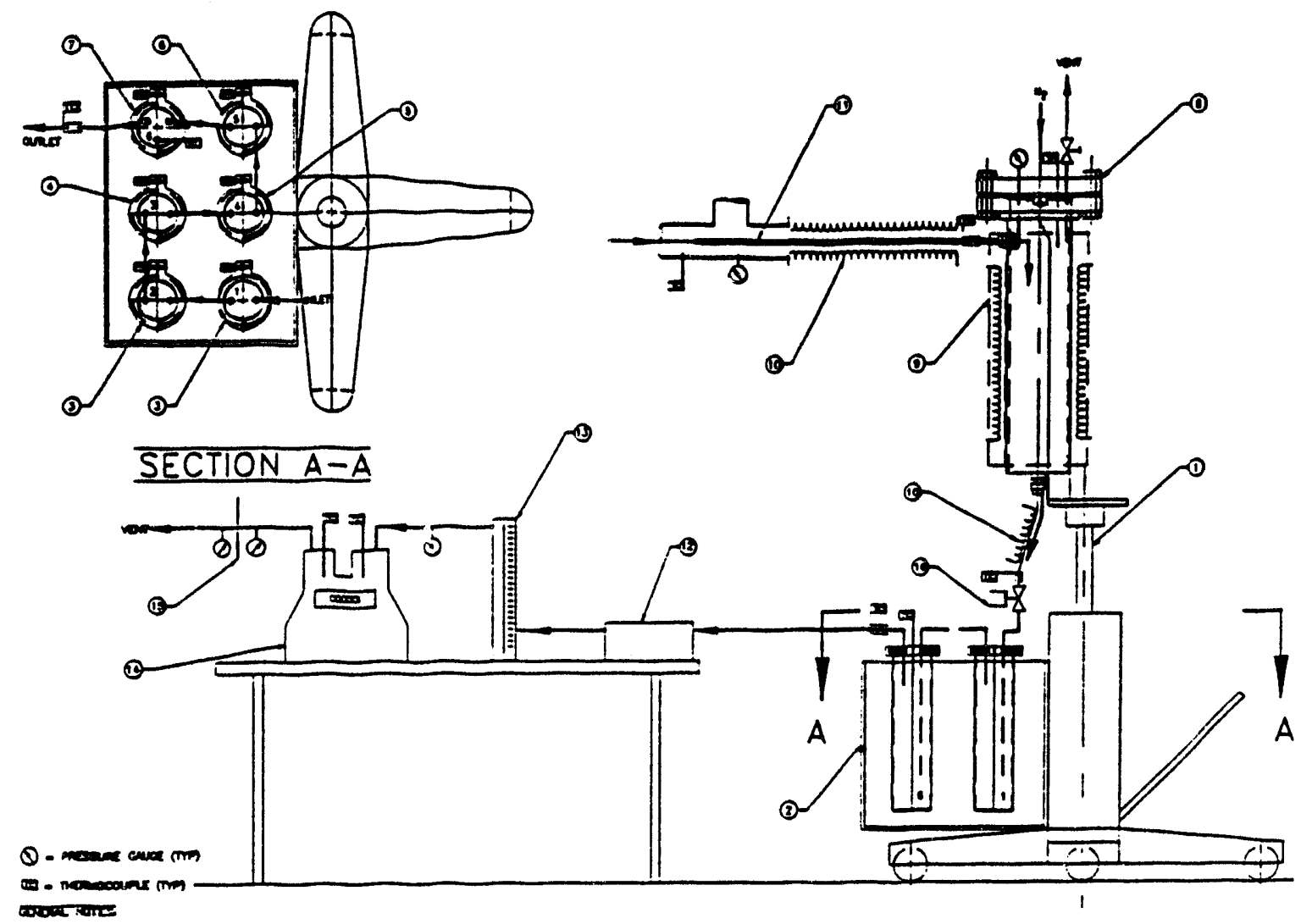

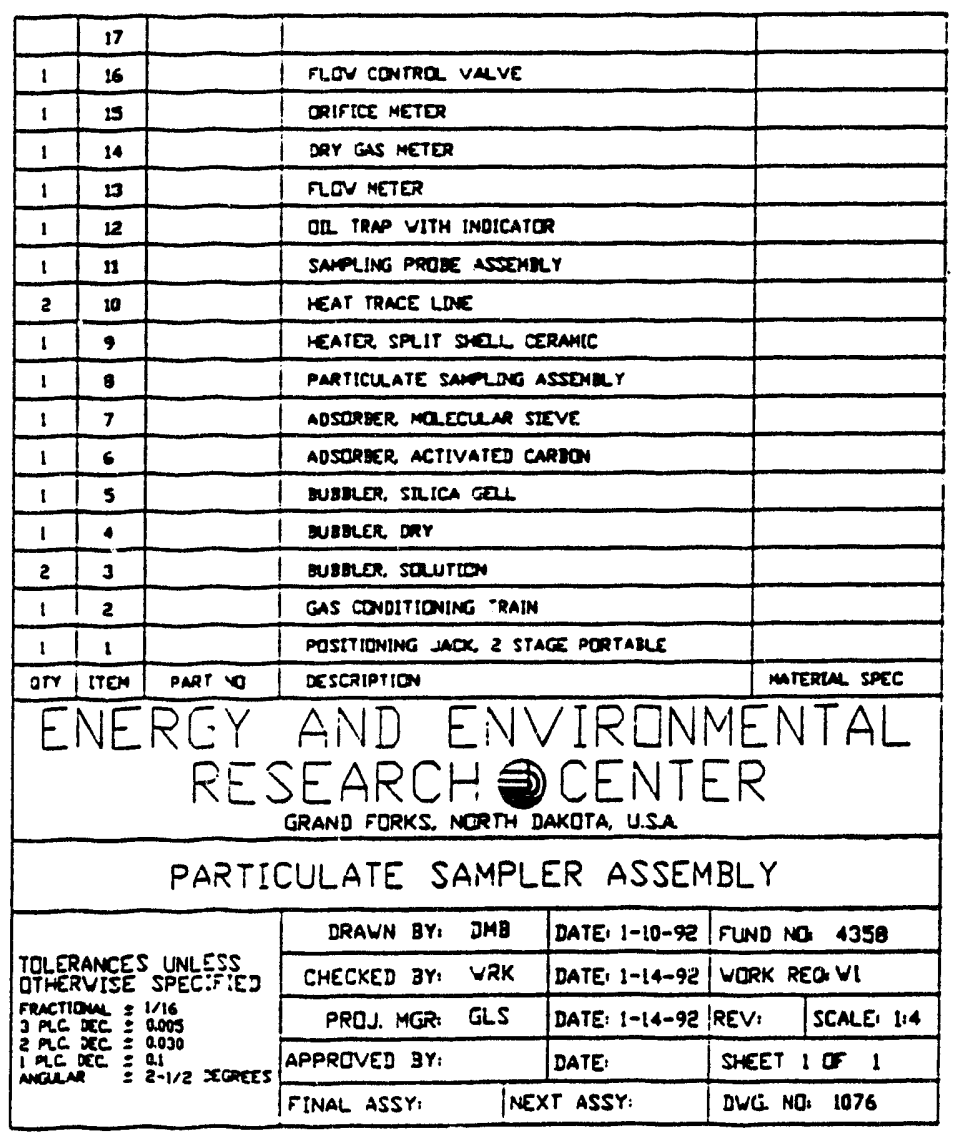

Figure 3. Test loop particulate sampling system. 
To be an effective getter, the clay material must not deposit once the sodium is fixed. This implies that the gettering material must be composed of small particles, typically less than $5 \mu \mathrm{m}$ in diameter, which will not separate from the flow of gas until collected in the particulate control system. Since clay particles normally have diameters smaller than this, they would appear to be ideal gettering agents. However, moist clays can be highly agglomerated due to surface moisture, so it is best if the clay feed is dry before feeding to reduce agglomeration.

Kaolin was preferred for the gettering test over other types of clays because it can be found in relatively pure form, containing less alkali and alkaline earth elements, which may flux the material upon heating. Also, kaolinite has a layered structure composed of a sheet of silica tetrahedra bonded on one side to a sheet of aluminum hydroxide octahedra, so it has a higher aluminum-to-silicon ratio than most other clays. Because of its higher aluminum content, and alkali fluxed particle will usually have a higher melting point than if it contained more silica. Kaolin is mined in a number of places in the United States and can be supplied in rock, dried powder, sieved dried powder, or slurry forms.

Although a small body of data is available about the getters in laboratory experiments, only limited data are available about the use of kaolin under carefully controlled coal combustion conditions, and no data are available about its use in pressurized coal combustion conditions. Therefore, four tests were performed to test the efficacy of kaolin as a getter in both atmospheric and pressurized coal combustion conditions, and to determine the mechanism of gettering. The kaolin used for these tests was provided as rock by J.M Huber Corporation of Macon, Georgia. It was dried, then ground with a mortar and pestle. Only fine powder was used for the gettering experiments.

The kaolin rowder was mixed with pulverized coal from the Spring Creek mine, Montana, in the ratio of 1 part kaolin to 2 parts ASTM coal ash. Spring Creek coal was chosen because it has relatively high sodium and low ash contents and because the sodium is present in the coal as an ion associated with carboxylic acid groups in the organic structure of the coal. Because of this association, the sodium is vaporized during combustion. Vaporized sodium that encounters an ash particle is typically absorbed by the particle. However, Spring Creek coal produces little ash, so much of the sodium remains in the vapor phase in the hot zone of the combustor. In cooler regions of the boiler, it may condense homogeneously to ultimately form submicron sodium sulfate particles. There is some contention as to whether sodium hydroxide condenses, then sulfates, or sodium sulfate directly condenses. Both vapor phase and condensed sodium phases are very reactive and could cause severe corrosion of ceramic hot-gas particulate pollution control devices such as candle or cross-flow filters. Therefore, Spring Creek was chosen as a "worst-case" example of a coal that may cause alkali corrosion of ceramic hotgas cleanup devices.

Four combustion tests were performed in all: one test each of raw 'spring Creek at atmospheric pressure, coal plus kaolin at atmospheric pressure, raw coal at 100 psi, and coal plus kaolin at 100 psi. The tests were performed in the EERC PDTF, which is described in detail in the July through December 1991 semiannual technical progress report for the Turbine Combustion Phenomena project being performed uncier the 
Cooperative Agreement at the EERC. The PDTF is capable of operating under the following conditions:

$\begin{array}{ll}\text { Temperature: } & \text { Ambient to } 2732^{\circ} \mathrm{F}\left(1500^{\circ} \mathrm{C}\right) \\ \text { Pressure: } & \text { Ambient to } 300 \text { psia }(20.4 \mathrm{~atm}) \\ \text { Orygen: } & 0 \text { to } 20 \mathrm{~mol} \% \\ \text { Gas Flow: } & 0 \text { to } 7.8 \mathrm{scfm}(220 \mathrm{~L} / \mathrm{min}) \\ \text { Residence Time: } & 0 \text { to } 5.0 \mathrm{sec}\end{array}$

- Optical access at any residence time

- Provision for char and ash collection

- Provision for ash deposition studies

For the entrained kaolin tests, fly ash samples were collected and size-segregated online with a series of two cyclones and a final nylon filter. To determine the efficacy of the kaolin additions in gettering, the weight distribution of elements among the different size ranges was used. Figure 4 shows two combination bar-line graphs that illustrate the weight percent of the major elements that were collected for each test in each size range. Two graphs are used, one for the pressurized tests, the other for the atmospheric tests. The bars represent the values for the raw coal tests, the lines represent tide values for the test of the coal/kaolin blend. For each element, the three data points, from left to right, are for the larger cyclone, the smaller cyclone, and the filter samples, respectively. Because different flow rates were used for the atmospheric tests versus the pressurized tests, the cut points of the cyclones were different, so the data should not be used to determine changes in weight distributions due to pressure, only changes due to the addition of the kaolin. Attempts to measure the actual size distributions of the collected samples via laser light scattering (Malvern) were not completely successful because of particle agglomeration. In general, however, particles collected in Cyclone 2 (larger cyclone) had diameters greater than 10 microns, in Cyclone 5 (smaller cyclone) the diameters were between 1 and 10 microns, and on the filter they were less than one micron in diameter.

Because the cyclones had different size cut points for the atmospheric versus pressurized tests, the effects of pressure on the size distributions of the elements are somewhat ambiguous. It is clear that the relative weight distributions of all elements except chlorine among the different particle sizes are not strongly affected by pressure. In each case, silicon, aluminum, and calcium all tend to be predominantly concentrated in the larger particles, with negligible fractions present in the submicron particles. In contrast, large percentages of the sodium, sulfur, and chlorine are found in the smallest particles. Sulfur was bimodally distributed, most likely present as calcium sulfate in the largest particles and as sodium sulfate in the smallest particles. In the raw coal tests, chlorine shows the only significant size shift due to pressure increase, from larger to smaller particles. The chlorine-containing particles in the smallest size range probably formed as the gas was quenched during sample collection, indicating that at higher pressure more chlorine (probably as chloride) may exist in the gas phase than at atmospheric pressure.

The most important conclusion about the gettering tests is that sodium is shifted strongly away from the smallest particles by the addition of kaolin. If we assume that the sodium sulfate in the smallest size fraction formed through homogeneous nucleation as the gas cooled (possibly during collection), then one half of the sodium was removed from 


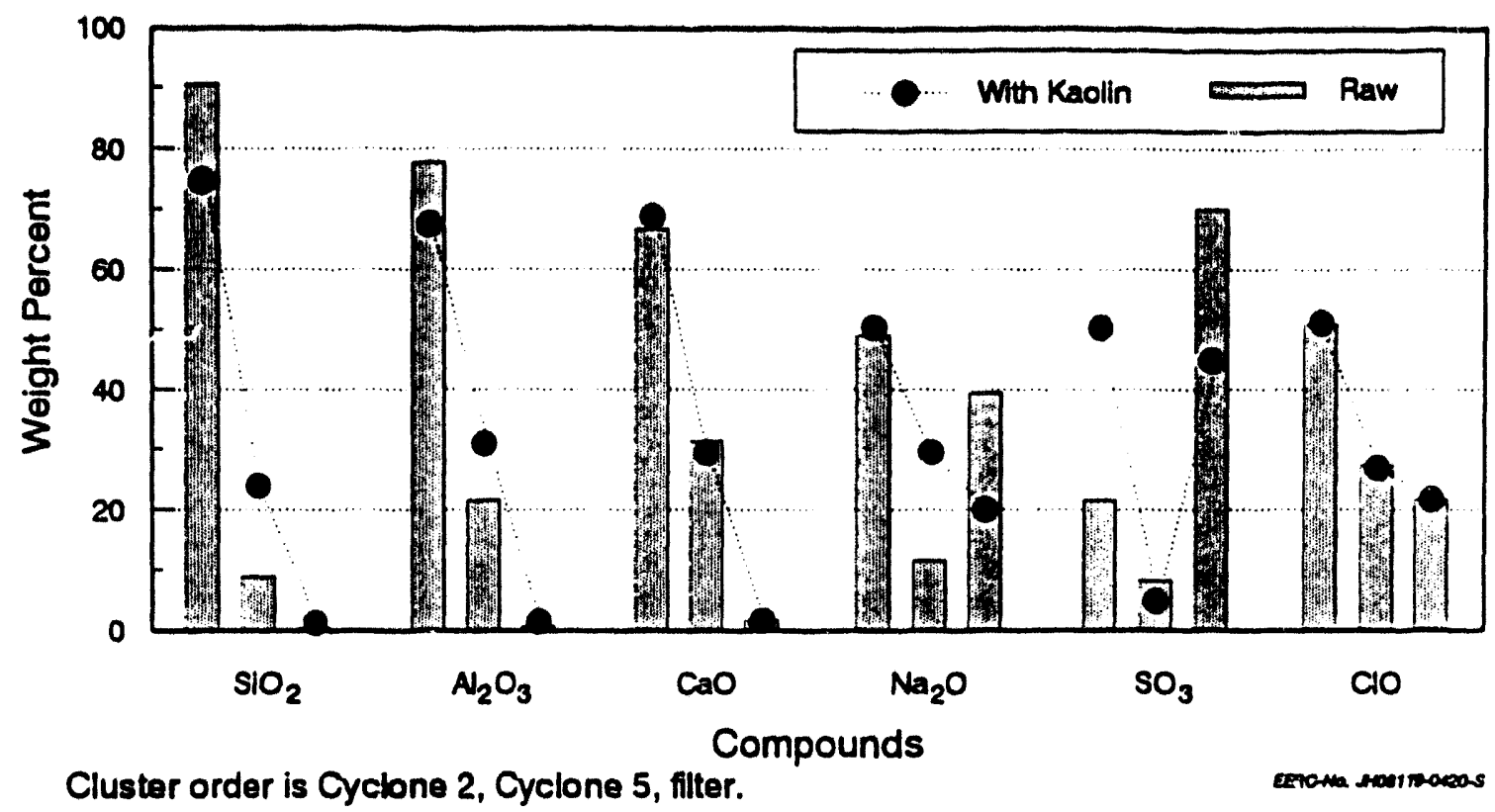

(a) Percent of each element in each size fraction in the atmospheric pressure tests.

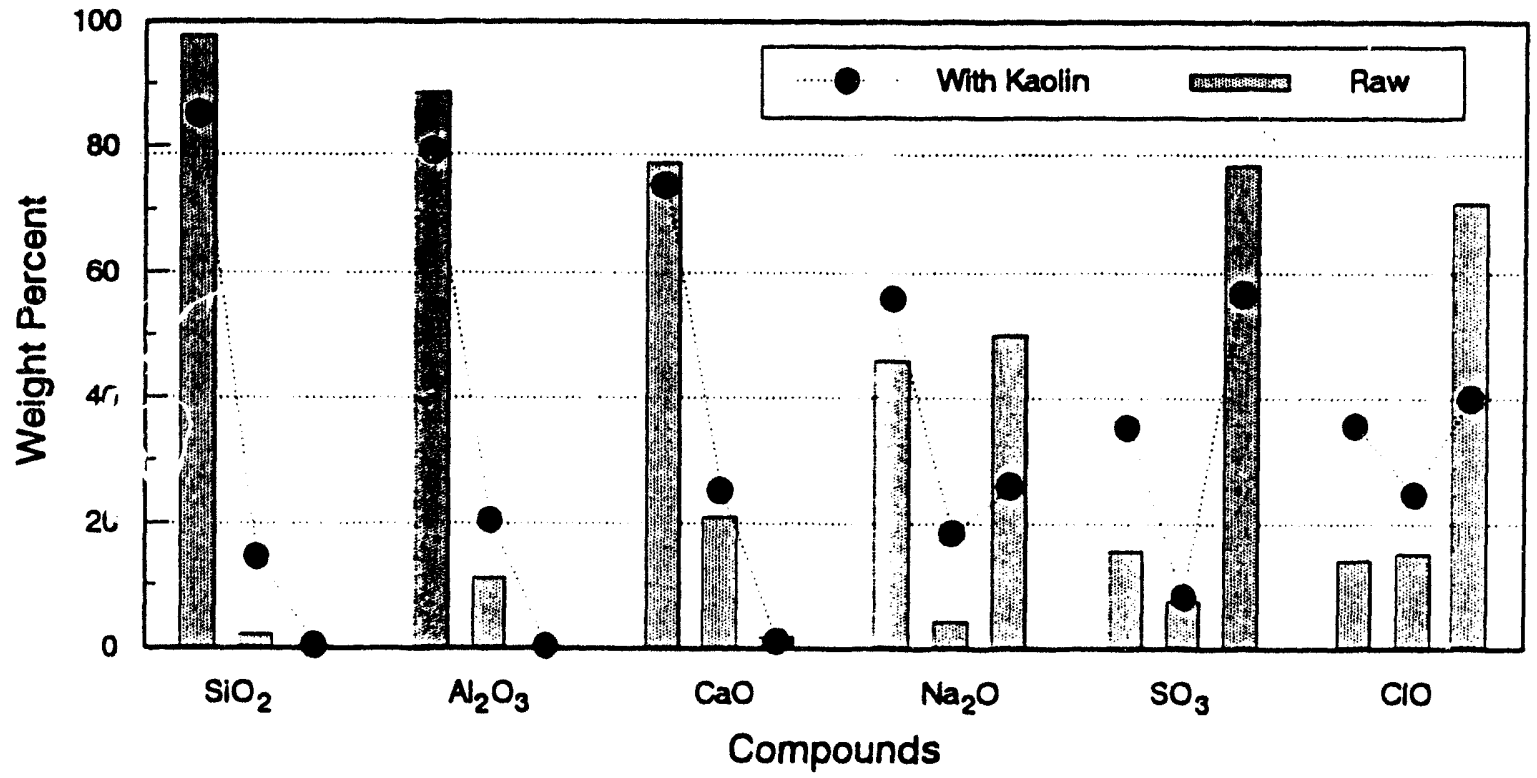

Cluster order is Cyclone 2, Cyclone 5, filter.

(b) Percent of each element in each size fraction in the high-pressure tests.

Figure 4. The percent of each element collected in each size fraction for the tests of kaolin as an alkali getter. 
the gas phase by the kaolin addition. This result holds both at at: 10spheric and higher pressure. Most of the sodium was shifted to the 1-to 10-micron size range, which is where the kaolin is concentrated. The concurrent shift in sulfur from the smallest to the largest size ranges indicates that the sodium was chemically combined with the kaolin, probably in the high-temperature zone, and that the kaolin did not merely serve as a condensation surface for sodium sulfate. Because much of the sodium was removed from the gas phase, the sulfur shifted to the largest size range by sulfating relatively more of the calcium-rich particles.

\subsection{Thermochemical Equilibrium Modeling. PHOEBE Database Modifications}

PHOEBE (PHase Ordering and EquiliBrium Evaluation) is a computer program developed at the EERC to calculate the thermochemical equilibrium composition of combustion products. The following objectives had been set forth for the improvements of the model for this year:

la Improve PHOEBE database

$2 b$ Run simulations

Both items were addressed and are now complete. Item 1a, the improvements to the PHOEBE database, required a substantially (approximately 4 months) longer period of time than had been originally anticipated. However, the database now contains about 850 species, which is a threefold increase from its former size of about 270 species. Additionally, the database has also been thoroughly cross-checked. Validation tests have also been conducted and the database modified depending on the results of these tests. We also wish to emphasize that we expect the updating and validation process to be an ongoing activity throughout the lifetime of this project.

A list of chemical compounds relevant to advanced coal combustion systems was compiled. A variaty of vapor-and liquid-phase species was specifically chosen to better represent fluidized-bed combustion systems. The requisite free energy of formation (FEF) data for each species were also collated and entered into the database. The current PHOEBE database contains approximately 370 chemical compounds with an average of more than two physical phases (gas, liquid, or solid) per compound. This makes a total of roughly 800 species, which is a threefold increase over the original database.

The original PHOEBE database was modified to a free-form ASCII database (FAD). This has the advantage that any conventional text-editing software can be used to edit the database. Also, since almost any text editor or word processor may be used to update, modify, or edit the database, specialized software to perform these tasks becomes redundant.

A database management utility that performs searching, retrieval, indexing, etc., was written (in C), debugged, tested, and is fully operational. Although these tasks can also be accomplished by some of the more advanced word processors, their specialized nature prohibits their execution by generic text editors.

Routines to curve-fit the FEF data of the species have alsu been written. These routines allow a wide variety of representations (linear, polynomial, rational, logarithmic, etc.). The curve-fit representations of the FEF data can thus be chosen in the most 


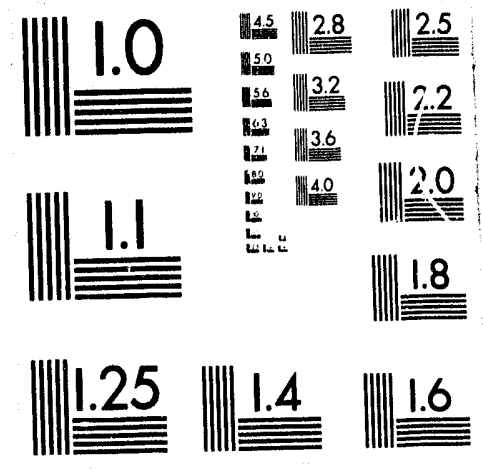



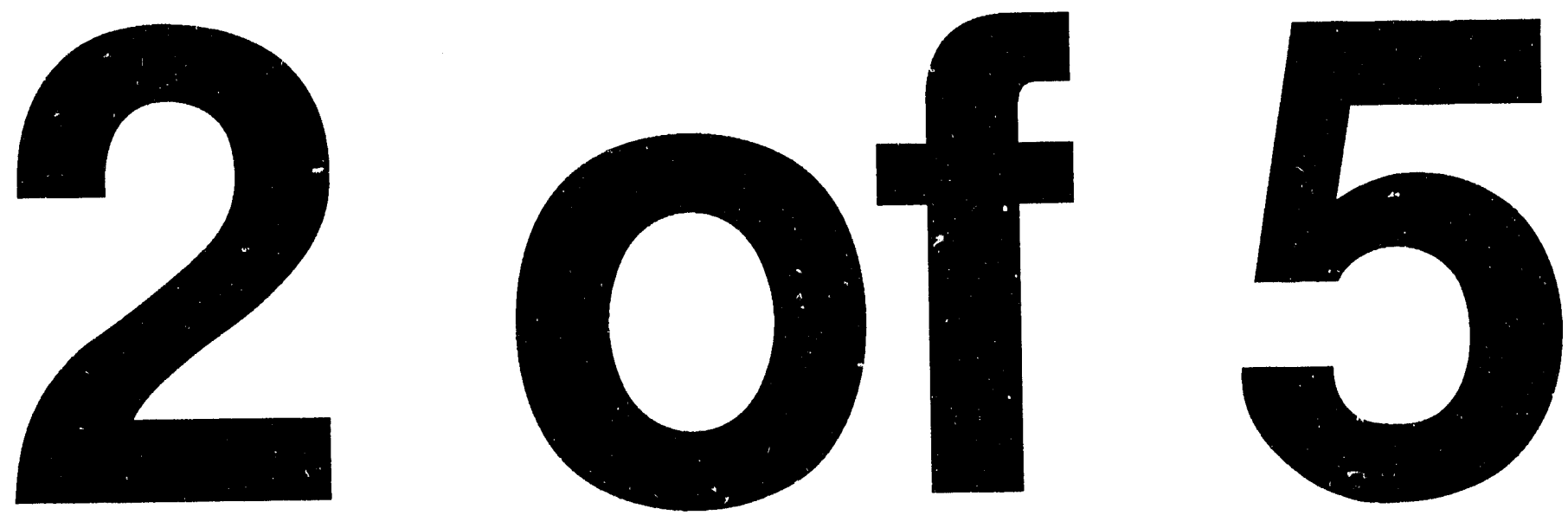
optimal manner. In most cases, the curve-fitted FEF data are used, if need be, at the computation level.

The thermodynamic systems simulations of Itcm $2 \mathrm{~b}$ have also been completed. Initially, very simple systems (like water, gas mixtures, etc.) with well-characterized thermodynamic behavior were simulated to validate the correctness of the overall PHOEBE algorithm, as well as to optimize the standard free energy of formation values for many of the species in the database. A total of about 20 such simple systems were simulated. During this stage, the algorithm also underwent a few iterations of revisions and changes. Two systems were selected for the final phase of this task item and their equilibrium behavior simulated. They were the $\mathrm{Al}_{2} \mathrm{O}_{3}-\mathrm{SiO}_{2}$ system and a portion of the $\mathrm{Na}_{2} \mathrm{O} \cdot \mathrm{Al}_{2} \mathrm{O}_{3} \cdot \mathrm{SiO}_{2}$ system. A comparison of the simulation results with the experimental phase diagrams shows acceptable results, the largest error in the simulated results being about $70^{\circ} \mathrm{C}$ in liquidus temperature for either system tested. Figure 5 is a plot of the experimental versus predicted phase diagram of a cross section of the ternary system $\mathrm{Na}_{2} \mathrm{O} \cdot \mathrm{Al}_{2} \mathrm{O}_{3} \cdot \mathrm{SiO}_{2}$. As can be seen from the figure, the predicted values track the experimental values well. It should be noted that both these systems were assumed to behave ideally (i.e., with unit-activity coefficients), so, necessarily, we expect errors in the predicted values since no system is ideal. Additionally, it must also be borne in mind that inherent inaccuracies exist in the FEF values in the database. All in all, therefore, it can be concluded that PHOEBE provides acceptably accurate representations of the equilibrium behavior of multiphase, multicomponent systems.

\section{$\mathrm{Na}_{2} \mathrm{O}-\mathrm{Al}_{2} \mathrm{O}_{3}-\mathrm{SiO}_{2}$}

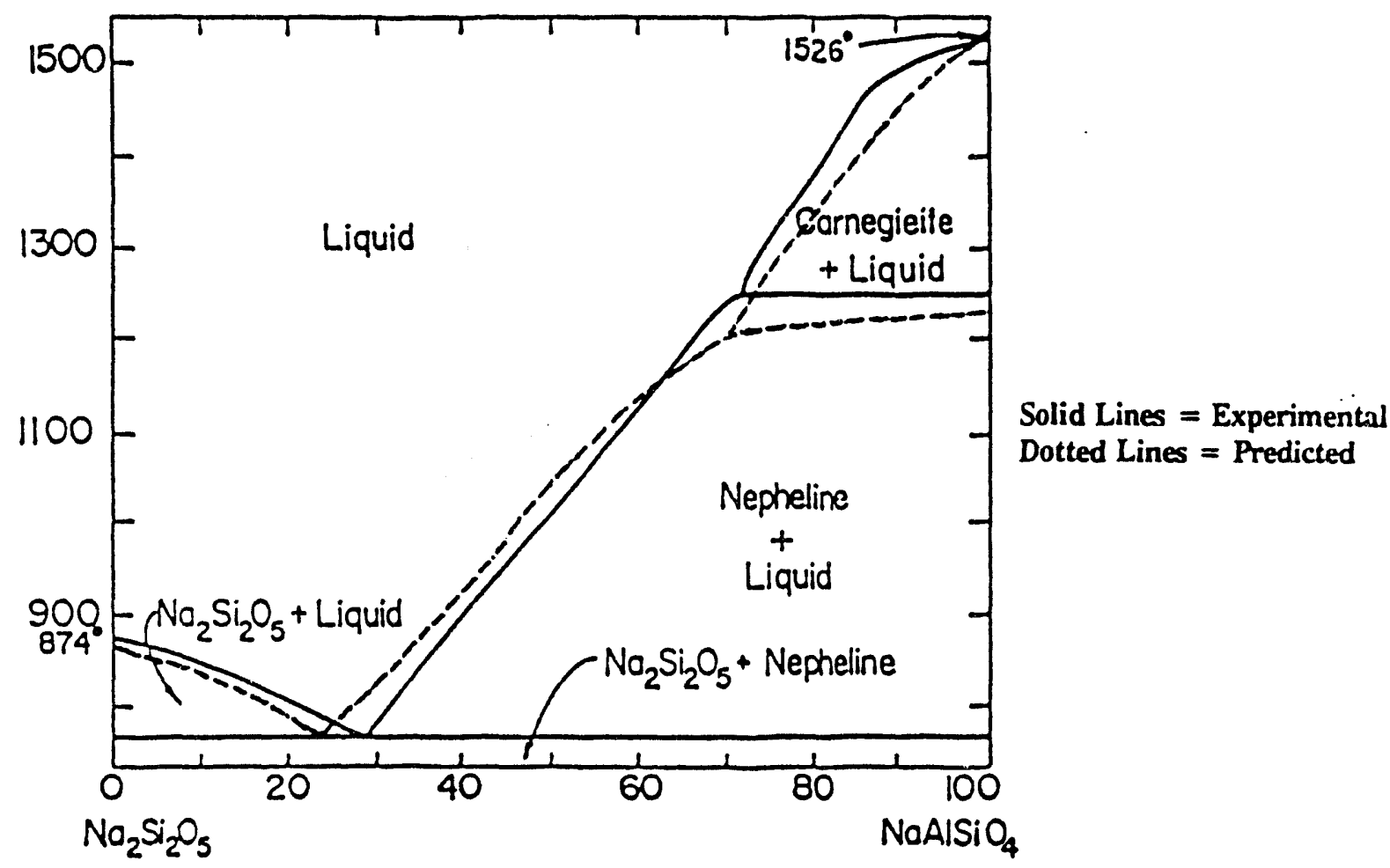

Figure 5. A plot of the experimental vs. predicted phase diagram for a cross section of the $\mathrm{Na}_{2} \mathrm{O}-\mathrm{Al}_{2} \mathrm{O}_{3}-\mathrm{SiO}_{2}$ system. 


\subsection{FUTURE WORK}

Future work will involve the use of PHOEBE to determine the most efficient combinations and quantities of alkali getters to use in combustion tests. In addition, alkali attack of ceramic materials that could be used in the construction of ceramic particulate filters will be investigated both with the PDTF and in laboratory experiments.

Future opportunities for the EERC to utilize the hot-gas test loop are numerous. The EERC can be utilized in a supporting role for the Wilsonville hot-gas cleanup facility by functioning as a screening facility for emerging cleanup technologies that lack long. term operating histories. As additional operational issues arise at Wilsonville, they may be addressed economically at the EERC.

The test loop will also be utilized for testing of new filter materials that are identified as a result of the bench-scale work done investigating alkali attack issues.

The EERC is also planning on establishing a consortium of hot-gas cleanup device developers for the purpose of operating the test loop for extended periods to provide performance data on the candidate cleanup systems.

\subsection{REFERENCES}

1. Lee, S.H.D; Johnson, I. "Removal of Gaseous Alkali Metal Compounds from Hot Flue Gas by Particulate Sorbents," Journal of Engineering for Power 1980, 102, 397-402.

2. Punjak, W.A. Shadman, F. "Aluminosilicate Sorbents for Control of Alkali Vapors During Coal Combustion and Gasification," Energy and Fuels 1988, 2 (5), 702-708. 


\subsection{ADVANCED RESEARCH AND TECHNOLOGY DEVELOPMENT}


3.1 Turbine Combustion Phenomena 


\title{
TURBINE COMBUSTION PHENOMENA
}

Final Technical Progress Report

for the Period April 1, 1986, through December 31, 1992

\author{
by
}

Michael L. Swanson, Research Engineer Michael D. Mann, Research Supervisor

James E. Tibbetts, Research Associate

Energy and Environmental Research Center

University of North Dakota

Box 8213, University Station

Grand Forks, ND 58202-8213

Task Contracting Officer's Representative: Leland Paulsoı

for

U.S. Department of Energy

Morgantown Energy Technology Center

P.O. Box 880

3610 Collins Ferry Road

Morgantown, WV 26507-0880

December 1992

Work Performed under Cooperative Agreement No. DE-FC21-86MC10637 
LIST OF FIGURES $\ldots \ldots \ldots \ldots \ldots \ldots \ldots \ldots \ldots \ldots \ldots \ldots \ldots$ ii

1.0 INTRODUCTION $\ldots \ldots \ldots \ldots \ldots \ldots \ldots \ldots \ldots \ldots \ldots \ldots \ldots \ldots \ldots \ldots \ldots \ldots \ldots$

2.0 OВJECTIVES $\ldots \ldots \ldots \ldots \ldots \ldots \ldots \ldots \ldots \ldots \ldots \ldots \ldots \ldots \ldots \ldots \ldots \ldots$

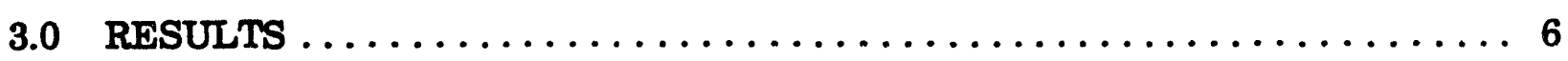

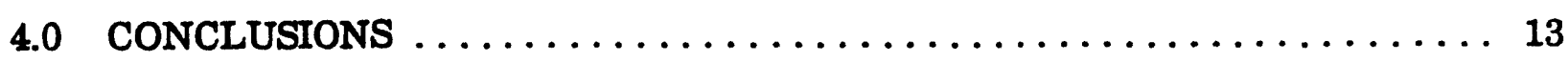

5.0 RECOMMENDATIONS $\ldots \ldots \ldots \ldots \ldots \ldots \ldots \ldots \ldots \ldots \ldots \ldots \ldots \ldots \ldots \ldots$

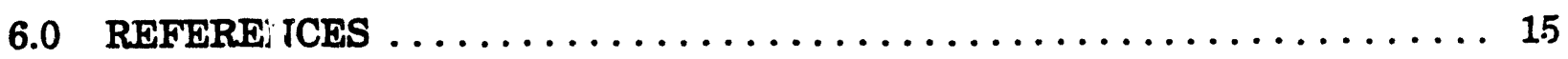




\section{LIST OF FIGURES}

Figure

$\underline{\text { Page }}$

1 Graph of carbon burnout as a function of combustion air temperature for parametric combustion tests 43-47 (LRT = long residence time; SRT = short residence time). . . . . . . . . . . . . . . . . . . . 8

2 Plot of carbon burnout against atomizing air-to-fuel ratio for parametric combustion tests $\mathbf{4 3 - 4 7}$ (LRT $=$ long residence time; $\mathbf{S R T}=$ short residence time $\ldots \ldots \ldots \ldots \ldots \ldots \ldots \ldots \ldots \ldots \ldots \ldots \ldots \ldots$

3 Plot of carbon burnout against fuel firing rate for parametric combustion tests $43-47$ (LRT = long residence time; SRT = short residence time)

4 Corrected SMD as a function of atomizing air-to-fuel ratio for tested CWFs and baseline water 


\section{TURBINE COMBUSTION PHENOMENA}

\subsection{INTRODUCTION}

The main obstacle to widespread use of low-rank coals (LRCs) for applications other than minemouth power generation is their high moisture, sometimes over $60 \%$. Conventional evaporative drying can remove all the moisture and produce a dried fuel that is acceptable if used immediately. However, no known evaporative process, including those followed with expensive oil coating, yields a dried bulk LRC that can withstand the rigors of shipping and handling. Evaporatively dried LRCs act like sponges and reabsorb moisture when exposed to high humidity. They generate copious amounts of dust when handled and are prone to spontaneous combustion $(1,2,3)$.

Coal-water mixtures (CWMs) technology is commercially available for high-valued bituminous coals using costly additives. Adding to the cost of bituminous CWMs is the requirement to include expensive micronizing to offset the inherent low reactivity, particularly for advanced applications. Recent advances in hydrothermal treatment of cheaper, more reactive LRCs at the University of North Dakota Energy and Environmental Research Center (EERC) have enabled LRCs to be used in CWMs. Hydrothermal treatment, commonly called hot-water drying (HWD), $(4,5)$ is a hightemperature, nonevaporative drying technique carried out at high pressure in water, during which the structure of the LRC is permanently altered. The process can be viewed as permanent moisture reduction through induced coalification with reuse of the water removed to slurry the HWD coal. HWD produces a coal-water fuel (CWF) with about the same energy density as the fee d coal, while retaining the high reactivity of the LRC. HWD low-rank coal-water fuels (LRCWFs) usually do not require costly additives, while yielding pseudoplastic fluids even at the extreme shear rates seen during atomization. Estimates of process economics have indicated that a minemouth HWD plant in the Powder River Basin can produce a LRCWF at around \$1.50/MM Btu, including coal costs.

Combustion tests assessing the technical feasibility of burning hydrothermally treated LRCWF in a atmospheric, bubbling fluidized-bed combustor (FBC) were performed at the EERC $(G)$. A low-rank CWF prepared from a Powder River Region subbituminous coal was successfully burned in a 18- $x$ 18-in FBC. The 60 wt\% dry solids CWF was pumped directly into the dense-bed zone of the combustor through a simple, water-cooled pipe without the aid of a nozzle or atomizing air. Operation of the combustor was extremely stable when firing with the $\mathrm{CWF}$ and a coal-water/limestone fuel mixture. Carbon burnout was very high, ranging from 99.4 to $99.7 \%$, which is equal or slightly greater than those obtained from screw feeding the same coal. $\mathrm{NO}_{\mathrm{x}}$ emissions were significantly lower than those seen burning the "as-received" coal. Limestone utilization was the same for the limestone added to the CWF as it was for the separate dry limestone feed.

The combustion behavior of hydrothermally treated LRCWF have been investigated in a $550,000 \mathrm{Btu} / \mathrm{hr}$ ash fouling furnace at the EERC (7) and a 400,000 Btu/hr vertical laboratory-scale combustor at Brigham Young University (8). Essentially complete carbon burnout $(99+\%)$ was achieved in most tests with residence times as short as 1.4 seconds. The LRC fuel combustion was more stable than high-rank CWFs combusted in both combustors under comparable conditions. Both projects reported that the LRC fuels were 
not as dependent on the quality of the atomization as were the high-rank fuels. The higher stability of the LRC fuels have been attributed to a higher percentage of volatile matter, higher reactivity, and nonagglomerating properties. Lower volumetric heat release rates have been measured with LRC fuels, as compared to the high-rank bituminous CWF, indicating the need for larger boilers with LRC fuels, which is consistent with current boiler practice using pulverized fuels. Compared with pulverized fuels, the flame produced in CWF combustion is distributed further through the furnace combustion zone with lower peak temperatures. Analyses of deposits produced in combustion of pulverized LRC fuels were primarily simple oxides and sulfates, while the deposits from the combustion of CWF were predominantly complex aluminosilicates.

Traditionally, heat engine fuels have been limited to clean fuels, such as natural gas or distillate fuels, which minimize the interrelated degradation processes of deposition, erosion, and corrosion. A coal-water slurry fuel has the potential of being injected and burned directly in a gas turbine or diesel engine utilizing injection and fuel handling methods similar to those employed with heavy petroleum fuels. Burning coal in a gas turbine is not a new idea, but commercial success has not been achieved. Under DOE sponsorship coal-water slurry fuels have been investigated as fuels for gas turbine engines for several years, but the major technical problems inhibiting commercialization are 1) deposits on the pressure and suction sides of the turbine blades reducing the gas flow area and turbine efficiency, 2) acceptable coal burnout given the short residence times inherent with gas turbine combustors, 3) corrosion of turbine blades by condensed alkali sulfates, 4) erosion of turbine blades and other components by ash particles entrained in the products of combustion, and 5) emissions control of $\mathrm{NO}_{\mathbf{z}}, \mathrm{SO}_{2}$, and particulates. The release of certain mineral matter species found in both raw and beneficiated coals can lead to ash deposition on surfaces, regardless of the ash content of the fuel. This deposition can lead to corrosion and metal loss of critical turbine components and, ultimately, to derating, unavailability, or catastrophic failure of the power generation system. Alkali metals and sulfur, existing as impurities in coal, have been identified as key components in the initiation of deposition and the onset of corrosion.

The efficient operation of advanced heat engine combustion systems depends on high CWF carbon burnout under short residence times. Atomization quality of CWF is an important parameter related to high carbon burnout in these systems. It has been reported that atomizing air-to-fuel mass flow ratio, relative velocity between the air and fuel, fuel velocity, and slurry rheology affect atomization performance. In addition, research efforts have indicated that additional factors such as extensional viscosity and coal particle agglomeration also might be important (9).

Combustion tests to evaluate the combustibility of LRCWF in a pressurized staged combustor were completed at the United Technologies Research Center (10). Conclusions from this research were that high levels of combustion efficiency can be achieved when firing LRCWFs, provided an adequate fuel energy density is available. A minimally processed Eagle Butte subbituminous CWF, which was limited to low coal loading (42 wt\%) and low energy density to preserve acceptable handling, was incapable of sufficient heat release to sustain stable combustion. HWD Eagle Butte slurries possessed higher solids loadings (up to $55 \mathrm{wt} \%$ ) and achieved stable combustor operation with highcornbustion efficiencies ( $>95 \%$ ). For the combustor used, a minimum heating value of $5000 \mathrm{Btu} / \mathrm{b}$ was required to maintain stable and efficient combustion. Combustion 
efficiency was found to increase with increasing energy density of the fuel. A HWD Velva (North Dakota) lignite also provided stable and efficient combustor operation.

General Motors Allison Gas Turbine Division (GM Allison) has completed two combustion tests with LRCWFs made at the EERC with a Powder River Basin coal in their full-scale 70-MM Btu/hr rich-quench-lean gas turbine combustor (11). Ash analyses from these tests indicate that the carbon burnout was very high, exceeding $99.9 \%$ in most cases. This burnout was much higher than the nominal $98 \%+$, which has been seen with a bituminous CWF. The collected ash was free of hard slag agglomerates or fused material. In addition, a four hour proof-of-concept combustion test was conducted on a Allison $501 \mathrm{~K}$ gas turbine with excellent combustion performance. A water-washable deposit was formed on the leading edge of the turbine blades (12). The deposit was characterized as primarily sodium and sodium-calcium sulfates. Atomization of a hydrothermally treated subbituminous CWF was conducted at GM Allison, and results from these tests indicate that the subbituminous CWF atomized as well as or better than thirteen other CWFs made from bituminous coal atomized in their atomization test facility (13).

General Electric Transportation Systems has also burned hydrothermally treated LRCWF using a 7FDL two-cylinder diesel engine (14). The bore and stroke of this particular engine is $9 "$ " $10.5 "$ and is rated for $1050 \mathrm{rpm}$. The burnout rates of the subbituminous fuels used were very high ( $>99 \%$ ), which was slightly higher than the bituminous CWFs, despite having a mean particle size three times higher than the particle size for the bituminous coal. No results have been presented on any increased injector wear caused by the LRCs higher ash levels.

\subsection{OB.JECTIVES}

The overall objective of the Turbine Combustion Phenomena Program has been to expand the scientific and engineering database for the combustion of LRC fuels in advanced pressurized combustion systems, such as those found in gas turbine engine applications. Fundamental research on the use of low-rank coal slurries for gas turbine engine applications has developed data that will 1) quantify the potential advantages of LRC higher reactivity and nonagglomerating tendencies, 2) help in determining fuel specifications, and 3) indicate needed design modifications in the gas turbine engines themselves. The intent of this research has been to establish the relationships between LRC properties and gas turbine engine operational parameters and compare these relationships with those established for diesel fuel and bituminous coal slurries.

The investigation of turbine combustion phenomena at EERC was a multiyear program. Six-year goals were established and are discussed in the following text.

\section{SIX-YEAR OBJECTIVES}

1. Technology and Market Assessment. To ensure that all sources of information to the project are thoroughly researched, EERC has performed an extensive survey of all published information concerning the use of coal and coal slurries in gas turbine applications. This information provided an understanding of the concerns and needs for the use of coal-derived fuels in these applications. The 
state-of-the-art for these technologies was determined and utilized to provide the proper direction for this program and limit duplication of effort. This effort has built upon a similar assessment of the market and technologies that was performed as a part of the Low-Rank Coal Slurry Combustion program.

2. Reactivity of Fuel in Pressurized Systems. The reactivities of dry and slurried LRCs are higher than those of bituminous coals, but the magnitude of these differerces was not well documented. Fast, simple, inexpensive experiments in a modified combustion bomb provided very basic information about the pressurized combustion behavior of LRC and slurries. This information is useful in determining the fuel specifications of slurries for use in heat engine applications. Data collected during these tests included the heat of combustion (calorimetry) of the sample, the sample burning time/reactivity (from pressure sensors), and the analysis of the products of combustion after combusting the test fuel under various conditions. Parameters to be studied included coal type, gas composition (percent oxygen), combustion bomb conditions at fuel injection, and system pressure. This testing provided semi-quantitative information in a fast and inexpensive manner.

3. Investigate the Fundamental Characteristics of Burning Low-Rank Coal Slurries in a Turbine System. A bench-scale gas turbine simulator was designed to measure the pressure, temperature, conversion, gas composition, vaporization of inorganics, deposition on simulated turbine blades and other system components, fuel reactivity, and ash particulate-size distributions resulting from the combustion of LRC slurries. These fundamental studies demonstrated the impact of various fuel properties on the combustor and turbine blades and led to the development of fuel specifications for the successful operation of low-rank slurries in a turbine application. This task continued throughout the first three years of the program.

4. Characterization of LRCs Atomization Properties. This task examined the pressurized atomization characteristics of LRC fuels with a Malvern 2600 particle-size analyzer and still photography in a pressurized spray chamber constructed at EERC. The combustion behavior of the previous fuels tested in the spray chamber and new fuels produced for the turbine project were evaluated under similar air-to-fuel and pressure ratios in the gas turbine simulator. This task also looked at different atomizer types in a effort to minimize spray-droplet-size distributions and increase combustion performance for a given rheology and atomizing air-to-fuel ratio.

5. Evaluation of LRC Fuel Agglomeration. The objective of this task was to evaluate the agglomerating or nonagglomerating tendencies of LRC fuels by sampling fly ash generated from slurry droplets at various positions along the axis of a pressurized drop-tube furnace recently constructed at EERC. Thus products of combustion particle-size distributions, as a function of residence time, and the starting particle-size distribution and droplet size can be measured to determine if the smaller particle-size distributions found in the LRC fly ash are the result of a gradual burnout of slurry droplet agglomerates or the result of agglomerate disintegration into its original particle-size distribution due to the high thermal friability of LRC fuels. 
6. Hot-Gas Cleanup. This effort has assessed available technology to determine specific needs with respect tc the removal of undesirable constituents from gas streams derived from high temperature/pressure combustion of LRC slurries, with emphasis on coal-specific problem areas. Initial work has been devoted to a review of the literature on the removal of contaminants from the coal-derived gas streams. Processes which are capable of removing $>90 \%$ of sulfur and/or nitrogen oxides, $>99 \%$ of particulates, and which reduce alkali vapors in the gas stream to $<25 \mathrm{ppm}$ are desired. The reported work has been evaluated to establish applicability to LRC slurry utilization. A summary of reviewed papers and reports has been prepared to identify processes according to overall performance, thermodynamics, economics, and environmental considerations. Special consideration has been given to gas cleaning methods which produce a salable product or zero discharge of waste and are cost-effective. Work toward this objective will continue during the course of the program. This task was primarily focused on the investigation of particulate hot-gas cleanup systems. The objective of this task was to evaluate potential hot-gas particulate cleanup techniques as to their relative probability of success and test the best two or three systems in the turbine simulator. This task would include a technology assessment that would build upon a previous literature search performed on hotgas cleanup techniques. These techniques could include, but would not be limited to, ceramic cross-flow filters and filter candles, nested fiber filters, cyclones, high-temperature/high-pressure electrostatic precipitators. This work involves tests with various CWFs in an effort to reduce fly ash particle-size distribution entering the deposition section of the turbine simulator to a minimum of $95 \%$ less than 5 microns in order to limit the amount of particle impaction on the turbine blades.

7. Ash Transformation Studies. The objective of this task was to investigate the ash transformations experienced by mineral matter in beneficiated LRC fuels. Very little research to date has investigated the effects of pressure and coal beneficiation on the reaction pathways taken by the mineral matter present in LRC fuels. These transformations should be dependent on the cleaning techniques used and the level of cleaning achievable on the various coal types. Mineral matter transformations of beneficiated LRC fuels under turbine operating conditions were investigated in a pressurized drop-tube furnace constructed at EERC. This drop-tube furnace is capable of combusting powdered coal particles under closely controlled conditions. The effects of residence time, temperature, pressure, atmosphere, and gas/fuel flow rates can be varied to examine their effects on ash transformations and carbon burnout. The drop tube also provides carbon burnout as a true function of residence time given the laminar gas flow. The effects of deposition probe temperature and the approaching gas velocity on the measured deposition rates can also be investigated. Another advantage of the pressurized drop-tube furnace is the small quantities of fuel (up to $1.0 \mathrm{gm} / \mathrm{min}$ ) needed to conduct extensive deposition and burnout testing as compared to the turbine simulator (approximately $150 \mathrm{lbs} / \mathrm{hr}$ ).

In addition, high ash fusion temperature fuels are needed under the assumption that low melting temperature ashes will stick to the cyclone wall or the ceramic material and will not be easily removed or cleaned from the hot-gas cleanup 
device. Technical work in this task consisted of combustion tests using fuels doped with additives selected for their ability to increase ash fusion

temperatures. These tests will measure the effect these additives have on the sticking coefficient and deposition rates measured at conditions similar to those utilized in previous deposition tests.

8. Investigation of Slagging Combustor Design. Should concurrent beneficiation of LRC studies at EERC indicate that acceptable ash levels and chemistry not be achievable, a vertically fired combustion zone would be built to replace the horizontally fired, rich combustion zone on the current turbine simulator. This modification would enable the combustor to operate in a slagging combustor mode versus the current nonslagging combustor mode. Work on this task would be dependent on the results of the work in progress and would be subject to DOE approval.

To meet the objectives of the program, a pressured combustion vessel was built to allow the operating parameters of a direct-fired gas turbine combustor to be simulated. One goal in building this equipment was to design the gas turbine simulator as small as possible to reduce the quantity of test fuel needed, while not undersizing the combustor such that wall effects would have a significant impact on the measured combustion performance. Based on computer modeling, a rich-lean, two-stage, nonslagging combustor was constructed to simulate a direct-fired gas turbine. This design was selected to maximize the information that could be obtained on the impact of LRCs unique properties on the gas turbine combustor and its turbomachinery. This combustor is a horizontally fired, refractory-lined, water-jacketed, two-stage combustion pressure vessel. This vessel is comprised of several removal sections for investigating combustor configuration and residence time effects. The combustor has a nominal 1-MMM Btu/hr firing rate and is designed to operate at pressures up to $250 \mathrm{psig}$ (18 atm) and lean zone exit temperatures of $2000^{\circ} \mathrm{F}\left(1100^{\circ} \mathrm{C}\right)$ with temperatures in the rich zone up to $2700^{\circ} \mathrm{F}\left(1480^{\circ} \mathrm{C}\right)$.

An objective which was added later to this project was to provide General Motors (GM) Allison Gas Turbine division with 20,000 gallons of CWF produced by the EERC's 6ton per day (tpd) hydrothermal drying Process Development Unit (PDU). The slurry was procured in 5000-gallon lots and shipped to GMI Allison Gas Turbine division in Indianapolis, Indiana, to be used in Allison's 70-MM Btu/hr pressurized gas turbine project. The test slurry characteristics were based on the recommendations of Allison and EERC personnel to ensure product quality. The main slurry characteristics specified were ash content, coal particle mean size, heating value, slurry viscosity, and sulfur concentration.

\subsection{RESULTS}

During the program, several production runs of LRC CWF were produced in conjunction with the Department of Energy (DOE) LRC beneficiation program at the EERC. Beulah lignite from North Dakota and Kemmerer and Spring Creek subbituminous coals from Wyoming and Montana were selected for pilot-scale processing because of their ability to be physically and chemically cleaned to approximately $2 \mathrm{wt} \%$ ash on the bench-scale. This treatment scheme includes physical coal cleaning by dense- 
media separation, wet grinding, chemical cleaning by nitric acid leaching, hydrothermal treatment, and final wet micronizing.

The physical cleaning step uses a dense-media separation process which consists mainly of classifying coal, feeding it into an air-actuated cone separator system, followed by a washing and recycling section. The clean coal was then pulverized and fed into a continuous acid-leaching column. This chemical cleaning was conducted using a 30 wt\% slurry mixed with a 4 wt\% nitric acid solution. The sample was concentrated using a solid-bowl centrifuge, reslurried, and fed into the HWD PDU.

The HWD treatment forces inherent moisture out of the coal structure using carbon dioxide formed during the decarboxylation of the coal, thereby increasing the heating value of the product fuel. Tars are also exuded from the coal structure during treatment, sealing the micropore structure, reducing the surface area, and increasing the hydrophobicity of the coal. After hot-water drying, coal product slurry was then concentrated to 60 to $70 \mathrm{wt} \%$ in a centrifuge, reslurried, and micronized to a CWF. An anionic dispersant, D319-2 (ammonium lignosulfonate), was added to the final CWF.

A two-stage, rich-lean, nonslagging combustor has been built to simulate the operating conditions of a gas turbine engine. Results from combustion tests on a 1-MM Btu/hr gas turbine simulator indicate that the LRC fuels exhibit superior burnout compared to the bituminous fuels due to their higher reactivity (15). During the course of this program, seventeen successful combustion tests using CWF were completed. These tests included seven tests with a commercially available Otisca Industries-produced Taggart seam bituminous fuel and five tests each with a physically and chemically cleaned, hot-water-dried (PC/AC/HWD) Beulah-Zap lignite and a chemically cleaned, hotwater-dried (AC/HWD) Kemmerer subbituminous fuel. Analyses of the emission and fly ash samples highlighted the superior burnout experienced by the LRC fuels as compared to the bituminous fuel even under a longer residence time profile for the bituminous fuel. The LRC fuels experience better burnout than the bituminous fuels. The LRC fly ash showed a decrease in particle size as compared to the starting fuel while the bituminous fuel showed an increase in particle size as compared to the starting fuel. These particlesize analyses provide some evidence of LRCs nonagglomerating properties as compared to bituminous fuels.

Statistical analysis of the carbon burnout data generated in a series of parametric combustion tests produced simple models to predict the carbon burnout achievable under a given range of operating conditions. These models indicate that fuel type has a significant effect on the measured carbon burnout. Figures 1 through 3 show the measured carvon burnout versus combustion air temperature, atomizing air-to-fuel ratio and fuel firing rate, respectively. These figures demonstrate that the LRC fuels had a carbon burnout of $98.2+\%$ which was not significantly affected by combustion air temperature, atomizing air-to-fuel ratio or fuel firing rate. However, the bituminous fuel had a maximum carbon burnout of approximately $97 \%$ and decreased $2.3 \%$ for each $100^{\circ} \mathrm{F}$ decrease in combustion air temperature below $840^{\circ} \mathrm{F}$. A decrease in the atomizing air-tofuel ratio from 1.25 to 0.75 would result in a $7.9 \%$ decrease in the carbon burnout. In addition, each $100,000 \mathrm{Btu} / \mathrm{hr}$ decrease below the 1-MMM Btu/hr maximum firing rate resulted in a $1.7 \%$ decrease in the measured carbon burnout. This information indicates that the bituminous fuel can perform almost as well as the LRC fuels in a base-loaded gas turbine scenario, but lacks the capability for turndown necessary in a peak-loaded turbine 


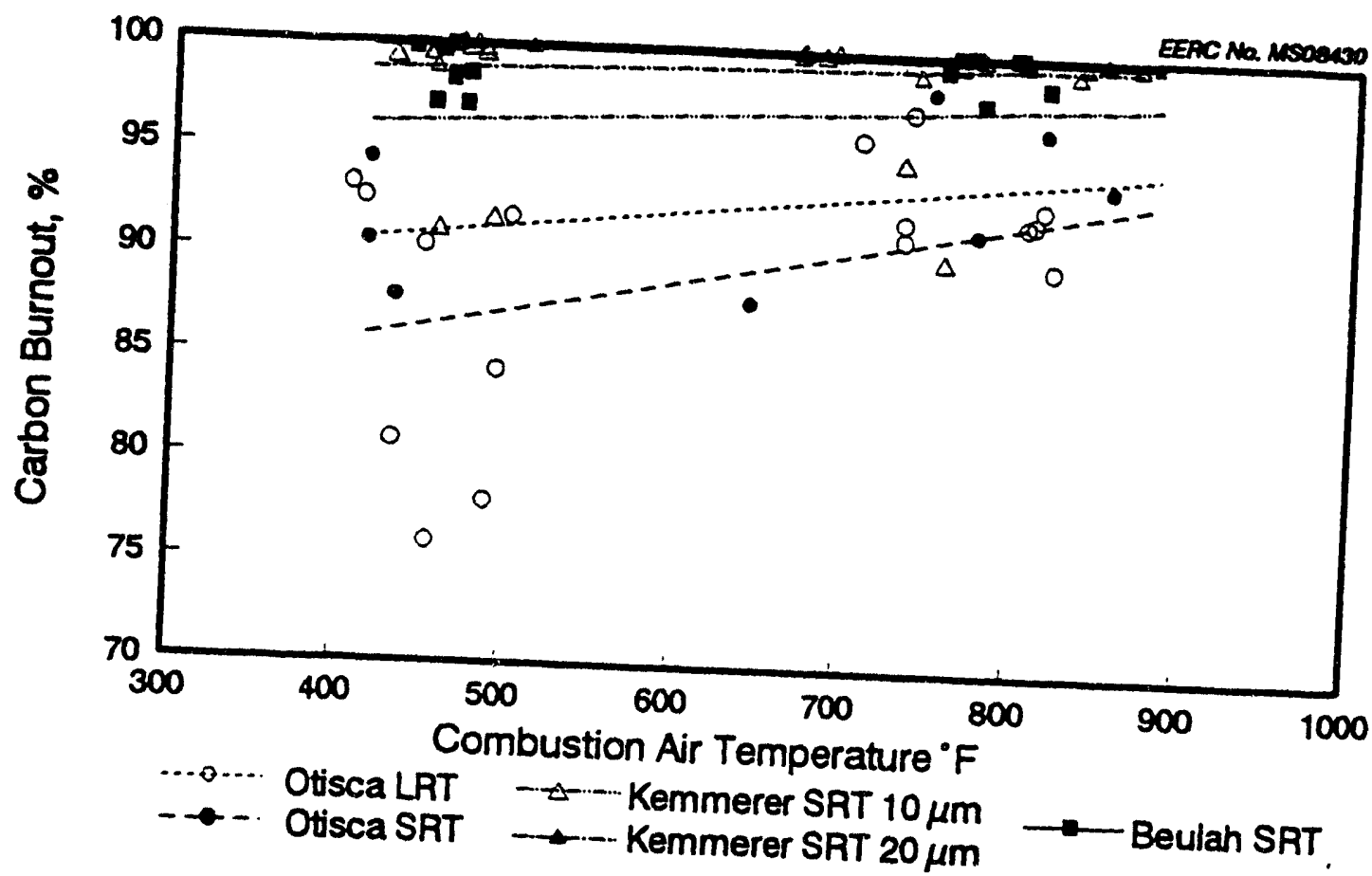

Figure 1. Graph of carbon burnout as a function of combustion air temperature for parametric combustion tests $43-47$ (LRT = long residence time; SRT = short
residence time).

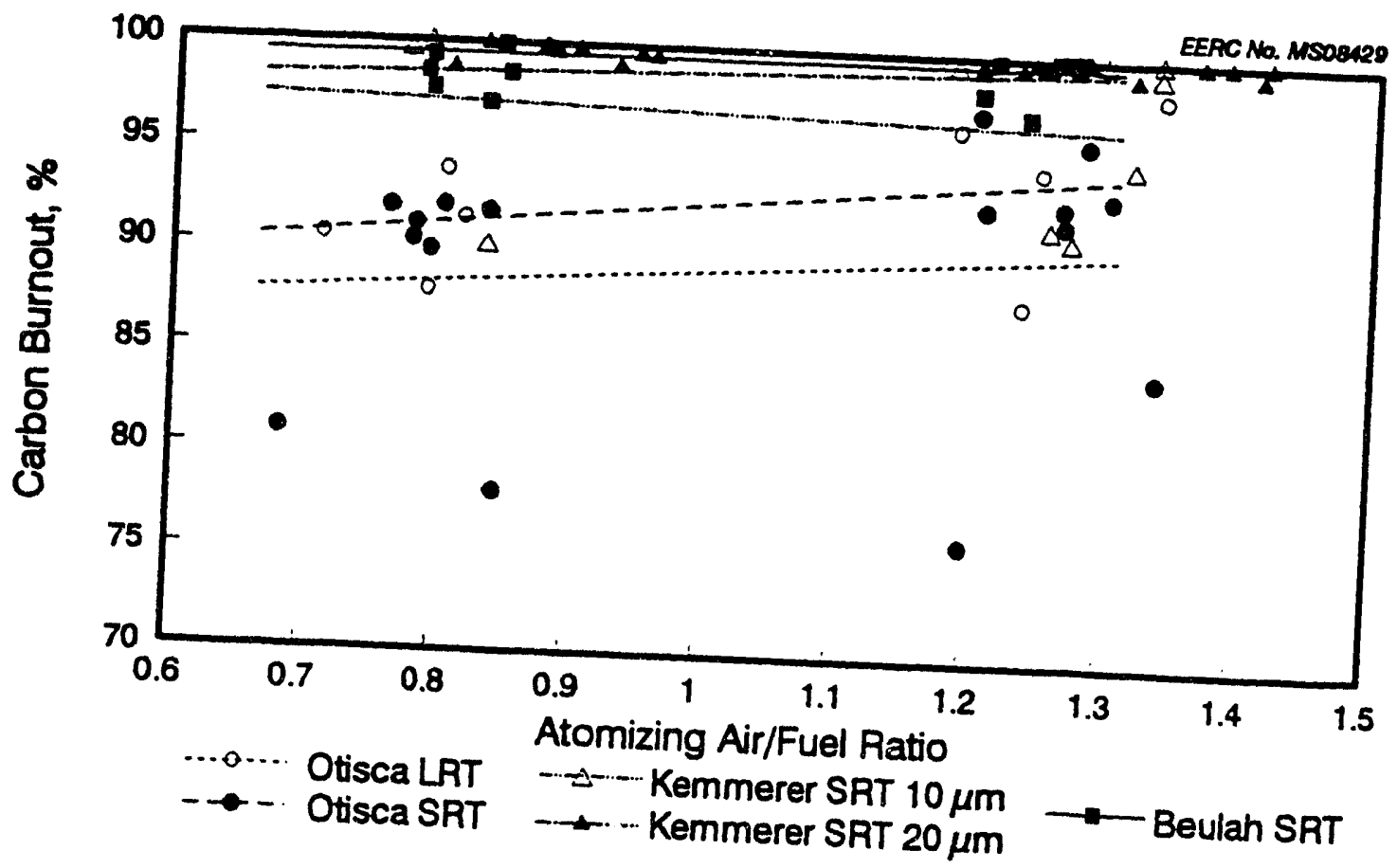

Figure 2. Plot of carbon burnout against atomizing air-to-fuel ratio for parametric combustion tests $43-47$ (LRT = long residence time; SRT = short residence time). 


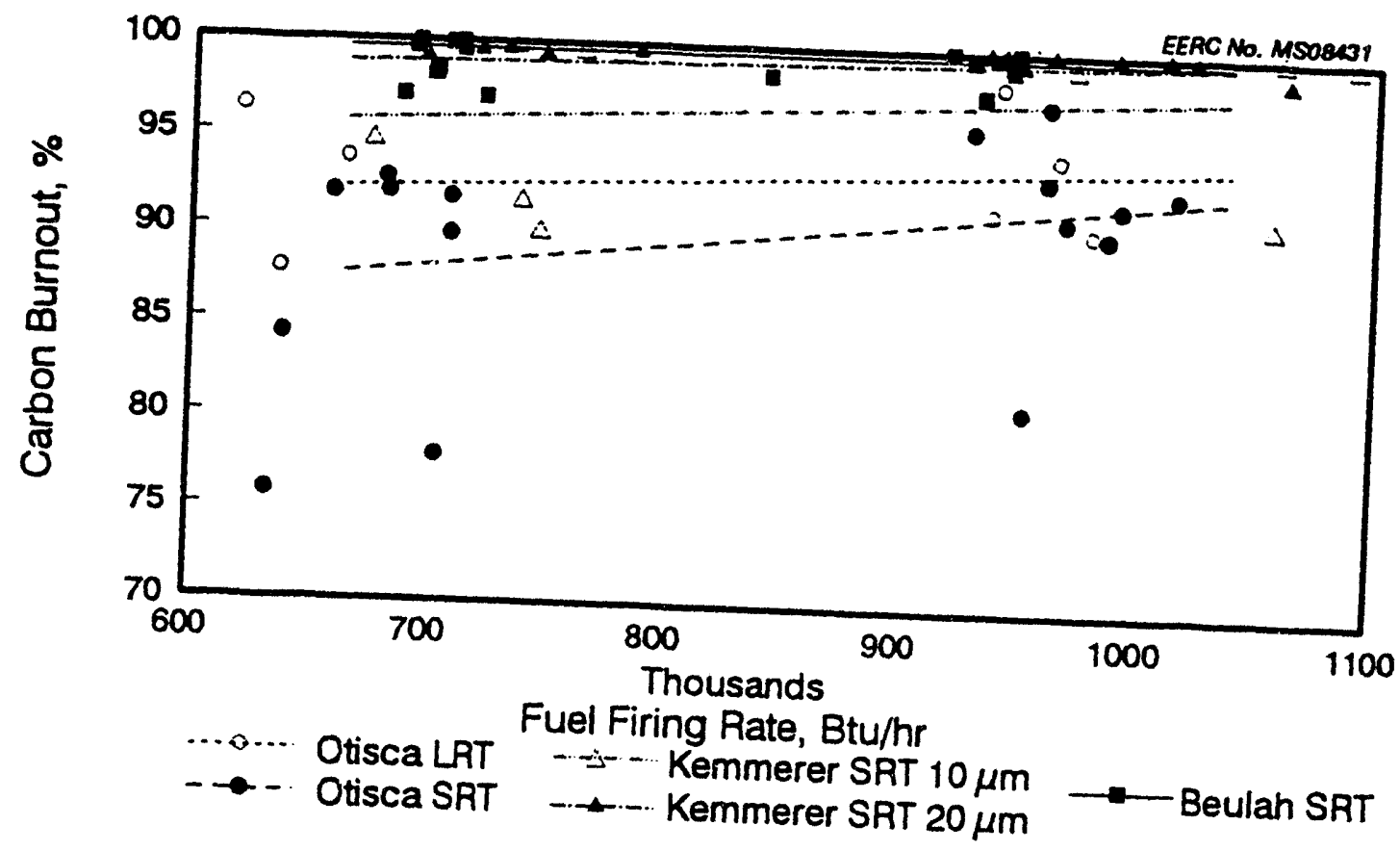
Figure 3. Plot of carbon burnout against fuel firing rate for parametric combustion tests
43-47 (LRT = long residence time; SRT = short residence time).

scenario. It should be remembered that this model is only valid between the ranges 1.0 MM Btu/hr).

As might be expected with the relatively high ash in the Beulah-Zap coal and lower ash fusion temperatures, significant ash deposition and slagging occurred in the turbine the physical cleaning process remains as suggests that the residual magnetite left from zone but is converted to hematite when magnetite in the reducing atmosphere of the rich encountered in the lean combustion zon it reaches the highly oxidizing atmosphere slurries had significantly larger zone. As indicated by material balances, the low-rank ash content and lower ash fusion temperatun the Otisca slurry, primary due to its high the ash does not indicate the preferential the turbine. These material balances indition of any component in a single area of much higher deposition potential, as demonted that the Beulah-Zap lignite fuel had a of ash recovered in the combustor. The $K$ strated by high levels (approximately $70 \mathrm{wt} \%$ ) than the Otisca fuel with approximately 12 to combustor. With the Otisca fuel combustion to $13 \mathrm{wt} \%$ of the ash being retained in the retained in the combustor while over $40 \mathrm{wt} \%$ tests, approximately $8 \mathrm{wt} \%$ of the ash was cyclone pot. This is probably the result of the of the Otisca fly ash was recovered in the (60\% or greater), thus a large percentage of the cyclone ash containing high levels of carbon char cenospheres and has not been released the fine mineral grains is still tied up in the internal surfaces to form deposits. In additiom the char particle where it could contact bituminous fuel tends to increase the efficien, the agglomerating nature of the 
turbine simulator, thereby collecting a higher percentage of particulate entering the cyclone.

An existing pressure vessel has been modified to include observation ports to perform atomization studies under typical turbine operating pressures and air flows. The main objective of this work is to determine if differences in atomization quality account for the improvements in carbon burnout experienced with the LRC fuels. The design of the spray chamber involves an existing 11.25-inch ID pressure vessel which has been modified to provide optical access perpendicular to the direction of the atomized spray. The optical access consists of two diametrically opposed 3-inch sight ports for the use of high-speed photography. In addition, a 2 -inch sight port, opposite of a 1 -inch national pipe thread port through which a sight pipe can be inserted, has also been added. The use of a sight pipe reduces the length of the spray which the Malvern 2600's laser beam must pass through and eliminates the potential for vignetting, which could occur if the beam were to pass through the complete spray cone. A honeycomb catalyst support is used as a flow straightener to provide a laminar flow of air around the atomizing nozzle. The height of the atomizer in relation to the optical ports is adjustable from outside the pressure vessel, thus allowing the atomizer position to be changed during a single atomization test.

Atomization testing was completed using a HWD Creek CWF with the Delavan 1.0-gal/min Swirl Air nozzle. This is the nozzle utilized during most of the combustion tests on the 1-MM Btu/hr gas turbine simulator. However, problems with a flat spray structure were encountered. A switch to the Delavan $2.5-\mathrm{gal} / \mathrm{min}$ nozzle, which has a larger orifice, gave acceptable performance at the expense of a lower than desired pressure ratio. Figure 4 shows the corrected Sauter mean diameter (SMD) for the three CWF atomized in the pressurized spray chamber. This figure indicates that the two HWD subbituminous CWFs atomized significantly better than the Otisca Industries produced Taggart seam bituminous CWF. This presumably is due to dilatant flow behavior of the Otisca CWF as compared to the pseudoplastic flow behavior of the HWD subbituminous CWF. The baseline water tests provided the best atomization behavior.

The emergence of advanced coal combustion technologies, such as coal slurry fired gas turbines, requires fundamental knowledge of the fuel combustion processes at elevated pressures. Of critical importance is the basic combustion kinetics and the fate of coal mineral matter in such systems. To address these issues, a pressurized drop-tube furnace (PDTF) was constructed to provide a low-cost test apparatus for conducting coal mineral matter transformation studies, deposition, burnout testing, and hot-gas cleanup studies under more controlled conditions. The PDTF is capable of operating under the following conditions:

Temperature: ambient to $2732^{\circ} \mathrm{F}\left(1500^{\circ} \mathrm{C}\right)$

Pressure: ambient to 300 psia (20.4 atm.)

Oxygen: 0 to $20 \mathrm{~mol} \%$

Gas Flow: 0 to $7.8 \mathrm{scfm}(220 \mathrm{~L} / \mathrm{min})$

Residence Time: 0 to $5.0 \mathrm{sec}$

A multipurpose sampling probe with provision for char and fly ash collection or for collecting ash deposits on a cooled substrate is available. A detailed description of the PDTF system is given in Swanson and others (16). 


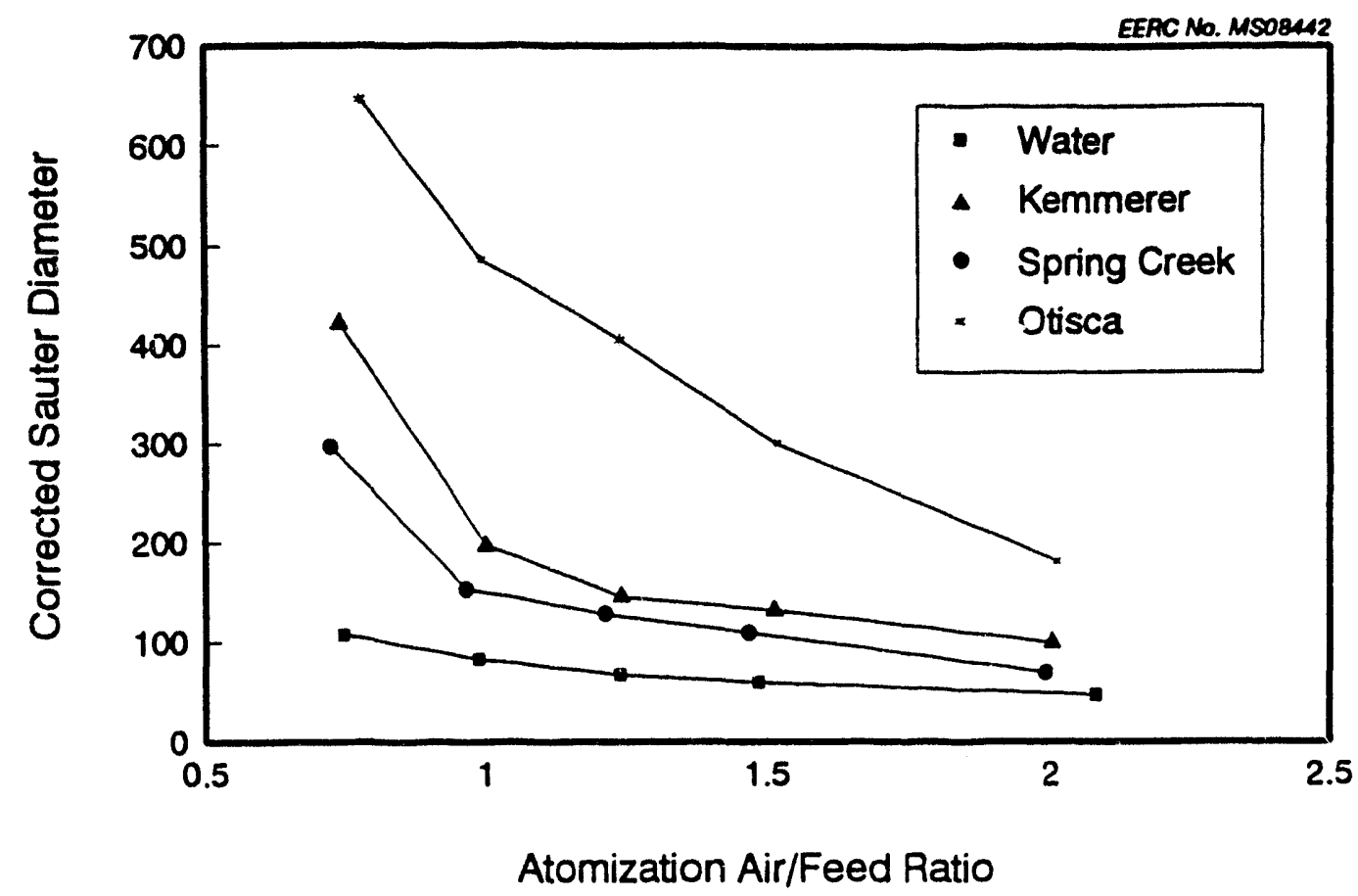

Figure 4. Corrected SMD as a function of atomizing air-to-fuel ratio for tested CWFs and baseline water.

Three scanning electron microscope/electron microprobe analysis (SEM/EMPA) techniques--computer-controlled scanning electron microscopy (CCSEM), scanning electron microscopy point count (SEMPC), and automated image analysis (AIA)-are presently used in ash behavior in combustion and gasification systems research at EERC. These techniques permit the study of transformations of inorganic constituents from the initial stages of coal conversion through the transformations that occur during ash deposition and slag formation. Their specific applications include 1) determination of the size, composition, and association of minerals in coals; 2) determination of the size and composition of intermediate ash components and fly ash; 3 ) determination of the degree of interaction (sintering) in ash deposits; and 4) identification and quantification of the components of ash deposits and slags; this includes liquid-phase composition, reactivity, and rystallinity.

Deposition testing of LRC fuels in the PDTF allowed the sticking fractions to be calculated for the tested fuels. These tests were all run at residence times of approximately $700 \mathrm{~ms}$, gas temperatures of $1150^{\circ} \mathrm{C}$, substrate temperatures of $900^{\circ} \mathrm{C}$, and gas velocities through the accelerator of approximately $850 \mathrm{ft} / \mathrm{s}$. These sticking fractions were ranked in the order PC/AC/HWD Beulah-Zap > PC/AC/HWD Spring Creek > HWD Spring Creek Allison fuel $>$ Otisca Taggart $>$ AC/HWD Kemmerer. Analysis of the deposits indicates that the Otisca fuel concentrated aluminum in the deposit. In the Kemmerer fuel deposit, a large increase in the concentration of calcium and sodium was observed in the deposit. The large increase in the calcium is due to the presence of calcium aluminosilicates in the coal ash which were not removed during the acid-cleaning process. The ash chemistry of the PC/AC/HWD Spring Creek fuel did not show any small 
significant increase in the concentration of any species in the deposits. The HWD Spring Creek fuel prepared for the Allison Gas Turbine Division showed a significant increase in the concentration of calcium and aluminum in the deposit, again probably due to the presence of lower melting calcium aluminosilicates and a significant decrease in the concentration of sodium in the deposit, as compared to the coal ash, probably due to the formation of volatile sodium species which did not impact and deposit on the deposition substrate. While the subbituminous fuel's ash chemistry was dominated by the formation of lower melting calcium aluminosilicates, the Beulah-Zap lignite ash chemistry was dominated by the low-melting-iron phases which can be attributed to residual magnetite left on the coal from the heavy-media physical cleaning process.

The fly ash combustion tests using beneficiated LRCs were conducted in the PDTF at $1300^{\circ} \mathrm{C}, 120 \mathrm{psia}$, and with a calculated residence time of 2.5 seconds. These highpressure tests utilized Cyclones 2 and 5 from a multicyclone set and a final filter to collect the fine aerosols. The multicyclones were calculated to have cut points of 3.0 and 0.45 $\mu \mathrm{m}$, respectively. Percent ash of the fly ash was determined using a modified thermogravimetric analysis (TGA) technique. Residence times are calculated based on center-line velocities equal to two times the plug-flow velocities.

Both the PC/AC/HWD/micronized and the Allison HWD/micronized Spring Creek fuels had lower sodium levels in the final filter fraction than the raw Spring Creek fuel. This is expected since acid-cleaning and HWD processes have been shown to reduce the sodium levels of the coal ash. However, the data indicates that for the hydrothermally treated fuel approximately the same percentage of the total sodium collected was recovered in the smallest-size fraction as was recovered with the as-received Spring Creek fuel. This data also indicates that acid cleaning of the fuel resulted in a significant decrease in the percentage of the sodium collected in the smallest-size fraction. A definite decrease in the amount of sodium recovered as submicron sodium sulfate or chloride aerosols or the final filter was observed with decreased sodium levels in the coal ash. This decrease indicates that benefication techniques such as acid cleaning and hot-water drying can substantially decrease the formation of the vapor-phase alkali species which participate in alkali sulfate induced deposition and corrosion of turbine blade materials in a direct coal-fired gas turbine.

Particle-size analysis of the three sized fractions was also conducted by SEM. These analyses indicate that the filter cake consists of very fine $(<1 \mu \mathrm{m})$ particles while Cyclorie 5 consisted of particles in the 1- to $4-\mu \mathrm{m}$ size range and Cyclone 2 consisted of the larger particle sizes.

Tests of kaolin as an entrained alkali getter in atmospheric and pressurized coal combustion systems were performed in the EERC PDTF system. The kaolin powder was mixed with pulverized coal from the Spring Creek mine in the ratio of 1 part kaolin to 2 parts ASTM coal ash. Four combustion tests were performed at gas temperatures of $1500^{\circ} \mathrm{C}$ in the main furnace and between $1000^{\circ}$ and $1100^{\circ} \mathrm{C}$ at the sampling point, with residence times of approximately 2 seconds; one test each of raw Spring Creek at atmospheric pressure, coal plus kaolin at atmospheric, raw coal at $100 \mathrm{psi}$, and coal plus kaolin at $100 \mathrm{psi}$. The results from the alkali gettering tests suggest that sodium is shifted strongly away from the smallest particles by the addition of kaolin. If we assume that the sodium sulfate in the smallest-size fraction formed when the gas was quenched during collection, then one half of the sodium was removed from the gas phase due to the 
kaolin addition. This result holds both at atmospheric and higher pressure. Most of the sodium was shifted to the 1- to 10-micron size range, which is where the kaolin is concentrated. The shift in sulfur from the smallest- to the largest-size ranges indicates that the sodium was chemically combined with the kaolin, probably in the hightemperature zone, and that the kaolin did not merely serve as a condensation surface for sodium sulfate. Because much of the sodium was removed from the gas phase, the sulfur shifted to the largest-size range by sulfating additional quantities of the calcium-rich particles.

\subsection{CONCLUSIONS}

General conclusions which can be drawn from the data presented in this report are as follows:

- Several production runs of LRC CWF were produced in conjunction with the DOE. LRC beneficiation program at the EERC.

- By hot-water drying, high moisture coals can produce CWFs with heating values equal to or greater than their parent coals.

- Coal-water fuels from HWD LRCs have exhibited excellent rheological properties, which greatly benefit the fuel in areas of overall handling performance and long. range transportation.

- High-shear results indicated that the flow behavior of Spring Creek CWF does not change significantly, even at shear rates as high as $200,000 \mathrm{sec}^{-1}$, and with adjustments in solids loading.

- Detailed chemical and mineralogic analyses for the raw and hydrothermally treated coal revealed that most of the salts of organic acid groups and soluble minerals are removed by the beneficiation process.

- A pressurized combustion vessel was successfully built to allow the operating parameters of a direct-fired gas turbine combustor to be simulated.

- Seventeen successful combustion tests using CWFs were completed in the pressurized combustion vessel. These tests included seven tests with a commercially available Otisca Industries-produced Taggart seam bituminous fuel and five tests each with a physically and chemically cleaned Beulah-Zap lignite and a chemically cleaned Kemmerer subbituminous fuel.

- Analyses of the emission and fly ash samples highlighted the superior burnout experienced by the LRC fuels as compared to the bituminous fuel even under a longer residence time profile for the bituminous fuel. The LRC fuels have highcarbon burnouts, ranging from 98.2 to $99.99 \%$, and appear to be relatively unaffected by other operating parameters; however, the bituminous fuel was significantly affected by combustion air temperature, atomizing air-to-fuel ratio, and fuel firing rate. 
- The LRC fly ash showed a decrease in particle size when compared to the starting fuel, while the bituminous fuel showed a increase in particle size when compared to the starting fuel. These particle-size analyses provide some evidence of LRCs nonagglomerating properties as compared to bituminous fuels.

- Ash material balances for the CWF combustion tests indicated that the BeulahZap lignite fuel had a much higher deposition rate than the Kemmerer subbituminous fuel and the Kemmerer fuel had higher deposition rates than the Otisca bituminous fuel.

- Atomization data indicates that the two HWD subbituminous CWFs atomized significantly better than the Otisca Industries-produced Taggart seam bituminous CWF, presumably due to the dilatant flow behavior of the Otisca CWF as compared to the the pseudoplastic flow behavior of the HWD subbituminous CWF.

- Deposition testing of LRC fuels in the PDTF allowed the sticking fractions to be calculated for selected fuels. These sticking fractions were ranked in the order PC/AC/HWD Beulah-Zap > PC/AC/HWD Spring Creek > HWD Spring Creek Allison fuel $>$ Otisca Taggart $>$ AC/HWD Kemmerer.

- Both the PC/AC/HWD/micronized and the Allison HWD/micronized Spring Creek fuels had lower sodium levels in the final filter fraction than the raw Spring Creek fuel. This decrease is due to the removal of significant quantities of sodium cations in the beneficiation process.

- Results from the alkali gettering tests suggest that sodium is shifted strongly away from the smallest particles by the addition of kaolin. If we assume that the sodium sulfate in the smallest-size fraction formed when the gas was quenched during collection, then one half of the sodium was removed from the gas phase due to the kaolin addition. Most of the sodium was shifted to the 1- to 10-micron size range, which is where the kaolin is concentrated. The shift in sulfur from the smallest- to the largest-size ranges indicates that the sodium was chemically combined with the kaolin, probably in the high-temperature zone, and that the kaolin did not merely serve as a condensation surface for sodium sulfate.

\subsection{RECOMMENDATIONS}

The ability of hot-gas cleanup techniques to control particulte and alkali emissions entering the expander of a gas turbine to acceptable levels are seen as the biggest obstacles in commercialization of direct coal-fired gas turbines. Recommendations for future work include hot-gas cleanup work on the PDTF and 1-MM Btu/hr gas turbine simulator as potential filters and particulate removal techniques become available. In addition, further alkali sampling and alkali gettering experiments could be conducted on the PDTF in order to obtain a better handle on the composition and phases of the vapor alkali species and to determine ways to control them in a high-temperature environment before entering the expander of a gas turbine. 


\subsection{REFERENCES}

1. Willson, W.G. et al. "Low-Rank Coal/Water Slurries for Gasification," final report; EPRI Report AP-4262, Nov. 1985.

2. Western Coal Report. Aug. 21, 1990; Vol. 774.

3. Western Coal Report. Sept. 11, 1990; Vol. 777.

4. Willson, W.G. et.al. "LRC Coal/Water Slurries for Gasification," Fuel Proc. Tech. 1987, 15, 157-172.

5. Willson, W.G. et al. "Low-Rank Coal/Water Slurries for Gasification: Phase 2 Analytic Studies," final report; EPRI AP-4905, Dec. 1986.

6. Zoebeck B.J.; Mann, M.D.; Potas, T.A.; Maas, D.J. "Firing Low-Rank Coal/Water Fuel in a Fluidized Bed Combustor," In Proceedings of the $14^{\text {th }}$ Biennial Lignite Symposium on the Technology and Utilization of Low-Rank Coals; Dallas, TX, May 1987.

7. Hauserman, W.B.; Patel, R.C.; Brown, R.A.; Hurley, J.P.; Steadman, E.N.; Jones, M.L. "Low-Rank Coal-Water Slurry Combustion," final report, DOE/FE/60181-2128 (DE87001016), Sept. 1986, 81 p.

8. Rawlins, D.C.; Germane, G.J.; Smoot, L.D. "Low-Rank Coal-Water Fuel Combustion in a Laboratory-Scale Furnace," Combustion and Flame 1988, 255-266.

9. Wildman, D.J.; Ekmann, J.M.; Dooher, J. "A Comparison of Rheological Data for Coal/Water Mixtures and Liquid Mixtures with Implication for Atomization," In Proceedings $14^{\text {th }}$ Conf. on Coal and Slurry Technology; April 1989, pp 503-514.

10. Rosfjord, T.J. "Low-Rank Coal Combustion Studies for Gas Turbine Applications," final report; DOE/FC/10615-2610 (DE88010272), Feb. 1988, 56 p.

11. Wilkes, C.; Thomas, W.H.; DeJulio, E.; Garrison, C.A.; Hillstrom, T.L.; Bourke, R.C. "Proof-of Concept Testing of a Coal-Fueled Industrial Gas Turbine System," In Proceedings of the Eighth Annual Coal-Fueled Heat Engines and Gas Stream Cleanup Systems Contractors Review Meeting, DOE/METC-91/6122 (DE91002091), Jul. 1991, pp 138-146.

12. Wenglarz, R.A.; Wilkes, C.; Bourke, R.C.; Mongia, H.C. "Coal-Water Slurry Testing of an Industrial Gas Turbine," ASME Paper 92-GT-260, 1992, 6 p.

13. Smith, C.J. Personal communication, Apr. 1991.

14. Hsu, B.D.; Flynn, P.L.; Confer, G.L. "Coal-Fueled Diesel Engine Performance--Fuel Effect," In Proceedings of the Seventh Annual Coal-Fueled Heat Engines and Gas Stream Cleanup Systems Contractors Review Meeting, DOE/METC-90/6110 (DE90000480), Mar. 1990, pp 262-271. 
15. Swanson, M.L.; Mann, M.D.; Moe, T.A. "Turbine Combustion Phenomena, Annual Report," Contract No. DE-FC21-86MC10637, Jan. 1990, 71 p.

16. Swanson, M.L.; Steadman, E.N.; Tibbetts, J.E. "Mineral Matter Transformations Under Turbine Operating Conditions in a Pressurized Drop-Tube Furnace," In Proceedings of Eighth Annual Coal-Fueled Heat Engines and Gas Stream Cleanup Systems Contractors Review Meeting, DOE/METC-91/6122 (DE91002091), Jul. 1991, pp 321-335. 
3.2 Combustion Inorganic Transformation 


\section{COMBUSTION INORGANIC TRANSFORMATIONS}

Final Technical Progress Report for the Period April 1, 1986, through December 31, 1992

by

Christopher J. Zygarlicke, Research Supervisor

Karen A. Katrinak, Research Associate

Energy and Environmental Research Center

University of North Dakota

Box 8213, University Station

Grand Forks, North Dakota 58202

Task Contracting Officer's Representative: Philip M. Goldberg

for

U.S. Department of Energy

Office of Fossil Energy

Pittsburgh Energy Technology Center

626 Cochran Mill Road

P.O. Box 10940, MS 922-H

Pitisburgh, Pennsylvania 15236

December 1992

Work Performed under Cooperative Agreement No. DE-FC21-86MC10637 
1.0 INTRODUCTION $\ldots \ldots \ldots \ldots \ldots \ldots \ldots \ldots \ldots \ldots \ldots \ldots \ldots \ldots \ldots \ldots \ldots \ldots$

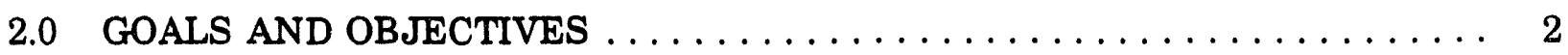

3.0 RESULTS AND CONCLUSIONS $\ldots \ldots \ldots \ldots \ldots \ldots \ldots \ldots \ldots \ldots \ldots \ldots$

3.1 Analytical Methods Development .................... 3

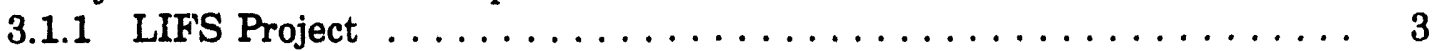

3.1.2 Development of Techniques for Analyzing Coal and Fly Ash Inorganics ......................... 6

3.1.2.1 Computer-Controlled Scanning Electron Microscopy ........ 6

3.1.2.2 Mass Balancing to Determine Organically Associated Content ... 7

3.1.2.3 Small Particulate Analysis Method $\ldots \ldots \ldots \ldots \ldots \ldots \ldots . \ldots \ldots$

3.2 Laboratory-Scale Combustion Testing $\ldots \ldots \ldots \ldots \ldots \ldots \ldots \ldots, 7$

3.2.1 Drop.Tube Furnace Construction and Operation ............ 8

3.2.2 Combustion Testing of Coals and a Coal Blend ............ 10

3.2.3 Combustion Testing of Synthetic Coal Model Mixtures ......... 15

3.3 Prediction of Fly Ash Particle Size and Composition ............. 16

3.3.1 Development of Mechanistic/Stochastic Model: ATRAN1 . . . . 17

3.3.2 Development of Expert System Model: ASHPERT $\ldots \ldots \ldots \ldots .17$

4.0 SUMMARY OF CONCLUSIONS $\ldots \ldots \ldots \ldots \ldots \ldots \ldots \ldots \ldots \ldots \ldots \ldots \ldots$

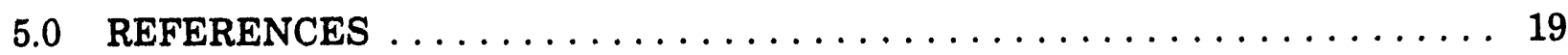

BIBLIOGRAPHY OF CIT-RELATED PRESENTATIONS, PUBLICATIONS,

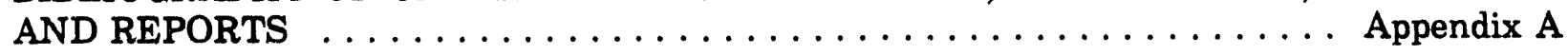

TABLES OF CONTENTS FOR CIT FINAL REPORTS $\ldots \ldots \ldots \ldots \ldots$ Appendix B

\section{LIST OF FIGURES}

Figure $\quad \underline{\text { Page }}$

1 Drop-tube furnace laboratory $\ldots \ldots \ldots \ldots \ldots \ldots \ldots \ldots \ldots \ldots$ 


\section{COMBUSTION INORGANIC TRANSFORMATIONS}

\subsection{INTRODUCTION}

The problems caused by the inorganic constituents in coal can have significant technological impacts. For example, inorganic constituents can, in some instances, cause severe operational problems in utility boilers. The problems include deposition on heattransfer surfaces, formation of fine particulates that are difficult to collect, and erosion and corrosion of boiler parts. Because of the importance of these problems, there is voluminous literature on the subject. A precise and quantitative knowledge of the distribution of inorganic constituents and their chemical and physical transformations may provide insights leading to solutions to these problems.

The extent of these problems depends upon the abundance and distribution of inorganic constituents. The inorganic constituents in low-rank coals are distributed within the coal matrix as cations associated with organic acid groups and clays, organically coordinated species, and discrete mineral grains. The mineral grains in pulverized coal are classified as either included (within a coal particle) or excluded (not associated with coal). The characteristics of the fly ash formed during combustion are dependent upon the chemical and physical transformations of the inorganic material.

The physical transformations of the inorganic constituents during the combustion process include 1) coalescence of individual mineral grains, 2) formation of cenospheres, and 3) evaporation and condensation of flame-volatilized species. The factors that influence the behavior of the inorganic constituents include combustion conditions and the form of the inorganic constituents in the coal. In the past, the composition of the coal ash produced under ASTM ashing conditions has been used to provide a crude guide as to the behavior of a specific coal during combustion. However, examination of the fly ash shows that many different types of particles are present, each having its own composition and probably its own melting behavior. Therefore, in order to understand and ultimately predict the behavior of the inorganic constituents during pulverized coal combustion, fundamental knowledge of the mechanism of fly ash formation must be elucidated.

The primary emphasis of this project was to determine and measure some of the critical inorganic transformations that occur during combustion. After acquiring a basic understanding of the mechanisms of ash formation, models were developed to predict fly ash size and composition. There were several critical issues that needed to be addressed in order to better understand the behavior of inorganic constituents during combustion. These included the following:

1. A method was devised for determining the abundance and distribution of inorganic constituents in pulverized coal. The predictive models required innovative techniques to quantify inorganics in coal. Two techniques were developed for determining coal inorganics. These techniques included a) chemical fractionation which involves selectively extracting inorganic elements based on their association in the coal, and b) computer-controlled scanning electron microscopy (CCSEM) which was used to quantify and size the mineral phases in the coal. 
2. Sodium volatilization in the coal-fired flame followed by subsequent condensation in the convective pass is a major problem associated with the use of low-rank coals in utility boilers. The volatility of sodium needs to be determined as a function of the association of sodium in the coal and of combustion conditions.

3. The interaction of organically bound cations and mineral phases during the combustion of a coal particle is not well understood. The interaction of these phases results in the formation of low melting point particles that can play a significant role in the formation of tenacious deposits in boilers. The interaction of these species needs to be determined as a function of combustion conditions, gas cooling rates, and the association of inorganic constituents.

\subsection{GOALS AND OBJECTIVES}

The overall objective of this project was the development of a unified picture of the physical and chemical changes that occur in coal inorganic matter during combustion. The research focused on three major tasks. The first task involved developing analytical methods for measuring the chemical and physical characteristics of coal inorganics and fly ash. With regard to coal analysis, CCSEM was developed to determine the distribution of discrete mineral grains in pulverized coals, and chemical fractionation, an existing technique, was modified and refined to provide quantities of inorganic constituents that are submicron in size and thus undetectable by the typical scanning electron microscope. Organically bound inorganics, such as sodium and calcium in low-rank coals, can be quantified using the chemical fractionation technique. The CCSEM and chemical fractionation techniques, therefore, provide a comprehensive means of quantifying all of the inorganic material in coals of varying ranks. In conjunction with CCSEM, an image analysis technique was developed to determine whether individual coal mineral particles were included within pulverized coal particles or excluded from the coal particles. With regard to fly ash, the CCSEM technique was also developed to measure the size and composition of individual fly ash particles, and a modified version of the CCSEM technique was used to size and chemically analyze submicron ash particulate. Another analytical technique that was investigated in this project was laser-induced fluorescence spectroscopy (LIFS). LIFS was specifically aimed at analyzing atomic sodium in coal. The objectives of this work included 1) building a LIFS spectrometer that was capable of detecting atomic sodium above 10.ppm concentrations for solutions, 2) assessing the feasibility of this technique for detecting the release of sodium when solids are introduced directly into a flame, 3) using this spectrometer to study the release of atomic sodium during coal combustion, and 4) developing a detailed knowledge of how a variety of factors including flame temperature/position, source of sodium, and gas stream composition affects the release of sodium under typical combustion conditions.

The second major task of this project involved combustion testing of seven coals of varying rank, one coal blend, and four synthetic coal model mixtures, for the purpose of studying inorganic transformations. All of the combustion testing was performed using a laboratory-scale drop-tube furnace (DTF). The DTF system was constructed at the onset of the project, with the primary purpose of having the ability to inexpensively generate multiple fly ash samples in a very short time while maintaining combustion conditions that mimic key full-scale combustion conditions. Feed rates for the DTF range from only 
0.1 to 1.0 grams of coal per minute; therefore, it is difficult to mimic all aspects of fullscale combustion. However, the DTF was designed and constructed to isolate the key operational parameters of real utility boilers such as gas temperature, gas velocity, particle residence time, and excess air. Fly ash and time-resolved chars were produced using various gas temperatures, particle residence times, and gas atmospheres.

Mechanisms of fly ash formation were derived by analyzing the initial coal inorganics and comparing that data with the fly ash characteristics, such as mineral and elemental composition and particle size.

The third major task of this project consisted of developing a model or expert system to predict fly ash composition and size from initial coal input data. Advanced coal mineral and organically bound inorganic analysis methods coupled with extensive laboratory fly ash formation studies were the basis for deriving both a mechanistic model and an expert system for prediction of fly ash size and composition. The mechanistic model is termed ATRAN1, and the expert system model is called ASHPERT. ATRAN1 combines the stochastic principle of random combining of inorganics during combustion with the mechanistic principles of coalescence, fragmentation, and decomposition of initial coal minerals during combustion. ASHPERT uses an expert system approach that essentially predicts the size and composition of fly ash generated from a given coal, based on a large database of known coal mineral and corresponding fly ash particle size and compositions. The expert system gives a first-order estimate of fly ash size and composition which can be easily integrated with other expert systems. Both models, ATRAN1 and ASHPERT, were tested using various coals and gave predicted results that were fairly similar to results obtained experimentally.

\subsection{RESULTS AND CONCLUSIONS}

\subsection{Analytical Methods Development}

\subsubsection{LIFS Project}

Many western low-rank coals contain significant quantities of alkali, primarily sodium, that is associated as salts of organic acid groups. Upon combustion, these alkali constituents will readily volatilize in the flame and condense downstream in the combustion system. The condensed alkali components can cause serious operational problems in combustion systems such as convective pass fouling. The flame-volatilized alkali can condense on surfaces of entrained fly ash particles, forming low melting point surface layers which can aid in the sticking of ash particles on heat-transfer surfaces. These alkali-containing phases can aid in forming a liquid that is responsible for the development of deposit strength due to viscous flow sintering and for the capture of impacting fly ash particles. In addition, the flame-volatilized alkali can condense homogeneously to form very small particles that can be very difficult to collect. These small particles have also been found on the inner layers of deposits.

Because organic alkalies (carboxylates) are relatively volatile, it is generally expected that these alkali vill vaporize in coal-fired combustors. Laboratory experiments have demonstrated that vaporization occurs in an oxygen environment. Many of the past studies have been concerned with the analysis of the reactants and products. This does not provide adequate information on the release of alkali during combustion. A probe is 
needed that would perform in situ measurement of the concentration of short-lived atomic alkali.

LIFS is well suited for probing various locations of flames to examine alkali release. The high powers and narrow bandwidths available from modern lasers allow their use as excitation sources in analytical techniques that have very low detection limits and very high selectivities for particular analytes. The fluorescent emission of sodium atoms excited by lasers has been studied over the past decade, including the detection of sodium in flames. As well as establishing the range and sensitivity of the technique, these studies have also probed the nature of the kinetic and optical processes taking place. The usual experimental arrangement includes a hydrogen/oxygen or hydrocarbon/oxygen flame with inert gas diluent and aqueous sodium solutions aspirated into the flame, as for classical atomic absorption spectroscopy. The most common excitation source is a pulsed or continuous wave dye laser operating at the wavelength of the sodium $D$ line. A detection limit of less than 10 sodium atoms $/ \mathrm{mL}$ in a flame at one atmosphere pressure has been achieved using saturated optical nonresonant emission spectroscopy for atomic detection. This corresponds to about one part in $10^{14}$ of the flame species. Nonresonant operation means that the $D_{1}$ line of the sodium $(589.6 \mathrm{~nm})$ is excited to detect emissions at the $D_{2}$ line $(589.0 \mathrm{~nm})$ or the reverse. This technique is feasible because the two excited states responsible for the emissions are equilibrated by collisional energy transfer under the relatively high-density conditions present in the flame.

The goal of this project was to define the variables that affect the release of sodium atoms from coals and model compounds at temperatures similar to those produced in fullscale boilers (1). LIFS was chosen for this task due to its high sensitivity for the detection of gas-phase atoms.

After optimizing the optical alignment and the laser output, work with sodium solutions began. A study of the effect of sodium concentration on the fluorescence showed that, at the leading edge of the flame, the fluorescence signal was found to be linearly dependent on the concentration of sodium.

The distribution of sodium species in the flame was also calculated using SOLGASMIX, which predicted that $39.8 \%$ of the sodium introduced would be present as atomic sodium at a flame temperature of $1548 \mathrm{~K}$. The measured value using LIFS was $7.0 \%$ at 0.42 inches above the flame.

Possible reasons for the difference between the predicted value and the measured value are:

- The sample introduction efficiency was incorrect.

- The database for the calculation was incomplete or incorrect.

- The system did not achieve a minimum free energy.

The most likely cause of the difference was that the flame did not reach a thermodynamic minimum.

Horizontal fluorescence profiles were obtained for a number of pure sodium salts: benzoate, chloride, montmorillonite, sulfate, and carbonate. Sodium benzoate, sulfate, and 
carbonate gave fluorescence signals similar to those for solutions. Sodium chloride and sodium montmorillonite gave signals much smaller than those for solution.

Horizontal fluorescence profiles were obtained for a series of Beulah lignites: plain Beulah lignite, demineralized Beulah lignite, and demineralized Beulah reloaded with sodium. The fluorescence signals were much higher for these solids than for sodium solutions and, at the leading edge of the flame, were linearly dependent on the concentration of the sodium fed into the flame.

Horizontal fluorescence profiles were obtained for a solid with sodium deposited upon it. Like the lignites, this solid gave a fluorescence signal much higher than that for sodium solutions.

The effect of sulfur and carbon dioxide on the sodium atom densities in the flame was studied. For the conditions used, no significant differences in the fluorescence signal were found.

Chars from Beulah lignite and solid sodium benzoate were analyzed to determine the percent of sodium in the solids that was vaporized. Both solids had some sodium remaining in their chars.

In conclusion, LIFS is a valuable tool in the study of sodium volatilization from solids in flames. With a LIFS system, sodium fluorescence can be observed from solids. Different solids did give different sodium atom densities in the flame. This difference is related to the matrix supporting the sodium. The solids that gave low sodium atom densities in the flame include sodium montmorillonite and sodium chloride. The montmorillonite results suggest that sodium tied up in aluminosilicates is not responsible for fouling in boilers. Solids that gave high sodium atom densities were those which had their sodium supported by a carbon matrix, including the Beulah lignites and the sodium benzoate on decolorizing carbon.

The sodium released from the Beulah lignites was linearly related to the sodium atom densities resulting in the flame from sodium benzoate and the sodium benzoate on decolorizing carbon.

The addition of elemental sulfur and carbon dioxide had no effect on the sodium atom densities resulting in the flame from sodium benzoate and the sodium benzoate on decolorizing carbon.

The analysis of the char resulting from burning a solid in the LIFS burner also proved to be a valuable technique for analyzing the fluorescence data. The Beulah lignite was found to release approximately $30 \%$ of its sodium, while the solid sodium benzoate released $70 \%$. These results emphasize the importance of the carbon matrix in reducing sodium to its atomic state.

With a LIFS system, it is possible to observe differing sodium atom concentrations in a flame. This LIFS study has shown the effect of different supporting matrices on the concentration of gaseous atomic sodium observed in a flame. 


\subsubsection{Development of Techniques for Analyzing Coal and Fly Ash Inorganics}

\subsubsection{Computer-Controlled Scanning Electron Microscopy}

A major analytical develop nent of the past six years has been the development of the computer-controlled scanning electron microscopy (CCSEM) method for the analysis of coal and fly ash (2-4). Results obtained using CCSEM have been crucial in furthering the understanding of inorganic transformations during combustion. Steps taken to develop the CCSEM method over the past six years have included rigorous testing and standardization using mineral standards and well-characterized coals (5); adaptation of software and hardware to allow for stage automation, multiple threshold capabilities, and data manipulation; programming to allow image analysis to determine mineral grain juxtaposition; the eliminetion of size biases associated with irregularly shaped grains and sample preparation; and the implementation of a three-magnification method coupled with using a higher video-sampling signal to improve the precision of quantifying coal minerals by about 50\% (6-11). Following extensive testing for accuracy of the CCSEM method, correction factors were calculated for derived particle diameters and for areas determined for cross-sectioned ash particles.

Several additions were made to the CCSEM method as the project progressed. A correction for improving the accuracy of CCSEM elemental compositions was devised (12). This procedure involves the extraction of $k$-ratios during acquisition of raw CCSEM data, followed by correction of these k-ratios for atomic number (Z), absorption (A), and fluorescence $(F)$ effects. This ZAF correction results in more accurate quantitative chemistries of individual fly ash particles or coal minerals. Three bituminous coals and five ashes were analyzed to test the CCSEM-ZAF technique. To determine the accuracy of the CCSEM-ZAF technique, coal and ash compositions determined through CCSEM were compared to bulk compositions as measured using x-ray fluorescence (XRF). Results indicate the CCSEM-ZAF data require corrections for $\mathrm{Ca}, \mathrm{Mg}$, and $\mathrm{Si}$, because these elements occur in significant concentrations in the submicron-size fraction.

Additionally, a round-robin CCSEM analysis has been initiated involving seven laboratories: EERC, Ames Laboratory at Iowa State University, Sandia National Laboratory, the University of Kentucky, the R.J. Lee Group, the Netherlands Energy Research Center, and CSIRO of Australia. In order to design the round-robin, information was gathered from each of the participating domestic laboratories regarding their CCSEM systems. The EERC then prepared a detailed protocol describing the scanning electron microscopy (SEM) system configuration for analysis of standard coals and sent the protocol together with sample sets to the participating laboratories (13). Three Argonne National Laboratory premium coals were initially selected, including Illinois \#6, Pittsburgh \#8, and Wyodak. After preliminary testing of these coals using CCSEM, it was decided to use a higher ash Canadian Prince coal instead of the Wyodak. The Prince coal was acquired from the European Centre for Coal Specimens. The results of the round-robin testing will be used to initiate standardization of the CCSEM technique.

Particle-by-particle scanning electron microscopy (PBPSEM) analysis has been developed as an automated technique (4). It uses advanced image analysis together with the standard CCSEM procedure to yield the size and composition of coal minerals on an individual particle basis. PBPSEM greatly enhances ash formation and deposition models by providing much more comprehensive coal input data. The PBPSEM program uses 
completely automated digital image acquisition, processing, and image segmentation. In PBPSEM, the major operational parameter affecting the sizing and location of particles is the determination of the difference between coal and minerals in the grey-level histogram. The method currently used for determining this difference works best for homogeneous systems.

\subsubsection{Mass Balancing to Determine Organically Associated Content}

A method has been devised to balance the mass of organically and mineralogically associated inorganics in coal so that their sum equals the total ash content of the coal (12). An algorithm to determine the distribution of organically associated inorganics was created using CCSEM, chemical fractionation, and XRF data. The inorganics are divided into soluble minerals, insoluble minerals, organically associated inorganics, and insoluble submicron minerals. The technique was modified to better estimate the amount of submicron silica. The mass balancing technique was tested on Kentucky \#9, Eagle Butte, and Kentucky \#9/Eagle Butte blend coals. Kentucky $\# 9$ contained little organically associated material, whereas the Eagle Butte coal had large amounts of organically associated calcium and magnesium. The quantity of organically bound material in the Kentucky "9/Eagle Butte blend was intermediate between that of the two parent coals.

\subsubsection{Small Particulate Analysis Method}

A new technique, termed scanning electron microscopy with image analysis (SEMIA), was developed for analysis of individual submicron ash particles (14). SEM-IA provides data similar to that of the CCSEM technique, but for smaller particles. A freezedried dispersion method was developed as an alternative sample preparation technique. Using this method, ash particles are suspended in propanol and dispersed onto pieces of vitreous carbon measuring approximately $1 \mathrm{~cm}^{2}$. Freeze drying maintains an adequate separation between particles, as required for SEM-IA. During analysis, size measurements of the individual particles are not made in real time as they are in CCSEM, but only after a large number of duplicate images of a sample field of view have been acquired and averaged to remove noise. This additional image processing step is necessary to obtain accurate size measurements for the smallest particles. The imageaveraging ability of the SEM-IA technique provides size and composition distribution data for particles with diameters an order of magnitude smaller than those that can be analyzed by CCSEM, or approximately $0.1-\mu \mathrm{m}$ minimum diameter.

\subsection{Laboratory-Scale Combustion Testing}

Coals contain a complex suite of inorganic species that include significant quantities of both organically associated cations and discrete minerals. Problems associated with inorganic constituents in coal combustion systems include ash deposition, fine particulate formation, and corrosion and erosion of boiler parts. Of specific interest are the interactions between those inorganic constituents that result in the formation of low melting point phases during combustion and gas cooling. These phases are often the cause of ash deposition problems on boiler heat-transfer surfaces. The formation of these low melting point phases is a result of a combination of complex physical and chemical transformations of inorganic components associated in and with the coal during the combustion process. The primary objective of the drop-tube furnace task was to determine the factors that affect the size and composition of the fly ash. This task was designed to 
study changes in the morphology and chemical associations of inorganic components in coals during combustion in a drop-tube furnace designed to simulate the time-temperature profile of a pulverized coal-fired utility boiler. The chemical and physical transformations of the inorganic constituents depend upon their association in the coal and upon combustion conditions. Volatilization and condensation of sodium was one of the key transformations investigated to gain insight into the formation of liquid phases in and on the surfaces of entrained ash particles.

\subsubsection{Drop-Tube Furnace Construction and Operation}

The drop-tube furnace was constructed as a laboratory-scale, entrained-flow tube furnace with the ability to combust coal and produce ash under closely controlled conditions. Combustion parameters such as initial hot zone temperature, residence time, and gas-cooling rate can be closely controlled and monitored (9-11, 15-19).

The furnace system is housed in a three-floor laboratory specifically designed for clean and efficient operation of the system, as shown in Figure 1. The furnaces are mounted on furnace bars extending through all three levels. The furnaces can be moved to accommodate specific applications. The adjoining control room provides a clean, climate-controlled environment for the electronic equipment associated with the drop-tube system.

The furnace assembly consists of a series of vertically oriented tube furnaces. These furnaces possess a total of five independently controlled, electrically heated zones. Each of these furnaces can be used separately or in conjunction with the other furnaces. This allows for maximum flexibility and precise control over combustion conditions.

Coal, primary air, and secondary air are introduced into the furnace system by means of a preheat injector. This system injects ambient temperature primary air and coal into the furnace from a water-cooled probe assembly at the center of the tube. Secondary air is typically heated to $1000^{\circ} \mathrm{C}$ and introduced into the furnace through a mullite flow straightener. Thus the material to be combusted is introduced into the top of the furnace along with preheated secondary air and travels down the length of the furnace in a laminar flow regime.

The coal feed system is designed to feed particles of various sizes at rates of 0.1 and 0.5 grams per minute and at primary carrier gas rates of approximately 1 liter per minute. The basic apparatus consists of a pressurized plastic cone, a stepper motor, and a feed tube. The cone acts as the coal hopper. As the motor rotates the feed tube, the coal falls through the small holes in the tubes and is carried out by the gas into the injector.

Fly ash is cooled by means of a fly ash-quenching probe that is reliable and versatile. Several collection devices can be added to the probe to collect the fly ash.

Size-segregating methods of fly ash collection can also be employed. The Environmental Protection Agency Southern Research Institute five-stage cyclone (EPAFSC) is used to make five equally spaced particle size cuts $\left(d_{80}\right)$ on a logarithmic scale within the range of 0.1 to 10.0 micrometers. The advantage of this system is its capability of collecting the relatively large sample amounts needed for subsequent chemical and morphological analyses. 


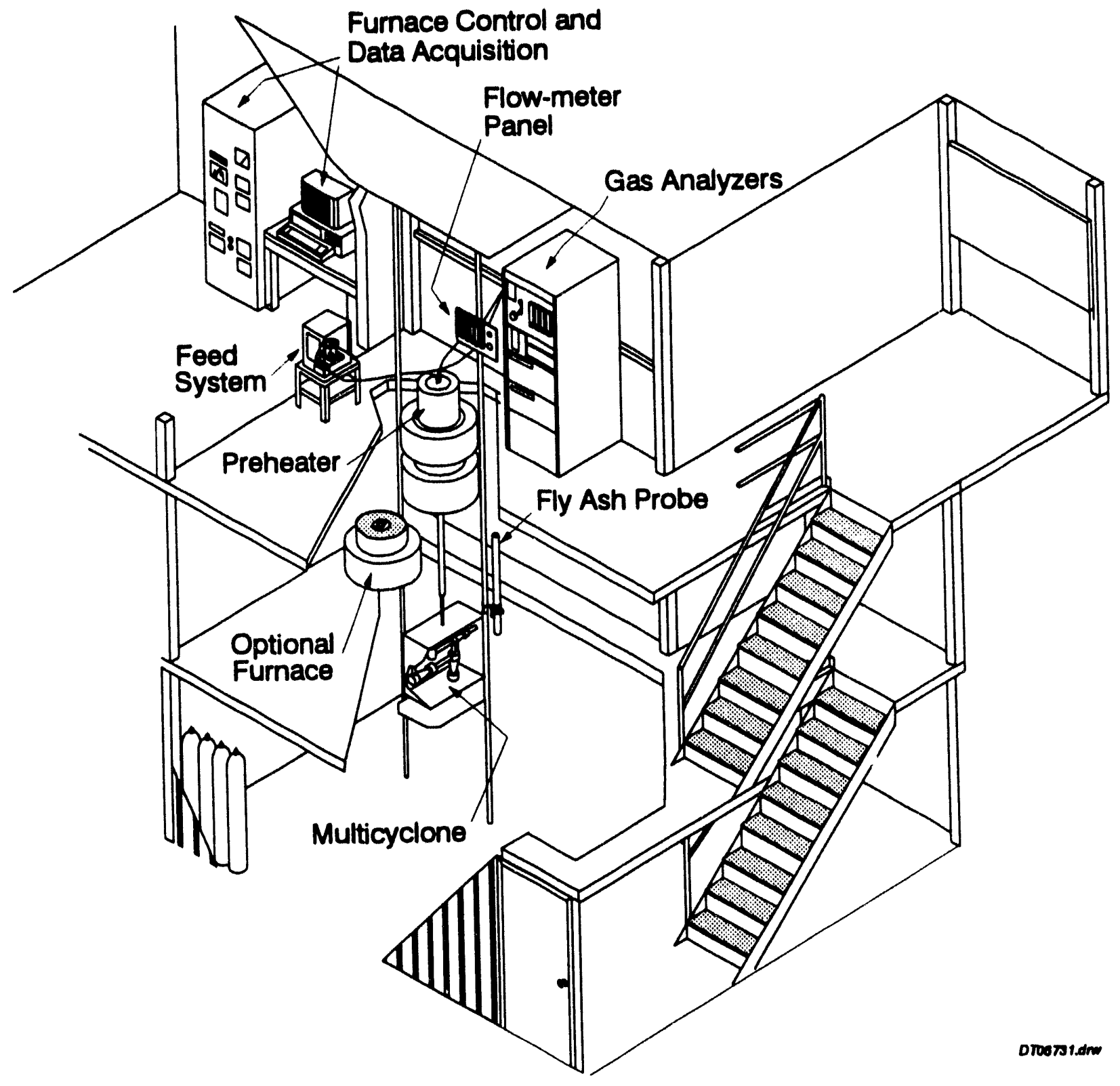

Figure 1. Drop-tube furnace laboratory. 
In addition to the EPAFSC, the University of Washington Mark 5 source test cascade impactor (STCI) is used during selected combustion tests. The STCI was developed as a means of measuring the size distribution of particles in stacks and ducts at air pollution emission sources. The Mark 5 impactor produces even-size cuts of fly ash particles by inertial separation. These data will be used for comparison with the EPAFSC data and to provide more detailed information concerning the effects of combustion conditions on the size distribution of the fly ashes.

A short residence time probe was designed and constructed to collect ash samples at any residence time. The probe consists of a series of four concentric, water-cooled, steel tubes. The outer shell is for introducing the quench gas at the top of the probe. The innermost shell removes the combustion gases, and the remaining shells carry the cooling water. The probe is covered with an alumina insulating cylinder 2 inches in outside diameter.

The probe is inserted in the bottom of the furnace at a set distance that is calculated from the desired residence time. The quench gas and the vacuum are turned on. The coal is fed through the preheat injector and collected with a cyclone or with the multicyclones.

\subsubsection{Combustion Testing of Coals and a Coal Blend}

The first step in the combustion testing phase of the CIT project was to select and prepare test coals. Seven coals were selected including 1) Monticello lignite (Texas), 2) Robinson subbituminous (Montana), 3) Eagle Butte subbituminous (Wyoming), 4) Upper Freeport bituminous (Pennsylvania), 5) Kentucky $\# 9$ bituminous (Kentucky), 6) San Miguel lignite (Texas), and 7) Beulah lignite (North Dakota). A blend of 70\% Eagle Butte and $30 \%$ Kentucky $\# 9$ was also tested. The coals were pulverized and sized in order to obtain a 53- to 74- $\mu \mathrm{m}$ sample and bulk $80 \%-200$-mesh sample for combustion testing. Fly ash was generated by combusting the coal in an initial hot zone of $1500^{\circ} \mathrm{C}$, with subsequent collection of the fly ash after 2 to 3 seconds residence time in a zone of $1200^{\circ} \mathrm{C}$. The coals were analyzed using chemical fractionation, CCSEM, proximate/ultimate, and XRF analyses.

The most abundant minerals found in the Monticello lignite were quartz, kaolinite, Ca-clay, and mixed aluminosilicate $(6,7)$. Very little pyrite was found. Quartz, kaolinite, and Ca-clay had grain sizes that were largely in the $>11-\mu \mathrm{m}$ range. Some of the aluminosilicate clays occurred as aggregates of 1 - to $3 \cdot \mu \mathrm{m}$ particles.

Comparisons among original mineral matter, inorganic phases in early stage chars, and final fly ash show a progressive reaction of organically bound $\mathrm{Ca}$ with quartz and aluminosilicate species derived from kaolinite. Inorganic ash droplets on the surface of Monticello short residence time char particles were very rich in $\mathrm{CaO}$ and consistently showed an aluminosilicate component with an $\mathrm{A} / \mathrm{Si}$ ratio of $1 / 1$. These particles were generally 1 to $3 \mu \mathrm{m}$ in average diameter and were often rich in $\mathrm{Fe}_{2} \mathrm{O}_{3}$.

Analysis of Robinson coal size fractions by CCSEM indicated that quartz, kaolinite, Ca-clay (montmorillonite), and pyrite were the most abundant mineral grains (7-9). Quartz was found to be most abundant in the larger-size categories ( $>11 \mu \mathrm{m}$ ). The size distribution of pyrite and kaolinite was variable. Overall, the majority of the mineral grains were greater than $11 \mu \mathrm{m}$. 
Short residence time combustion tests were conducted to produce chars from a Robinson 74- to 106- $\mu \mathrm{m}$-sized coal sample (7-9). It appeared that after 0.2 seconds of combustion, extensive fragmentation of larger-sized mineral grains occurred. The mechanism proposed for the fragmentation phenomenon in the first 0.2 seconds of combustion was based on the breakup of aggregates of aluminosilicate clays. At longer residence times of 0.5 and 0.8 seconds, there was successive coalescence of finer-sized inorganic phases. It is proposed that $\mathrm{CaO}$, which was very abundant in the organic fraction of the coal, reacted with aluminosilicate clays that were abundant as discrete minerals. Calcium silicate formed as a result of the assimilation of vapor- or liquid-phase $\mathrm{CaO}$ into the partially molten surface of quartz grains. Robinson char displays initial inorganic ash droplet formation within the first 100 milliseconds of combustion at $1300^{\circ} \mathrm{C}$. The smallest-sized inorganic ash particles that begin to form on the surface of the coal char range from 0.1 to $3 \mu \mathrm{m}$ in size. These initial combustion products are high in $\mathrm{Ca}$, and some contain significant amounts of $\mathrm{Na}$. Robinson fly ash produced from the 53- to 74- $\mu \mathrm{m}$ coal had major phases of quartz, amorphous kaolinite-derived, iron oxide, anhydrite, melilite, and plagioclase. Melilite and anhydrite were concentrated in the smaller-sized fraction of the fly ash, while iron oxide and quartz were concentrated in the larger-sized fractions. Kaolinite-derived phases were distributed evenly in all size factions. Average chemical compositions of the fly ash size fractions showed greater $\mathrm{CaO}$, $\mathrm{Na}_{2} \mathrm{O}$, and $\mathrm{SO}_{3}$ in the smaller-sized fractions.

The major minerals identified in the Beulah lignite were pyrite, kaolinite, and quartz (8). The 53- to 74- $\mu \mathrm{m}$ fraction of Beulah coal had much less pyrite than the $80 \%$ -200-mesh bulk coal. Minor amounts of gypsum and Ca-aluminosilicate were also observed. Quartz, kaolinite, and gypsum were most abundant in the 4.4- to 8.0- $\mu \mathrm{m}$ size range, while Ca-aluminosilicate was more concentrated in the 2.1- to 4.4- $\mu \mathrm{m}$ range. Chars were produced for this lignite in the drop-tube furnace and analyzed using CCSEM. The most common phases identified in the chars were Ca-aluminosilicate, quartz, aluminosilicate, gypsum, and iron oxide. Pyrite virtually disappeared from the chars after 200 milliseconds of coal particulate residence time.

Distributions of major inorganic components in the chars and their comparisons to similar components in the original coal revealed some interesting trends for the Beulah coal (8). The overall area percent distribution of the inorganic phases showed a general decrease in material with combustion residence time in the lower size ranges $(<8.0 \mu \mathrm{m})$ and an increase in material with time in the higher size ranges $(>8.0 \mu \mathrm{m})$. Quartz and kaolinite decreased in concentration with residence time, and $\mathrm{Ca}$-aluminosilicate increased dramatically with time. The above data may be indicative of coalescence of finer-grained minerals and interaction of organically bound inorganic constituents to form larger fly ash grains. In the case of kaolinite (or aluminosilicate) particles, there is strong evidence to suggest that these particles underwent a chemical transformation from kaolinite to Ca-aluminosilicate particles of nearly the same size. This inorganic transformation results in $\mathrm{Ca}$-aluminosilicate particles having nearly the same size distribution as the kaolinite particles $(4.4$ to $8.0 \mu \mathrm{m})$. The infusion of calcium from organically bound sites, with the mineral form of kaolinite, may have been the mechanism by which $\mathrm{Ca}$-aluminosilicate was formed.

The variation in composition and distribution of phases as a function of particle size was determined for Beulah lignite fly ash. Each stage of the multicyclone was analyzed using the scanning electron microscopy point count (SEMPC) technique. Iron oxide and 
quartz-derived particles were found in the larger sizes. Kaolinite-derived particles were found evenly distributed in Stages 2 through 5 . Sodium calcium sulfate was concentrated in Stage $6(<1.2 \mu \mathrm{m})$.

Three size fractions and a bulk sample of Eagle Butte coal were analyzed for mineral content using CCSEM (8). The major mineral phases observed were quartz, aluminosilicate, a calcium-aluminum-phosphorus mineral (possibly crandallite), gypsum, and calcite. Minor contents of apatite, $\mathrm{K}$ and $\mathrm{Ca}$ aluminosilicates, and barite were also observed. X-ray fluorescence analysis revealed high $\mathrm{CaO}$ contents in all of the Eagle Butte coal size fractions, ranging from $23 \%-27 \% \mathrm{CaO}$. Chemical fractionation revealed that most of the calcium was organically bound or in a finely sized carbonate or phosphate form for all three size fractions of the Eagle Butte coal.

The most abundant phases observed in the Eagle Butte fly ash multicyclone samples were calcium oxide followed by quartz and gehlinite (8). Fly ash that was classified as less than $6.0 \mu \mathrm{m}$ in the multicyclone showed very low amounts of crystalline or chemically ordered phases. The amount of unclassifiable amorphous species seems to decrease with decreasing size of fly ash. Iron in the Eagle Butte fly ash was more concentrated in the smaller-size fraction, most likely because iron was associated in the coal as finely dispersed carbonate or organically bound cations, or because iron particles in the largest fly ash size fraction were being coated with calcium aluminosilicates or other materials that mask the identity of an iron-bearing core material. Other trends noticed were that $\mathrm{Fe}_{2} \mathrm{O}_{3}$ and $\mathrm{SO}_{3}$ contents increased with decreasing particle size, and $\mathrm{SiO}_{2}$ increased with increasing particle size. The $\mathrm{SiO}_{2}$ and $\mathrm{Al}_{2} \mathrm{O}_{3}$ contents in the fly ash follow trends observed with the other test coals.

Chars produced from the Eagle Butte 53- to $74-\mu \mathrm{m}$ coal were all very high in $\mathrm{CaO}$. Other major phases produced during the combustion process were calcium silicate, calcium aluminate, and calcium aluminosilicate. Quartz was drastically reduced in content in the chars due to reaction with calcium aluminosilicate and $\mathrm{CaO}$. Submicron calcium-rich minerals or organically bound calcium are the source for ubiquitous CaO-rich inorganic ash droplets that appear on the surface of early stage chars. By 0.8 seconds of combustion, $95 \%$ carbon burnout had been achieved. The early stage chars show greater quantities of discrete phases that are 1.2 to $8.0 \mu \mathrm{m}$ in size, which is evidence for initial fragmentation of mineral grains. By 0.8 seconds, the char shows greater quantities of discrete phases or particles that are $>8.0 \mu \mathrm{m}$ in size, which is evidence for coalescence of fly ash particles.

The major phases observed in the Upper Freeport coal by CCSEM were quartz, mixed aluminosilicate (illite), kaolinite, and pyrite (8). Minor amounts of calcite and gypsum were also noted. The quartz grains were evenly distributed in the various size ranges except for the 74- to $106-\mu \mathrm{m}$ coal size fractions, where there was a high level of $>11-\mu \mathrm{m}$ quartz. Illite and pyrite were found most frequently in the $>11-\mu \mathrm{m}$-size fraction. The chars were collected in the DTF at five different residence times for the Upper Freeport coal. The general form of the mineral particle-size distribution remained the same through 0.8 seconds of combustion. The coal mineral and the char inorganic phases were bimodally distributed. Upper Freeport char morphologies were examined using the scanning electron microscope (SEM), and qualitative analyses were performed on selected particles to determine their relative elemental compositions (8). Thermogravimetric analysis (TGA) was performed on the chars to monitor carbon burnout. Many of the Fe- 
rich particles showed significant quantities of aluminosilicate in their composition, and illite-derived particles commonly had high $\mathrm{Fe}_{2} \mathrm{O}_{3}$ contents. Illite in the coal had lower $\mathrm{Si} / \mathrm{Al}$ ratios than the illite-derived material in the char. The data suggest that a depletion of $\mathrm{Si}$ in association with $\mathrm{Al}$ occurred during the combustion process.

An additional DTF run was made to collect Upper Freeport 0.05-second char, whereby the char was quenciled using the short residence time probe and then collected in the multicyclone. The major phases present in the Upper Freeport 0.05-second char were montmorillonite, illite, kaolinite, calcite or calcium oxide, anhydrite, plagioclase (anorthite-albite), quartz, and unclassified material. When compared to the coal, the char revealed a depletion of calcite, mixed aluminosilicate, illite, and pyrite; most likely because of melting and interaction with other liquid- or gas-phase inorganic components. The char showed an enrichment of quartz and kaolinite as compared to the coal.

Upper Freeport fly ash was generated from a 53- to $74-\mu \mathrm{m}$ coal size fraction and analyzed for inorganic phases using SEMPC. Illite-derived was the most abundant phase recognized by SEMPC. Illite-derived is an amorphous $\mathrm{K}$-aluminosilicate derived from the clay mineral illite.

Fly ash particle-size distributions were determined using the multicyclone and impactor for Monticello, Beulah, Robinson, Upper Freeport, and Eagle Butte ashes produced in the drop-tube furnace. The size distributions indicated that mineral coalescence was a dominating influence on the particle-size evolution. CCSEM analyses of coal minerals and bulk fly ash showed a similar result.

A fly ash particle classification scheme was developed based on particle morphology and composition. Four general types of particles have been initially classified for Beulah and Upper Freeport. Type 1 particles are spherical with a relatively smooth surface and are usually composed of $\mathrm{Fe}$-, $\mathrm{Ca}$-, and $\mathrm{Na}$-rich aluminosilicates. Type 2 particles display complex crystalline patterns at the particle surface and are composed primarily of $\mathrm{Fe}$ with minor amounts of $\mathrm{Ca}$ and $\mathrm{Na}$. Type 3 particles are aluminosilicates with $\mathrm{Al} / \mathrm{Si}$ ratios similar to kaolinite and have irregular surfaces. Type 4 particles have angular shapes and are rich in $\mathrm{Si}$.

Electron spectroscopy for chemical analysis (ESCA) was used to determine the form of selected elements and the composition of the surfaces of particles in the multicyclone size cuts for the Beulah lignite ash produced in the drop-tube furnace (8). The highest level of sodium was found on the surfaces of the particles in Stage $6(<1.2 \mu \mathrm{m})$. Aluminum and silicon levels were relatively constant, but dropped off in Stage 6 . Sulfur levels increased with decreasing particle size. The forms of sodium, calcium, and sulfur were determined for each stage of the multicyclone. Sodium was in a silicate form in Stages 1 to 5 and a sulfate form in Stage $6(<1.2 \mu \mathrm{m})$. Calcium was found to be in a silicate form in Stage 1 and a sulfate form in Stages 3 through 6.

Combustion testing was also completed for Kentucky \#9 coal, an Eagle Butte 75\%/Kentucky \#9 25\% coal blend, and San Miguel coal (9). The coals were combusted at $1500^{\circ} \mathrm{C}$. The coal was sized with Malvern analysis, and the fly ash particles and the minerals in the coal were sized with CCSEM. 
The combustion of Kentucky $" 9$ is highly dominated by the fragmentation process, with slight amounts of coalescence and possible fragmentation of a few of the larger mineral particles. Kentucky $\# 9$ coal contained about $15 \%$ ash and had high iron (20\%) and moderate calcium (3\%) and potassium (3\%) contents on a normalized oxide basis. The most abundant minerals were quartz, aluminosilicate (degraded illite or mixed clay), illite, pyrite, and, for the 74- to 106- $\mu \mathrm{m}$ and unsized fraction, siderite. Ash content decreased with increasing coal size, but mineral sizes increased. Variability in mineral content was noted for the different coal sizes analyzed by CCSEM. An increase in pyrite with coal size corresponded with an increase in iron oxide in the coal ash.

Kentucky \#9 fly ash showed interaction between iron in the pyrite with aluminosilicate to form Fe-aluminosilicates (9). Pyrite transformation was evidenced by reduction from $28 \%$ to $0 \%$, and iron oxide was increased from $8 \%$ to $22 \%$ of the minerals. Kentucky \#9 minerals that were $<10 \mu \mathrm{m}$ underwent coalescence to a size range mostly between 22 to $46 \mu \mathrm{m}$, while the largest Kentucky $\# 9$ minerals $(>46 \mu \mathrm{m})$, which include pyrite and illite, underwent fragmentation. Time-resolved studies showed that $\mathrm{K}$ aluminosilicate and iron oxide increased with time. Quartz content remained fairly constant from the coal to 0.8-second residence time char. The finest fraction of the Kentucky $\# 9$ size-segregated fly ash was enriched in $\mathrm{CaO}, \mathrm{SO}_{9}$, and $\mathrm{TiO}_{2}$.

Analysis of the fly ash resulting from combustion of the Eagle Butte/Kentucky $\# 9$ blend revealed definite interaction between the mineral components of the two different coals $(10,11)$. Viscosity distributions of liquid phases in the fly ash under slagging conditions for the blend were intermediate between that of a weighted average of the parent fly ashes and the Kentucky \#9. The base deposit of the blend grown under slagging conditions was effectively the same as that of the Kentucky \#9. Viscosity distributions of the main portion of the deposits grown under fouling conditions were similar for the blend and the parent coals. Iron-rich particles derived from the pyrite in the Kentucky $\# 9$ coal experienced only limited interaction with aluminosilicates, most of which had sources in the Kentucky \#9.

The combustion of San Miguel demonstrates partial fragmentation followed by coalescence (9). San Miguel lignite had about 53\% ash on a dry basis and was very low in iron (1.9\%) and calcium (3.5\%). Sodium content was intermediate at $2.5 \%$ of the ash. Sodium and calcium were $65 \%$ and $72 \%$ organically bound, respectively. The major minerals in the San Miguel lignite, as determined by CCSEM, were quartz, clinoptilolite, and an unknown aluminosilicate that was probably mixed clay or montmorillonite. Mineralogic compositions on a mineral basis were similar for 38- to 53-, 53- to 74-, and 74to $106-\mu \mathrm{m}$ coal fractions; however, larger minerals were observed with increased coal size. The total ash contents and elemental oxide chemistry were similar for the different coal size fractions.

Analysis of San Miguel short residence time char revealed that quartz and $\mathrm{K}$. aluminosilicate contents remained fairly consistent through the combustion process, relative to their content in the original coal. Aluminosilicate was slightly reduced, and Fe-aluminosilicate and calcium silicate were slightly increased. The particle-size distributions of the inorganic phases in the chars showed coalescence with increased residence time. Smaller minerals between 1 and $10 \mu \mathrm{m}$ decreased in abundance, and large inorganic phases between 22 to $46 \mu \mathrm{m}$ increased in abundance progressively until 0.5 seconds into combustion. The 0.5 - and 0.8 -second chars were nearly identical in 
particle size and composition. This observation may be a result of near $100 \%$ carbon burnout by 0.5 seconds of combustion.

Fly ash was produced at a residence time of about 2.6 seconds at $1500^{\circ} \mathrm{C}$ gas temperature and collected on a bulk filter for the San Miguel 53. to 74- $\mu \mathrm{m}$ and unsized coals (9). In general, the fly ashes were similarly composed. Aluminosilicate and $\mathrm{K}$-aluminosilicate decreased with combustion because of interaction with the other mineral components. SEMPC analysis of the size-segregated fly ash from the multicyclone showed major phases of quartz or silica, amorphous illite, and amorphous montmorillonite. The amorphous illite was evidently the derivative of potassium-rich zeolites in the coal. Most of the fly ash mass (89\%) was greater than $22 \mu \mathrm{m}$ in average diameter. It was observed that $\mathrm{SiO}_{2}$ and $\mathrm{K}_{2} \mathrm{O}$ oxides increased with increasing fly ash particle size, corresponding to greater amounts of the amorphous illite-derived phase. The finer fly ash fraction had more $\mathrm{CaO}$ and $\mathrm{Al}_{2} \mathrm{O}_{3}$.

Fly ash generated from combustion testing of the Kentucky \#9, Eagle Butte/ Kentucky \#9, and San Miguel coals was collected on bulk filters and also aerodynamically size-segregated in a six-stage multicyclone (9). The Kentucky \#9 multicyclone and cascade impactor data showed no change in particle-size distribution for different coal sizes or combustion temperatures. The San Miguel size distributions changed with both coal size and combustion temperature. The impactor and multicyclone data showed larger particlesize distributions for smaller initial coal sizes. Coalescence seems more prevalent for smaller coal sizes and lower temperatures, while fragmentation may dominate at higher temperatures and larger coal sizes. For the Eagle Butte/Kentucky \#9 blend, the fly ash revealed very little interaction between the mineral components of the two different coals.

\subsubsection{Combustion Testing of Synthetic Coal Model Mixtures}

Synthetic coal model mixtures provide an excellent means of studying inorganic transformations in a physically and chemically controlled system because the complexity of inorganic reactions that occur in real coal systems is minimized. Accurate quantities and sizes of known minerals can be included in a synthetic organic matrix in order to isolate specific reactions and transformations of selected inorganic constituents. A controlled combustion environment, such as a drop-tube furnace, is used to combust the model mixture. Additional key phenomena to be studied include fragmentation of the synthetic coal grains and coalescence of the inorganics within the synthetic coal particles.

The goal of the model mixture studies during this project was to produce and perform combustion testing on four model mixtures, including:

i. Sodium-silica-sulfur system (organically bound $\mathrm{Na}$ simulation).

2. Calcium-silica-sulfur system (organically bound $\mathrm{Ca}$ simulation).

3. Calcium-silica-sulfur system (mineral-bound $\mathrm{Ca}$ as calcite).

4. Iron-aluminosilicate system (using pyrite and kaolinite).

Initial experiments were performed simulating the reaction between organically bound calcium, quartz, and sulfur (10). Tests of sodium bicarbonate, quartz, and sulfur in the drop-tube furnace showed progressively more chemical interaction between $\mathrm{Na}$ and silica with increasing temperature. With increasing temperature, the sodium-silica particles not only increased in abundance, but also showed marked increase in the 
amount of $\mathrm{Si}$ being incorporated into Na-Si particles. Auger surface analysis of $\mathrm{Na}-\mathrm{Si}$ particles from the highest temperature run $\left(1500^{\circ} \mathrm{C}\right)$ showed that $\mathrm{Na}$ was present as a surface enrichment product and that no deeper reaction had taken place.

Semiquantitative results from an ESCA survey scan of the same material showed atomic concentrations of $43.3 \%$ carbon, $43.7 \%$ oxygen, $4.0 \%$ sodium, and $9.0 \%$ silicon. The interaction of sodium with sulfur was noted at temperatures between $900^{\circ}$ and $1100^{\circ} \mathrm{C}$ at longer residence times. This result was compared with SOLGASMIX calculations, and it was found that SOLGASMIX predicts the same general trend.

Synthetic coals containing sodium, silica, and sulfur; calcium (inorganic and organic), silica, and sulfur; and pyrite and kaolinite were produced and combusted in the drop-tube furnaces $(10,11)$. Fly ash was collected and analyzed using CCSEM to examine interactions among mineral species. The results obtained show that the $\mathrm{Na}$ (org.)-Si-S system exhibits interaction among species at $900^{\circ} \mathrm{C}$ to produce sodium sulfate-silicate phases; above $900^{\circ} \mathrm{C}$, silica dominates due to the loss of sodium and sulfur by devolatilization and decomposition. The particle-size distribution of the fly ash decreased with increasing temperature, as the result of either char fragmentation or the loss of low melting point sodium silicate or sulfate species which tend to "glue" or cause coalescence of the ash particles.

The Ca(org.)-Si-S and $\mathrm{Ca}$ (min.)-Si-S systems exhibit interactions, primarily between calcium and silica, throughout the $900^{\circ}$ to $1500^{\circ} \mathrm{C}$ temperature range. Unlike the $\mathrm{Na}$ (org.)-Si-S system, the calcium-containing system exhibited increased levels of $\mathrm{Ca}$ silicates with increasing temperatures. This is primarily due to the lower volatility of calcium as compared to sodium, allowing for more calcium to be retained on the char particle during combustion. Some anhydrite was formed, but was probably the result of $\mathrm{SO}_{2}$ reacting with the surface of the calcium or quartz grains in the cooling zone of the ash quench probe. Particle agglomeration was seen at the highest temperature studied for the $\mathrm{Ca}$ (org.)-Si-S and $\mathrm{Ca}(\mathrm{min}$.)-Si-S systems.

Interaction between ash components occurs over a broader temperature range for calcium-containing ash than for organic sodium-containing ashes. However, softening and rounding of the particles occur at lower temperatures for the sodium-containing ash. An enhanced rate of carbon conversion was observed for the $\mathrm{Ca}$ (org.)-Si-S over that of the $\mathrm{Ca}\left(\mathrm{min}\right.$.)-Si-S at $900^{\circ} \mathrm{C}$. This is in agreement with previous studies showing the catalytic effect of organically bound calcium during combustion. The Ca(org.)-Si-S and $\mathrm{Ca}$ (min.)-SiS systems give generally similar compositional diagrams over the temperature range examined, except for the scarcity of calcium-sulfur species in the Ca(org.)-Si-S system.

The Fe(min.)-Al-Si system loses nearly all the sulfur from the pyrite at $900^{\circ} \mathrm{C}$, leaving kaolinite and iron oxide. The system shows only a small degree of interaction between the kaolinite and iron until $1500^{\circ} \mathrm{C}$, when an increased amount of iron aluminosilicate components form.

\subsection{Prediction of Fly Ash Particle Size and Composition}

Two models have been developed to predict fly ash particle size and composition from initial coal composition: 1) a stochastic model, ATRAN1, which combines coal inorganics in a random manner and outputs a predicted fly ash particle size and composition; and 2) an expert system model, ASHPERT, which gives a first-order estimate 
of fly ash size and composition, relying heavily on a large empirical database. Both models input data obtained through CCSEM, chemical fractionation, bulk elemental composition, and proximate analyses.

\subsubsection{Development of Mechanistic/Stochastic Model: ATRAN1}

The stochastic model, ATRAN1, uses CCSEM coal data $(10,11,20,21)$. It is used to predict the partitioning of inorganics during combustion. The locked minerals are randomly coalesced by ATRAN1, based on their concentration in the coal and the degree of fragmentation of the char. CCSEM data for the liberated minerals are then added to the data for coalesced minerals to predict fly ash particle size and composition. A massbalancing algorithm is also included to extend ATRAN1 to lower-rank coals.

Four coals were used to test ATRAN1: Upper Freeport, Eagle Butte, Kentucky \#9, and a blend of Eagle Butte (70\%) and Kentucky $\# 9$ (30\%). Overall, the predicted and experimental fly ash size distributions and compositions compared fairly well. The predicted Eagle Butte fly ash contained a larger amount of nucleated submicron particles due to the large amount of organically associated constituents present in the coal. Experimental fly ash-produced using particle residence times and temperatures associated with fouling and slagging conditions in a boiler, was generated from the coals in order to compare experimental and predicted fly ash composition and size. Slagging conditions include shorter particle residence times and higher gas temperatures at the point of collection than fouling conditions. The CCSEM mineral-phase composition of the experimental blend fly ash compared fairly well with that of the predicted compositions. Particle-size distributions of the experimental and predicted fly ash also compared fairly well.

\subsubsection{Development of Expert System Model: ASHPERT}

The expert system, ASHPERT, is the first step in developing a rigorous theoretical predictive model $(10,11,21,22)$. The information input to ASHPERT consists of proximate/ultimate, chemical fractionation, XRF elemental composition and CCSEM data for a particular coal and corresponding fly ash. The fly ash included in the ASHPERT database can originate from drop-tube furnace tests or from pilot- or full-scale combustion sources.

Predicted (ASHPERT) versus experimental (drop-tube furnace) fly ash particle-size distributions and compositions were compared for Eagle Butte and Kentucky \#9 coals. The particle-size distributions were in error by approximately $15 \%$ to $25 \%$ at any given point along the particle-size distribution curve. Compositions were more in agreement, showing only $5 \%$ to $20 \%$ error for any given element. These results are fairly good, considering that only ten coals were loaded in the database at the time ASHPERT was run. The ASHPERT database presently includes 45 coals and ashes.

The mineral particle-type classification program MINER has also been incorporated into ASHPERT (11). This addition considerably enhances the applicability of ASHPERT in other areas of combustion modeling. 


\subsection{SUMMARY OF CONCLUSIONS}

The results of this 6-year project represent significant advances in the understanding of inorganic transformations during combustion. The continuous improvement and modification of analytical techniques, as well as the development and application of new techniques, is essential to the progress of combustion research. Analytical techniques have been emphasized in the Combustion Inorganic Transformations project, with the result that the methods developed as part of the project have become established as the standard for advanced characterizations of coals and combustion products. Laboratoryscale combustion testing, an efficient alternative to full-scale testing, has been another area of emphasis. As a result of these drop-tube experiments, our base knowledge of combustion reactions has increased sufficiently to allow the development of predictive computer models, the third area of emphasis in the CIT project. Work is continuing in all three areas, as appropriate parts of smaller industry-sponsored projects.

Some of the major accomplishments and contributions to combustion technology that resulted from this project are listed below:

1. Numerous reports, presentations, and publications have been generated through CIT which have contributed significantly to academic and industrial combustion. related technologies and knowledge bases. Appendix A contains a comprehensive bibliography of reported accessible literature related to the CIT project. Highlights of this list are entries for nine peer-reviewed journal articles and six published book articles which incorporated CIT funds and base research findings for deriving the major parts or all of the scientific results described in the publications. Also included in Appendix A are bibliographies of six final reports that describe in detail the results of the research conducted for a particular year. Appendix B gives the Table of Contents for each of the CIT final reports for each of the 6 years of the project.

2. Several major joint DOE-commercial industry research programs have resulted primarily due to the fundamental research efforts of the CIT project. Some of these projects include:

- Project Calcium (consortium of ten private companies and DOE)--This program studied lower-temperature ash deposition noted in the firing of many highcalcium fuels. A computer model was devised that predicts ash deposition rates in the cooler regions of a utility boiler convective pass, based on boiler configuration, operating parameters, and coal mineral content.

- Combustion Characterization of Beneficiated Fuels (ABB-CE/DOE/PETC)--This program examines the combustion behavior of beneficiated coals. The EERC's work involves characterization of the minerals behavior of these fuels during combustion.

- Coal Ash Behavior in Reducing Environments (consortium of four private companies and DOE)--This is a 3-year program studying inorganic transformations that occur in reducing environments, such as in an entrained flow gasifier. 
- Clean Coal Technology I Program (DOE/PETC, ABB-CE, EPRI)--This is a 3-year program that will determine the effects of coal cleaning on utility boiler performance and assist in the development of a model to predict coal behavior in combustion systems. The EERC's role is to characterize coal, ash, and deposits generated at full and pilot scale and to develop algorithms that describe inorganic transformations, ash deposition propensity, and ash deposit removability in a utility boiler during combustion.

- Development of Fireside Performance Indices (consortium of four private companies, EPRI, and DOE)-.The objectives of this project are to utilize advanced analytical methods of analysis, fundamental knowledge of the distribution of coal inorganic constituents, and experience in combustion ash transformation and deposition mechanisms developed at the EERC to formulate a series of fouling indices for low-rank coal, especially Powder River Basin coal.

- Over ten projects with utility and coal companies seeking information on how inorganics in their coals could be causing ash deposition and opacity problems in utility boilers during combustion.

3. Several pieces of software have been developed as a result of work performed in CIT, including a) PARTCHAR, a program that manipulates raw CCSEM data into meaningful tables of coal or ash particle sizes and mineralogies; b) ATRAN1, which predicts the particle size and composition of fly ash based on CCSEM analysis of a coal; and c) ASHPERT, an expert system model that predicts combustion fly ash composition and size based on CCSEM and proximate/ultimate data on a coal.

4. Finally, funds and resources provided by the CIT project have resulted in educational opportunities and scientific work experience for 12 undergraduate students, two masters students, and one doctoral student.

\subsection{REFERENCES}

1. Mills, M.E. "Sodium Release from Solids in Flames Studied Using Laser-Induced Fluorescence Spectroscopy," Masters Thesis, University of North Dakota, 1989.

2. Zygarlicke, C.J.; Steadman, E.N. "Advanced SEM Techniques to Characterize Coal Minerals," Scanning Microsc. Int. 1990, 4 (3), 579-589.

3. Jones, M.L.; Kalmanovitch, D.P.; Steadman, E.N.; Zygarlicke, C.J.; Benson, S.A. "Application of SEM Techniques to the Characterization of Coal and Coal Ash Products," In Advances in Coal Spectroscopy; Meuzelaar, H.L.C., Ed.; Plenum Press, 1992, pp 1-27.

4. Galbreath, K.C.; Brekke, D.W.; Folkedahl, B.C. "Automated Analytical Scanning Electron Microscopy and Image Analysis Methods for Characterizing the Inorganic Phases in Coal and Coal Combustion Products," Prepr. Pap.-Am. Chem. Soc., Div. Fuel Chem. 1992, 37 (3), 1170-1176. 
5. Zygarlicke, C.J.; Erickson, T.A.; Ramanathan, M.; Toman, D.L. "Improved Scanning Electron Microscopy Methods for Predicting Fly Ash Particle Size and Composition," In Proceedings of the Seventh Annual Coal Preparation, Utilization, and Environmental Control Contractors' Conference; July 15-18, 1991, pp 147-155.

6. Benson, S.A.; Radonovich, L.; Steadman, E.N. "Combustion Inorganic Transformations," Final Technical Progress Report for the Period April 1, 1986 . March 31, 1987 to U.S. DOE, Contract No. DE-FC21-86MC10637, EERC publication, Grand Forks, ND, 1987.

7. Benson, S.A.; Sweeney, P.G.; Abrahamson, H.B.; Zygarlicke, C.J.; Puffe, W.H.; Maldonado, M.E. "Combustion Inorganic Transformations," Final Technical Progress Report for the Period April 1, 1987 - March 31, 1988 to U.S. DOE, Contract No. DE-FC21-86MC10637, EERC publication, Grand Forks, ND, 1988.

8. Zygarlicke, C.J.; Benson, S.A.; Abrahamson, H.B.; Mills, M.E. "Combustion Inorganic Transformations," Final Technical Progress Report for the Period April 1, 1988 - June 30, 1989 to U.S. DOE, Contract No. DE-FC21-86MC10637, EERC publication, Grand Forks, ND, 1989.

9. Zygarlicke, C.J.; Benson, S.A.; Toman, D.L.; Steadman, E.N.; Brekke, D.W.; Erickson, T.A.; Hurley, J.P. "Combustion Inorganic Transformations," Final Technical Progress Report for the Period July 1, 1989 - June 30, 1990 to U.S. DOE, Contract No. DE-FC21-86MC10637, EERC publication, Grand Forks, ND, 1990.

10. Zygarlicke, C.J.; Toman, D.L.; Erickson, T.A.; Ramanathan, M.; Folkedahl, B.C. "Combustion Inorganic Transformations," Final Technical Progress Report for the Period July 1, 1990 - June 30, 1991, to U.S. DOE, Contract No. DE-FC2186MC10637, EERC publication, Grand Forks, ND, 1991.

11. Zygarlicke, C.J.; Katrinak, K.A.; Erickson, T.A.; Folkedahl, B.S.; Galbreath, K.C.; McCollor, D.P.; Ramanathan, M. "Combustion Inorganic Transformations," Final Technical Progress Report for the Period July 1, 1991 - June 30, 1992, to U.S. DOE, Contract No. DE-FC21-86MC10637, EERC publication, Grand Forks, ND, 1992.

12. Benson, S.A.; Zygarlicke, C.J.; McCollor, D.P. "Inorganic Transformations During Combustion: Coal and Ash Chemical Composition and Size Evolution," In Proceedings of the Eighth Annual Coal Preparation, Utilization, and Environmental Control Contractors' Conference; July 27-30, 1992, pp 81-88.

13. Galbreath, K.C.; Zygarlicke, C.J.; Benson, S.A.; Erickson, T.A. "Plan for Conducting a Round-Robin Study of the Computer-Controlled Scanning Electron Microscopy Method of Coal Mineral Analysis," Internal report generated by the University of North Dakota Energy and Environmental Research Center, Grand Forks, ND, Apr. 1992, $13 \mathrm{p}$.

14. Katrinak, K.A.; Brekke, D.W.; Hurley, J.P. "Freeze-Dried Dispersions for Automated Scanning Electron Microscope Analysis of Individual Submicron Airborne Particulates" In Proceedings of the 50th Annual Meeting of the Electron Microscopy Society of America; Bailey, G.W.; Bentley, J.; Small, J.A., Eds.; 1992, pp 408-409. 
15. Zygarlicke, C.J.; Steadman, E.N.; Benson, S.A. "Studies of the Transformations of Inorganic Constituents in a Texas Lignite During Combustion," Prog. Energy Combust. Sci. 1990, 16, 195-204.

16. Zygarlicke, C.J.; Toman, D.L.; Benson, S.A. "Trends in the Evolution of Fly Ash Size During Combustion," Prepr. Pap.-Am. Chem. Soc. Div. Fuel Chem. 199 , 35 (3), 621-636.

17. Brekke, D.W.; Zygarlicke, C.J.; Folkedahl, B.C.; Steadman, E.N. "Practical Application of Advanced Coal Analyses to Coal Blending," In Proceedings of the Eighth Annual International Pittsburgh Coal Conference; Pittsburgh, PA, Oct. 14-18, 1991, pp 12-18.

18. Zygarlicke, C.J.; McCollor, D.P. "The Effect of Coal Blending on Inorganic Transformations: A Study of an Eagle Butte/Kentucky "9 Coal Blend," In Proceedings of the Ninth Annual International Pittsburgh Coal Conference; Pittsburgh, PA, Oct. 12-16, 1992, pp 775-789.

19. Zygarlicke, C.J.; McCollor, D.P.; Benson, S.A.; Holm, P.L. "Ash Particle Size and Composition Evolution During Combustion of Synthetic Coal and Inorganic Mixtures," In Twenty-Fourth Symposium (International) on Combustion/The Combustion Institute; 1992, in press.

20. Erickson, T.A.; Zygarlicke, C.J.; Ramanathan, M.; Folkedahl, B.C. "Composition and Particle-Size Evolution of Kentucky "9," Prepr. Pap.-Am. Chem. Soc. Div. Fuel Chem. 1991, 36 (1), pp 158-165.

21. Zygarlicke, C.J.; Ramanathan, M.; Erickson, T.A. "Fly Ash Particle-Size Distribution and Composition: Experimental and Phenomenological Approach," In Inorganic Transformations and Ash Deposition During Combustion; Benson, S.A., Ed.; ASME for the Engineering Foundation, New York, 1992, pp 699-711.

22. Ramanathan, M. "Particle-Size and Composition Distribution in Coal Combustion Systems: Phenomenology and Expertise," In Proceedings of the Expert System Applications for the Electric Power Industry; Boston, MA, Sep. 9-11, 1991. 
APPENDIX A

BIBLIOGRAPHY OF CIT-RELATED PRESENTATIONS, PUBLICATIONS, AND REPORTS 


\section{BIBLIOGRAPHY OF CIT-RELATED PRESENTATIONS, PUBLICATIONS, AND REPORTS}

Benson, S.A.; Hurley, J.P.; Zygarlicke, C.J.; Steadman, E.N.; Erickson, T.A. "Predicting Ash Behavior in Utility Boilers: Assessment of Current Status," In Proceedings of the Third International Conference on the Effects of Coal Quality on Power Plants; La Jolla, CA, Aug. 25-27, 1992.

Benson, S.A.; Jones, M.L.; Harb, J.N. "Ash Formation and Deposition," In Fundamentals of Coal Combustion; Smoot, L.D., Ed.; Elsevier, 1993, in press.

Benson, S.A.; Radonovich, L.; Steadman, E.N. "Combustion Inorganic Transformations," Final Technical Progress Report for the Period Apr. 1, 1986 - Mar. 31, 1987, U.S. DOE, Contract No. DE.FC21-86MC10637, EERC publication, Grand Forks, ND, 1987.

Benson, S.A.; Sweeney, P.G.; Abrahamson, H.B.; Zygarlicke, C.J.; Puffe, W.H.; Maldonado, M.E. "Combustion Inorganic Transformations," Final Terhnical Progress Report for the Period Apr. 1, 1987 - Mar. 31, 1988, U.S. DOE Contract No. DE-FC21. 86MC10637, EERC publication, Grand Forks, ND, 1988.

Benson, S.A.; Zygarlicke, C.J.; McCollor, D.P. "Inorganic Transformations during Combustion: Coal and Ash Chemical Composition and Size Evolution," In Proceedings of the Eighth Annual Coal Preparation, Utilization, and Environmental Control Contractors' Conference; Jul. 27-30, 1992, pp 81-88.

Benson, S.A.; Kalmanovitch, D.P.; Zygarlicke, C.J.; Steadman, E.N. "Studies of Ash Deposit Formation from Powder River Basin and Fort Union Region Coals," In Proceedings of the Fifteenth Biennial Low-Rank Fuels Symposium; Ness, H.M., Ed.; DOE/METC-90/6109, May 1989, p 15.

Benson, S.A.; Steadman, E.N.; Kalmanovitch, D.P. "Studies of the Formation of Alkali and Alkaline Earth Aluminosilicates Using a Laboratory-Scale Furnace," In Proceedings of the Conference on the Effects of Coal Quality on Utility Boiler Performance; EPRI, Oct. 1987, p 12.

Benson, S.A.; Zygarlicke, C.J.; Jones, M.L. "An Overview of Ash Deposition during the Combustion of Western U.S. Coals," In Proceedings of the Conference on Effects of Coal Quality on Power Plants; St. Louis, MO, Sept. 1990.

Benson, S.A.; Zygarlicke, C.J.; Steadman, E.N.; Karner, F.R. "Geochemistry and Mineralogy of Fort Union Region Lignites," In Geology and Utilization of Fort Union Lignites; Finkelman, R.B.; Daly, D.J., Eds.; 1992.

Brekke, D.W.; Zygarlicke, C.J.; Folkedahl, B.C.; Steadman, E.N. "Practical Application of Advanced Coal Analyses to Coal Blending," In Proceedings of the Eighth Annual International Pittsburgh Coal Conference; Pittsburgh, PA, Oct. 14-18, 1991, pp 12. 18. 
Erickson, T.A. "The Fate of Flame-Volatilized Sodium during the Combustion of Pulverized Coal in Reaction with Silica and Sulfur (Studied with the Aid of a Synthetic Coal)," Master's Thesis, University of North Dakota, 1990.

Erickson T.A.; Ludlow, D.K.; Benson, S.A. "Fly Ash Development from Sodium, Sulfur, and Silica during Coal Combustion," Fuel 1992, 71, 15-18.

Erickson, T.A.; Zygarlicke, C.J.; Ramanathan, M.; Folkedahl, B.C. "Composition and Particle-Size Evolution of Kentucky "9," Prepr. Pap.-Am. Chem. Soc., Div. Fuel Chem. 1991, 36 (1), 158-165.

Galbreath, K.C.; Brekke, D.W.; Folkedahl, B.C. "Automated Analytical Scanning Electron Microscopy and Image Analysis Methods for Characterizing the Inorganic Phases in Coal and Coal Combustion Products," Prepr. Pap.-Am. Chem. Soc., Div. Fuel Chem. 1992, 37 (3), 1170-1176.

Galbreath, K.C.; Zygarlicke, C.J.; Benson, S.A.; Erickson, T.A. "Plan for Conducting a Round-Robin Study of the Computer-Controlled Scanning Electron Microscopy Method of Coal Mineral Analysis," Internal report generated by the University of North Dakota Energy and Environmental Research Center, Grand Forks, ND, Apr. $1992,13 \mathrm{p}$.

Hurley, J.P.; Schobert, H.H. "Ash Formation during Pulverized Subbituminous Coal Combustion: 1. Characterization of Coals and Inorganic Transformations during Early Stages of Burnout," Energy and Fuels 1992, 6 (1), 47.58.

Hurley, J.P.; Schobert, H.H. "Ash Formation during Pulverized Subbituminous Coal Combustion: 2. Inorganic Transformations during Middle and Late Stages of Burnout," Energy and Fuels 1993, in press.

Jones, M.L.; Kalmanovitch, D.P.; Steadman, E.N.; Zygarlicke, C.J.; Benson, S.A. "Application of SEM Techniques to the Characterization of Coal and Coal Ash Products," In Advances in Coal Spectroscopy; Meuzelaar, H.L.C., Ed.; Plenum Press, 1992, pp 1-27.

Jones, M.L.; Kalmanovitch, D.P.; Steadman, E.N.; Zygarlicke, C.J.; Benson, S.A. "Application of SEM Techniques to the Characterization of Coal and Coal Ash Products," Presented at 1st Symposium on Advances in Coal Spectroscopy, Salt Lake City, UT, Jun. 14-16, 1989.

Kalmanovitch, D.P.; Frank, M. "An Effective Model of Viscosity for Ash Deposition Phenomena," Presented at the Conference on Mineral Matter and Ash Deposition from Coal, The Engineering Foundation, Santa Barbara, CA, Feb. 21-26, 1988.

Kalmanovitch, D.P.; Zygarlicke, C.J.; Steadman, E.N.; Benson, S.A. "Deposition of Beulah Ash in a Drop-Tube Furnace under Slagging Conditions," Presented at the 197 ACS National Meeting in Dallas, TX, Apr. 9-14, 1988.

Katrinak, K.A.; Brekke, D.W.; Hurley, J.P. "Freeze-Dried Dispersions for Automated Scanning Electron Microscope Analysis of Individual Submicron Airborne 
Particulates," In Proceedings of the 50th Annual Meeting of the Electron Microscopy Society of America; Bailey, G.W.; Bentley, J.; Small, J.A., Eds.; 1992, pp 408-409.

Ludlow, D.K.; Erickson, T.A.; Benson, S.A. "Interaction of Sodium, Sulfur, and Silica during Coal Combustion," Energy and Fuels 1991, 5, 539.547.

McCollor, D.P.; Jones, M.L.; Benson, S.A.; Young, B.C. "Promotion of Char Oxidation by Inorganic Constituents," In Twenty-Second International Symposium on Combustion/The Combustion Institute; Pittsburgh, PA, 1988, pp 59-67.

Mills, M.E. "Sodium Release from Solids in Flames Studied Using Laser-Induced Fluorescence Spectroscopy," Master's Thesis, University of North Dakota, 1989.

Ramanathan, M. "Particle Size and Composition Distribution in Coal Combustion Systems: Phenomenology and Expertise," In Proceedings of the Expert System Applications for the Electric Power Industry Conference; Boston, MA, Sept. 9.11, 1991.

Schobert, H.H.; Karner, F.R.; Olson, E.S.; Kleesattel, D.R.; Zygarlicke, C.J. "New Approaches to the Characterization of Lignites: A Combined Geological and Chemical Study," In Coal Science; Volborth, A., Ed.; Elsevier Science Publishers, Amsterdam, 1987, pp 355-380.

Steadman, E.N.; Benson, S.A.; Zygarlicke, C.J. "Digital Scanning Electron Microscopy Techniques for the Characterization of Coal Minerals and Coal Ash," In Proceedings of the Sixteenth Biennial Low-Rank Fuels Symposium; Sponsored by UND Energy and Environmental Research Center and the Montana Coal Council, May 20-23, 1991, pp 200.215.

Steadman, E.N.; Zygarlicke, C.J.; Benson, S.A.; Jones, M.L. "A Microanalytical Approach to the Characterization of Coal, Ash, and Deposits," In Proceedings of the ASME Seminar on Fireside Fouling Problems; Provo, UT, Apr. 4-6, 1990, pp 74-86.

Sweeny, P.G.; Abrahamson, H.B.; Radonovich, L.R.; Ballintine, T.A. "Determination of Atomic Sodium in Coal Combustion Using Laser-Induced Fluorescence," Prepr. Pap.-Am. Chem. Soc., Div. Fuel Chem. 1987, 32 (4), 186.

Zygarlicke, C.J.; Benson, S.A.; Abrahamson, H.B.; Mills, M.E. "Combustion Inorganic Transformations," Final Technical Progress Report for the Period Apr. 1, 1988 - Jun. 30, 1989, U.S. DOE Contract No. DE-FC21-86MC10637, EERC publication, Grand Forks, ND, 1989.

Zygarlicke, C.J.; Benson, S.A.; Toman, D.L.; Steadman, E.N.; Brekke, D.W.; Erickson, T.A.; Hurley, J.P. "Combustion Inorganic Transformations," Final Technical Progress Report for the Period Jul. 1, 1989 - Jun. 30, 1990, U.S. DOE Contract No. DE-FC21-86MC10637, EERC publication, Grand Forks, ND, 1990.

Zygarlicke, C.J.; Erickson, T.A.; Ramanathan, M.; Toman, D.L. "Improved Scanning Electron Microscopy Methods for Predicting Fly Ash Particle Size and Composition," 
In Proceedings of the Seventh Annual Coal Preparation, Utilization, and

Environmental Control Contractors' Conference; Jul. 15-18, 1991, pp 147-155.

Zygarlicke, C.J.; Katrinak, K.A.; Erickson, T.A.; Folkedahl, B.S.; Galbreath, K.C.; McCollor, D.P.; Ramanathan, M. "Combustion Inorganic Transformations," Final Technical Progress Report for the Period Jul. 1, 1991 . Jun. 30, 1992, U.S. DOE Contract No. DE-FC21-86MC10637, EERC publication, Grand Forks, ND, 1992.

Zygarlicke, C.J.; McCollor, D.P. "The Effect of Coal Blending on Inorganic Transformations: A Study of an Eagle Butte/Kentucky "9 Coal Blend," In Proceedings of the Ninth Annual International Pittsburgh Coal Conference; Pittsburgh, PA, Oct. 12-16, 1992, pp 775-789.

Zygarlicke, C.J.; McCollor, D.P.; Benson, S.A.; Holm, P.L. "Ash Particle Size and Composition Evolution during Combustion of Synthetic Coal and Inorganic Mixtures." In Proceedings of the Twenty-Fourth Symposium (International) on Combustion/The Combustion Institute; 1992, in press.

Zygarlicke, C.J.; Ramanathan, M.; Erickson, T.A. "Fly Ash Particle Size Distribution and Composition: Experimental and Phenomenological Approach," In Inorganic Transformations and Ash Deposition during Combustion; Benson, S.A., Ed.; ASME for the Engineering Foundation, New York, NY, 1992, pp 699-711.

Zygarlicke, C.J.; Steadman, E.N. "Advanced SEM Techniques to Characterize Coal Minerals," Presented at Scanning Microscopy, Intl. Meeting, Bethesda, MD, May 1990.

Zygarlicke, C.J.; Steadman, E.N.; Benson, S.A. "Studies of the Transformations of Inorganic Constituents in a Texas Lignite during Combustion," Prog. Energy Combust. Sci. 1990, 16, 195-204.

Zygarlicke, C.J.; Toman, D.L.; Erickson, T.A.; Ramanathan, M.; Folkedahl, B.C. "Combustion Inorganic Transformations," Final Technical Progress Report for the Period Jul. 1, 1990 - Jun. 30, 1991, U.S. DOE Contract No. DE-FC21-86MC10637, EERC publication, Grand Forks, ND, 1991.

Zygarlicke, C.J.; Steadman, E.N. "Advanced SEM Techniques to Characterize Coal Minerals," Scanning Microsc. Int. 1990, 4 (3), 579-589.

Zygarlicke, C.J.; Steadman, E.N.; Benson, S.A.; Kalmanovitch, D.P. "Studies of the Transformations of Inorganic Constituents in a Texas Lignite during Combustion," Presented at the 197th ACS National Meeting in Dallas, TX, Apr. 9-14, 1988.

Zygarlicke, C.J.; Toman, D.L.; Benson, S.A. "Trends in the Evolution of Fly Ash Size during Combustion," Prep. Pap.-Am. Chem. Soc., Div. Fuel Chem. 1990, 35 (3), 621 636. 
APPENDIX B

TABLES OF CONTENTS FOR CIT FINAL REPORTS 


\section{TABLES OF CONTENTS FOR CIT FINAL REPORTS}

Final Technical Report for the Period April 1, 1986, through March 31, 1987

Page

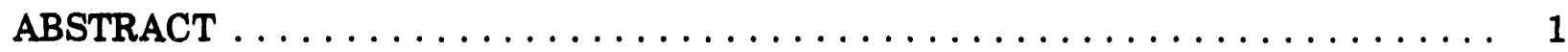

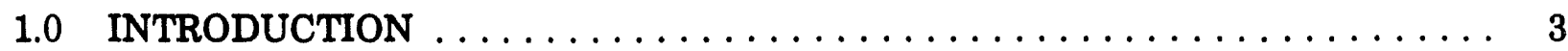

2.0 GOALS AND OBJECTIVES $\ldots \ldots \ldots \ldots \ldots \ldots \ldots \ldots \ldots \ldots \ldots$

3.0 TASK $3.2 \mathrm{a}$ LIFS PROJECT $\ldots \ldots \ldots \ldots \ldots \ldots \ldots \ldots \ldots \ldots \ldots \ldots \ldots$

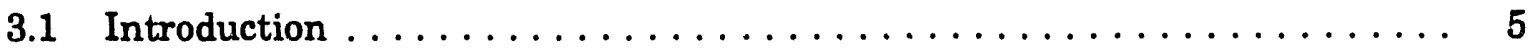

3.2 Experimental Equipment and Methods $\ldots \ldots \ldots \ldots \ldots \ldots \ldots \ldots$

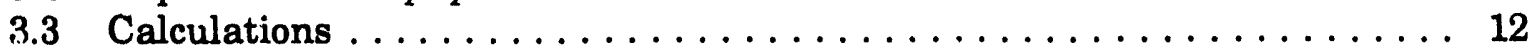

3.4 Results ................................ 20

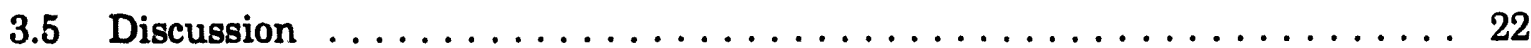

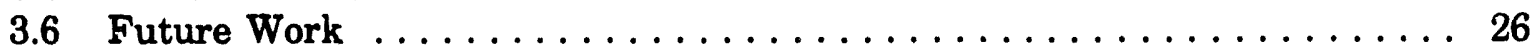

4.0 TASK $3.2 \mathrm{~b}$ DROP.TUBE FURNACE PROJECT $\ldots \ldots \ldots \ldots \ldots \ldots \ldots \ldots$

4.1 Introduction $\ldots \ldots \ldots \ldots \ldots \ldots \ldots \ldots \ldots \ldots \ldots \ldots \ldots \ldots \ldots \ldots$

4.2 Construction and Testing of Drop-Tube Furnace $\ldots \ldots \ldots \ldots \ldots \ldots$

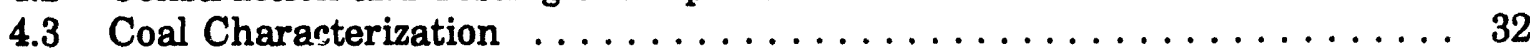

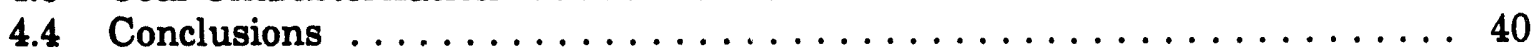

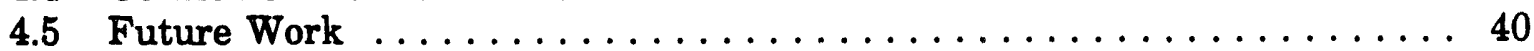

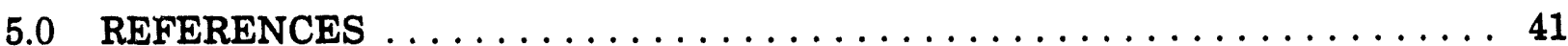


Final Technical Report for the Period April 1, 1987, through March 31, 1988

Page

EXECUTIVE SUMMARY $\ldots \ldots \ldots \ldots \ldots \ldots \ldots \ldots \ldots \ldots \ldots \ldots \ldots$

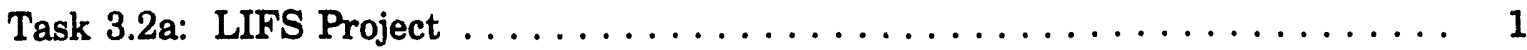

Task 3.2b: Drop-Tube Furnace Project . . . . . . . . . . . . . . . 2

INTRODUCTION $\ldots \ldots \ldots \ldots \ldots \ldots \ldots \ldots \ldots \ldots \ldots \ldots \ldots \ldots \ldots$

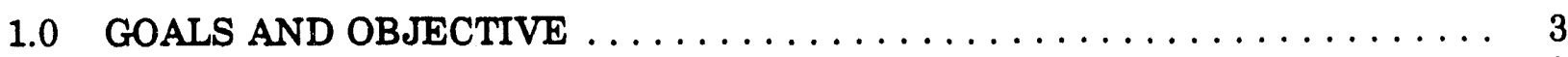

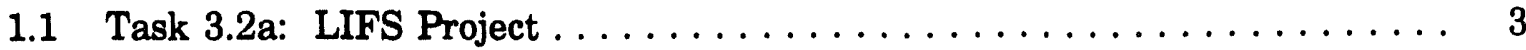

1.2 Task 3.2b: Drop-Tube Furnace Project $\ldots \ldots \ldots \ldots \ldots \ldots \ldots \ldots$

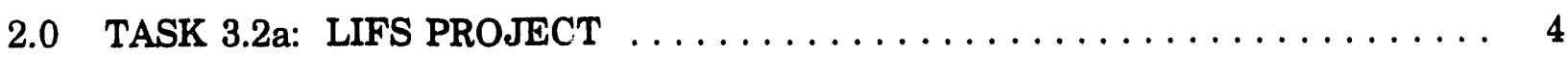

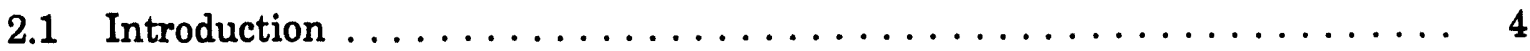

2.2 Experimental Equipment and Conditions ................. 4

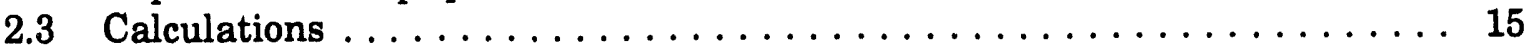

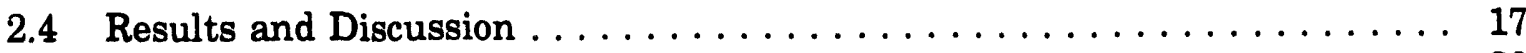

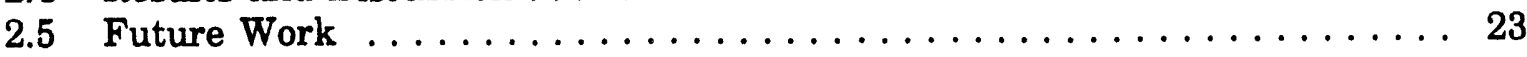

3.0 TASK $3.2 \mathrm{~b}:$ DROP-TUBE FURNACE PROJECT $\ldots \ldots \ldots \ldots \ldots \ldots \ldots \ldots \ldots$

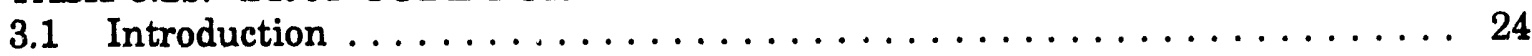

3.2 Equipment and Experimental Procedures $\ldots \ldots \ldots \ldots \ldots \ldots \ldots \ldots \ldots$

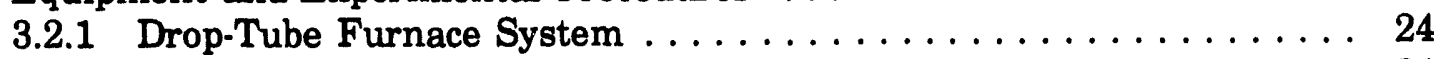

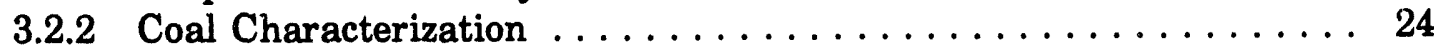

3.2 .3 Sodium-Silicon-Sulfur Studies .................. 31

3.2.4 Production of Fly Ash from Robinson and Monticello Coals . . . . . . 32

3.2.5 Interaction of Inorganic Constituents during

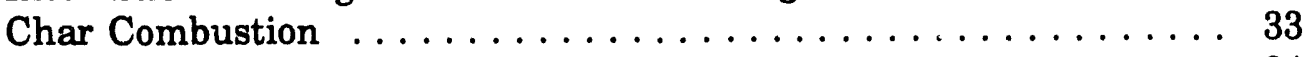

3.2.6 Analytical Techniques . . . . . . . . . . . . . . . . 34

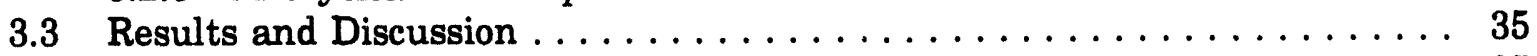

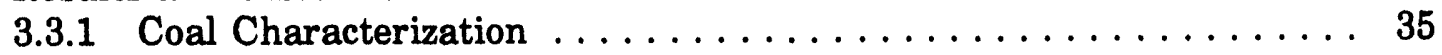

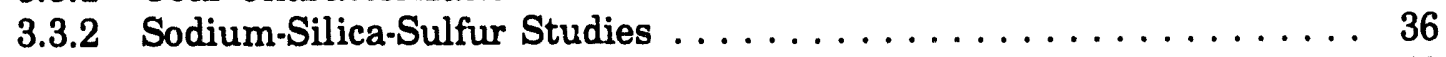

3.3.3 Robinson and Monticello Fly Ash Characterization .......... 43

3.3.3.1 Robinson Coal Fly Ash .................... 58

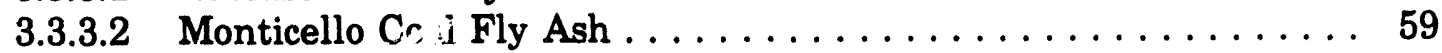

3.3.4 Surface Science Studies of Fly Ash . . . . . . . . . . . 53

3.3.5 Interaction of Inorganic Constituents during
Char Combustion $\ldots \ldots \ldots \ldots \ldots \ldots \ldots \ldots \ldots \ldots \ldots \ldots \ldots$

3.3.5.1 $\quad 0.8$-Second Residence Time Interval . . . . . . . . . . . . 58

3.3.5.2 0.5-Second Residence Time Interval . . . . . . . . . . . . 59

3.3.6 Statistical Analysis of the Test Matrix .............. 68

3.4 Conclusions ........................... 72

4.0 REFERENCES $\ldots \ldots \ldots \ldots \ldots \ldots \ldots \ldots \ldots \ldots \ldots \ldots \ldots \ldots \ldots$

APPENDIX A: DROP-TUBE FURNACE RUN CONDITIONS . . . . . . . . . A.1

APPENDIX B: MULTICYCLONE AND IMPACTOR DATA . . . . . . . B.1

APPENDIX C: FEDERAL ASSISTANCE MANAGEMENT SUMMARY REPORT . . C-1 
Final Technical Report for the Period April 1, 1988, through June 30, 1989

$\underline{\text { Page }}$

EXECUTIVE SUMMARY $\ldots \ldots \ldots \ldots \ldots \ldots \ldots \ldots \ldots \ldots \ldots \ldots \ldots$

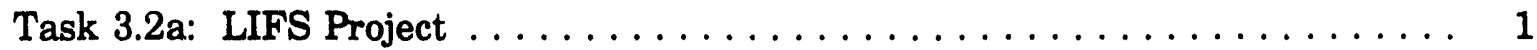

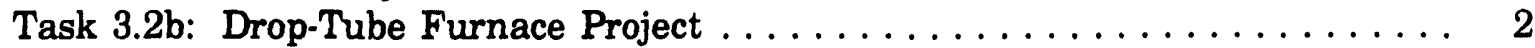

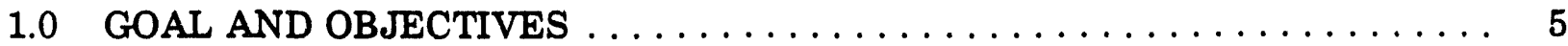

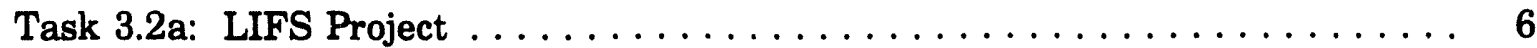

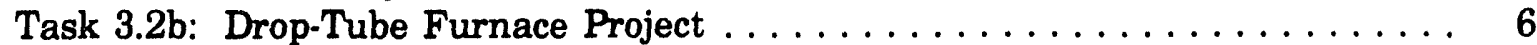

2.0 TASK $3.2 \mathrm{a}:$ LIFS PROJECT $\ldots \ldots \ldots \ldots \ldots \ldots \ldots \ldots \ldots \ldots \ldots \ldots \ldots$

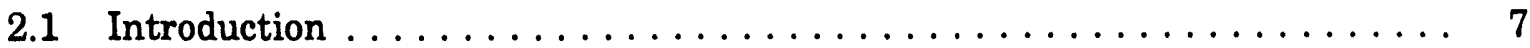

2.2 Experimental ............................. 8

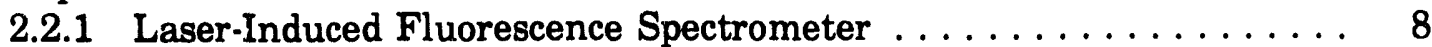

2.2.2 Sample Introduction $\ldots \ldots \ldots \ldots \ldots \ldots \ldots \ldots \ldots \ldots \ldots \ldots \ldots$

2.2.3 Solid Preparation $\ldots \ldots \ldots \ldots \ldots \ldots \ldots \ldots \ldots \ldots \ldots \ldots$

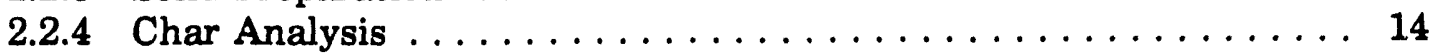

2.3 Calculations ............................ 17

2.4 Results and Discussion . . . . . . . . . . . . . . . . . . . 19

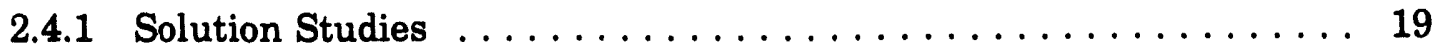

2.4 .2 Solid Feeders . . . . . . . . . . . . . . . . . . . . . 24

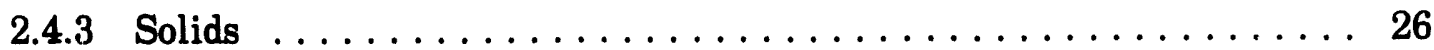

2.4.3.1 The Low Sodium-Releasing Solids . . . . . . . . . . . . . . 32

2.4.3.2 The Moderate Sodium-Releasing Solids . . . . . . . . . . . . . 32

2.4.3.3 The High Sodium-Releasing Solids . . . . . . . . . . . . . . 38

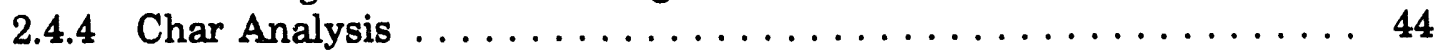

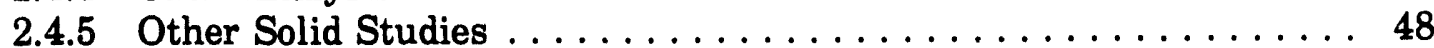

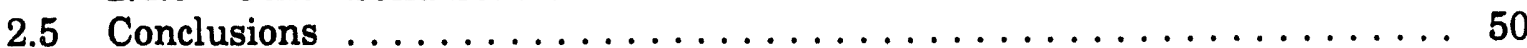

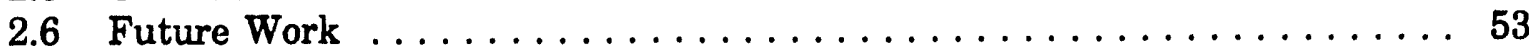

3.0 TASK $3.2 \mathrm{~b}$ : DROP-TUBE FURNACE PROJECT $\ldots \ldots \ldots \ldots \ldots \ldots \ldots$

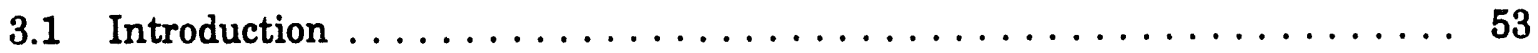

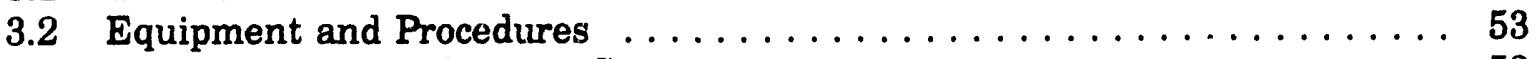

3.2.1 Drop-Tube Furnace System . . . . . . . . . . . . . 53

3.2.2 Characterization of Coal, Char, and Fly Ash ........... 58

3.2.3 Production and Characterization of Chars ............. 60

3.2.4 Production of Fly Ash . . . . . . . . . . . . . . 62

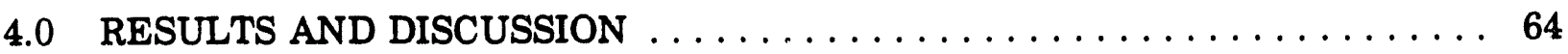

4.1 Characterization of Eagle Butte Coal, Char, and Fly Ash . . . . . . . . 64

4.1.1 Eagle Butte Coal Characterization ................. 64

4.1.2 Eagle Butte Char Characterization . . . . . . . . . . . . 70

4.1.3 Eagle Butte Char and Ash Droplet Morphology . . . . . . . 78

4.1.4 Eagle Butte Fly Ash Characterization . . . . . . . . . . . . . 84

(continued) 
Final Technical Report for the Period

April 1, 1988, through June 30, 1989 (continued)

$\underline{\text { Page }}$

4.2 Characterization of Upper Freeport Coal, Char, and Fly Ash . . . . . . 86

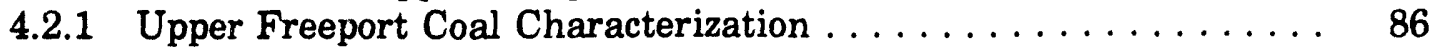

4.2.2 Upper Freeport Char Characterization ............... 89

4.2.3 Upper Freeport Char and Ash Droplet Morphology . . . . . . . . . 89

4.2.4 Upper Freeport Fly Ash Characterization ... . . . . . . . . . . . 101

4.3 Characterization of Robinson Coal, Char, and Fly Ash . . . . . . . . . 101

4.3.1 Robinson Coal Characterization .................. 101

4.3.2 Robinson Coal Char Characterization .................. 105

4.3.3 Discussion of Inorganic Transformation . . . . . . . . . . . . . 108

4.3.4 Kaolinite Transformation ...................... 108

4.3.5 Quartz Transformation ........................ 108

4.3.6 Gypsum Transformation ..................... 113

4.3.7 Formation of New Inorganic Phases . . . . . . . . . . . . 113

4.3.8 Robinson Char and Ash Droplet Morphology . . . . . . . . . . . 115

4.3.9 Characterization of Robinson Fly Ash . . . . . . . . . . . 118

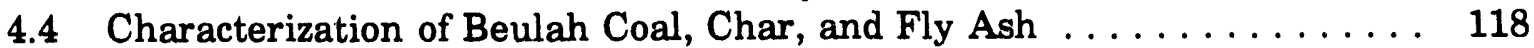

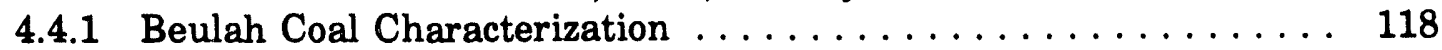

4.4.2 Beulah Char Characterization . . . . . . . . . . . . . . 125

4.4.3 Discussion of Inorganic Transformations . . . . . . . . . . . . 129

4.4.4 Beulah Fly Ash Characterization .................. 131

4.4.5 Surface Analysis of Beulah Multicyclone Fly Ash . . . . . . . . 136

4.5 Characterization of Monticello Coal, Char, and Fly Ash . . . . . . . . 138

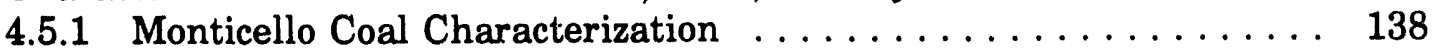

4.5.2 Characterization of Monticello Char . . . . . . . . . . . 146

4.5.3 Characterization of Monticello Fly Ash . . . . . . . . . . . . 148

4.5.4 Discussion of Inorganic Transformations for Monticello . . . . . . 150

4.5.5 Fly Ash Particle-Size Distributions as a Function of Different

Combustion Temperatures and Coal Sizes . . . . . . . . . 150

4.5.6 Fly Ash Classification Scheme . . . . . . . . . . . . . . . 152

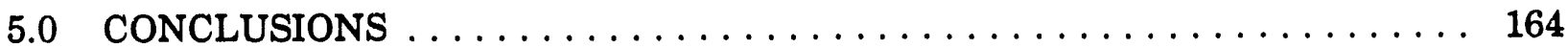

6.0 REFERENCES $\ldots \ldots \ldots \ldots \ldots \ldots \ldots \ldots \ldots \ldots \ldots \ldots \ldots \ldots \ldots$ 
Final Technical Report for the Period July 1, 1989, through June 30, 1990

\section{$\underline{\text { Page }}$}

LIST OF FIGURES $\ldots \ldots \ldots \ldots \ldots \ldots \ldots \ldots \ldots \ldots \ldots \ldots \ldots \ldots$

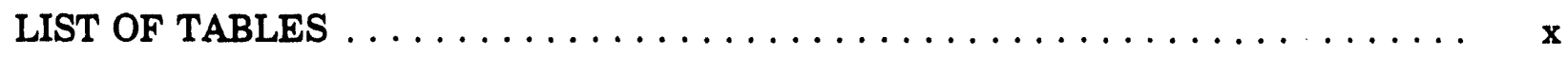

EXECUTIVE SUMMARY $\ldots \ldots \ldots \ldots \ldots \ldots \ldots \ldots \ldots \ldots \ldots \ldots \ldots$

Task 1: Improvement to the CCSEM Methodology .............. 1

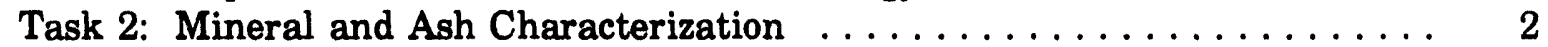

Task 3: Laboratory-Scale Combustion Testing .................. 4

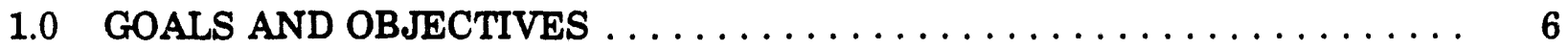

1.1 Task 1: Improvements to the CCSEM Methodology $\ldots \ldots \ldots \ldots \ldots \ldots$

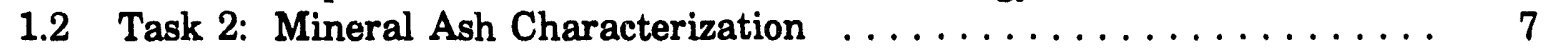

1.3 Task 3: Laboratory-Scale Combustion Testing . . . . . . . . . . . 7

2.0 TASK 1: IMPROVEMENTS TO THE CCSEM METHODOLOGY $\ldots \ldots \ldots .8$

2.1 Description of System $\ldots \ldots \ldots \ldots \ldots \ldots \ldots \ldots \ldots \ldots \ldots \ldots \ldots$

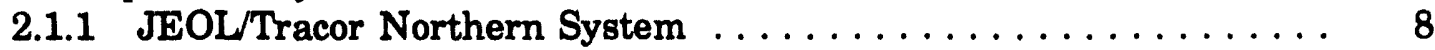

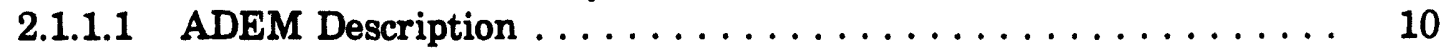

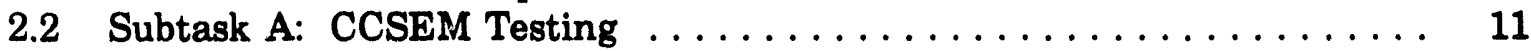

2.2.1 Proposed Changes to Present Analysis . . . . . . . . . . . 17

2.3 Subtask B: CCSEM Automation and Development ............ 18

2.3.1 CCSEM Automation ..................... 18

2.3.2 Relationship of Surface Area to Volume in CCSEM Analysis ... . 19

2.3.3 Graphic Output of CCSEM Analysis ............... 22

2.3.4 Improved Fortran Data Manipulation Program . . . . . . . . . 23

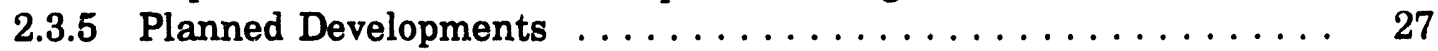

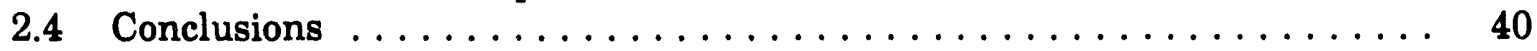

3.0 TASK 2: MINERAL AND ASH CHARACTERIZATION $\ldots \ldots \ldots \ldots \ldots \ldots$

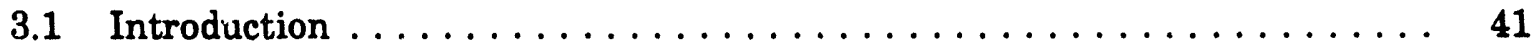

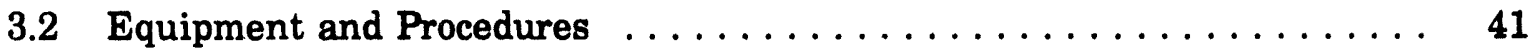

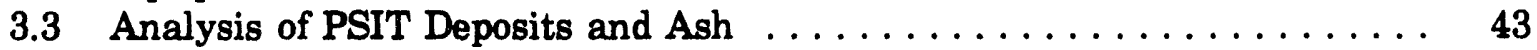

3.4 Characterization of Inorganics in Ash Using Surface Science

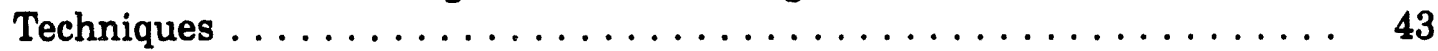

3.4 .1 Conclusions . . . . . . . . . . . . . . . . . . 54

3.5 Inorganic Transformations of Low-Rank Coal Studied in a

3.5.1 Introduction $\ldots \ldots \ldots \ldots \ldots \ldots \ldots \ldots \ldots \ldots \ldots \ldots$

3.5.2 The Down-Fired Combustor System $\ldots \ldots \ldots \ldots \ldots \ldots \ldots$

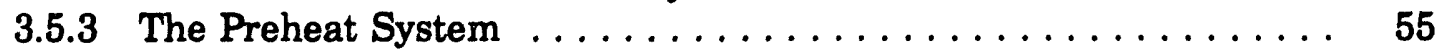

3.5.4 Sampling Equipment and Procedures $\ldots \ldots \ldots \ldots \ldots \ldots \ldots$

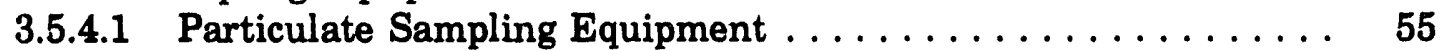

3.5.4.2 Temperature Measurement ................. 58

3.5.4.3 Gas Sampling $\ldots \ldots \ldots \ldots \ldots \ldots \ldots \ldots \ldots$

(continued) 


\section{Final Technical Report for the Period \\ July 1, 1989, through June 30, 1990 (continued)}

$\underline{\text { Page }}$

3.6 Analytical Equipment and Procedures $\ldots \ldots \ldots \ldots \ldots \ldots \ldots \ldots, 59$

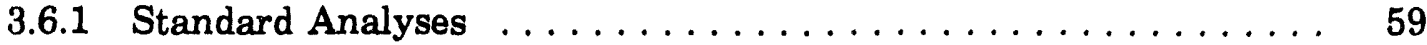

3.6 .2 CCSEM Analysis $\ldots \ldots \ldots \ldots \ldots \ldots \ldots \ldots \ldots \ldots, 60 \ldots \ldots$

3.6.3 TEM Analysis . ........................... 61

3.7 Experimental Measurements $\ldots \ldots \ldots \ldots \ldots \ldots \ldots \ldots \ldots \ldots, 63$

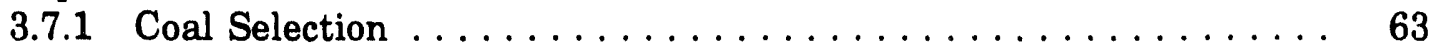

3.7.2 Combustion Test Conditions $\ldots \ldots \ldots \ldots \ldots \ldots \ldots \ldots \ldots 63$

3.7.2.1 Reproducibility of Coal-Firing Conditions $\ldots \ldots \ldots \ldots \ldots, 63$

3.7.2.2 Gas and Particle Temperatures . . . . . . . . . . . . . 65

3.7.2.3 Particle Velocity Determinations $\ldots \ldots \ldots \ldots \ldots \ldots \ldots \ldots 65$

3.7.2.4 Gas Composition Measurements . .............. 68

3.8 Results and Discussion of the Analyses of the Particulate Samples ..... 71

3.8.1 Changes in Aerodynamic Diameter ................ 71

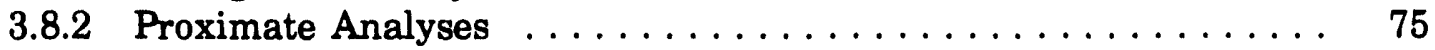

3.8.3 Inorganic Composition of the Coals $\ldots \ldots \ldots \ldots \ldots \ldots \ldots \ldots 79$

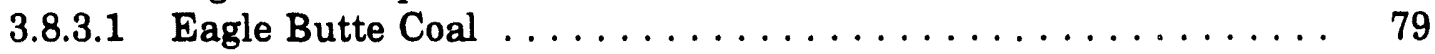

3.8.3.2 Robinson Coal ...................... 85

3.9 Inorganic Composition of the Port 1 Particulate Samples .......... 90

3.9.1 Eagle Butte Port $1 \ldots \ldots \ldots \ldots \ldots \ldots \ldots \ldots \ldots \ldots \ldots \ldots \ldots$

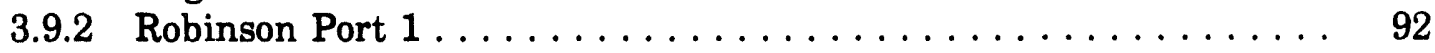

3.10 Inorganic Composition of the Port 2 Particulate Samples .......... 97

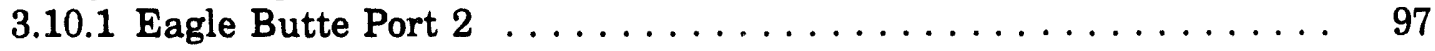

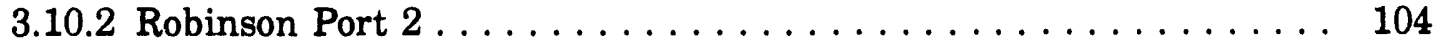

3.11 Inorganic Composition of the Port 10 Particulate Samples ......... 108

3.11.1 Eagle Butte Port $10 \ldots \ldots \ldots \ldots \ldots \ldots \ldots \ldots \ldots \ldots \ldots \ldots$

3.11 .2 Robinson Port $10 \ldots \ldots \ldots \ldots \ldots \ldots \ldots \ldots \ldots \ldots \ldots \ldots$

3.12 Conclusions - Similarities in the Composition and Behavior of

Both Eagle Butte and Robinson Coals ................. 115

3.12.1 Earlier Stages of Combustion - Coal to 0.07 Seconds ......... 115

3.12.2 Later Stages of Combustion - 0.07 to 2.4 Seconds . ......... 116

3.13 Interpretation of Fly Ash Particle-Size and Composition Evolution for

Beulah and Upper Freeport $\ldots \ldots \ldots \ldots \ldots \ldots \ldots \ldots \ldots \ldots, 118$

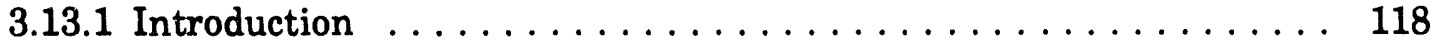

3.13.1.1 Beulah . .............................. 119

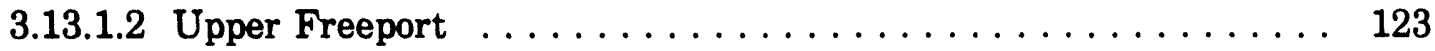

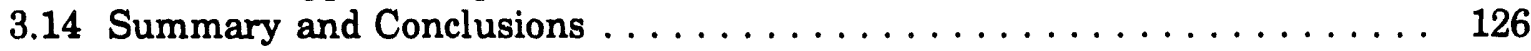

3.14 .1 Conclusions $\ldots \ldots \ldots \ldots \ldots \ldots \ldots \ldots \ldots \ldots \ldots \ldots \ldots \ldots \ldots \ldots$

4.0 TASK 3: LABORATORY-SCALE COMBUSTION TESTING . . . . . . . 131

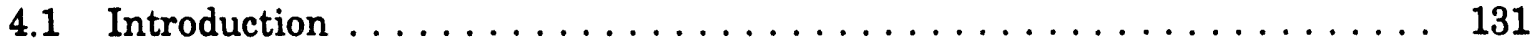

4.2 Equipment and Procedures $\ldots \ldots \ldots \ldots \ldots \ldots \ldots \ldots \ldots \ldots \ldots \ldots \ldots \ldots \ldots$

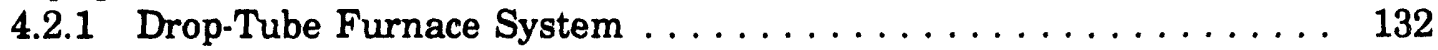


Final Technical Report for the Period

July 1, 1989, through June 30, 1990 (continued)

4.2.2 Preparation and Characterization of Kentucky \#9 and

San Miguel Coal, Char, and Fly Ash . . . . . . . . . . 137

4.3 Char and Fly Ash Production for Kentucky \#9 and San Miguel Coals

and for Synthetic Coal-Model Mixture Studies . . . . . . . . . . . . . 139

4.4 Results and Discussion . . . . . . . . . . . . . . . . . 139

4.4.1 Characterization of Kentucky $\# 9$ Coal . . . . . . . . . . . 139

4.4.2 Characterization of Kentucky \#9 Char and Fly Ash . . . . . . . 150

4.5 Characterization of San Miguel Coal . . . . . . . . . . . . . . 161

4.5.1 Characterization of San Miguel Char and Fly Ash . . . . . . . . 161

4.6 Particle-Size Distribution of Kentucky \#9 and San Miguel Fly Ash . . . . 171

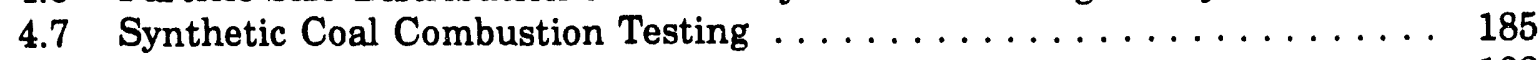

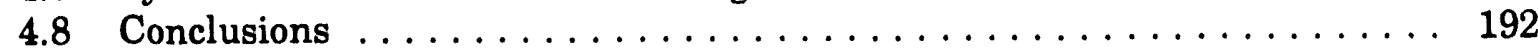

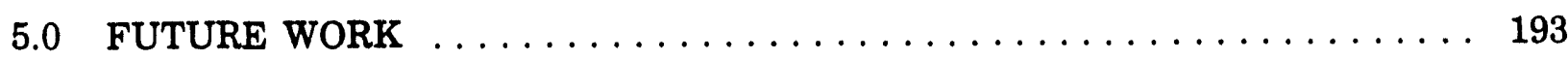

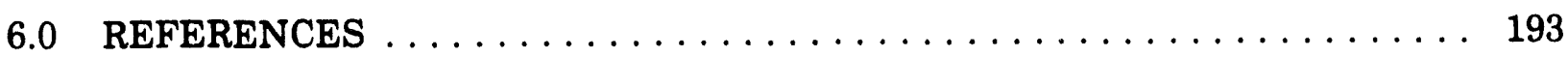


1.0 EXECUTIVE SUMMARY $\ldots \ldots \ldots \ldots \ldots \ldots \ldots \ldots \ldots \ldots \ldots \ldots$

1.1 Task 1: Improvements to the CCSEM Methodology $\ldots \ldots \ldots \ldots \ldots \ldots$

2.0 GOALS AND OBJECTIVES $\ldots \ldots \ldots \ldots \ldots \ldots \ldots \ldots \ldots \ldots \ldots \ldots$

2.1 Task 1: Improvements to the CCSEM Methodology $\ldots \ldots \ldots \ldots \ldots \ldots$

2.2 Task 2: Mineral Ash Characterization ................. 9

2.3 Task 3: Laboratory-Scale Combustion Testing . . . . . . . . . . . . 9

3.0 TASK 1: IMPROVEMENTS TO THE CCSEM METHODOLOGY $\ldots \ldots \ldots \ldots$

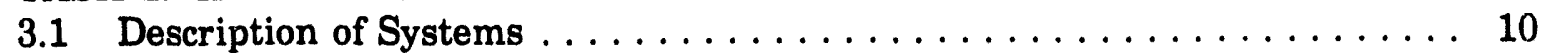

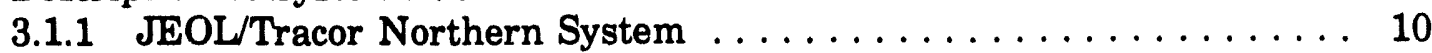

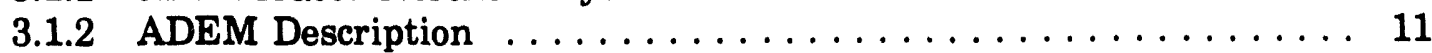

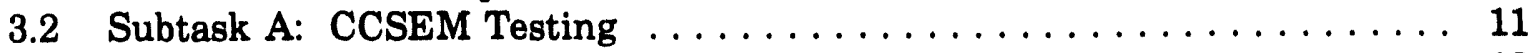

3.2.1 Particle-Size Testing . . . . . . . . . . . . . . . . . 12

3.2.2 Investigation and Improvements to CCSEM Precision . . . . . . . 13

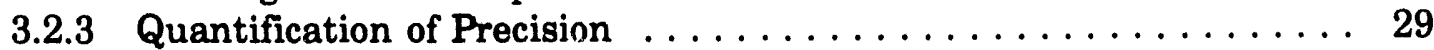

3.2.3.1 Statistical Evaluation of the Current CCSEM Method . . . . . . . 30

3.2.3.2 Experimental Precision Results ................. 32

3.2.4 Graphical Representation of Data . . . . . . . . . . . . . . 40

3.2.5 ZAF Feasibility and Testing $\ldots \ldots \ldots \ldots \ldots \ldots \ldots \ldots \ldots \ldots \ldots$

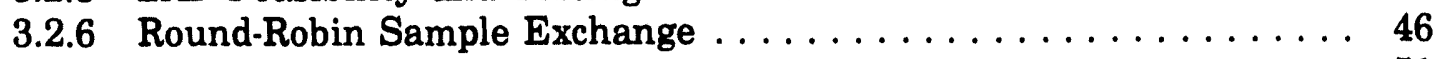

3.2.7 Investigation of CCSEM Accuracy . . . . . . . . . . . 51 
Final Technical Progress Report for the Period

January 1, 1991, through June 30, 1992

Page

LIST OF FIGURES $\ldots \ldots \ldots \ldots \ldots \ldots \ldots \ldots \ldots \ldots \ldots \ldots \ldots \ldots$ iv

LIST OF TABLES $\ldots \ldots \ldots \ldots \ldots \ldots \ldots \ldots \ldots \ldots \ldots \ldots \ldots \ldots \ldots$

1.0 EXECUTIVE SUMMARY $\ldots \ldots \ldots \ldots \ldots \ldots \ldots \ldots \ldots \ldots \ldots \ldots$

1.1 Task 1: Prediction of Fly Ash Particle Size and Composition . . . . . . . 1

1.2 Task 2: Laboratory-Scale Combustion Testing . . . . . . . . . . . . . . . 1

1.3 Task 3: Development of Analytical Methods ................. 3

2.0 GOALS AND OBJECTIVES $\ldots \ldots \ldots \ldots \ldots \ldots \ldots \ldots \ldots \ldots \ldots$

2.1 Task 1: Prediction of Fly Ash Particle Size and Composition . . . . . . 5

2.2 Task 2: Laboratory-Scale Combustion Testing . . . . . . . . . . . 6

2.3 Task 3: Development of Analytical Methods ............... 6

3.0 TASK 1: Prediction of Fly Ash Particle Size and Composition . . . . . . . . 6

3.1 Introduction . . . . . . . . . . . . . . . . . . . . . . . . 6

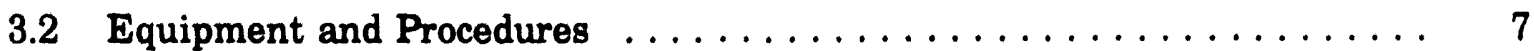

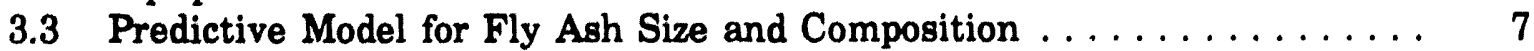

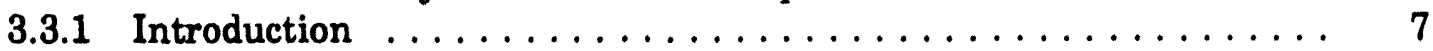

3.3.2 Experimental ...................... 7

3.3.3 Stochastic Model Development and Results ............. 8

3.3.4 Particle Size and Composition Distribution Expert System ..... . 8

3.3.4.1 Introduction . . . . . . . . . . . . . . . . . . . . . . 12

3.3.4.2 ASHPERT Database ....................... 13

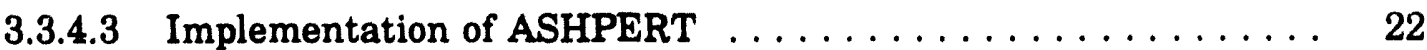

3.3.4.4 Prediction of Composition and Size for Unknown Coal . . . . . . 23

3.3.4.5 Conclusions .......................... 27

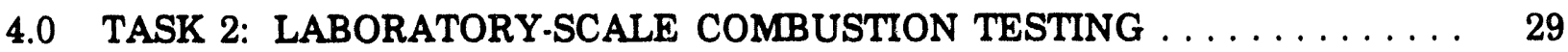

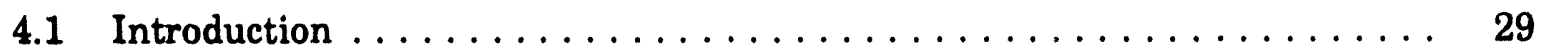

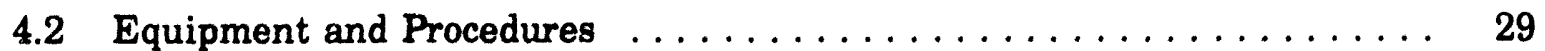

4.2.1 Drop-Tube Furnace System . . . . . . . . . . . . . . . . . 29

4.2.2 Determination of Carbon Conversion $\ldots \ldots \ldots \ldots \ldots \ldots$

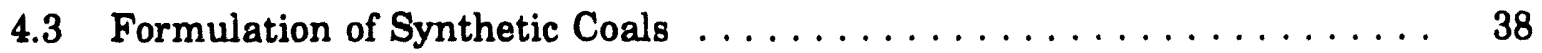

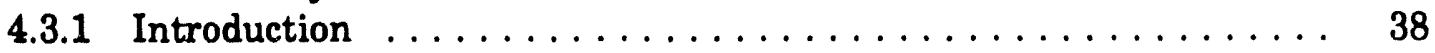

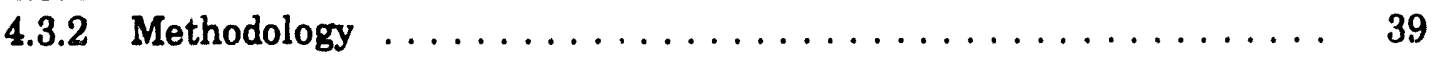

4.3 .3 Results ............................ 40

4.3.3.1 Inorganic Composition of the Synthetic Coals . . . . . . . . 40

4.3.3.2 Results of the Combustion Tests of the Synthetic Coals . . . . . . 40

4.3.4 Mineral Transformations in the Synthetic Coals ........... 41

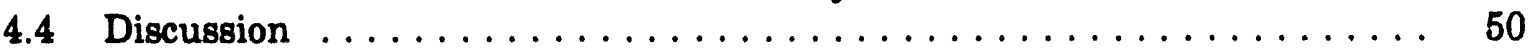

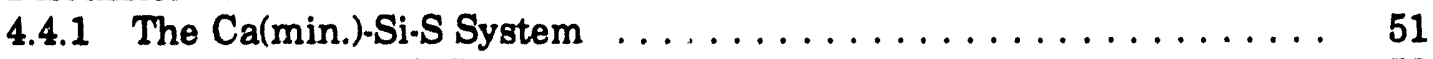

4.4.2 The Ca(org.)-Si-S System $\ldots \ldots \ldots \ldots \ldots \ldots \ldots \ldots \ldots \ldots \ldots$

(continued) 
Final Technical Progress Report for the Period

January 1, 1991, through June 30, 1992 (continued)

$\underline{\text { Page }}$

4.4.3 The $\mathrm{Na(org.)-Si-S} \mathrm{System} \mathrm{\ldots \ldots \ldots \ldots \ldots \ldots \ldots \ldots \ldots . \ldots \ldots} 53$

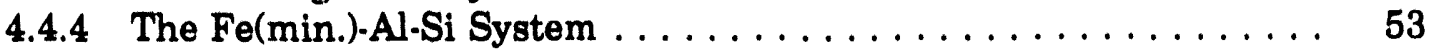

4.5 Combustion Testing of the Eagle Butte/Kentucky $\$ 9$ Blend . . . . . . . . 59

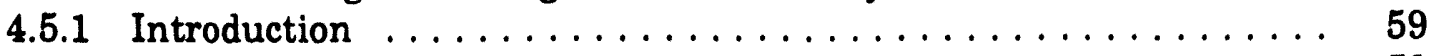

4.5.2 Methods ........................... 59

4.5.2.1 Eagle Butte/Kentucky \#9 Coal Blend Preparation . . . . . . . 59

4.5.2.2 Char and Fly Ash Production for Eagle Butte

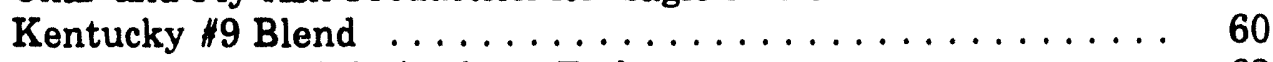

4.5.2.3 Coal, Char, and Ash Analysis Techniques ............ 62

4.5.3 Coal Characterization ..................... 63

4.5.4 Char and Fly Ash Characterization .............. 65

4.5.5 Conclusions ........................ 75

5.0 TASK 3: DEVELOPMENT OF ANALYTICAL METHODS . . . . . . . 77

5.1 Description of JEOL/Tracor Northern System $\ldots \ldots \ldots \ldots \ldots \ldots$

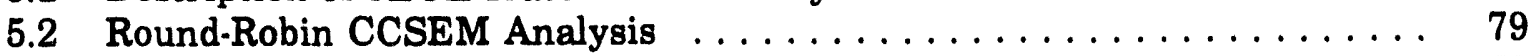

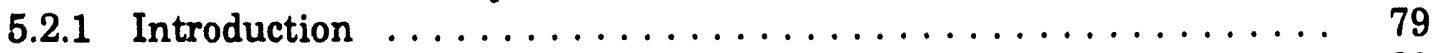

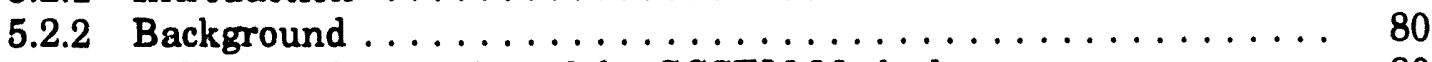

5.2.2.1 General Description of the CCSEM Method . . . . . . . . . . 80

5.2.2.2 Factors Affecting CCSEM Results ............... 80

5.2.3 Objectives and Organization of the CCSEM Round-Robin Study . . 81

5.2.3.1 Introduction . . . . . . . . . . . . . . . . . . 81

5.2.3.2 Contacted Personnel and Laboratories . . . . . . . . . . 83

5.2.3.3 Task 1: CCSEM Round-Robin Testing ................ 84

5.2.3.3.1 Sample Description, Preparation, and Distribution . . . . . . . 84

5.2.3.3.2 Analysis Guidelines . . . . . . . . . . . . . . . . 84

5.2.3.3.3 Analysis Reporting Requirements . . . . . . . . . . . 86

5.2.3.4 Task 2: Evaluation and Investigation of the Round-Robin

Analysis Results .................... 86

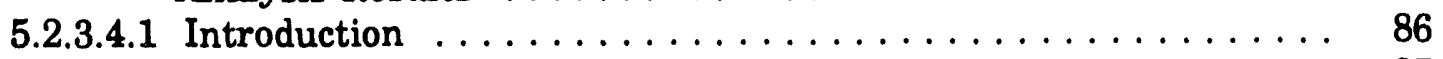

5.2.3.4.2 Standardization of CCSEM Data Reduction . . . . . . . . 87

5.2.3.4.3 Recommended CCSEM Procedure . . . . . . . . . . . . 87

5.2.3.5 Task 3: Reporting of CCSEM Round-Robin Test Study . . . . . . 87

5.2.3.5.1 Information Dissemination $\ldots \ldots \ldots \ldots \ldots \ldots \ldots$

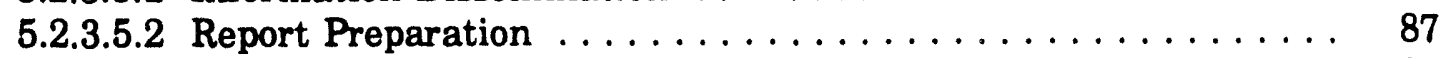

5.2.3.6 Proposed Additional Round-Robin Testing . . . . . . . . . . 87

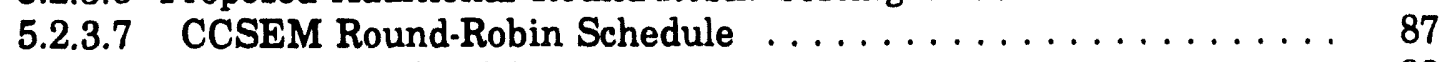

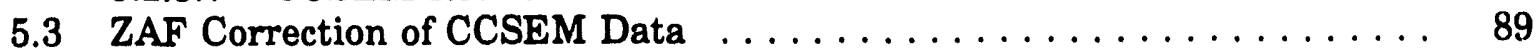

5.4 Particle-by-Particle Scanning Electron Microscopy (PBPSEM) . . . . . . 94

5.4.1 Introduction $\ldots \ldots \ldots \ldots \ldots \ldots \ldots \ldots \ldots \ldots \ldots \ldots \ldots$

5.4.2 Description of the PBPSEM Method ............. 95

5.4.2.1 Sample Preparation and Instrumentation $\ldots \ldots \ldots \ldots \ldots$

(continued) 
Final Technical Progress Report for the Period

January 1, 1991, through June 30, 1992 (continued)

Page

5.4.2.2 Digital Image Acquisition, Processing, and Analysis . . . . . . 95

5.4.2.3 Data Reduction and Reporting ................. 97

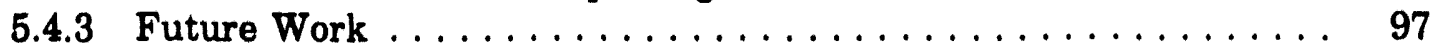

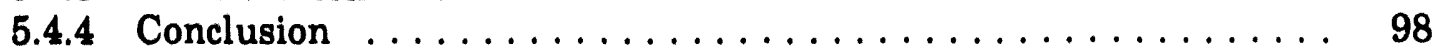

5.5 Mass Balancing of Inorganic Constituents in Coal . . . . . . . . . . . 98

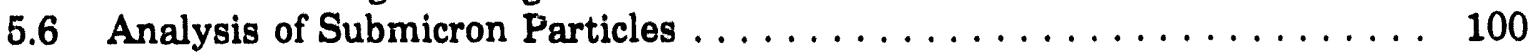

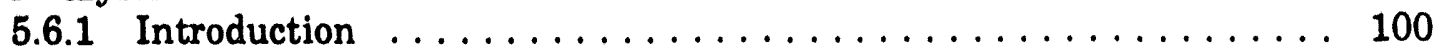

5.6.2 Sample Preparation Method . . . . . . . . . . . . . . . . . . 102

5.6.3 Scanning Electron Microscope Analysis of Submicron

Particles . . . . . . . . . . . . . . . . . . . . . 102

5.6.4 Tests of the SEM-IA Method . . . . . . . . . . . . . . 103

5.6.4.1 Test of Sampling Bias (Eagle Butte) . . . . . . . . . . . . . . 103

5.6.4.2 Comparison of SEM-IA and CCSEM Methods (Eagle Butte) . . . 104

5.6.4.3 Comparison of SEM-IA and CCSEM Methods (Eagle Butte/

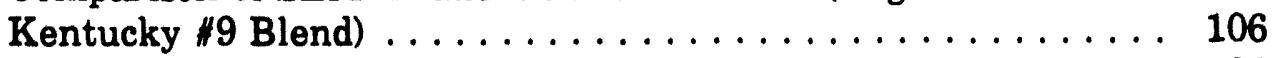

5.6 .5 Conclusions . . . . . . . . . . . . . . . . . . . 106

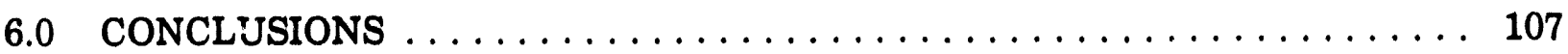

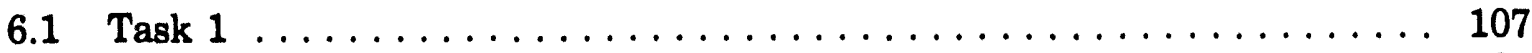

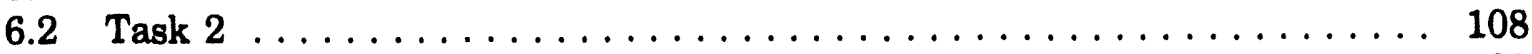

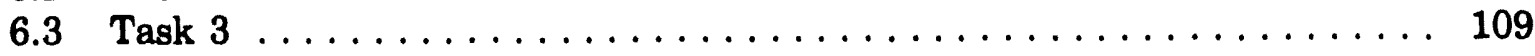

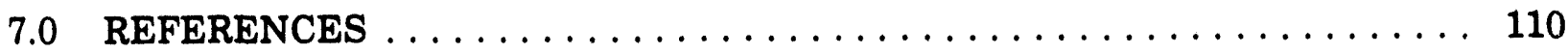

SUMMARY OF ORGANICALLY BOUND CONSTITUENTS IN PARENT COALS

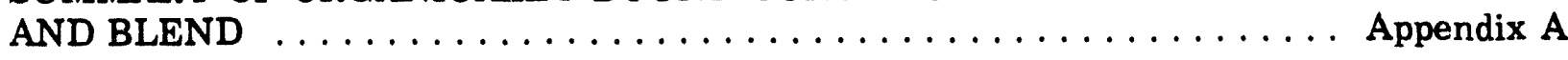




\section{3 (Combined with Section 3.2 in Year 4)}


3.4 Liquefaction Reactivity of Low-Rank Coals 


\title{
LIQUEFACTION REACTIVITY OF LOW-RANK COALS
}

Final Technical Progress Report

for the Period April 1, 1986, through December 31, 1992

\author{
by
}

Edwin S. 01son, Research Supervisor

Energy and Environmental Research Center

Box 8213, University Station

Grand Forks, North Dakota 58202-8213

Task Contracting Officer's Kupresentative: Dr. Udaya S. Rao

for

U.S. Department of Energy

Pittsburgh Energy Technology Center

626 Cochran Mill Road

P.0. Box 10940, MS 922-H

Pittsburgh, Pennsylvania 15236-0940

December 1992

Work Performed under the Cooperative Agreement No. DE-FC.21-86MC10637 
TABLE OF CONTENTS

Page

LIST $0 \mathrm{~F}$ TABLES .....................

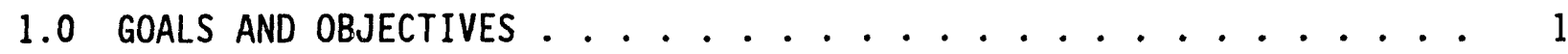

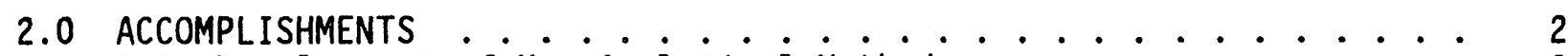

2.1 Development of New Analytical Methods .......... 2

2.1.1 Characterization of Oxygen Functional Groups ...... 2

2.1.2 Development of a New Instrument for Analysis of Depolymerized

Coal Products ................... 4

2.1.3 Accurate Determination of Molecular Weights of Liquefaction Intermediates ................ 5

2.1.4 Hydroaromatic Group Determination ......... 6

2.2 First-Stage Liquefaction ........... . 6

2.2.1 The Nature of the First-Stage Reaction . . . . . . 6

2.2.2 Pretreatment of Low-Rank Coals ........... 8

2.2.3 Catalysts for First-Stage Degelation........ 8

2.3 Catalysts for Coal Depolymerization .......... 13

2.3.1 Solid Supported Acid Catalysts ........... 14

2.3.2 Metal Sulfices on Acidic Layered Supports ....... 15

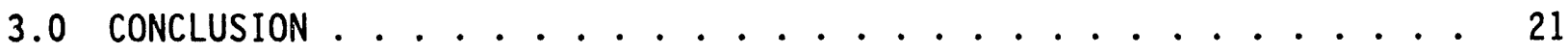

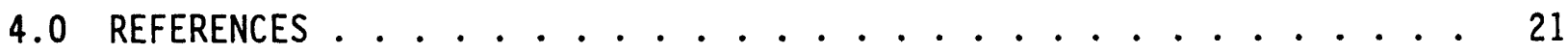

5.0 BIBLIOGRAPHY OF PUBLICATIONS EMANATING FROM THIS PROJECT $\ldots \ldots 22$

6.0 PATENTS EMANATING FROM THIS PROJECT . . . . . . . . . 26

\section{LIST OF TABLES}

Table

1 Catalytic Liquefaction of Coals . . . . . . . . . . 10 


\section{LIQUEFACTION REACTIVITY OF LOW-RANK COALS}

\subsection{GOALS AND OBJECTIVES}

Direct liquefaction of low-rank coals has been investigated at Grand Forks and other laboratories for several decades. Some of the reasons for this interest are the massive reserves of low-rank coals and the low cost of mining these coals. The mine-mouth cost is about 0.3 times that of bituminous coals. Low sulfur and nitrogen contents mean that less hydrogen is required to effectively remove these elements during liquefaction and upgrading to an environmentally acceptable distillate product. The low-rank coals contain more aliphatic material which results in the formation of more paraffins in the product.

There are, however, some inherent problems in low-rank coal liquefaction. The high moisture content may require preliminary drying. The high oxygen content of the low-rank coals increases the amount of hydrogen required during hydrotreating. The oxygen-containing compounds may be factors in retrogressive reactions leading to coking. Solid deposits, such as those that formed during the Wilsonville tests, could severely hinder operation with low-rank coals. High ash content, especially calcium salts, can result in very rapid deactivation of catalysts. The expense of cleaning the coals prior to liquefaction may be prohibitive. Low-rank coals are converted much more slowly to the asphaltene/preasphaltene stage than the bituminous coals.

The objectives of this project were to investigate the liquefaction reactions of low-rank coals and intermediate products formed during liquefactions and develop a scientific database so that problems of slow solubilization, retrogressive reactions, and catalyst deactivation can be evaluated and solved. Methods for deashing were developed based on a two-step process, so that soluble material is produced in high conversion in a first stage (with $\mathrm{CO}$ as an effective reducing gas), and the deashed soluble material is catalytically depolymerized and hydrotreated in a second stage so that catalyst deactivation is minimized and hydrogen is not wasted on carbon dioxide reduction. Novel catalysts for both the first-stage solubilization stage and the second-stage hydrocracking/hydrogenation processing were developed. These investigations required the development of new methods for analys is of polar, very high molecular weight, first-stage intermediates and the highly complex heteroatom-containing distillate compositions, as well as the initial coals.

The first-stage reaction in carbon monoxide converts coal to a soluble form with minimal cracking and hydrogenation. This processing can be accomplished without any catalyst or promoter other than the coal mineral matter present, but addition of hydrogen sulfide was found in earlier projects to promote the solubilization. A disadvantage of this method was that a substantial amount of sulfur was incorporated into the first-stage product. Removal of this sulfur consumed hydrogen in the second-stage hydrotreating. Objectives of this project were to understand how the carbon monoxide functions during the first-stage reaction of low-rank coals and what catalysts can be added to increase rates and conversions. 
The efficient production of environmentally acceptable distillate fuels requires catalysts for hydrogenation and cleavage (depolymerization) of the coal macromolecules during the second-stage reaction and removal of oxygen, nitrogen, and sulfur heteroatoms. The chemistry of this processing can be examined more cleanly using the solubilized coal intermediates from the first stage. The catalysts currently used in direct coal liquefaction are the same as those used in conventional petroleum refining; however, this application has not been very successful. Improvements in efficiency could be obtained if catalysts with longer life and better activity and selectivity were available. Rapid deactivation of the conventional $\mathrm{Co}-\mathrm{Mo}_{\mathrm{O}}$ and $\mathrm{Ni}-\mathrm{Mo}$ catalysts on an alumina support have been attributed to coke formation (1), metals deposition (2), and inhibition of the active center by chemisorbed compounds (3). Objectives of this research project are to develop and test novel heterogeneous catalysts for hydrotreatment upgrading of first-stage coal liquefaction products. The new hydrogenation catalysts are based on pillared clays and hydrotalcites, which have very large micropore dimensions to accommodate the coal macromolecules, but yet do not possess strong acidities which lead to coking at high temperatures. Another objective is to develop a solid acid catalyst for depolymerization of coal macromolecules. The acid catalys is process for coal liquefaction is believed to operate by ionic mechanisms. Some molten acids have successfully depolymerized coal, but the poor efficiencies of catalyst recovery and the corrosive nature of the catalyst made the process uneconomical.

\subsection{ACCOMPLISHMENTS}

\subsection{Development of New Analytical Methods}

\subsubsection{Characterization of Oxygen Functional Groups}

Oxygen functional groups are present in large amounts in low-rank coals and even in the first-stage 1iquefaction products. These moieties are believed to be important to both coal structure and coal reactivity. Information on the loss of the oxygen as water, phenolics, or carbon dioxide or the transformation to other groups is important obtain if we are to understand the reactivity of low-rank coals. Accurate determinations of oxygen functional groups is therefore essential. Progress was made in the methods for determination of carboxylic acid groups, and the basis for a new hydroxyl determination has been established.

Accurate methods for the quantitation of carboxylic acid groups is very important, since the number of these is large and changes considerably during coal processing above $300^{\circ} \mathrm{C}$. The new method is a modification of the barium ion-exchange method but uses high-speed blending which allows for a rapid and reliable determination. The blending method gave results similar to those obtained with the Schafer barium exchange method.

The quantitative analys is of hydroxyl groups in coals and coal liquefaction products has been studied by esterification methods. It is extremely important to have accurate determinations of hydroxyl groups since these are the major oxygen functional group present, and any large errors in the hydroxyl content value will thus significantly affect the values obtained for other oxygen functional groups, especially ethers, which have been determined by 
difference between total oxygen and oxygen in hydroxy, carboxy, and other carbonyl groups. The acetylation of coals with acetic anhydride using dimethylaminopyridine was shown to proceed to completion. Similarly, the hydrolysis of the acetate derivative also proceeded to completion, and the liberated acetic acid was reliably determined without interference by an isotope dilution/gas chromatography/mass spectroscopy (GC/MS) method. However, considerable variance was obtained in the determination of hydroxyl groups using this method. The acetylation method of Given, where the acetylation, hydrolysis of excess acetic anhydride, and the titration are done in one pot, was shown to produce substantial errors because of the hydrolysis of the acetate esters in the coal in the pyridine water mixture. This method is still being used elsewhere, but the results are far from the true values.

A novel method was developed for the determination of hydroxyl groups in coals. The new method involves preparation of the acety $1-1-{ }^{13} \mathrm{C}$ derivative, equilibrium exchange with a known quantity of acety $1-2-{ }^{13} \mathrm{C}$ chloride, and determination of the exchange ratio (acetyl-1- ${ }^{13} \mathrm{C} /$ acety $1-2-{ }^{13} \mathrm{C}$ ) in the coal derivative by solid-state cross polarization/magic angle spinning ${ }^{13} \mathrm{C}$ nuclear magnetic resonance (NMR), and in the recovered reagent by GC/Fourier transform infrared (FTIR) of the dimethyltert-butylsilyl acetate esters. The acetyl concentration, and hence the hydroxyl content, was calculated from the determined exchange ratio and the known amount of acetyl-2- ${ }^{13} \mathrm{C}$ chloride used in the exchange. The NMR was calibrated using integrated intensities from spectra of derivatized coal samples prepared with known mixtures of $\mathrm{C}-1$ - and $\mathrm{C}-2$ labeled acetyl. These were simple two-peak spectra uncomplicated by the natural abundance coal peaks. The GC/FTIR was similarly calibrated using silyl esters from known mixtures of 1 abeled acetyl chloride. Correspondence of the values from the NMR and the GC/FTIR determinations provided a test of the completeness of the exchange. The hydroxyl value for a Beulah lignite was determined to be $8.00 \mathrm{mmol} / \mathrm{g}$ (maf) by the NMR and 7.80 by the GC/FTIR. The closeness of these values ( $2 \%$ difference) indicates that the exchange was complete.

A new method was developed for moisture determinations in coals. It is extremely important to have accurate moisture content data in order to be able to accurately track the oxygen groups and hydrogen in coals during processing. Such data may not be provided by the ASTM drying weight loss method. An isotopic dilution method was tested, where a known amount of ${ }^{18} 0$-enriched water was added to the coal, the water was allowed to equilibrate at $100^{\circ} \mathrm{C}$, and the isotope dilution ratio was determined by reaction with trimethyl orthobenzoate to give methyl benzoate with the water oxygen appearing in the carbonyl oxygen. GC/FTIR/MS analysis gave the isotopic ratio from the ratio of the integrated intensities of the carbonyl stretching frequencies in the infrared spectra of the labeled and natural ester and the $(M-31)^{+}$ions in the mass spectra of the labeled and natural esters over the eluted peaks. A linear calibration was used for the mass spectral determination and a nonlinear calibration with polynomial fitting was used for the infrared determination, since there was a small amount of overlap between the carbonyl bands of analyte and standard water. The method gave very low errors with water with known concentrations of labeled oxygen. With an Argonne premium sample of Illinois \#6, a moisture content of $12.2 \%$ was obtained by the infrared method and $12.4 \%$ by the mass spectral method. Low-rank coals gave values a few percent higher than the ASTM fast-drying method. 


\subsubsection{Development of a New Instrument for Analysis of Depolymerized Coal Products}

The analysis of liquefaction products containing oxygen functional groups was significantly advanced by the development of combined instrumental techniques which separated components of complex mixtures by GC and obtained infrared and mass spectra of the eluting components. A serial GC/FTIR/MS system has been developed using an ion trap detector or mass analyzer which is interfaced to the light pipe in the FTIR spectrometer. A modification of the manufacturer-supplied open-split interface to the ion trap was required to obtain chromatographic results free of discrimination and activation effects. The flow rate of the helium makeup gas in the light pipe was used to control the amount of material which enters the ion trap. Hydrogen carrier gas was used for the chromatographic separations with no adverse effects on the mass spectra obtained.

The quantitative analysis of polar carboxylic acids has been advanced by the use of isotopic dilution with standards enriched in deuterium and oxygen-18, followed by GC/MS with an ion trap MS. Reliable and accurate analyses were performed on a series of aliphatic and aromatic polycarboxylic acids found in coal oxidation products. The GC/FTIR/MS system was used in investigations of various oxygen-containing fractions from liquefaction tests. It was very effective in characterizing different phenolic-type compounds and in distinguishing dibenzofurans from aryl and alkyl ethers.

Analytical methods for oxygen compound identification were further developed. A new method for ionization in an ion trap MS was devised. The mass spectrometer in our GC/FTIR/MS system has been modified with an automatic gain control so that the amount of ions being analyzed is controlled. This allows a greater dynamic range, more sensitivity, and the ability to vary the storage time (cool time) of the ions. Thus spectra which closely resemble the library electron impact (EI) spectra obtained with sector or quadrupole instruments can be obtained with short cool times, or useful spectra which result from self-chemical ionization can be obtained with long cool times. modified instrument has been useful in the identification of esters of the The oxidation products from low-rank coals and in the identification of polar oxygen-containing components of liquefaction products, such as ketones, alcohols, lactones, phenols, ethers, and quinones.

Significant improvements were made in the technique for quantitative analysis by isotope dilution GC/TIR spectroscopy. These improvements in the analysis of carboxylic acids found in the products of low-rank coal processing and oxidation resulted in a better statistical basis for the method. In the calibration curves now being used, integrated intensity ratios from the absorbance-reconstructed chromatograms are plotted versus the more precisely measured weight ratios. The method was more accurate than a GC/MS method developed with the same standards, analytes, and range of concentrations.

The addition of a helium afterglow discharge detector (HeAD) to the existing GC/FTIR/MS system resulted in a powerful analytical technique, which can provide high-confidence identification and quantitation of essentially any organic component. Coupling the four instruments plus a flame ionization detector required the development of a multiple open split interface. The HeAD instrument generates an afterglow plasma by radio-frequency irradiation of 
helium, which then excites and decomposes the analyte molecules. Atomic emission lines for carbon, sulfur, and phosphorus in the far ultraviolet are measured with an enhanced-sensitivity photodiode array, and hydrogen, chlorine, oxygen, and nitrogen are detected with a near-infrared-sensitive diode array. Sensitivities for the latter two elements are not yet satisfactory. The HeAD has been used in conjunction with the other instruments for qualitative analys is of liquefaction products. The interfacing was perfected for the novel coupled GC/FTIR/MS/atomic emission detection (AED)/flame ionization detection (FID) system and recently patented.

\subsubsection{Accurate Determination of Molecular Weights of Liquefaction Intermediates}

A more accurate method was developed for determining molecular weight distributions by gel-phase chromatography coupled with low-angle laser 1ight scattering (LALLS) and differential refractive index (DRI) detection. In this method, the second virial coefficients were determined in each of 100 equal time increments across the entire distribution of macromolecules eluting from the gel-phase column. Concentration and Rayleigh scattering factor data sets were obtained at each increment in successive analyses at four different concentrations of the analyte. Thus the molecular weights for each increment were determined from the increment data sets, rather than from one concentration and Rayleigh factor and a second virial coefficient for the whole sample $\left(A_{2}\right)$, which was determined by static LALLS. The method was tested with polystyrene standards and applied to supercritical methanol extracts from coals. Weight average molecular weights obtained from the molecular weight distribution of the coal extracts were close to those obtained by static LALLS, whereas the gel permeation chromatography (GPC)/LALLS values for a single concentration of sample were significantly lower than the static LALLS value. The distribution of the incremental virial coefficients $\left(A_{21}\right)$ showed the expected inverse exponential relationship with molecular weights in the case of polystyrene, but the relationship was more complex for coal macromolecules.

A second advance in the determination of accurate molecular weights of coal macromolecules was the finding that light is scattered highly anisotropically from all coal macromolecules in THF solution, in contrast with most synthetic polymers, and that the scattering factors determined for molecular weight determinations must be corrected for this anisotropic scattering in order to obtain acceptable results. The degree of anisotropy is directly related to the rank of the coal.

Several experiments were conducted to elucidate the discrepancy between molecular weight determinations by light scattering and size exclusion chromatography (SEC). These investigations used the model coal polymer poly(2,6-dimethylnaphthaleno-1,4-dioxybenzene). The polymer was heated in tetralin to convert most of it to a soluble form. The hexane-insoluble product was shown to have a high molecular weight by light scattering and a very low molecular weight by SEC (less than 1000 daltons). The latter result was then proved to be erroneous by attempted GC in a 2-m column under high-flow conditions with on-column injection, which showed that none of the material was volatile and could not have molecular weights in the 300- to 800-dalton range. The polymer liquefaction product possessed high depolarization ratios, high $\mathrm{dn} / \mathrm{dc}$ values, and high Rayleigh scattering factors similar to the nonvolatile, coal-derived liquefaction products. 


\subsubsection{Hydroaromatic Group Determination}

The method for determination of hydroaromatic groups in coals and coal liquids was further developed. This method involves dehydrogenation with dichlorodicyanobenzoquinone (DDQ), followed by ruthenium oxide oxidation and quantitative determination of the resulting aliphatic polycarboxylic acids. A new, highly accurate, quantitation method for the acid products that utilizes GC/FTIR was reported.

\subsection{First-Stage Liquefaction}

\subsubsection{The Nature of the First-Stage Reaction}

As discussed above in the objectives section, severe difficulties have been encountered in low-rank coal liquefaction that may be related to the high concentration of calcium and other possible inorganics in these coals. Rather than cleaning the coals, this project used an approach where the coal is converted to soluble form in a first-stage reaction, and most of the inorganic matter of the coals can then be easily separated as an insoluble residue along with a small amount of insoluble organic material. The solvent or vehicle for the initial reaction could be almost any stable liquid. Organic solvents such as aromatics, hydrogenated aromatics, recycled products, petroleum resids, alcohol, and water have all been investigated in this and other liquefaction projects.

Conditions for optimum production of soluble first-stage intermediateliquefaction products from three low-rank coals, Texas (Big Brown) lignite, North Dakota (Beulah) lignite, and Wyodak subbituminous, were obtained by running a matrix of temperature/solvent/moisture conditions. Products obtained after removal of solvent were extensively characterized with respect to oxygen functional groups, molecular weights, hydroaromatic groups, etc.

Initial work in this project determined that a hydroaromatic solvent such as tetralin gave superior conversions to THF-soluble products. Current liquefaction processes generally utilize a hydrogenated recycle solvent containing hydroaromatics that could serve as hydrogen donors. The tetralin used in the experiments above was intended to model this behavior. Reactions carried out in water and in tetralin/water mixtures gave good conversions at. higher pressures when carbon monoxide was used as the reducing gas. Later studies in first-stage catalysis used these aqueous conditions.

Carbon monoxide was successfully used as the reducing gas in these tests. Hydrogen was not effective as the reducing gas unless a transition metal or metal sulfide was used in the first stage, but we wished to avoid adding this type of catalyst because of its rapid deactivation by the coal mineral matter. Thus the majority of the studies in this project utilized carbon monoxide as the reducing agent. Initial studies demonstrated that addition of hydrogen sulfide to the CO gave $5 \%$ to $10 \%$ higher conversions of low-rank coals to THFsoluble products. Some of this sulfur was incorporated into the first-stage product, however. This sulfur could be removed in the second-stage hydrotreating (at the cost of hydrogen). Because of the better product quality, all the reactions carried out in this project with carbon monoxide in organic solvents used hydrogen sulfide as the promoter. 
The effects of reaction temperature were determined for the coals. Reactions at $325^{\circ}$ and $360^{\circ} \mathrm{C}$ gave poor conversions to THF solubles $(<60 \%)$, whereas reactions at $385^{\circ}$ and $400^{\circ} \mathrm{C}$ gave high conversions (>90\%) to THF-soluble materials. Minor portions of the products were soluble in hexane or dichloromethane. After removal of the solvent, very little of the product was distillable.

Molecular weights were determined for several of the reaction products. The dark colored materials required dilution of the sample to concentrations lower than usual, but since the molecular weights were very large, scattering was still easily observable. The weight average molecular weight of the THF solubles obtained from reactions at $363^{\circ} \mathrm{C}$ was $1.3-\mathrm{million}$ daltons. Products produced at higher temperatures were an order of magnitude lower in molecular weight.

The high molecular weights observed for the first-stage products were indicative that the initial solubilization stage is highly successful in breaking down the cross-1inks between the coal macromolecules. Part of this may be due to the fact that the products obtained at $>360^{\circ} \mathrm{C}$ are completely decarboxylated and partially dehydrated, thus ionic and hydrogen bonding are significantly lowered and the macromolecules are considerably less polar. Reduction of ketones and aromatic groups also occurs (see discussion below), which will reduce the polarity. It is doubtful that much hydrocracking of the $C-C$ bonds occurred; however, cleavage of aryl-benzyl ether bonds is very likely. Evidence presented below suggests that cleavage of some diaryl ether bonds may also occur in the presence of a suitable catalyst. Since the changes to the coal structure are significant in the first-stage reactions, a term for the process that is more representative than "solubilization" is needed. Thus the term "degelation" is used to indicate loss of the gel structure in the lowrank coal during the first-stage reaction.

A set of reactions was conducted with the Big Brown lignite in tetralin to determine the effect of moisture content on the reaction. Reactions were carried out with as-received, $15 \%$ moisture, and $<5 \%$ moisture feed coal. The coals were dried by distilling water from the slurry after addition of the solvent. The $15 \%$ moisture coal gave the highest conversion to THF solubles. A11 subsequent first-stage reactions were conducted at this moisture level.

Aqueous liquefaction reactions that utilize carbon monoxide as the reductant gas have been extensively investigated in this and other laboratories over many years (4-6). Basic catalysts have been employed to achieve higher conversions. The $\mathrm{CO} /$ water reduction was shown to be superior to hydrogen/water for the first stage of liquefaction. The CO/water first-stage reactions were performed mainly in the presence of homogeneous catalysts (see discussion below) or other added reductants, such as formate.

An interesting facet of these investigations was the discovery of unusual and unexplored products from liquefaction of low-rank coals in aqueous media. Products consisted of numerous lactones and ketones, in addition to phenolics. These products can help elucidate coal structure and formation. This work was reported in ACS Div. of Fuel Chem., Preprints 1989, 34, 832-838.

A study of acid-catalyzed reactions of low-rank coal in phenol solvent was completed. Results indicated initial dispersion followed by slight 
repolymerization, then slight depolymerization. Three coals gave similar products with high molecular weights (over 1 million). This work was reported in ACS Div. of Fuel Chem., Preprints 1989, 34, 597-600.

A flow-reactor was constructed to investigate reactions of coals in aqueous and alcohol systems containing various other oxygen-containing components (phenols, isopropanol, formaldehyde, formate) at temperatures up to $400^{\circ} \mathrm{C}$. Interfacing of the reactor effluent stream (under pressure) with an ultraviolet spectrometer was accomplished so that on-line measurements of rates of formation of soluble coal products could be obtained.

\subsubsection{Pretreatment of Low-Rank Coals}

The effects of pretreating the coals for the purpose of breaking apart the gel structure prior to heating were al so investigated. If the coal could be easily converted from the gel to a sol (colloidal solid dispersed in a liquid), the mass transfer limitations of reductants accessing the coal molecules will be minimized and the removal of reactive portions cleaved off the coal molecules will be more easily accomplished without reverse reactions occurring. High-shear/high-flow methods were developed for conversion of low-rank coals to hydrosols in high yields. Coals were blended in base in inert atmospheres to give the humate sols. Liquefaction experiments with the blended colloidal coal materials gave exactly the same conversions as the raw coals under similar conditions. Thus no advantage appears to result from this type of pretreatment for liquefaction. When oxidized coals were used or when air was admitted during the blending, high yields of humates with a much greater distribution of molecular weights were obtained, but these more soluble materials contained more oxygen than desired for the coal feeds. Other uses of the blended humates are currently being explored.

\subsubsection{Catalysts for First-Stage Degelation}

Catalysis of the first stage of coal liquefaction involves improving the rates of bond-cleavage reactions leading to breakdown of the gel structure of the coal (degelation) and of preliminary reduction reactions so that oils and asphaltene are produced without extensive retrogressive reactions. The catalysts should be able to effectively interact with the solid and colloidal coal matter, catalyzing the conversion to soluble oils at moderate temperature and pressure, while minimizing problems due to low surface areas or mass transfer. Thus the catalysts currently being investigated are basically homogeneous catalysts for preliminary reduction and other reactions that lead to solubilization. Thus various inorganic agents that are soluble in the reaction vehicle or solvent were investigated. Some of these (eg. sodium aluminate) are polymeric at the reaction conditions and are precursors for the clays and zeolites that are currently under investigation as second-stage liquefaction catalysts.

Coal liquefaction has been effectively carried out in a number of laboratories with carbon monoxide reductant in a water solvent (CO steam process). Australian workers demonstrated that sodium aluminate is able to catalyze the conversion of Australian coals in the Co/water system and in water/hydrogen donor solvent mixtures $(7,8)$. This project has focused on demonstrating an economical process for i iquefaction of Wyodak subbituminous coal, and aqueous sodium aluminate has been utilized as the catalyst. The 
conversion of Wyodak subbituminous coal to THF solubles in the aqueous/CO liquefaction with sodium aluminate was $89 \%$. This was substantially higher than that obtained with no added sodium aluminate. This high conversion was comparable with those obtained with hydrogen-donor solvents and hydrogen sulfide. Reactions utilizing hydrogen as the reductant gave low conversions with sodium aluminate.

The composition of the distillate, oil, and asphaltene product obtained after first-stage liquefaction of Wyodak coal in aqueous $\mathrm{CO}$ was determined for comparison with that obtained previously in organic solvents with CO or with hydrogen. As shown in Table 1, the toluene solubles amounted to $20 \%$ of the maf coal, and $42 \%$ of the coal was converted pentane solubles, $\mathrm{CO}_{2}$, and $\mathrm{H}_{2} \mathrm{O}$. The asphaltene and oil fractions are suitable for second-stage catalytic hydrogenation.

A large portion of the product could be distilled. The major products in the distillate were oxygenated compounds, such as methanol, 2-propanol (from acetone), and phenolics. In addition, there were hundreds of typical coalderived hydrocarbon components present in small amounts. These studies indicated that the volatile first-stage product from aqueous liquefaction contained large amounts of phenolics rather than hydrocarbons. This result offers the possibility, in coal processing, of removing the distillate and using it elsewhere, so that hydrogen needed for liquefaction is not wasted in deoxygenation of phenols.

The use of a mixed-solvent system for the $\mathrm{CO}$ reduction was investigated. A solvent composed of water and tetral in gave somewhat lower conversion with the Wyodak coal, but the pressure was lowered by a large factor. Hydrogen was donated to the coal from the tetralin, as well as from the water. Substituting an aromatic solvent or an alcohol solvent for the hydroaromatic tetralin gave lower conversions. CO/water reductions of $B 1$ ind Canyon bituminous coal in both water and water/tetralin mixture were also successful, but less so than the reactions of the Wyodak coal.

A nonhydrogenated solvent could be used if it gave equivalent conversions and product quality in the $\mathrm{CO} / \mathrm{mixed}$ water-organic solvent liquefaction. In order to determine the effects of the type of organic solvent on yields and product quality in mixed water-organic solvent liquefaction, the reactions of Wyodak coal were carried out in mixed solvents composed of water plus 1-methylnaphthalene and water plus ethanol, under reaction conditions similar to the water/tetralin reaction described above. Sodium aluminate-catalyzed liquefaction of Wyodak coal in water/1-methylnaphthalene and water/ethanol solvent systems gave $71 \%$ and $75 \%$ conversions, respectively. Compared with the water/tetralin system, water/1-methylnaphthalene and water/ethanol gave lower conversions. The reduced yields obtained with the aromatic and alcohol solvents mean that better results will probably be obtained in a process that uses a hydrogenated recycle solvent, as in the current Wilsonville art. It should also be pointed out that in the water/tetralin system, some of the tetral in was converted to naphthalene (see discussion below); thus the tetralin played some role in donating hydrogens to the first-stage liquefaction product. 
TABLE 1

Catalytic Liquefaction of Coals

\begin{tabular}{|c|c|c|c|c|c|c|}
\hline \multicolumn{7}{|c|}{$\begin{array}{l}\text { Reaction Temp. }=400^{\circ} \mathrm{C} \text {, Reaction Time }=30 \text { min } \\
\text { Reductant gas }(\mathrm{CO})=1000 \text { psi (at room temp.) }\end{array}$} \\
\hline $\begin{array}{l}\text { Catalyst } \\
(\mathrm{mmol} / \mathrm{g} \\
\text { coal) } \\
\end{array}$ & $\begin{array}{l}\text { Coal (as- } \\
\text { received, } \\
\text { g) }\end{array}$ & $\begin{array}{l}\text { Solvent (s) } \\
(\mathrm{g})\end{array}$ & $\begin{array}{c}\text { Conv. } \\
(\%)\end{array}$ & Tol-S & $\begin{array}{r}\text { Products } \\
\text { THF-S } \\
\end{array}$ & ${ }^{(\%)}$ Peni-S \\
\hline $\begin{array}{l}\mathrm{NaAlO}_{2} \\
(0.5)^{2}\end{array}$ & $\begin{array}{l}\text { Wyodak } \\
(5.0)\end{array}$ & Water $(20.0)$ & 89 & 20 & 27 & 42 \\
\hline $\begin{array}{l}\mathrm{NaAlO}_{2} \\
(0.5)^{2}\end{array}$ & $\begin{array}{l}\text { Wyodak } \\
(5.0)\end{array}$ & $\begin{array}{l}\text { Tetral in (5.2) } \\
\text { Water }(3.5)\end{array}$ & 79 & 19 & 30 & 30 \\
\hline $\begin{array}{l}\mathrm{NaAlO}_{2} \\
(0.5)\end{array}$ & $\begin{array}{l}\text { Wyodak } \\
(5.0)\end{array}$ & $\begin{array}{l}\text { 1-MeNaph }(5.0) \\
\text { Water }(3.5)\end{array}$ & 71 & 11 & 27 & 33 \\
\hline $\begin{array}{l}\mathrm{NaAlO}_{2} \\
(0.5)^{2}\end{array}$ & $\begin{array}{l}\text { Wyodak } \\
(5.0)\end{array}$ & $\begin{array}{l}\text { Ethanol }(5.1) \\
\text { Water }(3.5)\end{array}$ & 75 & 14 & 28 & 33 \\
\hline $\begin{array}{l}\mathrm{NaVO}_{3} \\
(0.5)^{2}\end{array}$ & $\begin{array}{l}\text { Wyodak } \\
(5.0)\end{array}$ & $\begin{array}{l}\text { Tetral in }(5.0) \\
\text { Water }(3.5)\end{array}$ & 72 & 14 & 30 & 27 \\
\hline $\begin{array}{l}\mathrm{NaAlO}_{2} \\
(0.5)\end{array}$ & $\begin{array}{l}\text { Blind } \\
\text { Canyon } \\
(5.3)\end{array}$ & Water (20.0) & 47 & 5 & 30 & 12 \\
\hline $\begin{array}{l}\mathrm{NaAlO}_{2} \\
(0.5)\end{array}$ & $\begin{array}{l}\text { B1 ind } \\
\text { Canyon } \\
(5.4)\end{array}$ & $\begin{array}{l}\text { Tetral in }(5.4) \\
\text { Water }(3.6)\end{array}$ & 58 & 14 & 25 & 19 \\
\hline
\end{tabular}

- Conversions are based upon the amount of initial coal (maf).

- Pentane solubles are by difference, al so includes the products extracted by ether from the distillate.

An understanding of how carbon monoxide reduces coal in first-stage liquefaction is essential for implementing improvements to the process and designing effective catalysts. Why does $\mathrm{CO}$ give better conversions to soluble materials than hydrogen? After several decades, little is understood about the mechanism of the aqueous CO reaction with coal or even with model organic compounds. Jones and others have shown that an aryl ketone (benzophenone) and an aryl carbinol are reduced (9). Bases were required for reduction of the ketone, and higher conversions were obtained for the carbinol reduction in the presence of base. Reduction of anthracene and quinoline were also effected with aqueous $\mathrm{CO}$; however, higher conversions of anthracene were obtained in the absence of base (10). The reduction of ketones with $\mathrm{CO}$ in aqueous sodium carbonate was explained by sodium-ion activation of the $\mathrm{CO}$ to give an intermediate, such as formate, that can donate hydride to the carbonyl. Reduction of anthracene or other hydrocarbons would appear to proceed by a different mechanism. 
A better understanding of the activation of $\mathrm{CO}$ for both ketone and aromatics reduction and the nature of the sodium aluminate catalys is is needed. Sodium aluminate could probably activate $\mathrm{CO}$ for hydride reduction of ketones as well as sodium carbonate, perhaps better. But does it also activate CO so that hydrogenation of hydrocarbons occurs? Can it lower activation energies for cleavage of bonds, such as in ether and carboxylate groups? The reactions of numerous model compounds were investigated in water/CO conditions, and the results were compared with those obtained in the absence of the sodium aluminate.

Naphthalene was not reduced by the CO/water system at $400^{\circ} \mathrm{C}$ with or without the addition of sodium aluminate catalyst (11). In contrast, anthracene was quite reactive under these conditions. This work demonstrated that higher conversions of anthracene were obtained with sodium aluminate than without this catalyst. But lower conversions were obtained with sodium hydroxide, which was consistent with Stenberg's results at higher temperatures.

Reactions of polycyclic aromatic hydrocarbons in the $\mathrm{CO} /$ water $/ \mathrm{NaAlO}_{2}$ system showed that those aromatics with linear arrangement (annellation) of the polycyclic rings are readily converted to hydroaromatics. The reactivities of the aromatics correlate with the ability to accept electrons (electron affinity) and form the radical anion intermediate. Thus a process involving single electron transfer (SET) from $\mathrm{CO}$ or a $\mathrm{CO}$ aluminate complex to the aromatic substrate is consistent with the reactivity data. With some aromatic compounds, the resulting radical anion may react rapidly with a water or hydroxyl such that a hydrogen ion $(\mathrm{H}+)$ is transferred. The rate of this protonation reaction may differ considerably for the various anion radical intermediates. In fact, the rate constants for protonation of perylene and fluorene radical anions are much lower than those of other aromatics (12). This may explain their lack of reactivity in the CO/water reduction tests discussed above. As in some other SET reactions, the hydrogen ion could begin bonding synchronously with the electron transfer in the more reactive aromatics (13). The radical resulting from the $\mathrm{H}+$ transfer will then react further with an electron donor to give the carbanion intermediate, which is again protonated. Further study of structure-reactivity data is needed to refine the SET concept for CO/water reductions. The role of the sodium aluminate may involve forming a complex with the carbon monoxide that can more effectively donate electrons in the reaction. The effect of the sodium aluminate is not. large, but it may be very important in optimizing the conversion of coal aromatic structures into hydroaromatic and other alkyl-bridged structures that are important in subsequent thermal or catalytic reactions.

These reactivity data suggest that (1 inear) aromatic systems in coals will be reduced in a first-stage 1 iquefaction process that uses $C O$ as the reducing gas. Hydrogen is added at critical sites in the structures such that the resulting hydroaromatic structures can effectively promote further reactions, such as radical capping, and prevent retrograde reactions that may occur during thermal processing. The effects of substituents on the reactivity of the aromatics were not studied, but since reactivities are usually affected significantly by substituents, especially heteroatoms, the reduction of these types of structures in coal in the catalytic CO/water system may be significant. 
The reactions of ketones with $\mathrm{CO} /$ water were also investigated as models for possible reactions that would occur in coal liquefaction. Since most of the aryl ketones have a high electron affinity, the reaction temperature was reduced to $350^{\circ} \mathrm{C}$, so that structure-reactivity effects could be more easily distinguished.

The reduction of anthrone in $\mathrm{CO} /$ water with sodium aluminate catalyst was slightly greater than in the reaction without sodium aluminate. The major products were anthracene and dihydroanthracene. The intermediate alcohol reduction product (anthrol) was not obtained, because it very rapidly dehydrates to anthracene. The reduction of other aryl and diaryl ketones in the absence of sodium aluminate were lower than that observed for anthrone. Reactivity data for reduction of the various ketones also showed a correlation with the electron affinities of the ketones.

The results of the model ketone reductions suggest that the $\mathrm{CO} /$ water $/ \mathrm{NaAlO}_{2}$ reduction of coals that are believed to contain significant amounts of aryl ketones will also produce significant reduction to less oxygenated and perhaps hydroaromatic structures. The presence of these structures may significantly lower the tendency of coal materials to undergo retrograde condensation reactions during further thermal and catalytic cracking reactions. Further work with quinones is planned to that we can determine whether the products from these reactions with CO/water will also be less likely to participate in the retrograde reactions.

The hydrocracking activity of the sodium aluminate-catalyzed co/water system was investigated using bibenzyl, diphenyl sulfide, and diphenyl ether as the test compounds. The reaction of bibenzyl was carried out at $425^{\circ} \mathrm{C}$ for 2 hours with aqueous sodium aluminate in the presence of 1000-psig initial CO pressure. A higher temperature was used, since the amount of hydrocracking observed in the studies discussed above was very small at those temperatures. The conversion of bibenzyl was $37 \%$, which is comparable with sodium carbonate catalyzed reaction (14). The major products were benzene, toluene, and ethylbenzene.

Stenberg and coworkers reported that c0/water effectively cleaves ary 1sulfur bonds in diphenyl sulfide $\left(64.4 \%\right.$ conversion) at $425^{\circ} \mathrm{C}$ in $\mathrm{CO} /$ water for 2 hours. Addition of sodium carbonate results in lower conversion (47\%) of diphenyl sulfide (15). However, we found conversions of only $18 \%$ for diphenyl sulfide in reactions without sodium aluminate under above conditions. Addition of sodium aluminate significantly improved the cleavage of the aryl-sulfur bond ( $28 \%$ conversion). Benzene was the only reaction product.

The reaction of diphenyl ether in co/water with and without sodium aluminate were carried out at $350^{\circ} \mathrm{C}$ for 2 hours in the presence of $1000 \mathrm{psi}$ of initial CO pressure. The results indicated that $\mathrm{CO}$ /water, both with and without sodium aluminate promoter, did not cleave aryl-oxygen bond.

Reactions of carboxylic acids in the CO/water/NaAlO, were investigated by using several model compounds to determine if there are any catalytic effects on decarboxylation or other reactions in this system. The reaction of naphthoic acid in $\mathrm{CO} /$ water gave $10 \%$ and $18 \%$ conversions of 1 -naphthoic acid into products at $300^{\circ}$ and $350^{\circ} \mathrm{C}$, respectively. The addition of sodium aluminate increased the conversion to $17 \%$ and $37 \%$ for $300^{\circ}$ and $350^{\circ} \mathrm{C}$ reactions, 
respectively. The dramatic catalytic effect of the sodium aluminate on decarboxylation may have a very important role in first-stage liquefaction, and more efforts to understand this effect are in progress. In addition to naphthalene (major product), trace amounts of tetral in were also formed in the sodium aluminate-catalyzed reactions. It is not known whether the naphthalene reduction occurred before or after decarboxylation. It is clear that higher temperatures are required for better decarboxylation kinetics for this type of acid. Thus future work will be conducted at $385^{\circ}$ and $400^{\circ} \mathrm{C}$.

The CO/water reaction with sodium hydroxide in place of sodium aluminate gave lower conversions (9\%) of acid into naphthalene at $300^{\circ} \mathrm{C}$. Al so, sodium hydroxide was added to the naphthoic acid to form sodium-1-naphthoate, and this salt was tested with sodium aluminate to give $12 \%$ and $19 \%$ conversions at $300^{\circ}$ and $350^{\circ} \mathrm{C}$, respectively. These reactions exhibit the lower reactivity of the carboxylate salt compared with the carboxylic acid form.

Besides catalyzing the decarboxylation of carboxylic acids, sodium aluminate may also have an effect on reactions of polyfunctional groups in the coal. There is also the possibility that the aluminate could moderate the alleged cross-linking effects during thermal treatments of coal. Therefore, carboxylic acids that have the potential for cross-linking or undergoing other reactions were investigated.

In contrast to the reaction of naphthoic acid, the reaction of 2-phenoxybenzoic acid with $\mathrm{CO} /$ water at $350^{\circ} \mathrm{C}$ for 2 hours (no sodium aluminate) resulted in almost complete decarboxylation. The phenoxy group thus increases the decarboxylation reactivity of the acid group by an electronic substituent effect. The reaction was accompanied by a small amount of reduction of the diaryl ether linkage to give benzene and phenol. No products resulting from addition of species derived from the carboxylate group to the adjacent ring to give a cyclic structure, such as dibenzofuran or xanthone, were observed. Thus no evidence for a cross-linking type of activity during decarboxylation could be obtained.

In the co/water reaction of 2-phenoxybenzoic acid with added sodium aluminate, a large portion of the substrate underwent a hydrolys is reaction of the diaryl ether to give phenol as the major product. Since the hydrolysis reaction did not occur in the sodium aluminate-catalyzed reaction of dipheny? ether (see discussion above), the significant change in the reactivity of the ether oxygen could be attributed to the effect of the ortho-carboxylate group in the presence of sodium aluminate. Perhaps this large synergistic effect on diaryl ether hydrolysis results from formation of a complex of the aluminate with the carboxylate that can catalyze the hydrolysis reaction. Again, no cyclic structure were found in the products.

The reaction of 2-benzylbenzoic acid with C0/water gave only $5 \%$ conversion of acid to diphenylmethane. Addition of sodium aluminate increased the conversion to $10 \%$. Although decarboxylation was slow for this substrate, the addition of sodium aluminate improved the reactivity by a large factor. No cracking of the arylmethylene bond of the 2-benzylbenzoic acid occurred in these reactions, and only a trace of anthracene, resulting from cyclization, was found. 


\subsection{Catalysts for Coal Depolymerization}

After the thermal degelation and dissolution of the coal, the intermediate products must be depolymerized and hydrogenated to produce the distillate product. This step requires higher temperatures and/or catalysts to be effective. Coal liquefaction processes may conduct these steps either separately or combined into a single operational stage as in the Wilsonville Process. However, when low-rank coals were heated with the hydrogenation catalyst present during the Wilsonville operation, the catalysts were rapidly deactivated by deposition. Thus, in our project, the soluble products from the thermal dissolution step are separated from the mineral matter and then subjected to extensive depolymerization and hydrogenolys is in a second step in order to convert the high molecular weight coal molecules to volatiles. Conversion to environmentally acceptable distillate fuels also requires catalysts for upgrading the distillate and removal of oxygen, nitrogen, and sulfur heteroatoms.

The catalysts currently used in coal liquefaction for depolymerization and hydrogenolysis of the solubilized coal macromolecules are the same as those used in conventional petroleum refining; however, this application has not been very successful. Improvements in liquefaction efficiency could be obtained if catalysts with longer life and better activity and selectivity were available. Rapid deactivation of the conventional $\mathrm{Co}-\mathrm{Mo}_{\mathrm{o}}$ and $\mathrm{Ni}-\mathrm{Mo}_{\mathrm{O}}$ catalysts on an alumina support have been attributed to coke formation (1), metals deposition (2), and inhibition of the active center by chemisorbed compounds (3).

Two types of hydrocracking catalysts were investigated in this project. These are 1) solid supported acid catalysts, and 2) metal sulfides dispersed on an acidic layered support. These are dic sed separately below.

\subsubsection{Solid Supported Acid C s}

In the preceding decade, molten zinc chloride was demonstrated to be an effective catalyst for the production of clean gasoline fuels; however, some disadvantages relating to its corrosiveness and loss during regeneration were noted. We have extensively investigated supported forms of zinc chloride which may overcome these problems (16). Silica gel-supported zinc chloride (SZC) was shown to be an effective catalyst for hydrotreating first-stage coal liquefaction products to a distillate fuel containing no sulfur. Higher conversions (53\%-68\%) were obtained with this catalyst than that with a commercially available $\mathrm{Ni}$-Mo catalyst $(35 \%)$. Extensive studies with model compounds were carried out with the objective of achieving a better understanding of the chemistry of hydrotreating coal liquids with solid strong acid catalysts. These studies showed that the SZC catalyst cleaves aryl sulfides, ethers, phenols, nitrogen heterocyclics, and alkylaromatic compounds. Alkyl transfer reactions also occur very readily. Molecular hydrogen is not utilized directly in the cleavage reaction, but it is needed to prevent coking and condensation reactions, and is indirectly incorporated into products. Products are consisten with a mechanism involving formation of carbonium ion intermediates, which are converted to products via hydride abstraction. The sources of the hydride ions apparently are various aromatic condensation intermediates. Tertiary alkanes are not effective hydride donors. Polynuclear aromatics are hydrogenated and cracked, but single ring aromatics are not. This is one of very few catalysts that can hydrocrack pyrene. 
Characterization of the SZC catalyst was carried out to provide further information on the nature of the zinc chloride in the catalyst. The acidic properties of the SZC catalyst were determined by several methods. Hammett acidities obtained by titrations with various weak bases demonstrated that the catalyst contained a relatively large number of highly acidic sites. Total acidities (Brönsted and Lewis) were determined by thermogravimetric pyridine adsorption-desorption experiments. Infrared studies of the pyridine-adsorbed catalyst also gave relatively large amounts of Brönsted and Lewis acid sites. Elemental analys is showed that very little of the chloride was lost in the preparation of the catalyst. Scanning electron microscopy/energy dispersive analysis (SEM/EDA) studies showed that the zinc chloride is evenly distributed over the surface of the silica gel support. $X$-ray diffraction indicated that recovered catalysts from hydrotreating tests had incorporated part of the sulfur released from the substrates as zinc sulfide (the rest becomes hydrogen sulfide). The zinc sulfide must be microcrystalline since it appeared in SEM/EDA maps to be evenly distributed on the surface of the silica gel support, rather than as crystals.

The optimum loading of zinc chloride on the silica gel support was investigated. Results from hydrotreating tests with 1 oadings of $5 \%, 16 \%$, and $50 \%$ zinc chloride, by weight on the silica gel, indicated that the $16 \%$ and $50 \%$ catalysts had essentially the same activity, whereas the activity of the $5 \%$ catalyst was substantially less. The $16 \%$ composition may represent close to exhaustive surface coverage by the zinc chloride. Because of the slow rates for some of the hydrotreating reactions at temperatures less than $400^{\circ} \mathrm{C}$, a catalyst-to-substrate ratio of 0.5 was found to give decent conversions in a reasonable time period. Carbon tetrachloride has been found to be a better solvent than water for the preparation of the silica gel-supported catalyst.

A catalyst was prepared by supporting zinc chloride on montmorillonite clay. This catalyst was effective in cleaving sulfides and alkybenzenes, however, condensation reactions to oligomeric products were more extensive than those with the silica gel-supported catalyst. Three hydrotreating tests with a low-severity liquefaction product from Wyodak subbituminous coal gave conversions of $53 \%, 57 \%$, and $62 \%$ to distillable 1 iquids. Pumice-supported zinc chloride was a considerably less effective catalyst than the silica gelsupported catalyst.

\subsubsection{Metal Sulfides on Acidic Layered Supports}

Catalytic functions required for hydrotreatment are hydrogenation of aromatics and hydrocracking of $\mathrm{C}-\mathrm{C}$ bonds as well as $\mathrm{C}-\mathrm{S}, \mathrm{C}-\mathrm{O}$, and $\mathrm{C}-\mathrm{N}$ bonds . Thus metal or metal sulfide sites provide activation activity for addition of hydrogen to aromatic rings or for hydrogen transfer, and acidic sites are essential for bond cleavage activity in coal liquefaction catalysts. High surface areas for the metal sulfide sites are desired for high activity, and this can be achieved by dispersion of the metals on a supporting material with some acidic properties.

Novel catalysts for hydrotreatment of initial solubilized coal liquefaction products were developed and tested in this project. The new hydrogenation catalysts utilize pillared clays as the supports for the metal sulfide sites. The structures of these support materials feature very large interlayer spacings that have the potential for generating spacious micropores 
that could accommodate the large coal macromolecules. Although the supports can possess strong acidities which could lead to coking at high temperatures, these effects are moderated by the presence of the bimetallic sulfide.

Acid smectite clays have been used as catalysts in petroleum-cracking and various other reactions. Unfortunately they dehydrate and collapse at temperatures above $200^{\circ} \mathrm{C}$. Acid zeolites are more stable at high temperatures; however, the pores are too narrow to be useful for coal macromolecules, and they are not effective in upgrading as compared with conventional $\mathrm{Ni}-\mathrm{Mo}$ or Co-Mo catalysts. In the pillared clays, large polyoxymetal cluster cations are exchanged (intercalated) between the negatively charged clay layers in place of the hydrated metal ions. When calcined to drive off the water, the polyoxymetal cations form pillars that maintain the clay layer structure, thus creating large spacings between the layers. These structures are stable to $450^{\circ}$ and $500^{\circ} \mathrm{C}$. Hypothetically, the micropore volumes will be large enough to accommodate macromolecules of the feedstock, which will be hydrocracked. Chromia-pillared clays, which have interlayer spacings somewhat larger than those present in alumina-pillared clays used in petroleum refining, have considerable potential for coal liquefaction.

The catalytic hydrocracking activities of various derivatives of natural montmorillonite clay were investigated. These derivatives included both pillared and unpillared forms of the clay, as well as the catalysts obtained by impregnating nickel-molybdenum sulfide on the pillared clay as a support. These tests were carried out in a rocking microreactor (tubing bomb) under 1000 psi of hydrogen at temperatures of $300^{\circ}$ to $400^{\circ} \mathrm{C}$. Bibenzy 1 (1,2-diphenylethane), diphenyl sulfide, diphenyl ether, and other hydrocarbon compounds were utilized as substrates to model the structural moieties of the coal, especially the bridging groups that are believed to link the aromatic clusters together. Some of the catalysts were then tested with first-stage coal 1iquids (10w-severity Wyodak liquefaction product), and conversions to distillate materials were determined.

In order to study the effects of acidic sites present on a clay, the concentration of acidic sites on montmorillonite was maximized by converting the clay to an acid-exchanged form. This form of montmorillonite was prepared by washing the cleaned sodium form of the clay with hydrochloric acid. The reaction of the acid-washed clay with bibenzyl at $350^{\circ} \mathrm{C}$ gave a $75 \%$ conversion of bibenzyl, whereas a blank hydrogenation reaction of bibenzyl with no clay or catalyst gave only $1 \%$ conversion to toluene. The yield of benzene resulting from the clay-catalyzed hydrocracking test was only $34 \mathrm{wt} \%$. The yields of ethyl benzene and toluene were very small (1.9\% for each). A two-step reaction of the bibenzyl is believed to occur, producing benzene and ethylbenzene in the first step, with ethylbenzene further cleaved to benzene and ethane in the second step. Yields of the gas products such as ethane were not measured. Toluene is produced in a different type of reaction. The higher yield of benzene compared with toluene in the montmorillonite reaction indicates that Brönsted acid catalysis (ipso protonation mechanism) is more important in the reaction than Lewis acid catalysis $(17,18)$. Much of the bibenzyl was converted to condensation products such as phenylethylbibenzyl. These products are formed from addition reactions (Friedel-Crafts reactions) of the carbonium ion intermediates with bibenzyl or products. The large amounts of condensation products observed in the reaction of bibenzyl with the clay indicate that the selectivity of the acid-washed clay for condensation versus cracking is poor. 
In previous liquefaction tests with coals that had been acid-washed, much lower conversions to soluble materials were obtained. The reasons for the poor yields from acid-washed coals may not be completely understood; however, the results obtained for acid-washed montmorillonite with bibenzyl indicate that increasing the acidity of the clay minerals in coal by acid washing may increase the amount of condensation occurring during the liquefaction, leading to formation of insolubles and coke.

Chromia-pillared montmorillonite was prepared with two different concentrations of chromia pillars. The low concentration chromia-pillared clay gave an $80 \%$ conversion of bibenzyl, but as with the acid-washed clay, low yields of benzene (27 wt\%), toluene ( 1 wt\%), and ethylbenzene ( 3 wt\%) were obtained from hydrocracking. Condensation products were abundant in the reaction products, indicating poor selectivity for hydrocracking. Results with the clay having a high concentration of chromia pillars gave somewhat higher conversion (93\%) and more benzene (47 wt\%). Formation of cyclohexanes by single ring hydrogenation reactions was not observed with either of the chromia-pillared clays or with the unpillared acid-washed clay.

A silica-pillared clay was also prepared and tested with bibenzyl. The reaction gave only a $38 \%$ conversion. The products were the same as obtained with the chromia-pillared clay: benzene and ethylbenzene. The relatively poor result with the silica-pillared clay discouraged further testing and suggested that new methods for pillaring with silica should be attempted.

Nickel and molybdenum were impregnated in the high chromia-pillared clay and sulfided to give the active clay-supported catalyst, and the hydrotreatment reaction with bibenzyl was conducted to determine the effectiveness. A conversion of $91 \%$ was achieved at $350^{\circ} \mathrm{C}$. This conversion is significantly better than the $64 \%$ conversion obtained with the high chromia-pillared clay support, which did not contain the nickel and molybdenum catalyst. The conversion increased to $99 \%$ when the reaction was carried out at $400^{\circ} \mathrm{C}$.

The products from the reactions of bibenzyl catalyzed by the nickelmolybdenum high chromia-pillared clay (NMHCPC) were found to be a mixture of aromatics and cycloalkanes. The major products were benzene and ethylbenzene, and the minor products were cyclohexane, methylcyclohexane, and alkylbenzenes. These products resulted from hydrocracking as well as hydrogenation of the aromatic compounds. In contrast to the reactions carried out with high chromia-pillared clay, the amounts of oligomeric condensation products formed during the reaction with NMHCPC were negligible. From these data, we conclude that the introduction of nickel and molybdenum has moderated the activity of the support so that selectivity for hydrocracking relative to condensation is obtained. The high conversion may be attributed to bimetallic sulfide activation of hydrogen to effect at least partial hydrogenation of the aromatic rings. Activation energies for bond cleavage reactions may be lower in the reduced intermediates. Carbonium ion intermediates are more easily reduced by hydride transfer reactions from the hydrogenated intermediates or dissociated hydrogen on the metal sulfide. Thus the carbonium ions are rapidly reduced and do not survive long enough to undergo addition reactions to aromatic rings that result in condensation and coking.

Reactions of the low chromia-pillared montmorillonite with other alkylbenzenes were investigated to determine if the reactions were consistent 
with the proposed carbonium ion mechanism. Isopropylbenzene (cumene) reacted very rapidly, giving $100 \%$ conversion. Benzene was the major product. The more rapid reaction is expected for a reaction involving cleavage of the aryl-alkyl bond of the ipso protonated ring intermediate to give the secondary isopropyl carbonium ion plus benzene. The reaction with phenyldecane occurred with $81 \%$ conversion to give benzene as the major product. A large number of various alkylbenzene and indan products were formed in the reaction as a result of carbonium ion rearrangements and cleavage reactions. Cyclohexanes were not observed in the reaction products.

Although single aromatic rings were not hydrogenated by the clay supports, it was interesting to find out whether multiring aromatic systems could be hydrogenated as they are with other acid catalysts such as zinc chloride. Thus pyrene was reacted with the chromia-pillared montmorillonite to determine if acid-catalyzed hydrogenation of the multiring systems could be effected. The conversion of pyrene to a hydrogenated pyrene mixture was found to be $15 \%$, which is considerably less than that observed for zinc chloride catalysts. For catalysts that contain molybdenum and other transition metals, hydrogenation of multiring systems occurs readily, and the clay support-catalyzed hydrogenation observed here is probably not going to be significant. The reaction at $350^{\circ} \mathrm{C}$ did not result in hydrocracking or rearrangements of the pyrene or hydropyrene rings to phenanthrene or other ring systems.

Ether cleavage reactions were investigated to determine the potential for catalytic hydrodeoxygenation reactions. In reactions of diphenyl ether to benzene and phenol, similar conversions were obtained with low chromia PC (30\% and $38 \%$ ), high chromia PC (35\%), and acid-washed montmorillonite (29\%). Lower conversion was obtained with silica-pillared montmorillonite (10\%). When the silica-pillared clay was used as a support for zinc chloride, the conversion improved to $20 \%$. These results are far inferior to that of zinc chloride supported on silica gel which gave $60 \%$ conversion.

Reactions of diphenyl sulfide were extensively investigated in order to determine the effects of pillaring and nickel molybdenum sulfide loading on hydrodesulfurization activities. The acid-exchanged form of montmorillonite gave a $99+\%$ conversion at $300^{\circ} \mathrm{C}$. The products were benzene and thiophenol in a molar ratio of 9.3:1. The relatively high benzene-to-thiophenol ratio shows that the catalyst is effective in cleaving both carbon-sulfur bonds of the diphenyl sulfide; that is, the thiophenol intermediate is further converted to benzene and hydrogen sulfide. The blank hydrogenation reactions of diphenyl sulfide carried out with no clay or catalyst present resulted in conversions of $1 \%$ at $300^{\circ} \mathrm{C}$ and $10 \%$ at $400^{\circ} \mathrm{C}$. The excellent conversion obtained with the acidexchanged clay may be attributed to the high acidity of the catalyst. The anionic aluminosilicate layers of the clay may also have some ability to stabilize cationic intermediates prior to a reduction step in the hydrodesulfurization mechanism.

The catalytic activity of sodium-exchanged montmorillonite was also tested at $300^{\circ} \mathrm{C}$ with diphenyl sulfide, and a conversion of on 1 y $11 \%$ was obtained. Both benzene and thiophenol were formed (molar ratio of $6.9: 1$ ). The sodiumexchanged clay has some residual Brönsted acidity due to polarization of the water of hydration of the sodium cations and to hydroxyl groups of the clay layers. 
Our hydrodesulfurization studies were then extended to the chromiapillarea montmorillonites. Hydrogenation of diphenyl sulfide with the low chromia PC resulted in a conversion of $95 \%$ to benzene and thiophenol in equimolar amounts. The high conversion can again be attributed to the high Brösted acidity of the pillared clay. Catalytic acidic sites may be present on the polyoxychromium cation pillars, since they retain some hydroxyl functionality (19).

Formation of equal moles of benzene and thiophenol in the pillared claycatalyzed reaction suggests that cleavage of only one carbon-sulfur bond of the diphenyl sulfide occurred. In order to determine if the second carbon-sulfur bond can actually be cleaved in this catalytic system, a reaction of thiophenol was carried out with chromia-pillared clay under the same conditions used for diphenyl sulfide. Analysis of the reaction products showed $95 \%$ conversion of the thiophenol to benzene. These results suggest that during the hydrogenation of diphenyl sulfide, the acidic sites in the clay may be poisoned by the hydrogen sulfide product. Further studies at higher temperatures are in progress to determine if the deactivation can be reversed.

The high chromia-pillared clay was also tested in the reaction with diphenyl sulfide. This catalyst gave a conversion similar to that obtained with the low chromia-pillared clay, but a much higher molar ratio of benzene to thiophenol (12:1) was found in this test. Thus the final step of the reaction, which involves hydrogenolysis of the thiophenol, proceeded much more completely with the high chromia-pillared clay catalyst.

Hydrotreating diphenyl sulfide with the nickel molybdenum HCPC catalyst resulted in a $98 \%$ conversion. A nearly quantitative amount of benzene was formed, with only a trace of thiophenol and small amount of cylcohexane from reduction of the benzene.

Information about the numbers, type, and strength of the acidic sites on the chromia-pillared clay and on the chromia-pillared clay-supported sulfided nickel molybdenum catalyst was desired in order to achieve a better understanding of the reactivity and selectivity in hydrocracking reactions.

Thermogravimetric techniques were used to determine accurately the total number of acid sites. In the TGA experiment, the weight increased by $5.9 \%$ for chromia-pillared clay and $4.69 \%$ for sulfided catalyst. The weight increase is due to the chemical adsorption of the pyridine at both Lewis and Brönsted acid sites and is a measure of the total acidity of the materials. The total acidity for chromia-pillared clay was calculated to be $0.75 \mathrm{meq} / \mathrm{g}$ and that of the $\mathrm{Ni}$-Mo catalyst was $0.60 \mathrm{meq} / \mathrm{g}$. Slow heating of the catalyst at $2^{\circ} \mathrm{C} / \mathrm{min}$ resulted in desorption of all of the chemically adsorbed pyridine by a temperature of $300^{\circ} \mathrm{C}$. The majority of the pyridine, $4.16 \mathrm{wt} \%$ for chromiapillared clay and $3.31 \%$ for the Ni-Mo catalyst, was desorbed between $105^{\circ}$ and $140^{\circ} \mathrm{C}$, while the remainder was desorbed between $140^{\circ}$ and $202^{\circ} \mathrm{C}$. The inflection points at $105^{\circ}$ and $140^{\circ} \mathrm{C}$ are taken to represent the onset of pyridine loss from weak and strong acid sites, respectively. From these data, the ratio of weak to strong acid sites is calculated for chromia-pillared clay to be 2.42 and for $\mathrm{Ni}$-Mo catalyst to be 1.79. Thus the Ni-Mo catalyst, which has the lower total acidity, has a larger proportion of strong acid sites.

Infrared spectroscopy of the pyridine complex was used to determine the relative proportion of Lewis and Brönsted acid sites in these two materials. 
In the infrared spectrum of the pyridine-adsorbed chromia-pillared clay, the bands at 1444 and $1541 \mathrm{~cm}^{-1}$ are assigned to the pyridine-Lewis acid coordination bond and the pyridine-Brönsted acid bond, respectively. Similarly in the chromia-pillared clay-supported nickel molybdenum catalyst, the bands at 1460 and $1530 \mathrm{~cm}^{-1}$ were assigned to the pyridine-Lewis acid and pyridineBrönsted acid bonds, respectively. The relative intensities of these bands were converted to the concentration ratio by using the respective extinction coefficients. The ratios of the concentrations of Lewis sites to Brönsted sites were 1.8 for chromia-pillared $\mathrm{Cl}$ ay and 2.3 for the supported $\mathrm{Ni}$-Mo catalyst. This change in the distribution of acid sites may be attributed to a decrease in the concentration of Brönsted acid sites. We do not yet know how these findings are related to the numbers of weak and strong acid sites and the relative reactivity of various supported catalysts. Much further work is needed to elucidate the role of acidity in determining catalytic hydrogenolysis activity.

Coal liquefaction tests were carried out with the first-stage product from Wyodak subbituminous coal (LSW) and $1000 \mathrm{psi}$ hydrogen at $400^{\circ} \mathrm{C}$ in rocking microreactors without added solvent, and the product was distilled to determine the conversion of the nonvolatile portion of the LSW to distillate. Acidwashed clay, pillared clay supports, and pillared clay-supported $\mathrm{Ni}$-Mo sulfide catalyst, as well as a commercial silica-alumina-supported $\mathrm{Ni}$-Mo catalyst, gave results paralleling the reactions with the test substrates described above. With a commercial nickel-molybdenum catalyst, the conversion 00 distillate was only $20 \%$ under the conditions used. The LSW in the presence of acid-washed montmorillonite gave a conversion of $10 \%$. The 10w chromia-pillared montmorillonite and high chromia-pillared montmorillonite with LSW gave very poor conversions ( $2 \%$ and $8 \%$, respectively) to distillate. Thus the supports by themselves are evidently too acidic or too nonselective to be useful for coal liquefaction, but the addition of metal sulfides to the support modifies this behavior substantially. A conversion of $29 \%$ to distillate was obtained for the nickel-molybdenum sulfide supported on the high chromia-pillared clay. This is a significant improvement over the conversion obtained with the commercial catalyst. Further testing is required to determine whether the catalysis is actually occurring in the interlayer micropores or simply on the outer surface of the clay. Higher conversions of the LSW to distillate were reported earlier for montmorillonite-supported zinc chloride catalyst (16). Zinc chloride complex catalysts are exceptionally active and efficient in cracking coal, but suffer some disadvantages such as deactivation and emission of hydrogen chloride in the presence of sulfur.

Elemental analyses of the hydrotreated LSW products obtained with the various clay supports and catalysts indicate that sulfur and nitrogen were cotally removed in the distillate obtained by hydrotreatment with all of the materials. All of the sulfur was removed from the bottoms by the treatment with the HCPC and the commercial catalyst, and most of the sulfur in the bottoms was removed by the NMHCPC catalyst $(0.2 \%$ remained). Nitrogen content was reduced somewhat from the value originally present by treatment with the HCPC and NMHCPC. The hydrogen contents in the bottoms fractions were increased by treatment with the commercial catalyst and NMHCPC, but lower hydrogen was found in the bottoms product from the acid-washed and HCPC clays.

Hydrotalcites were also investigated as supports for metal sulfide catalysts, and as catalysts themselves. Both the pillared hydrotalcites and 
molybdenum-loaded pillared hydrotalcites were ineffective in hydrocracking alkylbenzenes. However, both catalysts were highly effective for hydrodesulfurization of aryl sulfides and benzothiophenes. Hydrotalcite and pillared hydrotalcite gave benzene as the major product, whereas the molybdenum-loaded hydrotalcite gave cyclohexane in addition to benzene. Promising results were also obtained for hydrodeoxygenation of aryl ethers to benzene and hydrodenitrification of quinoline to various products.

\subsection{CONCLUSION}

First-stage liquefaction of U.S. low-rank coals was effected conveniently and efficiently with carbon monoxide and added homogeneous catalyst in a solvent system composed of water or a hydroaromatic compound or a mixture of the two. The reaction involves breaking down the gel structure of the coal into very high molecular weight macromolecules by a combination of reduction, decarboxylation, dehydration, and other deoxygenation reactions. The reduction mechanism is consistent with a single electron transfer step from the carbon monoxide-catalyst complex. This procedure allows the soluble intermediate product to be obtained free of inorganic species that will deactivate heterogeneous or dispersed catalysts required for depolymerization and hydrogenation of the coal material.

Hydrotreatment of first-stage coal liquids and model compounds with a selection of acidic and pillared clays with and without incorporated bimetallic hydrogenation catalysts showed that the combination of support acidity and hydrogen activation catalys is was effective in cleaving $C-S$ and alkyl-aryl bonds and hydrocracking coal materials. Some differences in the activities of the support were noted that depended on the nature and concentration of oxymetal ion used in pillaring the clay. Further efforts are needed to clearly understand these differences.

\subsection{REFERENCES}

1. Derbyshire, F. ACS Div. of Fuel Chem. Preprints 1988, 33 (3), 188.

2. Garg, D.; Givens, E.N. Fuel Proc. Techno1. 1984, 9, 29; Kovach, S.M.; Castle, L.J.; Bennett, J.V.; Svrodt, J.T. Ind. Eng. Chem. Prod. Res. Dev. $1978,17,62$.

3. Mills, G.A.; Beodeker, E.R.; Oblad, A.G. J. Amer. Chem. Soc. 1950, 72, 1554 .

4. Appe11, H.R.; Wender, I.; Miller, R.D. Prep. Pap.--Am. Chem. Soc., Div. Fuel Chem. 1969, 13, 39-44.

5. Sondreal, E.A.; Knudson, C.L.; Schiller, J.E.; May, T.H. Proc. 9th Biennial Lignite Symp.; DOE/GFERC/IC-77/1, 1977, pp 129-158.

6. Ross, D.S.; Green, R.K.; Monsani, R.; Hum, G.P. Energy Fuels 1987, 1287.

7. Jackson, W.R.; Lim, S.C.; Stray, G.J.; Larkins, F.P. Proc. 1989 Internat. Conf. on Coal Sci.; Tokyo, Dec. 1989, Vol. II, pp 815-818. 
8. Hughes, C.P.; Sridhar, T.; Chuan, L.S.; Redlich, P.J.; Jackson, W.R.; Larkins, F.P. USA/Australia Workshop on the Use of Low-Rank Coals; Billings, MT, May 1991 .

9. Jones, D.; Baltisberger, R.J.; Klabunde, K.J.; Woolsey, N.F.; Stenberg, V.I. J. Org. Chem. 1978, 43, 175-177.

10. Stenberg, V.I.; Wang, J.; Baltisberger, R.J.; Van Buren, R.; Woolsey, N.F. J. Org. Chem. 1978, 43, 2991-2994.

11. 01 son, E.S.; Sharma, R.K. "Semiannual Technical Progress Report for the Period July-December 1991, EERC Publication, 1991.

12. Levanon, H.; Neta, P.; Trozzolo, A.M. In Organic Free Radicals; ACS Symp. Series 69; Pryor, W.A., Ed.; Amer. Chem. Soc.: Washington, D.C., 1978, pp 401-409.

13. Pross, A. Acc. Chem. Res. 1985, 18, 212-219.

14. Stenberg, V.I.; Baltisberger, R.J.; Knittal, D.; Wettlaufer, D.; Woolsey, N.F.; Knudson, C. 14th Intersociety Conf., Boston, MA, Aug. 5-10, 1979.

15. Stenberg, V.I.; Baltisberger, R.J.; Klabunde, K.J.; Woolsey, N.F.; Severson, D.; Souby, M. "Quarterly Technical Progress Report for the Period Jul.-Sep. 1978," Contract No. EX-76-C-01-2211, 1978.

16. 01 son, E.S.; Dieh1, J.W.; Sharmi, R.K. ACS Div. of Fuel Chem. Preprints $1990,35(2), 563$.

17. Sharma, R.K.; 01son, E.S.; Dieh1, J.W. ACS Div. of Fuel Chem. Preprints 1990,35 (2), 463.

18. 01 son, E.S.; Dieh1, J.W.; Sharma, R.K. ACS Div. of Fuel Chem. Preprints 1991,36 (2), 578.

19. Pinnavaia, T.J.; Tzou, M.S.; Landau, S.D. J. Amer. Chem. Soc. 1985, 107, $4783-4785$.

\subsection{BIBLIOGRAPHY OF PUBLICATIONS EMANATING FROM THIS PROJECT}

- Sharma, R.K.; 01 son, E.S. "Catalysts for Aqueous/CO Liquefaction of Subbituminous Coal," Prepr. Pap.--Am. Chem. Soc., Div. Fuel Chem. 1992, 37, 992-997.

- 01 son, E.S.; Sharma, R.K. "New Catalysts for Production of Synthetic Fuels," U.S./Australian Low-Rank Coal Utilization Workshop, Billings, MT, 1991 .

- 01 son, E.S.; Sharma, R.K. "Application of Pillared :ontmorillonite Catalysts to Coal Liquefaction," CONFAB'91, Silver Creek, C0, Aug. 6-9, 1991. 
- Sharma, R.K.; 01 son, E.S. "Catalytic Hydrodesulfurization with Hydrotalcites," In Processing and Utilization of High-Sulfur Coals IV; Dugan, P.R.; Quigley, D.R.; Attia, Y.A., Eds.; Elsevier: Amsterdam, 1991, pp 377-384.

- Olson, E.S.; Dieh1, J.W.; Worman, J.J. "Analysis of Complex Organic Reaction Product Mixtures by GC/FTIR/MS/AED, "Pittsburgh Conf., Chicago, IL, Mar. 4-8, 1991, Abstracts, p 695.

- 01son, E.S.; Dieh1, J.W. "Anisotropy in Dilute Solutions of Coal-Derived Materials," Coal Structure and Reactivity, Queens College, Cambridge, UK, Sept. 5-7, 1990; Fuel 1991, 70, 349-351.

- Olson, E.S.; Yagelowich, M.; Diehl, J.W. "Molecular Weights and the Dispersion/Solubilization of Humic Material," In Proceedings of the First International Conference on Biological Processing of Coal; Orlando, FL, 1990.

- 01 son, E.S.; Dieh1, J.W.; Sharma, R.K. "Mechanism of Hydrotreating Reactions: Solid Acid Catalysis," Prepr. Pap.--Am. Chem. Soc., Div. Fuel Chem. 1991, 36, 578-585.

- Sharma, R.K.; Stanley, D.C.; Holm, P.L.; 01son, E.S. "Hydrotalcite Catalysis of Hydrotreating Reactions," Prepr. Pap.--Am. Chem. Soc., Div. Fuel Chem. 1991, 36, 570-577.

- 01 son, E.S.; Sharma, R.K.; Dieh1, J.W. "Hydrotreatment of Coal Gasification Liquid By-Product with a Solid Acid Catalyst," Prepr. Pap.--Am. Chem. Soc., Div. Fuel Chem. 1990, 35 (3), 611-614.

- Dieh1, J.W.; Kleinjan, S.B.; 01 son, E.S. "A Gas Chromatographic/Fourier Infrared Spectroscopy/Mass Spectrometry/Atomic Emission Detection/Flame Ionization Detection System," Spectros. Int. J. 1990, 8, 43-72.

- 01son, E.S.; Dieh1, J.W.; Sharma, R.K. "Hydrocracking with New Solid Acid Catalysts: Low-Severity Liquefaction Products from Low-Rank Coa1, "Prepr. Pap.--Am. Chem. Soc., Div. Fuel Chem. 1990, 35 (2), 563-569.

- 01 son, E.S.; Dieh1, J.W.; Sharma, R.K. "Hydroquinone Polymers: Models for Retrograde Reactions in Liquefaction Processing," Prepr. Pap.--Am. Chem. Soc., Div. Fuel Chem. 1990, 35 (2), 438-441.

- Sharma, R.K.; Dieh1, J.W.; 01son, E.S. "Hydrocracking with New Solid Acid Catalysts: Model Compound Studies," Prepr. Pap.--Am. Chem. Soc., Div. Fuel Chem. 1990, 35 (2), 414-422.

- Sharma, R.K.; Dieh1, J.W.; Olson, E.S. "Hydrodesulfurization with a New Solid Acid Catalyst," Processing and Utilization of High-Sulfur Coals III; Markuszewski, R.; Wheelock, T.D., Eds.; Elsevier, 1990, pp 735-743.

- Sharma, R.K.; 01 son, E.S.; Diehl, J.W. "Pillared Clays as Catalysts for Hydrodesulfurization and Liquefaction of Low-Severity Wyodak Products," Coal Chemistry Symposium, ACS 23rd Great Lakes Regional Meeting, Dekaib, IL, May 1990. 
- 01 son, E.S.; Froehlich, M.L.; Dieh1, J.W. "A New Hydroxyl Determination in Coals by CP/MAS ${ }^{13} \mathrm{C}$ NMR and GC/FTIR," Pacifichem 89, Honolulu, HI, Dec. 18-23, 1989.

- 01 son, E.S.; Dieh1, J.W. "Depolarization Ratios for Coal Macromolecules," First Pacific Polymer Conference, Maui, HI, Dec. 11-15, 1989, Preprints, pp 401-402.

- 01son, E.S.; Dieh1, J.W. "Fuel Analysis by GC/FTIR/ITD/FID Mass Spectrometry," Invited Presentation at FACSS XVI, Chicago, IL, Oct. 1989.

- Olson, E.S.; Dieh1, J.W. "Analysis of Fuels with a Coupled GC/FTIR/MS/AE/FID System," Invited Presentation at CONFAB 89, Laramie, WY, Aug. 1-4, 1989.

- 01 son, E.S.; Sharma, R.K.; Dieh1, J.W. "Unexplored Products from Reactions of Low-Rank Coal in Aqueous Systems," Prepr. Pap.--Am. Chem. Soc., Div. Fuel Chem. 1989, 34 (3), 832-838.

- 01 son, E.S.; Sharma, R.; Dieh1, J.W. "Reactions of Low-Rank Coals with Phenol," Prepr. Pap.--Am. Chem. Soc., Div. Fuel Chem. 1989, 34, 597-600.

- 01 son, E.S.; Dieh1, J.W. "Characterization of Coal Liquefaction Products by GC/FTIR/MS," 25th Internat. Symp., Adv. in Chromatogr., Aug. 29, 1988, Minneapolis, MN; J. Chromatogr. 1989, 468, 309-317.

- 01 son, E.S.; Dieh1, J.W. "Determination of Carboxylic Acids by Isotope Dilution Gas Chromatography/Fourier Transform Infrared Spectroscopy, "Anal. Chem. 1988, 60, 1920-1924.

- 01 son, E.S.; Diehl, J.W.; Froehlich, M.L. "Hydrosols of Low-Rank Coals: 1. Preparation and Properties," Fuel 1988, 67, 1053-1061.

- Olson, E.S.; Dieh1, J.W.; Froehlich. M.L. "Hydrosols of Low-Rank Coals: 2. Low-Temperature 0xidations," In Interfacial Phenomena in Biotechnology and Materials Processing; Attia, Y.A.; Moudgil, B.M.; Chander, S., Eds.; Elsevier: Amsterdam, 1988, pp 481-490.

- 01 son, E.S.; Dieh1, J.W. "Determination of Virial Coefficients in Size Exclusion Chromatography of Coal Macromolecules," 25th Internat. Symp., Adv. in Chromatogr. Aug. 29, 1988, Minneapolis, MN; submitted to J. of Chromatogr.

- 01 son, E.S.; Dieh1, J.W.; Horne, D.K.; Bale, H.D. "Extraction Rates and Porosity Changes of Coals in Supercritical THF," Prepr. Pap.--Am. Chem. Soc., Div. Fuel Chem. 1988, 33 (4), 826-831.

- 01 son, E.S.; Dieh1, J.W. "A New Determination of Exchangeable Oxygen in Coals," Prepr. Pap.--Am. Chem. Soc., Div. Fuel Chem. 1988, 33, 415-421.

- 01 son, E.S.; Dieh1, J.W.; Sharma, R. "Studies of Cataly'uic Upgrading of Low-Severity Liquefaction Products from Low-Rank Coals," Prepr. Pap.--Am. Chem. Soc., Div. Fuel Chem. 1988, 33, 332. 
- 01 son, E.S.; Dieh1, J.W.; Froehlich, M.L. "Ion Trap Mass Suectrometry for the Quantitative Analys is of Carboxylic Acids," ACS 196th Nat. Mtg., Los Angeles, CA, Sep. 25, 1988.

- Dieh1, J.W.; 01 son, E.S. "Studies and Applications of Cool-Time Induced Ionization in the Ion Trap Detector," Eastern Analytical Symposium, 1988.

- 01 son, E.S.; Dieh1, J.W. "Applications of GC/FTIR/MS in the Energy Field," 9th ACS Rocky Mt. Regional Meeting, Las Vegas, NV, Mar. 27, 1988.

- 01 son, E.S.; Worman, J.J.; Dieh1, J.W.; Uhrich, K. "Size Exclusion HPLC of Products from Low-Severity Liquefaction of Coals," 9th ACS Rocky Mt.

Regional Mtg, Las Vegas, NV, Mar. 27, 1988.

- Worman, J.J.; OIson, E.S.; Esslinger, M.; Knudson, C.; Diehl, J.W. "Characterization and Removal of Nitrogen Compounds in Coal Gasification Tar 0ils," 9th ACS Rocky Mt. Regional Mtg., Las Vegas, NV, Mar. 27, 1988.

- 01 son, E.S.; Dieh1, J.W. "Serially Interfaced Gas Chromatograph/Fourier Transform Infrared/Ion Trap Mass Spectrometer System," Anal. Chem. 1987, 59, 443-8.

- 01son, E.S.; Dieh1, J.W.; Froehlich, M.L. "Molecular Weights of Solubilized Lignite Macromolecules," Fuel 1987, 66, 992-5.

- Andermann, G.; Fujiwara, F.; Worman, J.; 01 son, E. "High Resolution X-Ray Fluorescence Spectroscopy: A Potentially Useful Technique for Chemical Bonding Studies in Fossil Fuels," Fuel 1987, 66, 932-4.

- 01 son, E.S.; Dieh1, J.W.; Froehlich, M.L. "Structural Features of Low-Rank Coals Important in Liquefaction, Bioconversion, and Gasification, " Coal Characterization for Conversion Processes Conference, Rolduc, Netherlands, Apr. 28- May 1, 1986; Fuel Proc. Tech. 1987, 15, 319-326.

- 01 son, E.S. "Structure and Reactivity of Big Brown Lignite," In Coal Science and Technology 11: Internat. Conf. on Coal Science; Moulijn, J.A.; Nater, K.A.; Chermin, H.A.G., Eds.; Elsevier: Amsterdam, 1987, pp 311-314.

- 01son, E.S; Dieh1, J.W.; Froehlich, M.L. "Preparation and Reactivities of Latexes from Low-Rank Coals," Prepr. Pap.--Am. Chem. Soc., Div. Fuel Chem. $1987,32,94-7$.

- 01 son, E.S.; Dieh1, J.W.; Froehlich, M.L.; Sharma, R. "Chemical Changes During Low-Severity Liquefaction of Big Brown Lignite," Direct Liquefaction Contractors' Review Meeting, Pittsburgh, PA, Oct. 6, 1987.

- Maas, D.J.; Potas, T.A.; Malterer, T.J.; 01 son, E.S.; Smit, F.J. "Low-Ash, Low-Rank Coal/Water Fuel," 4th Annual Pittsburgh Coal Conf., Sept. 30, 1987.

- Diehl, J.D.; 01son, E.S.; Froehlich, M.L. "Determination of Organic Acids by Isotope Ratio GC/FTIR/MS," Eastern Analytical Symposium, Sept. 13, 1987. 
- 01 son, E.S.; Dieh1, J.W.; Sharma, R.; Froehlich, M.L. "Processing of Low-Rank Coal Colloids," Symposium on Interfacial Phenomena in Biotechnology and Materials Processing, Boston, MA, Aug. 1987.

- Dieh1, J.W.; Froehlich, M.L.; 01son, E.S. "Isotope Ratio Quantitation of Organic Acids Using an Ion Trap Mass Spectrometer," MN Chromatography Forum Spring Symposium, May 20, 1987.

- 01 son, E.S.; Dieh1, J.W.; Malterer, T.J. "Colloidal Coal Cleaning Method for Low-Rank Coals," 14th Biennial Lignite Symposium, May 19, 1987.

- Heintz, M.J.; Dieh1, J.W.; 01 son, E.S. "C'benzofuranyl Poíysiloxane Stationary Phases for Capillary Gas Chromatography, "MN-ND Academy of Science, Apr. 25, 1987.

\subsection{PATENTS EMANATING FROM THIS PROJECT}

- Dieh1, J.W. "Open-Split Interface for Mass Spectrometers," U.S. Patent 4988 870, Jan. 29, 1991. 
3.5 Gasification Ash and Slag Characterization Final Report IS NOT Included (Project was extended to June 30, 1993) 


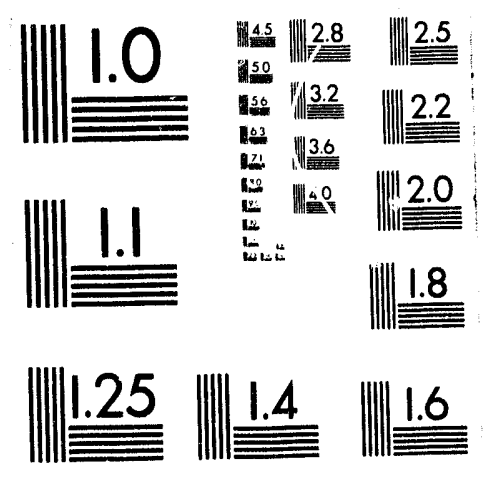



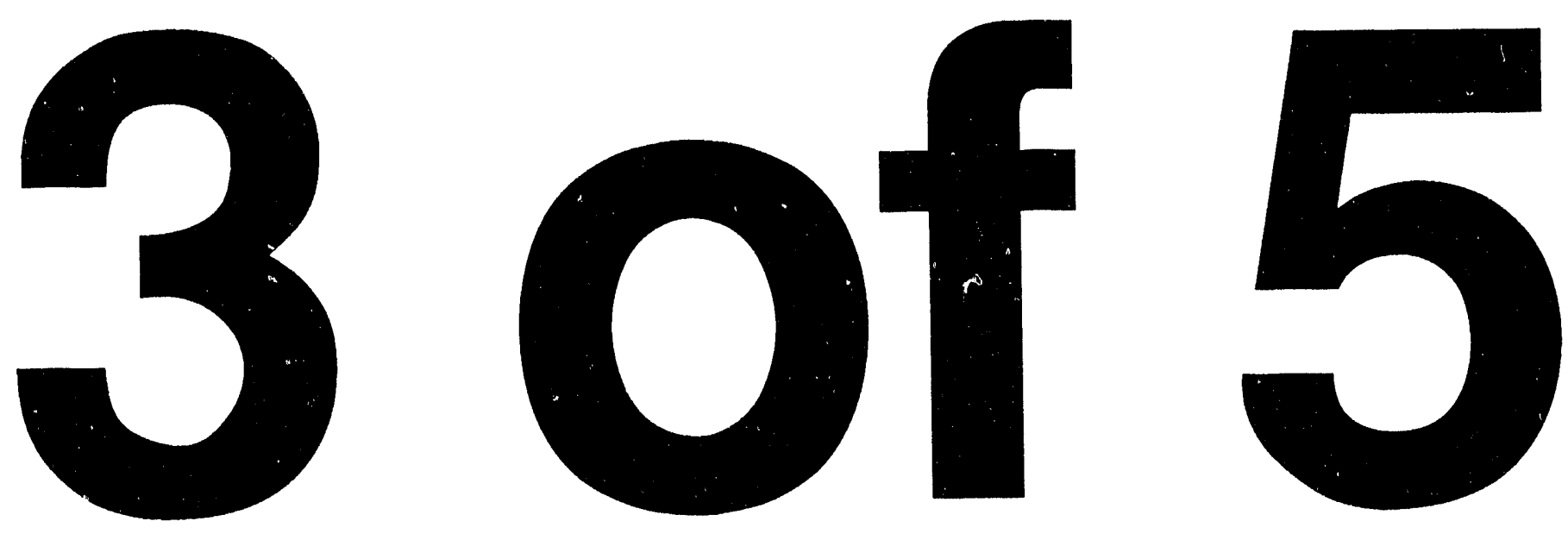


\subsection{Coal Science}




\title{
COAL SCIENCE \\ EARTH RESOURCE EVALUATION AND MANAGEMENT
}

\author{
Final Technical Progress Report \\ for the Period July 1, 1989, to December 31, 1992
}

by

Joseph H. Hartman, Project Manager

Energy and Environmental Research Center

University of North Dakota

Box 8213, University Station

Grand Forks, North Dakota 58202

Task Contracting Officer's Representative: Leroy Dockter

for

United States Department of Energy

Laramie Project Office

2020 Grand Avenue

Suite 450

P.0. Box 1189

Laramie, Wyoming 82070

December 1992

Work Performed under Cooperative Agreement No. DE-FC21-86MC10637 
1.0 INTRODUCTION $\ldots \ldots \ldots \ldots \ldots \ldots \ldots$

2.0 GOALS AND OBJECTIVES $\ldots \ldots \ldots \ldots$

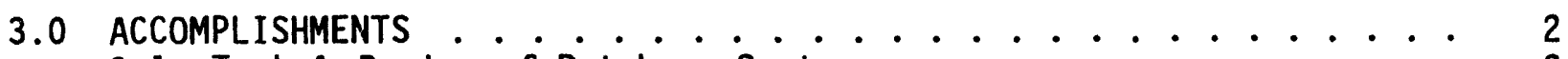

3.1 Task A-Review of Database Systems ........... 2

3.2 Task B-Acquisition of Hardware ............ 4

3.3 Task C-Database Design and Modifications . . . . . . . . . 6

3.4 Task D-Database Input and Augmentation .......... 8

3.5 Task E-Drilling Project .............. 9

3.6 Task F-Database Design Assessment and Modifications .... 10

3.7 Task G-Geochemical Database Studies .......... 11

3.8 Task H-Data Presentation ................ 12

3.9 Task I-Database Implementation ............. 13

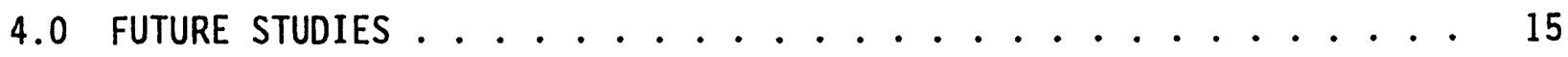

5.0 SUMMARY AND CONCLUSIONS ........................ 16

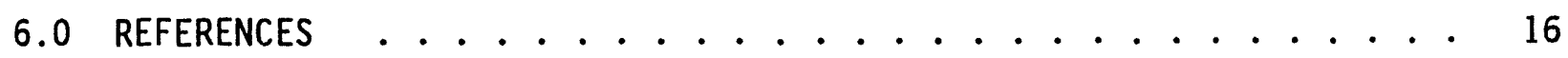

7.0 INFORMATION DISSEMINATION ....................... 17 


\section{COAL SCIENCE \\ EARTH RESOURCE EVALUATION AND MANAGEMENT}

\subsection{INTRODUCTION}

The general "Coal Science" objective of the Energy and Environmental Research Center (EERC) North Dakota Mining and Mineral Resources Research Institute (NDMMRRI) was directed towards a fuller utilization of energy and associated energy-related data, available as published and unpublished documents, to better evaluate resource potential through a thorough knowledge and understanding of the geologic context of the resource. This objective was implemented through computer-based data management systems involving specific field examples. Much of the coal data for the nonmarine Upper Cretaceous and Paleocene of the Western Interior of North America is 1ocked into a historic format that inhibits reinterpretation. Resource calculations are thus necessarily made on data that have typically 1) never been reevaluated, 2) been based on land surveys prior to the U.S. Geological Survey (USGS) 7.5-minute series mapping program, 3) been based on coal bed correlations that lack regional synthesis, 4) been based on coal bed correlations that lack temporal control, 5) been based on coal bed correlations that have not integrated surface and subsurface observations, and 6 ) been based on geologic observations that predate more rigorous approaches to stratigraphic nomenclature and field practices.

The initial development of the Coal Science project was based on previous knowledge as to the generalization and underutilization of a considerable amount of coal data in far-western North Dakota of the Williston Basin. Earlier work (Hartman, 1984) clearly indicated that the only expedient means of evaluating the numerous available geologic observations was to establish various systems that would allow for a wide variety of geologic observations to be easily cataloged, upgraded, and maintained. The Coal Science program was begun with these objectives.

Within the last three years, the central focus or theme of the Coal Science project has remained consistent. The focus was o develop and implement a (nonmarine) coal-oriented database management system that would permit (and document) the reevaluation and incorporation of a wide variety of data types (and qualities) to produce a uniform means of upgrading our understanding of the stratigraphic context of coal observations. A paramount objective of this system was that access to databases, their subsequent modifications, and the input and output of data be under the control of the primary user. The key word exemplifying the design of the computer system would be flexibility. In addition, the development of the databases would be based on a variety of test-case examples specifically chosen for their utility and variation. With this approach, databases would be revised or modified numerous times to meet specific project demands. Eventually, with the stabilization of the database design and field structure, database enhancements were added, such as improved relational database management features, that provided the user with considerably more computing power in the analysis and display of information.

In summary, the various databases of the Coal Science project, developed for the management of diverse coal-related stratigraphic and geochronologic 
information, have evolved from relatively simple useful designs to a system or complex of relatively sophisticated databases that are still fundamentally simple to operate, fulfilling the goal of maintaining user compatibility. Because of the basic software programming and the database design, established databases continue to grow and be utilized for a wide range of energy data management tasks.

\subsection{GOALS AND OBJECTIVES}

A summary of the tasks undertaken through the course of the Coal Science project represents a number of basic objectives. These include A) review of available database systems; B) acquisition of hardware; C) database design of the primary databases (e.g., *MNOS, *IJNIT, *LOC, and *SPP [see Section 3.3, Task (]); D) database input and augmentation; E) drilling project, used to assess and characterize database management of subsurface data through a specific case study; F) database design assessment and modification; G) geochemical database studies; $H$ ) data presentation, including various form designs, reports, export to graphic programming, and map display; and I) database implementation. Each of these lettered tasks was accomplished as part of an evolving process towards refining the capability of documenting and assessing the geologic context of coal bed data. There has not been, to my knowledge, a comparable approach to the reevaluation of historic coal stratigraphy within the context of modern geologic terminology and current field studies.

\subsection{ACCOMPLISHMENTS}

The following section will briefly detail the results of the various tasks as 1 isted above. This approach will show the continuity of the development of database management systems with the incorporation of old and new data to produce a synthesized product fully capable of resolving current resource assessment problems. As different tasks were assigned for each project year, the following task letters (e.g., "A") do not conform to previous usage. As enumerated here, these tasks represent a composite or synthesis of the goals and objectives of the Coal Science project.

\subsection{Task A-Review of Database Systems}

Previous experience suggested that currently available "off-the-shelf" data management and related programs were sufficiently robust to form the basis of the development of a Coal Science data management system. The following factors were considered in this decision: 1) the rapid and likely continued development of sophisticated commercial database management programs, 2) the substantial cost of in-house development of computer programming, and 3 ) the difficulty of assessing the NDMMRRI's overal1 1ongterm computer programming needs. Thus various programs were acquired and tested to determine the best data management system for use at the NDMMRRI. The general data management philosophy was to grow into a system, rather than force an approach because of programming limitations. The basic requirements of the system were that the 1) program designs be easily modifiable, and 2) data once entered be transferrable to other programs as new applications arise. 
The initial approach taken in database design and programming was to utilize a combination of a flat or semirelational data manager with a fully relational data managing system. This approach provided a powerful, yet easily modifiable, programming foundation, compatible with the then-current NDMMRRI user needs. The programs chosen for this purpose were Q\&Aं by Symantec and PARADOX ${ }^{\oplus}$ by Borland. Both programs are powerful, but differ in their approach to data management applications. Q\&A ${ }^{\oplus}$ is essentially a flat file manager with semirelational capabilities. PARADOX ${ }^{\circ}$ is a fully relational data management system with its own programming language.

Q\&A ${ }^{\oplus}$ has served as the main program for inputting, manipulating, and reporting 1 ignite, stratigraphic, and paleontologic data. Q\&A ${ }^{\mathbb{O}}$ differs from many programs (considered both a weakness and strength depending on the application) in its use of the "form" (versus table design) as the basis for data retrieva1. The main strengths of $Q \& A^{\oplus}$ are its 1) ease of data manipulation (within and between forms or as reported in tables), 2) available screenlength fields, 3) use of internal and multiple external (semirelational) lookup tables, 4) simple but powerful programming procedures, 5) full-feature use of macros, 6) special function keys for data entry replication, and 7) integration of file data with word processing and form merge capabilities. In regards to this later feature, $Q \& A^{\oplus}$ contains a word processor, known as the Write Module, that can be employed to utilize information from databases within Q\&A' 'S File Module. Thus text and data can be merged in any number of formats without redesigning files. Enhancement features (e.g., bold, italics, font scale) available to word processors can be added to data to clarify and augment data presentation. Bitstream fontware was acquired to permit the construction of Prestige fonts of any size and style (e.g., bold, italic, etc.) to allow for greater display power.

The cleverness of the overall design of $Q \& A^{\oplus}$ permitted the effective use of its most advanced functions without delay. Relational and programmable programs, such as PARADOX ${ }^{\circ}$, which are also simple to use at their basic level, become relatively complicated to achieve comparable Q\&A® results. For interactive daily use, where application needs change frequently, a computing system that is easily modified is required. Q\&A ${ }^{\top}$ works we 11 as a flexible on-line system for data inputting, updating, and retrieval. PARADOX ${ }^{\oplus}$, which is ultimately more powerful, represents application-oriented programming, which at this point in NDMMRRI data management considerations, is less important than flexibility. Compared to major-market database systems, such

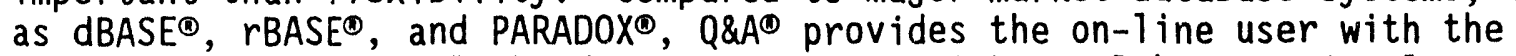
opportunity to control the data environment without elaborate ritual or protocol. In addition, the cost of $Q \& A^{\oplus}$, through the University of North Dakota, is inexpensive, and has now been acquired by a number of NDMMRRI users interested in expanding their database applications. PARADOX ${ }^{\circ}$ was initially used with $Q \& A^{\oplus}$ for certain data filing maintenance applications. PARADOX $\odot$ and $Q \& A^{\oplus}$ data files were exchanged using a common dBASE or ASCII interface. With the subsequent release of version 4.0 of $Q \& A^{\oplus}$, there has been no need for the continued use of PARADOX ${ }^{\oplus}$ within the developed Coal Science data management system. New $Q \& A^{\oplus}$ program features include 1) extended relational data management capabilities; 2) extended programming language; 3) increased (effectively unlimited) field length, with the capability of designing forms with portions of lengthy entries "hidden"; and 4) the ability to select data from pop-up windows for ease of database entry. Important secondary features include 1) word processing capabilities in the file module (e.g., within a 
given field), 2) spell checking in the File module; 3 ) the ability to change field names ("Set Field Names") for the purposes of programming and designing new forms in the Write module; 4) expanded macro program facilities, including creation of custom menus to manage access to directories and data; 5) new export and import capabilities with other database managers; 6) greater font control in the various modules; 7 ) a new compression backup utility; and 8) the ability to check for duplicate forms. Substantial use of these features has been made in the current design and implementation of NDMMRRI Coat Science databases.

\subsection{Task B-Acquisition of Hardware}

The decision was made early on that purchased computers would have to provide the most computing power for the available dollar. At the time the Coal Science project was undertaken, computing power, rated as machine clock speed, available RAM, caching systems, and available hard disk memory, was improving as the price was coming down. In effect, personal computers purchased through discount houses were never more powerful and, for the power, never cheaper. Through the course of the Coal Science project, computing power has continued to increase, and price has continued to drop. The major decision was to decide on the manufacturer. Gateway 2000 was chosen for the Coal Science project because, at the time, the prices of its computers were the least expensive, and the company's reputation was comparable to other discount mail-order houses. The more expensive computers, such as those manufactured by IBM, were as much as three to four times more expensive to achieve computing parity. In addition, there was no guarantee that the IBM machines would be more durable. An importan: earlier question was whether or not programming manufactured to run on IBM machines would properly run on IBM clones. To a large extent, these compatibility problems were becoming a thing of the past and were not found to be a problem using Gateway machines.

Through the course of the first year of the project, a computing systeni was established that used old and newly acquired components. The main data management computer was a Gateway $2000386-25 \mathrm{mHz}$ machine, with a math coprocessor, 150-MB hard drive, and memory and disk caching. A previously acquired EERC NDMMRRI computer was used for data input by NDMMRRI staff. This machine was a Standard 286, with a math coprocessor and 40-MB hard drive. The computers of the Coal Science data management system were cabled together for the transfer of files (not representing a true network). Data from either computer were outputted to either a Epson LQ-1050 wide carriage 1 ine printer or to a Hewlett-Packard Laser Jet II. Bitstream fontware was acquired to extend the flexibility of the output format to data management programs. The data and programming on the main data management computer was archived using an Everex external cassette tape backup system. Input devices include a previously acquired large format GTCO 2436L digitizing board and a video capture system by Jandel and Imaging Technology. Communication devices included a hardware link to the mainframe computing system at the University of North Dakota and a previously acquired MultiTech 1200-baud modem.

The above computing system has remained fully functional throughout the course of the project. Important changes to the system have been upgrades to various component parts to improve performance. These changes basically kept pace with changes in technology and advances in software capabilities, which almost required faster machines with bigger hard drives. The current 
operating system employs a Gateway 486-33 mHz machine with a 650-MB hard drive and caching capabilities as the main Coal Science data management computer. The $386-25 \mathrm{mHz}$ machine is used in software program development and data input, as we 11 as in generating reports and other documents. In addition, a Gateway $386 \mathrm{sx}$ and a Standard 286 computer serve as data inputting devices, most frequently staffed by students. Upgrades to the computers include another 150-MB hard drive for the 386 machine and another 40-MB hard drive for the 286 machine. In addition to the large-format GTGO pad, used primarily for digitizing large maps, a small-format Summagraphics SummaSketch ${ }^{\text {m }}$ II digitizing tablet was installed to function with various types of software used to construct charts and maps (see Task A). In addition, the HewlettPackard Laser Jet II was replaced with a Laser Jet III to improve graphic capabilities and provide for significantly greater font control.

To explore the capabilities of image analysis, which represents an important developing technology, a video system was acquired to capture and analyze a variety of image types that would otherwise have to be manually digitized or be treated qualitatively. The video system hardware runs on the main data management computer utilizing a PCVISIONplus ${ }^{\text {m }}$ framegrabber from Imaging Technology. This video image is derived from a Cohu CCD camera, lens (12.5- to 73-mm zoom), and TOYO diopters and is displayed on a high-resolution SONY Trinitron monitor. Photographs of captured or live video images are acquired from a SONY UC-850 video graphic (thermal) printer. The video system uses specialized programming to capture gray tone images for digitizing and numerical analysis. Initial hardware system incompatibility problems consisted of memory conflicts between video cards, capture programming, and the EVEREX tape backup system. These problems were initially resolved by establishing appropriate protocol (programming) to reconfigure the hardware for different applications. Thus the video system runs under its own configuration to resolve its hardware-specific requirements. In addition, high-contrast image problems, resulting primarily from camera low-light oversensitivity, were resolved through the acquisition of programming that permits control of image contrast outside of the imaging software environment. Subsequently, both the capture board and software (see Task A) were upgraded to take advantage of significantly improved image capture features and extended analysis capabilities. The older capture board will be installed on a different computer and used for macroimaging (discussed below) when laboratory space becomes available with the completion of a current construction project at the EERC.

As developed, the video system can capture images for analysis at three scales or levels of magnification: 1) large or macrosize objects (from 10 to $500 \mathrm{~mm}$ in length), 2) small three-dimensional objects (from 1 to $50 \mathrm{~mm}$ in length), and 3) very small or microsize, effectively two-dimensional, objects (less than $1 \mathrm{~mm}$ in size). Large-scale objects are viewed directly with the Cohu camera system. The camera and attachments are mounted directly to a modified Kodak MP3 copy stand. To facilitate the control of lighting during video photography, the copy stand was rewired so that each of the four highintensity lamps could be individually regulated. Relatively small specimens, or the closeup study of large specimens, require macrophotography. To achieve the ability to examine samples of this small size, a video-ready olympus stereomicroscope was acquired and integrated through a coupler to the video camera. This video system provides magnification from about $2.5 \mathrm{x}$ through about 50x and was used for image capture analysis and photography of nonmarine 
mollusks and mammals used in the environmental reconstruction and biochronologic organization of coal strata. Objects of microsize are studied under thin-section with high-powered stereomicroscopes. An EERC Zeiss microscope has been available for the purpose of video imaging of pollen for analysis. A video/microscope coupler, specific to Coal Science imaging research, was manufactured by Diagnostic Instruments to permit video numerical analysis of objects magnified up to $500 x$.

\subsection{Task C-Database Design and Modifications}

Several purposes are served by database management procedures. The foremost is the utilization of data in an effective manner. "Effective," however, is relative depending on goals and means of analysis available at a person's disposa1. An understanding of coal resources and their 1itho- and chronostratigraphic context were "effectively" met 70 years ago under the goals of the time. Today's goals are different only in that we require (or want) greater precision in our assessments of resource characterization and context, which necessitates more data more rigorously controlled to serve specific purposes. Resource management is in a state of flux, in part, because the techniques of database management are undergoing a revolution for the individual user due to advances in computer technology and software development. Computer-based data management applications require flexibility (and transportability) while we take advantage of developments in off-theshelf data acquisition, management, and display programming.

The data management program $Q \& A^{\oplus}$ by Symantec is particularly well-suited to the nature of geologic data where 1) a wide range of information types are employed to manage closely related and disparate data types; 2) applications vary, and form and report modifications are made frequently; and 3) extended documentation is necessary to track on inputted numeric and descriptive data. The primary $Q \& A^{\circ}$ form design is more appropriate than a table design employed by most other data managers.

Four main $Q \& A^{\oplus}$ databases control NDMMRRI data types: 1) geologic section or observation location information (*MNOS), 2) geologic section unit descriptions (*UNIT), 3) paleontologic specimen location and stratigraphic information (*LOC), and 4) taxon identification information (*SPP). The prefix "*" denotes a specific file name, such as "WB" for Williston Basin. A number of other databases are employed to "feed" basic information to these primary databases. These secondary databases serve several useful functions in promoting control over frequently general (descriptive) information. Examples of secondary databases include EPCODES (chronostratigraphic terminology), FMCODES (1ithostratigraphic terminology), COLOR (color coding, as per the Geological Society of America's Rock Color Chart (with Munsell color standards), and MAPS (U.S. Geological Survey 7.5-minute, 1:24,000-scale topographic quadrangles).

The *MNOS files contain information on the location of geologic observations, such as surface and subsurface measured sections. The *MNOS form contains 141 fields, representing four major types of field data: 1) reference information, including numbering systems; 2) location and landowner information; 3) 1itho- and chronostratigraphic information, including section thickness and elevation data; and 4) sample and specimen 
information. A detailed description of *MNOS field types, along with examples of forms and data, was presented by Hartman (1992).

The companion file to the *MNOS database is the *UNIT database. Like *MNOS files, a number of *UNIT databases use fields designed for restrictedvalue internal lookup tables. *UNIT files have 84 fields specific to the reference, measurement, and description of a unit (or bed) in a geologic section. A "unit" is a stratigraphic interval, identified by the geologist, that is sufficiently distinct from 1 ithologies above and below to represent a discrete portion of the overall geologic section. *UNIT databases can be related to *MNOS databases through the creation of derived fields in the Report Module of $Q \& A^{\oplus}$, thus expanding the capability of sorting *UNIT files on additional reference and location information. The majority of the *UNIT fields concern the naming, measurement, and description of unit data. As examples, the unit (bed) name and formational assignment are given also with necessary comments on revised lithostratigraphy. The unit thickness can be directly inputted in English (including nondecimal entries) or metric units, with automatic conversion to respective fields, or the thickness can be calculated from scaled measurements taken from drawings or photographs. Unit thickness can also be calculated from original structural data (e.g., pace and compass method) associated with the measurement of either the unit itself or the section in which it is found). The unit (or bed) description can be quoted in full from the original source and can be separated into its component parts to permit uniform interpretation and sorting on specific data types (e.g., fresh and dry colors, as per the Geological Society of America). *UNIT files use the COLOR and STRATCOL/STRATA files as external lookup tables to import color values and graphic and weathering symbol codes directly into a *UNIT database. Other fields manage information to provide uniform coding procedures for specific projects (e.g., NCRDS data fields) or computer programs (e.g., STRATCOL/STRATA). For example, the *UNIT database is designed to generate reports for the program STRATCOL/STRATA. With only minor modifications, these files can be directly read by STRATCOL/STRATA, thus quickly producing a graphic representation of the geologic unit. A detailed description of *UNIT field types, along with examples of forms and data, was presented by Hartman (1992).

* LOC files contain records on fossil localities and are specifically designed for micro- and macrofossil specimens. The * LOC file is similar to * MNOS files in general design, containing the nearly the same fields for reference and location data. Like the *MNOS form design, *LOC files contain a number of coding fields that are used for sort routines of age-related information and use the MAPS file as an external lookup table for map reference information. Also like *MNOS databases, *LOC databases use fields designed with restricted-value internal lookup tables (see discussion under $Q \& A^{\circledast}$ file modifications). *LOC files contain 138 fields organized into the following major field types: 1) reference information, including numbering systems, and a number of specialized fields for record management; 2) location systems, including elevation data; 3) 1itho- and chronostratigraphic information; and 4) paleontologic data. The * LOC database stratigraphy fields differ from *MNOS databases, in part, in that fields are designed to permit precise reference of a fossil locality to an intra- or extraformational stratigraphic marker or horizon. In addition, a locality can be placed in reference to the base or top of the enclosing formation. Various code fields document the predicted error associated with the placement of a locality relative to any of 
these horizons. Besides these "relative" stratigraphic fields, the elevation of a locality and its interpreted error can also be inputted. A11 of these fields can be entered in either English or metric units, with automatic conversion to respective fields. * $* 0 C$ database fields specific to paleontology are primarily concerned with the record of fossil discovery, collection, and identification. A detailed description of *LOC field types, along with examples of forms and data, was presented by Hartman (1992).

The *SPP database is a companion to *LOC files' and records' detailed information on the identification of taxa from a particular locality. The *SPP database can be used as an external lookup table to combine taxon identifications with stratigraphic and location data. Field types of the *SPP database include 1) taxon identification, 2) a simplified classification of the taxon, 3) repository and specimen numbers, 4) number of specimens, and 5) identification comments. Both old and revised identifications are recorded to provide a history of study on specific specimens and taxon names. *SPP uses the database MCLASS as an external lookup table to extract classification data. With *SPP, *LOC, and MCLASS databases, the stratigraphic range of taxa can be determined through a merge of the data from the three files.

\subsection{Task D-Database Input and Augmentation}

The geologic exposures of far-western North Dakota are largely derived from the drainage patterns produced by the Little Missouri and Missouri Rivers. The relatively good outcrops along these rivers and some of their tributaries have been the source of many independent coal and noncoal studies. Much of these data has never been assimilated for the purposes of detailed coal correlation, and is, for the most part, not part of any database system. As part of this Coal Science database design and management program for Williston Basin, selected stratigraphic data were cataloged and computerized from data sources relevant to exposures along the Little Missouri and Missouri Rivers in western North Dakota and adjacent areas in the drainage of the Yellowstone and Missouri Rivers in eastern Montana. Input study areas in North Dakota included 1) Bowman, Slope, and western Adams and Hettinger Counties; 2) Billings and Golden Valley Counties; and 3) McKenzie and Williams Counties. These county-based areas represent, to a certain extent, we11defined input data sets, based on the nature of available outcrops and county surface and subsurface studies. The input coverage in the adjacent counties in Montana is less comprehensive, which simply reflects project goals focused in North Dakota. Coverage in Montana included Roosevelt, Richland, Dawson, Wibaux, and Falion Counties. The stratigraphic data inputted for North Dukota represent primarily the Fort Union Group, which includes the Ludlow, Cannonba 11, Slope (upper Ludlow of some authors), Bullion Creek (= Tongue River in adjacent Montana), and Sentinel Butte Formations. The following M-number geological observations have been recorded in North Dakota: 1) 609 in Bowman County, 2) 49 in Adams County, 3) 1675 in Slope County, 4) 63 in Hettinger County, 5) 423 in Golden Valley County, 6) 344 in Billings County, 7) 178 in McKenzie County, and 8) 203 in Williams County. In Montana, M-number geological observations have been inputted as follows: 1) 64 in Roosevelt County, 2) 72 in Richland County, 3) 151 in Dawson County, 4) 110 in Wibaux County, and 5) 56 in Fallon County. In addition to these records, geologic observations were also recorded in the Williston Basin of northwestern South Dakota and east-central Montana. As part of this research, an annotated bibliography of unpublished and published coal-related observations 
has been compiled to facilitate computerization (see Hartman, 1992). In total, over 33,000 *UNIT forms were entered as part of the data input and augmentation portion of the Coal Science project.

A7though *MNOS and *UNIT information is computer-accessible, data management procedures were facilitated for a number of purposes by the creation of a paper-based "library" of computerized data. This entails, as necessary, the assembly of the original published and unpublished sources of the M-numbered sections (*MNOS and *UNIT databases) and ordering them in a set of (currently 30) ring binders for archival purposes. An archived hard copy system provides a permanent method of verifying the use of the M-number assigned to a particular geological observation.

\subsection{Task E-Drilling Project}

The drillirg and logging of test holes in far-western North Dakota was undertaken to 1) provide fundamental information on data management problems associated with subsurface litho-, bio-, and chronostratigraphic correlation of Paleocene lignite-bearing strata in western North Dakota and easternmost Montana, and 2) determine the most useful means of incorporating, managing, and interpreting the derived information. The two sites chosen were in northwestern Slope County (M2187) and in southwestern Golden Valley County (M2188), North Dakota. The strata represented by these sites include uppermost Cretaceous Fox Hills and Hell Creek Formations and the lower and middle Paleocene Ludiow, Slope, and basal Bullion Creek Formations. One of the sites (M2187) is located in the immediate vicinity of the stratotype of the Slope Formation. Both sites are on U.S. Forest Service property and required permits for access and drilling. As per permit requirements, geophysical and lithic data were submitted to the U.S. Forest Service as part of permit obligations associated with the drilling of two holes in slope and Golden Valley Counties, North Dakota.

Hole M2187 was drilled through strata of the Slope and Ludlow Formations of the Fort Union Group, the Hell Creek Formation, and into the Fox Hills Formation to a depth of $1040 \mathrm{ft}$. Hole M2188 was drilled from a higher stratigraphic level, intersecting strata of the Bullion Creek, Slope, and Ludlow Formations of the Fort Union Group and ended in the Hell Creek Formation at a depth of $760 \mathrm{ft}$. A record of lithic samples and a driller's log were made at both holes. Subsequently, both holes were plugged and restored.

During the course of the drilling activity, two surface sections were measured adjacent to the dri11 sites (M2252 for hole M2187, and M2253 for hole M2188). These sections were completed specifically to provide control on subsurface interpretation of the geophysical and drill sample record. A detailed comparison was made of the various overlapping portions of these records (see Hartman, 1991a). The primary data associated with drilling project included 1) the driller's record, 2) the lithic log, and 3) the geophysical logs. As a result of the drilling program, minor modifications were made to *MNOS and *UNIT files (designed under the program Q\&A® by Symantec). Data from both drill holes were incorporated into geologic cross sections summarizing the coal bed stratigraphy of Slope, Golden Valley, and Billings Counties. Secondary data derived from the dritl hole were the palynomorph analyses of "mud" lithic samples. Selected horizons were 
processed for palynomorphs to derive biochronological and environmental information on the coal-bearing strata associated with the transgressiveregressive events associated with the Cannonball Sea and the coal strata generally marking the Cretaceous-Tertiary $(K / T)$ boundary. Palynomorph and associated sedimentological studies were undertaken by Mr. Timothy J. Kroeger of the University of North Dakota Department of Geology and Geological Engineering (additional discussion under Research Studies).

\subsection{Task F-Database Design Assessment and Modifications}

The designs of all of the Coal Science databases were assessed and redesigned essentially on a continuous basis. Early changes in *MNOS, *UNIT, and * LOC database designs usually were the result of the determination of the need for a new field based on implementation of a database (as per examples in Task I, Section 3.9) and the drilling project (Task E, Section 3.5) Thus user needs were clearly defined by test case examples indicating what type of data control was required to produce the desired results. The designs of databases were also modified as a result of database augmentation. The need for faster and more accurate methods for data entry produced a number of substantial improvements in both field structure, nomenclature, and associated programming. Many of these improvements would probably not have been developed if relatively large and varied data sets had not been part of the Coal Science program. Many advanced data entry features, such as lookup windows for restricted data entry, required more initial setup on the part of the systems operator, but these efforts were more than repaid by the reduction in subsequent editing of inputted data.

Selected modifications to Q\&A๑ *MNOS, *UNIT, and * LOC databases included the following types of programming statements: 1) referential structure within a database, 2) set initial values, 3) data management of forms, 4) data management of forms between related databases, 5) conversions of various types of numeric data for ease of data entry and reporting, 6) numeric calculations to acquire standard input values, 7) internal lookups for data entry, and 8) external lookups for data entry. "Referential structure within a database" refers to the existence of the appropriate numbering system (e.g., M-number) and reference occurring at the top of each screen (e.g., five screens are used for the * $\angle O C$ database). "Set initial values feature" refers generally to log-on dates, enterer, or other consistent information for a data set to be entered in a form. This information is automatically entered upon adding a new form to a database. "Data management of forms" refers to date and time fields that automatically record any changes occurring to a particular form. "Data management of forms between related databases" refers to external lookup checks to determine if certain forms or values of importance to related forms in different databases have been entered and/or entered correctly. "Conversions of various types of numeric data" refers to 1) English-metric conversions for elevation, distances from section lines, relative stratigraphic horizons, unit and section thickness; 2) lettered section subdivision (e.g., abcd sec. 2) conversions to legal subdivision (e.g., NE $1 / 4 \mathrm{NW} / 4 \mathrm{SW} / \mathrm{SE} / \mathrm{h} \mathrm{sec}$. 2 ); and 3) generalized legal subdivision conversions from given distances from section lines. "Numeric calculations to acquire standard input values" refers to 1) the (automatic) determination of cumulative footages (in *UNIT databases) of geologic sections; 2) the determination of unit or section thicknesses from strike, dip, and pace information (various trigonometric calculations); and 3 ) the determination (under certain circumstances) of the 
stratigraphic horizon (such as the bottom of a unit) from other given values. "Internal lookups for data entry" refers to the use of popup windows for the selection and entry of (restricted) field values. Internal lookups of this type have been designed for STRATCOL/STRATA 1ithic categories, names of formations, crew chiefs, collectors, discoverers, reference citations, institutions, states, field areas, and regions. "External lookups for data entry" refers to the use of external (other) databases to enter specified values into appropriate (programmed) fields. External lookups are used in access quadrangle data (e.g., year, series, contour interval, etc.), color nomenclature, codes for series (epochs), stages (ages), formations, levels, and STRATCOL/STRATA graphic parameters.

Besides the *MNOS, *UNIT, and * LOC file modifications mentioned above, database "form" design modifications were made to a number of Write module output forms. A7so, databases, such as SPEC, were constructed for the purpose of controlling data associated with collected samples and for printing collection labels. The greater font control, available with Version 4 of $Q \& A^{\odot}$, makes possible the printing of the necessarily small form designs and associated data. Multiple copies of appropriate forms (for samples from the same location) are then easily produced in the merge-data portion of the Write module.

\subsection{Task G-Geochemical Database Studies}

In the context of the present coal Science program, the purpose of designing a coal geochemical database, or any other similar analysis-type database, was to place such observations into a geologic framework. Thus geochemically oriented data can be integrated with stratigraphic and paleontologic databases to better facilitate the reconstruction of paleoenvironments and produce more definitive coal-related stratigraphic correlations (e.g., coal bed finger printing). Such abilities thus afford a more comprehensive and meaningful interpretation of geologic history.

Isolated coal analyses, without geologic context, have limited (almost no) value in providing a means to correlate coal beds and coal-forming environments or to interpret depositional or diagenetic histories.

For the purposes of present database considerations, coal and rock geochemical data were downloaded from a mainframe database constructed for another project by LeFever and Murphy (1983). This data set was chosen because it was originally constructed using mainframe programming for the purpose of posing questions of concern to individuals in coal resource assessment. These databases incorporate standard analytical data (e.g., Btu value, sulfur content, etc.) along with stratigraphic and geographic data. Utilizing Q\&A®, *MNOS, and *UNIT files and formats, relatable geochemical databases were designed for 1) geographic, geologic, and bibliographic data; 2) Iithologic data; and 3) coal chemistry data (see Hartman, 1992 for discussion of databases and examples). All of the available data, representing several thousand initial observations, were incorporated into the above specifically designed $Q \& A^{\circledR}$ databases. Unfortunately, very few chemical observations can be tied to specific stratigraphic sections, let alone their placement relative to specific horizons. The use of the Lefever and Murphy (1983) database clearly illustrates the problems attendant in the taking, recording (in the field), and tracking of geochemical data by earlier coaloriented projects. A very low percentage of the "coal geochemistry" data can 
be specifically tied to a specific coal bed or even to a specific point on the ground. Thus much good geochemical data is of immediately limited value beyond its original intent.

\subsection{Task H-Data Presentation}

Display of information in maintained databases is the most important aspect of database utilization for the research scientist. Database management programs, such as $Q \& A^{\oplus}$, provide a means to show data in various output formats used to organize data for research and general publications, technical reports, presentations, and for the construction of illustrations, tables, and slides. Data are most commonly displayed in tables, as rows and columns of observations, or in forms, depending on the nature of the intended use. In addition, graphical representation of data is particularly important where data are inherently visual (e.g., geologic sections) or numeric (e.g., analyses). Of considerable importance to data visualization is the ease with which the data can be displayed. The visualization of data should be used as a tool in data analysis and not as an end in itself. The more easily data can be viewed, the more likely it will be used as a tool to permit the researcher to make better interpretations.

Along this line of reasoning, a number of modifications were made to the public domain program STRATCOL by Peter Guth (now referred to as STRATCOL/STRATA to denote the substantial number of changes that have been made to the program). STRATCOL/STRATA produces a graphic presentation of geologic logs from Q\&A ${ }^{\oplus}$ *UNIT database files. Improvements that have been made to STRATCOL include 1) a more comprehensive and realistic symbol 1ibrary, maintained as the Q\&A® external lookup file STRATCOL; 2) an accurate representation of metric or English scale (at whatever scale chosen); 3 ) available choices of geologic column width; 4) appropriate column display for either surface or subsurface sections; 5) two columns for unit annotations; and 6 ) elimination of restrictions on input file size and scale selection. Through the use of $Q \& A^{\circledR}$ and STRATCOL/STRATA, a graphic representation of a geologic column can be produced with a laser printer in a matter of a few minutes. Several hundred stratigraphic columns were produced at a variety of scales for numerous purposes through the course of Coal Science studies (see, for example, Hartman, 1991a).

A dual base map system was also developed to display and document coal Science project data for detail and general purposes. Geological and paleontological observations in *MNOS and *LOC databases were plotted on U.S. Geological Survey (USGS) 1:100,000- and 1:24,000-scale topographic maps covering far-western counties of North Dakota and adjacent areas in Montana. Most locations were plotted on linen-backed mosaics of $0.5^{\circ} \times 1^{\circ}, 1: 100,000$ topographic quadrangles for general display purposes. These mosaics were constructed to best reflect the likely distribution of data for certain study areas, including 1) the Fort Union corridor of Williams and McKenzie Counties, North Dakota, and Roosevelt and Richland Counties, Montana; 2) the northern portion of the Little Missouri River, McKenzie County, Montana; 3) the main north-south drainage system of the Little Missouri River in Billings and Golden Valley Counties, North Dakota; and 4) additional natural outcrop and subsurface study areas in Slope and Bowman Counties, North Dakota. Largescale maps (i.e., 1:24,000 scale) have both utility for both display and 
documentation of location and topographic information. Note that many coalrelated observations were originally collected without regard to elevation. Plotting on large-scale topographic maps provides the opportunity, given the nature of the observations, to closely approximate the elevation of a particular observation. Such controlled information is of considerable importance in attempting to correlate and contour a variety of geological data types. These maps can also be used as the basis for digitizing coal and related geological observations for use in geographic information system programming and geologic software.

In addition, numerous $Q \& A^{\oplus}$ Write module form reports were implemented throughout the course of Coal Science studies. These reports constitute a combination of primary text and merger of information from selected databases (for examples, see Hartman, 1992). Write module forms provide an additional means of cataloging selected data into whatever project-specific format is appropriate. Effectively, databases can be redesigned to meet any display need without affecting the primary form of the database file.

\subsection{Task I-Database Implementation}

Implementation or utilization of a database is the best means to realize the requirements for its effective use. Field, laboratory, and computer-based activities have greatly facilitated the diverse requirements for the construction and revision of Coal Science database systems. The use of databases as tools in research, rather than as a means simply to gather data for the purposes of generalization, provides a much more rigorous bas is for testing their design and utility. A few selected projects are discussed in the following section (see the section on Information Dissemination for a comprehensive list of projects utilizing Coal Science databases). In addition, I have included graduate and undergraduate student projects that have substantially benefitted from Coal Science databases. These projects included sedimentologic, lithostratigraphic, biochronologic, and paleoenvironmental research directed towards establishing a more rigorous basis of interpreting the coal-bearing strata of the northern Great Plains.

Research was undertaken in preparation of a manuscript with $\mathrm{Dr}$. Alan Cvancara of the University of North Dakota Department of Geology and Geological Engineering on the "Paleocene Stratigraphy and Molluscan Paleontology of the Cannonball (Brackish) and Ludlow (Nonmarine) Formations in Southwestern North Dakota." This work represents the essence of coal-based data management for the purposes of coal correlation. The above project represents the correlation of coal-bearing strata of the Slope (Ludlow of some authors) Formation in southern Golden Valley and Slope Counties, southwestern North Dakota. This work summarizes the stratigraphic occurrence of coalbearing strata relative to the occurrence of brackish water and freshwater fossils. All of the 110 plus sections and isolated geological observations are managed in $Q \& A^{\oplus}$ databases and have been graphically illustrated through modifications to the program STRATCOL/STRATA developed over the last one and a half years. On the basis of the stratigraphic framework 1) revised coal correlations has been proposed, 2) coal bed nomenclature has been revised, 3 ) the distribution of the tongues of the Cannonball Formation has been graphically illustrated, 4) the tongues of the Cannonball Formation will be formally named, and 3) the stratigraphic distribution of over 150 fossil localities has been plotted, providing a temporal and environmental context 
for interpreting the geologic history of the area. This work permits the construction of coal isopach and structure contour maps for the area. This study thus provides a foundation for the stratigraphic and paleoenvironmental interpretation of lower and middle Paleocene coal-bearing strata in southwestern North Dakota.

Research presented at an annual meeting of the Geological Society of America (GSA) summarized research conducted on the stratigraphy and molluscan paleontology across the Cretaceous-Paleocene boundary in the northern Great Plains (Hartman, 1991b). Information utilized in the preparation of this paper was derived from databases maintained in Q\&A® for the Williston, Powder River, and Crazy Mountains Basins in the northern Great Plains of the United States and Canada. Research delimited the occurrence of certain taxa through the uppermost Cretaceous Hell Creek and Lance Formations and Paleocene Ludlow, Tullock, and Bear Formations, providing biochronologic control for temporal correlations across North Dakota, Montana, Wyoming, and Saskatchewan.

A publication with Dr. Allen J. Kihm of Minot State University was presented as a poster session at the Sixth International Williston Basin Symposium (and Fourth Saskatchewan Petroleum Conference) in Regina, Saskatchewan. This paper concerned the stratigraphic and biochronologic context of pantodonts (vertebrates) in North Dakota. By more rigorously defining the stratigraphic and geographic position of a number of localities, the stratigraphic distribution of this group has been shown to be more temporally restricted than previously understood. This type of information permits more precise temporal (biochronologic) correlation of the coal-bearing strata of the upper Bullion Creek (Tongue River of some authors) and Sentinel Butte Formations. All of the stratigraphic and paleontologic data used to construct this paper and associated figures were organized through Q\&A( databases developed and tested through coal Science field and laboratory research.

Collaborative research, undertaken with Dr. David Krause of the State University of New York at Stony Brook, has resulted in a number of ongoing projects concerning the temporal organization of coal-bearing strata in the northern Great Plains. Such information bears on the development of an understanding of the chronology of the Cretaceous/Tertiary transition, representing a shift in paleoenvironments from noncoal to coal-dominated settings in this area and in the timing of the advances and retreats of the Cannonball Sea and associated coal-forming environments.

Research of T.J. Kroeger. Mr. Kroeger, a Ph.D. candidate in the University of North Dakota Department of Geology and Geological Engineering, undertook dissertation studies entitled "Paleoecology of Palynomorph Assemblages in the Upper Ludlow Formation (Paleocene), Southwestern North Dakota." Mr. Krneger's research has made extensive use of Q\&A® Coal Science databases, including the *MNOS and *UNIT databases, as we11 as others that have been specifically designed for sample record keeping in the laboratory and as acc:ession records into the collections of the University of North Dakota. Mr. Kroeger is in the process of analyzing and interpreting the palynomorph-bearing sediment samples for brackish and marine indicators to provide greater resolution in interpreting these environments in the western Slope and southwestern Golden Valley Counties, North Dakota, and in Dawson County, Montana. In addition to his dissertation studies, his research has 
identified the Cretaceous-Tertiary boundary in surface and subsurface samples in Slope County, North Dakota, and in surface samples from Makoshika State Park, Dawson County, Montana. This information will be used in conjunction with age information interpreted from the nearby Hiatt mammal locality for the purposes of establishing a chronostratigraphic framework for the transition between largely nonlignite-bearing to lignite-bearing strata along the Yellowstone River and el sewhere.

Research of W.D. Peck. Mr. Peck completed his Master of Science degree in the Department of Geology and Geological Engineering at the University of North Dakota. His project was entitled "The Stratigraphy and Sedimentology of the Sentinel Butte Formation (Paleocene) in South-Central Williams County, North Dakota." Mr. Peck made extensive use of Q\&Aं *MNOS and *UNIT databases for his stratigraphic and sedimentologic studies. As a part of current related studies, Mr. Peck, with Dr. Allen J. Kinm and this writer, has attempted to construct a coal-based correlation framework for the area between the Nesson Anticline and Fort Union. This effort utilizes the relatively numerous isolated reports of coal along the Missouri River that have been computerized into *MNOS and *UNIT databases. Aspects of our study were incorporated into Mr. Peck's thes is research.

Research of M.M. Rolland. Ms. Rolland has undertaken a senior thes is project, under this writer's supervision, in the Department of Geology and Geological Engineering at the University of North Dakota. The project is entitied "A Faunal Comparison of Selected Freshwater Mollusks from the Upper Cretaceous (Edmontian?) Fruitland Formation of the San Juan Basin, New Mexico, with the Hell Creek Formation (Lancian) of the Williston Basin, Montana-North Dakota." Ms. Rolland's study involves the paleontologic and stratigraphic study of nonmarine mollusks from the coal-bearing strata of the Williston Basin of North Dakota and Montana and the San Juan Basin of New Mexico. Research will be directed towards understanding the evolutionary history of selected nonmarine molluscan taxa to provide a more rigorous biochronologic framework for the correlation and paleoenvironmental interpretation of nonmarine strata in the Upper Cretaceous strata of the western interior of the United States. Studies to date have utilized Coal Science data management systems (i.e., *LOC database) to revise geologic and paleontologic data concerning relevant strata in North Dakota.

\subsection{FUTURE STUDIES}

Coal Science data management research effectively represents an ongoing process of development and utilization. The Coal science database management system serves and can serve in the future as 1) a means of tracking coaloriented geologic data, regardless of current project needs; 2) a means of utilizing these data for projects that can be specifically generated within the framework of established or possible $Q \& A^{\oplus}$ database programming; and 3) a front end for generating information in a format acceptable to other programs that may inherently not be well suited for data management (e.g., various types of graphics, or modeling, mapping programs). The approach taken in the Coal Science program has shown considerable success in all aspects of the three avenues of future studies given above. In almost all ways, these uses of Coal Science database management research are mutually compatible and 
necessary pathways to productive and rigorous use of any and all geographically and stratigraphically oriented coal data.

\subsection{SUMMARY AND CONCLUSIONS}

The general Coal Science objective of the EERC NDMMRRI was directed towards more effective and efficient use of geologic observations specific to the correlation and assessment of coal-bearing strata. The utilization of these observations required streamlined but flexible user-oriented data management programs that incorporated straightforward data inputting and output in the form most convenient for the user. Substantial amounts of currently useful and historically invaluable geologic data bearing on the correlation of coal beds are available for most coal-bearing areas. This is certainly the case in the lower Tertiary strata of the northern Great Plains in general and in western North Dakota specifically. This information exists as published and unpublished but accessible documents. The specific objective of this project was to implement, through computer-based data management systems, site-specific test-case field studies that utilized all currently available information for the assessment of efficient database management techniques in the evaluation of specific coal correlation problems. This project was fundamental to coal resource and geologic studies undertaken by the EERC. By its very nature, the Coal Science project has been unique in its blend and utilization of 1) historic and current coal-oriented geologic observations, and 2) in its use of 1itho-, bio-, and chronostratigraphic data to forge a geologic framework for refined coal correlation. The approach has been multidisciplinary and aimed at resolving specific questions beyond the scope of narrowly focused vested interests.

The focus of the first phase of this project was to establish the computerized basis for reevaluating North Dakota's lignite resource in a stratigraphic and paleontologic context. The goal of the second phase of the project was to establish realistic database case studies, including surface and subsurface data specifically taken with the design and construction of stratigraphic and paleontologic databases as a resulting product. The third phase was to set new and greater demands on the stratigraphic database design. Several thousand surface and subsurface data entries have been compiled from the uppermost Cretaceous and Paleocene Fort Union coal region of the Williston Basin, including far-western North Dakota and adjacent easternmost Montana. Database designs have continued to be modified to reflect a greater knowledge on the demands and needs of the end user. Unlike other databases that are constructed to summarize the data compiled, database research under the Coal Science program has attempted to design a flexible data management system that serves an ongoing interactive need to answer previously unconsidered resourcebased questions.

\subsection{REFERENCES}

Hartman, J.H., 1984, Systematics, biostratigraphy, and biogeography of 1 atest Cretaceous and early Tertiary Viviparidae (Mollusca, Gastropoda) of southern Saskatchewan, western North Dakota, eastern Montana, and northern Wyoming [Ph.D. thesis]: Minneapolis, University of Minnesota, 928 p., 19 pls. 
Hartman, J.H., 1991a, Coal science: Earth resource evaluation and management: Semiannual technical report for the period January-June 1991: DE-FC2186MC10637, EERC publication.

Hartman, J.H., 1991b, The stratigraphic distribution of nonmarine Mollusca across the Cretaceous-Tertiary boundary in the northern Great Plains, in the theme session "Nonmarine fossil record at the Cretaceous-Tertiary boundary": Geological Society of America, Abstracts with Programs, v. 23 , no. 5, p. A359 (includes presentation).

Hartman, J.H., 1992, Coal Science: Earth resource evaluation and management: Semiannual technical report for the period January-June 1992: DE-FC2186MC10637, EERC publication.

LeFever, R.D., and Murphy, E.C., 1983, Mining resources and potential problems associated with mining of Cenozoic rocks of the Williston and Powder River Basins, northern Great Plains: North Dakota Mining and Mineral Resources Research Institute, Bullet in No. 83-09-MMRRI-01, $170 \mathrm{p}$.

\subsection{INFORMATION DISSEMINATION}

The following professional publications, presentations, poster sessions, and reports were producing during the three-year Coal Science program. The list of entries is arranged in chronological order and is annotated to indicate presentations.

Hartman, J.H., 1989a, The T Cross Coal Bed (Paleocene, North Dakota): The importance of reevaluating historic data in geologic research: North Dakota Academy of Science, Proceedings, 81st Annual Meeting, v. 43, p. 49 (includes presentation).

Hartman, J.H., 1989b, Stratigraphy of uppermost Cretaceous and Paleocene nonmarine Mollusca in the Crazy Mountains Basin, south-central Montana: Montana Geological Society, 1989 Field Conference Guidebook, Montana, Centennial Edition, Geologic Resources of Montana, v. I, p. 163-172.

Hartman, J.H., 1989c, Coal science: Quarterly technical progress report for the period July-September 1989: DE-FC21-86MC10637, EERC publication.

Hartman, J.H., Buckley, G.A., Krause, D.W., and Kroeger, T.J., 1989, Paleontology, stratigraphy, and sedimentology of Simpson Quarry (Early Paleocene), Crazy Mountains Basin, south-central Montana: Montana Geological Society, 1989 Field Conference Guidebook, Montana, Centennial Edition, Geologic Resources of Montana, v. I, p. 173-185.

Hartman, J.H., Krause, D.W., Buckley, G.A., and Kroeger, T.J., 1989, Paleocene biochronology in the northern Great Plains: Nonmarine Mollusca and mammals from the Crazy Mountains Basin: Montana Geological Society, 1989 Field Conference Guidebook, Montana, Centennial Edition, Geologic Resources of Montana, v. II, p. xii-xiii (includes presentation).

Hartman, J.H., 1990a, Coal science: Quarterly technical progress report for the period October-December 1989: DE-FC21-86MC10637, EERC publication. 
Hartman, J.H., 1990b, Paleocene and Lower Eocene nonmarine molluscan biostratigraphy of the Powder River Basin, Wyoming-Montana: Geological Society of America, Rocky Mountain Section, Abstracts with Programs, $v$. 22 , no. 6, p. 14 (includes presentation).

Hartman, J.H., 1990c, Coal science: Quarterly technical progress report for the period January-March 1990: DE-FC21-86MC10637, EERC publication.

Hartman, J.H., 1990d, Coal Science: Annual technical progress report for the period July 1, 1989, through June 30, 1990, including the quarterly technical progress report for the period April through June 1990: DE-FC21-86MC10637, EERC publication.

Hartman, J.H., 1990e, Coal science: Earth resource evaluation and management: Quarterly technical progress report for July-September 1990: DE-FC2186MC10637, EERC publication.

Kihm, A.J., and Hartman, J.H., 1990, Chronostratigraphic implications of the mammal and nonmarine mollusk record of the Paleocene Fort Union Group in North Dakota: North Dakota Academy of Science, 82nd Annual Meeting, v. 44, p. 70 (includes presentation).

Hartman, J.H., 1991a, Coal Science: Quarterly technical progress report for the period October-December 1990: DE-FC21-86MC10637, EERC publication.

Hartman, J.H., 1991b, The stratigraphic distribution of nonmarine Mollusca across the Cretaceous-Tertiary boundary in the northern Great Plains, in the theme session "Nonmarine fossil record at the Cretaceous-Tertiary boundary": Geological Society of America, Abstracts with Programs, v. 23, no. 5, p. A359 (includes presentation).

Hartman, J.H., 1991C, Biochronology and evolution of early and middle paleocene nonmarine Mollusca of the Northern Great Plains: Final report to National Science Foundation: EERC publication, January.

Hartman, J.H., 1991c, Coal science: Earth resource evaluation and management: Semiannual technical report for the period January-June 1991: DE-FC2186MC10637, EERC publication.

Hartman, J.H., and Kihm, A.J., 1991, Stratigraphic distribution of Titanoides (Mammalia: Pantodonta) in the Fort Union Group (Paleocene) of North Dakota, in Christopher, J.E., and Haidl, F.M., eds., Sixth International Williston Basin Symposium: Saskatchewan Geological Society, Special Publication no. 11, p. 207-215 (includes poster session).

Kihm, A.J., and Hartman, J.H., 1991a, Titanoides primaevus, the first described Paleocene mammal from North Dakota: North Dakota Academy of Science, 83rd Annual Meeting, v. 45, p. 31 (includes presentation).

Kihm, A.J., and Hartman, J.H., 1991b, The age of the Sentinel Butte Formation, North Dakota: Society of Vertebrate Paleontology, Journal of Vertebrate Paleontology, v. 11 , supplement to no. 3, p. 40a (includes presentation). 
Hartman, J.H., 1992a, Fossil as a resource in research, education, and economics in North Dakota: North Dakota Academy of Science, v. 46 (84th Annual Meeting), p. 2 (includes presentation).

Hartman, J.H., 1992b, Fossil invertebrates as a resource in research, education, and economics in North Dakota: North Dakota Academy of Science, v. 46 (84th Annual Meeting), p. 4 (includes presentation).

Hartman, J.H., 1992C, Biochronology of uppermost Crecaceous and lower Tertiary nonmarine Mollusca of the northern Great Plains, U.S.A. and Canada, in the Fifth North American Paleontological Convention (Chicago), Abstracts with Programs: The Paleontological Society, Special Publication, No. 6, p. 123 (includes poster session).

Hartman, J.H., 1992d, Coal Science: Earth resource evaluation and management: Semiannual technical report for the period January-June 1992: DE-FC2186MC10637, EERC publication.

Hartman, J.H., 1992e, Coal Science: Earth resource evaluation and management: Semiannual technical report for the period July-December 1991: DE-FC2186MC10637, EERC publication.

Hartman, J.H., and Kihm, A.J., eds., 1992, A symposium on the "Paleontology in North Dakota: Fossils as a resource in research, education, and economics": North Dakota Academy of Science, v. 46 (84th Annual Meeting), p. 1-10.

Hartman, J.H., and Kihm, A.J., (in press, 1992), Chronostratigraphy of Paleocene strata in the Williston Basin, in Finkelman, R.B., Daly, D.J., Tewalt, S.J., eds., Geology and utilization of Fort Union Region lignites: UND Press, Environmental and Coal Assoc.

Krause, D.W., Wunderlich, R., Hartman, J.H., and Kroeger, T.J., 1992, Latest Cretaceous and early Paleocene mammals from Makoshika State Park, Williston Basin, eastern Montana: Journal of Vertebrate Paleontology, Abstracts of Papers, 52nd Annual Meeting, Royal Ontario Museum (Toronto), v. 12, supplement to no. 3, p. 38 a.

Krause, D.W., Wunderlich, R., Hartman, J.H., Kroeger, T.J., and Peck, W.D., (for 1992 submission), Latest Cretaceous and early Paleocene mammals from Makoshika State Park, Williston Basin, eastern Montana.

Hartman, J.H., (for January 1, 1993 submission; invitation accepted), Cretaceous and Paleocene stratigraphy and paleontology of eastern portion of the Crazy Mountains Basin, Montana: Road log and overview of recent investigations: Montana Geological Society, Energy and Mineral Resources of Central Montana, 1992 Field Conference Guidebook.

Hartman, J.H., Roth, B., and Kihm, A.J., (for 1993 submission), Stratigraphy and paleontology of a diverse assemblage of nonmarine Mollusca from the Sentinel Butte Formation of North Dakota (for submission to the North Dakota Academy of Science). 
Hartman, J.H., Peck, W.D., and Kihm, A.J., (for 1993 submission), Paleocene stratigraphy of the Nesson Anticline: Placement of the Bullion Creek-Sentinel Butte formational contact (for submission to the North Dakota Academy of Science).

Hartman, J.H., (for 1993 submission), Type and other historic molluscan localities from the Upper Cretaceous Fruitland and Kirtland Formations, San Juan Basin, New Mexico-Colorado: New Mexico Geological Society, Annual Field Guidebook.

Hartman, J.H., and Cvancara, A.M., (for 1993 submission), Paleontology and biostratigraphy of the brackish and freshwater Mollusca of the Paleocene Slope (Ludlow) Formation of southwestern North Dakota and southeastern Montana, in Belt, E.S., and Daly, D.J., eds., Geology and depositional environments of the Paleocene Fort Union Group, southwestern North Dakota [in preparation]. 


\subsection{COMBUSTION RESEARCH}


4.1 Atmospheric Fluidized-Bed Combustion 


\title{
ATMOSPHERIC FLUIDIZED-BED COMBUSTION
}

Final Technical Progress Report

for the Period Apri1 1, 1986, through December 31, 199?

by

Michael D. Mann, Research Supervisor

Ann K. Henderson, Research Engineer

Thomas A. Moe, Research Engineer

Energy and Environmental Research Center

University of North Dakota

P.0. Box 8213, University Station

Grand Forks, North Dakota 58202-8213

Task Contracting Officer's Representative: Dr. Art Hall

for

\author{
United States Department of Energy \\ Office of Fossil Energy \\ Morgantown Energy Technology Center \\ 3610 Collins Ferry Road \\ P. 0 . Box 880 \\ Morgantown, West Virginia 26507-0880
}

December 1992

Work Performed under Cooperative Agreement No. DE-FC21-86MC10637 
LIST OF FIGURES ..................... .

LIST OF TABLES .................... . .

1.0 BACKGROUND $\ldots \ldots \ldots \ldots$

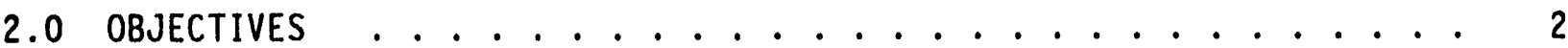

3.0 CHARACTERIZATION OF COALS ............... 3

3.1 Comparison of Coal Properties . . . . . . . . . . . . 3

3.2 Description of Equipment .............. 3

3.3 Thermal Performance ................. 6

3.4 Environmental Performance ................ . 7

3.4.1 Sulfur Oxide Emissions ............ 7

3.4.2 Nitrogen Oxide Emissions ............. 9

3.4.3 Particulate Emissions and Characterization ..... 9

3.5 Bed Material Agglomeration .............. 10

3.6 Summary . . . . . . . . . . . . . . . . 11

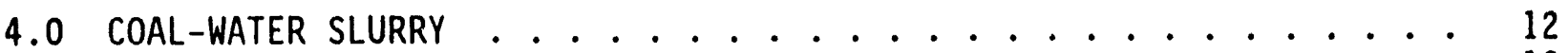

4.1 Test Description ................... 12

4.2 Coal-Water Fuel Properties . . . . . . . . . . . 13

4.3 Results and Discussion ................. 13

4.4 Summary .......................... 16

5.0 CORROSION, EROSION, AND DEPOSITION OF FBC BOILER TUBES $\ldots \ldots 16$

6.0 AdVANCED CONCEPTS: COAL PRETREATMENT CELL . . . . . . . . 20

7.0 SYSTEM SIMPLIFICATION . . . . . . . . . . . . . . . . 24

8.0 AGGLOMERATION AND DEPOSITION .............. 25

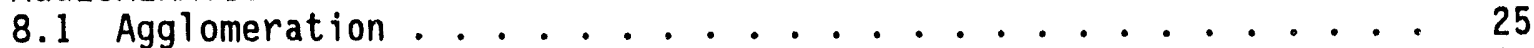

8.2 Deposition on Tube Surfaces .............. 26

8.3 Incidents in Full-Scale Systems . . . . . . . . . . 28

8.4 Agglomeration in Full-Scale Utilities Due to Operational

Upsets ................... 29

8.5 summary ....................... 30

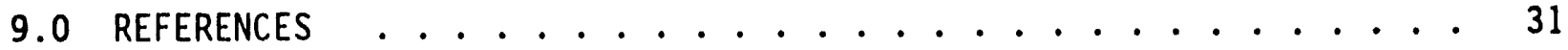




\section{LIST OF FIGURES}

Figure

Page

1

Coal pretreatment cell wit

with CFBC (100-MW capacity)

23

\section{LIST OF TABLES}

Table

Page

1 Effects of Coal Properties on AFBC System Design and Performance . 4

2 Analyses of Coals Used in EERC Comparative Study . . . . . . . 5

3 CWF Combustion Test Matrix ................ . 13

4 Average Test Conditions and Results . . . . . . . . . . . . 14

5 Summary of Test Data from 1000-Hour Tests . . . . . . . . . . 18

6 Comparative Statistics on Deposit/Scale Thickness . . . . . . . 28 


\section{FLUIDIZED-BED COMBUSTION OF LOW-RANK COALS}

\subsection{BACKGROUND}

The main driving forces behind the use of fluidized-bed combustion have primarily been environmental concerns, fuel flexibility, and compatibility with low-cost fuels. Both bubbling and circulating designs have been developed for operation at atmospheric pressure, and many industrial-scale units of both types are currently in operation. A limited number of larger utility boilers have recently been commissioned. In addition, pressurized fluidized-bed combustion (PFBC) is making its entrance on the utility scale with the PFB installed at the Tidd Station.

Even though fluidized-bed combustion technologies are being commercialized, a number of areas require further research. An integrated approach should be taken toward fluidized-bed combustion research, interrelating those problems generic to bubbling, circulating, and pressurized fluidized-bed combustion systems. The program should also be designed to address specific problems related to each of these areas. Major issues facing fluidized-bed combustion are listed below:

- Methods are needed to minimize corrosion and erosion of in-bed and convective pass tubes, refractory and support surfaces, and expander turbines. Work should focus on the following:

- Understanding mechanisms involving

- Mineralogical properties of the bed and coal

- Fluid mechanics of the bed

- Corrosion versus erosion

- Stress forces on tubes

- Assessing acceptable wastage levels

- Identifying cost-effective methods of combating tube wastage

- Developing systematic test devices

- Retrofit applications should be addressed for all types of FBCs. According to information from the American Boiler Manufacturing Association (ABMA), approximately 200 existing units are candidates for retrofit technologies. The FBC retrofits at Northern States Power's (NSP) Black Dog Station, Montana-Dakota Utilities (MDU) Heskett Station, and Colorado Ute's Nucla Station have demonstrated the feasibility of such applications.

- Fuel flexibility and characterization issues should be addressed to help users understand constraints of fuel switching, design considerations, and, most importantly, the economics involved in having fuel flexibility for the FBC.

- Agglomeration/sintering of bed material and deposition on tubes, support surfaces, and refractory, has been identified as a problem by both manufacturers and users of FBC technology. Problems have been documented for both bubbling and circulating beds, using a variety of 
fuels, including coal. The University of North Dakota Energy and Environmental Research Center (EERC) has extensive experience in this area to help understand and solve this operational problem.

- Scaleup effects need to be addressed so that vendors and users can take pilot-scale data and be assured that the large-scale system will perform as anticipated. This database has been growing rapidly with all of the new units starting operation; however, much information is still required.

- Advanced systems should be designed to resolve problems and improve overall FBC performance. These systems should:

- Increase volumetric heat release rates.

- Improve overall boller efficiency.

- Simplify fuel feed and ash removal systems.

- Decrease capital and operating costs.

- Improve turndown.

- Decrease the size of units to enable modular construction.

- Several problems related to emissions from $F B C$ systems need to be addressed:

- Better sorbent utilization would improve the economics of FBC.

- NO control is currently not a major problem, but could become more difficult with bubbling beds if standards become more stringent.

- Information indicates that particulate control problems may exist for certain types of ash. These ashes should be identified, and specific equipment and conditioning of other methods should be applied to resolve the problem.

- Hot-gas cleanup is required for PFBC to meet turbine specifications, in addition to new source performance standards (NSPS).

These problems and concerns could limit FBC from reaching its full potential. Special efforts should be taken to perform the necessary research to help FBC evolve to a mature technology, meeting the technical, economic, and environmental needs of the future.

\subsection{OBJECTIVES}

A number of major issues have been identified that warrant further research. The EERC has the capability to investigate several issues in bubbling atmospheric fluidized-bed combustion (AFBC). Some of these issues are proposed in this work plan. Other $F B C$ research should be funded, at least partially, by the industrial sector, either through Electrical Power Research Institute (EPRI) or private companies. Efforts should continue to transfer the expertise gained under previous Cooperative Agreements to the private sector. 
The overall goal of the low-rank coal (LRC) FBC program at the EERC is to develop a technology database so that industry can introduce economically and environmentally acceptable coal technology options to the marketplace. Research will address those areas where data gaps exist in fuel flexibility and performance, potential operating problems, environmental compliance, advanced concepts, and system simplification.

\subsection{CHARACTERIZATION OF COALS}

The main purpose of the coal characterization portion of the program was to examine the differences that exist between different coals, both as a function of rank and as a function of ash properties independent of rank, and to relate these differences to the design and performance of an AFBC.

Knowledge of specific properties is critical in the design phase, while an understanding of other properties is more critical during operation. The information presented here was obtained from the published literature and is supported with test results generated on the pilot-scale AFBC test facilities at the EERC. Since all of the data was generated with different fuels burned in the same unit, the differences in performance should be a clear depiction of the effects of coal properties, independent of system design. A summary of the effects of coal properties on AFBC system design and performance is presented in Table 1.

\subsection{Comparison of Coal Properties}

Coals are ranked based on established ASTM guidelines, according to their heating value, amount of volatiles, and fixed-carbon content. The low-rank coals are characterized as having low heating value, high volatile content, and high moisture. Conversely, the higher-rank coals are characterized by high heating values and a high fixed-carbon content. Generally speaking, the reactivity of the fixed carbon, or char, increases as rank decreases.

The quantity and nature of ash can vary widely, and is more a function of the region of the country and the geological conditions under which the coal was formed, rather than a function of rank. Many western coals have relatively high alkaline content as compared to their eastern counterparts; however, many of the coals in the Southwest have several of the same ash components as typical eastern coals. Sulfur, another critical coal property, is also more dependent on location than on rank, although most eastern coals have higher sulfur contents than do western coals. Therefore, when comparing the effects of coal properties on AFBC performance, it is critical to compare performance based on individual coal parameters, independent of rank.

The EERC has built an extensive database characterizing the performance of a variety of coals of all ranks. The analyses of these coals are shown in Table 2.

\subsection{Description of Equipment}

A bubbling $A F B C$ design was used for the evaluation of the general system effects described here, and all pilot-scale work was performed in the bubbling mode. The system consists of: 
TABLE 1

\section{Effects of Coal Properties on AFBC System Design and Performance}

\begin{tabular}{|c|c|c|c|}
\hline Coal Property & $\begin{array}{c}\text { Effect on System } \\
\text { Requirements and Design }\end{array}$ & $\begin{array}{l}\text { Effect on S.ystem } \\
\text { Thermal Performance }\end{array}$ & $\begin{array}{l}\text { Effect on System } \\
\text { Environmental Performance }\end{array}$ \\
\hline Heating Value & $\begin{array}{l}\text { Determines size of feed subsystem, combustor, } \\
\text { particulate collection equipment, and hot duct. }\end{array}$ & $\begin{array}{l}\text { Efficiency impacted by moisture and ash } \\
\text { content (see below). }\end{array}$ & Size of particulate collection devices. \\
\hline Moisture Content & $\begin{array}{l}\text { Can impact feed system design and capacity } \\
\text { and size of convective pass. }\end{array}$ & Higher moisture lowers thermal efficiency. & $\begin{array}{l}\text { Very high moisture can increase CO emissions due } \\
\text { to afterburning. }\end{array}$ \\
\hline Ash Content & $\begin{array}{l}\text { Determines size and type of particulate-control } \\
\text { subsystem and size of ash-handling } \\
\text { subsystems. }\end{array}$ & $\begin{array}{l}\text { Higher ash lowers thermal officiency via } \\
\text { heat losses from hot solids removal. }\end{array}$ & None, with proper design. \\
\hline $\begin{array}{l}\text { Volatiles/Fixod } \\
\text { Carbon Content }\end{array}$ & Impacts fuel feed method. & $\begin{array}{l}\text { Lower combustion efficiency for fuels with } \\
\text { low V/FC content. }\end{array}$ & None, with proper design. \\
\hline Sulfur Content ${ }^{*}$ & $\begin{array}{l}\text { Determines required capacity of sorbent } \\
\text { subsystem and ash-handling subsystem. } \\
\text { Higher sulfur usually dictates use of solids } \\
\text { recycle. }\end{array}$ & $\begin{array}{l}\text { Higher sulfur can lower thermal efficiency } \\
\text { va heat losses from added solids for SO, } \\
\text { control (seo ash content above). }\end{array}$ & $\begin{array}{l}\text { None, or proportional, } b \text { if regulated by site and } \\
\text { system size. Determines } \mathrm{SO}_{2} \text { omiseions (in } \\
\text { conjunction with alkaline ash) if uncontrolled. }\end{array}$ \\
\hline Nitrogen Content & $\begin{array}{l}\text { None, with common designs and typical } \\
\text { regulations. }\end{array}$ & None, with common designs. ${ }^{c}$ & Impacts $\mathrm{NO}_{\mathrm{x}}$ emissions. \\
\hline Chlorine Content & $\begin{array}{l}\text { Can impact selection of materials for cool end } \\
\text { components. May cause higher corrosion rates } \\
\text { of in-bed tubes. }\end{array}$ & $\begin{array}{l}\text { Typically none. Very high chlorides can } \\
\text { lower thermal efficiency by requiring } \\
\text { operation at higher exhaust temperatures. }\end{array}$ & Impacts $\mathrm{HCl}$ emissions. \\
\hline $\begin{array}{l}\text { Alkaline Ash } \\
\text { Content }\end{array}$ & Can reduce size of sorbent subsystems. & None. & $\begin{array}{l}\text { Higher ash alkalinity lowers uncontrolled SO, } \\
\text { emissions. }\end{array}$ \\
\hline $\begin{array}{l}\text { Sodium and } \\
\text { Potassium } \\
\text { Content }\end{array}$ & $\begin{array}{l}\text { High sodium can dictate fouling prevention } \\
\text { measures and allowance for agglomeration } \\
\text { (e.g., soot blowing, frequent bed draining). }\end{array}$ & $\begin{array}{l}\text { Higher sodium can lower thermal efficiency } \\
\text { via tube fouling and hoat losses from more } \\
\text { frequent hot solids removal. }\end{array}$ & $\begin{array}{l}\text { Higher sodium lowers uncontrolled } \mathrm{SO}_{x} \text { emissions. } \\
\text { Sodium tends to reduce fly ash resistivity for ESP } \\
\text { performance improvement; may also onhance fabric } \\
\text { filter performance. }\end{array}$ \\
\hline Ash Fusibility & $\begin{array}{l}\text { Low-fusion temperatures can impact design, } \\
\text { due to allowance for fouling and agglomeration } \\
\text { potential. }\end{array}$ & $\begin{array}{l}\text { Lower fusion temperatures impact thermal } \\
\text { efficiency in the same way as higher } \\
\text { sodium. }\end{array}$ & Typically none. \\
\hline
\end{tabular}

- The forms of sulfur can have an impact, with high pyrite content requiring longer gas residence time in the bed. The result may be increased operating pressure and blower capacity.

b Slower capacity.

b Sulfur content can determine $\mathrm{SO}_{x}$ emissions, depending on which regulation applies (o.g. NSPs may be required. Staged combustion designs can have higher CO

For low-NO, regulations, a staged combustion or postcombustion $\mathrm{NH}_{3}$-based suppression design may be required. 


\section{TABLE 2}

Analyses of Coals Used in EERC Comparative Study

\begin{tabular}{|c|c|c|c|c|c|c|}
\hline Coal Name: & $\begin{array}{l}\text { Gibbone } \\
\text { Creok }\end{array}$ & S. Halleville & Beulah & Sarpy Creok & Navajo & River King 1 \\
\hline Source: & Toxas & Texas & N. Dakota & Montane & Now Mexico & Illinois \\
\hline $\begin{array}{l}\text { Formation/Field: } \\
\text { Region: } \\
\text { Rank: }\end{array}$ & $\begin{array}{l}\text { Jackson } \\
\text { Gulf Cosst } \\
\text { Lignite B }\end{array}$ & $\begin{array}{l}\text { Wilcox } \\
\text { Gulf Coast } \\
\text { Lignite A }\end{array}$ & $\begin{array}{l}\text { Fort Union } \\
\text { Great Plains } \\
\text { Lignite A }\end{array}$ & $\begin{array}{l}\text { Tongue River } \\
\text { Powder River } \\
\text { Subbituminous B }\end{array}$ & $\begin{array}{l}\text { Fruitland } \\
\text { San Juan Basin } \\
\text { Subbituminous A }\end{array}$ & $\begin{array}{l}\text { Herrin } \$ 6 \\
\text { lllinois Basin } \\
\text { High Vol. C } \\
\text { Bituminous }\end{array}$ \\
\hline
\end{tabular}

Proximate Analysis,

$\%$ As.Fired

Moisture* 32.9

Ash 25.0

Volatile Matter $\quad 25.3$

Fixed Carbon

HHV, Btu/lb

5026
Ultimate Analyois,

$\%$ Dry Basis

Carbon

Hydrogen

Nitrogen

Sulfur

Oxygen

Chlorine

Ash

Ash Analysis

$\%$ of Ash

$\mathrm{SiO}_{2}$
$\mathrm{Al}_{2} \mathrm{O}_{2}$
$\mathrm{Fa}_{2} \mathrm{O}_{3}$
$\mathrm{TiO}_{2}$
$\mathrm{P}_{2} \mathrm{O}_{5}$
$\mathrm{CaO}$
$\mathrm{MgO}$
$\mathrm{Na}_{2} \mathrm{O}$
$\mathrm{K}_{2} \mathrm{O}$
$\mathrm{SO}_{3}$

Caiculated Velues

$\mathrm{Ca} / \mathrm{S}$ Molar Ratio Na/S Molar Ratio $A^{b} / S$ Molar Ratio Base/Acid ${ }^{\circ}$ FC Nolatiles

$\begin{array}{rr}62.0 & 38.0 \\ 18.5 & 16.0 \\ 3.6 & 12.0 \\ 1.0 & 1.2 \\ 0.2 & 0.5 \\ 6.2 & 13.0 \\ 1.4 & 3.9 \\ 0.5 & 0.2 \\ 0.8 & 0.9 \\ 5.9 & 14.8\end{array}$

29.1

12.4

29.5

28.9

7268

23.2

10.8

31.0

35.0

8037

58.6

4.6

1. 6

1.7

16.6

0.02

17.5

37.9
62.2

2.7

0.8

3.0

17.2

*.

14.1
24.2

10.0

28.6

37.2

8843

65.6

4.5

0.8

0.8

15.1

0.02

13.2
13.4

21.2

29.6

35.7

8771

56.6

4.3

1.1

0.8

12.5

0.03

24.6
7.3

20.3

29.8

42.6

9724
54.1

4.6

1.0

3.8

16.1

-.

20.3

- As-mined mnisture levels are higher for several of the coale tested.

b $\mathrm{Ca}+\mathrm{Na}$.

c $(\mathrm{Fe}+\mathrm{Ca}+\mathrm{Mg}+\mathrm{Na}+\mathrm{K}) /(\mathrm{Si}+\mathrm{Al}+\mathrm{Ti})$.

d Fixed carbon. 
- Fuel feed--screw-feed underbed or gravity-feed overbed.

- Sorbent/additive feed--solid sorbent was either fed separately, via gravity-fed overbed pipes, or premixed with the coal.

- Combustor--heat-exchange tubes in the bed, on-line bed draining capabilities, and with or without recycle subsystem for recycling elutriated solids/ash back to the combustor via cyclone and pneumatic reinjection.

- Particulate control--multicyclones/cyclones, baghouse, and electrostatic precipitator, alone or in combination, followed by a stack.

- Associated equipment, such as: blowers, fans, pumps, hoppers, bins, tanks, ash conveyors, instruments, and controls, to permit operation of the system.

The typical operating ranges of the EERC pilot unit for these tests were $1400^{\circ}$ to $1700^{\circ} \mathrm{F}$ combustor-bed temperature, 4- to $9-\mathrm{ft} / \mathrm{sec}$ superficial gas velocity, 17 - to 26 -inch static bed depth, ash recycle ratio of 0.0 to 1.0 , sorbent add rates of up to 5.5 alkali-to-sulfur ratio, and 0.5 to 2 second gas residence time. Detailed descriptions of the EERC AFBC test facilities are provided el sewhere $(1,2)$.

\subsection{Thermal Performance}

In comparing the proparties of some common solid fuels, the lignitic and subbituminous coals fall between the high carbon content and heating values of the higher-rank fossil fuels and the more reactive, high-volatile content biomass. Reactivity of the low-rank coals is related to porosity and surface area, volatiles-to-fixed carbon ratio, partially oxygenated organic structures, and catalytic effects of metallic cations within the coal structures. Thus the lower-rank coals will burn more completely and more rapidly than will a bituminous coal under similar operating conditions. Higher reactivity gives greater combustion efficiency, as measured by carbon conversion. Typical combustion efficiencies for low-rank coals range from $95 \%$ to over $99 \%$ in an $A F B C$, even without solids recycle, while bituminous coals typically have lower combustion efficiencies $(3,4)$. Combustion efficiencies for all coal types are greatly improved with ash recycle.

As the bed temperature increases, more carbon is burned out in the bed and combustion efficiencies increase. This is true for all the coals tested. At the higher bed temperatures, differences in carbon burnout between the various types of coals decrease.

Thermal performance is also influenced by the amounts of moisture and ash in the fuel. About $1000 \mathrm{Btu}$ are required to evaporate each pound of water entering with the feed coal. Since low-rank coals contain higher levels of moisture than do bituminous coals, more heat is lost during the combustion of low-rank coals as a result of evaporation. When operating at a specific temperature and excess air, the high-moisture, low-rank coals generate increased mass flows through the system per delivered Btu than the lowermoisture coals, resulting in a higher fraction of the energy being recovered 
in the downstream convective pass heat recovery unit. The overall system thermal efficiency is reduced due to greater stack losses for the highmoisture coals. Overall system thermal efficiency is also reduced by heat loss in the discharged ash of high-ash coals. Unrecoverable heat losses due to moisture effects were as high as $10.4 \%$ for the Gibbons Creek lignite, but only $3.8 \%$ for the River King bituminous. Heat losses due to ash and spent sorbent are much lower and depend on the total ash content of the coal relative to its heating value and sorbent requirements needed to meet NSPS. System efficiency can be improved by beneficiation of the coals and by ash removal and drying before combustion, but any modifications to improve coal quality would need to be determined before the design of the combustion system to take full advantage of the improvements.

Coal rank will have an effect on the initial design of an AFBC and the operation of an existing system. For example, a system designed for a lowrank coal would require a larger fuel feed system to generate the same amount of steam or electricity as a unit designed for a bituminous coal. Downstream heat transfer area would have to be greater for higher-moisture fuels to account for the higher flue gas flow rates due to the moisture. Units designed for bituminous coals would likely be required to utilize ash recycle to obtain acceptable levels of carbon burnout, while carbon burnout of many of the more reactive lower-rank coals are acceptable without recycle.

\subsection{Environmental Performance}

Emissions from an AFBC operating with a given coal can generally be controlled using proper system design and operation. While system requirements are dependent on coal properties, the actual emissions are dependent on the system design and operation. It is currently possible to meet all present or proposed national standards with state-of-the-art AFBC technology.

\subsubsection{Sulfur 0xide Emissions}

While firing coals in an $A F B C$, the amount of sulfur captured is primarily determined by the total alkali-to-sulfur ratio. The alkali (predominantly calcium and sodium) is provided by the mineral matter and cations contained within the coal and any added sorbent. The forms of alkali occurring in the coal and combustor operating conditions, especially temperature, are also important. Once the coal and sorbent properties are known, system design and operating specifications can be set to achieve virtually any level of sulfur capture. Although theoretical sulfur captures approaching $100 \%$ are possible, only $90 \%$ to $95 \%$ capture is considered economical (5). This is more than adequate to meet current NSPS.

The quantity of available alkali, from the coal itself or added sorbent, largely determines the sulfur oxide emissions generated from an AFBC. Most coals have some alkali in the ash material or as cations in the organic structure that is available for sulfur capture. Inherent alkali-to-sulfur ratios ranged from 0.2 for River King bituminous coal to 2.2 for Sarpy Creek subbituminous coal. This inherent alkali accounted for sulfur retentions of up to $55 \%$ in the case of the Beulah 1 ignite and as 10 as $5 \%$ for the River King coal under optimal conditions. The optimal conditions for maximum sulfur capture vary with coal. 
Although the total amount of alkali is indicative of how much sulfur capture to expect, it is the degree of availability of the inherent alkali and total sulfur in the coal that really determines the rate of sorbent alkali addition required to meet a particular emission standard. The form of the alkali has a significant effect on its ability to capture sulfur. Alkali utilization is a function of a variety of coal and sorbent properties. Coals in which the alkali is tied up predominantly as cations in the coal structure exhibit higher levels of alkali utilization than do those in which the alkali exists in the mineral matter of the extraneous coal ash. This is because of the more rapid release of the organically bound alkali, and its more intimate contact with the $\mathrm{SO}_{2}$ that is formed during combustion. The alkali utilization for coals containing a high ratio of organically bound alkali is much better than for those with a low ratio. Another factor affecting utilization of inherent alkali is the base-to-acid ratio. Those coals with a relatively high basic content have available alkali and a high driving force for sulfur capture. However, the sulfur must compete with silicates and other acidic components for available alkali in those coals with a low base-to-acid ratio.

The optimum bed temperature resulting in maximum sulfur capture varies somewhat with coal type. Bituminous coals tested at the EERC and by other researchers (6) show optimal sulfur capture at a bed temperature of approximately $1550^{\circ} \mathrm{F}$. Most of the low-rank coals tested, however, exhibit maximum sulfur capture at temperatures approximately $100^{\circ} \mathrm{F}$ lower. This is partially due to the coal structure and the forms and relationships of the sulfur and alkali in the coal itself. For the low-rank coals, the optimal temperature shifts upward with the use of ash recycle and approaches $1550^{\circ} \mathrm{F}$ at high ash recycle and sorbent addition rates.

In specifying design and operating conditions for an $A F B C$, it is critical to know how much sorbent addition is required to meet applicable emission standards. This can vary greatly with coal and sorbent types. For the coals tested, in order to retain $70 \%$ sulfur in the bed, the required alkali-tosulfur ratio ranged from 1.7 to 4.4 , depending on coal type. Looking only at the alkali-to-sulfur ratio, however, can be misleading. For example, although an alkali-to-sulfur ratio of 4.4 is required to meet $70 \%$ sulfur retention for Navajo subbituminous, compared to 2.5 for the River King bituminous, the total amount of sorbent added for the Navajo was much less, $5.9 \%$ of the coal feed compared to $18.5 \%$ for the River King, due to difference in the levels of sulfur and alkali in the coals. Emissions standards vary with coal type and typically range from $70 \%$ to $90 \%$ retention. Additional sorbent would be required to meet more stringent requirements.

When designing a new unit, or when considering fuel switching with an $A F B C$, it is important to understand the characteristics of the coal and sorbent to be used. As pointed out here, the alkali-to-sulfur ratio will have the greatest impact on sulfur retention and emissions. However, the required alkali-to-sulfur ratio will depend greatly on fuel properties. Likewise, the utilization of sorbent alkali can vary greatly between sorbents, and have a significant effect on the amount of sorbent addition required. It is, therefore, recommended that new designs or new fuels be based on either pilot plant testing of each specific fuel/sorbent combination or operating data from an existing unit burning that or a similar fuel. 


\subsubsection{Nitrogen Oxide Emissions}

The only emissions which are significantly affected by fuel properties (beyond the effects of system design and operation) are nitrogen oxides. The level of $\mathrm{NO}_{\mathrm{x}}$ emissions is determined by the coal nitrogen content and by the ratio of nitrogen content to large organic char-forming structures $(7,8)$. Testing at the EERC indicates that although nitrogen emissions are somewhat dependent on total nitrogen in the coal, a better correlation exists between the percent of fuel-bound nitrogen converted to $\mathrm{NO}_{x}$ anc the nitrogen content of the coal on a dry ash-free basis. For all the coals tested, the $\mathrm{NO}_{\mathrm{x}}$ emissions increased with increasing bed temperature and increasing excess air.

Nitrogen oxide emissions from $A F B C$ are inherently low, and experimental work and experience from operational AFBC facilities have indicated that NO, emissions beyond the low thermal NO, "background" levels can be controlled by the proper design and operation (e.g., staged combustion) of AFBC systems. This indicates that $A F B C$ systems may not be 1 imited by fuel nitrogen content, and that the fuel properties only determine the system requirements to achieve the desired level of $\mathrm{NO}_{\mathrm{x}}$ emission control. There are also several types of $\mathrm{NH}_{3}$-based postcombustion $\mathrm{NO}_{x}$ suppression subsystems which can be applied to $A F B C$ systems if further reduction of $N 0_{\text {, emissions is required. This }}$ indicates that, although for a specific design and operating scenario $N_{*}$ emissions are fuel-specific, the emissions can be controlled within a given range by proper design and operation.

\subsubsection{Particulate Emissions and Characterization}

In the fluidized-bed combustion process, coal is burned in a bed of noncombustible material. This noncombustible bed consists of some combination of coal ash, added sorbent for $\mathrm{SO}_{2}$ capture, and/or another selected inert material. A significant portion of the bed material is generally entrained with the flue gas leaving the combustor and must be collected by particulate control equipment. The particulate matter entrained from an AFBC has different physical and chemical properties than fly ash generated in a conventional pulverized coal combustor due to the lower temperature at which an $A F B C$ is operated and because of the sorbent or inert bed material entrained along with the coal ash in the AFBC flue gas. These chemical and physical differences, as well as potentially higher particulate concentrations, will affect the design and operation of the final particulate control device, whether it be a fabric filter or an electrostatic precipitator (ESP).

When considering the use of a fabric filter as the final collection device for FBC particulates, two important considerations arise. The first is control of pressure drop at reasonable air-to-cloth ratios. Studies performed outside the EERC have shown that higher tube sheet pressure drops are observed when collecting FBC fly ashes than when collecting pulverized coal fly ashes at the same air-to-cloth ratios $(9)$. The second important consideration is the collection efficiency of fabric filters when collecting FBC particulates. The collectibility of several coals has been evaluated at the EERC using a baghouse with woven glass bags. Though particulate collectibility was not the primary focus of the pilot-scale combustion studies, some general comparisons can be made for the coals tested. A general trend of increasing collectibility with increased pressure drop (caused by a buildup of fly ash dust cake on the bags) was observed. More importantly, significant differences are seen 
in the relative collectibility of FBC fly ashes from various coals. Collection efficiencies greater than $99.0 \%$ were observed for the River King and Sarpy creek coals. However, efficiencies dropped off significantly for the Navajo and Gibbons Creek fly ashes, ranging from $97.5 \%$ to $98.0 \%$ for the Navajo, down to $92.8 \%$ to $97.0 \%$ for the Gibbons Creek fly ash. Particulate emiss ons ranged from a low of $0.00151 \mathrm{~b} / \mathrm{MM} \mathrm{Btu}$ for one of the River King tests to greater than $0.301 \mathrm{~b} / \mathrm{MM}$ Btu for some of the Gibbons Creek tests, which is significantly higher than the 1979 NSPS limit of $0.03 \mathrm{lb} / \mathrm{MM}$ Btu. This data indicates that differences exist in the collectibility of various AFBC fly ashes, and care must be taken in choosing the proper air-to-cloth ratio, bag material and weave, number of compartments (affects increase in $\Delta P$ during cleaning), use of sonic horns, and type of baghouse to ensure adequate particulate removal.

To evaluate the potential effectiveness of ESP systems collecting FBCgenerated particulates, laboratory measurements have been made at the EERC on composite samples of fly ash collected during pilot-scale fluidized-bed combustion tests with several coals. The laboratory resistivity measuring apparatus used allows simulation of the actual flue gas conditions encountered during the combustion tests. Measurements made on fly ashes collected from baseline tests (inert bed material without ash recycle or sorbent addition) with several coals indicates that, while there is much variability in fly ash resistivity based on chemical composition, there was not a significant difference between $F B C$ ash resistivity and that of fly ashes generated in a conventional pc-fired unit. The addition of sorbent can greatly increase the resistivity of FBC fly ash by changing the chemical composition. Large increases in resistivity with 1 imestone addition were observed for the Gibbons Creek lignite, but were not as evident for the Navajo and Sarpy Creek coals. The effect of ash recycle on fly ash resistivity appears to be relatively insignificant.

\subsection{Bed Material Agglomeration}

Uniformity of $A F B C$ bed conditions is maintained by the active nature of the suspended particles within the size range compatible with the velocity of rising gases. When particles within the bed grow in size due to the accumulated deposition of fine-sized fuel ash onto the particles (agglomeration), maldistribution of air, fuel, and gases can occur, and the uniformity of the bed conditions is lost. If the upset is sufficiently large, the maldistributed region affects thermal performance of the system via reduced local heat transfer to the immersed heat-extracting surfaces in the bed. If agglomeration is not controlled, the inactive region can increase sufficiently so that performance deteriorates, and major areas of the bed are defluidized. In extreme cases, massive solidification of solids within the combustor can occur, resulting in premature shutdown and permanent damage to the combustor refractory, distributor surfaces, and in-bed tubes.

Although there are a number of factors affecting agglomeration, the properties of the coal ash are the most significant. Extensive work at the EERC (10) and Babcock and Wilcox (11) in the operation of the MDU 80-MW Heskett Station $A F B C$ has shown that agglomeration under normal AFBC operating conditions can be expected for those coals with high levels of sodium and potassium in the ash. An example is testing performed with Beulah North Dakota lignite, which has from $6 \%$ to $12 \%$ sodium in the ash. During pilot- 
scale testing performed at the EERC and Babcock and Wilcox, and in the operation of the MDU 80-MW Heskett Station AFBC, agglomeration of the bed material was observed. The agglomeration appeared shortly after start-up of the system in all cases, and caused catastrophic shutdown after only 50 hours of operation in tests at the EERC, which used no bed drain and no fresh bed material makeup.

The detrimental performance of a system with agglomeration of bed solids can be reduced by several possible modifications to the system operating procedures, or to the fuel. Extra calcium-rich sorbent or "sodium-getter" additives could be fed to the system. The system could be operated in a lowagglomerating temperature regime or at higher bed material drain rates. The sodium content of the fuel could be reduced by ion exchange. Each modification exhibits economic limitations which must be considered when evaluating the effectiveness of the procedure. To determine the best option for minimizing the impact of agglomeration, the properties of each coal and the interaction of coal ash with sorbent and bed materials should be evaluated. High bed material drain rates and fresh bed material addition are currently being used at the Heskett Station to control agglomeration.

\subsection{Summary}

Coals are ranked by ASTM according to heating value and the volatiles and fixed-carbon contents. These differences mainly affect the thermal

performance of the AFBC. Other properties, such as the ash level and chemical composition of the ash, are not rank-specific. The low-rank western coals are typically characterized as having a high volatile content, high moisture, high ash content, low sulfur, and high alkali content in the coal ash. The highrank eastern coals are characterized by high heating values, high fixed carbon, low moisture, and high sulfur. There are many variances to these general trends, including variations within the same mine. These variances can have a major impact on the design and performance of the AFBC; therefore, actual coal properties, independent of rank, should be used to evaluate a specific application.

Although the properties of the fuel determine potential emissions of $\mathrm{SO}_{2}$, particulates, $\mathrm{CO}$, and hydrocarbons, these can all be controlled to acceptable limits by proper combustor design and operation. Even the emissions of $\mathrm{NO}_{\mathrm{x}}$ and $\mathrm{HCl}$, which are highly dependent on fuel properties, can be controlled with additional subsystems at extra cost. Thus the environmental performance for $\mathrm{NO}, \mathrm{HCl}$, and sometimes $\mathrm{SO}_{2}$ are determined by the fuel-specific properties, while particulates, $\mathrm{CO}$, hydrocarbons, and usually $\mathrm{SO}_{2}$ are determined by system-controllable parameters. The thermal efficiency of AFBC systems is dependent on moisture, ash, sulfur, sodium, and fouling components in the coal.

The design fuel and any potential fuels that may be used in an AFBC system must be specified prior to the design of the system, as fuel properties have a significant impact on design and operation. These design-point conditions can be projections from pilot-scale tests, extrapolation from similar fuels or systems, or copies of existing successful systems. Care must then be taken to ensure that the system is designed to handle not only the typical properties of a particular coal supply, but also the extremes. With proper information, experienced designers and operators can exercise 
independent control of many parameters to achieve desired performance and costs, while taking into account fuel type and fuel properties.

\subsection{COAL-WATER SLURRY}

Testing has been performed at the EERC assessing the technical feasibility of burning low-rank coal-water fuels (CWF) in a fluidized-bed combustor. The objectives of the low-rank CWF testing were twofold. The first objective was the design and fabrication of a probe for the direct injection of slurry into the dense-bed zone of a bubbling FBC. The second objective was the actual combustion testing of a low-rank CWF in the 18 " $\times 18$ " bubbling FBC at the EERC. The low-rank CWF used for the testing was prepared using the EERC's hydrothermal coal dewatering process, a process for the removal of liquid water from high-moisture coal by heating the coal under pressure in a water medium.

The bubbling-bed test furnace was modified to allow for the slurry feed. The skid-mounted feed system includes a progressive cavity pump which is gravity fed from the feed tank. A variable speed drive on the pump controls the CWF feed rate, which is measured by a Micromotion flowmeter with digital indicator. The CWF is generally agitated before introduction to the feed tank. An air-operated mixer is also provided in the feed tank to continuously mix the CWF during the test.

A CWF injection probe was designed and fabricated for this testing. The steel probe's simple design consisted of a straight, water-cooled stainless steel pipe. The major difference between this probe, designed for low-rank CWF, and those used by other investigators (12-14) for higher-rank coals is the absence of atomizing air, which inhibits the agglomerating tendencies of higher-rank CWFs. CFW was introduced into the FBC bed approximately 3 inches above the nozzle air distributor. Air was continuously supplied through the probe during start-up (before feed was initiated) to prevent any plugging of tha probe by the bed material. This air was discontinued when CWF feed was started.

\subsection{Test Description}

The CWF used for these tests was produced from a Powder River Region subbituminous coal from the Absaloka Mine (Sarpy Creek field, Rosebud-McKay bed), which is located in the northeastern part of Bighorn County in Montana. This coal was chosen for CWF testing because as-received Sarpy Creek coal had been previously well characterized with the 18 " $\times 18^{\prime \prime}$ FBC at the EERC.

The CWF combustion test matrix is presented in Table 3 . The test series consisted of five separate test periods. A superficial gas velocity of $5 \mathrm{ft} / \mathrm{sec}$ and $20 \%$ excess air were specified for all tests in the matrix. Silica sand (No. 10) was used for bed material (static bed depth was maintained at 2.8 feet for all tests). Tests 1 through 3 were run at different bed temperatures, ranging from $1450^{\circ}$ to $1650^{\circ} \mathrm{F}$. Tests 4 and 5 were designed to compare the effectiveness of adding sorbent ( 1 imestone) mixed with the CWF versus adding dry limestone separately to the bed. 
TABLE 3

CWF Combustion Test Matrix*

\begin{tabular}{ccc}
\hline Test Number & Bed Temperature $\left({ }^{\circ} \mathrm{F}\right)$ & Limestone Addition \\
\hline 1 & 1450 & None \\
2 & 1550 & None \\
3 & 1650 & None \\
4 & 1550 & $\begin{array}{c}\text { Pulverized limestone mixed } \\
\text { with the CWF } \\
\text { Dry limestone (-8 } x+20 \\
\text { mesh) added separately to } \\
\text { the bed }\end{array}$ \\
\hline
\end{tabular}

- Al1 tests were performed at $5-\mathrm{ft} / \mathrm{sec}$ gas velocity and $20 \%$ excess air. No. 10 silica sand was used as bed material. Static bed depth was maintained at $2.8 \mathrm{ft}$.

\subsection{Coal-Water Fuel Properties}

Approximately 10,000 pounds of Sarpy Creek CWF (60 wt\% solids) were prepared using the hydrothermal dewatering process. The coal was processed at $625^{\circ} \mathrm{F}$ and then centrifuged to 65 to $70 \mathrm{wt} \%$ dry solids cake for storage. A coal-water/limestone fuel was prepared for Test 4 by adding pulverized limestone during the reslurrying process. This coal-water/limestone fuel was also mixed to produce a fuel that was $60 \%$ solids by weight. Dry limestone was crushed to $-8 x+20$ mesh for Test 5 . The 1 imestone was obtained from the Big Horn Limestone Company in Montana. Analyses of the coal-water and the coalwater/limestone fuels are presented in Table 4.

Both fuels showed stability up to eight hours, and have been stable up to five days in some cases. The fuel with added limestone was slightly more stable than the CWF without limestone. These fuels were prepared without any chemical additives to enhance flow behavior or stability. Therefore, any favorable flow behavior or stability of the fuels as compared to similar sized and quality as-mined coal were a result of the EERC hydrothermal dewatering process or the limestone addition.

\subsection{Results and Discussion}

After the slurry-feeding probe was designed and fabricated, the entire CWF feed system was tested during a short shakedown run. The following week the unit was restarted, and testing was performed according to the test matrix outlined in Table 3. A summary of the data from the five test periods is presented in Table 4. The data for each test period was collected and averaged during steady-state operation of the FBC unit.

Combustion efficiencies were determined for each test period using the input-output method. This method of calculation determines the amount of 
TABLE 4

Average Test Conditions and Results

\begin{tabular}{lrrrrr}
\hline & $\begin{array}{r}\text { Test } \\
\text { No. } 1\end{array}$ & $\begin{array}{r}\text { Test } \\
\text { No.2 }\end{array}$ & $\begin{array}{r}\text { Test } \\
\text { No. 3 }\end{array}$ & $\begin{array}{r}\text { Test } \\
\text { No. } 4\end{array}$ & $\begin{array}{r}\text { Test } \\
\text { No. 5 }\end{array}$ \\
\hline Bed Temperature $\left({ }^{\circ} \mathrm{F}\right)$ & 1450 & 1547 & 1654 & 1553 & 1550 \\
Freeboard Temperature $\left({ }^{\circ} \mathrm{F}\right)$ & 1670 & 1734 & 1797 & 1788 & 1735 \\
Gas Velocity (ft/sec) & 5.0 & 5.1 & 5.1 & 5.0 & 5.1 \\
Excess Air (\%) & 19.9 & 19.6 & 20.6 & 20.7 & 21.1 \\
Static Bed Depth (ft) & 2.8 & 2.8 & 2.8 & 2.8 & 2.8 \\
Slurry Feed Rate (1b/hr) & 146.1 & 140.5 & 135.8 & 147.6 & 141.2 \\
Total A/S Mole Ratio & 1.68 & 1.66 & 1.84 & 2.69 & 3.01 \\
Sulfur Retention (\%) & 47.5 & 34.0 & 22.9 & 51.8 & 59.9 \\
Total Alkali Utilization $(\%)$ & 28.3 & 20.5 & 12.5 & 19.2 & 19.9 \\
SO Emissions (1b/MM Btu) & 0.84 & 1.06 & 1.17 & 0.85 & 0.69 \\
NO Emission (1b/MM Btu) & 0.18 & 0.21 & 0.26 & 0.22 & 0.22 \\
Combustion Efficiency $(\%)$ & 99.4 & 99.7 & 99.7 & 97.4 & 99.3 \\
\hline
\end{tabular}

uncombusted carbon in the fly ash as a fraction of the total carbon input with the fuel. Combustion efficiencies of the first three test periods (all without limestone addition) were very high, ranging from $99.4 \%$ to $99.7 \%$. The efficiency appeared to increase slightly with increasing bed temperature. These values are equal to or somewhat higher than combustion efficiencies previously determined when testing Sarpy Creek as-received coal (as-received coal screw fed into combustor). More freeboard burning than normal was noted during the CWF testing, as evidenced by high freeboard temperatures. The freeboard temperature was generally between $140^{\circ}$ and $230^{\circ} \mathrm{F}$ higher than the average bed temperature, with less temperature difference at the higher bed temperatures. The freeboard burning is probably not a significant problem, but will shift additional heat transfer into the convective passes of an actual boiler. For previous testing with as-received coal $(-1 / 4$ in.) screw fed into the bed, freeboard temperatures were generally less than $100^{\circ} \mathrm{F}$ higher than the average bed temperature.

Combustion efficiencies, although determined for tests with limestone addition (Tests 4 and 5 ), should not be compared to the tests without limestone addition. Uncalcined limestone $\left(\mathrm{CaCO}_{3}\right)$ can add significant quantities of $\mathrm{CO}_{2}$ to the uncombusted carbon in the fly ash, thereby "artificially" lowering the combustion efficiency.

Carbon monoxide (CO) emissions were low during the CWF testing, generally less than $200 \mathrm{ppm}$. Some small intermittent CO spikes were seen throughout the 
testing. The low co levels at excess air levels of approximately $20 \%$ were another indication of good fluidization and combustion stability.

Emissions of $\mathrm{NO}_{\mathrm{x}}$ were very low when burning the CWFs, ranging from $0.18 \mathrm{1b} / \mathrm{MM} \mathrm{Btu}$ at $1450^{\circ} \mathrm{F}$ to $0.26 \mathrm{lb} / \mathrm{MM}$ Btu at $1650^{\circ} \mathrm{F}$. These emissions are significantly lower than those when burning the same coal as-received into the $F B C$, which resulted in $N_{x}$ emissions ranging from 0.24 to $0.58 \mathrm{lb} / \mathrm{MM} \mathrm{Btu}$. The emissions of $\mathrm{NO}_{\mathrm{x}}$ when burning the CWF are well below limits set by the 1979 New Source Performance Standards (NSPS) of $0.6 \mathrm{lb} / \mathrm{MM}$ Btu.

In Tests 1 through 3 , the emissions of $\mathrm{SO}_{2}$ were investigated when burning CWF at various bed temperatures. Additional sorbent was not used during these three tests in order to quantify the sulfur capturing capacity of Sarpy Creek's alkaline ash. Sulfur retention was highest at $1450^{\circ} \mathrm{F}(47.5 \%)$ and decreased as bed temperature was increased, dropping to $22.9 \%$ retention at $1650^{\circ} \mathrm{F}$. These results are not significantly different than those observed previously when testing as-received Sarpy Creek coal. In the previous testing, the maximum sulfur retention al so occurred at $1450^{\circ} \mathrm{F}$.

To meet NSPS, additional sulfur capture is required when burning Sarpy creek coal. Therefore, Tests 4 and 5 were included to compare the efficiencies of two different methods of adding limestone to the bed. In Test 4, pulverized limestone was added directly to the CWF during the slurrying process. Pumping this coal-water/limestone fuel into the bed resulted in a very simple feed system for both the coal and limestone. In Test 5 , dry 1 imestone $(-8 \times+20$ mesh) was added to the bed pneumatically, separate from the CWF. A higher retention was observed for the separately injected limestone (59.9\%) than for the limestone mixed with the slurry $(51.8 \%)$. This difference is due to the fact that more limestone was added in Test 5 (dry limestone feed) than Test 4 (1 imestone mixed in slurry). The total molar alkali-to-sulfur ratio (A/S) for Test 5 was 3.01 , which is somewhat greater than 2.69 for Test 4 . The total A/S takes into account the calcium and sodium contributed by both the inherent coal ash and the added limestone. To compare the sulfur capture in Tests 4 and 5 on an equal basis, it is necessary to look at the alkali utilization rather than simple sulfur retention. Alkali utilization is calculated by dividing the sulfur retention by the alkali-to-sulfur ratio. Alkali utilization, like sulfur retention, increases with decreasing bed temperature over the range of temperatures studied. The form of calcium (there was no detectable sodium in the limestone and only very little in the coal ash) or the method by which it was added had little effect on its utilization. All three tests run at the same bed temperature $\left(1550^{\circ} \mathrm{F}\right)$, which included the two methods of limestone addition and a test without 1 imestone addition, had essentially identical alkali utilizations: $19.2 \%, 19.9 \%$, and $20.5 \%$.

Samples of bed material drained from the FBC after each test period were submitted for elemental and size analysis. From the sieve analys is, little particle growth was evident. Visual observation of the bed-material particles and elemental analysis indicated very little ash deposited on the surface of these particles. The fine ash was elutriated from the bed before it was able to react with the silica sand bed material. Since ash does not collect in the bed, it is probable that a continuous bed rernoval system will not be required when burning CWFs of the coal. 


\subsection{Surmary}

A low-rank CWF prepared from a Powder River Region subbituminous coal using the EERC's hydrothermal coal dewatering process was successfully burned in a 18" $x 18$ " atmospheric bubbling FBC. The 60 -wt\% dry solids CWF was pumped directly into the dense-bed zone through a simple, water-cooled pipe without the aid of a nozzle or atomizing air. Significant results from the testing include:

- The CWF exhibited flow behavior that was acceptable for short-term handling and ease of feeding. In addition, there was no detrimental rheological effect to hydrothermally treated low-rank CWF from the addition of limestone for sulfur capture.

- Limestone utilization for the reduction of $\mathrm{SO}_{2}$ emissions was equal for pulverized 1 imestone added directly to the CWF versus dry limestone added separately to the bed $(-8 x+20$ mesh). The utilization appeared significantly dependent on bed temperatures.

- Combustion efficiency as measured by carion burnout was very high, ranging from $99.4 \%$ to $99.7 \%$. These efficiencies are equal to or slightly greater than efficiencies previously obtained for the asreceived Sarpy Creek coal when screw fed into the same FBC.

- Emissions of $\mathrm{NO}_{x}$ when burning CWF were significantly lower than previously seen when burning the same coal as-received. Emissions ranged from 0.18 to $0.26 \mathrm{lb} / \mathrm{MM} \mathrm{Btu}$, increasing slightly with increasing bed temperature.

- Little growth in bed particle size or increase bed weight was noted during the CWF testing. Therefore, a continuous spent-bed removal system may not be required when burning CWFs produced from similar coals.

\subsection{CORROSION, EROSION, AND DEPOSITION OF FBC BOILER TUBES}

Systematic studies were performed at the EERC investigating the effects of coal properties on corrosion, erosion, and deposition of fluidized-bed combustion heat-transfer surfaces. Seven coals were tested covering a range of ash properties and coal rank. The test coals included two Texas and one North Dakota lignite, a Montana and a New Mexico subbituminous coal, and an Illinois and a Kentucky bituminous coal. The 1000-hour tests were performed using an $8 " \times 8$ " bubbling fluidized bed operated at a velocity of $7.5 \mathrm{ft} / \mathrm{sec}$, an average bed temperature of $1550^{\circ} \mathrm{F}$, and an excess air level between $20 \%$ and $30 \%$. Limestone was used as the bed material and was fed at a rate to achieve NSPS for the coals tested.

The goal of this work was to identify differences and similarities in materials performance between the different tests. Individual measurements for each metallographic feature were taken. Results presented in this summary are generally averages for different categories. Data anomalies are averaged out, and an overall picture of how metal loss was affected by the various parameters under study is presented. Therefore, this summary is meant to 
present the relative trends observed. Absolute numbers for metal loss, sulfide penetration, deposit/scale formation, and other metallographic features at full scale will vary from unit to unit, depending on geometry, operating conditions, and other factors. With this qualification, the general trends observed are shown in Table 5 and listed below:

- Coal type, metal type, and surface temperature all had a statistically significant effect on the amount of metal loss. As determined by diameter-loss measurements, the following trends were observed:

- The ranking of metal loss as a function of coal type, from highest to lowest, was Pyro, South Hallsville, Gibbons Creek, Beulah, River King, Sarpy Creek, and Navajo. Average metal loss ranged from 122 microns across the diameter for the Pyro test to 41 microns for the Navajo. This would relate to 61 and 20 microns for each wall, respectively.

- Metal loss was 5 times as great for the carbon steel as compared to the 304-, 316-, and 347-stainless steels. The 347-stainless steel was the best performer of the stainless steels tested.

- Metal loss decreased with increasing temperature for the in-bed tubes and increased with increasing temperature for the convective pass tubes.

- No statistical differences in metal loss were observed between the in-bed, splash zone, and convective pass tubes.

- The amount of metal loss increased with an increase in the calcium and 1 imestone feed rates, but decreased with an increase in the sulfur and sodium feed rates. Bed chemistry parameters causing a higher metal loss included the $\mathrm{S} / \mathrm{Ca}$ ratio and the $\mathrm{CaO}$ content in the bed. Bed chemistry parameters causing less metal loss as they increased were the mean bed particle size, the sodium and potassium concentrations, the $\mathrm{SO}_{3}$ concentration, the $\mathrm{SiO}_{2}$ and $\mathrm{Al}_{2} \mathrm{O}_{3}$ weight ratios, and the base-to-acid ratio.

- Measurements of metal loss determined across the diameter of the tube differed from those taken across the tube wall for some cases. The diameter loss measurements are believed to be more accurate, as they were a direct before-and-after measurement at the same location, where wall loss measurements were not.

- Coal type, metal type, surface temperature, and location all had statistically significant effects on the amount of sulfide penetration resulting from the 1000-hour exposure. The following trends were observed:

- The greatest amount of sulfide penetration was observed for the test using Pyro coal, followed by Beulah, Gibbons Creek, Sarpy Creek, South Hallsville, Navajo, and River King. Pyro, the worst case, had an average sulfide penetration of 52 microns, while the sulfide penetration of the River King test averaged 12 microns. 
TABLE 5

Summary of Test Data from 1000-Hour Tests

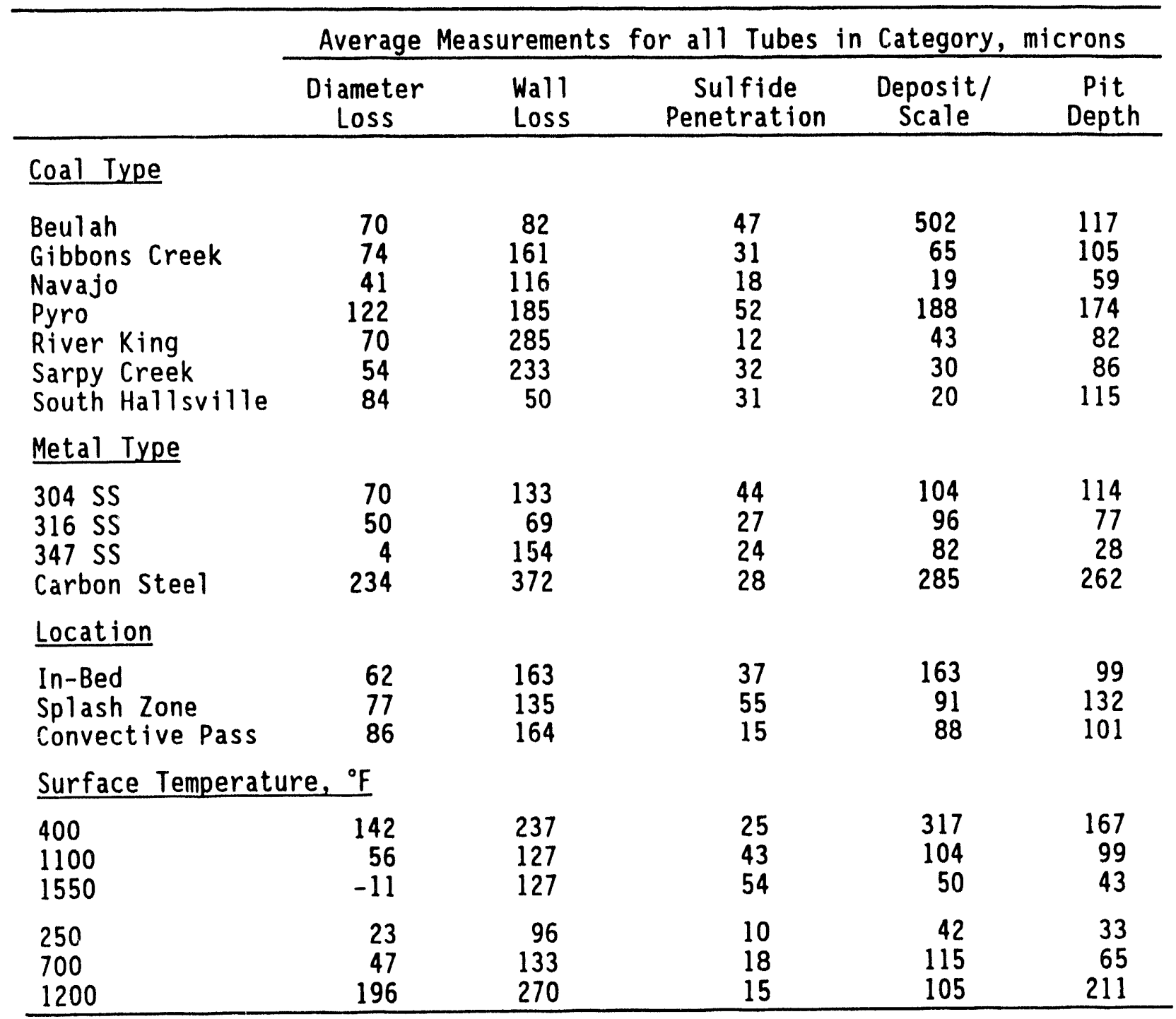

- Sulfide penetration was the greatest for the 304-stainless steel tubes, and was similar for the 316-stainless, 347-stainless, and carbon steels.

- The depth of sulfide penetration increased with increasing metal surface temperature.

- Sulfide penetration was greatest in the splash zone, followed by the in-bed tubes, with the least amount of penetration occurring in the convective pass tubes. 
- An increased sulfur feed rate caused deeper sulfide penetration and thicker deposits on tubes. As the mean bed particle size decreased, sulfide penetration increased.

- Coal type, metal type, and surface temperature had statistically significant effects on the amount of deposit/scale buildup on the heat-transfer tubes. The following trends were observed:

- The largest amount of scale/deposit was observed with the Beulah lignite. In this case, deposits as thick as $1 / 2$ inch were observed. Deposit/scale thickness from the other tests ranged from 19 to 188 microns. Deposit/scale thickness increased in the following order: Navajo, South Hallsville, Sarpy Creek, River King, Gibbons Creek, Pyro, and Beulah.

- The carbon steel tubes had almost three times as much buildup as the stainless steel tubes. Little difference was noted between the stainless steels.

- Deposit/scale was much greater for the in-bed tubes than for the splash zone and convective pass.

- Analysis of the deposit/scale showed that the majority of the matrix was calcium sulphate- or sodium sulfate-based.

- The deposit/scale thickness increased with increases in the sulfur and sodium feed rates and decreased with increases in the limestone feed rate and average bed particle size.

- The heat-transfer coefficient was significantly reduced, up to $40 \%$ in the worst case, as a result of the deposit/scale buildup on the tube surfaces.

- Similar deposit/scale buildup was noted at the MDU 80-MW Heskett Station and the NSP 130-MW Black Dog Station when firing coals similar to those used in the EERC tests.

- Of the materials tested, 347-stainless steel showed the best overall performance, followed by the 304- and 316-stainless steels. The carbon steel tubes, in most cases, exhibited performance that would be unacceptable to a boiler operator.

- Several coal-related properties affect metal performance. Some of these are measured directly, while others, such as the composition of bed material, are measured indirectly. Trends were as follows:

- As the sulfur feed rate increased, so did metal loss, sulfide penetration, and the amount of deposition.

- Increasing amounts of calcium fed with the coal (not including that contributed by the limestone) tended to increase metal loss and sulfide penetration. 
- The deposit/scale thickness and sulfide penetration increased with an increasing sodium feed rate.

- Higher limestone feed rates tended to reduce metal loss, sulfide penetration, and deposit/scale thickness.

- Tests with smaller bed particle size exhibited more metal loss, sulfide penetration, and deposition than tests with larger bed particle size.

- An increase in the silica-to-alumina and base-to-acid ratios decreased metal loss.

It is hoped that this information will help designers and users of bubbling fluidized beds to evaluate the impact of coal properties, metal type, metal surface temperature, and location of the corrosion, erosion, and deposition on tubes in the FBC. This data should be used carefully, as this summary was based on average values for different categories. As in most cases, there may be exceptions for different cases, and results should be examined on a tube-by-tube basis if trying to match a specific application. It should be remembered that other factors, including tube bundle geometry and operating conditions, also influence the level of corrosion and erosion and must be taken into consideration when evaluating potential wear. Details of this work are presented in the EERC topical report entitled "Corrosion, Erosion, and Deposition of AFBC Boiler Tube Surfaces."

\subsection{ADVANCED CONCEPTS: COAL PRETREATMENT CELL}

The coal pretreatment cell was developed as a new process for an advanced $F B C$ system. The impetus of the original program was to develop a new system or improve existing equipment to realize a reduction in overall capital and operating costs, increase boiler and overall efficiency, and/or reduce emission levels.

A multiphasic approach was taken to accomplish the goals of this task. Initially, a systematic listing of identifiable problems in current $F B C$ technology was developed. A second step involved breaking down the $F B C$ process into individual processes, such as calcination, sulfation, drying, devolatilization, carbon burnout, etc. Conditions needed to optimize each of these processes, independent of the rest of the process, were determined, based on EERC experience, FBC theory, and published results.

Using the list of problems and the individual process constraints developed in the first two steps, new concepts that could be incorporated into a design to solve a particular problem or improve performance of a certain subsystem were formulated. These ideas were qualitatively screened and refined based on technical, environmental, and economic criteria.

Based on these preliminary efforts, the EERC focused attention on developing a pretreatment cell to be used in conjunction with any number of FBC designs. The operation and function of the pretreatment cell, as developed, begins with raw coal being fed into the pretreatment cell. In the pretreatment cell, moisture will be driven off, some devolatilization will 
occur, and the coal will be fragmented into smaller pleces. The extent and severity of these processes can be controlled by varying several operating parameters. Air-to-fuel ratio and residence time are the primary control variables. The reactions and changes will occur using heat generated from combusting a small portion of the coal, so no external heat source will be required.

The pretreatment cell will be operated as a fluid bed. Velocity and vessel design are chosen to allow classification of the fuel. Existing data show that an optimal size exists for fuel fed into an $F B C$, in terms of both top and bottom size. As a result, coal sizing is often a significant operating cost. Large-sized coal (top size determined by testing) will be fed into the pretreatment cell. The vessel is designed with less cross-sectional area on the bottom (high velocity) than at the top of the bed surface (lower velocity) so that the entire bed will be fluidized even when feeding 1 arge coal particles. Smaller chunks of coal will be removed from the top of the bed to be fed into the combustor. The larger chunks will remain in the lower level of the bed until they become reduced in size due to drying, volatilization, and the action of the bed. This action will allow the use of coal with a larger top size, thereby reducing coal preparation costs.

In most combustor designs, excessive fines cause reduced combustion efficiency due to elutriation. In the pretreatment cell, velocities will be maintained at a sufficient level to remove fines below 200 mesh. These fines will be removed from the top of the pretreatment cell with the moisture and volatiles and will become a part of a low-Btu gas stream that can be burned using conventional burners, as will be discussed later. Therefore, only a minimal amount of fines will be fed into the combustor, and carbon burnout should increase.

Moisture and some volatiles will be driven off in the pretreatment cell. This will be done at a very low air-to-fuel ratio, using only heat from the coal. The gas stream from this process, combined with the coal fines, will make up a low-Btu gas that can be used somewhere else in the system, such as in the freeboard or convective pass of the combustor. Pretreatment can have several applications, but maintaining steam quality during turndown may have the greatest potential benefit. Coal pretreatment can not only smooth out the steps when load is controlled by removing segments of bed, but should also increase the range of turndown.

Removal of the moisture and volatiles in the pretreatment cell will also act as an "equalizer" for the fuel being fed into the main combustor. All fuel burned in the combustor will be similar in terms of moisture and volatiles and should vary only in the ash. This feature should increase the overall fuel flexibility of the unit.

Mass and energy balances have been performed using this concept. A comparison was made using a conceptual 200-MW bubbling FBC with and without a pretreatment cell. Data for the FBC under normal operation was taken from a previous EPRI study (15). For the case using the pretreatment cell, data taken from previous work $(16,17)$ was used to generate material and energy balances around the pretreatment cell. For the combustor, velocities and excess air levels the same as the base-case FBC were used. This anaiysis showed a reduction of $17 \%$ in the overall plan area, even with the pretreatment 
cell included. This will be accompanied by a significant reduction in height for the pretreatment cell versus the height of the fluid bed it replaces.

This should result in substantial reductions in capital costs.

Mass and energy balance calculations also indicate an optimal total airto-fuel ratio of 1.105 . This calculation was done assuming an air-to-fuel ratio of 1.20 for all combustion processes and is compared to a total air-tofuel ratio of 1.20 for the base-case $F B C$. The resulting lower air-to-fuel ratio indicates higher overall boiler efficiency and should result in lower capital costs because of reduced fan requirements. Figure 1 shows a conceptual drawing (relatively to scale) on how the pretreatment cell would be incorporated into a CFBC.

To summarize, the proposed advanced concept should have many advantages over conventional fluid-bed combustion, including the following:

- Minimal coal preparation will be required. Both fines and large coal particles will be efficiently handled.

- The pretreatment cell will be smaller, requiring fewer feed points and less plan area than the equivalent amount of combustor that it replaces. The total height requirement for the pretreatment cell will also be less than that of the combustor it rep1aces.

- Fuel flexibility will increase by "equalizing" the fuel (in terms of moisture and volatiles) that is being fed into the combustor.

- The total plan area of the pretreatment bed and the combustor will be approximately $17 \%$ less than for an equivalently sized conventional $F B C$.

- Turndown will be improved by maintaining steam quality at low load conditions.

- Higher volumetric heat-release rates are expected.

- Tighter constraints on coal size, both top and bottom size, will result in higher combustion efficiency and higher heat removal in the fluid bed.

- Staging of air and lower total air usage should result in lower NO. emissions.

- Separate burning of the volatiles and char may result in lower $\mathrm{N}_{2} \mathrm{O}$ emissions.

- Start-up may be accomplished without the use of an auxiliary burner.

- The pretreatment cell may be retrofittable to existing units, with similar benefits realized.

- The pretreatment cell will be small enough to allow for modular construction. 


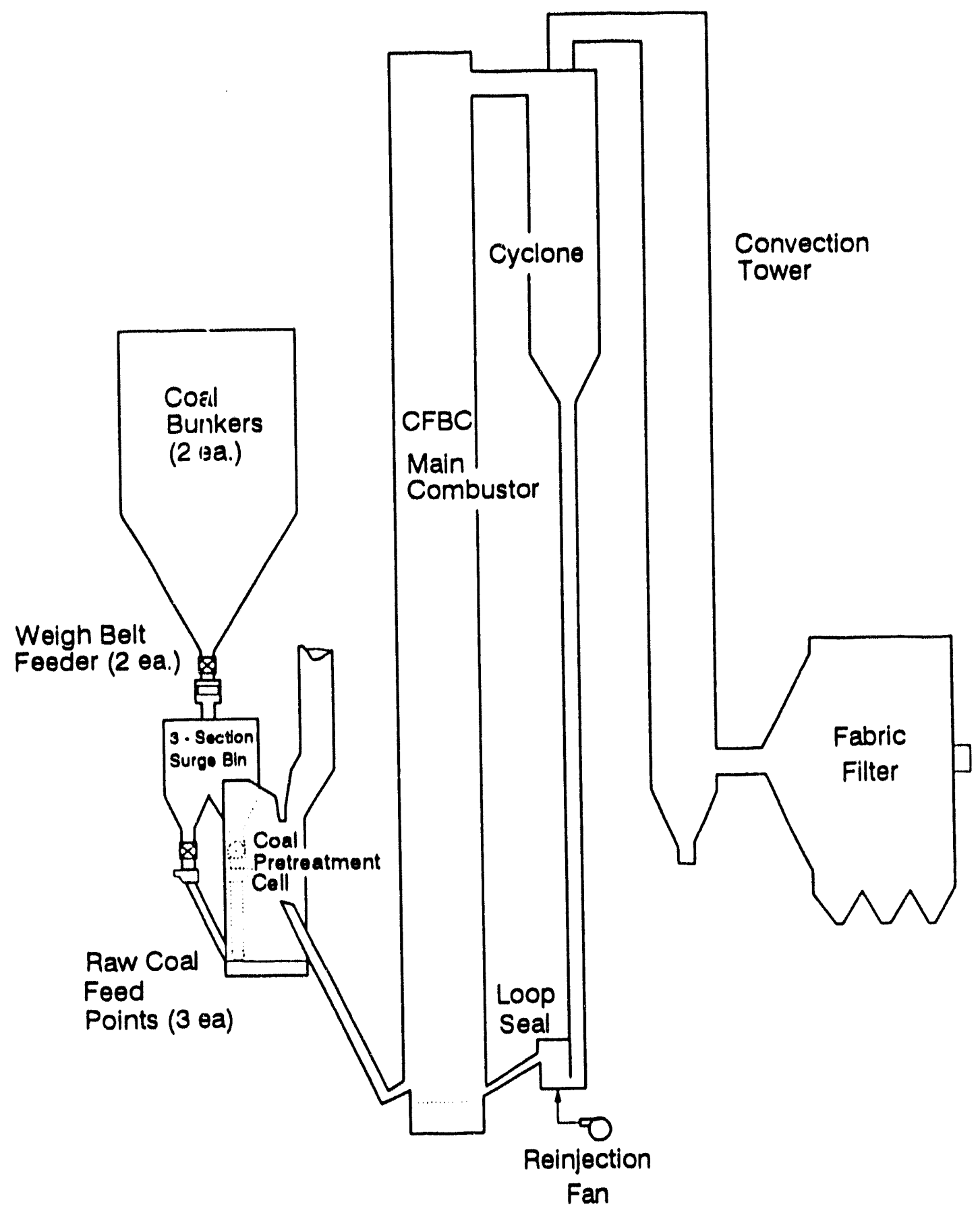

Figure 1. Coal pretreatment cel1 with CFBC (100-MW capacity). 


\subsection{SYSTEM SIMPLIFICATION}

As more and more bollers utilize fluidized-bed combustion systems because of their efficiency, fuel flexibility, and low emissions capability, it becomes increasingly important to understand the control philosophy required to optimize these features. A FBC consists of a large number of interrelated variables which must be carefully controlled for optimum performance. The level of control is dictated by the type of FBC system, the application of the system, and the availability of trained personnel to operate the system. $A$ study was completed that evaluated existing control systems and needs and proposed alternatives for improved control. Results are summarized below.

Market potential for the use of AFBC technology in the commercial and industrial sectors is great; however, to increase the acceptability of this technology, low cost, reliability, and ease of operation must be inherent to the system. This can be accomplished, in part, by the development of a good control system. The control system must be developed to the point where the boiler will be controlled within desired operational parameters without the availability of highly trained operators. One method of accomplishing this is to establish expert systems that will become the "trained experts" to perform the bulk of control activities, thereby allowing the owners of small boilers to operate with minimal personnel. Optimizing the control of the operating parameters should make the $F B C$ easier to operate, reducing operating costs while increasing system reliability.

An expert system is a knowledge-based computer system that can mimic the human thought process. The computer is able to reason according to a set of predefined rules to solve a problem that would otherwise require an expert or significant expertise to solve. Expert systems can capture a lifetime of individual expertise and make that expertise available to practitioners who lack comparable abilities for solving problems in the field. An expert system augments a process control system by evaluating the data and drawing conclusions. The common goal of all expert systems is to tap the ability of the computer to store large amounts of technical know-how, to access this data when needed, and to make intelligent judgments about likely causes of failure or poor performance.

The function of control systems is to compare desired values (set points) and actual values (output variables) to adjust the amount of fuel, air, and water (manipulated variables) to make the output variables match the set points. A skillful operator manipulates the control variables to optimize the boiler performance, rather than simply making the system run. An expert control system would be expected to do the same.

A number of different and sometimes conflicting factors go into the control philosophy of a plant. Some of these factors are operating objectives, economic operating conditions, regulatory requirements, and physical process constraints. Specific priorities must be established, such as the choice between maximum efficiency and maximum reliability and the choice between equipment protection or continuity of operation.

Many operations may be controlled automatically, rather than manually, for several reasons. A degree of automation keeps operator work load at manageable levels; if an operator is relieved of routine tasks, he can 
concentrate on optimizing plant performance, with a corresponding increase in plant efficiency. Limiting the number or complexity of operator functions will reduce the possibility for human error and, thereby, decrease equipment damage. Adding automatic functions can reduce the amount of time required for start-up and shutdown. Increased automation does require additional capital cost for computers, controllers, software, and instrumentation, so the desired level of automation must be carefully considered.

The most effective boiler control system is one which is stable and responsive; that is, the controlled variables remain close to their set point values without cycling and recover quickly from system disturbances without excessive overshoot or oscillation.

As power plants become more complex, improved control systems, state-ofthe-art diagnostics, and expert systems will become essential. Technology has progressed to the point where we can make available, quickly and accurately, knowledge that only existed before in the minds of a few scattered "experts."

\subsection{AGGLOMERATION AND DEPOSITION}

Although FBCs typically operate at low temperatures $\left(1450^{\circ}\right.$ to $\left.1700^{\circ} \mathrm{F}\right)$, evidence from pilot, industrial, and utility boilers indicates that certain ash components have the potential to cause ash-related problems. These problems can manifest themselves as agglomeration and sintering of the bed material, or as deposition on the heat-exchanger tube surfaces. The EERC performed bench- and pilot-scale tests, in addition to sampling from full-scale units, to uncover the underlying mechanisms of agglomeration and deposition. Results from this work are summarized below.

\subsection{Agglomeration}

Under steady-state conditions, reaction between various ash species and the bed particles occurs. At the initial stages, ash species deposit on the surface of the particles. The process has been observed for both quartz and limestone particles. The species that deposit tend to be sulfate-rich, indicating that the overall process at this stage is that of sulfate-tosulfate sintering. At this stage, limited evidence of localized melting exists. The process continues, resulting in the formation of a thick ash she11 (about 10\% of the particle diameter). The next stage can be seen as the onset of agglomeration. This occurs when two or more ash-coated bed particles cohere to form a larger particle. The cohesion is via the sulfate-rich ash coating due to sulfate-to-sulfate sintering. If the cohesion continues, the next stage will occur, which is the most serious, and may result in the formation of large agglomerates and the eventual slumping of the bed.

A fluidized bed is capable of tolerating a fraction of bed particles in the oversized range; however, once the oversized particles exceed a critical value, the degree of mixing will be reduced. With poor mixing, localized high temperatures are reached for relatively extended periods of time. This leads to the melting of ash species and, in some cases, the bed material. The cohesion under these condition is via a silicate matrix. This matrix results in accelerated cohesion, reaction, formation of a more liquid phase, and 
growth of agglomerates, compared to the sulfate sintering that occurs at the earlier stages.

The critical stages of agglomeration can be summarized as follows:

1. Initial deposition/condensation of volatile alkaline ash species and fine-grained calcium on the surfaces of bed particles.

2. Sulfation of the alkalies to form alkali sulfates. This may occur before, during, and/or after deposition.

3. Adhesion and cohesion of additional ash species on the initial ash layer.

4. Cohesion of two or more particles to form an agglomerate via sulfate sintering.

5. The formation of a large agglomerate.

6. The fraction of oversized particles exceeding the critical value for the fluidizing conditions.

7. The formation of high-temperature zones within the bed due to poor fluidization.

8. The high temperature causing ash melting and the formation of a molten silicate melting.

The initial stages have been shown by detailed surface science and scanning electron microscopy to be due to sulfate formation at the surface of the bed particle $(1,18-22)$. The importance of sulfate in the agglomeration process was shown by Bobman $(2,23)$ during experiments with a 2 " fluidized-bed reactor. It was shown that agglomeration of fly ash particles with quartz and limestone beds only occurred when $\mathrm{SO}_{2}$ was added to the fluidizing air.

Furthermore, the tests had to be conducted for relatively long periods, at least 48 hours, before significant agglomeration occurred. This further confirmed that the agglomeration was occurring due to the sulfate sintering mechanism, as liquid-phase sintering associated with an aluminosilicate melt would be expected to be rapid.

The importance of the form of sodium in the coal is evident when comparing results from tests with a North Dakota lignite, a Texas lignite, and an Illinois \#6 bituminous. Although the coals had sodium plus potassium levels of $9.1 \%, 7.2 \%$, and $3.4 \%$, respectively, agglomeration was only noted for the case with the North Dakota lignite where the sodium occurred in a form that allowed volatilization during combustion (1).

\subsection{Deposition on Tube Surfaces}

Sodium, potassium, calcium, and sulfur can play a similar role in deposition on in-bed and convective heat-transfer surfaces in the fluid bed. Evidence accumulated by the EERC $(24,25)$ and other researchers $(26-28)$ indicates that tube deposits are the result of a combination of fine-grained deposit-forming particles arriving at the tube surface followed by 
sticking/bonding of those particles onto the surface. Condensation of alkaline salts from the vapor phase occurs in the temperature range of $1000^{\circ}$ to $1475^{\circ} \mathrm{F}$. At the same time as these alkali salts are condensing and forming sticky surfaces, fine-grained ash particles (<1 micron) are arriving at the tube surface. These fine-grained particles are predominantly calcium oxides and sulfates. These particles then become bonded to the tube surface via a sintering process. Sintering of the deposits continues after initial deposition, forming deposits with a dense matrix. Other ash species can then be trapped within this captive surface, as noted by inclusion of iron oxide and other ash constituents in analyzed deposits.

Based on the proposed mechanism and on results from pilot-and full-scale testing, the importance of the elemental and mineralogical composition of coal mineral matter becomes obvious. Coals with organically bound alkalies cause more deposition than those with no alkali or clay-associated alkalies. The presence of certain aluminosilicates within the ash matrix may fix these alkali elements within a viscous melt phase, thereby nullifying their depositforming potential.

A series of pilot-scale tests were performed by the EERC to study the impact of coal type on deposition, erosion, and corrosion. Seven 1000-hour tests were performed utilizing a Beulah North Dakota lignite, a Sarpy Creek Montana subbicuninous coal, a Navajo New Mexico subbituminous coal, Gibbons Creek and South Hallsville Texas lignites, a River King 111 inois \#6 bituminous coal, and a Pyro Kentucky \#9 bituminous coal. These coals represent a wide range of coal and ash properties (properties given in Reference 29). Coal ash properties significantly affect the amount of tube deposition. The amount of deposition is also controlled by metal type, temperature, and tube location, as illustrated in Table 6 . This deposition has an adverse affect on heat transfer, with heat-transfer coefficients decreasing by over $40 \%$ during the course of a run for the worst cases.

An analysis of variance indicated that a higher sulfur content in the coal causes thicker deposits on the tubes. Deposit thickness was found to increase significantly as the amount of sodium fed into the unit increased. There was no correlation, however, between the amount of sodium and potassium in the bed and the deposit thickness. The total amount of calcium added to the coal had no impact on deposit thickness, but the thickness showed an increase with calcium when only the organic portion was considered. Total deposit thickness decreased with an increase in limestone feed rate. It should be noted that the elemental contents in the coal were compared on a $1 \mathrm{~b} / \mathrm{MM}$ Btu basis, not as weight percent in the coal.

These results substantiate the proposed mechanism. Coals with higher concentrations of volatile alkalies showed higher deposition rates. The presence of calcium was critical in the deposit formation, but all forms of calcium present in the coal did not result in major depositional problems. As in the case of the agglomeration work, coals that produced more $\mathrm{SO}_{2}$ showed a higher propensity to form a sulfate-based matrix, which is the bas is for initiating the deposit. Analysis of the deposits showed the major phase in the deposit was a calcium/sodium sulfate material. Although limestone addition increases the total amount of calcium in the bed, the resultant 
TABLE 6

Comparative Statistics on Deposit/Scale Thickness*

\begin{tabular}{lccrrr}
\hline & $\begin{array}{c}\text { Number of } \\
\text { Observations }\end{array}$ & $\begin{array}{c}\text { Lowest } \\
\text { Value }\end{array}$ & $\begin{array}{c}\text { Highest } \\
\text { Value }\end{array}$ & $\begin{array}{c}\text { Mean } \\
\text { Valandard } \\
\text { Deviation }\end{array}$ \\
\hline $\begin{array}{l}\text { Temperature, }{ }^{\circ} \mathrm{F} \\
250\end{array}$ & 20 & 0 & 210 & 42 & 66 \\
400 & 31 & 0 & 1560 & 317 & 473 \\
700 & 20 & 0 & 580 & 115 & 193 \\
1100 & 54 & 0 & 720 & 104 & 190 \\
1200 & 23 & 0 & 600 & 105 & 182 \\
Coal Type & & & & & \\
Beulah & 29 & 120 & 1560 & 502 & 349 \\
Gibbons Creek & 29 & 10 & 520 & 65 & 128 \\
Navajo & 27 & 0 & 150 & 19 & 34 \\
Pyro & 17 & 10 & 1240 & 188 & 385 \\
River King & 24 & 0 & 370 & 43 & 73 \\
Sarpy Creek & 23 & 3 & 150 & 30 & 31 \\
South Ha17svi11e & 26 & 0 & 50 & 20 & 14 \\
Metal Type & & & & & \\
304 SS & 48 & 0 & 1100 & 104 & 215 \\
316 SS & 49 & 0 & 720 & 96 & 179 \\
347 SS & 47 & 0 & 910 & 82 & 175 \\
Carbon Steel & 31 & 0 & 1560 & 285 & 433 \\
Location & & & & & \\
In-Bed & 92 & 0 & 1560 & 163 & 319 \\
Splash Zone & 63 & 0 & 600 & 91 & 160 \\
Convective Pass & 20 & 0 & 650 & 88 & 177 \\
\hline
\end{tabular}

- The minimum and maximum values from each tube were used in the statistical analysis. All units are microns.

calcium sulfate is in the form of larger limestone-based particles and does not appear to impact the overall deposition process. In fact, the decrease in deposition noted with increased limestone addition may be due to dilution. Similar results have been reported by other researchers (26-28).

\subsection{Incidents in Full-Scale Systems}

Both agglomerates and in-bed tube deposits from full-scale boilers have been recovered and studied at the EERC. The following description of these materials provides additional evidence in support of the previous discussion. This analysis also shows the importance of using advanced analytical techniques for analyzing these deposits and elucidating whether the noted problem is due totally to ash chemistry, or in combination with a system upset. 
The 80-MW bubbling FBC at the MDU Heskett Station has experienced deposition on both in-bed and convective pass heat-transfer surfaces, causing significant reduction in overall heat transfer. The superheat steam temperature decreased by $40^{\circ} \mathrm{F}$ over a four-month period due to deposition on the inbed superheat tubes. The unit is fired with Beulah lignite and has a bed material of river sand. Deposits from this unit were collected and analyzed using $x$-ray fluorescence, $x$-ray diffraction (XRD), electron probe microanalys is (EPMA), and scanning electron microscopy point count (SEMPC). The focus of the analysis was to establish the mechanism of deposit formation and growth. Detailed results are published elsewhere (24).

Analytical results show that the Beulah coal ash has a definite prcpensity for deposition. The formation of an ash coating on bed material is a precursor to agglomeration. The ash coating is derived from the coal, in particular, the calcium, sulfur, and sodium. The deposits, including the ash coating, possess chemical compositions very different from the spent-bed material, indicating that the deposition mechanism is a selective process. All deposits are predominantly enriched in calcium and sulfur. Significant iron enrichment was observed in the convective pass deposit; however, it did not appear responsible for the deposit growth.

The evidence suggests that deposit growth is due to the formation and presence of sodium calcium sulfate in the bed. This material is formed from the organically bound sodium and calcium in the Beulah coal reacting with sulfur. There was no free calcium observed in the deposits. Sulfate species tend to sinter. The matrix was too fine-grained to establish the presence of a melt phase. It should be noted that molten sulfate systems tend to crystallize rapidly upon cooling. The mode of growth may be a molten sulfate phase. Certainly the presence of sodium with the calcium would be expected to lower the melting point. The presence of nepheline, anorthite, and gehlenite suggests relatively high-transient temperatures within the bed. The silicate phases, while exhibiting melting behavior, were not present in significant quantities to have a significant effect on deposition phenomena.

\subsection{Agglomeration in Full-Scale Utilities Due to Operational Upsets}

The cases and mechanisms of agglomeration and deposition discussed so far are the result of coal ash chemistry under normal operating conditions in the $F B C$. However, agglomeration can also occur due to maldistribution of air, temperature upset, or other operational difficulties. The cause of agglomeration can be determined by using advanced analytical techniques to examine the raw coal, the original and spent-bed material, and any agglomerates that form. The following example presents results from a study done at the EERC on an agglomerate formed in the 130-MW bubbling FBC at the NSP B1ack Dog Station.

The agglomerate was supplied by NSP personnel after excessive agglomeration was observed during a shakedown test with Sarpy Creek, a Powder River subbituminous coal, and an inert-bed material of fired clay. The agglomerate was dense and consisted of two distinct regions, classified as sintered and slag-like. The two regions and the virgin bed material were analyzed using SRD, EPMA, and SEMPC. The focus of the analys is was to elucidate the reason for the agglomerate formation: specifically, was it related to ash chemistry or operating conditions? 
The data indicated that the sintered deposit was due to the melting of the ash species which acted as the adhesive between the kaolinite particles. There was relatively little interaction between the ash matrix and the kaolinite-bed material, as shown by the fact that there were 1 imited amounts of kaolinite-derived particles in the sintered deposit. The data contrasts markedly with that of the slag samples. The low quantity of pire kaolinite and kaolinite-derived particles and the presence of crystalline millite indicates that extensive melting and recrystallization from the melt took place. In order for this to occur, temperatures in excess of $2400^{\circ} \mathrm{F}$ are required. This indicates that excessive temperatures were reached in the combustor which were directly responsible for the agglomeration. There was no evidence to suggest that the agglomeration was due to the reaction of alkaline ash components to form a sticky matrix at the average operating temperature of $1750^{\circ} \mathrm{F}$.

\subsection{Summary}

Advances in analytical techniques for examining coal minerals, fly ashes, and deposits have improved the understanding of agglomeration and tube deposition in FBC systems. Both of these phenomena appear to be initiated by the same basic mechanism and are directly related to the amount and distribution of sodium, potassium, calcium, and sulfur in the feedstock.

Agglomerates and deposits are initiated and formed by the same general mechanism. Organically bound-alkali species are volatilized during coal combustion and condense on bed-material surfaces or on in-bed tubes. The condensation mechanism involves gas-to-solid condensation, either in the combustion gases forming partially fused or solid crystals. These can subsequently adhere to cooled surfaces in the combustor. Condensation can also occur directly by nucleation and growth on the substrate.

Alkali species can form sulfates, either in the gas phase or immediately upon condensation. These alkali sulfates sinter over a period of time, forming a very tenacious fine-grained, dense layer. In the case of agglomeration, two or more particles can stick together to form an agglomerate via this sulfate sintering, eventually causing defluidization. Tube deposition will impair heat transfer and reduce boiler load.

Knowledge of the total alkali in a fuel is not sufficient to predict the potential for agglomeration or deposition. The alkali must be in a form that will allow it to be volatilized during combustion, i.e., organically bound. Those alkalies associated with clay minerals are generally not available to participate in deposition or agglomeration. Other minerals associated with the fuel are also important. Aluminosilicate phases can compete for the released alkali and form higher melting point clays, rendering the alkalies inert in terms of agglomerate and deposit formation. Therefore, it is imperative to know the mineralogical composition of a fuel, as well as its chemical composition.

Advanced analytical techniques, especially SEMPC, are important in forensic studies of problems encountered in operating systems. The use of this technique can help determine whether agglomeration problems are due to ash chemistry or to combustor-operating conditions. This distinction is important, as the method of mitigation will be different for the two 
instances. With proper understanding of the fuel and its potential for agglomeration and deposition, even potentially problem fuels such as Beulah North Dakota 1 ignite, with $8 \%$ to $12 \%$ of its ash present as organically bound sodium, can be successfully burned in utility-scale plants, as evidenced by the highly successful operation of the 80-MW Heskett Station. Information gathered from this type of analysis has also been used by the operators of the NSP BIack Dog Station to modify start-up and fluidizing procedures, to virtually eliminate their agglomeration problem.

\subsection{REFERENCES}

1. Hajicek, D.R.; Zobeck, B.J.; Mann, M.D.; Miller, B.G.; Ellman, R.C.; Benson, S.A.; Goblirsch, G.M.; Cooper, J.L.; Guillory, J.L.; Eklund, A.G. "Performance of Low-Rank Coal in Atmospheric Fluidized-Bed Combustion," Technology Transfer Report DOE/FE/60181-1869, Oct. 1985.

2. Mann, M.D.; Hajicek, D.R.; Zobeck, B.J.; Kalmanovitch, D.P.; Bobman, M.H.; Kadrmas, R.J.; Grewal, N.S. "Fluidized-Bed Combustion of Low-Rank Coals-Final Report," DOE/FC/60181-2127, Sept. 86.

3. Perna, M.A. "B\&W/EPRI Fuels Characterization Test Program-Initial Test Results from the 1' x 1' AFBC," 1986 EPRI Seminar on Atmospheric Fluidized Bed Combustion Technology for Utility Applications, EPRI CS5186, Jul. 1987.

4. Dania1, P.L. et al. "6-by-6-ft Atmospheric Fluidized Bed Combustion Development Facility, 1980 Test Results," EPRI CS-3115, Jun. 1983.

5. Simbeck, D.R. "Review and Status of Technology, Economics, and Markets for Fluidized Bed Combustion," Presented at CIBO Conference, Dec. 1987, St. Louis, M0, 1987.

6. Miller, S.E. et al. "Preliminary Analysis of 6- $\times 6$-ft AFBC Facility Emissions," EPRI CS-3188, Ju1. 1983.

7. Beer, J.M. et al. "NO Formation and Reduction in Fluidized-Bed Combustion of Coal," Sixth International Conference on Fluidized-Bed Combustion, Atlanta, GA, Apr. 1980.

8. Ciliberti, D.F. "Nitrogen Oxide Emissions," Experimental/Engineering Support of EPA's FBC Program: Final Report, Vol. II, EPA-600/7-80-0156, Jan. 1980.

9. Cushing, K.M. "Fabric Filtration-Atmospheric Fluidized Bed Combustion Versus Pulverized-Coal Combustion, "Ninth International Conference on Fluidized Bed Combustion, Boston, MA, May 1987.

10. Bobman, M.H. et al. "A Study of Bed Agglomeration Resulting from the AFBC of Low-Rank Coals, "Eighth International Conference on Fluidized Bed Combustion, Houston, TX, Mar. 1985. 
11. Gerre1, R.L.; Strong, D.N. "Description of 80-MW Fluidized-Bed Retrofit at Montana-Dakota Utilities Co.," EPRI Seminar on Atmospheric Fluidized Bed Technologies for Utility Application, EPRI CS-5186, Jul. 1987.

12. Roberts, A.G.; Pillai, K.K.; Barker, S.N.; Carpenter, L.K. "Combustion of Run-of-Mine Coal-Water Mixtures in a Small PFBC," In Proceedings of the Seventh International Conference on Fluidized Bed Combustion; 1982, Vol. 1, pp 482-489.

13. Hoy, H.R.; Roberts, A.G.; Scott, R.L. "Operation of a Small Combustor on Dry Coal and on Coal-Water Mixtures of Pressures up to 20 atm., "In Proceedings of the Eighth International Conference on Fluidized Bed Combustion; 1985, Vol. 1, pp 291-306.

14. Rowley, D.R.; Lau, I.T.; Friedrich, F.D. "Combustion of Coal-Water Slurries and Coal Tailings in a Fluidized Bed," In Proceedings of the Eighth International Conference on Fluidized Bed Combustion; 1985, Vol. II, pp $962-980$.

15. Dunlop, W. "Evaluation of Alternative Steam Generation Designs for Atmospheric Fluidized-Bed Combustion Plants," EPRI CS-5296, July 1987.

16. Gomez, M.; Landers, W.S.; Wagner, E.O. "Entrained Bed Carbonization of Highly Fluid Bituminous Coals," U.S. Bureau of Mines Report, RI7141, June 1968.

17. Boley, C.C.; Fegley, M.M. "Design and Operation of Two Refractory-Lined Internally Heated Entrained-Bed Carbonizers," Grand Forks Energy Research Center Report GFERC/RI-77/1, U.S. Department of Energy, 1977.

18. Perkins, D., III; Brekke, D.W.; Karner, F.R. "Analys is of Atmospheric Fluidized-Bed Combustion Agglomerates," Technical Information Service, U.S. Department of Energy, DOE/FC/10489-1694, Apr. 1984.

19. Brekke, D.W.; Karner, F.R. "Analysis and Characterization of Atmospheric Fluidized-Bed Combustion Agglomerates, "Fossil Energy AB18-80FC10120, 1982.

20. Benson, S.A.; Karner, F.R.; Goblirsch, G.M.; Brekke, D.W. "Bed Agglomerates Formed by Atmospheric Fluidized-Bed Combustion of a North Dakota Lignite," 183rd National Meeting, American Chemical Society, Division of Fuel Chemistry, Las Vegas, NV, Mar. 29 - Apr. 2, 1982, 1982 , Vol. 27, No. 1, pp 174-181.

21. Goblirsch, G.M.; Benson, S.A.; Hajicek, D.R.; Cooper, J.L. "Sulfur Control and Bed Material Agglomeration Experience in Low-Rank Coal AFBC Testing," In Proceedings of the Seventh International Conference on Fluidized-Bed Combustion; Philadelphia, PA, DOE/FC-1005, 0ct. 1982.

22. Goblirsch, G.M.; Benson, S.A.; Karner, F.R.; Rindt, D.K.; Hajicek, D.R. "AFBC Bed Material Performance with Low-Rank Coals," Twelfth Biennial Lignite Symposium, Grand Forks, ND, DOE/FE/60181-5, May 18-19, 1983. 
23. Bobman, M.H.; Hajicek, D.R.; Zobeck, B.J. "A Study of Bed Agglomeration Resulting from the AFBC of Low-Rank Coals," Eighth International

Conference on Fluidized-Bed Combustion, Houston, TX, DOE/METC-85/6021, Mar. 1985, Vol. 3, pp 1399-1407.

24. Mann, M.D.; Kalmanovitch, D.P. "Ash Deposition on AFBC Applications Involving Western Fuels," Seminar on Fireside Fouling Problems, Provo, UT, Apr. 4-6, 1990.

25. Kalmanovitch, D.P.; Hajicek, D.R.; Mann, M.D. "Corrosion and Erosion in a Fluidized-Bed Combustor: Effect of Bed Chemistry," Corrosion '89, New Orleans, LA, Mar. 1989.

26. Hodges, N.J.; Marsh, M.K. "The Effect of Salt Minerals on Deposit Formation During Fluidized-Bed Combustion of Coal," Fuel Processing Technology $199024,367-374$.

27. Oakey, J.E.; Minchener, A.J.; Stringer, J. "Ash Deposition in Atmospheric-Pressure Fluidized-Bed Combustion Systems, "Journal of the Institute of Energy 1990 208-219.

28. Hodges, N.J.; Richards, D.G. "The Fate of Chlorine, Sulphur, Sodium, Potassium, Calcium, and Magnesium During the Fluidized-Bed Combustion of Coal," Fuel $198968,440-445$.

29. Mann, M.D.; Kalmanovitch, D.P.; Hajicek, D.R. "The Impact of Coal Properties on Corrosion and Erosion of FBC Boiler Tubes," Fifteenth Biennial Low-Rank Fuels Symposium, Minneapol is, MN, DOE/METC-90/6109, May 1989.

\subsection{AFBC PUBLICATIONS AND PRESENTATIONS GENERATED BY THE EERC}

Benson, S.A.; Karner, F.R.; Goblirsch, G.M.; Brekke, D.W. "Bed Agglomerates Formed by Atmospheric Fluidized-Bed Combustion of a North Dakota

Lignite," 183rd National Meeting, American Chemical Society, Division of Fuel Chemistry, Las Vegas, NV, Mar. 29-Apr. 2, 1982, Vol. 27, No. 1, pp 174-181.

Bobman, M.H.; Hajicek, D.R.; Zobeck, B.J. "A Study of Bed Agglomeration Resulting from the AFBC of Low-Rank Coals," 8th International Conference on Fluidized-Bed Combustion, Houston, TX, Mar. 1985, DOE/METC-85/6021, Vol. 3, pp 1399-1407.

Bobman, M.H.; Ketelle, D.T.; Kalmanovitch, D.P. "Microscopic Examination of Lignite Ash and Silica Sand Agglomerates in a Two-Inch Fluidized-Bed Reactor," 78th Annual Meeting of the North Dakota Academy of Science, Grand Forks, ND, Apr. 1986, Vol. 40, p 102.

Bradley, W.J.; Pancino, S.; Keairns, D.L.; Newby, R.A.; Ulerich, N.H.; Goblirsch, G.M.; Heher, W.M. "Effect of Subbituminous Western Coal Ash on AFBC Power Generating Costs," AIChE National Meeting, Apr. 1979, $44 \mathrm{p}$. 
Brekke, D.W.; Karner, F.R. "Analys is and Characterization of Atmospheric Fluidized-Bed Combustion Agglomerates," Fossil Energy 1982, AB18$80 \mathrm{FC} 10120$.

Goblirsch, G.M.; Benson, S.A.; Hajicek, D.R.; Cooper, J.L. "Sulfur Control and Bed Material Agglomeration Experience in Low-Rank Coal AFBC Testing," In Proceedings of the Seventh International Conference on Fluidized-Bed Combustion; Philadelphia, PA, DOE/FC-1005, 0ct. 1982.

Goblirsch, G.M.; Benson, S.A.; Karner, F.R.; Rindt, D.K.; Hajicek, D.R. "AFBC Bed Material Performance with Low-Rank Coals," Twelfth Biennial Lignite Symposium, Grand Forks, ND, DOE/FE/60181-5, May 18-19, 1983.

Goblirsch, G.M.; Fehr, R.W.; Sondreal, E.A. "Effects of Coal Composition and Ash Reinjection on Sulfur Retention Burning Lignite and Western Subbituminous Coals," In Proceedings of the Fifth International Conference on Fluidized-Bed Combustion; Washington, D.C., Dec. 1977 , Vol. 2.

Goblirsch, G.M.; Mann, M.D. "A Review of Low-Rank Coal AFBC Testing," In Proceedings of the Engineering Foundation Conference on Combustion of Tomorrow's Fuel's; Santa Barbara, CA, DOE/FC-1006, Nov. 7-12, 1982.

Goblirsch, G.M.; Ness, H.M. "Fluidized-Bed Combustion Tests on Lignites and Subbituminous Coals at the Grand Forks Energy Technology Center," DOE Symposium on Environmental Control Activities, Washington, D.C., Nov. $1978,18 \mathrm{p}$.

Goblirsch, G.M.; Sondreal, E.A. "Low-Rank Coal Atmospheric Fluidized-Bed Combustion Technology," Symposium on Technology and Use of Lignite, Grand Forks, ND, DOE/GFETC/IC-79/1, May 1979, pp 75-107.

Goblirsch, G.M.; Sondreal, E.A. "Fluidized Combustion of North Dakota Lignite," Symposium on Technology and Use of Lignite, Grand Forks, ND, DOE/GFERC/IC-77/1, May 1977, pp 82-99.

Goblirsch, G.M.; Sondreal, E.A. "Effects of Operating Parameters on the Sulfur Retention of Alkaline Ash During Fluidized-Bed Combustion of a North Dakota Lignite," In Proceedings of the Fluidized-Bed Combustion Technology Exchange Workshop; April 1977, pp 111-121.

Goblirsch, G.M.; Talty, R.D. "Recent Developments in Fluidized-Bed Technology for Lignites and Subbituminous Coals in the U.S.A.," In Proceedings of the Fluidized Combustion: Systems and Applications Conference; London, Engl and, Nov. 3-5, 1980, 9 p.

Goblirsch, G.M.; Vander Molen, R.H.; Wilson, K.; Hajicek, D.R. "AFBC Testing of North Dakota Lignite," Sixth International Fluidized-Bed Conference, Atlanta, GA, Apr. 1980.

Goblirsch, G.M. et a1. "AFBC Bed Material Performance with Low-Rank Coals," Twelfth Biennial Lignite Symposium, Grand Forks, ND, DOE/METC/84-13, Feb. 1984 , Vo1. 2, pp 578-581. 
Grewal, N.S. "Heat Transfer Between Tubes and Gas-Solid Fluid Bed," In Handbook of Heat and Mass Transfer; Cheremisinoff, N.P., Ed.; Gulf Publishing Company: Houston, TX; 1986; Vol. 1, pp 609-644.

Grewal, N.S. "Development of Reliable Predictive Heat-Transfer Correlation for Low-Rank Coa1-Fired Fluid-Bed Combustor," U.S. Department of Energy, Office of Fossil Energy, DOE/FC/10489-1694, Feb. 1984.

Grewal, N.S.; Goblirsch, G.M. "Heat Transfer to Horizontal Tubes in a PilotScale Fluidized-Bed Combustor Burning Low-Rank Coals," Chemical

Engineering Communications 1985, 39, 43-68.

Grewal, N.S.; Goblirsch, G.M. "Heat Transfer to Horizontal Tubes in a PilotScale Fluidized-Bed Combustor Burning Low-Rank Coals," ASME Annual Meeting on Heat Transfer, Seattle, WA, DOE/FC/60181-16, Jul. 1983.

Grewal, N.S.; Hajicek, D.R. "Experimental Studies of Heat Transfer from an Atmospheric Fluidized-Bed Combustor to an Immersed Array of Horizontal Tubes," Seventh International Heat-Transfer Conference, Munich, Federal Republic of Germany, Sept. 1982.

Grewal, N.S.; Menart, J.; Hajicek, D.R.; Zobeck, B.J. "Heat Transfer to Horizontal Tubes Immersed in a Fluidized Combustor," 1986 ASME Winter Annual Meeting, West Lafayette, IN, Nov. 1986.

Grewal, N.S.; Zobeck, B.J.; Mann, M.D.; Hajicek, D.R. "Heat Transfer in Fiuidized-Bed Coal Combustors," Ninth National Heat and Mass Transfer Conference, 1988.

Grewal, N.S.; Zobeck, B.J.; Mann, M.D.; Hajicek, D.R. "Evaluation of HeatTransfer Correlations for Fluidized-Bed Boiler Tubes, " 1987

International Conference on Fluidized-Bed Combustion, Boston, MA, May 1987.

Hajicek, D.R.; Kalmanovitch, D.P.; Mann, M.D.; Kadrmas, R.J. "Corrosion/ Erosion Resulting from the Fluidized-Bed/Combustion of Low-Rank Coals," 1987 International Conference on Fluidized-Bed Combustion, Boston, MA, May 1987.

Hajicek, D.R.; Mann, M.D. "Atmospheric Fluidized-Bed Combustion of Wood Chips for Valmont Industries," final report submitted to Valmont Industries, Inc.; Apr. 1988.

Hajicek, D.R.; Zobeck, B.J.; Mann, M.D.; Miller, B.G.; Ellman, R.C.; Benson, S.A.; Goblirsch, G.M.; Cooper, J.L.; Guillory, J.L.; Eklund, A.G. "Performance of Low-Rank Coal in Atmospheric Fluidized-Bed Combustion," Technology Transfer Report DOE/FE/60181-1869, Oct. 1985.

Hall, R.R.; McCabe, M.M.; McGrath, D.; Sears, D.R. "Material Balance in Atmospheric Fluidized-Bed Combustion of North Dakota Lignite," Presented at the Seventh International Conference in Fluidized-Bed Combustion, Philadelphia, PA, Oct. 25-27, 1982, DOE/METC/83-48, DE83-008374, pp 11271130 . 
Henderson, A.K; Mann, M.D. "Developing an Expert Control System for Fluidized-Bed Combustors," report of work performed under USDOE Agreement No. DE-FC21-86MC10637, May 1990.

Henderson, A.K.; Moe, T.A.; Hajicek, D.R.; Mann, M.D. "Design and Operation of the EERC Pilot-Scale Circulating Fluidized-Bed Combustor, "Sixteenth Biennial Low-Rank Fuels Symposium, Billings, MT, May 1991.

Henke, K.R.; Zobeck, B.J.; Mann, M.D.; Moretti, C.J. "Leaching Studies of Sol id Wastes from Fluidized-Bed Combustion Tests of Low-Rank Coals," 1987 International Conference on Fluidized-Bed Combustion, Boston, MA, May 1987.

Jones, M.L.; Goblirsch, G.M. "Combustion Testing of San Miguel Lignite," In Proceedings of the Gulf Coast Lignite Conference; Houston, TX, DOE/FC1007, Nov. 1982.

Kalmanovitch, D.P.; Hajicek, D.R.; Mann, M.D. "Agglomeration Phenomena in Fluidized-Bed Combustors," 10th International Conference on Fluidized-Bed Combustion, San Francisco, CA, Apr. 1989.

Kalmanovitch, D.P.; Hajicek, D.R.; Mann, M.D. "Corrosion and Erosion in a Fluidized-Bed Combustor: Effect of Bed Chemistry," Corrosion '89, New Orleans, LA, Mar. 1989.

Kalmanovitch, D.P.; Hajicek, D.R.; Mann, M.D. "Corrosion and Erosion in Fluidized-Bed Combustor Utilizing Low-Rank Coals," Corrosion '88, St. Louis, MO, Mar. 1988.

Kalmanovitch, D.P.; Hajicek, D.R.; Mann, M.D. "The Effects of Coal Ash Properties on the Corrosion/Erosion/Deposition of FBC Boiler Tubes," 10th International Conference on Fluidized-Bed Combustion, San Francisco, CA, Apr. 30-May 3, 1989.

Kalmanovitch, D.P.; Hajicek, D.R.; Mann, M.D. "Materials Performance in an AFBC Using Western Coals," Corrosion '87, St. Louis, M0, Mar. 1987.

Kalmanovitch, D.P.; Hajicek, D.R.; Mann, M.D. "Materials Performance in a Fluidized-Bed Combustor," Paper presented at the 10th International Fluidized-Bed Conference, San Francisco, CA, Apr. 1989.

Kalmanovitch, D.P.; Mann, M.D.; and Hajicek, D.R. "The Effects of Coal Ash Properties on FBC Boiler Tube Corrosion, Erosion, and Ash Deposition," Paper presented at the 10th International FBC Conference, ASME, New York, NY, Jan. 1989.

Majkrzak, R.S. "Fluidized-Bed Combustion of High-Alkali Ash, Low-Sulfur Western Coals," M.S. Thesis, University of North Dakota, Grand Forks, $1976,80 \mathrm{p}$.

Mann, M.D.; Collings, M.E.; Botros, P.E. "Nitrous Oxide Emissions in Fluidized-Bed Combustion: Fundamental Chemistry and Combustion Testing," Progress in Energy and Combustion Science, in press. 
Mann, M.D.; Collings, M.E.; Botros, P.E. "Effect of Operating Parameters on $\mathrm{N}_{2} \mathrm{O}$ Emissions in a 1-MW CFBC," Eighth Annual International Pittsburgh Coal Conference; Pittsburgh, PA, Oct. 1991.

Mann, M.D.; Galbreath, K.C. "The Role of Ash Chemistry and Operating Parameters on Ash Agglomeration and Deposition in FBC Systems," Inorganic Transformations and Ash Deposition During Combustion; Benson, S.A., Ed.; American Society of Mechanical Engineers: New York, 1992, pp 773-789.

Mann, M.D.; Hajicek, D.R. "Fuel Flexibility and CFBC," Pittsburgh Coal Conference, Pittsburgh, PA, Sept. 12-18, 1988.

Mann, M.D.; Hajicek, D.R.; Zobeck, B.J. "Performance Characteristics of Texas Lignite in AFBC," 14th Biennial Lignite Symposium on the Technology and Utilization of Low-Rank Coals, Dallas, TX, May 1987.

Mann, M.D.; Hajicek, D.R.; Zobeck, B.J.; Kalmanovitch, D.P.; Bobman, M.H.; Kadrmas, R.J.; Grewal, N.S. "Fluidized-Bed Combustion of Low-Rank Coals," final report; DOE/FE/60181, Jun. 1986.

Mann, M.D.; Hajicek, D.R.; Zobeck, B.J.; Kalmanovitch, D.P.; Bobman, M.H.; Kadrmas, R.J.; Grewal, N.S. "Fluidized-Bed Combustion of Low-Rank Coals," final report for the Period Ending Jun. 30, 1986; U.S. Department of Energy, DOE/FE/60181-2127, Sept. 1986.

Mann, M.D.; Hajicek, D.R.; Zobeck, B.J.; Miller, B.G. "FBC: An Environmentally and Economically Acceptable Alternative for Burning LowRank Coal," 13th Biennial Lignite Symposium, Bismarck, ND, DOE/FE/60181148, May 1985.

Mann, M.D.; Kalmanovitch, D.P. "Ash Deposition in AFBC Applications Involving Western Fuels," Seminar on Fireside Fouling Problems, Provo, UT, Apr. 4-6, 1990.

Mann, M.D.; Kalmanovitch, D.P.; Hajicek, D.R. "Corrosion, Erosion, and Deposition of AFBC Boiler Tube Surfaces," topical report prepared for METC; Cooperative Agreement DE-FC21-83FE60181 and DE-FC21-86MC10637, Morgantown, WV, Apr. 1991.

Mann, M.D.; Kalmanovitch, D.P.; Hajicek, D.R. "The Impact of Coal Properties on Corrosion and Erosion of FBC Boiler Tubes," Fifteenth Biennial LowRank Fuels Symposium, Minneapol is, MN, DOE/METC-90/6109, May 1989.

Mann, M.D.; Kalmanovitch, D.P.; Hajicek, D.R. "Boiler Tube Corrosion/Erosion/Deposition Resulting from Fluid-Bed Combustion," 1987 Joint Power Generation Conference, Miami, FL, Oct. 1987.

Mann, M.D.; Perna, M.; Imsdah1, B. "Design of Montana-Dakota Utilities 80-MW AFBC Retrofit," 14th Biennial Lignite Symposium on the Technology and Utilization of Low-Rank Coals, Dallas, TX, May 1987.

Mann, M.D.; Zobeck, B.J.; Hajicek, D.R. "Comparison of FBC Performance as a Function of Coal Rank," 1988 Joint Power Generation Conference, Philadelphia, PA, Sept. 1988. 
Perkins, D., III; Brekke, D.W.; Karner, F.R. "Analys is of Atmospheric Fluidized-Bed Combustion Agglomerates," Technical Information Service, U.S. Department of Energy, DOE/FC/10489-1694, Apr. 1984.

Severson, A.L.; Benson, S.A. "X-Ray Fluorescence Methods for Determination of Minor Elements in Particulate Emissions from Low-Rank Coal Combustion," Minor Proceedings, North Dakota Academy of Science, 1982, Vol. 36.

Smith, G.W.; Hajicek, D.R.; Myles, K.M.; Goblirsch, G.M.; Mowry, R.W.; Teats, F.G. "Demonstration of a Hydration Process of Reactivating Partially Sulfated Limestone Sorbents," Argonne National Laboratory, Argonne, IL, ANL/CEN/FE-80-23, 1980.

Sondreal, E.A.; Gronhovd, G.H.; Kube, W.R. "Research and Development Relating to Lignite Use in Power Production," Gulf Coast Lignite Conference: Geology, Utilization, and Environmental Aspects, Austin, TX, Jun. 1976, Conf. Proc., 1978, pp 100-124.

Swanson, M.L.; Moe, T.A.; Mann, M.D. "Advanced Coal Combustion," In Proceedings of the Heat Engine Contractors' Review Meeting; Morgantown, WV, Mar. 21-23, 1989.

Talty, R.D.; Hajicek, D.R.; Benson, S.A; Vander Molen, R.H.; Owen, M.L. "Fluidized-Bed Combustion Studies of Texas Lignite," In Proceedings of the Technology and Use of Lignite; Eleventh Biennial Lignite Symposium, San Antonio, TX, DOE/GFETC/IC-82/1, Jun. 1982, pp 565-605.

Talty, R.D.; Hajicek, D.R.; Jones, M.L.; Sears, D.R. "Performance Characteristics of Low-Rank Coals in Atmospheric Fluidized-Bed Combustion," Sixteenth Intersociety Energy Conversion Engineering Conference, Atlanta, GA, Aug. 9-14, 1981.

Zobeck, B.J.; Hajicek, D.R.; Mann, M.D.; Kadrmas, R.J. "FBC: An Attractive Energy-Producing Alternative for the Industrial and Commercial Markets," International Conference on the Lessons Learned Since the $0 i 1$ Embargo, Grand Forks, ND, DOE/FE/60181-206, May 1986.

Zobeck, B.J.; Mann, M.D.; Hajicek, D.R.; Kadrmas, R.J. "Western U.S. Coal Performance in a Pilot-Scale Fluidized-Bed Combustor, "9th International Conference on Fluidized-Bed Combustion, Boston, MA, May 1987.

Zobeck, B.J.; Mann, M.D.; Potas, T.A.; Maas, D.J. "Firing Low-Rank Coal-Water Slurry in a Fluidized-Bed Combustor," 14th Biennial Lignite Symposium on the Technology and Utilization of Low-Rank Coals, Dallas, TX, May 1987. 


\subsection{Beneficiation of Low-Rank Coals}




\title{
BENEFICIATION OF LOH-RANK COALS
}

Final Technical Progress Report

for the Period April 1, 1986, through December 31, 1992

\author{
by \\ Mark A. Musich, Research Supervisor \\ Chris M. Anderson, Research Engineer \\ Raymond A. DeWal1, Research Chemist \\ Energy and Environmental Research Center \\ University of North Dakota \\ Box 8213, University Station \\ Grand Forks, North Dakota 58202-8213
}

Task Contracting Officer's Representative: Richard B. Read

U.S. Department of Energy

Pittsburgh Energy Technology Center

P.0. Box 10940, MS 922-H

Pittsburgh, Pennsylvania 15236-0940

December 1992

Work Performed under Cooperative Agreement No. DE-FC21-86MC10637 


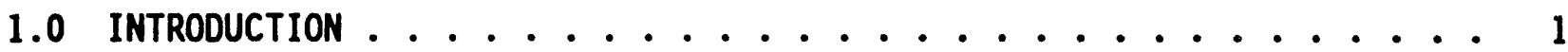

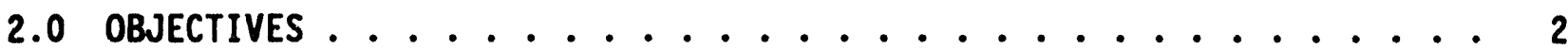

3.0 RESULTS AND DISCUSSION .................. 2

3.1 Coal Selection for Fuel Production ............ 2

3.2 Physical Cleaning .................. 3

3.3 Chemical Cleaning .................. 4

3.4 Hot-Water Drying ................ 5

3.4.1 Rheological Properties .............. 6

3.4.2 Pilot-Scale Continuous Deep Cleaning . . . . . . . . 6

3.4.3 Partial 0xidation .............. 7

3.4 .4 Chemical Additives ............... 7

3.4.5 Coal-Water Fuel Process Water Treatment ........ 8

3.5 Acid Cleaning/0il Agglomeration ............ 9

3.5.1 Development of Experimental Procedure ....... 9

3.5.2 Development of Agglomerate and Process Water Analytical

Techniques ................... 11

3.5.3 Agglomerating 0ils Tested and 0il Characterization .... 12

3.5.4 Characteristics of Chemically Cleaned and Agglomerated

LRCs ................... 13

3.5.5 Material Balances, Consumption of Aggiomerating $0 i 1$ and

Acid ................... 14

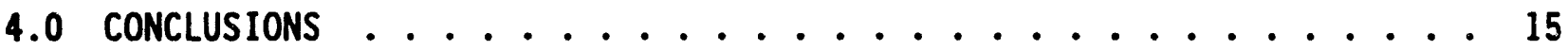

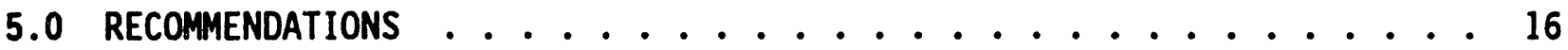

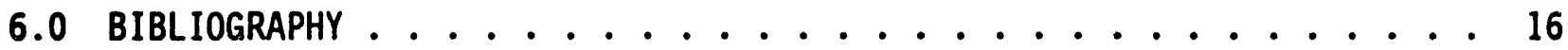




\section{BENEFICIATION OF LOH-RANK COALS}

\subsection{INTRODUCTION}

Low-rank coals (LRCs) represent nearly half of the estimated coal resources in the world. In many developing nations, LRCs are the only source of low-cost energy. LRCs are typically present in thick seams with less overburden than bituminous coals, making them recoverable by low-cost surface mining. However, even though LRCs burn much more rapidiy and completely and usually have much lower sulfur than bituminous coals, they are often regarded as inferior fuels and have not played a significant role in the international steam coal market. LRCs are hindered by the characteristics which differentiate LRCs from bituminous coals, namely, high moisture content, extensive porosity, and high concentration of oxygen functional groups.

In addition, as much as, or more than, $50 \%$ of the inorganic material in LRCs occurs as ion-exchangeable cations bound to the organic coal matrix as salts of humic acids or phenolics and cannot be removed by simple physical cleaning methods. Two-thirds of the surface-minable lignite in North Dakota may contain more than 4 wt\% $\mathrm{Na}_{2} \mathrm{O}$ in the ash. Because of the limited supply of low-sodium-content lignite and the high cost of conventional means for dealing with the ash-fouling problem, a driving force exists for development and application of a viable method to reduce or eliminate boiler fouling by the reduction of sodium content in the coal.

In addition to ash content, sulfur content is important because of its role in sulfur dioxide emissions. Initially, this program used target sulfur contents of 0.5 wt\% sulfur. Another DOE program used a slightly higher sulfur criterion of 1 wt\% or less for the design of residential furnaces. Because most sulfur in LRCs occurs as organically bound sulfur and finely disseminated pyritic sulfur, little sulfur removal was expected when cleaning techniques are applied.

During the past six-year period, the EERC demonstrated that low-ash, lowsulfur liquid or dry fuels could be produced from LRCs employing beneficiation techniques such as physical and chemical cleaning, hydrothermal treatment, and agglomeration. The first approach investigated integrating the beneficiation techniques of physical cleaning, chemical cleaning, and hydrothermal treatment to produce a low-ash pumpable coal-water fuel (CWF). The LRC CWFs could compete against bituminous CWFs to replace the more costly fuel oils used in industrial or utility boilers or diesel fuels used in advanced combustion systems. Physical cleaning, to remove discrete minerals, and chemical cleaning, to remove ion-exchangeable elements, were investigated as methods of reducing the ash content to less than 1 wt\% on a dry basis. Direct formulation of low-ash LRC CWFs using bituminous CWF preparation techniques was impractical because of the inherent disadvantages of LRCS, namely high moisture content, extensive porosity, and high concentration of oxygen functional groups. Consequently, the EERC development of hot-water drying, a hydrothermaltreatment process, was investigated as a method of mimicking the coalification process to reduce coal hydrophilicity and to improve the water slurryability of LRCs. These processes were developed on a bench scale and, ultimately, the continuous pilot scale to facilitate quantitative production of CWFs for pilotscale combustion testing. Studies concentrated on the development of methods 
and conditions for physical and chemical cleaning and on the relationship of hydrothermal-treatment conditions, particle size, and additives to CWF rheological properties.

The second approach investigated an $0 i 1$ agglomeration process whereby lowash LRCs could be aggregated into a lump fuel form suitable for transportation by conventional means and utilizable in conventional or advanced combustion systems. Agglomeration was also investigated as a method of producing a lowmoisture, high-heating value fuel with resistance to moisture reabsorption similar to that achieved by hydrothermal-drying techniques. A bench-scale process was developed that combined a chemical-cleaning first-stage for ionexchangeable element removable with a reconstitution second-stage employing a suitable agglomerating oil. Studies concentrated on determining agglomerating oils compatible with the hydrophilic LRC surfaces, developing appropriate agglomerate and process water analytical techniques, quantifying the utilization of agglomerating oil and cleaning chemicals, optimizing agglomerating conditions, and investigating methods of oil recovery from agglomerates.

\subsection{OBJECTIVES}

The overall objectives of the Low-Rank Coal Beneficiation project were to develop techniques to reduce the moisture and inorganic contents and increase the heating value of LRC to produce high-quality dry products and/or coal-water fuels (CWF). The following areas were investigated during the six-year LowRank Coal Beneficiation program:

1. Coal selection for physical, chemical, and hot-water drying beneficiation investigations

2. Physical cleaning for reduction of coal minerals and pyritic sulfur

3. Chemical cleaning for reduction of cationic inorganics, specifically the species associated with boiler deposition

4. Hot-water drying to produce stable, liquid fuel suitable for fuel-0il fired boilers or advanced heat-engines

5. 0 il agglomeration to produce a handleable and stable dry fuel from chemically cleaned coal

\subsection{RESULTS AND DISCUSSION}

\subsection{Coal Selection for Fuel Production}

Coal selection criteria were based on raw coal analysis; washability data; mine location, with respect to the number of heating degree-days (HDD) greater than 6000; and mine distance from major population centers. A heating degreeday is defined as the unit that represents one degree of decrease from a given point in the mean daily outdoor temperature, in this instance $291 \mathrm{~K}\left(18^{\circ} \mathrm{C}\right)$. 
Seven coals were identified as candidates for study in the LRC beneficiation programs: Beulah and Velva lignites from North Dakota; Jacobs Ranch, Kemmerer, and Skull Point subbituminous coals from Wyoming; Spring Creek subbituminous coal from Montana; and Usibelli subbituminous coal from Alaska. The coals had a sufficient reserve base, met climate requirements, and showed excellent amenability to initial cleaning studies.

Quantitative petrographic analyses were performed to determine the nature and distribution of mineral matter in LRCS. This information was combined with the detailed inorganic analyses for the cleaned LRCs to determine the degree of mineral matter liberation and eventually to predict mineral matter liberation in other LRCS. The three major maceral groups in low-rank coals were found to be 1) huminite, 2) liptinite, and 3) inertinite. Each of these groups had a characteristic range of reflectance values and contained macerals that were in some manner related to one another.

The LRCs tested contained up to $50 \%$ of the ash as distinct mineral mattar, and the remaining $50 \%$ of the ash, which was not detectable by polarizing light microscope, existed as ion-exchangeable cations. This fraction of the inorganics should be relatively easy to remove using ion-exchange methods.

\subsection{Physical Cleaning}

Float-sink washability was the standard method for determining the cleanability of the candidate coals. The various float-sink specific gravity fractions represented theoretical limits attainable by gravity separation. Static separation was most often used for coarse-coal size fractions $(9.5 \mathrm{~mm}$ to $2.36 \mathrm{~mm}$ ), whereas a centrifugal separation method was used for fine-coal size fractions $(-2.36 \mathrm{~mm})$.

Initial physical cleaning of micronized and combustion-grind LRCs was performed by centrifugal washability testing using Certigrav true specific gravity solutions. Standard ASTM static washability was performed on $-6.4-m m x$ $0.84-\mathrm{mm}$ fractions of select coals to determine the level of cleaning to be expected using pilot-scale, dense-media separation techniques.

Physical cleaning of subbituminous coals using washability techniques removed mostly silicon and iron-bearing minerals and some minerals containing aluminum. Physical cleaning of lignites removed significant portions of all the elements analyzed in the ash, except calcium and magnesium. The results indicate that the inorganic material was found throughout the coal matrix.

Subbituminous coals produced small amounts of 1.3 float, but generally produced significant quantities of product at 1.4 specific gravity. Coal-ash separations at 1.4 specific gravity were variable, with ash reductions ranging from 19 to 66 wt\%. North Dakota and Texas lignites were less responsive to washability than higher-rank coals; float yields at 1.3 and 1.4 specific gravity were generally low and ash reductions were much lower than for higherranked coals. The possibility exists that a lignite processed in a physical cleaning circuit might behave less predictably than a bituminous coal. This is because of the inherent variability of most lignites and the property changes associated with humidity and temperature. Physical cleaning by washability resulted in ash reductions, yields, and energy recoveries of $25 \%$ to $40 \%, 55 \%$ to $72 \%$, and $62 \%$ to $74 \%$, respectively. 
The candidate subbituminous coals were not evaluated for sulfur reduction by washability physical cleaning because of their low inherent sulfur content. The Beulah lignite with a 1 wt\% sulfur content, distributed as 53 wt\% pyritic sulfur and 47 wt\% organic sulfur, was reduced to 0.44 wt\% by physical cleaning. The majority of the sulfur reduction, $95 \mathrm{wt \%}$, was due to removal of pyritic sulfur. The coal yield was 61 wt\%, indicating that physical cleaning may be a cost effective method of producing a $\mathrm{SO}_{2}$ compliant fuel from this lignite.

Froth flotation exhibited little potential for beneficiating low-rank western coals. The frothing agent, methyl isobutyl carbinol (MIBC), which is successfully used in bituminous coal flotation, was generally not effective in producing stable froths with LRCs. The poor performance of MIBC with LRCs was attributed to the hydrophilic LRC surfaces, unlike the more hydrophobic bituminous coals. Other commercial frothing agents designed to stimulate coal floatability by blocking coal surface hydrophilic sites may have potential to improve the floatability of LRCs. Chemical cleaning to remove inorganics associated with the hydrophilic sites was unsuccessfully tested as a method of increasing LRC hydrophobicity and floatability.

\subsection{Chemical Cleaning}

The EERC investigated chemical cleaning to reduce the cation content of LRCs. The method involved mixing pulverized coal with a dilute acid solution for a specified amount of time.

The stability of cations attached to the carboxyl groups in lignite ranges from sodium, as the least stable, to the hydrogen ion, as a nondissociated weak humic acid, as the most stable. Cations, other than the hydrogen ion, form strong electrolytes with the carboxylic group and can be more easily replaced. Sodium removal was a function of particle size and moisture content of the lignite, the ionic strength of the solution, contact time, lignite-to-solution ratio, and the equilibrium between ions in the solid and in solution.

LRC chemical cleaning was performed by leaching with four strong acids (nitric, hydrochloric, sulfuric, and hydrofluoric) and three strong bases (sodium, potassium, and ammonium hydroxide). The acid-leaching process removed mainly sodium, calcium, magnesium, and a small amount of silica. Acid leaching tended to concentrate aluminum and ferric oxide and, to a lesser extent, titanium and potassium oxide. The combination of physical and chemical cleaning concentrated the clean coal ash in silica, aluminum, calcium, and iron. Concentrations of these components indicated that particles such as clays or, in the case of ferric oxide, pyrite were finely disseminated throughout the coals. The overall performance of chemical cleaning were ash reductions of 40 to $60 \mathrm{wt} \%$, yields of 86 to $91 \mathrm{wt} \%$, and energy recoveries of $90 \%$ to $93 \%$.

Caustic leaching of LRCs with low-concentration bases, designed to solubilize and separate humic acids from inorganics, proved to be impractical because of extreme difficulty dewatering the product. Also acidification and centrifugation were required to recover the coal from the caustic solution. Due to the extensive amount of processing and difficulty in recovering the coal, caustic leaching was not investigated further. 
A preliminary assessment of the colloidal coal-cleaning (CCC) technique for LRCs was evaluated. This process used higher base concentrations and intense shreading using a homogenizer to solubilize the humates. As with caustic leaching, CCC required an acidification step to recover humic acids and repetitive and intense washing to remove residual base cations from the product.

\subsection{Hot-Water Drying}

The EERC pioneered the development of a low-rank coal-water fuel (LRCWF) technology, referred to as hot-water drying (HWD), which can efficiently "dewater" LRCs and enhance the coal surface to allow formulation of an environmentally benign, easily transportable liquid fuel.

HWD is hypothesized to simulate nature's coalification process in a condensed time scale of minutes rather than geological eras. Changes effected by the drying process included irreversible removal of moisture, shrinkage of the pore structure, and enhancement of heating value by removal of oxygen. As a liquid fuel form, HWD LRCs were impervious to dust generation and spontaneous combustion, problems commonplace with raw or conventionally dried LRCs.

HWD enhanced the energy densities of LRCWFs, typically $30 \%$ for subbituminous coals, $50 \%$ for 1 ignites, and up to $70 \%$ for brown coals. Results indicated very slight ash reductions, yields ranging from $80 \%$ to $93 \%$, and energy recoveries of $82 \%$ to $95 \%$. Ash reductions were primarily by removal of sodium and potassium, which are depositional bad actors during pulverized coal combustion. Depending upon the coal processed, and its associated moisture content, the HWD process was determined to be a potential net water producer, allowing the CWFs to be formulated entirely using the inherent moisture of the raw coal.

Hydrophobic tars, which exude to the surface during the HWD process, were considered to be primary actors in the mechanism of hot-water drying. These tars are hypothesized to cool on the coal surface, sealing micropore entrances and preventing reabsorption of water. In an attempt to identify tar production, solid-state ${ }^{13} \mathrm{C}$ nuclear magnetic resonance spectrometry (NMR) was used to determine the carbon structure of the raw coals and to detect changes in structure due to hydrothermal treatment. The tars were extracted from raw and HWD coal with methylene chloride and methanol and the residues were characterized using $50-\mathrm{MHz}$ solid-state ${ }^{13} \mathrm{C}$ NMR spectrometry. The results showed a higher tar yield for the HWD coals relative to the raw coals and a significant decrease in carbony $1 /$ carboxyl and methoxy groups, with little change to the other organic groups, due to HWD. A significant decrease in al iphatic hydrocarbons due to HWD accounted for the increased tar yield.

To further characterize the tar production, a viscosity study was performed using a Haake D100/300 sensor system for the RV100 concentric cylinder viscometer. Viscosity data on raw LRC water slurries were recorded as a function of temperature to $553 \mathrm{~K}\left(280^{\circ} \mathrm{C}\right)$. In all cases, the viscosity decreased with increased temperature to $483 \mathrm{~K}\left(210^{\circ} \mathrm{C}\right)$, with the greatest rate of viscosity change occurring between 303 and $363 \mathrm{~K}\left(30^{\circ}\right.$ and $\left.90^{\circ} \mathrm{C}\right)$. The viscosity remained constant or, in some cases, increased as temperature increased from 483 to $553 \mathrm{~K}\left(210^{\circ}\right.$ to $\left.280^{\circ} \mathrm{C}\right)$. In the ranges where the viscosity 
increased, tar formation from mild pyrolysis was believed to have contributed to higher viscosities.

\subsubsection{Rheological Properties}

Knowledge of the sensitivity of CWF flow behavior and viscosity to solids content and temperature is important when designing storage and pumping circuits for slurry-fed combustors and gasifiers. Changes in slurry viscosity and other flow properties, because of variations in solids content and temperature, can drastically alter the energy requirements for pumping and the pressure requirements for atomization. Therefore, the influence of solids content, particle size, and HWD temperature on the CWF flow properties were determined by experiment.

One study identified the effect of solid concentrations on the viscosity of various HWD CWFs over the range of 50 to $1000 \mathrm{~Pa} \cdot \mathrm{sec}$. Throughout the entire viscosity regime, the HWD CWFs were characterized as pseudoplastic or shear thinning. Typically viscosity increased at a rate of approximately 75 to $100 \mathrm{~Pa} \cdot \mathrm{sec}$ in the low-viscosity region ( 50 to $200 \mathrm{~Pa} \cdot \mathrm{sec}$ ), 100 to $125 \mathrm{~Pa} \cdot \mathrm{sec}$ in the medium-viscosity region $(200$ to $500 \mathrm{~Pa} \cdot \mathrm{sec})$, and 125 to $175 \mathrm{~Pa} \cdot \mathrm{sec}$ in the high-viscosity region ( 500 to $1000 \mathrm{~Pa} \cdot \mathrm{sec}$ ) per 1 wt\% increase in solids content. The viscosities were directly affected by coal type and its responsiveness to HWD, HWD temperature, and particle-size distribution.

Viscosity tests were completed on a variety of particle-size distributions (PSD) with a HWD Wyoming subbituminous coal. Depending upon selected PSD, CWF energy densities ranged from 15,100 to $18,800 \mathrm{~kJ} / \mathrm{kg}(6500$ to $8100 \mathrm{Btu} / 1 \mathrm{~b})$ on a fuel basis. Optimum particle-size conditions were determined using the RosinRammler equation, with a size-distribution constant of 0.9 . An $80 / 20$ mix ( $80 \%$ coarse coal and $20 \%$ fine coal) provided a near-optimum particle-size distribution for the bimodal mixture. The average particle size of the coarse coal was 75 microns, while the fine material average particle size was 10 microns. The micronized CWFs had lower solids content and energy densities at equivalent viscosities because of their narrow particle-size distributions. Since reaction time and carbon burnout are critical in advanced combustion systems, micronizing is necessary for bituminous coals and bituminous CWFs. This may not be the case for the highly reactive LRCs and HWD LRCWFs.

Tests on lignite and subbituminous coals also determined the effects of HWD temperature on energy density. Hot-water-dried lignite CWF energy densities increased from $13,000 \mathrm{~kJ} / \mathrm{kg}(5600 \mathrm{Btu} / \mathrm{lb})$ to over $14,200 \mathrm{~kJ} / \mathrm{kg}$ $(6100 \mathrm{Btu} / 1 \mathrm{~b})$, on a fuel basis, when the HWD temperature was increased from 543 to $603 \mathrm{~K}\left(270^{\circ}\right.$ to $\left.330^{\circ} \mathrm{C}\right)$. Subbituminous HWD CWF energy densities improved from 16,300 to $18,600 \mathrm{~kJ} / \mathrm{kg}(7000$ to $8000 \mathrm{Btu} / 1 \mathrm{~b})$ at similar test conditions.

\subsubsection{Pilot-Scale Continuous Deep Cleaning}

Pilot-scale fuel capabilities were developed to prepare sizable quantities of low-ash CWF from LRCs for advanced combustion applications. The preparation scheme included physical and chemical cleaning followed by hot-water drying. Final fuel preparation included size optimization and, in some cases, the use of additives. 
Dense-media cone separation was used to physically clean the coal in preparation for clean CWF production. The dense-media cone separator, designed to process coal sized from 6.3 to $0.85 \mathrm{~mm}$, utilized a slurry of magnetite to physically separate the coal from the extrarieous mineral matter. The clean coal product was produced at the rate of $150 \mathrm{~kg} / \mathrm{hr}$. Prior to any further utilization of the physically cleaned product, the coal was dried to remove surface moisture and pulverized. Pilot-scale chemical cleaning was performed in a downflow column equipped with a mixing shaft and level activated control valve. The pulverized coal, in a dilute slurry, and acid were introduced at the top of the column. Acid cleaning was performed at a rate of $180 \mathrm{~kg} / \mathrm{hr}$ of coal-water mixture. The sample was centrifuged to recover the acid-cleaned coal for HWD testing. The hot-water-drying system was operated at $270 \mathrm{~kg} / \mathrm{hr}$, processing up to 1000 micron coal-water slurry at 513 to $603 \mathrm{~K}\left(240^{\circ}\right.$ to $\left.330^{\circ} \mathrm{C}\right)$ and 2,760 to $15,200 \mathrm{kPa}$ (400 to $2200 \mathrm{psi}$ ) for residence times of 1 to 60 minutes.

Good correlation was achieved between bench- and pilot-scale results; CWFs were produced with less than 1.5 wt\% ash and energy densities ranging from 13,900 to $18,600 \mathrm{~kJ} / \mathrm{kg}(6000$ to $8000 \mathrm{Btu} / \mathrm{lb})$, depending on the particle-size distribution. Coal-water fuel rheological characterization was al so performed, with respect to particle-size distribution, additives, and temperature.

\subsubsection{Partial Oxidation}

Partial oxidation (PO) was investigated as a method of supplying a portion of the required process heat for HWD by in situ combustion of the coal. The process appeared feasible, as combustion was easily initiated using oxygen after first preheating the slurry to $473 \mathrm{~K}\left(200^{\circ} \mathrm{C}\right)$. However, temperature control was difficult while using a batch system.

The overall economic benefits of PO-HWD over HWD were not determined, although an electrical cost savings would probably be realized by supplying a portion of the thermal requirements by direct (internal) heating. However, additional product gas and PO-HWD coal analysis (proximate, ultimate, and heating vaiue) would have to be performed to determine the cost differential. The results of preliminary calculations indicated an approximate process heat cost savings of $35 \%$.

The PO-HWD coals, to a limited extent, also had enhanced float-sink washability, relative to conventional HWD coal. Presumably, the surface tars normally present after conventional HWD were consumed during PO. Consequently, any previous inhibition of mineral liberation because of the tar coating was somewhat alleviated by PO. Product yields and heating values were much lower with PO products than with HWD products due to the consumption of coal by combustion.

\subsubsection{Chemical Additives}

Additive packages were identified that would allow the LRCWFs to meet DOE energy density, flow behavior, and storage life specifications. A screening study was performed to determine the effectiveness of chemical additives for increasing the solids loadings for the clean CWFs. Generally, the nonionic surfactants were more effective than anionic dispersants. Anionic dispersants were ineffective, as no increase in solids content was realized for the two 
types tested. The anionic additives disperse and stabilize solids by the principles of electrostatic dispersion or positive-negative charge. This phenomenon was adversely affected by the ionic strength of the CWF aqueous medium. The ionic strength was possibly caused by residual acid from the chemical cleaning and other water-soluble ions in the aqueous medium of the CWF. The $\mathrm{pH}$ of the CWF from the clean products ranged from 4 to 5 , rendering the anionic additives ineffective. The nonionic surfactants behave on the principles of steric dispersion and stabilization, which are physical phenomena. Therefore, the nonionic additives were generally insensitive to $\mathrm{pH}$ changes or ionic strength in aqueous medium. The high molecular weight BASF $F$ series additives-copolymers of ethylene oxide and propylene oxide-were effective on a clean lignite in the screening tests.

Long-term stability was a concern with CWFs, especially when considering the fuel for residential, commercial, or industrial combustion applications. Depending on the percentages of soluble, multivalent cations in the coal, HWD promoted stability in CWFs prepared from LRCs by leaching available cations out of the coal. Studies indicated that a 0.2 wt\% xanthan gum loading was sufficient for 6-month storage stability of the cleaned lignite CWF. In addition to stabilization compounds, formaldehyde added at 0.1 wt\% was necessary to prevent mold growth.

Testing also investigated CWF's resistance to rheological and stability variations during freeze-thaw cycling. Shear stress versus shear rate relationships identified the before-and-after flow behavior characteristics of the fuel. Freeze-thaw testing indicated slight increases in solids content and viscosity ranging from $5 \%$ to $20 \%$ above those of the original sample. These increases were attributed mainly to evaporation during the testing process. The low solids and viscosity increases indicated that the CWFs were relatively unaffected by freeze-thaw. The CWFs were al so stable after freezing, although rheologies of the HWD sample exhibited a slight difference in flow behavior. The sample, pseudoplastic before freezing, exhibited yield-pseudoplastic characteristics after freezing. Therefore, coal-water mixtures containing additives and stabilizers can be frozen, thawed, and remixed without any major stability or viscosity changes occurring to the fuel.

\subsubsection{Coal-Water Fuel Process Water Treatment}

The production of CWF by the hot-water, coal-drying process resulted in the generation of process effluent water. Due to the hydrothermal coal dewatering process, a portion of the sodium and other water-soluble inorganic constituents are transferred from the coal particles to the aqueous medium. Additionally, water-soluble organic compounds are extracted from the coal particles by the process water. Mechanical concentration of the processed coal produces a damp HWD coal and a contaminated effluent water by-product (centrate), which contains coal fines, dissolved inorganics, and water-soluble organics.

The centrate from mechanical concentration (continuous centrifugation), collected after hydrothermal processing of a subbituminous coal, was used for treatability studies. The treatment process addressed the reduction of suspended solids prior to subsequent secondary and tertiary treatment processes. Two methods of suspended solids removal were investigated for 
CWF product recovery and centrate pretreatment: chemical coagulation/ precipitation, and ultrafiltration.

Initial jar tests with acidification of the raw CWF centrate resulted in solids separation of $200-\mathrm{mL}$ solids/L wastewater at a dosage of $1-\mathrm{mL} / \mathrm{L}$ concentrated sulfuric acid. Due to the encouraging initial jar-testing results on fresh centrate samples, additional efforts should be directed at coagulation/precipitation for the separation of colloidal suspended solids from fresh CWF centrate.

Ultrafiltration used a membrane process to separate solids and high molecular weight dissolved materials from the centrate. Results indicated that the flux (filtration rate) remained relatively stable for the 4 hours of testing. A computer model, based on several effects, was formulated to predict the flux through the membranes. Preliminary results indicated ultrafiltration is a technically viable means for removal and recovery of solids from CWF centrates; however, more testing should be completed because a major concern with membrane-based filtration systems is the length of time that the unit can run between cleanings without significant loss in filtration rates.

An activated sludge system was selected to evaluate aerobic biological system secondary treatment of HWD process water. The activated sludge process utilized a suspended, mixed growth of aerobic microorganisms that used the organic materials in wastewater as substrates. Testing was conducted to determine removal rates of biochemical oxygen demand $\left(\mathrm{BOD}_{\mathrm{s}}\right)$, chemical oxygen demand (COD), and total organic carbon (TOC). At steady-state operating conditions, average $\mathrm{BOD}_{5}$ removal was $95.7 \%$ and $\mathrm{COD}$ and TOC removal varied from $20 \%$ to $38 \%$ and $40 \%$ to $60 \%$, respectively, depending upon cell residence times.

\subsection{Acid Cleaning/0il Agglomeration}

\subsubsection{Development of Experimental Procedure}

The EERC agglomeration process, in its present stage of development, incorporates a chemical-cleaning first-stage with a fine, clean coal reconstitution second-stage. During chemical cleaning, 1-part pulverized coal and 2-parts dilute acid are intensely mixed using a high-shear homogenizer to liberate the organically associated alkali and alkaline earth metals plus other acid-soluble minerals. The fine, acid-cleaned coal is recovered by adding a specified quantity of agglomerating oil. Agitation by stirring causes wetting of the coal particles by the oil; formation of agglomerates occurs due to repeated collisions of the oiled coal particles. The 2- to 4-mm agglomerates are separated from the chemicaliy liberated inorganics, which remain solubilized in the process water by a simple screening technique.

Preliminary development work on the EERC agglomeration process was performed by Knudson and Mack to obtain rudimentary information on the effect of particle size, oil-to-coal ratios, and agglomeration mixing speeds and times. Initially, chemical cleaning was facilitated by sonication, which was presumed to aid separation of discrete mineral matter. However, after limited testing, sonication was considered impractical and unscalable to pilot, development, or production size. Furthermore, the benefits of sonication for enhanced mineral separation were not definitively proven. Sonication was first replaced by low-speed T-bar mixing, then ultimately replaced with high-shear 
homogenizer mixing. This latter method was presumed to be superior to sonication or low-speed mixing for ensuring penetration of the acid into the pores of the coal. A second major process modification was the elimination of surfactant as an agglomeration pretreatment. The surfactant, typically Triton $x-100$, was presumed to lower the solution surface tension and aid wetting of the coal surface by the agglomerating oil. However, the water solubility and LRC compatibility of the preferred agglomerating oils facilitated successful agglomeration without the surfactant. Elimination of the surfactant, used in concentrations up to $60 \mathrm{~kg} / \mathrm{metric}$ ton $(120-1 \mathrm{~b} / \mathrm{ton}) \mathrm{coal}$, was also considered to benefit process economics.

Statistical matrix testing was used as a method to optimize the agglomeration of Beulah lignite with crude phenol (a coal-derived oil). The parameters were particle-size, acid contact time, chemical-cleaning mixing speed, oil mixing time, agglomeration mixing speed, acid strength, and oil concentration. The statistical matrix tests estabilished levels for chemicalcleaning and agglomeration parameters, some of which are still used. Preferred coal sizes were $-0.59 \mathrm{~mm} \times 0.075 \mathrm{~mm}$, as particles below $0.075 \mathrm{~mm}$ resulted in low agglomerate yields. An oil mix time of 2 minutes was optimum for maximizing ash reduction, although, typically, an agglomeration time of 5 minutes maximized recovery of coal solids. Optimum agglomerating oil mix speeds were 400 to $800 \mathrm{rpm}$, with the latter value more commonly used, and the optimum oil-to-coal ratio was $1 \mathrm{~mL} / \mathrm{g}$. Depending on the measured response during matrix testing, the optimum acid-cleaning mixing speed and time gave significantly varying results. The optimum levels for high-shear mixing speed and acid-cleaning time to maximize ash reduction, as determined by one-at-atime experiments, were $5000 \mathrm{rpm}$ and 1 to 2 minutes, respectively.

The parametric values obtained with the Beulah lignite, i.e., acid concentrations between 0.75 and 6.0 wt\% and 011 -to-coal ratios of $1 \mathrm{~mL} / \mathrm{g}$, were used as initial parametric levels when evaluating new coals. The optimum oil level for maximizing coal recovery and the optimum acid concentration for maximizing ash reduction were typically obtained by one-at-a-time experiments.

Strong acids-nitric, hydrochloric, and sulfuric-were equally effective at reducing the inorganic contents of LRCs over the range of 0.75 to 6.0 wt\% acid. Unrinsed samples of LRCs cleaned with these acids had higher concentrations of nitrogen (probably as $\mathrm{NO}_{3}^{-}$), chlorine (as $\mathrm{Cl}^{-}$), or sulfur (as CaSO ${ }_{4}$ ) compared to the raw coals. The $\mathrm{NO}_{3}^{-}$and $\mathrm{Cl}^{-}$were easily removed by water rinsing; the removal of $\mathrm{CaSO}_{4}$ required secondary washing with a dilute solution of formic or nitric acid. Because of the negatives associated with high chlorine and sulfur levels, nitric acid became the preferred acid for chemical cleaning.

The capacity of the batch, bench-scale agglomeration process, initially developed using 50 grams of coal per test, was successively increased by factors of 2, 4, and 30 times. Typically, agglomeration tests to assess new coals or oils were performed with 50 grams of coal per test. Sufficient quantities of agglomerates were produced using 200 grams of coal per test to facilitate all analyses required for subsequent 011 , water, and solids balances. Sufficient quantities of agglomerates were produced at 1500 grams of coal per test to allow parametric thermal deoiling tests and stability tests. 


\subsubsection{Development of Agglomerate and Process Water Analytical Iechniques}

Concurrent with the development of the chemical-cleaning/oil agglomeration process, several analytical techniques were evaluated for determining the oil content of agglomerates (raw, air-dried, deoiled) and process water and for determining the residual acid content of process water. These analyses were presumed critical for determining the consumption of the more costly raw materials-oil and acid.

Thermogravimetric analysis (TGA) was the first method evaluated for determining oil content of the agglomerates. TGA directly determined the fractions of the light $0 i 1$, oil, volatile matter, fixed carbon, and ash. The sum of the light oil plus oil fractions was presumed to represent the agglomerate oil content. However, fixed-carbon recoveries calculated with the TGA results were generally well in excess of 100 wt\% indicating 1) the agglomerating oil contained a fraction in the fixed-carbon distillation range, and 2) agglomerating oil polymerization may have occurred during the rapid TGA, resulting in further production of fixed carbon. Agglomerate oil contents were al so calculated by difference from the sum of the mass of light oil, oil, volatile matter, fixed carbon, and ash in the agglomerates and raw coal. The calculation methods resulted in 0 il contents at least 8 to 11 wt\% higher than oil contents directly obtained from TGA. Consequently, pending appropriate modifications, TGA was considered unsatisfactory for directly or indirectly determining agglomerate oil content. Nonaqueous titration to measure cresol content and tetrahydrofuran (THF) solubility, also tested as agglomerate oil content measurement methods, proved to be inadequate. The most recently evaluated technique, Soxhlet extraction, appeared suitable for analyzing raw and air-dried agglomerates. Thermally treated agglomerates could not be analyzed for oil content by Soxhlet extraction because heat treatment is hypothesized to polymerize some of the agglomerating oil, intibiting complete elution by the extraction solvent.

Initially, ASTM method D271 and TGA analysis were evaluated for determining the moisture content of air-dried agglomerates. These weight-loss measurement techniques proved unreliable because of the concurrent loss of agglomerating oil. The Karl Fischer titrimetric analysis technique was ideal for moisture analysis because it could be performed in the presence of volatile organics. Azeotropic distillation, used in conjunction with the Soxhlet extraction method, also proved suitable for determining agglomerate moisture content. Presentiy, direct comparisons have not been made among the latter two methods; however, advantages of Karl Fischer analysis include less waste and faster analysis time compared to azeotropic distillation. One drawback to the former method was the small sample size, which can produce results unrepresentative of the bulk agglomeration test sample.

Two methods were investigated for measuring the residual agglomerating oil content in the process water: total carbon (TC) analysis and solvent extraction. Total carbon was a fast, very reproducible combustion/infrared method for determining the carbon content of water. The total oil content of the water was calculated from TC analysis presuming that the oil composition (i.e., wt\% carbon) in the process water was equivalent to the initial agglomerating oil. Based on preliminary oil balances with mono- and multicomponent agglomerating oils, TC analysis appeared satisfactory for 
indirectly determining the agglomerating oll content of process water. Solvent extraction, a common technique for process water oil recovery, was investigated in a single test as an analytical technique. The calculated oil content, as determined from solvent extractions, was approximately 2.5 times higher than that achieved by TC analysis.

Acid consumption during the chemical-cleaning stage was determined by comparing the molar strengths of the initial and final acid-cleaning solutions. Titration of the acid solution with a dilute base was performed after chemical cleaning, but prior to agglomeration to eliminate the interference of the agglomerating oils. The method of titration was a highly repeatable technique for determining acid consumption.

\subsubsection{Agglomerating 0ils Tested and 0il Characterization}

A number of agglomerating oils were evaluated as primary bridging liquids during the development of the chemical-cleaning/oil agglomeration process. These oils included the coal gasification-derived crude phenol and tar oil streams, 1 iquefaction-derived V161 and V178 naphthas, several mild gasification-derived tars, a used petroleum-based crankcase oil, a reagent grade $m$-cresol $0 i 1$, and a commercial cresylic acid. Crude phenol or a crude phenol/tar oil blend were primarily used during development of the agglomeration process and the associated analytical techniques. The other agglomerating oils were tested to assess the versatility of the process.

Several agglomerating oils were evaluated as binding oils to be used in conjunction with the primary agglomerating oil or bridging liquid. These oils included tar oil, creosote oil (coal-derived), asphalt, and red crude and decant oil (both petroleum-based).

Crude phenol or crude phenol/tar oil were the agglomerating oils against which the other oils were compared. The crude phenol, tar oil, crude phenol/tar $0 i 1, m$-cresol, and cresylic acid were determined to be very effective for agglomerating chemically cleaned LRCs using low-shear mixing ( 400 to $800 \mathrm{rpm}$ ). The time required to achieve agglomeration varied between oils and ranged from 2 to 5 minutes for crude phenol, tar oil, crude phenol/tar oil, and $m$-cresol to as high as 7 to 15 minutes for cresylic acid. The agglomerating 0 il $/ \mathrm{coal}$ ratio al so varied, ranging from 0.6 to $0.7 \mathrm{~mL} / \mathrm{g}$ for cresylic acid to 0.9 to $1.0 \mathrm{~mL} / \mathrm{g}$ for the other low-shear compatible oils.

Agglomeration was not possible at low-shear mixing conditions using the liquefaction-derived oils, mild gasification-derived tars, or used crankcase 0i1. Surfactants or high-shear mixing were required to effect agglomeration with these tars/oils. Surfactant concentrations up to $40 \mathrm{~kg} / \mathrm{metric}$ ton ( $80 \mathrm{lb} / \mathrm{ton})$ of coal aided agglomeration using the 1iquefaction naphthas at oilto-coal ratios of 0.5 to $0.6 \mathrm{~mL} / \mathrm{g}$. Mild gasification tars, thinned in a solvent (butanol or pentane), successfully agglomerated LRCs at concentrations of $0.6 \mathrm{~g}-\mathrm{tar} / \mathrm{g}$ coal when using high-shear mixing. The used crankcase oil, at oil-to-coal ratios of only $0.3 \mathrm{~mL} / \mathrm{g}$, agglomerated LRCs only after high-shear mixing.

Attempts were made to correlate the agglomeration conditions, i.e., lowshear mixing versus high-shear mixing or surfactant addition, against the composition of the agglomerating oils; i.e. the polar content and oxygen 
polar functionalities, such as the hydroxyl group (OH). Agglomerating oil aliphatics, branched aliphatics, aromatics, and polar contents were determined by open-column chromatography, and oxygen contents were determined by difference using ASTM method D3176 ultimate analysis.

The agglomerating oils, which required only low-shear mixing to effect agglomeration, had the highest polar and oxygen contents; the converse was true for the tars/oils requiring surfactants or high-shear mixing. The relationship between agglomeration conditions and oil composition appeared to be more dependent upon oxygen content and less dependent upon polar content. The polar contents of the most effective oils ranged from 80 wt\% for the crude phenol/tar oil mixture to 100 wt\% for the "pure" $0 i 1, m$-cresol. The polar contents of the less effective oils ranged from 13 wt\% for used crankcase $0 i 1$ to 54 wt\% for the mild gasification tars. The oxygen contents of the more effective oils did not vary significantly and ranged from 12 to $15 \mathrm{wt}$. The oxygen contents of the less effective oils were considerably lower and ranged from only 0.7 to 3.1 wt\%. Based on preliminary testing, determination of polar and oxygen contents may be a useful method for screening oils for use in agglomeration processes employing low-shear mixing.

\subsubsection{Characteristics of Chemically Cleaned and Agglomerated LRCs}

Agglomeration was successfully accomplished with a number of LRCs, including Morwell and Yallourn brown coals from Australia; Indian Head, Beulah, and Center lignites from North Dakota; Calvert lignite from Texas; Wyodak, Fort Union, Eagle Butte, and Kemmerer subbituminous from Wyoming; Spring Creek subbituminous from Montana; Beluga subbituminous from Alaska; and a lignite from Czechoslovakia.

The majority of agglomeration te Beulah lignite using crude phenol or $b_{1}$.., of crude phenol as a bridging e performed with the baseline liquid and low concentrations of other coal- or petroleum-derived oils as binding oils. The tests with the other LRCs used crude phenol or crude phenol/tar $0 i 1$ as the agglomerating oil. Typically, the binding oils were mixed with the bridging liquids in concentrations of 3 to 9 wt\%. The concept of blending a bridging and binding oil was developed presuming that thermal deoiling would be required to recover the bridging liquid. The binding oil would add strength to the agglomerates following thermal deoiling; however, the validity of this concept was not ascertained pending the development of an adequate thermal deoiling system and accurate, repeatable agglomerate analysis and strength determination techniques.

Chemical cleaning of the LRCs prior to agglomeration resulted in significant reduction of ion-exchangeable inorganics, principally sodium, magnesium, potassium, and calcium; the discrete mineral content was increased as a result. Maximum LRC inorganic reduction was typically achieved at acid concentrations between 3.0 and $6.0 \mathrm{wt} \%$. The maximum reduction in ASTM ash content typically ranged from 65 to $80 \mathrm{wt} \%$ for North Dakota 1 ignites; the ash reductions were only 30 to 40 wt\% with the Texas lignite because the ash in this coal has a lower ion-exchangeable inorganic content. Similarly, because the ASTM ashes of the subbituminous coal studied had a lower proportion of ionexchangeable inorganics compared to the lignite coal ashes, the maximum ash reductions for the subbituminous coals typically ranged from 35 to 50 wt\%. The ASTM ash contents of air-dried North Dakota lignite agglomerates were as low as 
1.0 to 1.5 wt\%, and air-dried agglomerates made with Wyoming and Montana subbituminous coals were as low as 1.5 to 2.0 wt\%. At the acid concentrations required for maximum inorganic reduction, the removal of sodium approached 100 wt\%, and the removal of magnesium and calcium approached 70 to 80 wt\%.

The air-dried agglomerates produced from all LRCs, even brown coals, were characterized by low moisture contents, 2 to 5 wt\%. The moisture contents of the raw coals, in comparison, ranged from 20 to 25 wt\% for the subbituminous coals, 30 to 35 wt\% for the lignites, and between 50 and 65 wt\% for the brown coals.

The dewatering during agglomeration and subsequent air-drying significantly increased the fuel heating value relative to the raw coals. The heating values of the air-dried agglomerates ranged from approximately 27,900 to $30,200 \mathrm{~kJ} / \mathrm{kg}(12,000$ to $13,000 \mathrm{Btu} / \mathrm{lb})$. The raw coal heating values, in comparison, ranged from 14,900 to $17,200 \mathrm{~kJ} / \mathrm{kg}(6400$ to $7400 \mathrm{Btu} / \mathrm{lb})$ for the lignites and 18,600 to $20,900 \mathrm{~kJ} / \mathrm{kg}$ ( 8000 to $9000 \mathrm{Btu} / \mathrm{lb})$ for the subbituminous coals.

\subsubsection{Material Balances, Consumption of Agglomerating $0 i 1$ and Acid}

The most reasonable oil, water, and solids balances were attained using azeotropic distillation and Soxhlet extraction to determine agglomerate moisture and $0 i 1$ content. The oil content of the process water was determined using total carbon analysis. The raw agglomerate moisture content ranged from 28 to $32 \mathrm{wt} \%$, and the raw agglomerate oil content was approximately $37 \mathrm{wt} \%$ This concentration of $0 i 1$ represented about 83 to $87 \mathrm{wt} \%$ of the 0 il added during the agglomeration process. The balance of the $0 i 1,13$ to $17 \mathrm{wt}$, remained solubilized in the process water. Depending upon the volume of water added during rinsing and washing, the concentration of oil in the process water ranged from $\sim 11,500$ to $16,500 \mathrm{mg} / \mathrm{L}$.

Air-drying the raw agglomerates resulted in significant evaporation of surface moisture and agglomerating 0il. Approximately 27 to 32 wt\% of the agglomerating $0 i 1$ evaporated, and between 85 to 95 wt\% of the moisture evaporated. The significant evaporation of moisture during air-drying, relative to the evaporation of oil, resulted in a concentration of oil with the oil content typically reaching 41 to $43 \mathrm{wt} \%$.

Acid consumptions and acid costs were determined for cleaning Beulah lignite (7.4 wt\% ash, moisture-free [mf]) and Spring Creek subbituminous (5.1 wt\% ash, mf) using nitric acid with concentrations of 0.75 to 6.0 wt\%. Ash contents of acid-cleaned Beulah ranged from 6.3 to $3.1 \mathrm{wt} \%$ (mf), and the acid consumption associated with these ash contents ranged from 2.1 to $8.51 \mathrm{~b}$ of concentrated acid per $100 \mathrm{lb}$ of coal. Similarly, ash contents of acidcleaned Spring Creek ranged from 4.2 to $2.9 \mathrm{wt} \%$ (mf), and the acid consumption ranged from 2.3 to $7.91 \mathrm{~b}$ of concentrated acid per $100 \mathrm{lb}$ of coal.

The nitric acid costs for cleaning Beulah lignite and Spring Creek subbituminous coal, over the range of acid concentrations studied, were $\$ 4$ to $\$ 17 /$ ton coal and $\$ 5$ to $\$ 14 /$ ton coal, respectively. 


\subsection{CONCLUSIONS}

Initial petrographic analyses were investigated to determine the distribution and size of mineral matter in several LRCs. These analyses were used as a guide for the degree of grinding necessary to achieve mineral liberation. Clean coals with less than $2 \mathrm{wt} \%$ ash on a dry basis were produced on the bench scale and continuous pilot scale using physical-and chemical-cleaning techniques. Selectivity of the cleaning processes were quite different for the various LRCs. CWFs - with less than 1 wt\% ash, energy densities over $17,400 \mathrm{~kJ} / \mathrm{kg}$ (7500 Btu/lb), and a solids loading over $60 \mathrm{wt} \%$-were prepared after optimizing particle-packing efficiency and using additives. The flow behavior of the CWFs with the complete additive package presented no serious handling problems, as the fuels exhibited near Newtonian flow behavior over the shear-rate range tested. Dilatant flow behavior resulted if the particle size was too small.

Ultrafiltration was a technically viable means for removal and recovery of suspended solids from centrifuge centrates. Activated sludge treatment of the ultrafilter permeate was effective at removing $\mathrm{BOD}_{5}$.

The low initial cost of the raw LRCs improved the economic feasibility of producing low-ash CWF by offsetting the relative expense of chemical cleaning and reagents in the processing scenario. The additional cost of micronizing was not onerously significant. However, micronizing adversely affected product solids concentration and flow behavior. Until process and product refinements are made in the micronizing area, it is recommended that this process addition be avoided.

The EERC chemical-cleaning/oil agglomeration process was successfully used on brown, lignitic, and subbituminous coals. Nitric, hydrochloric, and sulfuric acids were equally effective in reducing the inorganic content of LRCs. Water washing removed nitrate and chloride ions, which adhered to the nitric and hydrochloric acid-cleaned coals. Secondary acid washing removed calcium sulfate that precipitated as a result of using sulfuric acid for chemical cleaning. Removal of coal inorganics was maximized within the range of 0.75 to $6.0 \mathrm{wt} \%$ acid. The preferred oils for agglomerating LRCs were characterized by high polar and oxygen contents and were typically coal-derived oils. The preferred oils required only low-shear mixing to cause LRC agglomeration.

ASTM and TGA proximate analysis techniques were inappropriate for determining the moisture and oil contents of agglomerates. Karl Fischer titration and azeotropic distillation were suitable for determining agglomerate moisture content, and Soxhlet extraction was suitable for determining agglomerate oil content. Total carbon analysis was suitable for determining the residual oil content of the process water.

The chemical-cleaning/oil agglomeration process resulted in significant dewatering (moisture reduction) of LRCs. Inorganic reduction was typically higher for lignites compared to subbituminous coals because of the higher concentration of ion-exchangeable inorganics in the lignites. 


\subsection{RECONMENDATIONS}

Qualitative and quantitative analysis of the hot-water-dried products should be performed in order to understand mechanisms such as tar evolution. Froth flotation testing should be conducted on the dilute HWD product slurry. It has been stated that the HWD coal becomes hydrophobic in nature following hot-water drying. Therefore, froth flotation should be more effective on this product rather than the hydrophilic raw LRC. The only concern is that the tar evolved during the HWD may trap minerals in the coal particles, reducing the separation of coal and minerals.

Pilot-scale HWD testing should be used to address heat-transfer issues in order to integrate a process effluent heat exchange system and improve process efficiencies. An extended run on the pilot-scale unit should be performed to address issues of heat capacity, thermoconductivity, and any potential scaling problems during heating.

Thermal deoiling for agglomerating oil recovery needs to be more thoroughly investigated. The recovered oils should be characterized to determine suitability for recycle or sale as an upgraded product. Thermally deoiled agglomerates should be evaluated for strength and stability toward dust generation, spontaneous combustion, and moisture reabsorption. An appropriate bridging/binding oil combination should be selected based on strength and stability of the agglomerates. Combustion testing should be performed on thermally deoiled agglomerates to determine the reduction in depositional tendencies due to reduction of the ion-exchangeable inorganic content. A preliminary plant design and associated economics should be made on a nominally sized continuous agglomeration plant with and without chemical cleaning.

In order to characterize the behavior of the various ash components in selected coals and their beneficiated products, a detailed characterization of the coals should be performed before and after beneficiation. The methods of characterization should include computer-controlled scanning electron microscopy, chemical fractionation, and standard ASTM techniques. An additional objective would be to establish predictive methods to evaluate ash behavior from cleaned and beneficiated LRCs and to design new beneficiation processes and/or optimize current procedures. Detailed characterization techniques will provide insight into the effects of various beneficiation processes and help develop new methods.

These and other process developments are viewed as critical to further establish the usage of LRC and create new domestic and international markets.

\subsection{BIBLIOGRAPHY}

Berggren, M.H.; Swanson, W.W. "Development of Dispersing Additives for U1tra-Clean Coal-Water Slurry Fuels," 12th International Conference on Slurry Technology, New Orleans, LA, Mar. 31 - Apr. 3, 1987.

Bowling, K.M. et al. "Ultraclean Coal-Based Pseudoliquid Fuels Processes, Properties, and Prospects," J. of the Institute of Energy 1988, Dec., 179-84. 
Brown, D.J. "Fine Coal Cleaning," final report for the period ending Mar. 31, 1986; U.S. Department of Energy, Morgantown Energy Technology Center, DOE/FE/60181-2091, Technical Information Center, Jun. 1986.

Cheremisinoff, N.P.; Gupta, R. Handbook of Fluids in Motion; Ann Arbor Science Publishers: Ann Arbor, MI, 1983; pp 135-78.

Karner, F.R. et al. "Geochemical Variation of Inorganic Constituents in a North Dakota Lignite," in The Chemistry of Low-Rank Coals; Schobert, H.H., Ed; ACS Symposium Series 264, 1984, pp 175-194.

Knudson, C.L.; Rindt, J.R.; Hetland, M.D.; Mack, P. "Direct Liquefaction of Low-Rank Coals," annual technical progress report for Apr. 1987 Mar. 1988; EERC publication, 1988.

Maas, D.J. et al. "Advanced Processes for Premium Low-Rank Coal/Water Fuel Production," annual technical report for the period Apr. 1, 1987 to Mar. 31, 1988; DE-FC21-86MC10637, EERC publication, 1988.

Maas, D.J. et a1. "Advanced Processes for Slurry Production," annual technical report for the period Apr. 1, 1986 to Mar. 31, 1987;

DE-FC21-86MC10637, EERC publication, 1987.

Mack, P. "0il Agglomeration," University of North Dakota Energy and Environmental Research Center, In-House Report, Sept. 22, 1987.

Malterer, T.J., et al. "Screening of Low-Rank Coals for Low-Ash Fuel Preparation," In Proceedings of the 13th International Conference on Coal and Slurry Technology; Denver, C0, Apr. 12-15, 1988, Coal Slurry Technology Association, Washington, D.C., 1988, pp 443-457.

Mining Information Services. 1985 Keystone Coal Industry Manual; McGraw Hill Publications: New York, 1985.

Musich, M.A. et al. "Beneficiation of Low-Rank Coals," annual report for the period Jul. 1, 1990, through Jun. 30, 1991; EERC publication, Aug. 1991.

Musich, M.A. et al. "Beneficiation of Low-Rank Coals," semiannual report for the period Jul. 1, 1991, through Dec. 31, 1991; EERC publication, Jan. 1992.

Musich, M.A. et a1. "Beneficiation of Low-Rank Coals," semiannual report for the period Jan. 1, 1992, through Jun. 30, 1992; EERC publication, Jul. 1992.

Potas, T.A. et al. "Low-Rank Coal Beneficiation," quarterly technical progress report, DE-FC21-86MC10637; EERC publication, Feb. 198.

Potas, T.A.; Anderson, C.M. "Rheology of Low-Ash, Hot-Water-Dried CoalWater Fuels," 13th Int. Conf. on Coal \& Slurry Technology, Denver, CO, Apr. 12-15, 1988. 
Potas, T.A. et al. "Continuous Production of Deep-Cleaned Low-Rank Coal," In Proceedings of the 14th International Conference on Coal and Slurry Technology; Clearwater, FL, Apr. 1989, pp 593-602.

Potas, T.A. et al. "Beneficiation of Low-Rank Coals," final report for the period Apr. 1, 1988, through Jun. 30, 1989; EERC publication, Aug. 1989.

Potas, T.A. et al. "Beneficiation of Low-Rank Coals," annual report for the period Jul. 1, 1989, through Jun. 30, 1990; EERC publication, Sept. 1990.

Potas, T.A. et al. "Beneficiation of Low-Rank Coals, "quarterly report for the period Jul. 1, 1990, through Sept. 30, 1990; EERC publication, Nov. 1990.

Smit, F.J., Amax Extractive Research \& Development; Maas, D.J., University of North Dakota Energy Research Center. "Preparation and Analyses of Low-Rank Coals for Combustion Applications," final report; Contract No. DE-AC18-84FC10623, EERC publication, Oct. 1986.

Timpe, R.C.; Knudson, C.L.; Mack, P. "Beneficiation of a Bituminous Coal and a Lignite Coal by Agglomeration Using Novel Binding 0i1," ACS Div. Fuel Preprints 1988, 33 (2), 352-358. 


\subsection{Combustion Characterization of Low-Rank Fuels}

(COMPLETED 10-31-90) 
4.4 Diesel Utilization of Low-Rank Coals (COMPLETED 12-31-90) 
4.5 Produce and Characterize HWD Fuels for Heat Engine Applications (COMPLETED 10-31-90) 


\subsection{Nitrous Oxide Emissions}

Final Report IS NOT Included

(Project was extended to September 30, 1993) 
4.7 Pressurized Fluidized-Bed Combustion 
Final Technical Progress Report

for the Period July 1, 1990, through September 30, 1992

by

Michael D. Mann, Research Supervisor John R. Rindt, Research Supervisor

Melanie D. Hetland, Research Engineer

Ann Henderson, Research Engineer

Energy and Environmental Research Center

University of North Dakota

Box 8213, University Station

Grand Forks, North Dakota 58202

Task Contracting Officer's Representative: Dr. Donald Bonk

for

U.S. Department of Energy

Morgantown Energy Technology Center

3610 Collins Ferry Road

Morgantown, West Virginia 26507

December 1992

Work Performed under Cooperative Agreement No. DE-FC21-86MC10637 
LIST OF TABLES ...................... . .

1.0 BACKGROUND $\ldots \ldots \ldots \ldots$

2.0 GOALS AND OBJECTIVES .................. 2

2.1 Carbonizer Performance Evaluation ........... 2

2.2 Fate of Alkali in PFBC Systems .............. 2

2.3 Bench-Scale Reactor Testing ............. 3

3.0 RESULTS AND DISCUSSION ................. 3

3.1 Carbonizer Performance Evaluation ........... 3

3.1.1 Addition of the 4-1b/hr Continuolis Fluidized-Bed

Reactor (CFBR) to the Test Matrix ....... 3

3.1 .2 Results of Testing Performed on the $4-1 \mathrm{~b} / \mathrm{hr}$ CFBR ... 3

3.1.3 Description of the 100-1b/hr Mild Gasification Process Development Unit (MGPDU) ........... 4

3.1.3.1 Modifications Required to Integrate the $100-1 \mathrm{~b} / \mathrm{hr}$ MGPDU into the SecondGeneration PFBC Carbonizer Program . . . . . 4

3.1.3.2 ASME Boiler Code Certification ....... 5

3.1.4 Results of Testing Performed on the $100-1 \mathrm{~b} / \mathrm{hr}$ MGPDU . . 5

3.1 .4 .1 Run PO1E . . . . . . . . . . . . 6

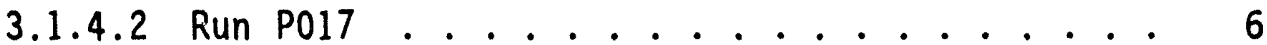

3.1 .4 .3 Run $\mathrm{P} 018 \ldots \ldots$. . . . . . . . . . 7

3.1 .4 .4 Run $\mathrm{PO22} \ldots \ldots . \ldots . \ldots 8$

3.1 .5 Discussion of Results ............ 10

3.2 Fate of Alkali in PFBC Systems ............ 12

3.2.1 Measurement Techniques ............ 13

3.2.2 Alkali Evolution under Reducing Conditions ...... 14

3.2.3 Alkali Getters ............... 17

3.3 Bench-Scale Reactor Testing ............... 19

3.3.1 Bench-Scale Reactor Design ........... 19

3.3.2 Sulfur Retention Efficiency ........... 20

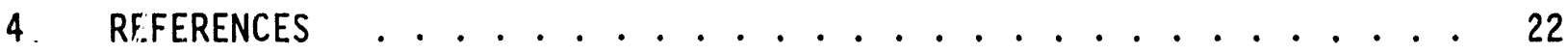

APPENDIX A: UND ENERGY AND ENVIRONMENTAL RESEARCH CENTER

100-LB/HR MILD GASIFICATION PROCESS DEVELOPMENT UNIT

(MGPDU) DESCRIPTION ................ . . . .

APPENDIX B: UND ENERGY AND ENVIRONMENTAL RESEARCH CENTER

4-LB/HR CONTINUOUS FLUIDIZED-BED REACTOR (CFBR)

MILD GASIFICATION UNIT DESCRIPTION 


\section{LIST OF TABLES}

Table

Page

1 Tests Run in the $4-1 b / h r$ CFBR ............. 4

2 Operating Conditions of Tests Run in the 100-1b/hr MGPDU .... 6

3 Results of Analysis of P018 Feed, Char, and Agglomerates . . . . 8

4 Comparison of Predicted P022 Run Period 1 Product Slate with Actual Product Slate .............. 10

5 Comparison of Predicted P022 Run Period 3 Product Slate with Actual Product Slate .............. 11

6 Elemental Analysis of Char and Cyclone Fines from P022 Run Period 3 


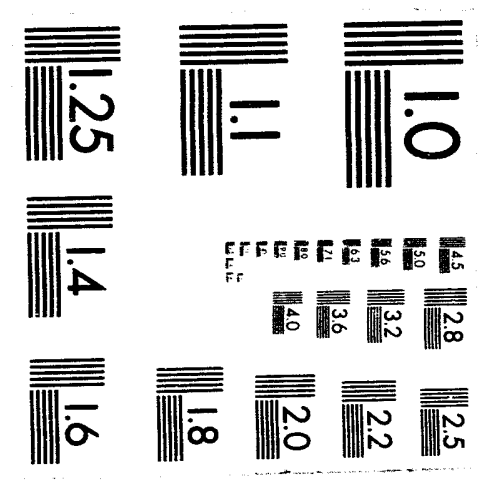



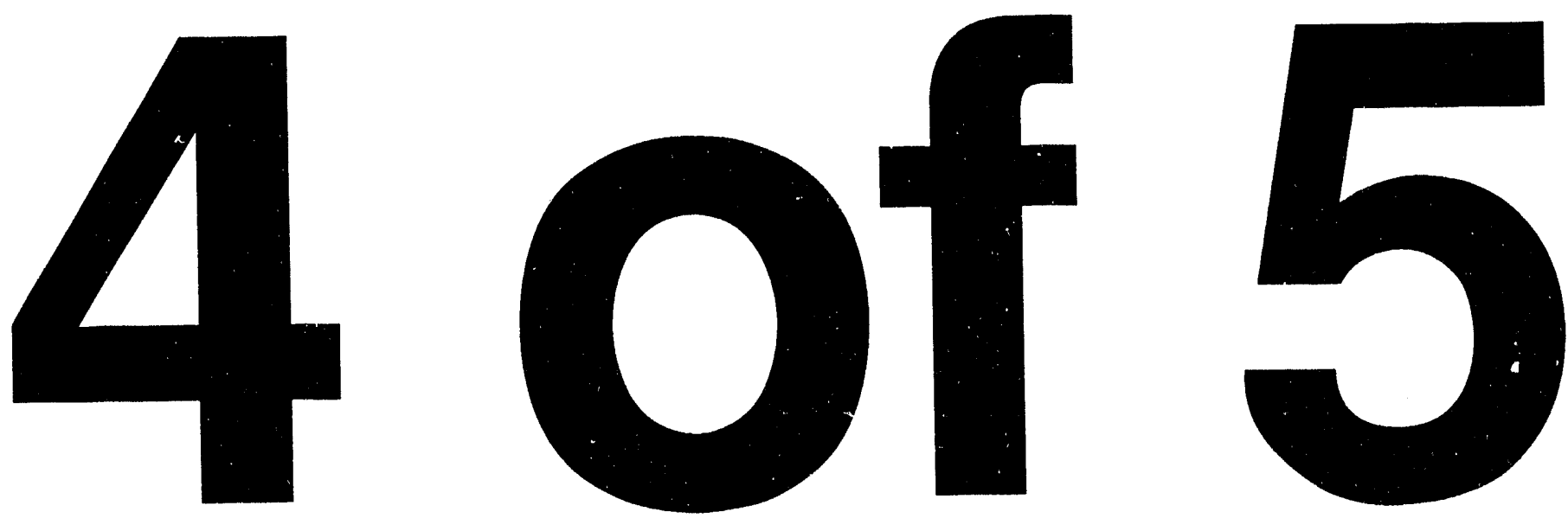


\section{PRESSURIZED FLUIDIZED-BED COMBUSTION}

\subsection{BACKGROUND}

Pressurized fluidized-bed combustion (PFBC) has several advantages that make it attractive as a technology of the future. Some of these advantages are:

- Increased efficiency and reduced capital and generating costs compared to pc-fired boilers equipped with flue gas desulfurization (FGD).

- Modular units without the usual economy-of-scale penalty.

- Reduced combustor size permitting shop fabrication and field erection, thereby greatly shortening construction lead time.

- High-sulfur fuels burned in the presence of sorbent in the FBC eliminate the need for FGD.

- Reduced combustion temperature $\left(1400^{\circ}-1700^{\circ} \mathrm{F}\right.$ versus $3000^{\circ} \mathrm{F}$ for a pulverized coal-fired boiler) which results in significant reduction of $\mathrm{NO}_{x}$ emissions.

- Increased heat-transfer rate to the working fluid.

- Increased fuel versatility.

- Easily handled by-product material consisting of clinker-free, granular, smooth-flowing ash which may be easily disposed of in a landfill or potentially sold for industrial or agricultural applications.

Major technical uncertainties identified by industry as critical areas for PFBC commercialization are:

- Hot-gas cleanup for gas turbine protection, with particular reference to coal alkalies.

- Materials survivability for heat exchanger, gas turbine, and solids handling equipment.

- Solids handling improvement in feeding, distribution, and bed removal.

- Combustor configuration, including the heat-transfer bundles, distributor plate, fuels utilization, and operational parameters.

Some of these problems are being addressed by programs such as those at Grimethorpe and New York University. Others will hopefully be resolved during operation of the three demonstration plants using first-generation technology. These plants are the AEP 70-MWe Tidd Station at Brilliant, Ohio; the 79-MWe Escatron Power Plant in Spain; and the 135-MWe Energi Vartan plant in Stockholm, Sweden. Although these plants show improved efficiency over atmospheric systems, they are still significantly below gas-turbine 
efficiency. In an attempt to increase these efficiencies, several companies are actively involved in the development of second-generation PFBC systems. The goals of the second-generation system are a $45 \%$ coal-to-electricity efficiency, $20 \%$ cost-of-electricity advantage over pc-fired systems, modular design for shop fabrication, to meet or exceed new source performance standards (NSPS), and the ability to operate on a wide range of coals.

\subsection{GOALS AND OBJECTIVES}

The overall goal of the PFBC program at the Energy and Environmental Research Center (EERC) is to generate both fundamental and process information that will foster the development of an economical and environmentally acceptable second-generation PFBC concept. The goal is to focus on generic issues, such as the fate of alkali in PFBC systems, sorbent utilization, and carbonizer performance, while providing input to assist in the development of second-generation systems.

During the last two years of this Cooperative Agreement (7/90-6/92), work focused on three main areas: carbonizer performance, fate of alkal $i$, and increased sorbent utilization. Objectives are discussed below.

\subsection{Carbonizer Performance Evaluation}

In order for a second-generation PFBC to achieve $45 \%$ efficiency, it is likely that the coal must be partially gasified in a carbonizer or a partial gasifier and the char residue burned in the PFBC. This will produce gas streams that can be cleaned at an intermediate temperature (e.g., $1600^{\circ} \mathrm{F}$ ) and then afterburned to obtain temperatures higher than those obtainable directly from the PFBC, thereby increasing the efficiency of the gas turbine. Information needs to be generated to determine the extent of gasification desired to obtain the highest efficiency while maintaining the benefits of the PFBC in terms of meeting environmental standards. The partial gasification step is referred to here as carbonization.

The goal of this task is to use the existing EERC mild gasification reactor, with some modification, to develop a database at temperatures and pressures representative of those for a second-generation system. Gas, tar, and liquid yields for selected coals will be determined. The fate of sulfur and alkali will be investigated. The amount of tar generated, its properties, and the elimination of tar will be studied to determine whether or not it will pose problems in the hot-gas cleanup device.

\subsection{Fate of Alkali in PFBC Systems}

Alkali in the coal, especially that organically bound, will volatilize even at the low temperatures typical of a fluid-bed gasifier or combustor. This alkali can cause problems in both the filter media and the turbine. The EERC will focus on developing an understanding of how the alkalies are released so that methods of rendering them harmless can be found. Alkali gettering to keep the alkali in the bed is one potential method of protecting the filter and turbine. Some work will be done on the pilot-scale bubbling and circulating atmospheric fluid beds. Because the vapor pressures of the alkali species are low and not greatly influenced by pressure, it is felt that 
data from the atmospheric units will be applicable to pressurized systems. Work will also be done on the bench-scale pressurized reactor. PHOEBE, a thermodynamic code for predicting gas-solid-liquid-equilibrium stages, will be used as a tool to help predict trends with changing operating conditions and coal types.

\subsection{Bench-Scale Reactor Testing}

A bench-scale reactor will be built to study PFBC reaction kinetics and conversions. The reactor will be designed around an already existing piece of equipment to minimize costs. Design efforts will attempt to minimize the impacts of the small size on the usefulness of the data, while providing for a wide range of conditions applicable to combustion and gasification in bubbling and entrained/circulating fluidized beds. A 3-inch-ID reactor is envisioned. This reactor will be used to study sorbent utilization and alkali gettering. It is important to improve sorbent utilization and minimize the amount of sorbent feed and waste disposal. Extending the operating conditions where conventional sorbents are effective may help improve the overall efficiency of the PFBC. If properly designed, it is envisioned that this reactor could also be used for studying $\mathrm{N}_{2} \mathrm{O}$ emissions, if time and budget allow.

\subsection{RESULTS AND DISCUSSION}

\subsection{Carbonizer Performance Evaluation}

\subsubsection{Addition of the 4-1b/hr Continuous Fluidized-Bed Reactor (CFBR) to the Test Matrix}

Limited operation of the EERC $4-1 \mathrm{~b} / \mathrm{hr}$ continuous gasifier was added to the experimental matrix due to delays encountered with the certification process for the primary gasification vessel and with delivery of equipment needed for system modifications. A description of this unit is provided in Appendix $B$. The rationale was that use of the smaller unit would enable the effects of various operating conditions to be investigated more easily, resulting in more efficient testing on the $100-1 \mathrm{~b} / \mathrm{hr}$ unit. The information gathered during the $4-1 \mathrm{~b} / \mathrm{hr}$ tests was to be used to determine the conditions at which the 100-1b/hr unit would yield the most useful data. Because it is possible to obtain only three data points each week with the $100-1 \mathrm{~b} / \mathrm{hr}$ unit, it was critical that the most meaningful test points be run on this unit.

\section{1 .2 Results of Testing Performed on the $4-1 \mathrm{~b} / \mathrm{hr}$ CFBR}

Five tests were performed on the 4-1b/hr unit. The conditions of these tests are given in Table 1. The first and second tests (using Wyodak subbituminous coal) were successfully completed. During the third test, the Pittsburgh No. 8 coal agglomerated approximately 15 minutes into the run. An error in prerun calculations had set the actual $\mathrm{Ca} / \mathrm{S}$ ratio at 0.45 rather than the planned 1.75. The low dolomite add rate may have increased the tendency for the high-swelling Pittsburgh No. 8 coal to form agglomerates during carbonization. 
TABLE 1

Tests Run in the $4-1 \mathrm{~b} / \mathrm{hr}$ CFBR

\begin{tabular}{lrrrrc}
\hline Run & M169 & M170 & M171 & M172 & M173 \\
\hline Coal & Wyo & Wyo & Pitts $8^{\circ}$ & Wyo & Pitts 8 \\
Avg. Bed Temp., ${ }^{\circ} \mathrm{F}$ & 1562 & 1562 & 1562 & 1562 & 1562 \\
Pressure, psig & 25 & 55 & 55 & 165 & 150 \\
Coal Size, inch & $-1 / 4$ & $-1 / 4$ & $-1 / 4$ & $-1 / 4$ & $-1 / 4$ \\
Dolomite Size, mesh & -30 & -30 & -30 & -30 & -30 \\
Dolomite/Coal, wt. ratio & & 1.00 & 4.40 & & \\
\hline
\end{tabular}

- Wyodak subbituminous coal.

- Pittsburgh No. 8 bituminous coal.

Run M172 was initiated using Wyodak subbituminous coal. Steady-state conditions were reached at $1562^{\circ} \mathrm{F}$ and $150 \mathrm{psig}$. Run M173 began when the coal hopper was switched and Pittsburgh No. 8 coal was fed. Bed agglomeration occurred after approximately 30 minutes, forcing shutdown of the run.

Data which could be reduced indicated that the results of the carbonizer testing agreed reasonably well with the results seen during mild gasification testing. Tar yields in the carbonizer operational mode were low to nonexistent. Partial-gasification-produced char yields were similar to those produced during mild gasification, with the exception that the pressurized carbonizer char contained less volatiles.

\subsubsection{Description of the $100-1 \mathrm{~b} / \mathrm{hr}$ Mild Gasification Process Deve Topment Unit (MGPDU)}

The MGPDU was designed to process $100 \mathrm{lb} / \mathrm{hr}$ of feed coal on a dry basis and is capable of drying, carbonizing, and calcining both caking and noncaking coals in pressurized fluid-bed reactors as well as separating char, liquid, and gaseous products. The system was designed for integrated operation, and because provisions were made so that carbon zation could take place without the use of the calciner, the unit works wel? within the secondgeneration PFBC program. A description of the MGPDU is presented in Appendix A.

\subsubsection{Modifications Required to Integrate the 100-1b/hr MGPDU into the Second-Generation PFBC Carbonizer Program}

Several minor modifications to the MGPDU were required to ensure that the unit could be operated at the carbonizer test conditions of $150 \mathrm{psi}$ and $1600^{\circ} \mathrm{F}$. The modifications included the replacement of all slide valves on the primary cyclone, secondary cyclone, coal feed system, and char product receiver with ball valves. Pressurized site ports were added to the coal feed system and the natural gas burner flame detection sensor. A pressurized burner was constructed and used to replace the existing system. The conical section of the pressurized coal hopper, the bottom of the char receiver, and the primary cyclone inlet wall were reinforced. The first water scrubber gas/liquid separation cyclone was modified to prevent the water entrainment 
observed during cold-flow model testing. A small gas slipstream condensation train was added to assist in the accurate determination of tar yields. Minor process control reprogramming was performed so that the carbonizer could operate with heat generation from either a natural gas burner or by internal oxidation using oxygen or air. A natural gas compressor was refurbished and piped in for this purpose. All flanges and closures were reevaluated and retorqued.

\subsubsection{ASME Boiler Code Certification}

The mild gasifier system (carbonizer, calciner, and support systems) was originally designed for service at atmospheric pressure. In order to determine that the system was safe for operation at pressures up to $150 \mathrm{psig}$ and to comply with the North Dakota State Boiler laws, it was necessary to perform a thorough analysis of the vessels and associated piping systems. Components of the system that met the legal definition of an unfired pressure vessel according to North Dakota State Boiler laws were analyzed in accordance with the ASME Boiler Pressure Vessel Code Section VIII, Divisions 1 and 2. The piping system and components were analyzed in accordance with the B31.3 piping codes. Approval was given to operate the system under pressure in the interim, based on the preliminary set of calculations. Some modifications were recommended and made based on the findings of the analysis, although no serious defects or code violations were found. The system proved to be fully capable of being operated at the design conditions identified for the various components.

The carbonizer vessel of the 100-1b/hr mild gasification unit was hydrostatically pressure-tested to $130 \mathrm{psi}$, with Twin City Testing serving as the independent observer to certify the testing procedures. Approval was given by the North Dakota state inspector to operate the carbonizer vessel under pressure. A11 piping modifications were completed, including the installation and pressure testing of new high-pressure/high-temperature valves.

\subsubsection{Results of Testing Performed on the $100-7 \mathrm{~b} / \mathrm{hr}$ MGPDU}

A computer model of the MGPDU was developed for use in determining the various gas flows necessary to meet the Foster-Wheeler test specifications for all matrix points. The model is interactive, calculating flow rates and expected products based upon the coal and dolomite feed rates, proximate and ultimate analyses of the coal, and run conditions. Due to heat losses, keeping the carbonizer at a reaction temperature of $1600^{\circ} \mathrm{F}$ requires that more coal be burned for heat than the $30 \%$ required by Foster-Wheeler. It was decided that additional heat could be supplied through the combustion of natural gas and a stoichiometric amount of air.

A test was performed in the pressurized carbonizer mode to determine the maximum flow rates possible for the various gas streams (purge $\mathrm{N}_{2}$, transport $\mathrm{N}_{2}, \mathrm{O}_{2}$, natural gas, the stoichiometric amount of air needed to burn the natural gas, and makeup $\mathrm{N}_{2}$ needed to achieve the desired superficial velocity). The maximum flow rate information was compared with the various gas flow rates needed to successfully complete the experimental matrix. It was noted that some of the gas flow rates needed to complete the matrix were outside of the operational range of the equipment. To lower the gas flow rate 
through the system, it was decided to use propane as the additional heat source rather than natural gas. The computer model was used to recalculate the gas flow rates necessary for the start-up sequence and test matrix using propane.

Following shakedown of the $100-1 \mathrm{~b} / \mathrm{hr}$ unit, five tests were performed. The operating conditions for these tests are given in Table 2.

\subsubsection{Run P016}

Operation of the unit during Run P016 was consistent with design criteria until feed problems were encountered. Shortly after the feed problems developed, support instrumentation failure resulted in equipment dysfunction in the downstream quench train, producing another system upset. Further attempts to achieve steady-state operation were unproductive, and the test was terminated.

The problem with the feed system was determined to be contamination in the feed coal/dolomite mixture, and the problem with the quench train was satisfactorily resolved by instrumentation and control replacement.

\subsubsection{Run P017}

Maintenance was performed on the unit, new feed material was prepared, and a second run was attempted. During this run, the unit operated very well at atmospheric conditions. A feed problem was encountered during stepwise sequential increases in pressure. At pressures over 30 psi, water condensation was noted in the pneumatic transport feed line. The water was noted in the drip leg below the transport zone. This condition apparently led to a plugged feed line. When the coal feed stopped, the internal temperature

\section{TABLE 2}

Operating Conditions of Tests Run in the 100-1b/hr MGPDU

\begin{tabular}{lcccccc}
\hline Test Number & P106 & P017 & P018 & P022-1 & P022-2 & P022-3 \\
\hline Coal & Wyodak $^{\mathrm{a}}$ & Wyodak & Pitt. $8^{\mathrm{b}}$ & Wyodak & Wyodak & Pitt.8 \\
Average Bed Temp., ${ }^{\circ} \mathrm{F}$ & 900 & 1150 & $1650^{\mathrm{c}}$ & 1625 & 1625 & 1625 \\
Pressure, psig & $50-80$ & $50-80$ & 125 & 7 & 56 & 56 \\
Coal Mix Feed Rate, 1b/hr & 100 & 100 & 100 & 94 & 94 & $54.1^{\mathrm{e}}$ \\
Coal Feed Size, inch & $-1 / 4 \times 0$ & $-1 / 4 \times 0$ & $-1 / 4 \times 0$ & $-1 / 4 \times 0$ & $-1 / 4 \times 0$ & $-1 / 4 \times 0$ \\
Dolomite Feed Size, mesh & $8 \times 16$ & $8 \times 16$ & -30 & NA & NA & NA \\
Dolomite/Coal Ratio & $15 / 85$ & $15 / 85$ & $30 / 70$ & $23 / 77$ & $23 / 77$ & $23 / 77$ \\
Air Flow, Scfh & 3400 & 3400 & 3600 & 2200 & 3900 & 2900 \\
Velocity, ft/sec & $2-3$ & $2-3$ & $0.5-1$ & 6.1 & 5.6 & 2.8 \\
\hline
\end{tabular}

a Wyodak subbituminous coal.

Pittsburgh No. 8 bituminous coal.

c Average value - temperature ranged from $1110^{\circ}$ to $2190^{\circ} \mathrm{F}$.

- Mixture of coal and Plum Run dolomite.

- Average value, feed rate increased during test period. 
increased enough to cause bed sintering, terminating the run after approximately 20 hours of operation at a pressure of $90 \mathrm{ps} i$.

In an effort to eliminate the coal feed difficulties, the function of the transport line during the pressurized carbonizer mode of operation was analyzed. Heat balance is difficult to maintain at this scale, and as a result, the gas-phase streams into the unit are heated. During mild gasification, a significant amount of the heat is supplied by the combustion of natural gas. In the pressurized carbonizer mode of operation, most of the heat is supplied by internal combustion. This means that, during operation, the air entering the system is essentially at room temperature. The transport tube passes through the natural gas combustion zone before entering the primary reactor. As the feed coal/dolomite mixture and preheated transport gas pass through the natural gas combustion zone, enough heat is lost to the incoming, room-temperature air to allow the condensation of a significant amount of either coal feed moisture or combustion moisture in the transport tube. This reduces the velocity of the transport nitrogen and disturbs its natural flow, causing agglomeration and plugging problems in the tube. It was decided that, prior to Run P018, minor equipment modifications and procedural changes would be adopted. The transport nitrogen feed line was modified to permit the use of air as well as nitrogen, meaning that room-temperature air could be used as the pneumatic transport gas. It was thought that this would eliminate the condensation problem and overcome a decrease in the net gas transport velocity during pressurization.

\subsubsection{Run P018}

The equipment modifications suggested by the results of Run P017 were completed prior to the performance of Run P018. In addition, a sight port was added to the high-pressure burner. This enabled evaluation of a problem that had been experienced with lighting the burner at pressures over $30 \mathrm{psi}$. The sight port showed that the burner was lighting, but that the flame sensor was not "seeing" it. The sensor was moved, and the burner operated correctly.

The natural gas burner system had been modified and successfully operated at $1650^{\circ} \mathrm{F}$ and pressures up to $125 \mathrm{psi}$. The water quench system operated very well at pressures above 30 psi, preventing water from vaporizing in the first-stage system. The second-stage scrubber level instrumentation failed during heatup, but was monitored manually and did not present a problem. The electronic instrumentation for the coal transport velocity determination failed, and an operator took field readings to determine fluidization velocity. Due to the temperature loss caused by the introduction of a large amount of air, the transport gas was not introduced until shortly before the initiation of coal feed.

Within 10 minutes of the start of coal feed, large pressure fluctuations were noted in the bed and transport tube. Reactor temperature fluctuated from $1100^{\circ}$ to $2190^{\circ} \mathrm{F}$. Cycles between the temperature fluctuations occurred in a matter of minutes and were the result of inconsistent air flow to the reactor. A11 of the air was fed to the reactor through the transport tube. The tube plugged, diminishing the transport air flow and resulting in insufficient air to maintain reactor temperature. When the plug was blasted free, too much air entered the system. After approximately 1 hour, the feed system plug could not be blasted free, and the run was discontinued at that point. 
Agglomerated coal was found at the bottom of the reactor, above the top of the char removal point. Clear passage was not evident at any point in the plug. It appears that the plug actually occurred in the main reactor and portions of the plug material fell to the bottom of the reactor and into the transport tube.

Table 3 presents the results of proximate/ultimate analyses of the feed coal, feed coal + dolomite, P018 char, and plug material from two locations. The data show that the agglomerates were enriched in ash relative to the feed coal/dolomite mixture. The agglomerate sample taken from near the bottom of the reactor contained more moisture and volatile matter than the agglomerate sample taken approximately $4 \mathrm{ft}$ up the reactor. The agglomerates that were not found at the base of the reactor consisted almost entirely of fixed carbon and ash, indicating that this area experienced very high temperatures.

\subsubsection{Run P022}

This run consisted of three test periods, designated P022-1 through P022-3. Agglomeration had been noted during earlier runs using Pittsburgh No. 8 bituminous coal; therefore, to ensure a successful system start-up, the run was initiated using Wyodak subbituminous coal, and the first test period consisted of operation using Wyodak coal at $7 \mathrm{psig}(1.5 \mathrm{~atm})$ and $1625^{\circ} \mathrm{F}$. Char, condensate, and product gas samples were quantitatively taken during this test period.

TABLE 3

Results of Analys is of P018 Feed, Char, and Agglomerates

\begin{tabular}{|c|c|c|c|c|c|}
\hline & Pitts $8^{\circ}$ & $\begin{array}{l}\text { Coal/ } \\
\text { Dolomite } \\
\text { Mixture }\end{array}$ & $\begin{array}{l}\text { P018 } \\
\text { Char }\end{array}$ & $\begin{array}{c}\text { P018 } \\
\text { Reactor } \\
\text { Plug } \\
\end{array}$ & $\begin{array}{c}\text { P018 } \\
\text { Reactor } \\
\text { Plug }^{\circ}\end{array}$ \\
\hline $\begin{array}{l}\text { Proximate Analysis, } \\
\text { wt\% as-received } \\
\text { Moisture } \\
\text { Volatile Matter } \\
\text { Fixed Carbon } \\
\text { Ash }\end{array}$ & $\begin{array}{r}2.20 \\
36.29 \\
50.30 \\
11.20\end{array}$ & $\begin{array}{r}2.60 \\
38.08 \\
39.20 \\
20.11\end{array}$ & $\begin{array}{l}20.70 \\
19.76 \\
30.16 \\
29.37\end{array}$ & $\begin{array}{r}2.00 \\
18.45 \\
20.78 \\
58.75\end{array}$ & $\begin{array}{r}0.80 \\
10.23 \\
43.57 \\
45.39\end{array}$ \\
\hline $\begin{array}{l}\text { Ultimate Analysis, } \\
\text { wt\% mafe basis } \\
\text { H } \\
\mathrm{C} \\
\mathrm{N} \\
\mathrm{S} \\
\mathrm{O}^{+}\end{array}$ & $\begin{array}{r}5.34 \\
81.33 \\
1.56 \\
3.76 \\
7.98\end{array}$ & $\begin{array}{r}5.18 \\
81.06 \\
1.36 \\
3.17 \\
9.20\end{array}$ & $\begin{array}{r}1.64 \\
82.81 \\
1.10 \\
3.42 \\
11.00\end{array}$ & $\begin{array}{r}2.48 \\
85.29 \\
1.40 \\
6.07 \\
4.74\end{array}$ & $\begin{array}{r}0.70 \\
99.47 \\
1.56 \\
5.03 \\
-6.77\end{array}$ \\
\hline
\end{tabular}

- Pittsburgh No. 8 bituminous coal.

- Pittsburgh No. 8 and Plum Run dolomite.

- Located at the bottom of the reactor.

a Located 4 feet up the reactor.

- Moisture- and ash-free.

' Calculated by difference. 
Once steady-state conditions were achieved during the first test period, the pressure was increased and the unit allowed to come to steady state again. The second test period consisted of operation of the unit on Wyodak coal at $1625^{\circ} \mathrm{F}$ and $56 \mathrm{psig}(4.8 \mathrm{~atm})$. Product gas samples were taken during this test period, but condensate and char samples were not.

When the pressure was maintained at $56 \mathrm{psig}(4.8 \mathrm{~atm})$ and the temperature at $1625^{\circ} \mathrm{F}$, the feed was abruptly changed from Wyodak to Pittsburgh No. 8 coal. The coal/dolomite feed rate was increased over the course of the entire third run period, from 20 to $80 \mathrm{lb} / \mathrm{hr}$. A hot spot developed on the side of the vessel where an unused nozzle had been insufficiently insulated, and the run was terminated. Following shutdown, no evidence existed of the extensive agglomeration of the Pittsburgh No. 8 coal that had occurred during the earlier attempts to carbonize it. A product gas sample was taken during the run period, and the char present in the cyclones and the char hopper at the end of the run was collected. A sample of the condensate was not taken during this run period.

The product gas samples that were collected during P022 were analyzed by gas chromatography. Char samples were analyzed for moisture, fixed carbon, volatile matter, and ash contents (proximate analysis); for $\mathrm{C}, \mathrm{H}, \mathrm{N}, \mathrm{S}$, and 0 (by difference) contents (ultimate analysis); and via $x$-ray fluorescence analysis to determine the inorganic constituents of the ash. The condensate was filtered and the solids subjected to determination of moisture, volatile matter, fixed carbon, ash, and sulfur contents; heating value; and solubility in tetrahydrofuran (THF). The condensate liquids were analyzed for total organic carbon and total phenolic contents. The density of the liquid fraction of the condensate was also determined.

A good mass balance could only be performed for the first run period due to the lack of quantitative samples. Because the data necessary to perform the mass balances were unavailable, the yield structure for the third run period (performed with Pittsburgh No. 8 coal) was determined in an alternate manner. The computer model of the mild gasification unit, that had been developed for use in determining the various gas flows necessary to meet the experimental matrix conditions, was modified to predict the product slate of carbonization. The model was originally developed using three steps:

1. Input of the flow rates and analyses of the feedstocks

2. Description of the chemical reactions occurring within the vessel with respect to the production of heat (i.e., burning methane and/or coal)

3. Performance of a heat balance over the system to obtain an estimate of the reactor heat loss

Additional information was added to the model so that it could be used to predict the yield structure of the carbonizer tests. The following information was incorporated during modification of the model:

4. Description of the chemical reactions taking place within the carbonizer 
5. Development of chemical boundary machine constants based upon the behavior of the system during operation using Wyodak coal

6. Determination of the quantity of char produced

7. Determination of the quantity and speciation of product gases

8. Performance of mass and material balances on the system and the inclusion of this information in the model

9. Performance of an elemental balance over the vessel proper

10. Definition of the fourth reaction zone (in the water scrubber) and the reactions occurring there

11. Verification of mass, material, elemental, and heat balances for the entire system

\subsubsection{Discussion of Results}

Once completed, the model was used to predict the product slate of the first run period. This predicted product slate is compared to the actual product slate in Table 4. As the table shows, the model accurately predicts

TABLE 4

Comparison of Predicted P022 Run Period 1 Product Slate with Actual Product Slate ${ }^{a}$

\begin{tabular}{|c|c|c|}
\hline \multicolumn{3}{|c|}{ Wyodak } \\
\hline Coal: & Predicted & Actual \\
\hline $\begin{array}{l}\text { Product Gas, } 1 \mathrm{~b} \\
\mathrm{O}_{2} \\
\mathrm{H}_{2} \\
\mathrm{CO}_{2} \\
\mathrm{~N}_{2} \\
\mathrm{CO} \\
\mathrm{CH}_{4} \\
\mathrm{H}_{2} \mathrm{O}\end{array}$ & $\begin{array}{c}66 \\
30 \\
617 \\
1355 \\
410 \\
27 \\
5.5\end{array}$ & $\begin{array}{c}21 \\
30 \\
577 \\
1430 \\
402 \\
22 \\
5.6\end{array}$ \\
\hline Total & 2510.5 & 2487.6 \\
\hline Condensate, $1 \mathrm{~b}$ & 322 & 294 \\
\hline $\operatorname{Char}\left(\operatorname{maf}^{b}\right), 1 b$ & 62 & 62 \\
\hline Dolomite + Ash, Ib & 110 & 91 \\
\hline Water in Char, Ib & 4.9 & 4.7 \\
\hline closure & $100 \%$ & $98.14 \%$ \\
\hline Char Yield & $13.8 \%$ & $11.2 \%$ \\
\hline
\end{tabular}

- Total quantities produced during run period with Wyodak coal.

- Moisture- and ash-free. 
the product slate for the run period using Wyodak subbituminous coal. There is little reason to expect that it could not also be successfully used to predict the product slate of the carbonization of Pittsburgh No. 8 bituminous coal.

Table 5 compares the predicted product slate for run period 3 with the actual product slate (such as could be calculated) from the Pittsburgh No. 8 run period. Not all values could be compared due to the lack of samples, but the predicted and actual gas product slates agree fairly well. The char samples collected during this run period were taken from the char hopper and the cyclones. The ultimate analys is of the char in the char hopper was quite different from that of the cyclone fines, as can be seen in Table 6 . Based

TABLE 5

Comparison of Predicted P022 Run Period 3 Product Slate with Actual Product Slate ${ }^{a}$

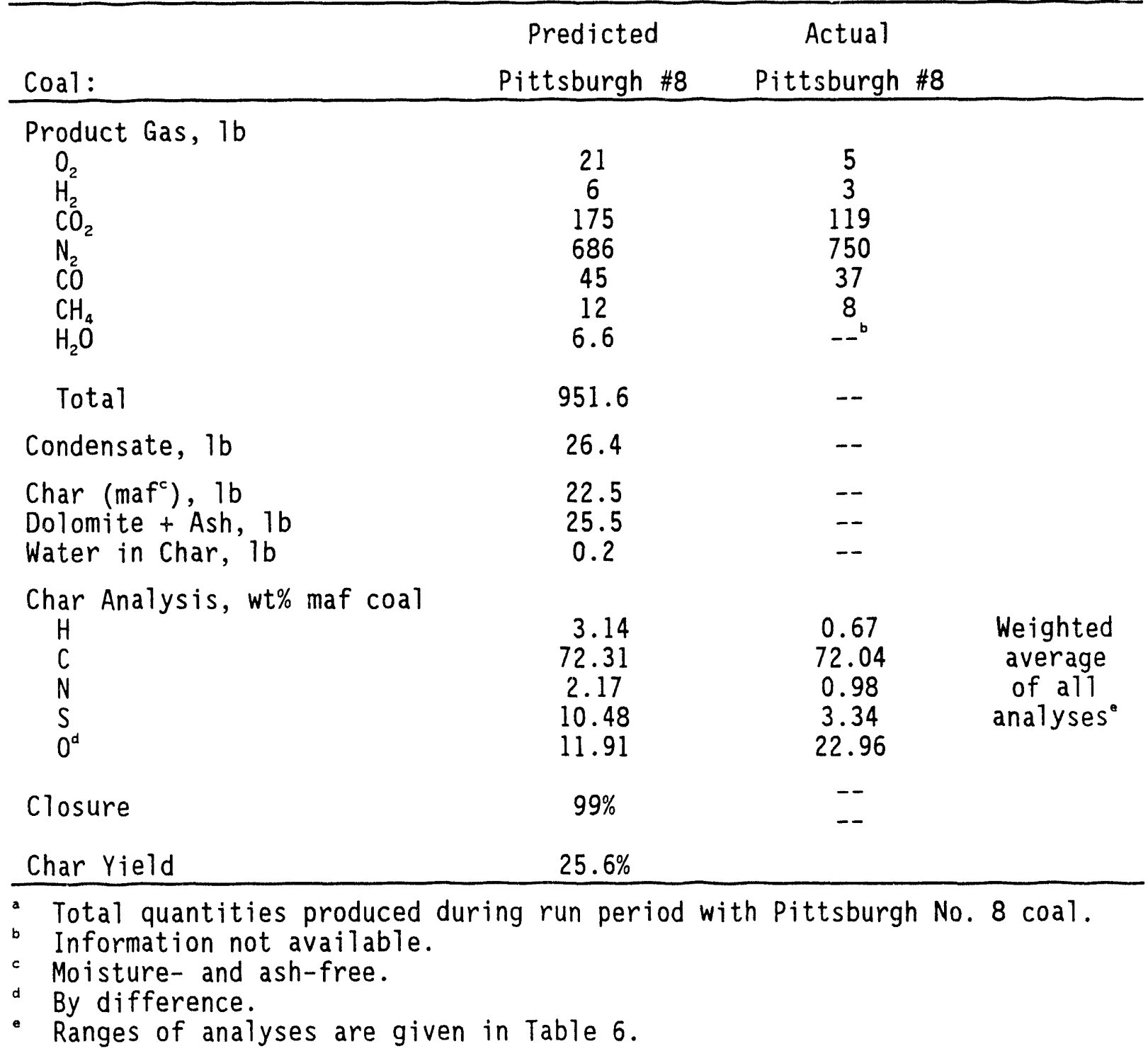


TABLE 6

Elemental Analysis of Char and Cyclone Fines from P022 Run Period $3^{\mathrm{a}}$

\begin{tabular}{ccc}
\hline & Char Hopper & Cyclone Fines \\
\hline$H$ & 0.91 & 0.54 \\
$C$ & 90.10 & 62.99 \\
$N$ & 1.37 & 0.76 \\
S & 9.29 & 0.05 \\
$0^{b}$ & -1.69 & 35.64 \\
\hline
\end{tabular}

All values in wt\% on a moisture- and ash-free basis.

By difference.

upon the quantities collected from each location during the Wyodak run period, these values were weighted to arrive at an average char analysis, which is shown in Table 5. The predicted and average values agree fairly well when it is taken into account that small real differences at this scale can result in dramatically different percentages. It should also be noted that most of the predicted values fall within the range defined by the two char analyses.

Based upon the product slate predicted using the computer model, it appears that operation at $1625^{\circ} \mathrm{F}, 4.8 \mathrm{~atm}$, and the gas flow rates noted in Table 1 results in a char yield of approximately $25 \mathrm{wt} \%$ of the Pittsburgh No. 8 coal fed to the system.

\subsection{Fate of Alkali in PFBC Systems}

Data from turbine-operating experience using residual $0 i 1$ and from PFBC experiments indicate that alkali metal compounds play a large role in the amount of deposition and hot corrosion experienced by turbomachinery (1). If pressurized fluidized-bed combustion is ever to become a commercial reality, an understanding of the extent of alkali metal compound emissions from the combustor, its effect on the turbine, and ways for controlling these emissions is needed.

Sodium and potassium compounds exist in the coal in similar chemical forms. Sodium and potassium are constituents of clay minerals; $\mathrm{NaCl}$ is present in the coal bed moisture and as a discrete mineral in the coal. While $\mathrm{KCl}$ is also found in the groundwater, potassium is present in the coal largely as nonvolatile aluminosilicates. The potassium can then be released from the silicates as $\mathrm{KCl}$ through an exchange reaction with $\mathrm{NaCl}$ vapor. Both $\mathrm{NaCl}$ and $\mathrm{KCl}$ have significant vapor pressures at $900^{\circ} \mathrm{C}(3.0-$ and $5.3-\mathrm{mmHg}$, respectively), so their vapor is expected in the PFBC flue gas.

Researchers at Westinghouse concluded, based on thermodynamic modeling, that the release of sodium increases with increasing temperature, increasing chlorine content of the fuel, and decreasing $\mathrm{SO}_{2}$ levels in the gas and decreases with increasing pressure (1). These studies also indicated that the major sodium and potassium species evolved should be $\mathrm{NaCl}$ and $\mathrm{KCl}$; however, alkali metal sulfates can result from the reaction of the chlorides with gaseous sulfur compounds. 


\subsubsection{Measurement Techniques}

One concern in understanding the fate of alkali in a PFBC system is the ability to measure the amount of alkali volatilized under these conditions. Several techniques have been developed to measure the alkali levels in flue gases. These techniques include in situ techniques such as laser-induced fluorescence spectroscopy (LIFS); laser-induced photo and fluorescence (LIPF); laser-induced breakdown spectroscopy (LIBS); hot-extraction techniques, such as the Ames alkali monitor and the METC Fiber Optic Alkali Monitor (FOAM) analyzer; and a batch-type, condensation cold trap such as the alkali and particulate sampling train (APST) technique. One additional technique is the use of a fixed bed of alkali sorbent material in which a known amount of flue gas is passed through the bed for a given time, after which the bed material is regenerated and analyzed for its alkali content.

The EERC has performed some testing using a LIFS system to look at the concentration of $\mathrm{Na}$ atoms in a small-scale burner (2). These tests looked at sodium in solution, solid-phase sodium compounds, sodium impregnated on carbon, and three different Beulah lignite coal samples. These samples were a demineralized Beulah lignite, a demineralized Beulah lignite with sodium acetate impregnated back into the sample, and a raw Beulah lignite. The form of the sodium in solution was found to have no effect on the concentrations measured. The solid-phase sodium salts (benzoate, sulfate, and carbonate) gave signals similar to the solutions, while the sodium montmorillonite and chloride gave signals much less than those observed for solutions. The coal and char samples gave signals higher than the solutions, and there was a linear response of the coal samples with $\mathrm{Na}$ concentration in the sample. Solgasmix, a thermodynamic code for predicting the equilibrium composition of various inorganics in high-temperature environments, was used to predict how much $\mathrm{Na}$ would be in the atomic state. The code did agree with the general observations that $\mathrm{NaCl}$ and sodium montmorillonite liberated less $\mathrm{Na}$ when combusted; however, the predictions were $30 \%$ to $70 \%$ in error since the mole fraction values put into the program were that much in error.

Los Alamos National Laboratory has performed some laboratory testing with a photofragment fluorescence technique which is capable of identifying different anions of the same alkali (3). This technique is based on the UV laser-induced photodissociation of alkali-containing compounds. Sodium and potassium compounds can be distinguished by their characteristic emission wavelength ( $589 \mathrm{~nm}$ for $\mathrm{Na}^{+}, 766 \mathrm{~nm}$ for $\mathrm{K}^{+}$). Variation of the threshold energy wavelength should allow good discrimination between alkali compounds with different anion groups. Research indicates that the instrument is sensitive down to 0.03-ppb $\mathrm{NaCl}$ and 0.4-ppb KCl, 0.1-ppb NaOH and 7-ppb KOH, and $0.01-\mathrm{ppb} \mathrm{Na} \mathrm{SO}_{4}$ and $0.3-\mathrm{ppb} \mathrm{K}_{2} \mathrm{SO}_{4}$. This research concluded that, in predominately binary mixtures of the chloride anion with the hydroxide or sulfate anion, the photofragment fluorescence technique will be able to distinguish the concentration of each compound. However, in mixtures containing comparable amounts of the hydroxide and sulfate anions, the spectra are similar enough to make concentration measurements difficult. Research with the photodissociation fluorescence technique is being continued at PSI Technologies, Co., in testing on their laminar flow drop-tube furnace (4). Results have been obtained which indicate that chlorine is the specieslimiting compound in the formation of $\mathrm{NaCl}$. Solgasmix was used to validate the dependence of $\mathrm{NaCl}$ formation on the chlorine levels in the coal. 
Additional kinetic modeling was performed to determine that the $\mathrm{NaCl}$ equilibrium is approached in approximately $5 \mathrm{~ms}$.

Work at Argonne National Lab (ANL) has compared the Ames alkali monitor, the METC FOAM analyzer, an APST condensation technique, and the alkali sorbent bed (5-9). Their results indicate that hot-extraction techniques result in considerable condensation of alkali on the heated sample lines, even at temperatures up to $950^{\circ} \mathrm{C}$. The $\mathrm{Na}$ concentrations were found to be approximately 0.1 to $0.3 \mathrm{ppm}$ with this technique. The APST batch-type condensation train gives alkali levels between $0.6-$ and $1.0-\mathrm{ppm} \mathrm{Na}$, while the sorbent bed gives values between 1.3- and 1.5-ppm Na, which is 15 times higher than the current industrial gas turbine limit of $0.024 \mathrm{ppm}$ of alkali. The discrepancies in the numbers have been attributed to the absorption of the alkali on the heated sample lines, while the sorbent bed is right in the flow gas, so there is no sample line to change the concentrations. The sorbent bed numbers could be inflated due to some contamination by particulate.

Thermodynamic equilibrium studies have been conducted at the EERC using the Solgasmix and PHOEBE codes. Solgasmix is a free energy minimization code developed by Eriksson (10). PHOEBE is a Gibbs free energy minimization program developed at the EERC by Ramanathan, Kalmanovitch, and Ness $(11,12)$. Solgasmix was tested extensively in-house and appeared to perform adequately, although the occasional output of erroneous results was discovered. PHOEBE was found to perform better than Solgasmix in calculations on the binary $\mathrm{Al}_{2} \mathrm{O}_{3}: \mathrm{SiO}_{2}$ system and the $\mathrm{Na}_{2} \mathrm{O}: \mathrm{Al}_{2} \mathrm{O}_{3}: \mathrm{SiO}_{2}$ ternary systems. PHOEBE was in very good agreement with the binary system and showed some interchange between the primary and secondary (or secondary and tertiary) phases in the predicted values.

A review of the literature being used to design the carbonizer for the Foster Wheeler second-generation PFBC system indicates that the dry tar had ash levels ranging from 0.1 to $3.2 \mathrm{wt} \%$ ash (avg. $1.0 \mathrm{wt} \%$ ) (13). While some of the ash could be the result of fine fly ash carrying over out of the carbonizer, some of the ash is probably due to the volatilization of alkali metal compounds which would not be collectible by a hot-gas cleanup device such as ceramic candle filters, etc. The presence of organic vapors in the gas stream will also make the sampling and identification of alkali compounds more difficult. The organic vapors are known to absorb UV radiation which will preclude the use of any laser-induced fluorescence technique because they fluoresce in the UV wavelengths. Condensation cold-trap sampling trains would also condense the organic tars, making the analyses for alkali compounds much more difficult. A fixed bed of sorbent material could potentially work as an alkali meacurement device, provided the bed is maintained at the same temperature as the gas/tar stream to prevent the condensation of tars on the sorbent material.

\subsubsection{Alkali Evolution under Reducing Conditions}

Alkali sampling from the Texaco slagging gasifier has been reported by Haas and others (14) using the METC/Idaho National Engineering Laboratory (INEL) fiber optic alkali meter. This sampling was conducted at $650^{\circ}$ to $700^{\circ} \mathrm{C}$ and $365 \mathrm{psia}$. The observed alkali concentrations were 10 to $20 \mathrm{ppbw}$ for each of both sodium and potassium using a Pittsburgh \#8 bituminous coal. These concentrations were comparable to alkali concentrations measured from a PFBC 
system at the Argonne National Laboratory ( 30 to $40 \mathrm{ppbw} \mathrm{Na}$ and 10 to $30 \mathrm{ppbw}$ K).

A study by Greene and others (15) used a molecular beam mass spectrometer (MBMS) system mounted on a we11-characterized coal reactor. Results from this study indicate that the sodium is volatilized from the coal particle during the coal devolatilization step and occurs, principally, as the atomic species rather than as the oxide or hydroxide. This sodium is quickly converted to an unknown gaseous species or a condensed phase such as a fume. High initial concentrations have been detected in the vicinity of the coal particle $(<1 \mathrm{~mm})$ with concentrations exceeding 700-ppm maximum and averaging $>100 \mathrm{ppm}$. These concentrations are not representative of the alkali concentration in the final flue gas; however, these data can be used to calculate fluxes of alkali away from the coal particle as a function of time. It should be noted that data indicate that less sodium was volatilized under simulated gasification operating conditions than under simulated PFBC operating conditions. This surprising resuit could be the result of higher particle temperatures being achieved under the simulation of PFBC operating conditions than under the simulated gasification operating conditions. Another possibility was that less of the alkali was volatilized as an atomic species, but was volatilized as a chloride species which was not subject to analysis.

Knudsen cell mass spectroscopy work on low-temperature ashed samples of Illinois \#6 and Wyodak coals was conducted by SRI International (16). In the work with the Wyodak subbituminous coal, $\mathrm{NaCl}$ and $\mathrm{KCl}$ were observed as vapor species above the coal ash, but these species were not detected above the Illinois \#6 coal ash. The chlorine levels in the Wyodak were approximately three times higher than in the Illinois \#6 sample. The previously unobserved species $\mathrm{NaBS}_{2}$ and $\mathrm{KBS}_{2}$ were identified above both the Illinois \#6 and Wyodak coal ash samples. This study indicated that the vapor pressure of atomic species decreased substantially with increasing $\mathrm{O}_{2}$ concentration in the gas, and the other alkali species decreased slightly with increasing $\mathrm{O}_{2}$, except for the hydroxide species which showed an increasing concentration with increasing oxygen. This work also indicated that at the $800^{\circ}$ to $900^{\circ} \mathrm{C}$ operating temperature range for our carbonizer testing, the chlorides would have the highest vapor concentrations under gasification operating conditions. The concentration of the alkali chlorides was either not found or found in concentrations less than that predicted with a thermochemical equilibrium code. Some preliminary thermochemical equilibrium calculations indicate that in-bed desulfurization may enhance alkali vaporization due to the replacement of alkali by alkaline earth elements in stable aluminosilicate phases in the ash.

Thermochemical equilibrium calculations performed on the combustion and gasification of peat indicate that, under reducing conditions, the concentrations of vapor-phase alkali are approximately two orders of magnitude higher than that under the PFBC operating conditions $(17,18)$. The sodium and potassium concentrations in the product gas under PFB gasification conditions ranged from $7.5 \mathrm{ppm}$ at $700^{\circ} \mathrm{C}$ to $76.2 \mathrm{ppm}$ at $900^{\circ} \mathrm{C}$, while the sodium and potassium concentrations in the $P F B C$ flue gas ranged from $0.05 \mathrm{ppm}$ at $800^{\circ} \mathrm{C}$ to $5.9 \mathrm{ppm}$ at $1000^{\circ} \mathrm{C}$. The concentration of the vapor-phase alkali was strongly dependent on the operating temperature and pressure. An increase in operating temperature from $800^{\circ}$ to $900^{\circ} \mathrm{C}$ in the PFBC environment increased the vaporphase alkali metal concentrations approximately one order of magnitude. 
However, an increase in operating temperature in the gasification environment increased the vapor-phase alkali metal concentration approximately $70 \%$. An increase in pressure from 1 to 10 bar was calculated to decrease the conceniration of alkali metals by approximately one order of magnitude in the temperature range from $800^{\circ}$ to $900^{\circ} \mathrm{C}$ under PFBC operating conditions. An increase in operating pressure from 1 to 10 bar was calculated to produce a less than a iwofold decrease in alkali concentration in the same temperature range under gasification operating conditions. A strong dependence on the chlorine content was also calculated, with higher concentrations of vaporphase alkali metals occurring with higher concentrations of chlorine in the fuel. Under PFBC operating conditions, the gas phase was calculated to contain alkali chlorides and to a lesser extent hydroxides with some $\mathrm{Na}_{2} \mathrm{SO}_{4}$ al so present at higher temperatures. All of the volatilized alkali species show a steady but small increase in concentration with an increase in the alkali content of the fuel. The liquid phase consists principally of the alkali sulfates.

Under gasification operating conditions, the volatilized alkali metals consist primarily of chloride and hydroxide compounds, with dichlorides and atomic alkali compounds also being present at lower concentrations than the monochlorides. The hydroxide concentration in the gasification product gas shows a steady or slightly increasing concentration with increasing alkali levels in the fuel, while the chloride concentration shows a decrease with increasing alkali level. The liquid phase consists of chlorides and carbonates, with the chloride concentration being one order of magnitude higher than the carbonates.

These thermochemical equilibrium data were compared to experimental data collected from a pressurized fluid-bed unit which can be run in both the combustion and gasification mode. At a bed temperature of $840^{\circ} \mathrm{C}$ in the PFBC mode, approximately $0.3 \%$ of the potassium and $1.4 \%$ of the sodium were volatilized in the bed, resulting in an alkali concentration of approximately $1.1 \mathrm{ppmw}$. This concentration is significantly higher than the thermochemical equilibrium calculations would indicate.

At a bed temperature of approximately $830^{\circ} \mathrm{C}$ and a freeboard temperature of approximately $860^{\circ} \mathrm{C}$ in gasification modes, the sodium concentration ranged from 2.1 to $4.3 \mathrm{ppmw}$, while the potassium ranged from 0.8 to $1.1 \mathrm{ppmw}$. This corresponds to $2.4 \%$ to $4.6 \%$ of the sodium and $0.7 \%$ to $1.1 \%$ of the potassium being volatilized. The sodium concentrations are slightly less than those calculated, while the potassium concentration is significantly less than that calculated in the thermochemical equilibrium code. While the ash chemistry of peat is probably significantly different than that of coal, the general trends displayed in this study are still expected to be true.

The current data indicate that the concentration of volatilized alkali metal species should be higher for a given coal under the reducing conditions of the carbonizer than the oxidizing conditions of the circulating PFBC system. The presence of approximately $0.08 \mathrm{wt} \%$ chlorine in the Pittsburgh \#8 test coal suggests that alkali chlorides will be present in significant quantities, especially in the carbonizer product gas. 


\subsubsection{Alkali Getters}

Alkali released during PFBC applications and present in the vapor phase in the flue gas has been measured in the range of 0.1 to $10 \mathrm{ppmw}$ (19-21). This is considerably higher than the $0.024 \mathrm{ppmw}$ recommended by turbine manufacturers, even though it represents only about $1 \%$ to $2 \%$ of the total alkali in the coal. Therefore, some form of alkali removal is required.

A number of researchers and developers have been working with various alkali getters to remove alkali from the hot-gas stream. Since contacting the alkali with the getter is critical, varicus packed-bed and granular-bed filters have been used. Westinghouse $(22,23)$, Argonne National Laboratory $(19,24,25)$, and the Coal Research Establishment (26) have all looked at alkali getters in a packed bed, while the work done at Combustion Power Company (CPC) $(27,28)$ and New York University (NYU) $(20,29)$ utilized a granular-bed filter (GBF) design. The University of Arizona considered using the getter in situ with the combustion or gasification process $(21,30)$. At least 13 different potential alkali getters have been tested by these various institutions. The three most successful getters tested have been bauxite, kaolinite, and emathlite. Alkali is captured by bauxite primarily by physical adsorption. Some chemical fixation by the clay impurities also occurs. Bauxite has been tested as an alkali getter at temperatures ranging from $1350^{\circ}$ to $1850^{\circ} \mathrm{F}$. The apparent activation energy for the bauxite was low, indicating that temperature has only a small impact on its ability to adsorb alkali. In contrast, kaolinite and emathlite remove alkali by chemical reaction of the sodium and potassium with these silicate-based minerals. Kaolinite has a high activation energy, indicating it is sensitive to temperature, with alkali removal increasing with increasing temperature. Emathlite had a small activation energy, indicating its relative insensitivity to temperature.

The maximum temperature limitations will differ for these three getters. The emathlite reacts with the sodium to form albite, a sodium aluminosilicate compound. Albite has a melting temperature of $1832^{\circ} \mathrm{F}$. At temperatures above $1832^{\circ} \mathrm{F}$, a glass will form which could potentially cause sticking and agglomerating problems within the bed. Kaolinite, on the other hand, will form nephelite and/or carnegieite, depending upon the temperature of the bed. The relative melting point of nephelite, which is the favored species at higher temperatures, is $2840^{\circ} \mathrm{F}$. If a granular bed of nephelite proves to be an effective alkali getter and particulate removal device, it would have the distinct advantage of operating at combustor exit temperatures, eliminating the costly steps of cooling, cleaning, and reheating the flue gas. Bauxite will not melt until $3600^{\circ} \mathrm{F}$; however, its adsorption capacity will decrease as the temperature increases.

Preliminary kinetic analysis of alkali capture rates with alumina silicate (such as bauxite) additives indicate that, in the $1500^{\circ}$ to $2000^{\circ} \mathrm{C}$ region, alkali capture rates are 100 times faster than the similar kinetic capture process found with sulfur and calcium oxide (31). Activated bauxite has been found to be twice as effective as diatomaceous earth at removing alkali vapors from gas streams $(5,9)$. Alkali gettering is best achieved by passing the products of combustion (POC) through a packed bed of activated bauxite pellets. Greater than $99.9 \%$ removal of $\mathrm{NaCl}$ vapor has been achieved in a simulated $\mathrm{PFBC}$ flue gas at $800^{\circ} \mathrm{C}, 5 \mathrm{~atm}, 3.4 \%$ water vapor, but with no $\mathrm{SO}_{2}$. The $\mathrm{NaCl}$ was found to have reacted with the bauxite to form water- 
soluble sodium meta-aluminate. In contrast, the $\mathrm{NaCl}$ vapor in the same simulated PFBC flue gas with $\mathrm{SO}_{2}$ was captured as a condensed-phase sodium sulfate. The sodium sulfate could either be formed as aerosols in the gas phase and captured by the bauxite bed, or the sodium sulfate could be formed over the surface of the bauxite through a heterogeneously catalyzed reaction (9). Due to the high predicted capture rates, the direct injection of alumina silicate additives into the combustor should also be very effective (31); however, the alkali-saturated sorbent tends to be sticky. This stickiness probably will present problems for hot-gas cleanup devices such as ceramic cross-flow filters and cyclones; however, further research is needed to determine the significance of this problem.

Pilot-scale tests have been performed by ANL on their pilot-scale PFBC using bauxite as an alkali getter $(19,24,25)$. Tests were performed at $1560^{\circ}$ and $1610^{\circ} \mathrm{F}$ using a lignite from Beulah, North Dakota. Flue gas concentrations of 1.4- to 1.5-ppmw sodium and 0.1-ppmw potassium were measured at the inlet to the filter device. Using a packed bed of bauxite with a particle size ranging from 2 to $2.4 \mathrm{~mm}$ effected greater than $99 \%$ removal of the alkali. The outlet alkali measurements were less than 10 ppbw. Adsorption data were collected that can be used for preliminary design scaleup.

The CPC GBF was tested at NYU using Beulah 1ignite with $8.0 \%$ ash and $0.62 \%$ sodium (as $\mathrm{Na}_{2} \mathrm{O}$ ) in the coal as the fuel $(20,29)$. The PFBC pilot plant was operated at temperatures ranging from $1490^{\circ}$ to $1600^{\circ} \mathrm{F}$ and 6.9 to 9.2 atmospheres. Both 2- and 3-mm mullite particles were tested. The average alkali content in the flue gas entering the GBF was measured to be $1.25 \%$ of the sodium and $1.12 \%$ of the potassium in the coal. The measured alkaligettering efficiency for all of the tests was between $90 \%$ and $96 \%$, with a possible error of $5 \%$. The outlet alkali concentration ranged from 3 to $20 \mathrm{ppbw}$, which is below the $24-\mathrm{ppmw}$ recommended turbine tolerance limit. In this work, no attempt was made to determine the mechanism of capture, i.e., whether the alkali reduction was due to condensation on the filter media, capture of fine alkali sulfate dust and aerosol particles, physical adsorption, or chemical absorption and reaction. Therefore, although it was proven that the concept will simultaneously capture particulate and alkali, no scaleup data were obtained.

A more practical study was performed by Westinghouse, focusing on emathlite as the getter material (22). Results from the testing indicated that the concept of using a fixed bed of emathlite pellets is a practical technique for alkali removal from hot flue gases. Process development tests included a 102-hour test where gas containing 10-ppmv $\mathrm{NaCl}$ was reduced to less than 0.2 ppmv (detection limits). In other studies, alkali removal of greater than $99 \%$ was demonstrated, with a reduction of sodium to below the $20-p p b$ turbine tolerance level. A commercialized process has been identified for manufacture of the emathlite pellets. In that testing, the kinetics were found to be insensitive to temperature over the range of $1426^{\circ}$ to $1651^{\circ} \mathrm{F}$. The absorption rate was proportional to the alkali gas-phase concentration, with no capacity limitations due to absorption limitation at low gas-phase alkali concentrations. The Westinghouse research was based on a packed-bed design, and it was felt that it would be necessary to install a particulate cleanup device ahead of the sorbent bed. Westinghouse had envisioned a long time between replacement of the bed material (one-half to one year) and had concerns about bed pluggage due to the fly ash. The use of a GBF would 
preclude this from happening. An important finding from the Westinghouse work was that no attrition of the emathlite pellets was noted during any of the testing. Recommendations were to use $6-\mathrm{mm}$ pellets for the packed bed.

All of these studies have been performed using combustion gases. In a combustion atmosphere, most of the alkali material is vaporized during combustion and will be present as a sulfate. At the typical filter temperatures $\left(1450^{\circ}\right.$ to $\left.1650^{\circ} \mathrm{F}\right)$, a majority of the sulfates will have condensed on the surface of other ash particles, or as fine particles and aerosols (26, $32,33)$. The removal of the alkali in this form is difficult because of the need to capture the fine sulfate particles and either remove them as sulfates or provide the contact necessary to react the sulfates with the getter material. The good performance results by ANL, NYU, and Westinghouse indicated this is possible.

Less testing has been done for gasification systems. Thermodynamic calculations for a reducing atmosphere indicate that the alkali will be present as hydroxide vapors or chloride vapors for high-chlorine coals.

The effect of chlorine on the performance of alkali getters has been reported by Singh and others (34) under both PFBC and gasification conditions. Under both sets of operating conditions, the presence of $\mathrm{HCl}$ in the flue gas is expected to decrease the getter efficiency, although gasification operating conditions seem to be more significantly affected. Increasing pressure and decreasing temperature also seem to improve the getter efficiency. Potential getter reactions for alkali chloride compounds all form $\mathrm{HCl}$ in the product gas; therefore, if there is a high $\mathrm{HCl}$ concentration in the product gas, it limits the gettering reaction due to the thermochemical equilibrium. Methods for the removal of $\mathrm{HCl}$ were studied (35), but they used a $\mathrm{Na}_{2} \mathrm{CO}_{3}$-based mineral at lower operating temperatures $\left(535^{\circ}-650^{\circ} \mathrm{C}\right)$.

Work from previous researchers has demonstrated that alkali getters can be effective in removing alkali from both combustion and gasification gas streams. Both packed-bed and granular-bed filters have been utilized. Drawbacks include the need for a particulate removal device both before and after a packed bed and the expense of the added pressure vessels to contain the packed or granular bed. The granular bed may be cost-effective if both particulate and alkali control can be achieved. However, because of the disadvantages associated with packed and granular beds, in situ removal of alkali may be preferred. A getter, used in the same manner as a sorbent is used to remove sulfur, would not add any significant cost to the system, would be easy to maintain, and could be used in both oxidizing and reducing atmospheres. During the next program year, the EERC will continue to pursue the use of in situ alkali getters for second-generation systems.

\subsection{Bench-Scale Reactor Testing}

\subsubsection{Bench-Scale Reactor Design}

As discussed during the project review meeting at METC in August 1990 , the EERC had planned to make use of an existing bench-scale reactor as a pressurized fluid-bed reactor (PFBR). As design efforts proceeded, the number of limitations imposed on the PFBR design by using the existing equipment kept increasing. These limitations included reactor height and diameter, coal and 
sorbent feed options, air preheat capabilities, and the amount of heat duty the reactor could handle. Therefore, it was decided that a stand-alone reactor should be designed to ensure that the reactor could meet all of the objectives of this project.

The pressurized fluidized-bed reactor has been designed and is being constructed to allow extensive alkali and hot-gas cleanup testing on a costeffective manner over a wide range of operational conditions. Preheated fluidizing gas at temperatures up to $1000^{\circ} \mathrm{F}$ and pressures up to $150 \mathrm{psig}$ will be supplied at the bottom of the reactor through a 1 -in Schedule 40 pipe at sufficiently high velocities to prevent the sized bed material from dropping out during operation. Bed material can be sampled or collected using a lock hopper system located at the bottom of the reactor. The fluidizing gas enters into the 3-in Schedule 80 main section of the reactor through a conical transition. The operating velocities in the 3 -in section will allow some internal recirculation of the fluidized-bed material. External heaters will be used for heating and maintaining the reactor and hot cyclone at temperatures up to $2000^{\circ} \mathrm{F}$ for atmospheric operation and up to $1700^{\circ} \mathrm{F}$ for operation at 150 psig.

Limestone, inert bed material, or ash generated from a combustor or by an ashing procedure can be added at the start of a test using a lock hopper system. Selected additives and coal can be fed separately at controlled rates during testing. Coal feed, when utilized, will be maintained at a low rate to el iminate any heat removal requirements from the reactor. Fluidizing gas can be supplied as air or as various mixtures of nitrogen, oxygen, carbon dioxide, carbon monoxide, sulfur dioxide, and nitrogen oxides to result in a flue gas similar to that generated in a full-scale fluidized-bed boiler. Different oxidizing and reducing condition tests can also be conducted. An alkali sampling probe can be inserted through the top of the reactor or through the top of the hot cyclone for when hot-gas cleanup testing is being conducted.

A data acquisition/control system will be used to monitor and record all critical pressures, temperatures, and flows and to remotely control the numerous valves distributed throughout the system. All high-pressure feed and collection hoppers will be monitored with pressure transmitters. A solidssampling port and a gas-sampling port will be at the top of the combustor.

\subsubsection{Sulfur Retention Efficiency}

The sulfur retention efficiency in the combustor is influenced by many factors, including gas and solids residence times in the bed and freeboard, bed temperature, reactivity of the sorbent, particle size, and oxygen concentration at the bottom of the bed. Within the range of operating conditions of PFBC, the sulfur retention increases with increased bed temperature, $\mathrm{Ca} / \mathrm{S}$ molar ratio, and gas residence times.

In a PFBC, limestone is less effective than dolomite in removing $\mathrm{SO}_{2}$ on the basis of $\mathrm{Ca} / \mathrm{S}$ molar ratio. A probable explanation is that a prerequisite of good sulfur retention efficiency is the development of porosity in the sorbent particles. With limestones, porosity is developed due to calcination which occurs readily at atmospheric pressure, but with greater difficulty in a pressurized system because the partial pressure of $\mathrm{CO}_{2}$ corresponding to high pressure in the bed is higher than the equilibrium partial pressure of $\mathrm{CO}_{2}$ for 
$\mathrm{CaCO}_{3}$. As a result of the difficulty in achieving calcination of 1 imestone at high pressure, the effectiveness of 1 imestones is reduced. Dolomite is about twice as effective as 1 imestone, and $90 \%$ sulfur retention efficiency can be expected with dolomite with a $\mathrm{Ca} / \mathrm{S}$ molar ratio of 1.5 under typical $\mathrm{PFBC}$ operating conditions.

The sulfur retention efficiency can be improved for bubbling-bed PFBCs at the expense of process efficiency by a) employing low fluidizing velocity which requires a smaller bed particle size, b) using deep beds and hence longer residence time, and c) recycling fines captured by the primary cyclones. It can also be improved by as much as $30 \%$ by using two-stage combustion.

Although dolomite does provide a porous sorbent for PFBC operation, it is still very probable that limestone would be a preferable sorbent selection for use in any PFBC system, based upon results obtained at Grimethorpe (36). Because limestone has a higher $\mathrm{CaCO}_{3}$ content and because the $\mathrm{Mg}$ component of dolomite does not react with $\mathrm{SO}_{2}$, limestone can be as efficient as dolomite in a PFBC system when a sorbent/sulfur mass ratio basis is utilized. It is the mass ratio that will ultimately determine the sorbent requirements and output solids disposal in practical and economic terms.

Based on tests carried out in a small combustor, correlations have been proposed for sulfur capture and can be used with reasonable accuracy to estimate the performance of a sorbent in a large combustor. One such correlation, proposed by the International Energy Agency (IEA) group (36), is:

$$
R=100(1-\exp (-M C))
$$

where $R$ is the sulfur-removal efficiency; $C$ is the molar ratio of calcium in the sorbent to sulfur in the fuel fed; and $M$ is a parameter dependent on sorbent properties and operating conditions, principally bed height, fluidizing velocity, and bed temperature. The parameter $M$ is given by the following correlation:

$$
M=A t^{1 / 2} \exp (4600 / T)
$$

where $t(=H / V)$ is gas residence time, $H$ is the bed height, $V$ is the fluidizing velocity, $T$ is the bed temperature, and $A$ is a reactivity index ( $A$ $=38$ and 50 for Whitewall and Plum Run dolomites, respectively).

However, for a reliable estimate of the sulfur retention by either dolomite or limestone added to the bed, one still must rely heavily upon experimental work carried out under operating conditions closely approximating those that will apply in a commercial plant. It is also expected that operation in a circulating mode will greatly enhance sorbent utilization, and that any predictive equations proposed should be modified to account for the operating characteristics of the circulating bed. 


\subsection{REFERENCES}

1. "An Investigation of Hot Corrosion and Erosion Occurring in a FluidizedBed Combustor-Gas Turbine Cycle Using Coal as Fue1," report to ERDA; FE/1536-2, May 1977.

2. Benson, S.A.; Abrahamsom, H.A.; Zygarlicke, C.J.; Mills, M.E. "Combustion Inorganic Transformations," final technical report, Apr. 1988 - Jun. 1989, Contract DE-FC21-86MC10637, EERC publication, 1989.

3. 01denberg, R.C. "Optical Detection of Corrosive Compounds," In Proceedings of the Advanced Research and Technology Development Direct Utilization, Instrumentation, and Diagnostics Contractors' Review Meeting; DOE/METC-89/6108 (DE90000424), 0ct. 1989; Vol 1., pp 87-99.

4. Helbe, J.J.; Srinivasachar, S.; Boni, A.A.; Charon, 0.; Modestino, A. "Measurement and Modeling of Vapor-Phase Sodium Chloride Formed During Pulverized Coal Combustion," CST90-05-23, 1990, in press.

5. Lee, S.H.D.; Carls, E.L. "Measurement of Alkali Metal Vapors and Their Removal from a Pressurized Fluidized-Bed Combustor Process Stream," Annual Report ANL/FE-89-1, Oct. 1987 - Sept. 1988, 57 p.

6. Lee, S.H.D.; Carls, E.L. "Measurement of Alkali Metal Vapors and Their Removal from a Pressurized Fluidized-Bed Combustor Process Stream," Annual Report ANL/FE-88-4, Oct. 1986 - Sept. 1987, 37 p.

7. Lee, S.H.D.; Myles, K.M. "Alkali Metal Vapor Removal from a Pressurized Fluidized-Bed Combustor Process Stream," Annual Report ANL/FE-88-3, 0ct. 1985 - Sept. 1986, 44 p.

8. Lee, S.H.D.; Henry, R.F.; Smith, S.D.; Wilson, W.I.; Myles, K.M. "Alkali Metal Vapor Removal from a Pressurized Fluidized-Bed Combustor Flue Gas," Annual Report ANL/FE-86-7, 0ct. 1984 - Sept. 1985, $39 \mathrm{p}$.

9. Johnson, I.; Lee, S.H.D. "Alkali Metal Vapor Removal from a Pressurized Fluidized-Bed Combustor Flue Gas," Annual Report ANL/FE-81-59, Oct. 1980 - Sept. 1981, 29 p.

10. Eriksson, G. "Thermodynamic Studies of High-Temperature Equilibria," Chemica Scripta 1974, 8, 193.

11. Ramanathan, M.; Ness, S.; Kalmanovitch, D. "New Techniques for Thermochemical Phase Equilibrium Predictions in Coal Ash Systems - I," 197th Annual Meeting of ACS, Dallas, TX, Apr. 1989.

12. Ramanathan, M.; Kalmanovitch, D.; Ness, S. "New Techniques for Thermochemical Phase Equilibrium Predictions in Coal Ash Systems - II," Sixth International Conference on High Temperatures - Chemistry of Inorganic Materials, Gaithersburg, MD, Apr. 1989. 
13. Boley, C.C.; Fegley, M.M. "Design and Operation of Two RefractoryLined, Internally Heated, Entrained-Bed Carbonizers," GFERC/RI-77/1, $1977,38 \mathrm{p}$.

14. Haas, W.J., Jr.; Markuszewski, R.; Eckels, D.E.; Lee, S.H.D.; Carls, E.L.; Leininger, T.F.; Robin, A.M. "Fiber Optic Alkali Meter Sampling;" In Proceedings of the Seventh Annual Heat Engine Contractors' Review Meeting; DOE/METC-90/6110 (DE90000480), Mar. 1990, pp 391-402.

15. Greene, F.T.; Robaugh, D.; O'Donnell, J.E. "Provide Alkali Species Profiles Using a Well-Characterized Coal Reactor, "final report; DOE/MC/21091-2727 (DE89011691), Oct. 1988, p 83.

16. SRI Internationa1. "Vaporization of Trace Element Species from Coal under Gasification and Combustion Conditions; "final report; DOE/MC/2361-2723 (DE89011687), Mar. 1989.

17. Mojtahedi, W.; Backman, R. "The Fate of Sodium and Potassium in the Pressurized Fluidized-Bed Combustion and Gasification of Peat," $J$. Institute of Energy 1989, 62 (453), 189-196.

18. Mojtahedi, W.; Kurkela, E.; Nieminen, M. "Release of Sodium and Potassium in the PFB Gasification of Peat," J. Institute of Energy 1990, 63 (456), 95-100.

19. Lee, S.H.D.; Swift, W.M. "A Fixed Granular-Bed Sorber for Measurement and Control of Alkali Vapors in PFBC; "In Proceedings of the 1991 International Conference on Fluidized-Bed Combustion; Montreal, Canada, April 21-24, 1991; Vol. 1.

20. Zakkay, V.; Gbordzoe, E.A.M.; Radhakrishnan, R.; Sellakumar, K.M.; Patel, J.; Kasinathan, R.; Haas, W.J., Jr.; Eckels, D.E. "Particulate and Alkali Capture from PFBC Flue Gas Utilizing Granular-Bed Filter (GBF)," Combust. Sci. and Tech. 1989, 68, 113-130.

21. Punjak, W.A.; Uberoi, M.; Shadman, F. "High-Temperature Adsorption of Alkali Vapors on Solid Sorbents," AIChE J. 1989, 35 (7).

22. Bachovchin, D.M.; Alvin, M.A.; Dezubay, E.A.; Mulik, P.R. "A Study of High-Temperature Removal of Alkal $j$ in a Pressurized Gasification System," final report; DOE/MC/20050--2226, 0ct. 1986.

23. Bachovchin, D.M.; Alvin, M.A. "A Study of High-Temperature Removal of Alkali in a Pressurized Gasification System," In Proceedings of the Gas Stream Cleanup Papers from DOE/METC-Sponsored Contractors' Review Meetings in 1987; DOE/METC-87/6082, Oct. 1987.

24. Lee, S.H.D.; Johnson, I. "Removal of Gaseous Alkali Metal Compounds from Hot Fiue Gas by Particulate Sorbents," J. of Engineering for Power $1980,102$. 
25. Lee, S.H.D.; Myles, K.M. "Alkali Measurement in PFBC and its Control by a Granular Bed of Activated Bauxite," In Proceedings of the 1987 International Conference on Fluidized-Bed Combustion; Boston, MA, May 3-7, 1987; Vol. 2.

26. Scandrett, B.; Clift, R. "The Thermodynamics of Alkali Removal from Coal-Derived Gases," Journal of the Institute of Energy 1984, 391-397.

27. Goldback, G.; Haas, J. Combustion Power Company, Inc. Personal communication, June 17, 1991.

28. Wilson, K.B. "Granular-Bed Filter Evaluation in a Pressurized Fluid-Bed System," In Proceedings of the Fifth Annual Contractors' Meeting on Contaminant Control in Coal-Derived Gas Streams; Morgantown, WV, DOE/METC-85/6025, May 1985.

29. Radhakrishnan, P.; Zakkay, V.; Agnone, A. "Alkali and Gas Emissions from PFB Combustion of Lignite," Combust. Sci. and Tech. 1986, 50, 271-281.

30. Uberoi, M.; Punjak, W.A.; Shadman, F. "The Kinetics and Mechanism of Alkal i Removal from Flue Gases by Solid Sorbents," Prog. Energy Combust. Sci. 1990, 16, 205-211.

31. Zauderer, B.; Marsten, C.H.; Fleming, E.; Myles, K.M.; Johnson, T.; Smyk, E.B. "Combustion and Fuel-Bound Contamination Control with a Staged-Cyclone Coal Combustor for Gas Turbines," In Proceedings of the Second Annual Heat Engines Contractors' Meeting; May 1985, pp 110-123.

32. Spacil, H.S.; Luthra, K.L. "Volatilization/Condensation of Alkali Salts in a Pressurized Fluidized-Bed Coal Combustor/Gas Turbine Combined Cycle," J. Electrochemical Soc.: Solid-State Science and Technology $1982,129(9), 2119-2126$.

33. Mojtahedi, W.; Backman, R. "Release of Alkali Metals in Pressurized Fluidized-Bed Combustion and Gasification of Peat," Technical Research Center of Finland, Publication 53, 1989.

34. Singh, A.; Clift, R.; Reed, G.P.; Schofield, P.; Bower, C.J. "Thermodynamic Calculations of the Effects of Chlorine on Alkali Removal from Hot Coal-Derived Gases," In Proceedings of the International Chemical Engineering Symposium on Gas Cleaning at High Temperatures; 1986, pp 167-176.

35. Krishnan, G.N.; Wood, B.J.; Korens, N.; Anderson, G.L. "HighTemperature Coal Gas Chloride Cleanup for Molten Carbonate Fuel Cell Applications," In Proceedings of Sixth Annual Contractors' Review Meeting on Contaminant Control in Coal-Derived Gas Streams; DOE/METC86/6042 (DE86001088), Ju1. 1986, pp 48-57.

36. Proceedings of the International Energy Agency Grimethorpe Technology Transfer Workshop; St. Louis, MO, JuTy 15-18, 1984, DOE/METC, Morgantown, WV, 1984. 
APPENDIX A:

UND ENERGY AND ENVIRONMENTAL RESEARCH CENTER

100-LB/HR MILD GASIFICATION PROCESS DEVELOPMENT UNIT (MGPDU) DESCRIPTION 
Task 4, which includes the 100-1b/hr MGPDU, was initiated in November 1988. This task includes 1) the design, construction, and operation of the PDU; 2) product analysis and upgrading studies, some of which will be performed under subcontracts; and 3) a technical and economic evaluation leading to a decision on further scaleup to a l-ton/hr pilot plant and a subsequent demonstration plant. The MGPDU will serve two principal purposes in the development of this technology: 1) provide proof of concept for an integrated design operating on specific design coals, and 2) produce char and liquid products for upgrade testing and market evaluation.

\section{PROCESSING CAPABILITIES}

The MGPDU has been designed to process $100 \mathrm{lb} / \mathrm{hr}$ of feed coal (dry basis). The system incorporates capabilities for drying, carbonizing, and calcining caking and noncaking coals in fluid-bed reactors and for separating char, liquid, and gaseous products. The system is designed for integrated operation, and provisions have been made so carbonizing can take place without having to utilize the calciner.

Heat for carbonization and for the calciner are principally supplied by hot flue gas from stoichiometric combustion of natural gas, or, in a later commercial design, by combustion of process-derived gas and waste coal from coal cleaning in a fluid-bed combuster. Combustion is external to the gasification reactors and is air-blown to avoid the cost of an oxygen plant in the commercial design. Provisions for steam injection have been made vecause of the sulfur removal effects of the steam and the increase in liquid quality, as seen under Task 2. High-temperature steam can also be employed in the calciner for the production of activated carbon, or to increase the $\mathrm{H}_{2}$ and $\mathrm{CO}$ content of the gas passed from the calciner to the carbonizer during integrated operation.

\section{FLOW SHEET AND PROCESS DESCRIPTION}

The flow sheet shown in Figure $A l$ is subdivided into eight sections which have been lised as the basis for organizing the detailed design. The subsequent section on nomenclature contains the letter codes, area codes, and individual unit names. Table 1 indicates the general area designations.

\section{Area 100 - Coal Preparation}

Illinois No. 6 and Indiana No. 3 feed coals may be washed at the mine and are crushed and screened at the EERC to a typical size of $1 / 4$ inch by 0 . The Wyoming feed coal is screened to a similar size, but is not washed. The option of drying the feed coal before it is fed to the carbonizer is a test variable. The main purpose for drying is to limit the moisture entering the gasification train in tests at low-steam input to the carbonizer so as to reduce or eliminate the net production of wastewater condensate. Moisture reduction is performed in a nonintegrated mode using a roto louver dryer available at the EERC. If lower moisture contents are desired, the coal can be further dried at low temperature $\left(<570^{\circ} \mathrm{F} / 300^{\circ} \mathrm{C}\right)$ in the carbonizer. 


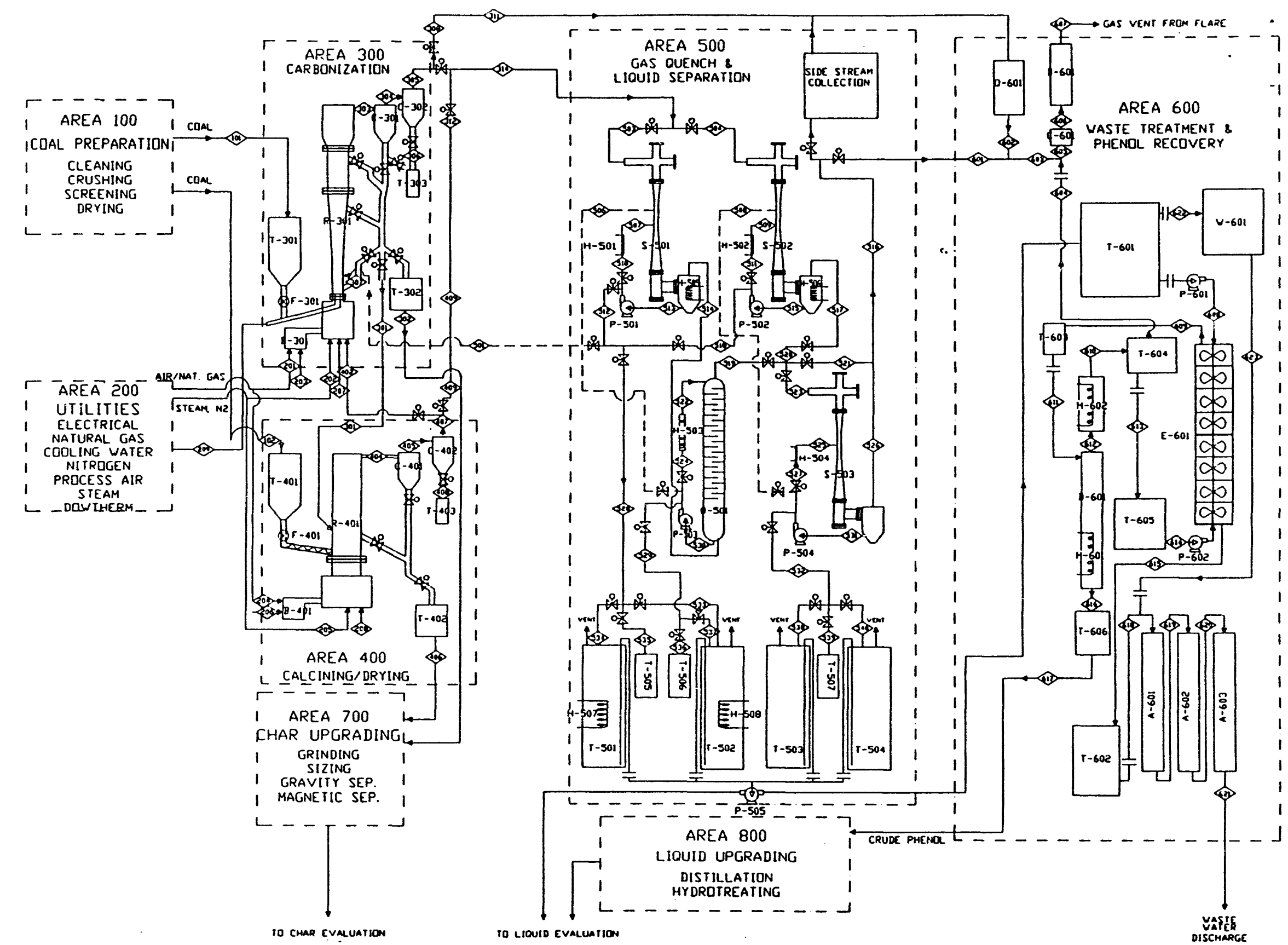

Figure A1. Flow sheet for EERC $100-1 \mathrm{~b} / \mathrm{hr}$ process development unit. 
TABLE Al

Area Descriptions

\begin{tabular}{ll}
\hline Area & Name \\
100 & Coal Preparation \\
200 & Utilities \\
300 & Carbonization \\
400 & Calcining \\
500 & Gas Quench \& Liquid Separation \\
600 & Waste Treatment \& Phenol Recovery \\
700 & Char Upgrading \\
800 & Liquid Upgrading \\
\hline
\end{tabular}

\section{Area 200 - Utilities}

Utilities that are necessary include 1) electrical services, 2) natural gas, 3) cooling water, 4) nitrogen, 5) process air, 6) steam boiler and superheater, and 7) a high-temperature heating/cooling system. In addition, a contingency design has been developed for refrigerated cooling for a light-oil condenser, if needed. All utilities were in existence except the steam boiler and superheater, the high-temperature heating/cooling system, and the refrigerated cooler contingency. The heating/cooling system is capable of operating at elevated temperatures in order to cool the tar that is recirculated to the tar venturi scrubber. This system is necessary in order to avoid low metal temperatures that would cause "freezing" of tar on the heat-transfer surface. In the other scrubber heat exchangers, cooling water is used.

\section{Area 300 - Carbonization}

The carbonizer is designed as a spouted-bed gasifier, based on favorable results with caking coals in the COALCON and KRW gasifier systems. The operative principle allowing use of caking coal in this design is the dilution of the entering coal by an internal recycle of char to the bottom of the tapered bed, where high velocity and low bed density also reduce agglomeration. A similar regime existed in the $400-1 \mathrm{~b} / \mathrm{hr}$ fast fluid-bed Perry carbonizer previously used on caking coals at the EERC. In the event that agglomeration problems are encountered in the MGPDU operating on Indiana No. 3 feed coal, product char from the char receiver will be fed into the bottom of the gasifier to augment internal char dilution. Still another means for controlling agglomeration that may be applicable to this design involves the use of a coarse sand bed in the high-velocity section, as employed by CSIRO in Australia. Successful use of this technique would require segregation of the coarse sand in the high-velocity section to avoid contamination of the char withdrawn from the top of the bed in a low-velocity region. Char residence time can be varied by bed height, with the base design being 30 minutes.

The carbonizer operates at temperatures from $900^{\circ}$ to $1110^{\circ} \mathrm{F}\left(480^{\circ}\right.$ to $\left.600^{\circ} \mathrm{C}\right)$ with steam partial pressures from $10 \%$ to $60 \%$. During integrated operation, the carbonizer receives hot gas from the calciner; depending on the atmosphere and resulting gasification reaction in the calciner, this gas can 
be made to contain significant levels of $\mathrm{H}_{2}$ and $\mathrm{CO}$ reductant to assist in sulfur removal. The coal is entrained and fed into the bottom of the reactor using preheated nitrogen $\left(575^{\circ} \mathrm{F} / 300^{\circ} \mathrm{C}\right)$. Char can be drawn from a variety of locations and injected into the calciner or the tote bin, or reinjected into the system.

\section{Area 400 - Calcining}

The calcining reactor is a modification of the bubbling fluid-bed reactor presently used in the EERC hydrogen production project. The conditions for calcining involve the lowest gas velocity that can maintain stable operation in a deep char bed, so that the required char residence time at calcining temperature can be achieved with minimum gas flow and energy input. Calcining takes place at temperatures up to $1475^{\circ} \mathrm{F}\left(800^{\circ} \mathrm{C}\right)$. This unit also evaluates the potential for activated carbon production by using a combination of steam and flue gas. During integrated operation, hot gas leaving the calciner is directed to the carbonizer.

\section{Area 500 - Gas Quench and Liquid Separation}

The quench and separation area can receive gas from either the carbonizer or the calciner. The objective in the design of this area is to produce separate tar and oil fractions that meet primary product requirements. In addition, the quench system should provide trouble-free operation without tendency to plug and, ideally, should produce no wastewater condensate. The approach for this study is to provide both direct-contact tar and oil scrubbers (V-501 and Q-501) and direct-contact water scrubbers (V-502 and $V-503)$. Three of the units are venturi scrubbers with liquid introduced on a flooded disk above the throat of the venturi or through a nozzle perpendicular to gas flow at the opening in the throat. This design allows flexibility both for cooling and particulate removal and for controlling plugging caused by particulates in the tar recycle stream.

A sidestream sampling unit is used to gather a fraction of the gas to determine removal efficiency of the quench units. Bench-scale testing is also possible to evaluate other potential condensable removal methods, such as using Rectisol.

Gas 1 iquor from the scrubbers is pumped to 55-galion drums for transfer to other tanks.

\section{Area 600 - Waste Treatment and Phenol Recovery}

Operation with appreciable steam in the carbonizing gas or on highmoisture coal without drying will inevitably produce wastewater condensate that must be treated prior to discharge. The wastewater cleanup methods that are available at the EERC include solvent extraction and distillation to remove phenols and trace organics, granular activated carbon for polishing before discharging, and alternatively activated sludge treatment of the raw waste stream. These processes will not be integrated in the operation of the MGPDU. The extraction step will be used only for study of phenol recovery. A high-temperature flare is used to discharge all product and vent gases. 


\section{Area 700 - Char Upgrading}

Requirements in this area have not been finally established. Upgrading operations that may be performed include grinding, screening, gravity separation, and magnetic separation. Char products to be evaluated include form coke, carbon pellets, char-iron ore pellets, and activated carbon. These operations will be subcontracted.

\section{Area 800 - Liquid Upgrading}

On-site liquid upgrading at the EERC will be limited to distilling and hydrotreating the condensables utilizing existing equipment. Small lots of 5 to 10 gallons of oil and light oil will be stabilized by removing olefins and other gum-forming compounds. The stabilized liquid(s) will then be sent to a subcontractor for evaluation as a blending stock for No. 3 diesel fuel. Evaluation of the oil, light oil, and crude phenol streams for production of chemicals (e.g., phenol and benzene) will be performed by subcontractors offsite. No pretreatment or stabilization is planned for the liquids in this instance. These products will be upgraded only in the quantities needed for end-user testing.

\section{NOMENCLATURE}

\section{MGPDU Unit Names}

\section{Letter Codes}

T - Storage Tank or Hopper

C - Cyclone, Knockouts, etc.

$\mathrm{H}$ - Heat Exchanger (heating or cooling)

$R$ - Reactor

A - Sieve Column

B - Fired Apparatus - Boiler, Flue Gas Generator

$P$ - Pumps

Q - Quench Towers

D - Distillation

E - Liquid/Liquid Extraction

$F$ - Feeders

$S$ - Venturi Scrubbers

$V$ - Valve

W-Activated Sludge

\section{Area Codes}

$100-$ Coal

200 - Utilities

300 - Carbonization

400 - Calcining/Drying

500 - Gas Quench and Liquid Separation

600 - Waste Treatment and Phenol Recovery

700 - Char Upgrading

800 - Liquid Upgrading 


\section{EERC/AMAX MGPDU Equipment List}

ID No. Name

$\begin{array}{ll}\text { B-201 } & \text { Steam Boiler } \\ \text { B-202 } & \text { Steam Superheater } \\ \text { A-201 } & \text { Boiler Feedwater Treatment } \\ T-201 & \text { Sparge Tank } \\ H-201 & \text { Dowtherm System } \\ \text { R-301 } & \text { Carbonizer } \\ \text { T-301 } & \text { Carbonizer Feed Hopper } \\ \text { F-301 } & \text { Carbonizer Feeder } \\ \text { B-301 } & \text { Carbonizer Flue Gas Generator } \\ \text { C-301 } & \text { Primary Carbonizer Cyclone } \\ \text { T-302 } & \text { HV Char Storage Bin } \\ \text { C-302 } & \text { Secondary Carbonizer Cyclone } \\ \text { T-303 } & \text { Char Fines Collection Bin \#1 }\end{array}$

R-401 Calciner

T-401 Calciner Feed Hopper

F-401 Calciner Feeder

B-401 Calciner Flue Gas Generator

C-401 Calciner Cyclone

T-402 LV Char Storage Bin

C-402 Secondary Carbonizer Cyclone

T-403 Char Fines Collection Bin \#2

\begin{tabular}{|c|c|}
\hline $\begin{array}{l}S-501 \\
H-501 \\
P-501 \\
H-505 \\
S-502 \\
H-502 \\
P-502 \\
H-506 \\
Q-501 \\
H-503 \\
P-503 \\
S-503 \\
H-504 \\
P-504 \\
H-507 \\
H-508 \\
T-501 \\
T-502 \\
T-503 \\
T-504 \\
T-505 \\
T-506 \\
T-507 \\
P-505\end{array}$ & 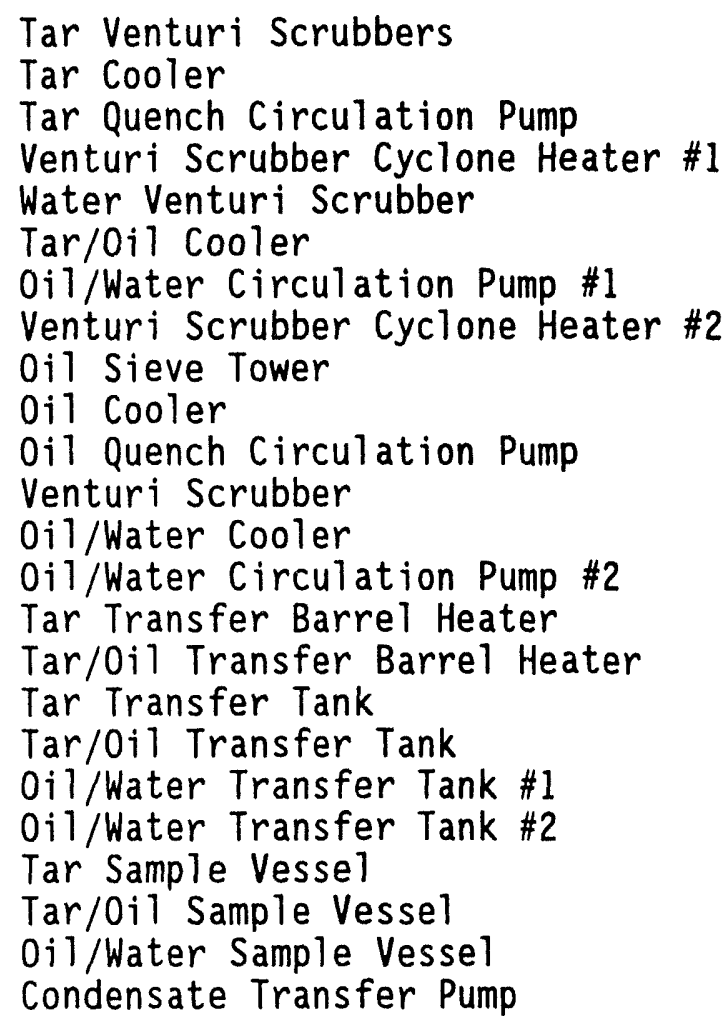 \\
\hline
\end{tabular}


ID No. Name

Q-601 Emergency Tar Quench Vesse1

B-601 Flare

C-601 Flare Knockout Poi

T-601 Wastewater Storage Tank

P-601 Wastewater Pump

E-601 Extraction Column

T-603 Spent Solvent Storage Tank

$\mathrm{H}-602$ Solvent Condenser

D-601 Solvent Recovery Column

H-601 Solvent Recovery Reboiler

T-606 Crude Pheno? Storage Tank

T-604 Clean Solvent Receiver Tank

T-605 Clean Solvent Feed Tank

P-602 Solvent Pump

T-602 Solvent Ext. WW Storage Tank

A-601/3 WW Polishing Adsorber \#1, \#2, \#3

W-601 Activated Siudge Unit 


\section{APPENDIX B:}

UND ENERGY AND ENVIRONMENTAL RESEARCH CENTER 4-LB/HR CONTINUOUS FLUIDIZED-BED REACTOR (CFBR) MILD GASIFICATION UNIT DESCRIPTION 


\section{COAL FEED SYSTEM DESIGN}

Figure $B 1$ shows the coal feed system in relation to the bottom of the reactor. A "star" feeder, which is not shown, was placed directly above the 2 -inch flange shown in the figure. This feeder drops a specific volume of coal at selected intervals into the auger system. A small amount of purge gas is also fed into the auger system. The purge and high-speed auger are used to swiftly move the coal into the reactor before devolatilization can occur. Thus, the coal will be out of the feed system before agglomeration can occur to plug the feed system.

Plugging often occurs in small coal feed systems because a small volume of material moves through a very narrow opening, coal particles stick due to high-moisture content, and backflashing of hot gases from the gasifier causes swelling. Plugging had been experienced on the $30-1 \mathrm{~b} / \mathrm{hr}$ pressurized fluid-bed gasifier (PFBG) used on the Hydrogen Production from Coal Project. The problem was resolved on the PFBG by slightly pressurizing the coal hopper and purging the auger; consequently, these features were added to the design of the 4-1b/hr CFBR. The coal feed system has been calibrated for mass flow rates for several of the feed coals. Since the densities of the coals are slightly different, the star feeder revolution rate will vary with coal rank and crush size in order to maintain a constant mass flow rate. The mass flow rates for the feed system 1 ie between $0.51 \mathrm{~b} / \mathrm{hr}$ and $8.01 \mathrm{~b} / \mathrm{hr}$.

\section{REACTOR}

The reactor was constri:cted of $316 \mathrm{H}$ stainless steel, Schedule 80 pipe. Figure B2 shows an isometric drawing of the unit. Figure B3 shows the machine drawing of the reactor, which includes thermocouple numbers and heights. The first section, which is attached to the coal feed system, is made of 3 -inch pipe and is 33 inches in length. The next section is made of 4-inch pipe, 18.75 inches in length. The two sections are connected with a $316 \mathrm{H}$-weld reducer. The top and bottom flanges (1500 1b) are composed of 316H-grade stainless steel, with Flexicarb stainiess steel gaskets rated to $1650^{\circ} \mathrm{F}$ $\left(900^{\circ} \mathrm{C}\right)$ and $200 \mathrm{psia}$. The unit was designed such that the top of the fluid bed lies 33 inches above the coal injection point. A char off-take leg at the top of the bed is the primary means of solids removal from the reactor. A ball valve facilitates the collection of char product while the system is operating.

The gasifier currently uses two ceramic fiber heaters capable of achieving temperatures of $1800^{\circ} \mathrm{F}\left(980^{\circ} \mathrm{C}\right)$. The bottom heater is rated at 2500 watts and the top at 1775 watts. These heaters wi11 maintain the gasifier temperature and eliminate hot spots. Using external heaters allows the evaluation of internal and external heating methods for process development and scaleup.

\section{CYCLONE}

A 3-inch-diameter cyclone is the secondary means of solids removal from the system. Like the char collection pot on the reactor, a ball valve allows the changing of the solids catch pot while the system is operating. The 


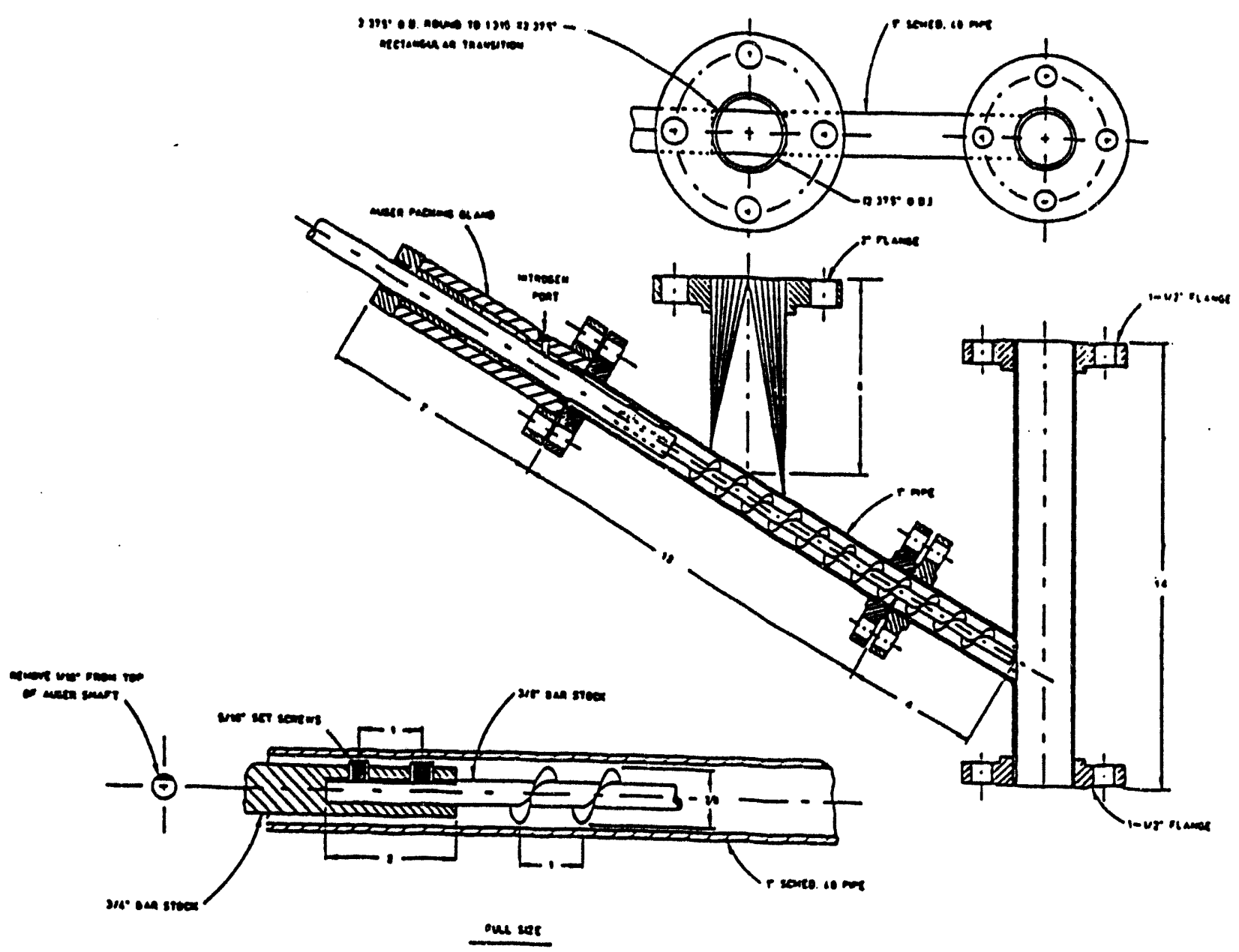

Figure B1. Coal feed system for the CFBR. 


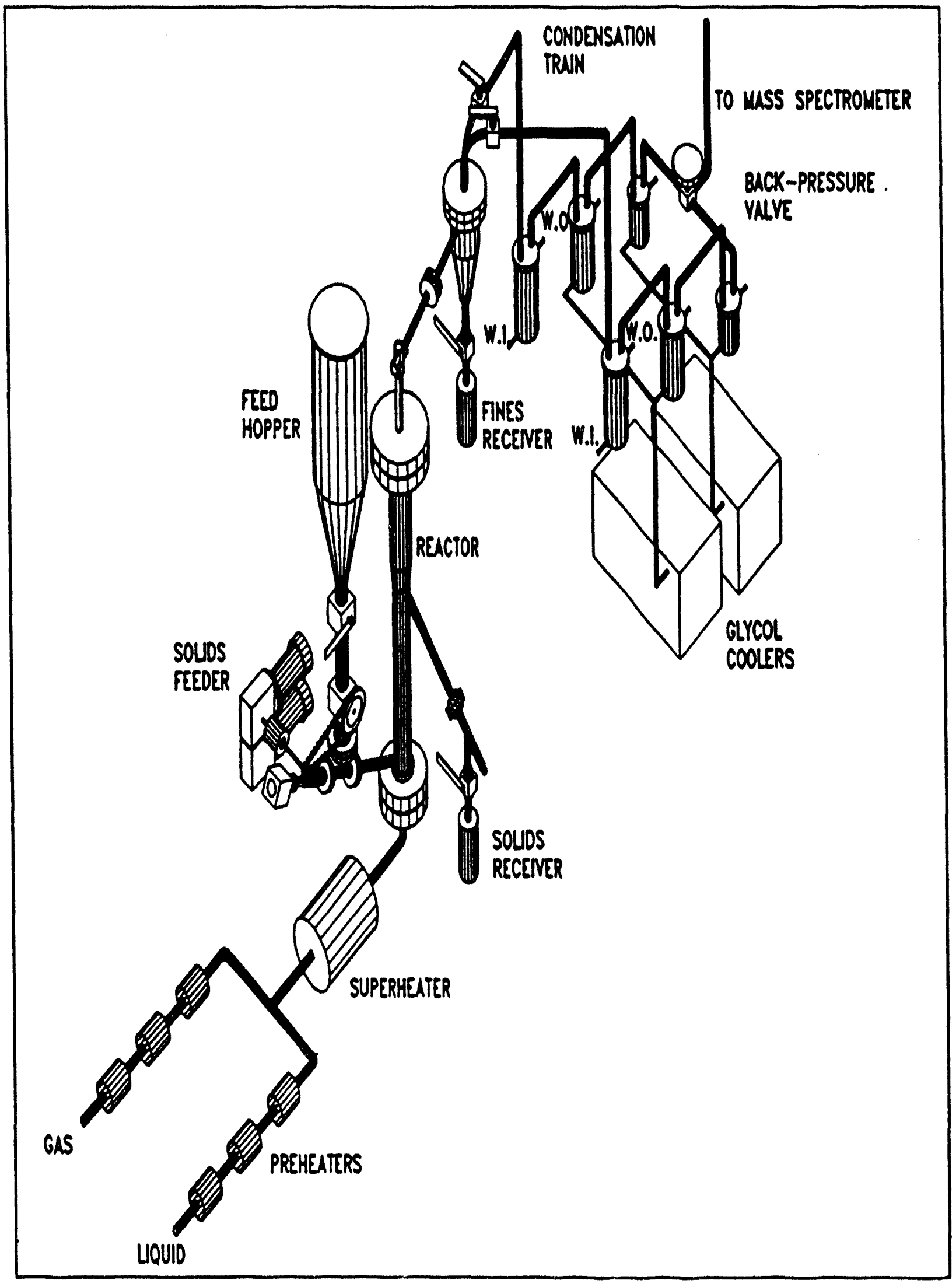

Figure B2. Four-1b/hr CFBR schematic. 


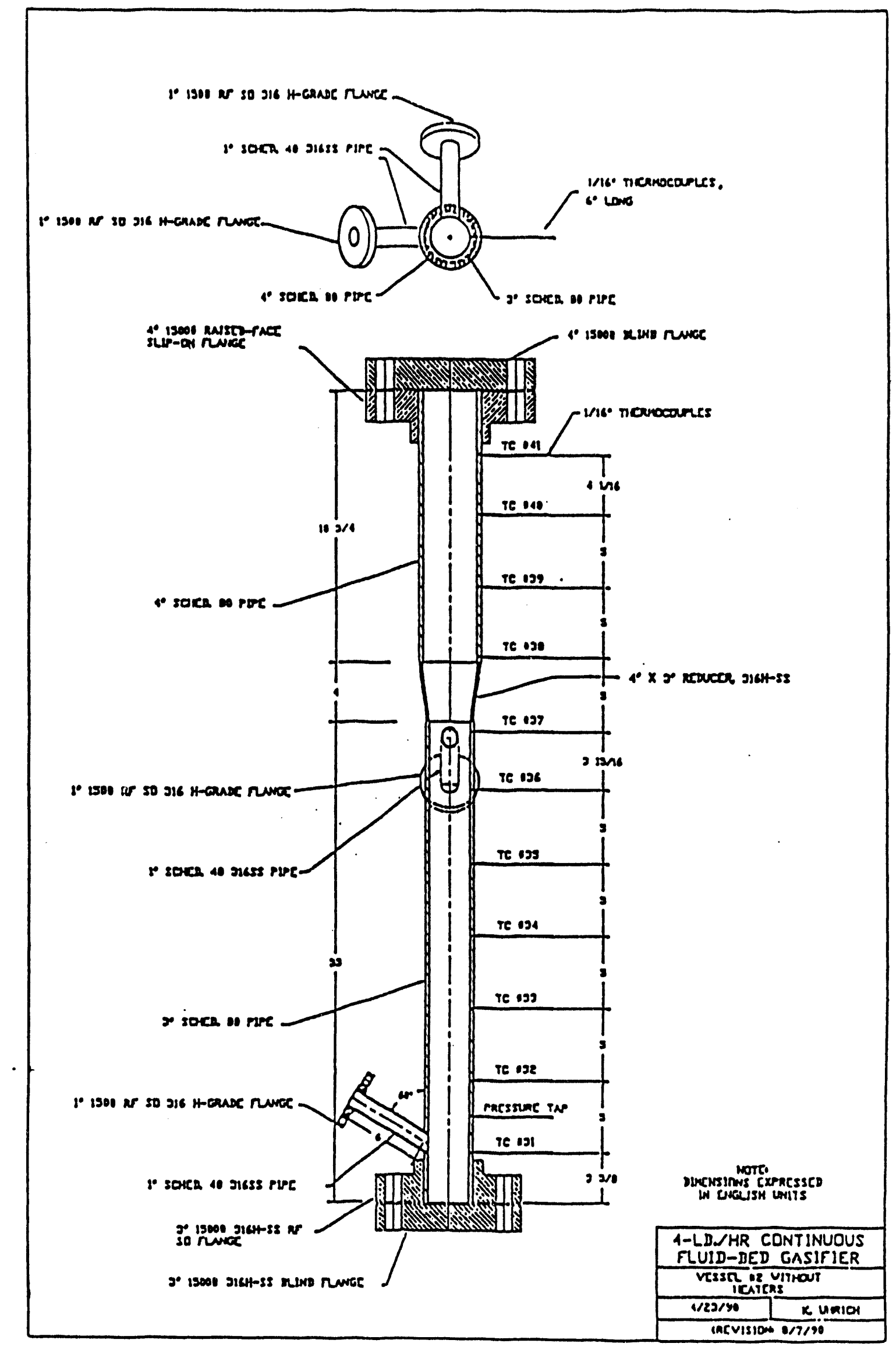

Figure B3. Four-1b/hr continuous fluid-bed gasifier. 
cyclone is made of Schedule 80,3 -inch, $316 \mathrm{H}$ stainless steel pipe. It is heated with a ceramic fiber heater capable of operating at a temperature of $1650^{\circ} \mathrm{F}\left(900^{\circ} \mathrm{C}\right)$ and 200 psia. During preliminary tests, large quantities of char carryover in the condensate stream from the cyclone were not observed; therefore, a secondary filter was not needed for this system.

\section{CONDENSER SYSTEM}

Three 4-inch-diameter vessels are used to remove all condensables from the gas stream. Two separate trains were installed: one for mass balance sampling, and the other for heatup, un-steady-state conditions, and cooldown. The first condenser pot is indirectly cooled by water and typically cools the gas stream from $570^{\circ} \mathrm{F}\left(300^{\circ} \mathrm{C}\right)$ to $200^{\circ} \mathrm{F}\left(95^{\circ} \mathrm{C}\right)$. The next two condensers are glycol-cooled. The exit gas temperature is typically $50^{\circ} \mathrm{F}\left(10^{\circ} \mathrm{C}\right)$. A glass wool filter was used to capture aerosols passed through the condenser system.

\section{INSTRUMENTATION AND CONTROL}

An integrated controller, PC-based software, and data acquisition system were developed for the unit. The unit has 16 Barber-Colman Series 990 temperature controllers, which are directly linked to an AT-compatible computer using Genesis $s^{\oplus}$ software. Data from this system are directly transferred to Lotus ${ }^{\oplus}$ spreadsheet work files, so that data reduction time is greatly reduced. 


\subsection{LIQUEFACTION RESEARCH}

$$
-
$$


5.1 Low-Rank Coal Direct Liquefaction 


\title{
LOW-RANK COAL DIRECT LIQUEFACTION
}

Final Technical Progress Report

for the Period July 1, 1989, through December 31, 1992

by

\author{
Melanie D. Hetland, Research Engineer \\ John R. Rindt, Research Supervisor \\ Energy and Environmental Research Center \\ University of North Dakota \\ P.0. Box 9018 \\ Grand Forks, North Dakota 58202-9018
}

Task Contracting Officer's Representative: Mr. Michael J. Baird

for

U. S. Department of Energy

Pittsburgh Energy Technology Center

P.0. Box 10940

Pittsburgh, Pennsyivania 15236-0940

December 1992

Work Performed under Cooperative Agreement No. DE-FC21-86MC10637 
TABLE OF CONTENTS

Page

LIST OF FIGURES ...................... . .

LIST OF TABLES ..................... . . . . . .

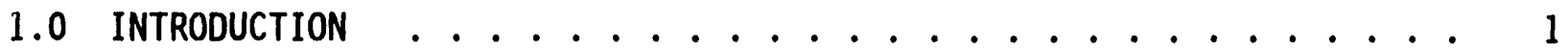

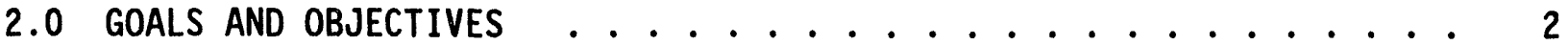

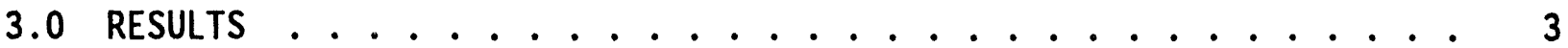

3.1 Preliminary Mechanistic Study of Liquefaction Reactions .... 3

3.1.1 Comparison of Functional Group Reactivity During

3.1.2 Comparison of Retrograded and Nonretrograded Products

3.2 Step 1 - Pretreatment . . . . . . . . . . . . . 8

3.3 Step 2 - Solubilization ............... 9

3.4 Step 3 - Polishing ................... 14

3.5 Step 4 - Hydrotreatment ................. 14

4.0 CONCLUSIONS ..................... 20

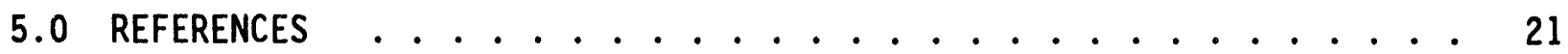

APPENDIX A: GENERIC RUN INSTRUCTIONS . . . . . . . . . . A-1 


\section{LIST OF FIGURES}

Figure

Page

$1{ }^{23} \mathrm{C}$ NMR spectra of typical low- and high-rank coals. . . . . . . 4

$2{ }^{13} \mathrm{C}$ NMR spectra of IOM remaining after processing; values indicate conversion levels................. 6

$3{ }^{13} \mathrm{C}$ NMR spectra showing differences between retrograded and nonretrograded product ................. 8

4 Experimental matrix for integrated run series . . . . . . . . . 16

\section{LIST OF TABLES}

Table

Page

1 Functional Group Locations on Solid ${ }^{13} \mathrm{C}$ NMR Spectra . . . . . . . 5

2 Reaction of Functional Groups During Direct Liquefaction . . . . . 6

3 Product Slates of the Mechanistic Studies Tests on a Water/Gas Shift-Free Basis . . . . . . . . . . . . . 7

4 Variables Screened During Pretreatment Studies . . . . . . . . 9

5 Summary of Pretreatment/Solvation Tests using Hydrogen-Donating Solvents ................ . 10

6 Comparison of Pretreated and Non-Pretreated Tests . . . . . . 12

7 Summary of Solvation Tests using Hydrogen-Donating Solvents . . . 13

8 Summary of Polishing Step Tests . . . . . . . . . . . . . 15

9 Mass Balances and Product Slates of the Polishing Tests . . . . 15

10 Conditions of Integrated Run Series . . . . . . . . . . . 17

11 Product Slates of Integrated Run Series . . . . . . . . . 18

12 Comparison of Effect of Solubilization and Polishing Temperatures on Final Hydrotreated Product Slate . . . . . . . . . 19

13 Comparison of Gas Plus Water Production for Integrated Run Series... . . . . . . . . . . . . . . . 19 


\section{LOW-RANK COAL DIRECT LIQUEFACTION}

\subsection{INTRODUCTION}

Direct liquefaction is a process in which coal is converted to liquid products by adding hydrogen to coal that has been slurried in a solvent. The hydrogen addition takes place at elevated temperatures and pressures. The process was invented by Friedrich Bergius in 1913 and has remained relatively unchanged since its extensive use by Germany for the production of liquid fuels during World War II (1). Some improvements in conversion and product slate were noted when researchers in the United States substituted bituminous coal for the German brown coal. Attempts to use low-rank coals (LRCs) instead of bituminous coals have not been as successful. From the results of work performed earlier this decade, it is apparent that LRCs are very reactive (2). Current processing approaches work well with the less-reactive, higher-rank coals (HRCS), but when the LRCs are subjected to the optimum HRC processing conditions, they react too rapidly for the available hydrogen sources and result in a more retrograde product. On the surface, this may appear to be inconsistent with the accomplishments of the older German technology using LRCS. However, the older technology's conditions were so severe that even the retrograde products were eventually converted to distillate material. With the development of a less brute-force approach (i.e., everything developed since WWII), the subtleties of relative coal reactivity, particularly that shown between LRCs and HRCs, make it necessary to pay closer attention to the chemistry of the process.

Unfortunately, the reactions taking place during direct liquefaction are not fully understood. Due to their complexity, analyses of these chemical reactions have never led to universally accepted mechanisms, rate-determining step(s), critical reaction pathway(s), or reaction kinetics. Because very little is known about the actual reactions that occur during coal liquefaction, especially during the critical initial steps, improvements in product yield and/or quality are currently accomplished through largely empirical changes in the processing parameters and/or equipment. The current liquefaction approach assumes that the reactions occurring at the usually severe conditions provide the best way to convert coal to liquid products.

The apparent higher reactivity of LRCs offers a key to improved conversions and/or yield structures and/or lower processing severity. Changes utilizing this reactivity could improve the economic viability of the technology. Effective use of LRCs in direct liquefaction may require a fairly substantial change in the direct liquefaction process as it is currently known.

In an approach taken by the Reaction Engineering Group of the Energy and Environmental Research Center (EERC), the initial coal solubilization can be considered as reverse coalification and the subsequent upgrading as reforming or refining. Because of the high-severity conditions, single-stage liquefaction forces reverse coalification and refining to occur at the same time. The results of past efforts using this type of processing speak for themselves: this brute-force method produces a number of product streams, only one of which is the desired, value-added product. Mechanistically, it is somewhat easier to view these almost mutually exclusive processes as different, 
sequential steps. Staged liquefaction, as it currently exists (i.e., at least two reactors in series), is an attempt to best utilize the differences in preferred conditions for each step of a two-step method. Unfortunately, the processing parameters employed during both stages are usually so severe that the same type of high-temperature, high-pressure reactions occur (i.e., coalification), or at least compete, in both stages.

Dramatic improvements in the liquefaction process may be possible if the reactions involved are not required to compete against each other. Processing conditions must be changed, and the changes must be determined by an increased understanding of the reactions taking place. At the EERC, it is assumed that the structure of coal is comprised of physically and chemically tangled, highly cross-linked molecules. The molecular structures of premium distillate fuels, by comparison, are discrete molecules of similar size and chemical nature, having virtually no chemical or physical attachments. Using these two presumptions, it is possible to map potential mechanical and chemical mechanisms for the process of liquefaction.

The first step in liquefaction should be to "untangle" the coal structure, while the second step should be to "organize" the untangled pieces so that those of similar size and chemical nature are first separated from the remaining material and then stabilized to prevent back reactions. This simplistic, two-step mechanism will be used to develop a more effective scheme for coal liquefaction. It seems logical that, in order to prevent coalification reactions, "untangling" of the coal structure should take place at lowseverity conditions.

Tailoring the processing parameters to the liquefaction reactions taking place, the EERC has developed a multistep direct 1 iquefaction process specifically for LRCs consisting of pretreatment, solubilization, polishing, and hydrotreatment.

\subsection{GOALS AND OBJECTIVES}

Since 1986, the primary objective of the Low-Rank Coal Direct Liquefaction program has been to develop an LRC liquefaction process that results in increased levels of conversion to distillable liquids. The work effort to meet this objective has included:

- A preliminary mechanistic study of the retrograde reactions that occur as a function of typical liquefaction processing.

- Screening of various preconversion treatments.

- Development of a multistep process that results in virtually complete solubilization of the LRC in the solvent prior to hydrotreatment.

- An investigation of the effects of the use of hydrogen-donating solvents during liquefaction.

- Integration of all steps of the process. 


\subsection{RESULTS}

As mentioned in Section 1.0, the EERC has developed a four-step liquefaction process consisting of:

- Step 1 - Pretreatment, which was investigated during FY89-90 and FY90-91.

- Step 2 - Solubilization.

- Step 3 - Polishing, which was investigated during FY88-89, Task K.

- Step 4 - Hydrotreatment.

Generic instructions for performance of these tests are given in the appendix.

This process was developed based, in part, upon earlier research (i.e., prior to 1986) performed at the EERC that showed that:

- Low-severity processing of lignites resulted in better conversion and yield structure than did the typically higher-severity single-stage liquefaction.

- Syngas is a more effective reductant than pure hydrogen gas.

- Hydrogen donor solvents are more effective than hydrogen gas for the hydrogenation of coal liquids.

- CO acts almost exclusively via the water/gas shift reaction.

- $\mathrm{H}_{2} \mathrm{~S}$ acts primarily as a hydrogen shuffler, typically from the gas phase to the liquid phase.

Knowledge of liquefaction reactions gained during a preliminary mechanistic study was also used in the development of the multistep process.

\subsection{Preliminary Mechanistic Study of Liquefaction Reactions}

Low- and high-rank coals are significantly different from each other. This is shown in Figure 1 , which compares the ${ }^{13} \mathrm{C}$ nuclear magnetic resonance (NMR) spectra of a typical bituminous coal and a typical lignite. To aid in reading the NMR spectra contained in this report, Table 1 lists the locations of various functional groups on solid ${ }^{13} \mathrm{C}$ NMR spectra. Lignite contains considerably more phenolic, carboxyl, and methoxyl groups than the bituminous coal, which is comprised primarily of aliphatics and heavy aromatic groups. Due to these differences, the two probably do not react in the same manner during liquefaction processing.

To arrive at a better understanding of the reactions that occur during typical liquefaction of lignite, a preliminary mechanistic study was performed. Four batch tests were conducted. Three of the tests were performed at conditions designed to result in conversions of nominally $10 \%$, $55 \%$, and $95 \%$. A test was also made at conditions selected intentionally to 

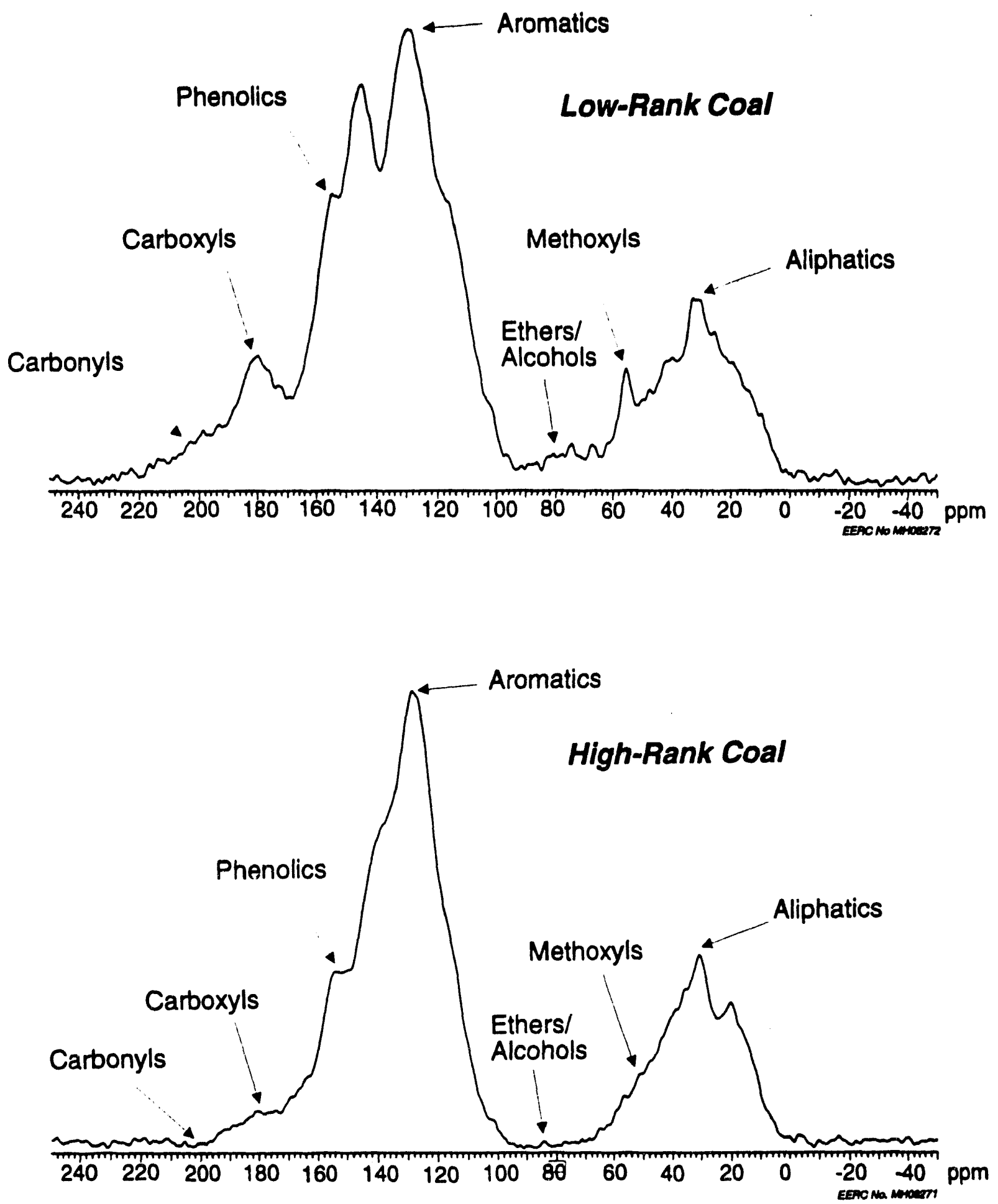

Figure 1. ${ }^{13} \mathrm{C}$ NMR spectra of typical low- and high-rank coals. 
TABLE 1

Functional Group Locations on Solfd ${ }^{13} \mathrm{C}$ NMR Spectra

\begin{tabular}{lc}
\hline Functional Group & Shift, ppm \\
\hline & \\
Carbonyl & $230-190$ \\
Carboxyl & $190-170$ \\
Phenolic & $170-148$ \\
Aromatic & \\
Alkyl Substituted & $148-136$ \\
Unsubstituted & $136-90$ \\
Ether/Alcohol & $90-60$ \\
Methoxyl & $60-50$ \\
Aliphatic & \\
$-\mathrm{C}-,-\mathrm{CH}-$ & $50-36$ \\
$-\mathrm{CH}-$ & $36-24$ \\
Aromatic- $-\mathrm{CH}_{3}$ & $24-16$ \\
Alkyl - $\mathrm{CH}_{3}$ & $16-0$ \\
\hline
\end{tabular}

result in the production of retrograded product at an intermediate level of conversion.

\subsubsection{Comparison of Functional Group Reactivity During Liquefaction}

The insoluble organic matter (IOM) remaining at the end of each reaction was analyzed in detail using ${ }^{13} \mathrm{C}$ NMR spectroscopy to provide a description of the reaction mechanisms as a function of conversion. Area-scaled spectra (i.e., all spectra were put on the same basis for comparison purposes) were constructed to provide information concerning the changes taking place in the coal functional groups during conversion. When the spectra are compared (as in Figure 2), it can be seen that the first functional groups to react were the ethers/aicohols, the methoxyl groups, most of the alkyl aliphatic groups, and some of the alkyl and unsubstituted aromatic groups. These reactions took place when the first $9 \%$ of the coal was converted. During the conversion of the next $51 \%$ of the coal (i.e., from $9 \%$ to $60 \%$ conversion), most of the carboxy 1, phenolic, and aliphatic groups reacted. The carbonyl, alky 1 aromatic, remaining ether/alcohol, and remaining methoxyl groups reacted during the time when $60 \%$ to $94 \%$ of the coal was converted. After $94 \%$ of the coal had been converted, the IOM which remained was primarily comprised of unsubstituted aromatic groups. The order of reaction of the functional groups is summarized in Table 2 .

During the course of conversion of the coal, the liquid product yields reflect the large increase in phenolic products, and the gas product yields reflect the increased conversion of $\mathrm{CH}, \mathrm{CH}_{2}$, and $\mathrm{CH}_{3}$ groups to hydrocarbon gases. This is seen in the water/gas shift-free product yields given in Table 3. 


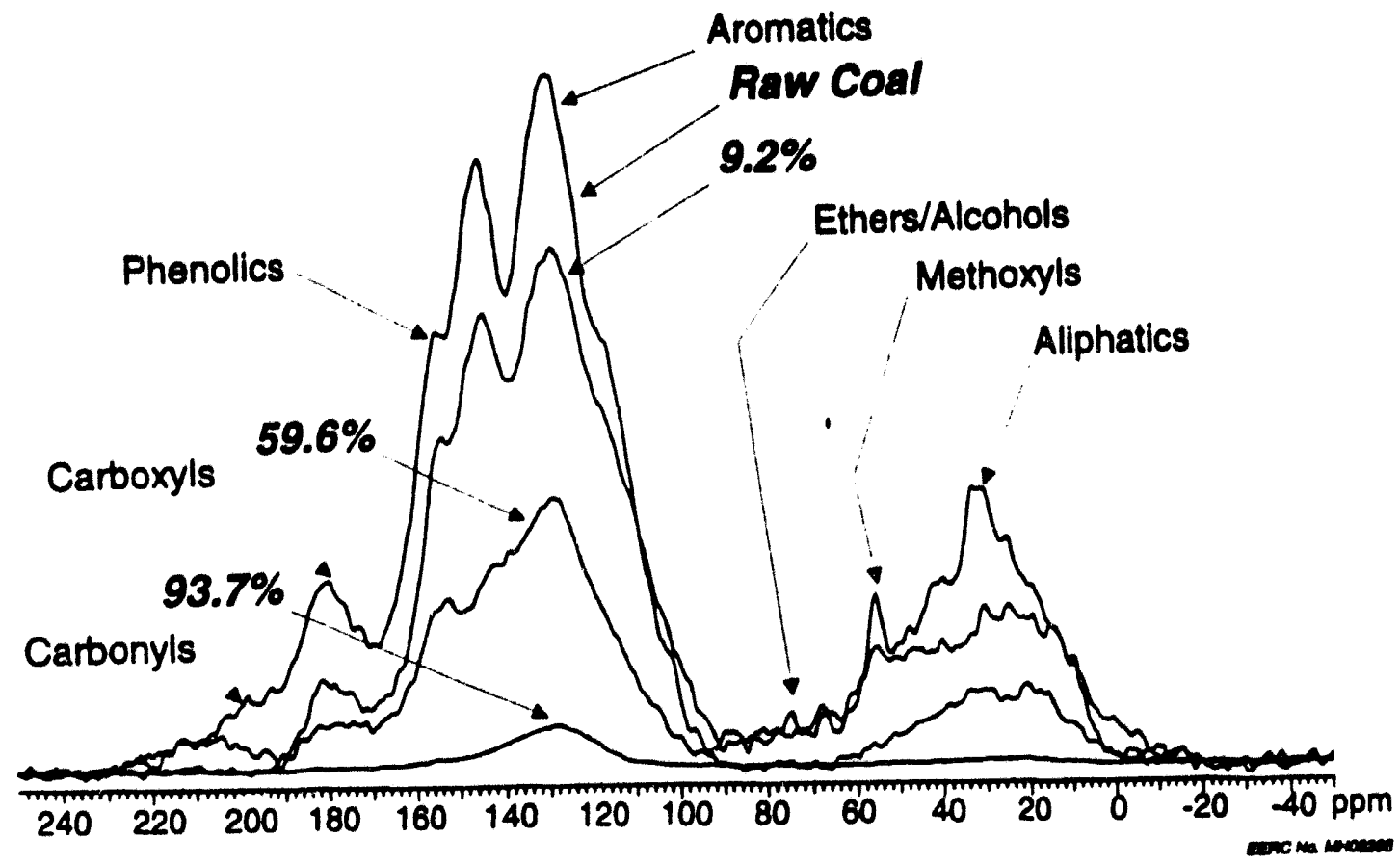

Figure 2. ${ }^{13} \mathrm{C}$ MMR spectra of IOM remaining after processing; values indicate conversion levels.

\section{TABLE 2}

Reaction of Functional Groups During Direct Liquefaction

\begin{tabular}{lll}
\hline 0\%-9.2\% Conversion & $\begin{array}{l}9.2 \%-59.6 \% \\
\text { Conversion }\end{array}$ & $59.6 \%-93.7 \%$ Conversion \\
\hline & & \\
Some ethers/alcohols & Carboxyls & Carbonyls \\
Methoxyls & Phenolics & Alkyl aromatics \\
Alkyl aliphatics & Aliphatics & Remaining ethers/alcohols \\
$\begin{array}{l}\text { Some alkyl and unsubstituted } \\
\text { aromatics }\end{array}$ & & Remaining methoxyls \\
\hline
\end{tabular}


TABLE 3

Product Slates of the Mechanistic Studies Tests on a Water/Gas Shift-Free Basis

\begin{tabular}{|c|c|c|c|c|}
\hline Run No. & N469 & N474 & N468 & N475 \\
\hline Conversion, $\%$ & 9.2 & 59.6 & 93.7 & 61.5 \\
\hline Avg. Temp., ${ }^{\circ} \mathrm{C}$ & 201 & 303 & 354 & 444 \\
\hline Avg. Pressure, psig & 1750 & 2505 & 3071 & 3570 \\
\hline \multicolumn{5}{|l|}{ Products ${ }^{b}$} \\
\hline $\mathrm{CO}$ & 0.00 & 0.00 & 0.00 & 2.09 \\
\hline $\mathrm{H}_{2}$ & 0.04 & 0.43 & 1.06 & -2.88 \\
\hline $\mathrm{CO}_{2}$ & 4.38 & 18.86 & 9.92 & 16.47 \\
\hline $\mathrm{C} 1-\mathrm{C} 3$ & 0.25 & 0.52 & 1.36 & 4.31 \\
\hline $\mathrm{H}_{2} \mathrm{~S}$ & -5.89 & -7.76 & -5.29 & 2.61 \\
\hline Total Gas & 2.26 & 22.80 & 38.61 & 22.60 \\
\hline $\mathrm{H}_{2} \mathrm{O}$ & 0.43 & -10.02 & -24.58 & -11.90 \\
\hline Ash & 0.85 & 0.60 & -0.57 & -0.11 \\
\hline IOM & 91.38 & 40.20 & 6.29 & 38.49 \\
\hline Distillable 0ils & -77.53 & -47.41 & -0.15 & 0.00 \\
\hline $\begin{array}{l}\text { Soluble Resid } \\
\text { Total Liquid }\end{array}$ & $\begin{array}{l}82.61 \\
97.74\end{array}$ & $\begin{array}{l}93.82 \\
77.20\end{array}$ & $\begin{array}{l}80.40 \\
61.39\end{array}$ & $\begin{array}{l}50.93 \\
77.40\end{array}$ \\
\hline
\end{tabular}

- Products of this run were retrograded in nature.

- Values given as wt\% of maf coal fed to the system, on a water/gas shiftfree basis.

The greatest production of $\mathrm{CO}_{2}$ was seen when most of the carboxyl and phenolic functional groups were released from the coal during the $9 \%$ to $60 \%$ range of conversion. The water/gas shift reaction was the most evident during the release of the aromatic functional groups toward the end of the conversion process. This can be seen in both the water consumption and $\mathrm{CO}_{2}$ production given in Table 3. The majority of the hydrogenation takes place at this point in the processing as hydrogenation is virtually the only reaction in which the aromatics will take part.

The largest incorporation of $\mathrm{H}_{2} \mathrm{~S}$ occurred during the $9 \%$ to $60 \%$ conversion range, coinciding with the largest release of $\mathrm{CO}_{2}$ and phenolics as well as the highest yield of total liquids. This may indicate a mechanistic link between the removal of the phenolic and carboxyl groups and the fact that sulfur apparently replaces the oxygen in many of the bonds. 


\subsubsection{Comparison of Retrograded and Nonretrograded Products}

Two runs were performed at conditions which resulted in similar conversions of coal but different product yield structures. As Table 3 shows, the two tests took place via different mechanisms. The higher-temperature/ higher-pressure test underwent substantially more cracking reactions than the less severe test, as seen in the production of hydrocarbon gases. The production of solubles was approximately the same for the two tests. A shift in carbon balance can be seen when the two tests are compared. Approximately twice as much of the carbon in the feed coal was present in the product gas of the more severe run as in the product gas of the less severe run. In other words, the carbon utilization efficiencies were grossly affected at the expense of the production of desirable liquids. Comparison of the ${ }^{13} \mathrm{C}$ NMR spectra of the IOM remaining after processing for both runs corroborates these data. As Figure 3 shows, the product of the more severe test consisted primarily of heavy aromatics, while the product of the less severe test retained more of the features of the original lignite.

\subsection{Step 1 - Pretreatment}

Low-severity pretreatments were screened to evaluate their impact on the direct 1 iquefaction of Indian Head lignite. The rationale was that a completely solvent-soluble feed to the catalytic upgrading stage would not be as likely to undergo retrograde reactions as feed containing both the soluble fractions of converted coal and unconverted organic residue. If this were the case, it would result in a higher conversion of coal to desired liquid products than is usually obtained during direct liquefaction. As part of this solubilization process, it was hypothesized that pretreatment might reduce

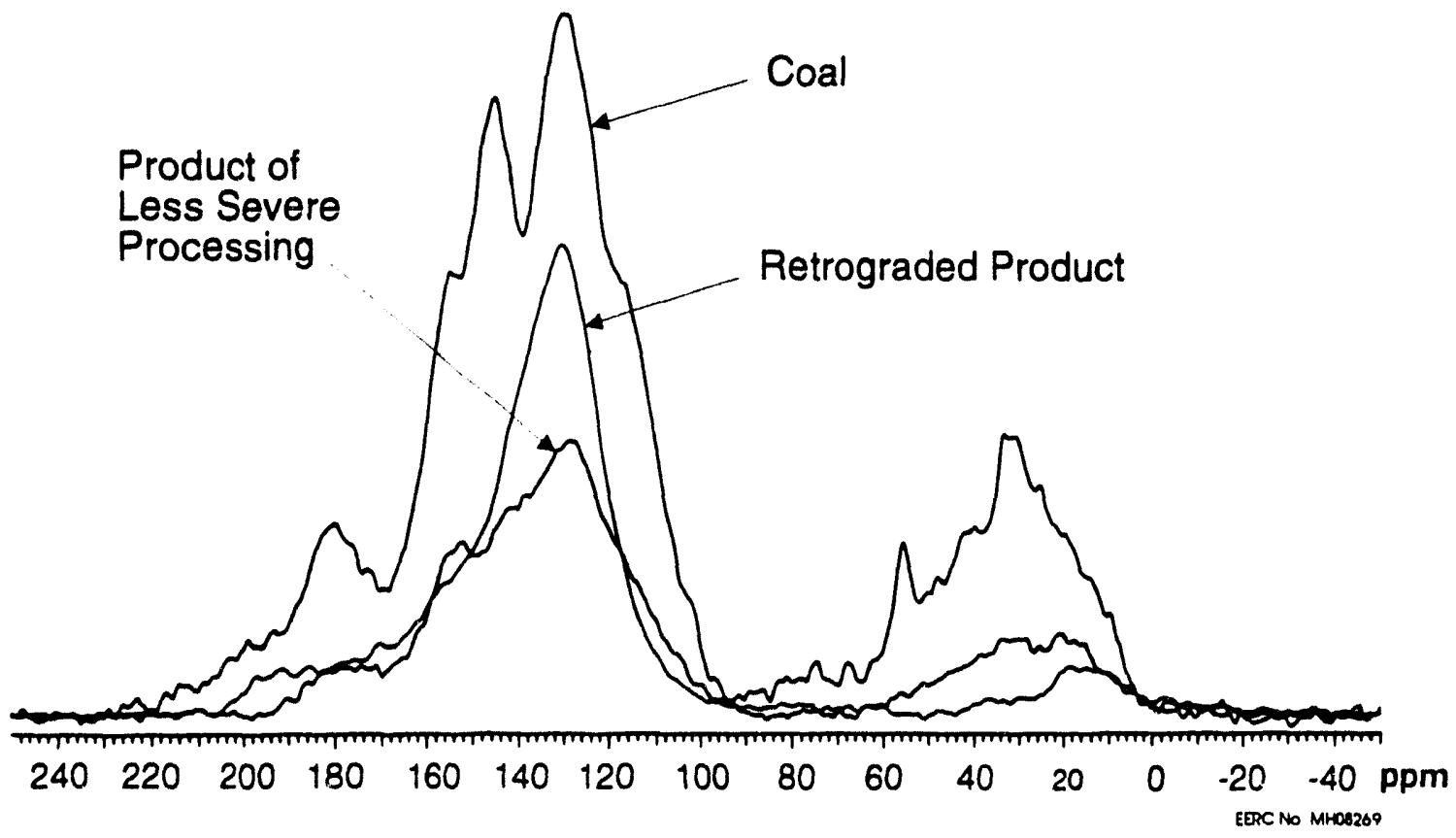

Figure 3. ${ }^{13} \mathrm{C}$ NMR spectra showing differences between retrograded and nonretrograded product. 
retrograde behavior by placing hydrogen or radical capping agents in the correct location to facilitate "untangling" of the coal structure. When used in this report, the term "pretreatment" refers to anything done to the coal prior to noticeable formation of soluble materials.

Several preconversion treatment schemes were devised and screened for their effectiveness. An initial screening was carried out using the $20-\mathrm{cm}^{3}$ microreactor system. A second screening was performed using hydrogen-donating solvents in the batch autoclave system. The information gathered during these two screenings was combined, and the most promising schemes were tested further. Table 4 lists the pretreatment variables that were screened, and Table 5 presents the product slates (after solubilization) and molar hydrogento-carbon ratios of these tests.

As can be seen in Table 5, it appears that a 60-minute soak in HA061 (hydrogenated coal-derived anthracene oil) at $175^{\circ} \mathrm{C}$ in the presence of argon and $\mathrm{H}_{2} \mathrm{~S}$ enhances whichever reaction is taking place without substantially affecting the overall conversion. In the case of a pyrolysis-type reaction (N524), the use of pretreatment greatly increased the production of product gases and water while decreasing the production of soluble liquid products. In a liquefaction reaction such as N528, the use of pretreatment resulted in a decrease in the quantity of gaseous products and an increase in the production of soluble liquids. These trends can be clearly seen in Table 6 , which places the yield structure of Runs N524 and N528 side by side with yield structures of the equivalent non-pretreated tests.

\subsection{Step 2 - Solubilization}

The purpose of this step is to solubilize as much of the coal as possible to enable more efficient hydrotreatment during a later step. Hydrotreatment is not attempted during this step. Tests were performed to study the effects of various hydrogen-donating solvents, gases, and pressures on the solubilization of the coal. A summary of these solubilization tests is presented in Table 7. The same matrix was performed again incorporating solvent-specific pretreatments. Additional data points were added at that time. Table 5 presented the results of the study incorporating pretreatment.

TABLE 4

Variables Screened During Pretreatment Studies

\begin{tabular}{lccc}
\hline Solvent & Gas $^{\circ}$ & Additive $^{b}$ & Temperature \\
\hline A04 & $\mathrm{H}_{2}$ & $\mathrm{Na}$ & $110^{\circ} \mathrm{C}$ \\
phenolic & $\mathrm{CO}$ & $\mathrm{H}_{2} \mathrm{~S}$ & $175^{\circ} \mathrm{C}$ \\
tetralin & $\mathrm{Ar}$ & none & $250^{\circ} \mathrm{C}$ \\
& none & & \\
Reaction time $=60$ min for all tests & & \\
\hline
\end{tabular}

"1000 psi gas charged.

Additive $=5$ wt $\%$ of maf coal fed to the system. 
TABLE 5

Summary of Pretreatment/Solvation Tests using Hydrogen-Donating Solvents

\begin{tabular}{|c|c|c|c|c|c|c|c|c|}
\hline & N501/N502 & N503/N504 & N505 & N506 & N507/N508 & N509/N510 & N511/N512 & N513/N514 \\
\hline $\begin{array}{l}\text { Matrix Point } \\
\text { Solvent } \\
\text { Additive } \\
\text { Gas } \\
\text { Residence Time, min } \\
\text { Avg. Temp., }{ }^{\circ} \mathrm{C} \\
\text { Max. Temp., }{ }^{\circ} \mathrm{C} \\
\text { Avg. Pressure, psi } \\
\text { Max. Pressure, psi } \\
\text { Conversion, \% }\end{array}$ & $\begin{array}{c}1 \\
\text { A04 }+ \text { Tetral in } / \mathrm{N} 501 \\
\mathrm{H}_{2} \mathrm{~S} / \text { None } \\
\mathrm{Ar} / \mathrm{CO} \\
60 / 60 \\
184 / 375 \\
187 / 379 \\
2230 / 3867 \\
2240 / 4000 \\
93.3\end{array}$ & $\begin{array}{c}2 \\
\text { A04/N503 } \\
\text { None/None } \\
\mathrm{H}_{2} / \mathrm{CO} \\
60 / 60 \\
179 / 375 \\
181 / 380 \\
2100 / 3700 \\
2115 / 3865 \\
86.1\end{array}$ & $\begin{array}{c}3 \\
\mathrm{~A} 04 \\
\text { None } \\
\mathrm{H}_{2} \\
20 \\
420 \\
421 \\
3734 \\
3800 \\
55.5\end{array}$ & $\begin{array}{l}4 \\
\text { HAO61" } \\
\text { None } \\
\mathrm{H}_{2} \\
20 \\
414 \\
418 \\
3880 \\
3905 \\
80.1\end{array}$ & $\begin{array}{c}5 \\
\text { HA061/N507 } \\
H_{2} S / \text { None } \\
\text { Ar/CO } \\
60 / 60 \\
123 / 372 \\
124 / 373 \\
1730 / 3727 \\
1730 / 3875 \\
87.6\end{array}$ & $\begin{array}{c}6 \\
\text { HA061/N509 } \\
H_{2} S / \text { None } \\
\text { Ar/CO } \\
60 / 60 \\
178 / 375 \\
180 / 377 \\
2141 / 3750 \\
2225 / 4000 \\
89.1\end{array}$ & $\begin{array}{c}7 \\
\text { HA061/N511 } \\
H_{2} S / \text { None } \\
\text { CO/CO } \\
60 / 60 \\
175 / 375 \\
176 / 376 \\
2075 / 3740 \\
2095 / 3825 \\
88.6\end{array}$ & $\begin{array}{c}8 \\
\mathrm{CAI}^{\mathrm{C}} / \mathrm{N} 513 \\
\mathrm{H}_{2} \mathrm{~S} / \mathrm{None} \\
\text { CO/CO } \\
60 / 60 \\
115 / 371 \\
117 / 375 \\
1864 / 3737 \\
1748 / 3780 \\
89.3\end{array}$ \\
\hline $\begin{array}{l}\text { Products } \\
\text { CO } \\
\mathrm{H}_{2} \\
\mathrm{CO}_{2} \\
\mathrm{Cl}^{-} \mathrm{C} 3 \\
\mathrm{H}_{2} \mathrm{~S} \\
\text { Total Gas }\end{array}$ & $\begin{array}{r}-50.73 \\
0.72 \\
93.75 \\
0.92 \\
5.06 \\
49.72\end{array}$ & $\begin{array}{r}-32.36 \\
0.64 \\
65.63 \\
0.65 \\
0.13 \\
34.69\end{array}$ & $\begin{array}{r}0.00 \\
-1.87 \\
21.58 \\
10.21 \\
0.00 \\
29.92\end{array}$ & $\begin{array}{r}0.09 \\
-2.96 \\
17.55 \\
8.32 \\
0.00 \\
23.00\end{array}$ & $\begin{array}{r}-32.34 \\
0.52 \\
73.31 \\
0.49 \\
3.66 \\
45.62\end{array}$ & $\begin{array}{r}-36.01 \\
0.38 \\
77.62 \\
0.79 \\
3.94 \\
46.72\end{array}$ & $\begin{array}{r}-34.61 \\
0.43 \\
62.24 \\
0.75 \\
1.97 \\
30.79\end{array}$ & $\begin{array}{r}-41.98 \\
0.38 \\
70.94 \\
0.76 \\
3.37 \\
33.47\end{array}$ \\
\hline $\begin{array}{l}\mathrm{H}_{2} \mathrm{O} \\
\text { Ash } \\
\text { IOM } \\
\text { THF Solubles } \\
\text { Total Liquid }\end{array}$ & $\begin{array}{r}-25.76 \\
-0.39 \\
6.70 \\
69.73 \\
50.28\end{array}$ & $\begin{array}{r}-23.62 \\
-0.10 \\
13.95 \\
75.08 \\
65.31\end{array}$ & $\begin{array}{r}2.15 \\
-0.34 \\
44.51 \\
23.76 \\
70.08\end{array}$ & $\begin{array}{r}0.39 \\
-1.26 \\
19.90 \\
57.98 \\
77.00\end{array}$ & $\begin{array}{r}-16.98 \\
-1.18 \\
12.40 \\
60.13 \\
54.38\end{array}$ & $\begin{array}{r}-38.13 \\
-1.49 \\
10.88 \\
82.03 \\
53.28\end{array}$ & $\begin{array}{l}-5.60 \\
-1.31 \\
11.45 \\
64.67 \\
69.21\end{array}$ & $\begin{array}{r}-21.73 \\
-1.04 \\
10.74 \\
78.56 \\
66.53\end{array}$ \\
\hline $\begin{array}{l}\text { Molar H:C, Feed } \\
\text { Molar H:C, After Pret. } \\
\text { Molar H:C, Product }\end{array}$ & $\begin{array}{l}0.9827 \\
0.8320 \\
0.8868\end{array}$ & $\begin{array}{l}0.7673 \\
0.7796 \\
0.8517\end{array}$ & $\begin{array}{l}0.7646 \\
-- \\
0.7486\end{array}$ & $\begin{array}{l}0.8925 \\
-- \\
0.9018\end{array}$ & $\begin{array}{l}0.9003 \\
0.9138 \\
0.9784\end{array}$ & $\begin{array}{l}0.8905 \\
0.9138 \\
1.0576\end{array}$ & $\begin{array}{l}0.8933 \\
0.9569 \\
0.9034\end{array}$ & $\begin{array}{l}1.0613 \\
0.9614 \\
0.9964\end{array}$ \\
\hline
\end{tabular}

- Coal-derived anthracene oil.

Hydrotreated A04.

- Values given as wt\% of maf coal fed to the system; neyative values indicate consumption; positive values indicate production. 
TABLE 5 (continued)

Summary of Pretreatment/Solvation Tests using Hydrogen-Donating Solvents

\begin{tabular}{|c|c|c|c|c|c|c|c|c|}
\hline & N519/N522 & N519/N523 & N519/N524 & N525/N526 & N525/N527 & N525/N528 & N525/N530 & N549/N551 \\
\hline $\begin{array}{l}\text { Matrix Point } \\
\text { Compares to } \\
\text { Solvent } \\
\text { Additive } \\
\text { Gas } \\
\text { Residence Time, min } \\
\text { Avg. Temp., }{ }^{\circ} \mathrm{C} \\
\text { Max. Temp., }{ }^{\circ} \mathrm{C} \\
\text { Avg. Pressure, psi } \\
\text { Max. Pressure, psi } \\
\text { Conversion, \% }\end{array}$ & $\begin{array}{c}9 \\
\text { N477 } \\
\text { HA061/N519 } \\
H_{2} S / \text { None } \\
\text { Ar/None } \\
60 / 60 \\
184 / 370 \\
187 / 374 \\
2106 / 600 \\
2125 / 638 \\
54.7\end{array}$ & $\begin{array}{c}10 \\
N 483 \\
H A 061 / N 519^{\prime} \\
H_{2} S / \text { None } \\
\text { Ar/None } \\
60 / 60 \\
184 / 372 \\
187 / 381 \\
2106 / 631 \\
2125 / 663 \\
57.5\end{array}$ & $\begin{array}{c}11 \\
N 484 \\
H A 061 / N 519^{\circ} \\
H_{2} S / \text { None } \\
\text { Ar/None } \\
60 / 60 \\
184 / 367 \\
187 / 375 \\
2106 / 953 \\
2125 / 995 \\
70.0\end{array}$ & $\begin{array}{c}12 \\
N 487 \\
H A 061 / N 525 \\
H_{2} S / \text { None } \\
\text { Ar/Ar } \\
60 / 60 \\
176 / 372 \\
178 / 376 \\
2000 / 3581 \\
2000 / 3628 \\
60.1\end{array}$ & $\begin{array}{c}13 \\
N 485 \\
H A 061 / N 525 \\
H_{2} S / \text { None } \\
\text { Ar/ } / H_{2} \\
60 / 60 \\
176 / 378 \\
178 / 380 \\
2000 / 3352 \\
2000 / 3390 \\
79.4\end{array}$ & $\begin{array}{c}14 \\
N 486 \\
\text { HA061/N525 } \\
H_{2} S / \text { None } \\
\text { Ar/CO } \\
60 / 60 \\
176 / 376 \\
178 / 381 \\
2000 / 3434 \\
2000 / 3560 \\
81.0\end{array}$ & $\begin{array}{c}15 \\
N 499 \\
\text { HAO61/N525 } \\
H_{2} S / \text { None } \\
\text { Ar/CO } \\
60 / 60 \\
176 / 373 \\
178 / 380 \\
2000 / 728 \\
2000 / 745 \\
33.1\end{array}$ & $\begin{array}{c}16 \\
N 476 \\
\text { A04/N549 } \\
H_{2} S / \text { None } \\
\text { Ar/Ar } \\
60 / 60 \\
174 / 373 \\
176 / 376 \\
2100 / 4227 \\
2110 / 4260 \\
38.72\end{array}$ \\
\hline $\begin{array}{l}\text { Products } \\
\text { CO } \\
\mathrm{H}_{2} \\
\mathrm{CO}_{2} \\
\mathrm{Cl}-\mathrm{C} 3 \\
\mathrm{H}_{2} \mathrm{~S} \\
\text { Total Gas }\end{array}$ & $\begin{array}{r}0.20 \\
0.09 \\
9.28 \\
1.23 \\
5.69 \\
16.48\end{array}$ & $\begin{array}{r}12.17 \\
0.05 \\
7.74 \\
0.17 \\
0.19 \\
20.32\end{array}$ & $\begin{array}{r}12.56 \\
0.17 \\
21.19 \\
2.18 \\
2.56 \\
38.65\end{array}$ & $\begin{array}{r}0.08 \\
0.05 \\
6.86 \\
0.62 \\
3.61 \\
11.22\end{array}$ & $\begin{array}{r}0.25 \\
-2.71 \\
9.12 \\
1.20 \\
2.93 \\
10.78\end{array}$ & $\begin{array}{r}-54.25 \\
1.01 \\
73.46 \\
0.97 \\
2.90 \\
24.09\end{array}$ & $\begin{array}{r}-14.71 \\
0.90 \\
25.96 \\
1.45 \\
1.26 \\
14.85\end{array}$ & $\begin{array}{r}0.00 \\
0.05 \\
14.01 \\
1.32 \\
3.72 \\
19.10\end{array}$ \\
\hline $\begin{array}{l}\mathrm{H}_{2} \mathrm{O} \\
\text { Ash } \\
\text { IOM } \\
\text { THF Solubles } \\
\text { Total Liquid }\end{array}$ & $\begin{array}{r}10.97 \\
0.01 \\
45.35 \\
27.28 \\
83.52\end{array}$ & $\begin{array}{r}7.37 \\
0.14 \\
42.55 \\
29.61 \\
79.68\end{array}$ & $\begin{array}{r}7.89 \\
0.29 \\
29.97 \\
23.20 \\
61.35\end{array}$ & $\begin{array}{l}-2.23 \\
-0.23 \\
39.94 \\
51.30 \\
88.78\end{array}$ & $\begin{array}{l}14.48 \\
-0.64 \\
20.62 \\
54.76 \\
89.22\end{array}$ & $\begin{array}{r}-22.75 \\
-0.96 \\
18.97 \\
80.65 \\
75.91\end{array}$ & $\begin{array}{r}-40.31 \\
4.26 \\
66.87 \\
54.33 \\
85.15\end{array}$ & $\begin{array}{r}8.69 \\
0.34 \\
61.28 \\
10.59 \\
80.90\end{array}$ \\
\hline $\begin{array}{l}\text { Molar H:C, Feed } \\
\text { Molar H:C, After Pret. } \\
\text { Molar H:C, Product }\end{array}$ & $\begin{array}{l}0.8983 \\
0.8925 \\
0.8357\end{array}$ & $\begin{array}{l}0.8983 \\
0.8933 \\
0.8359\end{array}$ & $\begin{array}{l}0.8983 \\
0.9110 \\
0.8006\end{array}$ & $\begin{array}{l}0.9098 \\
0.8562 \\
0.8259\end{array}$ & $\begin{array}{l}0.9098 \\
0.8562 \\
0.8125\end{array}$ & $\begin{array}{l}0.9098 \\
0.8562 \\
0.9724\end{array}$ & $\begin{array}{l}0.9098 \\
0.8562 \\
0.8154\end{array}$ & $\begin{array}{l}N A^{n} \\
N A \\
N A\end{array}$ \\
\hline
\end{tabular}

- Tests performed during FY89-90 Task 2.

- 3 g HA061 added to preheated slurry before solubilization.

- 112.2 g HA061 added to pretreated slurry before solubilization.

n Elemental balance was not completed for this test. 
TABLE 6

Comparison of Pretreated and Non-Pretreated Tests

\begin{tabular}{|c|c|c|c|c|}
\hline & \multicolumn{2}{|c|}{ Pyrolysis } & \multicolumn{2}{|c|}{ Liquefaction } \\
\hline & $\begin{array}{l}\text { Non-Pret. } \\
\text { N484 }\end{array}$ & $\begin{array}{l}\text { Pretreated } \\
\text { N519/N524 }\end{array}$ & $\begin{array}{c}\text { Non-Pret. } \\
\text { N486 }\end{array}$ & $\begin{array}{l}\text { Pretreated } \\
\text { N525/N528 } \\
\end{array}$ \\
\hline $\begin{array}{l}\text { Solvent } \\
\text { Additive } \\
\text { Gas } \\
\text { Residence Time, min } \\
\text { Avg. Temp., }{ }^{\circ} \mathrm{C} \\
\text { Max. Temp. }{ }^{\circ} \mathrm{C} \\
\text { Avg. Pressure, psi }\end{array}$ & $\begin{array}{c}\text { HA061 } \\
\text { HA061 } \\
-- \\
60 \\
371 \\
375 \\
1425 \\
1450 \\
67.9\end{array}$ & $\begin{array}{c}\text { HA061/N519 } \\
\mathrm{H}_{2} \mathrm{~S} / \text { None } \\
\text { Ar/None } \\
60 / 60 \\
184 / 372 \\
187 / 381 \\
2106 / 631 \\
2125 / 663 \\
57.5\end{array}$ & $\begin{array}{c}\text { HAO61 } \\
-- \\
\text { CO } \\
62 \\
373 \\
376 \\
3665 \\
3740 \\
87.7\end{array}$ & $\begin{array}{c}\text { HAO61/N525 } \\
\mathrm{H}_{2} \mathrm{~S} / \text { None } \\
\text { Ar/CO } \\
60 / 60 \\
176 / 376 \\
178 / 381 \\
2000 / 3434 \\
2000 / 3560 \\
81.0\end{array}$ \\
\hline $\begin{array}{l}\text { Products: } \\
\text { CO } \\
\mathrm{H}_{2} \\
\mathrm{CO}_{2} \\
\mathrm{C} 1-\mathrm{C} 3\end{array}$ & $\begin{array}{r}0.26 \\
0.02 \\
14.22 \\
1.35 \\
0.00 \\
15.85\end{array}$ & $\begin{array}{r}12.17 \\
0.05 \\
7.74 \\
0.17 \\
0.19 \\
20.32\end{array}$ & $\begin{array}{r}-33.63 \\
0.41 \\
65.04 \\
1.03 \\
0.06 \\
32.91\end{array}$ & $\begin{array}{r}-54.25 \\
1.01 \\
73.46 \\
0.97 \\
2.90 \\
24.09\end{array}$ \\
\hline $\begin{array}{l}\mathrm{H}_{2} \mathrm{~S} \\
\text { Total GaS } \\
\mathrm{H}_{2} \mathrm{O}\end{array}$ & $\begin{array}{l}-1.17 \\
-0.74 \\
32.08 \\
53.99 \\
84.16\end{array}$ & $\begin{array}{r}7.37 \\
0.14 \\
42.55 \\
29.61 \\
79.68\end{array}$ & $\begin{array}{r}-12.96 \\
-0.81 \\
12.35 \\
68.50 \\
67.08\end{array}$ & $\begin{array}{r}-22.75 \\
-0.96 \\
18.97 \\
80.65 \\
75.91\end{array}$ \\
\hline Ash & & & & \\
\hline IOM & & & & \\
\hline $\begin{array}{l}\text { THF Solubles } \\
\text { Total Liquid }\end{array}$ & & & & \\
\hline
\end{tabular}

The fact that product quality is improved through the use of a hydrogendonating solvent can be seen in the molar hydrogen-to-carbon ratios of the products of the tests. The molar $\mathrm{H}: \mathrm{C}$ ratio for the tests using $\mathrm{HAO}$. $\mathrm{C}$ as the solvent was generally higher than the molar $\mathrm{H}: \mathrm{C}$ ratio for the tests in which either $\mathrm{AO4}$ (coal-derived anthracene nil) or tetralin were used. In addition, increases in molar $\mathrm{H}: \mathrm{C}$ ratios were noted for some of the tests in which HA061 was used as the solvent, most often when $C O$ was present as the solubilization reductant. Increases in molar $\mathrm{H}: \mathrm{C}$ ratios were not noted when $\mathrm{AO} 4$ was the solvent. The highest product molar $\mathrm{H}: \mathrm{C}$ ratio was produced when the solubilization processing conditions consisted of a temperature of $375^{\circ} \mathrm{C}$, a pressure of 3500 psi, a residence time of 60 minutes, and the use of $\mathrm{CO}$ as the reductant. 
TABLE 7

Summary of Solvation Tests using Hydrogen-Donating Solvents

\begin{tabular}{|c|c|c|c|c|c|c|c|c|c|c|}
\hline & N476 & N477 & N480 & N483 & N484 & N485 & N486 & N487 & $\mathrm{N} 497$ & N499 \\
\hline $\begin{array}{l}\text { Products } \\
\mathrm{CO} \\
\mathrm{H}_{2} \\
\mathrm{CO}_{2} \\
\mathrm{Cl}^{\circ}-\mathrm{C} 3 \\
\mathrm{H}_{2} \mathrm{~S} \\
\text { Total Gas }\end{array}$ & $\begin{array}{r}0.26 \\
0.45 \\
13.52 \\
1.19 \\
0.20 \\
15.62\end{array}$ & $\begin{array}{l}0.14 \\
0.02 \\
7.48 \\
0.67 \\
0.00 \\
8.31\end{array}$ & $\begin{array}{r}0.21 \\
0.01 \\
9.82 \\
0.80 \\
0.00 \\
10.84\end{array}$ & $\begin{array}{r}0.22 \\
0.02 \\
12.64 \\
1.13 \\
0.02 \\
14.03\end{array}$ & $\begin{array}{r}0.26 \\
0.02 \\
14.22 \\
1.35 \\
0.00 \\
15.85\end{array}$ & $\begin{array}{r}0.38 \\
0.19 \\
15.29 \\
1.60 \\
0.09 \\
17.55\end{array}$ & $\begin{array}{r}-33.63 \\
0.41 \\
65.04 \\
1.03 \\
0.06 \\
32.91\end{array}$ & $\begin{array}{r}1.72 \\
0.03 \\
12.84 \\
1.10 \\
0.00 \\
15.69\end{array}$ & $\begin{array}{r}0.61 \\
0.03 \\
19.04 \\
1.42 \\
0.07 \\
21.17\end{array}$ & $\begin{array}{r}33.42 \\
0.08 \\
17.07 \\
1.91 \\
0.00 \\
52.48\end{array}$ \\
\hline $\begin{array}{l}\mathrm{H}_{2} \mathrm{O} \\
\text { Ash } \\
\text { IOM } \\
\text { Solubles } \\
\text { Total Liquid }\end{array}$ & $\begin{array}{l}-4.77 \\
0.53 \\
74.7 \\
13.93 \\
84.39\end{array}$ & $\begin{array}{l}-3.87 \\
-0.34 \\
38.47 \\
57.45 \\
91.71\end{array}$ & $\begin{array}{r}6.02 \\
-0.05 \\
46.87 \\
36.31 \\
89.15\end{array}$ & $\begin{array}{r}4.01 \\
-0.69 \\
33.07 \\
49.57 \\
85.96\end{array}$ & $\begin{array}{l}-1.17 \\
-0.74 \\
32.08 \\
53.99 \\
84.16\end{array}$ & $\begin{array}{r}1.87 \\
-0.95 \\
27.82 \\
53.71 \\
82.45\end{array}$ & $\begin{array}{r}-12.96 \\
-0.81 \\
12.35 \\
68.50 \\
67.08\end{array}$ & $\begin{array}{r}3.98 \\
-0.64 \\
41.00 \\
39.97 \\
84.31\end{array}$ & $\begin{array}{r}7.79 \\
-0.90 \\
51.22 \\
20.72 \\
78.83\end{array}$ & $\begin{array}{l}-5.53 \\
-1.21 \\
41.78 \\
12.47 \\
47.52\end{array}$ \\
\hline $\begin{array}{l}\text { Feed } H: C^{c} \\
\text { Product } H: C^{c}\end{array}$ & $\begin{array}{l}0.7627 \\
0.6773\end{array}$ & $\begin{array}{l}0.8912 \\
0.8922\end{array}$ & $\begin{array}{l}0.9587 \\
0.8183\end{array}$ & $\begin{array}{l}0.8948 \\
0.8500\end{array}$ & $\begin{array}{l}0.9133 \\
0.8600\end{array}$ & $\begin{array}{l}0.9075 \\
0.8885\end{array}$ & $\begin{array}{l}0.9121 \\
0.9208\end{array}$ & $\begin{array}{l}0.9031 \\
0.8558\end{array}$ & $\begin{array}{l}1.0221 \\
0.8668\end{array}$ & $\begin{array}{l}0.8934 \\
0.8701\end{array}$ \\
\hline
\end{tabular}

\footnotetext{
None used.
Values given as wt\% of maf coal fed to reactor. Negative values indicate a consumption; positive values indicate a production.
}

c Molar H-to-C ratio. 
The data also indicated that:

- Nascent hydrogen from the water/gas shift reaction was more readily used than hydrogen gas.

- The use of $\mathrm{H}_{2} \mathrm{~S}$ improved solubilization.

- Merely heating the feed slurry did not improve solubilization.

- Solubilization of the coal could be improved through the use of specific, solvent-dependent pretreatments.

\subsection{Step 3 - Polishing}

The purpose of the polishing step is to complete the solubilization of the more intractable portions of the coal prior to hydrotreatment. The mechanistic study (discussed in Section 3.1) indicated that the coal-derived liquids were very phenolic in nature. Using the chemistry rule of "like dissolves like," this knowledge was incorporated into the design of the polishing step.

Two solubilization/polishing test sequences were performed. The run conditions are summarized in Table 8 , while Table 9 presents the product slates of the tests. Table 9 shows that virtually all of the solvent used during the test was recovered during the processing. Conversion to THF solubles calculated for the tests was high: 96.4 wt\% for the test with HA061 as the polishing-step additive and $101.6 \mathrm{wt} \%$ for the test with phenolic solvent as the polishing-step additive. The product slate indicates that minimal quantities of gas were produced during processing in either case, relative to the moisture- and ash-free (maf) coal fed to the system. In both combinations, about $90 \mathrm{wt} \%$ of the maf coal fed to the system was converted to soluble material, which was the desired product. The run performed with HA061 added during the polishing step resulted in a lighter product, in that the resulting soluble material consisted of both soluble resid and distillable oils. The product of the test in which phenolic solvent was added during the polishing step was comprised almost exclusively of soluble resid. Insoluble organic material was present in the product of the HA061 test, but was not detectable in the product of the phenolic solvent test.

The presence of excess $\mathrm{H}_{2} \mathrm{~S}$ in the product gas of the $\mathrm{N} 443 / 444$ run sequence in which HA061 was added in the polishing step indicates that not only was the sulfur incorporated from the $\mathrm{H}_{2} \mathrm{~S}$ completely removed, but some sulfur present in the feedstocks was also removed. In the phenolic solventadded test, almost all of the sulfur incorporated into the coal structure during the processing sequence was removed.

\subsection{Step 4 - Hydrotreatment}

Steps 1-3 (pretreatment, solubilization, and polishing) were performed in an integrated fashion. The products were catalytically hydrotreated to demonstrate the maximum hydrotreatability of the solubilized slurry and to provide products that could be compared to the products of existing processes. The testing was performed using the "best" pretreatment and solubilization. steps that had been evaluated during earlier work (see Sections 3.2 and 3.3). 
TABLE 8

Summary of Polishing Step Tests

\begin{tabular}{|c|c|c|c|c|c|c|}
\hline & $\begin{array}{l}\text { Run } \\
\text { No. }\end{array}$ & $\begin{array}{c}\text { Temp. } \\
\left(C^{\circ}\right)\end{array}$ & $\begin{array}{c}\text { Avg. Press. } \\
\text { (psi) }\end{array}$ & $\begin{array}{c}\text { Res. Time } \\
\text { (min) }\end{array}$ & Reductant & Additive \\
\hline $\begin{array}{l}\text { Solubilization } \\
\text { Polishing }\end{array}$ & $\begin{array}{l}\text { N443 } \\
\text { N444 }\end{array}$ & $\begin{array}{l}374 \\
430\end{array}$ & $\begin{array}{l}3373 \\
3831\end{array}$ & $\begin{array}{l}60 \\
12\end{array}$ & $\begin{array}{l}\mathrm{CO} \\
\mathrm{H}_{2}\end{array}$ & $\begin{array}{c}\mathrm{H}_{2} \mathrm{~S} \\
\mathrm{HAO61}\end{array}$ \\
\hline $\begin{array}{l}\text { Solubilization } \\
\text { Polishing }\end{array}$ & $\begin{array}{l}\text { N447 } \\
\text { N448 }\end{array}$ & $\begin{array}{l}374 \\
412\end{array}$ & $\begin{array}{l}3470 \\
4092\end{array}$ & $\begin{array}{l}60 \\
19\end{array}$ & $\begin{array}{l}\mathrm{CO} \\
\mathrm{H}_{2}\end{array}$ & $\begin{array}{l}\mathrm{H}_{2} \mathrm{~S} \\
\mathrm{POH}\end{array}$ \\
\hline
\end{tabular}

TABLE 9

Mass Balances and Product Slates of the Polishing Tests

\begin{tabular}{lrr}
\hline & $N 443 / N 444$ & $N 447 / N 448$ \\
\hline Additive" & $H A 061$ & $P O H$ \\
Material Balance, wt\% & 96.91 & 97.40 \\
Solvent Recovery, wt\% & 102.36 & 100.30 \\
Conversion to THF Solubles, wt\% & 96.44 & 101.56 \\
Product Slate, wt\% maf coal in & & \\
CO & & -36.12 \\
$\mathrm{H}_{2}$ & -34.82 & -0.64 \\
$\mathrm{CO}$ & -0.79 & 67.35 \\
$\mathrm{Cl}$ C3 & 66.78 & 2.22 \\
$\mathrm{H}_{2} \mathrm{~S}$ & 2.14 & -1.64 \\
$\mathrm{H}_{2} \mathrm{O}$ & 2.53 & -16.90 \\
Ash & -23.32 & -2.56 \\
IOM & -1.13 & -2.03 \\
Distillable 0ils & 4.91 & 1.47 \\
Soluble Resid & 11.99 & 88.85 \\
\hline
\end{tabular}

- Additive was added in an amount equal to approximately 25 wt\% of the original pasting solvent.

- Positive values indicate production of the component; negative values indicate consumption. 
Figure 4 shows the experimental matrix for the tests. As the figure shows, the testing was performed according to a tree diagram-type of matrix.

Performing the tests in this manner, i.e, using the same feed slurry whenever possible, enabled direct comparisons to be made between the run sequences.

Two Step 1 runs were performed at identical conditions to obtain sufficient pretreated slurry for the remaining processing. The pretreated slurries from these two runs, N553 and N554, were combined into a bulk sample. (All analyses were performed on the bulk sample rather than on the individual pretreated slurries.) Pretreated slurry was then solubilized in two batches, one at $-375^{\circ} \mathrm{C}$ (N555) and one at $\sim 350^{\circ} \mathrm{C}$ (N556). The solubilized products of each of these Step 2 runs were polished (Step 3) at either $460^{\circ} \mathrm{C}$ (N558 and N557) or $435^{\circ} \mathrm{C}$ ( $N 559$ and N560) with a small amount of added cresylic acid. Each polished product was combined with a heavier vehicle solvent (hydrogenated anthracene $0 i 1)$ and distilled to remove a quantity of water and light, highly oxygenated solvent/coal-derived liquid equal to that added during the polishing step. Finally, each of the polished product slurries from step 3 was hydrotreated in Step 4 (N562, N564, N563, and N566, respectively). The multistep run sequences are referred to in this report by the run numbers of their hydrotreatment steps. The specific run solvents, additives, and conditions for each step of the four run sequences are given in Table 10.

Testing was performed in the EERC's hot-charge, batch autoclave system. The 1-gallon autoclave was used when larger quantities were processed (i.e., during Steps 1 and 2 [pretreatment and solubilization]). The 1-liter autoclave was used for the polishing and catalytic upgrading (Steps 3 and 4). Karl Fischer water, ash, and tetrahydrofuran (THF) solubility analyses were performed on the feed and product slurries. Due to a lack of funding, elemental analyses were performed for only a few runs.

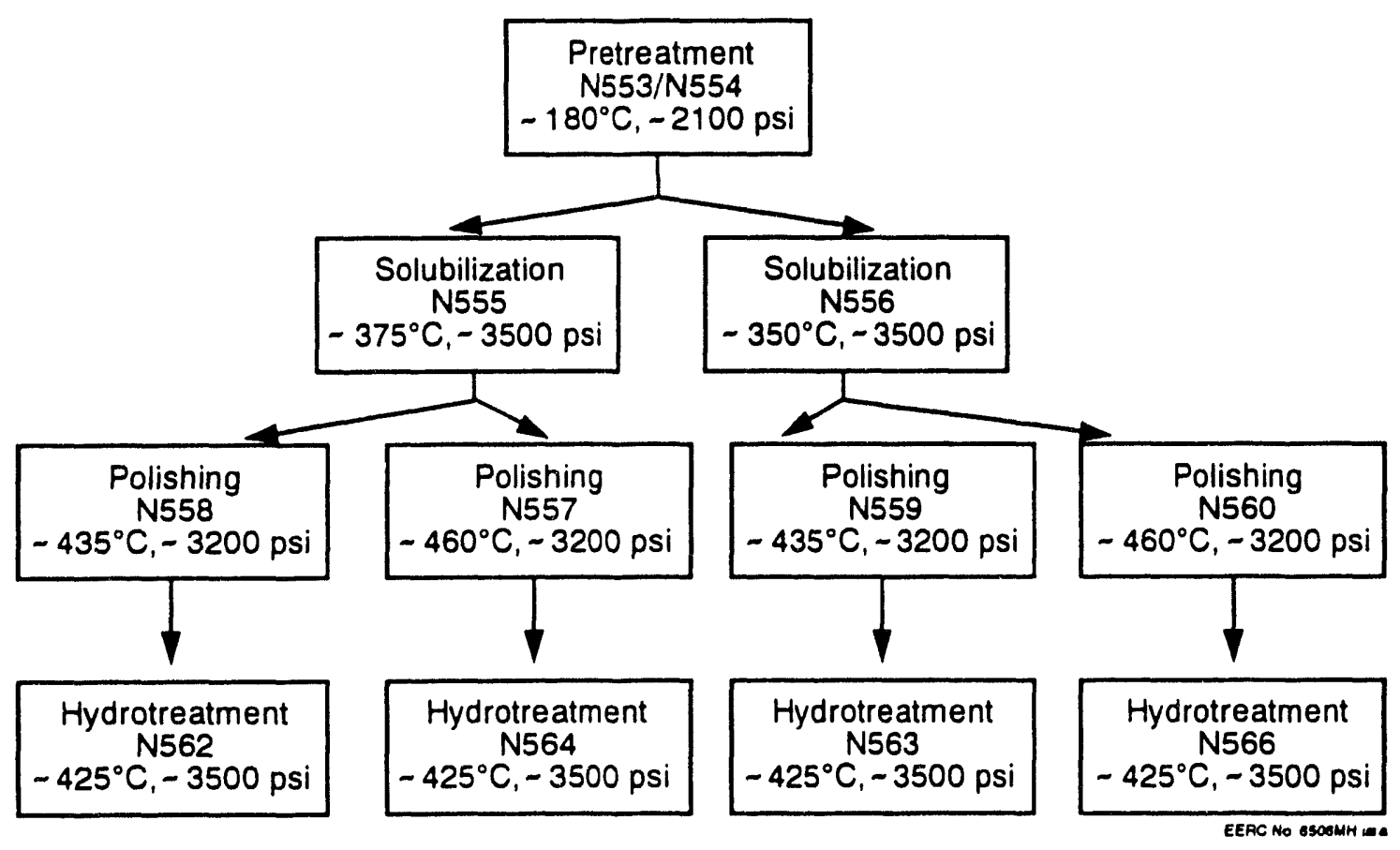

Figure 4. Experimental matrix for integrated run series. 
TABLE 10

Conditions of Integrated Run Series

\begin{tabular}{|c|c|c|c|c|}
\hline & N562 & N563 & N564 & N565 \\
\hline $\begin{array}{l}\text { Step 1 - Pretreatment } \\
\text { Run No. } \\
\text { Solvent } \\
\text { Additive } \\
\text { Gas } \\
\text { Avg. Temp., }{ }^{\circ} \mathrm{C} \\
\text { Max. Temp., }{ }^{\circ} \mathrm{C} \\
\text { Avg. Pressure, psi } \\
\text { Max. Pressure, psi } \\
\text { Residence Time, min }\end{array}$ & $\begin{array}{c}N 553+N 554 \\
H A 061^{*} \\
H_{2} S \\
A r \\
179 \\
184 \\
2064 \\
2100 \\
60\end{array}$ & $\begin{array}{c}\mathrm{N} 553+\mathrm{N} 554 \\
\mathrm{HAO61} \\
\mathrm{H}_{2} \mathrm{~S} \\
\mathrm{Ar} \\
179 \\
184 \\
2064 \\
2100 \\
60\end{array}$ & $\begin{array}{c}N 553+N 554 \\
\mathrm{HA061} \\
\mathrm{H}_{2} \mathrm{~S} \\
\mathrm{Ar} \\
179 \\
184 \\
2064 \\
2100 \\
60\end{array}$ & $\begin{array}{c}N 553+N 554 \\
H A 061 \\
H_{2} S \\
A r \\
179 \\
184 \\
2064 \\
2100 \\
60\end{array}$ \\
\hline $\begin{array}{l}\text { Step } 2-\text { Solubilization } \\
\text { Run No. } \\
\text { Feed } \\
\text { Additive } \\
\text { Gas } \\
\text { Avg. Temp., }{ }^{\circ} \mathrm{C} \\
\text { Max. Temp. }{ }^{\circ} \mathrm{C} \\
\text { Avg. Pressure, psi } \\
\text { Max. Pressure, psi } \\
\text { Residence Time, min }\end{array}$ & $\begin{array}{c}\text { N555 } \\
\text { N553+N554 } \\
\text { None } \\
\text { CO } \\
375 \\
385 \\
3488 \\
3600 \\
60\end{array}$ & $\begin{array}{c}\text { N556 } \\
\text { N553+N554 } \\
\text { None } \\
\text { C0 } \\
353 \\
354 \\
3460 \\
3515 \\
60\end{array}$ & $\begin{array}{c}\text { N555 } \\
\text { N553+N554 } \\
\text { None } \\
\text { C0 } \\
375 \\
385 \\
3488 \\
3600 \\
60\end{array}$ & $\begin{array}{c}\text { N556 } \\
\text { N553+N554 } \\
\text { None } \\
\text { C0 } \\
353 \\
354 \\
3460 \\
3515 \\
60\end{array}$ \\
\hline $\begin{array}{l}\text { Step } 3 \text { - Polishing } \\
\text { Run No. } \\
\text { Feed } \\
\text { Additive } \\
\text { Gas } \\
\text { Avg. Temp., }{ }^{\circ} \mathrm{C} \\
\text { Max. Temp., }{ }^{\circ} \mathrm{C} \\
\text { Avg. Pressure, psi } \\
\text { Max. Pressure, psi } \\
\text { Residence Time, min }\end{array}$ & $\begin{array}{c}N 558 \\
N 555 \\
\mathrm{CA}^{\mathrm{b}} \\
\mathrm{H}_{2} \\
435 \\
437 \\
3190 \\
3226 \\
20\end{array}$ & $\begin{array}{c}N 559 \\
N 556 \\
\text { CA1 } \\
H_{2} \\
433 \\
435 \\
3363 \\
3435 \\
20\end{array}$ & $\begin{array}{c}N 557 \\
N 555 \\
C A 1 \\
H_{2} \\
458 \\
461 \\
3200 \\
3275 \\
20\end{array}$ & $\begin{array}{c}N 560 \\
N 556 \\
C A 1 \\
H_{2} \\
461 \\
465 \\
3439 \\
3540 \\
20\end{array}$ \\
\hline $\begin{array}{l}\text { Step } 4 \text { - Hydrotreatment } \\
\text { Run No. } \\
\text { Feed } \\
\text { Additive } \\
\text { Gas } \\
\text { Avg. Temp., }{ }^{\circ} \mathrm{C} \\
\text { Max. Temp., }{ }^{\circ} \mathrm{C} \\
\text { Avg. Pressure, psi } \\
\text { Max. Pressure, psi } \\
\text { Residence Time, min }\end{array}$ & $\begin{array}{c}\mathrm{N} 562 \\
\mathrm{~N} 558 \\
\text { She } 11424 \\
\mathrm{H}_{2} \\
423 \\
426 \\
3459 \\
3655 \\
180\end{array}$ & $\begin{array}{c}N 563 \\
N 559 \\
\text { She } 11424 \\
H_{2} \\
424 \\
425 \\
3461 \\
3635 \\
180\end{array}$ & $\begin{array}{c}N 564 \\
N 557 \\
\text { She } 11424 \\
H_{2} \\
422 \\
426 \\
3525 \\
3675 \\
180\end{array}$ & $\begin{array}{c}N 566 \\
N 560 \\
\text { She } 11424 \\
H_{2} \\
420 \\
421 \\
3554 \\
3675 \\
180\end{array}$ \\
\hline
\end{tabular}

- Hydrogenated coal-derived anthracene oil.

bresylic acid solvent. 
Mass and material balances were performed for the run sequences based upon maf coal fed to the pretreatment step. Allowances were made for the removal of sample aliquots for analysis. Combining the analytical results and the material balances resulted in the calculation of product slates for the integrated run series. In other words, product slates were calculated for the entire four-step system based upon maf coal fed to the pretreatment step. These product slates are presented in Table 11.

Tables 12 and 13 summarize this information and organize it in a simplified manner to permit easier comparisons between run series. As seen in Table 12, comparison of solubilization (Step 2) at $350^{\circ} \mathrm{C}$ and at $375^{\circ} \mathrm{C}$ shows that higher-temperature solubilization ultimately resulted in less gas + water production (about 17 wt\% compared to $34 \mathrm{wt} \%$ ) and more total liquid product (about 70-80 wt\% compared to $59 \mathrm{wt} \%$ ) than solubilization at the lower temperature. More of the hydrotreated liquid product was in the form of premium distillate (66 wt\% compared to 31-56 wt\%) when the slurry had been solubilized at $375^{\circ} \mathrm{C}$.

TABLE 11

Product Slates of Integrated Run Series

\begin{tabular}{|c|c|c|c|c|}
\hline Hydrotreatment Run No. & N562 & N563 & N564 & N566 \\
\hline Solubilization Temp., ${ }^{\circ} \mathrm{C}$ & 375 & 353 & 375 & 353 \\
\hline Polishing Temp., ${ }^{\circ} \mathrm{C}$ & 435 & 433 & 458 & 461 \\
\hline $\begin{array}{l}\text { Gas out } \\
\mathrm{CO} \\
\mathrm{H}_{2} \\
\mathrm{CO}_{2} \\
\mathrm{Cl}^{2}-\mathrm{C} 3 \\
\mathrm{H}_{2} \mathrm{~S}\end{array}$ & $\begin{array}{r}-65.92 \\
-1.50 \\
114.26 \\
11.53 \\
1.48\end{array}$ & $\begin{array}{r}-36.92 \\
-0.93 \\
93.05 \\
13.50 \\
0.58\end{array}$ & $\begin{array}{r}-63.20 \\
-5.46 \\
116.00 \\
11.70 \\
0.92\end{array}$ & $\begin{array}{r}-36.44 \\
-2.64 \\
93.65 \\
14.38 \\
0.42\end{array}$ \\
\hline $\mathrm{H}_{2} \mathrm{O}$ & -42.57 & -34.12 & -42.27 & -35.32 \\
\hline Total Gas + Water & 17.27 & 35.16 & 17.68 & 34.04 \\
\hline $\begin{array}{l}\text { Liquid out } \\
\text { Oxygenated Liquids } \\
\text { Premium Distillate } \\
\text { Soluble Residuum }\end{array}$ & $\begin{array}{r}9.13 \\
66.04 \\
4.12\end{array}$ & $\begin{array}{r}-0.13 \\
56.35 \\
3.33\end{array}$ & $\begin{array}{r}2.49 \\
67.08 \\
3.26\end{array}$ & $\begin{array}{r}17.77 \\
31.46 \\
9.00\end{array}$ \\
\hline Total Liquids & 79.29 & 59.55 & 72.83 & 58.23 \\
\hline Unconverted IOM & 3.36 & 7.60 & 9.12 & 6.43 \\
\hline Total, All Products & 99.93 & 102.31 & 99.64 & 98.70 \\
\hline
\end{tabular}


TABLE 12

Comparison of Effect of Solubilization and Polishing Temperatures on Final Hydrotreated Product S1 ate*

\begin{tabular}{lcrrr}
\hline Hydrotreatment Run No. & N563 & N566 & N562 & N564 \\
Solubilization Step Temp., ${ }^{\circ} \mathrm{C}$ & 353 & 353 & 375 & 375 \\
Polishing Step Temp., ${ }^{\circ} \mathrm{C}$ & 433 & 461 & 435 & 458 \\
Gas + Water Yield & 35.16 & 34.04 & 17.27 & 17.68 \\
Liquid Yield & & & & \\
$\quad$ Distillate & 56.35 & 31.46 & 66.04 & 67.08 \\
$\quad$ Soluble Resid & 3.33 & 9.00 & 4.12 & 3.26 \\
$\quad$ Oxygenates & -0.13 & 17.77 & 9.13 & 2.49 \\
$\quad$ Total & 59.55 & 58.23 & 79.29 & 72.83 \\
Conversion, \% maf coal & & & & \\
$\quad$ fed to system & 92.40 & 93.57 & 96.64 & 90.88 \\
\hline
\end{tabular}

- Yields are given as percentage of maf coal fed to the pretreatment step. Positive values indicate production of a component; negative values indicate a consumption.

TABLE 13

Comparison of Gas Plus Water Production for Integrated Run Series"

\begin{tabular}{lcccc}
\hline Hydrotreatment Run No. & N563 & N566 & N562 & N564 \\
Solubilization Step Temp., ${ }^{\circ} \mathrm{C}$ & 353 & 353 & 375 & 375 \\
Polishing Step Temp., ${ }^{\circ} \mathrm{C}$ & 433 & 461 & 435 & 458 \\
Pretreatment & 2.00 & 2.00 & 2.00 & 2.00 \\
Solubilization & 17.95 & 17.95 & 8.29 & 8.29 \\
Polishing & & & & \\
CO2 & 4.77 & 5.42 & 2.55 & 4.50 \\
C1-C3 & 6.77 & 7.62 & 2.91 & 2.75 \\
Other & 3.01 & 2.61 & -0.21 & 0.15 \\
Total Polishing & 14.55 & 15.65 & 5.25 & 7.40 \\
Hydrotreatment & 0.66 & -1.56 & 1.73 & 0.00 \\
& & & & \\
\hline
\end{tabular}

- Gas + water yields are given as the percentage of maf coal fed to the pretreatment step. Positive values indicate production of a component; negative values indicate a consumption. 
When the polishing (Step 3) temperatures are compared, it can be seen that the higher-temperature polishing $\left(\sim 460^{\circ} \mathrm{C}\right)$ resulted in yields that were similar to those of the lower-temperature polishing $\left(\sim 435^{\circ} \mathrm{C}\right)$, but that the liquid product slates were very different. This is especially noticeable for $\mathrm{N} 563$ and $\mathrm{N} 566$, the run series with $353^{\circ} \mathrm{C}$ solubilization. The lowertemperature polishing step resulted in substantial differences in yields of distillate, soluble resid, and oxygenates. In this case, the higher polishing temperature seems to have cracked more of the coal-derived material, resulting in the production of far more oxygenates at the expense of distillate production. The higher polishing temperature also resulted in an increased production of soluble resid. The same differences were not as obvious for the N562 and $\mathrm{N} 564$ run series with $375^{\circ} \mathrm{C}$ solubilization. Slightly more distillate and soluble resid were produced when the higher polishing temperature was used, but far fewer oxygenates were produced. The highest overall conversions were produced when polishing was performed at the lower temperature. The higher polishing temperature seems to have retrograded some of the phenolic material, resulting in a conversion loss at the expense of the production of the oxygenates.

A comparison of the gas + water yields is presented in Table 13 . As the table shows, $2.0 \mathrm{wt} \%$ of the maf coal fed to the system was removed during the pretreatment (Step 1) as gaseous products. Twice as much of the maf coal left the system as gas during both the solubilization and polishing steps (Steps 2 and 3 , respectively) when the solubilization was performed at $\sim 350^{\circ} \mathrm{C}$. The gaseous product slates of the polishing step were very different for the run series performed at higher solubilization temperatures compared to those performed at lower solubilization temperatures. It appears that more $\mathrm{CO}_{2}$ is produced at higher polishing temperatures, but that the hydrocarbon gas (C1-C3) yield is about the same. studies:

The following conclusions could be drawn from the results of these

- As part of the integrated run sequence, solubilization (Step 2) performed at $375^{\circ} \mathrm{C}$ produces higher yields of better-quality hydrotreated liquid products than solubilization performed at $\sim 350^{\circ} \mathrm{C}$.

- As part of the integrated run sequence, polishing (Step 3) performed at $\sim 435^{\circ} \mathrm{C}$ results in desirable liquid product slates and high conversion levels without the retrograding that was noticed at the higher polishing temperature.

- Of the run sequences tested, it would appear that a run sequence incorporating a solubilization step at $375^{\circ} \mathrm{C}$ and a polishing step at $435^{\circ} \mathrm{C}$ (i.e., a run series similar to that of N562) would produce the greatest yield of high-quality, desirable products.

\subsection{CONCLUSIONS}

The positive results of the tests performed to date using the EERC's multistep LRC liquefaction process indicate that future work should be performed in two areas: 
- The four-step sequence matrix should be performed using phenolic solvent rather than $\mathrm{HAO61.}$

- The range of effective hydrotreatment conditions should be determined.

After these two areas have been investigated, process optimization on a batch scale can begin, followed by one or more continuous demonstration runs.

\subsection{REFERENCES}

1. Committee on Production Technologies for Liquid Transportation Fuels, Energy Engineering Board, Commission on Engineering and Technical Systems, and National Research Council. 1990. Fuels to Drive Our Future. Washington, DC: National Academy Press.

2. Rindt, J.R. and S.J. Cisney. 1983. Low-Temperature Liquefaction of North Dakota Lignite. Presented at the Direct Coal Liquefaction Contractors' Review Conference, 16-17 November, Pittsburgh, PA. 


\section{GENERIC RUN INSTRUCTIONS}

Slurry (can be fed to any of the first three steps): solvent-to-maf coal ratio $=3: 1$

If necessary, water is added to bring the water content to 30 wt\% of the maf coal in the feed slurry

When used, additives $=5$ wt\% of the maf coal in the original feed slurry

\section{Step 1 - Pretreatment Step}

Slurry as mixed according to the instructions given above

Additive may be used according to the instructions given above

Gas is added in an amount equal to 10 gmoles gas $/ 200 \mathrm{~g}$ maf coal in original feed slurry

\section{Step 2 - Solubilization Step}

Slurry as mixed according to the instructions given above $\underline{\text { R }}$ pretreated slurry from pretreatment step

Additive may be used according to the instructions given above

Gas is added in an amount equal to 10 gmoles gas $/ 200 \mathrm{~g}$ maf coal in original feed slurry

\section{Step 3 - Polishing Step}

Slurry as mixed according to the instructions given above (for a blank run) $\underline{O R}$ product slurry from solubilization step

Gas is added in an amount equal to 10 gmoles gas $/ 200 \mathrm{~g}$ maf coal in original feed slurry

\section{Interstep Distillation}

Prior to distillation, vehicle solvent is added in a quantity equal to what is expected will be removed as overheads; i.e., equal to the cumulative quantity of oxygenated solvent added during any of the previous steps.

Distillation takes place at nominally $120^{\circ} \mathrm{C}$ and 4 psia. 


\section{Step 4 - Catalytic Hydrotreatment}

Solubilized and/or polished slurry is used as the feed

Shell 424 catalyst is used in a weight ratio of 1 part catalyst to 2 parts maf coal in the original feed slurry

Hydrotreatment is performed at a constant gas pressure of $2500 \mathrm{psi}$. This pressure is maintained during heatup and hydrotreatment through the addition of gas.

Specific runs can be reproduced by following these instructions and performing the run using the gas, additive, and operating conditions listed in the table in the main body of this report. 
6.0 GASIFICATION RESEARCH 
6.1 Production of Hydrogen and By-Products from Coals 


\title{
CATALYTIC GASIFICATION OF LOW-RANK COALS FOR HYDROGEN PRODUCTION
}

Final Technical Progress Report

for the Period April 1, 1986, to September 30, 1992

by

\author{
William B. Hauserman, PE \\ Senior Research Engineer \\ Energy and Environmental Research Center \\ University of North Dakota \\ Box 8213, University Station \\ Grand Forks, North Dakota 58202-8213
}

Task Contracting Officer's Representative: Justin Beeson

for

U.S. Department of Energy

Morgantown Energy Technology Center

P.0. Box 880, MS CO4

Morgantown, West Virginia 26507-0880

December 1992

Work Performed under Cooperative Agreement No. DE-FC21-86MC10637 
LIST OF FIGURES ....................... . LIST OF TABLES ..................... $\ldots \ldots$

1.0 INTRODUCTION AND SCOPE $\ldots \ldots \ldots \ldots$

2.0 PROJECT JUSTIFICATION . . . . . . . . . . . . . 1

3.0 OBJECTIVES: ORIGINAL AND FINAL .............. 1

4.0 PROJECT HISTORY: ACCOMPLISHMENTS AND PROBLEMS . . . . . . . 3

5.0 SALIENT CONCLUSIONS $\ldots \ldots \ldots 6 \ldots$

6.0 RECOMMENDATIONS ...................... 7

7.0 BIBLIOGRAPHY $\ldots \ldots \ldots \ldots$ 


\section{LIST OF FIGURES}

Fiqure

Page

1 Markets for hydrogen from coal .............. 2

\section{LIST OF TABLES}

Table $\quad \underline{\text { Page }}$

1 Comparison of Normalized Product Gas Analyses. . . . . . . . 5 


\section{CATALYTIC GASIFICATION OF LOW-RANK COALS FOR HYDROGEN PRODUCTION}

\subsection{INTRODUCTION AND SCOPE}

This is a final summary report by the Energy and Environmental Research Center (EERC) for a six-year program exploring the effects of catalytically enhanced reactivity of coals to accelerate gasification rates for the production of hydrogen and methane. This project has consisted of bench-scale laboratory efforts; continuous pilot-scale process simulations; literature surveys; limited efforts dealing with solid, liquid, and gaseous coproducts; and subcontracted economic feasibility studies. Most of the technical highlights of this project are covered in the reports and papers cited in the bibliography.

\subsection{PROJECT JUSTIFICATION}

Since the mid-1970s, the United States has been in a state of apprehension over the next energy crisis and in eager anticipation of the next generation of energy supplies. While still unresolved, it appears reasonably certain that, for decades to come, the U.S. will, or should, rely increasingly on coal, simply because it is cheap and we have a lot of it. It is also apparent that somewhere within the shifting, multiple scenarios predicted, there is an expanded market for hydrogen as an end product or as an essential intermediate. This is summarized in Figure 1, showing the full array of potential markets for hydrogen from coal. Except for reforming natural gas, itself a valuable commodity, no other means of hydrogen production appears to be approaching economic competitiveness within several decades. Therefore, any medium-term policy of increased hydrogen production must depend upon coal.

The primary emphasis of this project has been on the effects of catalysis to accelerate reaction rates and increase yields, thus increasing gasifier throughput capacities and reducing capital costs. The fundamental measurement of steam-char reaction rates and initial screening of possible catalysts is by thermogravimetric analysis (TGA), which is established as a standard evaluation tool, is cost-effective, and has provided most of the useful data to date. More costly continuous process testing then serves to predict yields, compositions, and throughput capacities and to reveal specific equipment design problems to be solved in the course of process design for commercialization.

\subsection{OBJECTIVES: ORIGINAL AND FINAL}

As defined in annual research plans and in other reports throughout this project, its initial objectives, restated briefly, have been as follows:

- To determine optimum gasifier conditions and catalyst selections for production of either hydrogen, methane, condensable products, marketable char, or activated carbon.

- To develop empirical kinetic models to predict product yields under real-world conditions. 


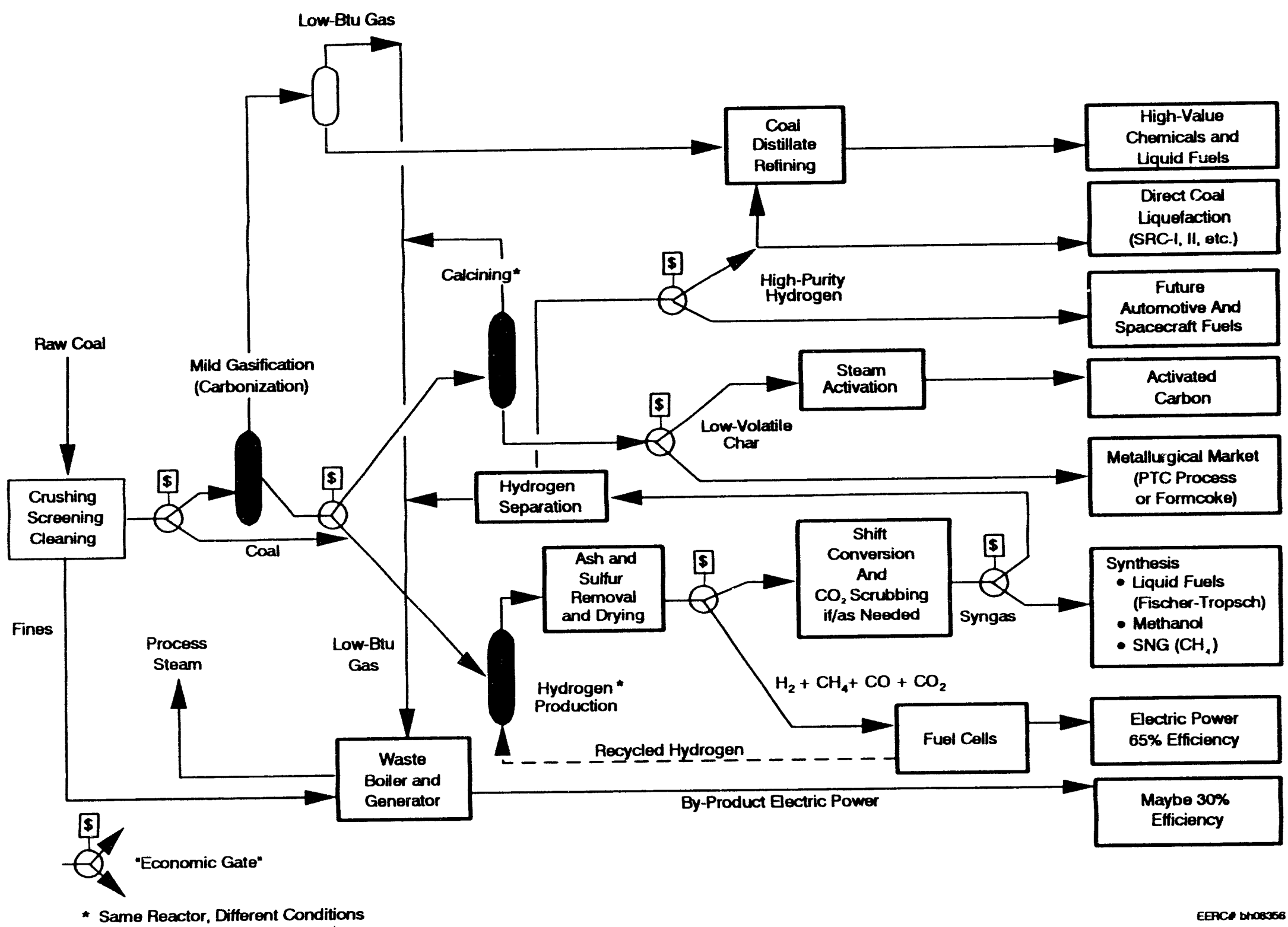

Figure 1. Markets for hydrogen from coal. 
- To explore the potential for in-bed sulfur capture.

- To apply these objectives primarily to rignite and subbituminous coals.

During the course of the project, emphasis was expanded to cover hydrogen-methane mixtures, as the preferred feed to advanced fuel cells, which if combined with gasifiers in integrated designs may eventually achieve overall efficiencies approaching $60 \%$. For this application, the project scope was expanded to include maximizing methane-hydrogen combinations from bituminous coals. These and future EERC efforts are being coordinated with Energy Research Corporation, a leader in the development of molten carbonate fuel cells.

In retrospect, exploring the original, broadly defined objectives has revealed considerable merit in more avenues of inquiry than could be covered by the time and funds available. In successive annual research plans, task objectives were adjusted to achieve balance between 1) generating more preliminary screening data, 2) demonstrating feasibility by continuous process testing, and 3) exploring peripheral areas, such as solid or liquid coproducts, catalyst recovery, and gas separation or enrichment, all within the severe limitations of time and funding and the priorities of related projects.

\subsection{PROJECT HISTORY: ACCOMPLISHMENTS AND PROBLEMS}

TGA analyses of a broad variety of coals and catalysts have been in progress throughout the project and are continuing under related projects. TGA tests have covered lignites, bituminous, and subbituminous coals, defining their intrinsic and catalyzed reactivities in the range of interest $\left(600^{\circ}\right.$ to $800^{\circ} \mathrm{C}$ ).

Peripheral studies included measurements of a specific surface area of coal and chars, as a physical factor critical to realization of the potential benefit of catalysis. The density of exposed active sites is proportional to the specific surface area, which changes during the course of gasification. A practical application of such knowledge is the production of activated carbon, by incomplete gasification under conditions to produce a char with maximum porosity and active site density. No pilot-scale tests were done in this area, although a literature survey of the state of the art in activated carbon production was produced.

Early in the project, a pilot-scale, atmospheric, continuous, fluidizedbed gasification system was designed and built. This pilot demonstration unit (PDU) had a feed capacity of $40 \mathrm{ib} / \mathrm{hr}$ injected by a screw feeder at the bottom of a refractory-lined vessel with a 6-inch inside diameter. As the mainstream of the project, extensive test matrices were carried out with two lignites and a subbituminous coal, at $700^{\circ}$ to $800^{\circ} \mathrm{C}$, in fluidized beds of limestone, silica, taconite, and coal alone. Added heterogeneous catalysts included trona, nahcolite (both common sodium-bearing minerals), and commercial $\mathrm{K}_{2} \mathrm{CO}_{3}$ and $\mathrm{CaCO}_{3}$, for comparison with each other and with the coal's native or intrinsic reactivities. Over 50 successful, scheduled runs were accomplished, generating engineering data for potential design use. 
Based on the best available set of PDU data, an economic feasibility study was done by Black and Veatch Engineers, to compare the profitability of plants producing high-purity hydrogen, methanol, or electricity by use of the product gas in a molten carbonate fuel cell. All cases assumed a subbituminous coal in a fluidized reactor bed of limestone as the catalyst.

An ongoing, parallel study by the EERC (experimental) and Fluor-Daniel Engineers, under subcontract to Energy Research Colporation, assumes an eastern bituminous coal, to produce hydrogen-methane mixtures for advanced fuel cells, which in turn may produce electricity at overall efficiencies approaching $60 \%$. This study has also addressed the use of potassiumimpregnated bituminous coal. It has, so far, produced a multioption engineering cost study by Fluor-Daniel, and continuing efforts are in progress.

Following completion of the above test matrix, the PDU was dismantled, rearranged, and integrated with an adjacent mild gasification process system, so that the hydrogen production PDU could, as an alternative function, serve as the calciner or second stage of the two-stage process to produce metallurgical char as well as gas and liquid products. The first-stage vessel was also designed to serve as either a carbonizer for mild gasification or as a pressurized fluid-bed combustion test unit. The modified process was also designed for operation at pressures up to $150 \mathrm{psig}$ and included a test loop for the evaluation of hot-gas cleanup devices.

Following this renovation, a substantial amount of time and funding was required to bring the PDU to full operational status. Although the combined, two-stage process, funded under other projects, was never operated as such, the calciner stage was again used briefly in the hydrogen production PDU mode. Following several shakedown tests and minor modifications, mainly of instrumentation and downstream gas cleanup and scrubbing components, the system was restored to complete operability, yielding some data on operation with Wyodak coal in a limestone bed, but with no catalyst impregnation. At this point, escalating operating costs indicated serious limitations on the extent of useful data that might be expected from continued pilot operation on this scale.

To extract more useful data from the remaining project funding, scheduled runs were downscaled and carried out in a $1-1 \mathrm{~b} / \mathrm{hr}$ continuous process unit (CPU), producing the most recent conclusions of this report. This smaller unit was electrically heated and fed steam and nitrogen only, without combustion of any of the fuel for process heat, making it a less complete process simulation than the larger PDU. This system had a well-established history of operation in the mild gasification mode. Fed at the $1-1 \mathrm{~b} / \mathrm{hr}$ level, with the residence time limited by a bed overflow, carbon consumption was incomplete, allowing determination of effective reactivities.

While yield data based on small pilot tests are of dubious validity, gas compositions are a fair prediction of what a mechanically similar, commercialscale version of the process should deliver. Table 1 compares inert-free product gas analyses from the most significant runs in this project with corresponding data from state-of-the-art gasifiers of other designs, all operating at far higher pressures than the near-atmospheric EERC tests and with no catalytic materials added. All three EERC data sets shown are for Wyodak subbituminous coal with a limestone bed only and no potassium 
TABLE 1

Comparison of Normalized Product Gas Analyses

\begin{tabular}{lrrrrrrr}
\hline & \multicolumn{2}{c}{$\begin{array}{c}\text { EERC } \\
\text { PDU }\end{array}$} & EERC & & & \\
& & CPU & \multicolumn{3}{c}{ State-of-the-Art Gasifiers } \\
\hline & & & & Lurgi & IGT & Destec & Texaco \\
& $(1)$ & $(2)$ & $(3)$ & $(4)$ & $(5)$ & $(6)$ & $(7)$ \\
\hline$\% \mathrm{H}_{2}$ & 44.7 & 45.5 & 58.6 & 40.9 & 38.6 & 41.0 & 38.5 \\
$\% \mathrm{CO}$ & 9.1 & 10.8 & 8.2 & 14.2 & 37.6 & 38.0 & 44.9 \\
$\% \mathrm{CO}_{2}$ & 43.0 & 40.1 & 25.0 & 32.3 & 19.7 & 21.0 & 16.5 \\
$\% \mathrm{CH}_{4}$ & 2.6 & 2.7 & 8.0 & 10.9 & 4.2 & 0.1 & 0.2 \\
$\mathrm{C}_{2}+$ & 0.5 & 0.8 & 0.3 & 1.6 & -- & -- & -- \\
\hline
\end{tabular}

(1) Early run, used as basis of Black and Veatch economic study.

(2) Final run of project, following renovation.

(3) Externally heated, no in-bed combustion.

(4) Great Plains Gasification Plant, Beulah, ND, fixed bed, large-scale commercial operation.

(5) Institute of Gas Technology, U-Gas Process, fluidized bed, pilot plant data, scheduled for commercialization.

(6) Dow Chemical Co., Plaquemine, LA, entrained bed, pilot plant data, process in commercial operation.

(7) Pilot plant data.

added. While overall yields, efficiencies, carbon conversion, and throughput capacities are optimized by proper process design for commercial-scale plants, Table 1 indicates that the simplest of process options covered by this study, a fluidized limestone bed with no potassium or other more effective catalyst added, is a promising source of high-hydrogen syngas for use in fuel cells or other hydrogen applications.

To augment TGA for feed-catalyst-condition screening, a new research tool, the integrated bench-scale gasifier (IBG) has completed preliminary shakedown testing and shows a good possibility of essentially replicating TGA data on a larger scale, of 200-300 grams, as compared with 20-50 milligrams for the TGA. Unlike the TGA, this unit can provide samples of residual ash or char and condensible liquid coproducts large enough for complete analys is and multiple or replicate gas samples. Extensive use of this unit is presently scheduled for two related projects.

All the conclusions, summarized below, favor impregnated potassium as the optimum catalyst. TGA data, however, indicate that sodium is roughly comparable, although it acts as a flux and causes agglomeration of char and ash. Sodium was rejected early in the project when pilot operations, on the PDU scale, feeding raw trona or nahcolite as the sodium source, revealed serious bed agglomeration or clinkering problems, which have al so been reported for high-sodium coals in other fluid-bed gasifiers. While sodium in any form appears unacceptable for use in fluidized-or fixed-bed gasifiers, it is far cheaper than potassium. A worthy area of further research would, therefore, be development of a novel gasifier with a violent circulation 
pattern to break up agglomerates. This is also important because any leaching process to recover potassium from the ash will inevitably recover and accumulate sodium from the coal in the potassium recycle.

Among peripheral interests pursued during the project was limited, exploratory testing of the vortex venturi concept, to enrich product gases, concentrating hydrogen and rejecting carbon dioxide, by means of a supercyclone achieving centrifugal force fields of $10,000 \mathrm{G}$ to $20,000 \mathrm{G}$, with laminar flow and no moving parts. Cold simulation, using costly helium-argon mixtures in very short tests in the final working days of the project, indicated that significant separations are possible at modest pressure drops. No further work is planned at present. If any future tests are to be costeffective, they must be far more extensive and be conducted on the site of a pressurized gasifier in continuous operation.

\subsection{SALIENT CONCLUSIONS}

The general, overriding conclusions from the TGA tests are as follows:

- Low-rank coals consistently show greater native or intrinsic reactivities than higher-rank coals.

- Reactivities, at the same temperature, may increase by up to two orders of magnitude, with the addition of certain catalysts.

- Heterogeneous or contact catalysis occurs when coal is simply mixed with granular catalytic materials, such as limestone, taconite, nahcolite, trona, or salts of potassium, calcium, or sodium. A durable heterogeneous catalyst may be a fluidized reactor bed of limestone or taconite.

- Homogeneous catalysis, which has proven consistently more effective than heterogeneous catalysis, occurs when the same catalytic elements in solution are chemically bonded to carboxylic active sites $\left(-\mathrm{COO}^{-}\right)$ on the coa?'s organic structure.

- Monovalent alkalies ( $K, \mathrm{Na}$ ) are far more effective than divalent alkali earths $(\mathrm{Ca}, \mathrm{Mg})$, when applied with the same degree of ionic mobility.

- Reactivity increases with catalyst addition up to a saturation point, at which all active sites are saturated, beyond which further addition of catalyst has no further effect.

The following are conclusions drawn from 1-16/hr CPU tests and are generally confirmed by TGA results:

- Impregnation of Wyodak coal with potassium hydroxide, at a potassium to fixed carbon ratio of around 0.2 or greater, roughly doubles the gasification reaction rate in fluidized beds of 1 imestone.

- Economically viable potassium impregnation will require an efficient leaching step for potassium recovery. Ash-leaching studies, 
associated with these tests, using Wyodak coal, indicate that potassium recoveries well over $95 \%$ can be achieved.

- Depending on the coal and potassium impregnation level, the high catalyst levels may cause some agglomeration problems in fluidized beds, which may be obviated by a bed of some crushed rock, such as 1 imestone or taconite, which will also contribute catalytic effects.

- In a fluidized bed of taconite, the reaction rate enhancement by potassium impregnation was substantially greater than in a limestone bed. This was not predictable from TGA measurements and is attributed to interaction between the potassium and reduced iron.

- Ash analyses and potassium balances for these tests indicated striking, consistent, but unexplained, differences as to how the potassium may be combined in beds of limestone, taconite, or coal ash alone. The mobility of potassium, and, hence, its catalytic effectiveness, appears to be substantially enhanced or limited by its reactions with mineral components in the bed or coal ash. Major differences can thus be expected in reactions between potassium or sodium catalysts and the ash of different coals, which will affect the ease of catalyst recovery.

- The CPU represents the barest minimum scale on which continuous process evaluation can be reliable. Any future tests limited to this scale should involve longer runs, multiple replications of material balance periods, and multiple samplings of all products to provide statistical credibility.

- In all gas samples, $\mathrm{H}_{2} \mathrm{~S}$ levels fell below the detectable analytical limit, precluding any observation of in-bed sulfur capture for the conditions studied. This is consistent with the use of low-sulfur $(S=0.63 \%$ maf) Wyodak coal.

- Results from these studies are inconclusive regarding the potential use of sodium as an economical alternative to potassium catalyst. Relatively large pilot-scale tests are needed to determine whether preimpregnation of sodium or potassium on feed coal, as homogeneous catalysts, will result in the agglomeration problems observed with heterogeneous trona and nahcolite earlier in this project. Because of the very small bed size, the $4-1 b / h r$ unit is not suitable to study mechanical factors affecting bed fluidization.

- All the work reported here assumes fluidized-bed gasification. There is no a priori reason to doubt that the rate enhancement by catalysis could not also be achieved in a more traditional "fixed-bed" gasifiers, such as existing Lurgi, Wellman-Galusha, or Stoic designs.

\subsection{RECOMMENDATIONS}

Based on the above conclusions and experience gained during this project, the following specific recommendations are submitted for continued, near-future research efforts or as design assumptions for engineering economic studies: 
- Feed coal impregnation with potassium, in any soluble form, is the recommended means of rate-enhancing catalysis, subject to sitespecific economics of supply and effectiveness of recovery by ash leaching.

- Taconite should be further explored as a bed material for gasifier design, in combination with potassium impregnation, if a bed material is needed for thermal and mechanical stability.

- TGA and IBG tests to establish saturation levels, with potassium and sodium, should be done on any candidate coal for catalytic gasification.

- For any combination of coal and heterogeneous catalyst under serious consideration, tests should be done to establish the form of the catalyst and its leachability from the coal's ash at continuous equilibrium conditions.

- Sodium, as a heterogeneous catalyst, should be evaluated as an economical alternative to potassium, but in connection with efforts on novel gasifier designs that can tolerate or prevent agglomeration.

- Future test matrices should include high-sulfur coals in taconite beds to test sulfur-capture effects, as well as the effects of sulfidation on alkali catalysts.

- The application of catalytic rate enhancement to fixed-bed gasification should be explored.

Based on overall observations made in the course of this project, some less-specific recommendations for the future course of research in catalytic gasification appear justified.

For firm engineering design data and identification of operating problems, future efforts should be done on a pilot plant scale. Such a facility should be dedicated to the single purpose of hydrogen/methane production, on a budgetary scale big enough to ensure complete shakedown operation and extended runs of at least a week on each set of conditions considered, with several replications of all runs showing promise for commercial-scale designs. Any such demonstration project must include operation for a year or two, so that shakedown operation and the inevitable aborted runs and anomalous data sets do not consume major portions of a project budget.

As one such potential system, the EERC has on hand nearly all of the components of a slagging, fixed-bed gasifier that consumed up to 22 tons/day of lignite and subbituminous coals at $350 \mathrm{psig}$, until 1982 . This unit could be reassembled and modified for use in an atmospheric fluidized-bed mode, with a probable capacity of 5 tons/day, based on the specific capacity of the more recent $40-1 \mathrm{~b} / \mathrm{hr}$ tests, using a limestone bed with no additional catalyst. This capacity could be substantially increased by operation at $350 \mathrm{psig}$ and possibly further doubled by the use of potassium catalyst.

As an alternative approach to further, completely subsidized pilot operations, a small demonstration gasification project should be considered, 
integrated with a utility plant to reduce the capital and fixed operating costs of facilities and auxiliary systems. Such a system could achieve at least partial economic self-sufficiency. Once it is in operation, relatively inexpensive tasks would be to vary the bed material and impregnate weeklong runs of feed coal, with potassium or other catalysts. The first step along this route would consist of site-specific feasibility studies to establish the costs and benefits of such demonstration plants. Preliminary calculations suggest that the capital cost of such a demonstration facility, assuming an air-blown gasifier, could be reduced by possibly $40 \%$, by using the marginal capacity of auxiliary components shared with the host power plant. Steam, cooling water, ash disposal, and feed handling and crushing would be services purchased from the host plant at variable cost, offset by sale to the utility of the product gas or electric power produced by a molten carbonate fuel cell. From an operability point of view, such a utility add-on demonstration unit should have a capacity of at least 40 tons per day. Depending on the financial structure of the project and the effectiveness of its integration with an existing electric utility, it is possible that such a partially subsidized operation could cost the funding agency no more than a fully subsidized, stand-alone pilot plant on the scale described above.

\subsection{BIBLIOGRAPHY}

Hauserman, W.B. "Catalytic Coal Gasification for Hydrogen Production, Pilot Plant Data and Scaleup Considerations: Final Semiannual Report," Jan. 1 - Jun. 30, 1992, EERC publication.

Hauserman, W.B. et al. "Production of Hydrogen and By-Products from Coal," semiannual technical progress report, Jul. 1 - Dec. 31, 1991, EERC publication.

Hauserman, W.B. et al. "Production of Hydrogen and By-Products from Coal," annual technical progress report, Jul. 1, 1989 - Jun. 30, 1990, EERC publication.

Meyers, S.A.; Tanner, A.L.; Moss, T.E. (Fluor-Daniel Inc.) "The Design of Gasifiers to Optimize Fuel Cell Systems: Final Report," Prepared for Energy Research Corporation, Oct. 1991 (sited here as result of parallel and continuing type of effort under related project).

Sears, R. et al. "Pilot-Scale Demonstration of Producing Hydrogen Using LowRank Coals," Int. J. Hydrogen Energy 1991, 16 (8), 521-529.

Sears, R. et al. "Production of Hydrogen from Low--Rank Coals: Hydrogen-fromCoal Continuous Process Unit Testing," topical report, USDOE Contract No. DE-FC21-86MC10637, Aug. 1989.

Sinor, J.E. "Production of Hydrogen from Low-Rank Coals: Industrial Market Assessment of the Hydrogen Produced from Low-Rank Coals," USDOE Contract No. DE-FC21-86MC10637, Ju1. 1988.

Stoddard, L.E. et al. (Black and Veatch Inc.) "Production of Hydrogen from Low-Rank Coals," final report for the period ending May 1, 1989, USDOE Contract No. DE-FC21-86MC10637, 1989. 
Timpe, R.C. et al. "Characterization of Gasification Coal Char," In Proceedings of the Seventh Annual International Pittsburgh Coal Conference; 1990.

Timpe, R.C. et al. "Production of Hydrogen from Low-Rank Coals: Char Properties and Reactivities," topical report, USDOE Contract No. DEFC21-86MC10637, EERC publication, May 1989. 


\subsection{Sulfur Forms in Coal}




\title{
SULFUR FORMS IN COAL
}

\author{
Final Technical Progress Report \\ for the Period July 1, 1990, to June 30, 1992
}

by

Dr. Steven B. Hawthorne, Research Supervisor

Ronald C. Timpe, Research Associate

Dr. Peter K.K. Louie, Research Associate

Energy and Environmental Research Center

University of North Dakota

Box 8213, University Station

Grand Forks, North Dakota 58202-8213

Task Contracting Officer's Representative: Dr. Jagdish Malhotra

for

U.S. Department of Energy

Office of Fossil Energy

Morgantown Energy Technology Center

P.0. Box 880 , MS CO4

Morgantown, West Virginia 26507-0880

December 1992

Work Performed under Cooperative Agreement No. DE-FC21-86MC10637 
LIST OF FIGURES ...................... . .

LIST OF TABLES .....................

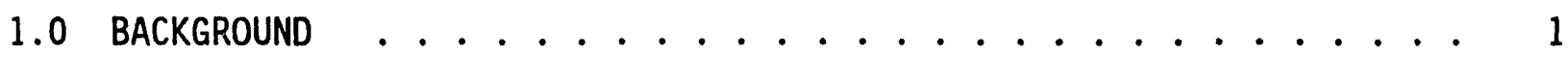

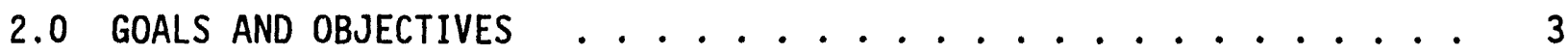

3.0 RESULTS . . . . . . . . . . . . . . . . . 5

3.1 GC/AED as a SuTfur-Specific Analytical Technique $\ldots 5$

3.2 Efficiency of Extraction and Trapping of Elemental Sulfur . . 6

3.3 Elemental Sulfur in Illinois Bituminous Coals and Lignite

3.4 Interconversion of Sulfur Forms . . . . . . . . 7

3.5 Correlation Between Elemental Sulfur and Total Sulfur .... 7

3.6 Correlation Between $S_{8}$ and Sulfatic Sulfur ........ 8

3.7 Correlation Between Elemental Sulfur and Pyritic Sulfur ... 8

3.8 Correlation Between Elemental Sulfur and Organic Sulfur . . . 8

3.9 Correlation Between Pyritic and Sulfatic Sulfur ....... 9

3.10 Effects of Coal Particle Size on SFE Kinetics ........ 9

3.11 Effect of High-Temperature Extraction on Acid-Extracted Coal 10

3.12 High-Temperature On-Line Extraction .......... 10

3.13 Effect of Chemical Reactants on SFE of Sulfur ........ 11

3.14 Sample Preparation for Stable Sulfur Isotope Experiments and Background Information Related to This Work ....... 11

3.15 Comparison of Forms of Sulfur Determined by Different Laboratories . . . . . . . . . . . . 13

3.16 Comparison of Elemental Sulfur Value Obtained by SFE and Other Existing Techniques ............ 14

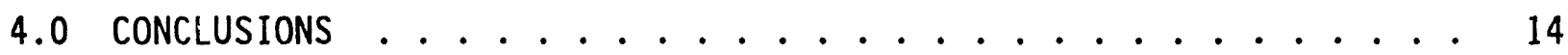

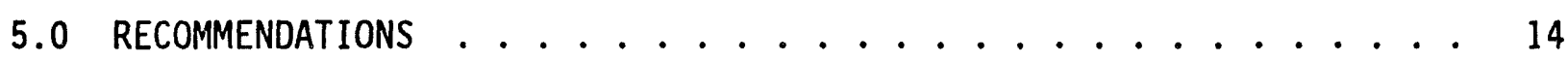

6.0 PRESENTATIONS AND PUBLICATIONS ................. 15

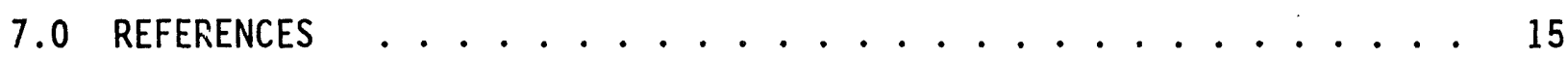




\section{LIST OF FIGURES}

Figure

Page

1 Schematic diagram of the SFE system for mixing and pumping

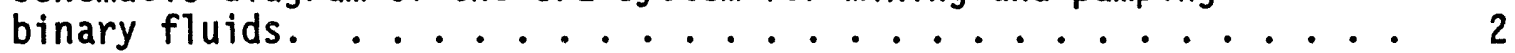

2 A typical GC/AED chromatogram of an SFE coal extract (IBC-101) showing the carbon $(193 \mathrm{~nm})$ and sulfur $(181 \mathrm{~nm})$ channels. . . . 6

\section{LIST OF TABLES}

Table

Page

1 Proximate and SUlfur Analyses of SFE Test Coals ... . . . . . 4

2 Sulfur Forms Analyses of Coal Samples Used in This Work . . . . . 5

3 Elemental Sulfur in a Suite of Coal Samples . . . . . . . . 8

4 Effect of Supercritical $\mathrm{CO}_{2}$ Extraction of Acid-Extracted IBC-101 at $450^{\circ} \mathrm{C} / 400 \mathrm{~atm} \ldots \ldots . \ldots 10 . \ldots 1 . \ldots 1 . \ldots$

5 Sulfur Isotopic Composition of Fractions Obtained from IBC-107 . . . . . . . . . . . . . . 13

6 Elemental Sulfur in Illinois Bituminous Coal Sample IBC-101 . . . 13 


\section{SULFUR FORMS IN COAL}

\subsection{BACKGROUND}

A major problem facing the coal industry now and in the future is high sulfur levels in coal, leading to unacceptable atmospheric $\mathrm{SO}_{2}$ concentrations and, in turn, resulting in environmental consequences from acid rain. Currently, three solutions to this problem are occasionally used. The first is the most obvious: that is, to stop using high-sulfur coal or dilute (blend) it with low-sulfur coal. This, however, is not easy when one considers that low-sulfur coal deposits are far from inexhaustible, and lowsulfur coals, especially low-sulfur bituminous coals, are becoming more difficult to find. Fuel switching from coal to natural gas or fuel oil is also considered a viable option (1). The second solution is postcombustion flue gas scrubbing with reagents to remove sulfur species. This is expensive, with less-than-excellent efficiency, and produces additional waste for disposal. Even so, the scrubbed generating capacity in this country is expected to increase by $43 \%$ over the next eight years (1). A third solution, that is, precombustion sulfur removal, is occasionally used. Physical cleaning-such as washing, froth flotation, selective agglomeration, magnetic separation, and solvent extraction-remove some pyrite and other inorganic sulfur forms. Chemical cleaning-such as acid washing and molten caustic leaching-remove some "organic" sulfur as well as inorganic sulfur. None of these methods remove the quantities necessary to reduce the sulfur in a medium- or high-sulfur coal to the desired level (1.2-1b S/MM Btu) in a manner that is feasible. In order to develop a successful method of removing sulfur from coal or char prior to combustion, the chemistry of removal must be elucidated. An improved method of chemical analysis of coal is the first step in that direction.

The accurate and precise analysis of a solid material, such as coal, requires that the analytical method utilize energy, solvent, or reagent that can effectively permeate the matrix and contact the element of interest. Physicochemical barriers preventing such contact have proven formidable when attempting sulfur analysis of solid coal by conventional technologies. Analysis of coal for sulfur by volatilization of sulfur moieties is limited by their volatilities and vapor transport through the matrix, and liquid extraction of those moieties is limited by conventional solubility and permeability. Chemical derivatization for ${ }^{13} \mathrm{C}$ nuclear magnetic resonance (NMR) spectroscopy is reagent transport 1 imited, ${ }^{33} S$ NMR is 1 imited by absorption bandwidth, and $x$-ray techniques are 1 imited to surface analysis by the inability to penetrate the solid more than a few angstroms. Given these drawbacks, a technique that would allow solvent penetration into the entire sample and dissolution of the sulfur species, with the ability to obtain those species intact in a form that can be identified and quantified by conventional analytical methods, would advance sulfur science immeasurably.

A method that might provide the desired improvement is supercritical fluid extraction (SFE). SFE as a separations method is superior to the other extraction methods, including Soxhlet extraction. Because of the relatively poor mass transfer in liquids, liquid solvent extractions are inherently slow. Compared to liquid solvents, supercritical fluids have several characteristics that make them attractive extraction solvents as well as media for selective 
reactions. First, supercritical fluids have solvent strengths similar to those of liquid solvents, but, in contrast to liquid solvents, they have lower viscosities $\left(10^{-4}\right.$ versus $\left.10^{-3} \mathrm{~N}-\mathrm{sec} / \mathrm{m}^{2}\right)$ and higher solute diffusivities $\left(10^{-4}\right.$ versus $10^{-5} \mathrm{~cm}^{2} / \mathrm{sec}$ ), which greatly improve mass transfer and greatly reduce the time for quantitative extractions (and reactions) to be performed. Second, the polarity of a supercritical fluid changes with its density as described by several correlations (2-4), including the simple empirical correlation proposed by Giddings $(5): \delta=1.25 P_{c}^{1 / 2}\left(\rho / \rho_{1}\right)$, where $\delta$ is the Hildebrand solubility parameter, $P_{c}$ is the critical pressure of the fluid, $\rho$ is the density of the supercritical fluid, and $\rho_{1}$ is the density of the fluid in its liquid state. As shown by these correlations, the selectivity of a supercritical fluid for a target analyte can be optimized by simply controlling the extraction pressure (and, to a lesser extent, the temperature). Supercritical fluids are also available that have widely varying polarities ranging from low-polarity fluids (e.g., ethane) to moderately polar fluids (e.g., $\mathrm{CO}_{2}$ ) to polar fluids (e.g., water), which, along with pressure and temperature control, gives the analyst an extremely wide range of extraction solvent polarities to perform selective extractions. Modifiers can be added to the fluid to change its polarity. Figure 1 is a schematic of SFE system for mixing fluids. Third, in contrast to popular belief, analytical-scale (not process-scale) SFEs are experimentally simple and inexpensive to perform, requiring small samples and resulting in minimal waste.

Preliminary investigations into utilizing supercritical $\mathrm{CO}_{2}$ combined with pyrolysis to extract organic sulfur from an Indiana bituminous coal were very

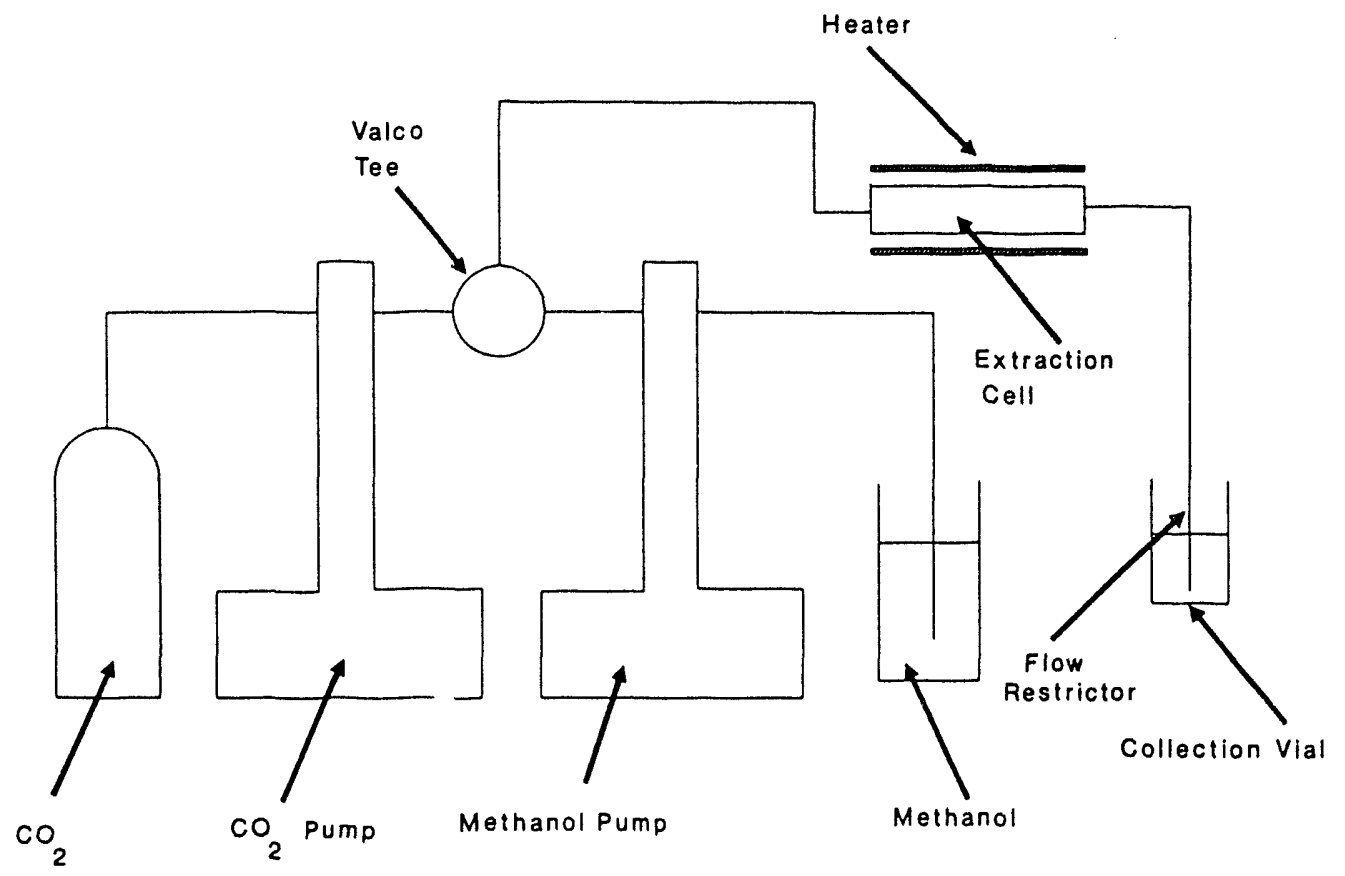

Figure 1. Schematic diagram of the SFE system for mixing and pumping binary fluids. 
encouraging; i.e., this procedure reduced the organic sulfur content by ca. $50 \%$ and thus correlated well with the results of liquid solvent extractions. Unfortunately, while more than 50 organic sulfur compounds were identified in the supercritical $\mathrm{CO}_{2}$ extract, these species could not quantitatively account for the extracted organic sulfur. Some evidence that the "missing" extracted organic sulfur compounds were quite volatile sulfur forms was obtained using a simple and reliable method, developed and validated in our laboratory, for directly coupling Thermogravimetric Analysis with mass spectrometry (TGA/MS).

Equipment capable of tolerating the rigors of SFE conditions at temperatures from ambient to $450^{\circ} \mathrm{C}$ was investigated as a means of extracting organic sulfur compounds. Cell heaters capable of the required range of temperatures and designed with safety in mind, but not commercially available, were built at the EERC. Sample cells were initially fabricated from stainless steel tubing and Swagelock and Parker fittings and found to be satisfactory when tested at the most rigorous of expected operating conditions. This past year, however, commercial cells made by Keystone ${ }^{T M}$ were obtained that have proven to be a superior substitute for the home-built cells and are currently being used for the SFEs.

Several collection solvents were screened and toluene was selected on the basis of its superior collection efficiencies and gas chromatography (GC) characteristics.

Extraction with supercritical $\mathrm{CO}_{2}$ at $\mathrm{ca} .45^{\circ} \mathrm{C}$ and $400 \mathrm{~atm}$ was shown to be selective toward removal of elemental sulfur, primariiy $S_{B}$. The extraction kinetics for removal of elemental sulfur were improved with $\mathrm{CHCl}_{2} \mathrm{~F}$ (Freon 22) or $\mathrm{CO}_{2} / 10 \% \mathrm{CH}_{3} \mathrm{OH}\left(\mathrm{CO}_{2}\right.$ with methanol as a modifier $)$, reducing extraction time to less than 20 minutes.

Good agreement of GC/MS data for the concentration of elemental sulfur in coal using two independent techniques (a selective triphenylphosphine reaction and selective SFE) was achieved early on in this project. The addition of the atomic emission detector (AED) and a Siever's sulfur-specific detector (SCD) provided a more convenient means of analyzing supercritical fluid extracts specifically for sulfur. Component separation by GC with detection and quantitation of sulfur species by AED minimizes the usual chromatographic complications caused by large numbers of components and coelution of compounds of interest with extraneous compounds.

Validation of the technique was initiated with preliminary spiking experiments involving $S_{8}$ on sand and glass beads. The results showed that extraction of elemental sulfur with $\mathrm{SF} \mathrm{CO}_{2}$ was reproducible.

\subsection{GOALS AND OBJECTIVES}

The overall objective of this project was to develop methodology to enable the rapid and accurate identification and quantitation of sulfur species in what is now referred to as the organic sulfur component of coal. To accomplish this, the following specific objectives must be met:

- To investigate and develop the use of SFE and pyrolysis/SFE (PYR/SFE) for the selective extraction of organic forms from coal. 
- To identify and quantitate the individual sulfur organics recovered using SFE procedures.

- To investigate and develop the use of selective pyrolysis and/or chemical oxidation/reduction for the determination of organic sulfur forms in coal.

- To evaluate and incorporate other promising sulfur speciation techniques.

\section{Coals}

Heavily studied and well-characterized medium-sulfur coals were selected as the bases for this research program. Four coals from the Illinois Basin Coal Sample Program at the Illinois State Geological Survey were obtained: IBC-101, which served as the basis of the SFE methods development program; IBC-102, IBC-106, IBC-107, which served as the basis for mechanism studies involving sulfur form transformations as determined by stable sulfur isotope analysis; and IBC-109. Additional coals, an Alaskan subbituminous, a North Dakota lignite, and an Indiana bituminous, were analyzed in selected experiments. The analyses of these coals are shown in Table 1.

The sulfur analyses shown in Table 1 include results that accompanied the IBC samples; results obtained at the EERC with a LECO sulfur analyzer; and results obtained from an independent commercial laboratory, Minnesota Valley Testing Laboratory (MVTL). Table 2 contains the ASTM sulfur forms analyses results on the same coals. Although some of these values appeared in the

TABLE 1

Proximate and Sulfur Analyses of SFE Test Coals

\begin{tabular}{|c|c|c|c|c|c|}
\hline Coal Samples: IBC- & 101 & 102 & 106 & 107 & 109 \\
\hline $\begin{array}{l}\text { Moisture } \\
\text { Volatile Matter } \\
\text { Fixed Carbon } \\
\text { Residue }\end{array}$ & $\begin{array}{r}10.20 \\
36.12 \\
44.69 \\
9.01\end{array}$ & $\begin{array}{r}8.28 \\
35.75 \\
50.90 \\
5.08\end{array}$ & $\begin{array}{r}6.41 \\
37.03 \\
48.82 \\
7.72\end{array}$ & $\begin{array}{r}5.31 \\
37.51 \\
46.01 \\
11.19\end{array}$ & $\begin{array}{r}3.58 \\
33.56 \\
54.34 \\
8.55\end{array}$ \\
\hline $\begin{array}{l}\text { Total Sulfur } \\
\text { EERC } \\
\text { IBCSP } \\
\text { MVTL } \\
\end{array}$ & $\begin{array}{l}4.13 \\
4.36 \\
4.44 \\
\end{array}$ & $\begin{array}{l}3.35 \\
3.30 \\
3.27 \\
\end{array}$ & $\begin{array}{l}3.53 \\
3.77 \\
3.68 \\
\end{array}$ & $\begin{array}{l}3.54 \\
3.72 \\
3.59 \\
\end{array}$ & $\begin{array}{l}1.13 \\
1.13 \\
1.00 \\
\end{array}$ \\
\hline Coal Samples: & \multicolumn{2}{|c|}{ Alaska } & \multicolumn{2}{|c|}{ ND Lignite } & \\
\hline $\begin{array}{l}\text { Moisture } \\
\text { Volatile Matter } \\
\text { Fixed Carbon } \\
\text { Residue }\end{array}$ & \multicolumn{2}{|c|}{$\begin{array}{r}17.01 \\
37.89 \\
40.21 \\
4.88\end{array}$} & \multicolumn{2}{|c|}{$\begin{array}{r}26.70 \\
30.20 \\
36.31 \\
6.75\end{array}$} & \\
\hline $\begin{array}{l}\text { Total Sulfur } \\
\text { EERC } \\
\text { MVTL }\end{array}$ & \multicolumn{2}{|c|}{$\begin{array}{l}0.19 \\
0.14 \\
\end{array}$} & \multicolumn{2}{|c|}{$\begin{array}{l}0.80 \\
0.87 \\
\end{array}$} & \\
\hline
\end{tabular}

- Total sulfur values determined by the EERC.

- Total sulfur values determined by MVTL laboratories, Inc., Bismarck, ND. 
TABLE 2

Sulfur Forms Analyses of Coal Samples Used in This Work

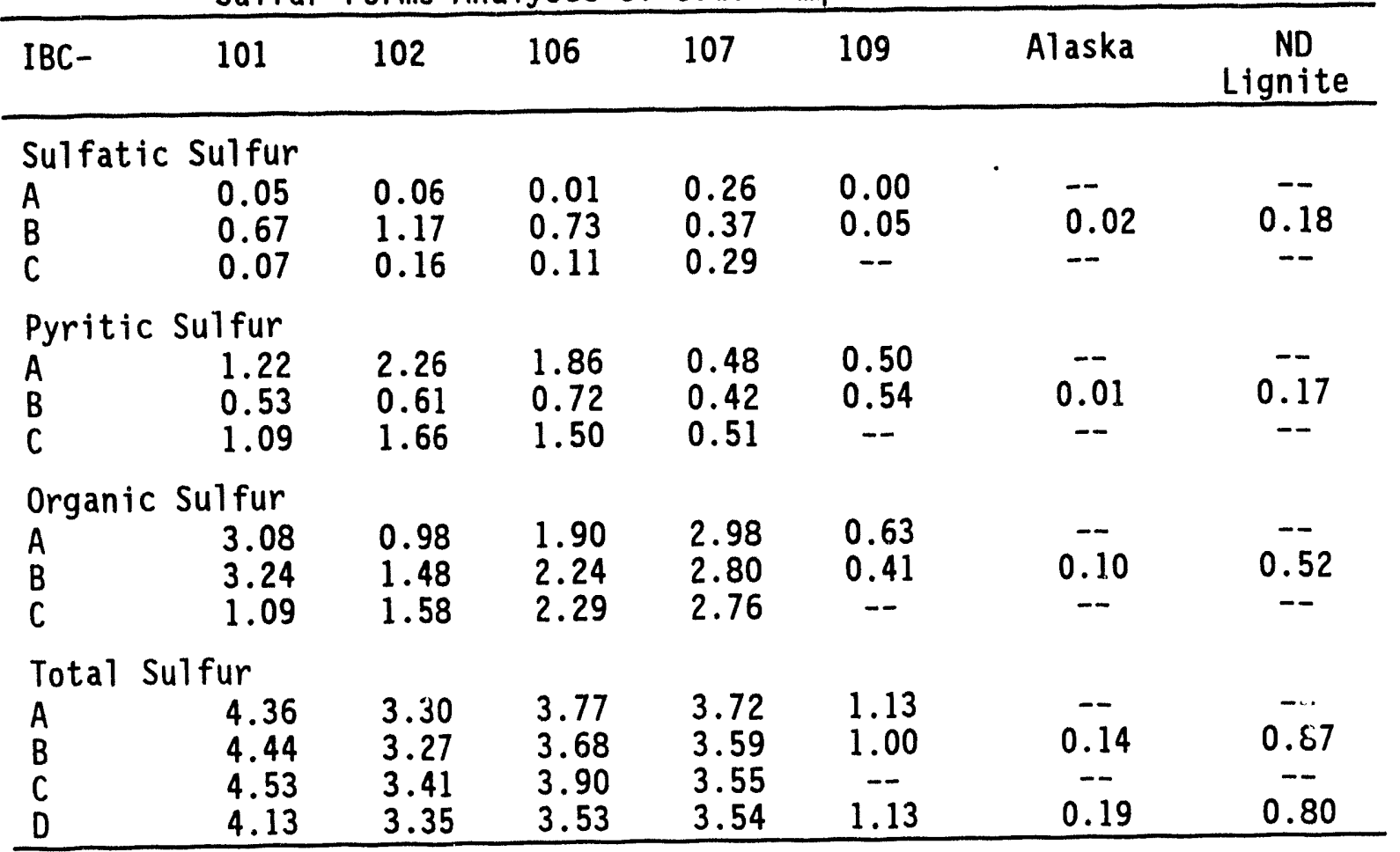

A Data after Illinois Basin Coal Sample Program.

B MVTL Laboratories, Inc., Bismarck, ND (12/9/91).

C MVTL Laboratories, Inc., Bismarck, ND (9/21/90).

D EERC.

previous reports, they are included here again for the convenience of the interested reader. Most of the work in this period was carried out with IBC-101, some with IBC-102, and only selected tests with the remainder of the coals.

\subsection{RESULTS}

\subsection{GC/AED as a Sulfur-Specific Analytical Technique}

The analysis of extracts from SFEs of coal required an analytical technique that has demonstrated reliability in terms of accuracy and precision. The reliability of the GC/MS is well-known and needs no further comment. The performance of the GC/AED and its application in sulfur species determination have been described by Sullivan and Quimby (6) and Tillota and others (7). Besides being accurate and precise, this analytical system requires a small sample size and generates minimal waste and, therefore, was the technique of choice for the analyses of SF extracts.

A typical chromatogram of coal extract analyzed by GC/AED with sulfur and carbon channels detected at 181 and 193 nanometers $(\mathrm{nm})$, respectively, is given in Figure 2. The absence of a corresponding carbon peak with the 

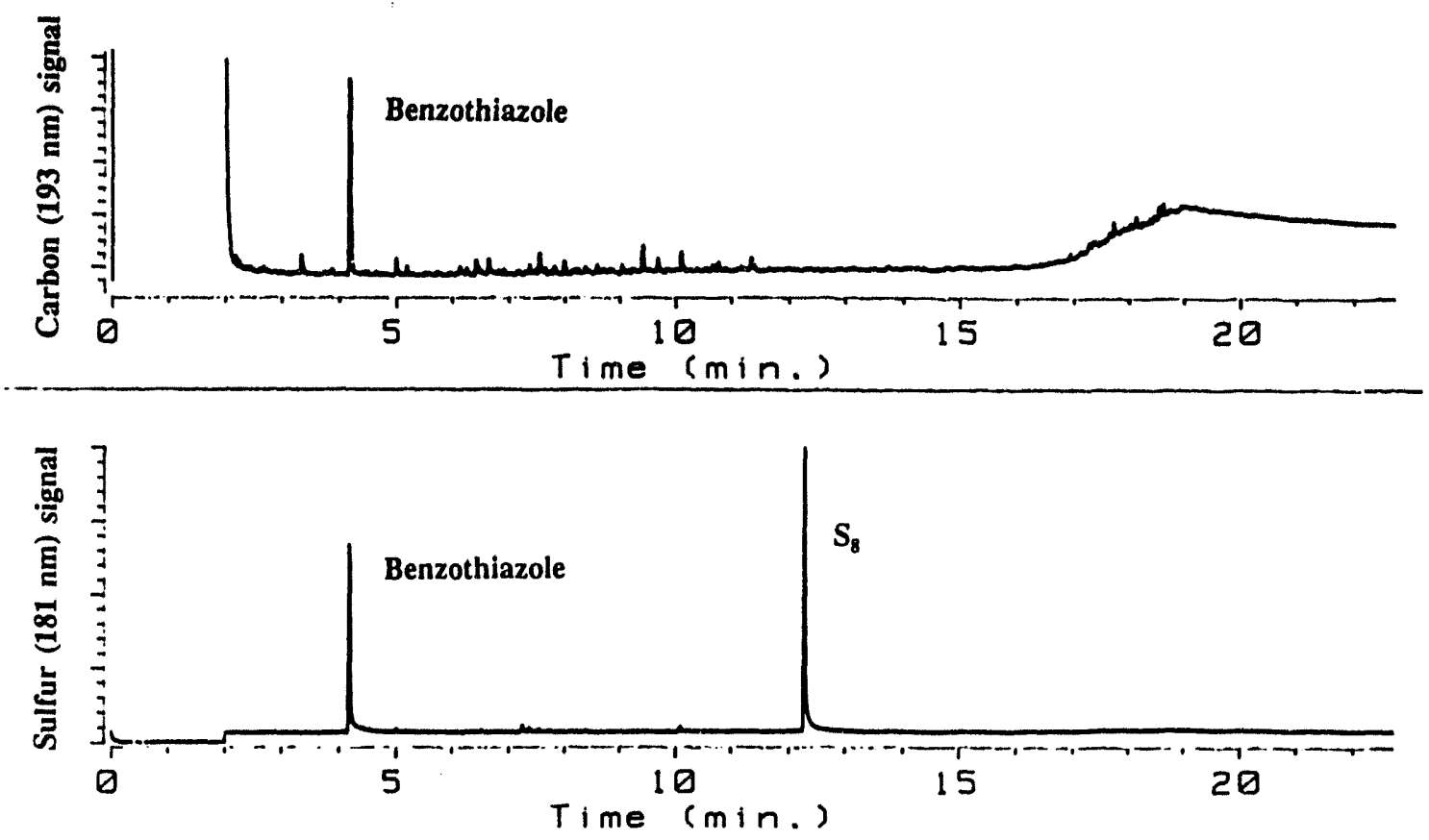

Figure 2. A typical GC/AED chromatogram of an SFE coal extract (IBC-101) showing the carbon $(193 \mathrm{~nm})$ and sulfur $(181 \mathrm{~nm})$ channels.

elemental sulfur detected indirectly confirmed, while GC/MS directly confirmed, the identity of the elemental sulfur peak. Elemental sulfur can be determined quantitatively by adding a known amount of internal standard, benzothiazole, to the coal extract prior to the GC/AED sulfur determination. Linear calibration curves of the GC/AED with elemental sulfur in toluene covering the concentration range between 10 to $1000 \mu \mathrm{g} / \mathrm{mL}$ were obtained. The correlation coefficient $\left(R^{2}\right)$ of the calibration curve was 0.9992 .

\subsection{Efficiency of Extraction and Trapping of Elemental Sulfur}

Elemental sulfur-spiked sea sand extractions and elemental sulfur extraction kinetics experiments reported earlier (8) indicated that elemental sulfur can be extracted and determined by using SFE followed by GC/AED analysis. Further investigation into aspects of removing elemental sulfur from the coal matrix was warrarited in this suite of experiments in order to confirm that elemental sulfur can be extracted quantitatively fr'sm coal in its native form and no sulfur forms transformation occurred during che SFE step.

Elemental sulfur spike recovery experiments were performed with preextracted IBC-101 coal (-200 mesh) to assess the efficiencies of elemental sulfur removal and its subsequent trapping with toluene. Blank extractions of 
the preextracted coal matrix used in this spiking runs were carried out as a check, and no detectable amount of elemental sulfur was found.

Quadruplicate elemental spiking experiments were performed to determine the efficiency and reproducibility of the SFE and resulted in an average of $96 \%$ recoveries. The high percentage of elemental sulfur recoveries from these spiking experiments demonstrated that the SFE/GC/AED extract analysis technique is capable of quantitatively determining elemental sulfur from the coal matrix.

The sulfur extractions from preextracted coal al so showed that elemental sulfur is not an artifact of the extraction process. It is unlikely that elemental sulfur was formed during the SFE since essentially all the spiked elemental sulfur was recovered and further blank extraction of the preextracted coal did not yield further elemental sulfur. Similarly, it is unlikely that additional sulfur is formed as the result of transformation of pyrite in coal to ferrous sulfide and elemental sulfur, since that reaction generally begins at $450^{\circ}$ to $500^{\circ} \mathrm{C}(9)$, while the extractions were performed at only $110^{\circ} \mathrm{C}$.

\subsection{Elemental Sulfur in Illinois Bituminous Coals and Lignite Samples from Alaska and North Dakota}

The method was further evaluated by extracting elemental sulfur from a suite of coal samples which included Beulah (North Dakota) and Alaskan lignite and IBC-101, IBC-102, IBC-106, IBC-107, and IBC-109 bituminous coals with SF $10 \%$ methanol $/ \mathrm{CO}_{2}$ at $110^{\circ} \mathrm{C}$ and $400 \mathrm{~atm}$. The amounts of elemental sulfur in these selected coal samples determined by SFE/AED ranging from 2 to $3500 \mu \mathrm{g} S_{8} / g$ (coal) are given in Table 3. Apart from the Alaskan lignite sample, the relative standard deviations (RSDs) associated with the elemental sulfur determinate are generally very good, demonstrating that SFE followed by GC/AED yields the precision necessary for an analytical method for extracting elemental sulfur from coal.

\subsection{Interconversion of Sulfur Forms}

Information regarding possible interconversion of sulfur forms is another important result of this study. With the sulfur forms data provided by the Illinois Basin Coal Sample Program (IBCSP) and analyses performed by MVTL Laboratories, Inc. (Table 2), together with the elemental sulfur values determined in a suite of coal samples (Table 3 ), some preliminary correlations relating sulfur forms in coal can be made.

\subsection{Correlation Between Elemental Sulfur and Total Sulfur}

Correlations were sought between weight percent elemental sulfur and weight percent total sulfur from data provided by IBCSP and MVTL for the suite of coals investigated. A similar comparison was done for Alaskan subbituminous and North Dakota lignite from data determined by MVTL. There were no apparent correlations between elemental sulfur and total sulfur in coal when using either the total sulfur results from either IBCSP or MVTL. 
TABLE 3

Elemental Sulfur in a Suite of Coal Samples

\begin{tabular}{lcr}
\hline Sample & $\mu g\left(S_{8}\right) / g(\text { coal })^{\circ}$ & \%RSD \\
\hline Alaska & $2.0 \pm 0.3$ & 13.9 \\
Beulah & $128 \pm 4$ & 3.3 \\
IBC-101 & $1100 \pm 60$ & 5.7 \\
IBC-102 & $3500 \pm 75$ & 2.1 \\
IBC-106 & $2000 \pm 32$ & 1.6 \\
IBC-107 & $490 \pm 23$ & 4.6 \\
IBC-109 & $26 \pm 1$ & 5.0 \\
\hline
\end{tabular}

- moisture-free basis

\subsection{Correlation Between $S_{8}$ and Sulfatic Sulfur}

No apparent correlation was found between elemental sulfur measured with SFE and the sulfatic sulfur value provided by IBCSP. However, the same elemental sulfur values correlate well with sulfatic sulfur value provided by MVTL. There are significant increases in sulfatic sulfur values of all the Illinois Basin Coal samples, as determined by MVTL, compared with values provided by the IBCSP. This is explained by coal sulfur oxidation that occurs during weathering and is consistent with one of the current coal sulfur oxidation mechanisms which suggests that sulfatic sulfur is one of the products formed when the pyritic sulfur in coal is oxidized. The magnitude of sulfatic sulfur increase is most noticeable with samples IBC-101, IBC-102, and IBC-106, where the weight percent increases are $0.62,1.11$, and 0.72 coal wt\%, respectively.

\subsection{Correlation Between Elemental Sulfur and Pyritic Sulfur}

Elemental sulfur correlates well with pyritic sulfur values provided by IBCSP. The correlation between elemental sulfur and pyritic sulfur by using the MVTL values is not as good as the one using IBCSP values. Nevertheless, a nonlinea: increase of elemental sulfur as a function of weight percent of pyriti: sulfur in a coal pattern can be found in both correlation graphs. Apart from sample IBC-109, a noticeable reduction of pyritic sulfur values can be in with samples IBC-101, IBC-102, IBC-106, and IBC-107. This pyritic sulfy reduction not only is consistent with the current coal sulfur oxidation mechanisms, which suggests that pyritic sulfur is oxidized, the products being sulfatic and elemental sulfur, but also corresponds to the increase of sulfatic sulfur present in the coal samples as described above.

\subsection{Correlation Between Elemental Sulfur and Organic Sulfur}

There are no apparent correlations between elemental sulfur and the weight percent of organic sulfur of either the IBCSP or MVTL for the coal samples, suggesting that interconversion of organic to elemental sulfur is not a major pathway. 


\subsection{Correlation Between Pyritic and Sulfatic Sulfur}

There is no obvious correlation shown between pyritic and sulfatic sulfur contents in a coal sample. However, the reduction of pyritic sulfur in a coal is accompanied by a corresponding increase in sulfatic sulfur. Samples IBC-101, IBC-106, and IBC-107 showed a reasonably linear correlation between the two sulfur forms. Samples IBC-102 and IBC-109, however, did not. The sulfatic sulfur value for sample IBC-102 appears to increase significantly more than the rest of the samples, while only a small increase in sulfatic sulfur value was found in sample IBC-109. The higher sulfatic value of sample IBC-102 may be explained by its high initial pyritic sulfur, some of which may have been already partially oxidized, though not completely, to sulfatic sulfur. The small increase seen in sample IBC-109 may be attributed to competition for oxygen between organic sulfur and pyritic sulfur resulting in loss of $\mathrm{SO}_{\mathrm{x}}$ from the organic fraction rather than formation of sulfate.

\subsection{Effects of Coal Particle Size on SFE Kinetics}

Particle-size distributions of coal sample IBC-101, ground to pass -60 mesh $(250 \mu \mathrm{m}),-100$ mesh $(149 \mu \mathrm{m})$, and -200 mesh $(74 \mu \mathrm{m})$ for this study, were investigated by the Malvern particle-size test. The distribution pattern determined by the Malvern test appears to agree well with the expected pattern.

Coal samples IBC-101, IBC-102, IBC-106, IBC-107, Alaskan lignite, and North Dakota lignite were subjected to the Malvern particle-size test and found to have defined and consistent patterns.

Kinetics extractions of elemental sulfur from coal with $10 \%$ methanol $/ 90 \%$ $\mathrm{CO}_{2}$ at $110^{\circ} \mathrm{C}$ and $400 \mathrm{~atm}$ were performed with coal particle sizes ground to pass $-60-,-100-,-200$-mesh sizes. The cumulative amounts of $S_{8}$ extracted versus time normalized with elemental sulfur values obtained from five individual extractions on the three particle sizes $(-60,-100,-200$ mesh, ground under a stream of argon) of sample IBC-10I indicated that the two smallest coal particle sizes $(-200$ and -100$)$ were slightly faster than the -60-mesh size. However, after 30 minutes of SFE, essentially all of the extractable elemental sulfur on the coal matrix was removed regardless of particle size. This suggests that the elemental sulfur extracted is likely to be at the surface of the coal particles. In addition, since no significant increase of elemental sulfur was extracted with the smallest coal particle size, the amount of elemental sulfur within the coal mairix is negligible.

Five individual 30-minute extractions of $-2.00-,-100$-, and -60 -mesh IBC-101 by $\mathrm{SF} \tilde{\mathrm{c}}$ with $10 \%$ methanol/ $\mathrm{CO}_{2}$ at $110^{\circ} \mathrm{C}$ and 400 atm were performed to determine the reproducibility of the SFE method to extract and quantify elemental sulfur. The RSDs of elemental sulfur determined in coal sample IBC-101 with particle sizes of $-60,-100$, and -200 mesh were $6.1,3.4$, and 5.7 , respectively. There were essentially no significant differences in the amount of elemental sulfur extracted from the three particle sizes used, further demonstrating that the amount of elemental sulfur removal after 30 minutes of SFE is independent of coal particle size. 


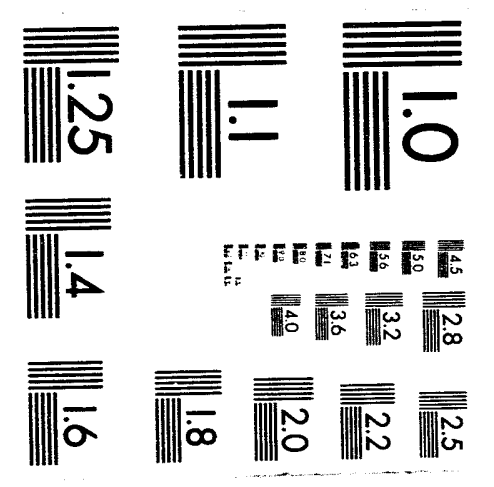



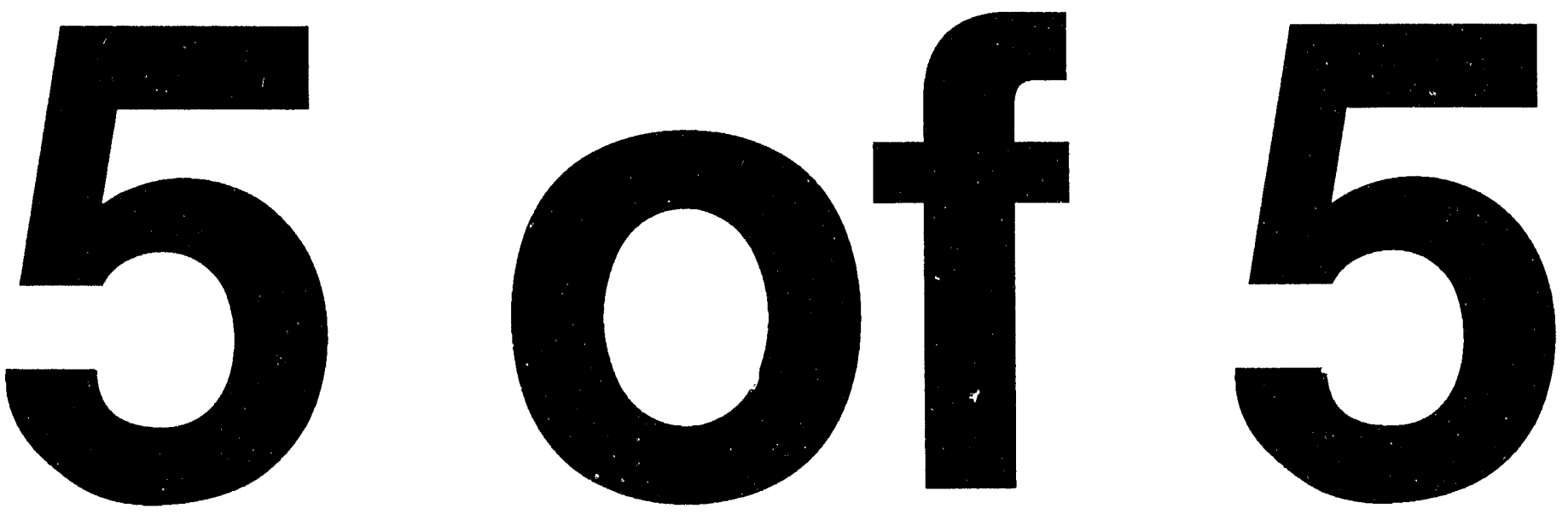


\subsection{Effect of High-Temperature Extraction on Acid-Extracted Coal}

Supercritical fluid extraction (SFE) of organic sulfur from bituminous coal was studied using $\mathrm{SF} \mathrm{CO}_{2}$ to extract organic sulfur from a coal that had inorganic sulfur removed by the Riley method described above. Total sulfur analysis results of the acid-extracted residues before and after SFE are shown in Table 4. The sulfur extracted, calculated on acid-extracted coal basis, ranged from $38 \%$ to $47 \%$ in three experiments, indicating that the method enabled the removal of nearly one-third to one-half of the "true" organic sulfur. Periodic envelopes of true organosulfur compounds can be seen by overlaying the sulfur chromatograms. Individual compounds have not yet been identified.

\section{TABLE 4}

Effect of Supercritical $\mathrm{CO}_{2}$ Extraction of Acid-Extracted IBC- 101 at $450^{\circ} \mathrm{C} / 400 \mathrm{~atm}$

\begin{tabular}{lccccc}
\hline Sample & Sample Wt & \multicolumn{4}{c}{ Wt\% Sulfur after SFE } \\
\hline & & As-Run & MF-Coal Basis & Removed & \% Removed \\
\cline { 2 - 6 } EX-203 & 0.4683 & 1.77 & 1.28 & 1.12 & 46.8 \\
EX-205 & 0.4673 & 2.01 & 1.45 & 0.95 & 39.5 \\
EX-206 & 0.4471 & 2.08 & 1.50 & 0.90 & 37.6 \\
& & \multicolumn{5}{c}{ Wt\% Sulfur Before SFE } \\
\cline { 2 - 5 } Raw Coal & & \multicolumn{5}{c}{4.36} \\
Acid-Extracted & & \multicolumn{5}{c}{2.40} \\
\hline
\end{tabular}

\subsection{High-Temperature On-Line Extraction}

On-line PYR/SFE/cryogenic trapping/GC with the mass spectrometer (MS) as a detector to analyze elemental sulfur-free IBC-101 reduced loss of sulfur compounds normally encountered in the solvent-trapping procedure, allowing the more volatile of the major gas chromatographable species to be identified. Total ion chromatograms showed all gas chromatographable components detected by the MS, resulting in many sulfur peaks buried under other organic compound peaks. AED chromatograms of non-sulfur-containing species were not seen on the sulfur chromatograms due to the different wavelengths monitored for each. Correlation of peaks in the sulfur chromatogram with those of the nonsulfur chromatogram showed which components are true organosulfur compounds. The AED information enables the sorting of peaks in the total ion chromatogram of the MS, which allows identification of individual sulfur compounds in the extract.

Sample IBC-101 bituminous coal was extracted with supercritical $10 \%$ methanol $/ \mathrm{CO}_{2}$ at $400 \mathrm{~atm}$ to remove elemental sulfur. Several fractions of the elemental sulfur-free IBC-101 were then extracted using the on-line method. Selected ion-current chromatograms showed the $C_{1}-C_{5}$ thiophenes, which make up a large portion of the volatile species. 
Several additional sulfur compounds along with benzene, phenol, toluene, indan, indene, and other polynuclear aromatics, were also identified. Again the thiophenes were identified, but ethylene sulfide, benzo[b]thiophene, dibenzothiophene, and thianthrene were prominent in the chromatogram.

\subsection{Effect of Chemical Reactants on SFE of Sulfur}

Methods of removai of sulfur tested included SFEs of IBC-101 under mild pyrolysis conditions with and without the presence of chemical reagents. Dynamic extractions with supercritical $\mathrm{CO}_{2}$ at $400 \mathrm{~atm}$ and $450^{\circ} \mathrm{C}$ in the absence of chemical reactant were successful in removing nearly 50 wt\% of the sulfur from the coal, while supercritical $10 \%$ methanol $/ \mathrm{CO}_{2}$ extraction under the same conditions was successful in removing nearly 60 wt $\%$ of the sulfur from the coal. Supercritical fluid extractions (SFE) of IBC-101 containing $50 \mathrm{wt} \%$ added $\mathrm{NaOH}$ at the same conditions as above resulted in sulfur removals of slightly more than $50 \mathrm{wt} \%$ for each of the fluids. Dynamic SFE of $50 \mathrm{mg}$ of IBC-101 spiked with $200 \mu \mathrm{L}$ of $85 \% \mathrm{H}_{3} \mathrm{PO}_{4}$ under the same conditions as the above resulted in $>60$ wt\% sulfur reduction when extracted with $10 \%$ methar $1 / \mathrm{CO}_{2}$ and $85 \mathrm{wt} \%$ reduction of sulfur when extracted with $\mathrm{CO}_{2} . \quad \mathrm{H}_{3} \mathrm{PO}_{4}$ solubility in $\mathrm{SF} 10 \%$ methanol $/ \mathrm{CO}_{2}$ was greater than in $\mathrm{SF} \mathrm{CO}_{2}$, as evidenced by the amount of $\mathrm{H}_{3} \mathrm{PO}_{4}$ in the extract. Therefore, the residence time of the acid in the reaction cell during a dynamic extraction was significantly shorter in the $10 \%$ methanol $/ \mathrm{CO}_{2}$ extraction, allowing for shorter reaction time and accounting for reduced sulfur removal.

Extraction of coal with supercritical water has several attractive aspects. Included in the list of attractive features are the environmental acceptability of water, the polar nature (though not near the polarity of the liquid) of water as a SF with respect to other commonly used fluids, the variety of modifiers available for use with water, the specific heat capacity of SF water, and the cost of the water. At the test conditions of the initial supercritical water extraction of $I B C-101,>50 \%$ by weight of the sulfur as measured on an absolute scale was extracted. Additional extractions and extraction strategies with SF water are planned.

\subsection{Sample Preparation for Stable Sulfur Isotope Experiments and Background Information Related to This Work}

The results of sulfur forms analyses shown in Table 2 indicate that sulfatic sulfur increases on prolonged ( $>6$ months) exposure to air. The pathway followed by the sulfur seems to be by way of pyritic sulfur oxidation, as also indicated by Table 2. A method of investigating the pathway has been designed using a coal (IBC-107) that has a natural sulfur probe, i.e., unusually high levels of stable ${ }^{34} \mathrm{~S}$ isotope, and is described below. The original coal and the residue of IBC-107 from the Riley acid extraction, with the high ${ }^{34} \mathrm{~S} /{ }^{32} \mathrm{~S}$, are excellent candidates for testing the potential for organic and pyritic sulfur conversion to elemental sulfur.

Coal IBC-107 was selected for stable sulfur isotope analysis because of the large isotopic difference of $\sim 22 \%$ between pyritic and organic sulfur (10). Because of this large isotopic difference, sulfur isotopic determination on the elemental sulfur obtained selectively by SFE may be applied to resolve the source of elemental sulfur in coal. Initially, two portions of $\sim 4.5 \mathrm{~g}$ of IBC-107 (-200-mesh size) coal were extracted with SF $10 \%$ 
methanol in $\mathrm{CO}_{2}$ in a $10-\mathrm{mL}$ Keystone extraction ceil fitted with a stainless steel restrictor for 2 hours. An additional 15-minute extraction was performed during which no elemental sulfur was extracted as determined by GC/AED. The large coal sample sizes extracted were necessary in order to obtain a sufficient quantity $(\sim 4 \mathrm{mg})$ of elemental sulfur for isotopic determination. About half of the SF extracted coal was extracted with nitric acid (11) to collect the pyritic and sulfatic sulfur from the coal. Another portion of the SF extracted coal was extracted by the Canfield technique (12) to obtain the pyritic sulfur in coal. Stable sulfur isotope determinations were performed on the seven coal extracts and residues by an experienced research group headed by Professor Simon Bottrell in Leeds, UK, using an established procedure with stable sulfur isotope MS. In addition, total sulfur determination on all of the five solid residues were carried out. Data from the stable isotope determinations coupled with the total sulfur values of the five solid residues and original coal samples provided information regarding sulfur forms transformation mechanisms in the coal matrix which should lead back to the original source of elemental sulfur in coal. Table 5 shows the data obtained from the stable sulfur isotope analyses.

The analytical values for organic sulfur in the residues following Riley and Canfield extractions were identical within the precision of the isotope measurement. The analyses of the inorganic sulfur fraction collected during each of the extractions are not the same, but the difference is easily explained. Whereas the Canfield method liberates sulfur as $\mathrm{H}_{2} \mathrm{~S}$ exclusively from metallic sulfides, the Riley method oxidizes metallic sulfides to sulfates which cannot be separated from inherent sulfate. The Canfield method, then, gives what is expected to be a more accurate estimate of pyritic sulfur by measuring the isotope ratio in the liberated $\mathrm{H}_{2} \mathrm{~S}$, while the inorganic sulfur in the Riley extract is determined from the total sulfate (sulfate and oxidized pyritic sulfur). In samples with low sulfate, the latter measurement fairly represents the pyritic sulfur, whereas in samples with high sulfate levels the sulfur in the Riley extract is interpreted as inorganic, but not exclusively pyritic sulfur.

Table 5 shows that the Riley acid extraction and the Canfield extraction separate the coal sulfur into fractions having nearly identical organic ${ }^{34} S /{ }^{32} S$ isotope ratios. The organic, pyritic, and total sulfur ratios compare favorably with those of other researchers (13). Interpretation of the data shown in Table 3 suggests that the elemental sulfur $(P L-2)$ is related to the inorganic sulfur, but is inconclusive as to whether the relationship is exclusive; i.e., the argument can also be made that both inorganic and organic sulfur contribute to the formation of elemental sulfur.

To expand on the above findings, two additional coals, IBC-102 and IBC-106, were prepared for sulfur stable isotope analysis. The preparation included SFE to collect the elemental sulfur from the coal and Riley extraction to remove inorganic sulfur from the SF extracted residue. The Canfield extraction was carried out on the SF extracted residue at the Stable Isotope Laboratory. These samples, along with raw coal, were sent to the Stable Isotope Analysis group in Leeds, UK, for analysis. 
TABLE 5

Sulfur Isotopic Composition of Fractions Obtained from IBC-107

\begin{tabular}{|c|c|c|c|}
\hline Sample & Preparation & $\delta^{34} S^{\circ} \%_{00}$ CDT & Error (\%) \\
\hline PL-1 & Parr bomb oxidation of total coal & +6.5 & \pm 0.2 \\
\hline PL-2 & $\begin{array}{l}\text { Parr bomb oxidation of } S_{8} \text { in SF extract } \\
\text { collected in toluene }\end{array}$ & +13.4 & \pm 0.2 \\
\hline$P L-3 x$ & $\begin{array}{l}\text { Pyrite sulfur extracted from PL-3 } \\
\text { by acidic chromous chloride. } \\
\text { (Canfield method) }\end{array}$ & +26.4 & \pm 0.4 \\
\hline$P L-3 r$ & $\begin{array}{l}\text { Organic } S \text { (residue from Canfield } \\
\text { extraction) by Parr bomb oxidation }\end{array}$ & +1.6 & \pm 0.2 \\
\hline PL-4 & Inorganic $S$ in Riley* extract of $\mathrm{PL}-3$ & +12.1 & \pm 0.2 \\
\hline PL-5 & $\begin{array}{l}\text { Organic } S \text { (residue from Riley } \\
\text { extraction) by Parr bomb oxidation }\end{array}$ & +1.5 & \pm 0.2 \\
\hline
\end{tabular}

*Boiling $2 \mathrm{~N} \mathrm{HNO}_{3}$ for 30 minutes.

\subsection{Comparison of Forms of Sulfur Determined by Different Laboratories}

Table 2 contains sulfur forms analysis results obtained from different laboratories. These values were obtained to represent the results of more conventional analyses in evaluating the SFE method and in the preliminary formulation of a mechanism to explain the occurrence of elemental sulfur in coal.

\section{TABLE 6}

Elemental Sulfur in Illinois Bituminous C \&l Sample IBC-101

\begin{tabular}{llll}
\hline $\begin{array}{c}\text { Extraction } \\
\text { Method }\end{array}$ & \multicolumn{1}{c}{$\begin{array}{c}\text { Analytical } \\
\text { Method }\end{array}$} & $\begin{array}{c}\text { Sulfur, } \\
\text { wt\% }\end{array}$ & \multicolumn{1}{c}{ References } \\
\hline Soxhlet & GC/Hall Detector & 0.07 & Duran and others, 1985 (14) \\
SFE & GC/AED & 0.11 & This work \\
Batch/PCE & GC/MS & 0.23 & Narayan and others, 1988 (16) \\
Soxhlet & GC/MS & 0.10 & Stock and. Wolny, 1990 (15) \\
Soxhlet & HPLC/Spectroscopic & 0.03 & Buchanan and others, 1989 (17) \\
& Bacteriological & 0.02 & Schicho and others, 1988 (18) \\
\hline
\end{tabular}

aPerchloroethylene extraction. 


\subsection{Comparison of Elemental Sulfur Value Obtained by SFE and Other Existing Techniques}

Elemental sulfur values of the IBC-101, -200-mesh size sample, together with the literature values, are given in Table 6 for comparison. There is good agreement of our data with Duran and others (14) and with Stock and Wolny (15). An original value of $1.54 \%$ elemental sulfur in the IBC-101 coal was provided by Narayan (16). However, further work performed by Narayan $(15,16)$ has led to the realization that results from the wrong coal sample may have inadvertently been reported, and a revised value of $0.23 \%$ was subsequently reported by Stock and Wolny (15), although it is unclear to the authors of this paper as to how this number was determined.

\subsection{CONCLUSIONS}

Pyrolysis of medium- to high-sulfur bituminous coals under inert (argon) gas up to $800^{\circ} \mathrm{C}$ removes an amount of sulfur approximately equivalent to the pyritic sulfur in the coal. Similar results are obtained when heating the coal in reducing atmospheres, such as hydrogen gas or syngas $\left(\mathrm{H}_{2} / \mathrm{CO}\right)$. The true organic sulfur is not easily removed by thermal means at ambient conditions. The ASTM sulfur forms method calls for direct measurement of total sulfur and sulfatic sulfur directly. However, the larger fractions of sulfur, i.e., pyritic and organic sulfur, are measured indirectly. Since the chemistries of reaction of these two fractions are substantially different, the design of a method for removal of sulfur from coal. is very difficult if error is made in categorizing sulfur forms. ASTM organic sulfur consists of true organic, elemental sulfur, and other acid-insoluble sulfur species. Therefore, a forms method that directly measures additional classes of sulfur compounds is needed. Elemental sulfur can be determined by SFE using $10 \%$ methanol $/ \mathrm{CO}_{2}$ at $110^{\circ} \mathrm{C}$ and 400 atm and analysis by GC/AED. Sulfatic sulfur can be determined by a gravimetric method. Canfield acid extraction removes pyritic sulfur, allowing the determination of true organic sulfur by sulfur analysis of the Canfield residue. Direct analysis of Canfield extract gives pyritic sulfur. Water, at supercritical conditions, removed up to $85 \%$ of the sulfur when extracting coal spiked with $\mathrm{H}_{3} \mathrm{PO}_{4}$.

\subsection{RECOMMENDATIONS}

1. SFE techniques-such as the elemental sulfur method developed in this project-are rapid, reliable, and reproducible with a relative standard deviation (RSD) of $\pm 5 \%$, and generate minimal waste. SFE with and without chemical reagents to differentiate and remove other sulfur forms, particularly organic, from coal should continue to be investigated.

2. Supercritical water has shown promise in removing sulfur from coal. Additional extractions of coal with SF water with and without reagents should be investigated.

3. Confirmation of forms analyses as they are developed is needed. Stable sulfur isotope analyses of fractions of IBC-101, IBC-102 and 
IBC-106 should be completed to determine whether this technique has such potential.

4. Investigation of sulfate sulfur by $\mathrm{HCl}$ extractions under several conditions and comparison of ASTM sulfate value with that of Canfield extraction.

\subsection{PRESENTATIONS AND PUBLICATIONS}

Eckert-Tilotta, S.E.; Hawthorne, S.B.; Miller, D.J. "Comparison of Commercially Available Atomic Emission and Chemiluminescence Detectors for Sulfur-Selective Gas Chromatographic Detection," J. Chrom. 1992, $591,313-323$.

Timpe, R.C.; Louie, P.K.K.; Miller, D.J.; Hawthorne, S.B. "Determination of Organic Sulfur Species in Coal by Supercritical Fluid Extraction," Pittsburgh Coal Conference, Oct. 1991.

Louie, P.K.K.; Timpe, R.C.; Hawthorne, S.B.; Miller, D.J. "Determination of Elemental Sulfur in Coal by Supercritical Fluid Extraction (SFE) and Fas Chromatography with Atomic Emission Detection (GC/AED), "Fuel, in press.

Louie, P.K.K.; Timpe, R.C.; Miller, D.J.; Hawthorne, S.B. "Determination of Elemental and Organic Sulfur in Coal Using Supercritical Fluid Extraction (SFE) and Pyrolysis/SFE," In Proceedings of the Pittsburgh Conference; 1992, New Orleans, LA, p 529.

\subsection{REFERENCES}

1. Sanda, A.P., Ed. "Coal in the News," Coal 1992, 97 (8), 5-19.

2. Allada, R.A. "Solubility Parameters of Supercritical Fluids," Ind. Eng. Chem. Process Res. Dev. 1984, 23, 344-348.

3. Rao, V.S.G.; Mukhopadhyay, M. "Effect of Covolume Dependency of the Energy Parameter on the Predictability of SCFE Data Using the PengRobinson Equation of State," J. Supercritical Fluids 1989, 2, 22-29.

4. Bartle, K.D.; Clifford, A.A.; Shilstone, G.F. "Prediction of Solubilities for Tar Extraction by Supercritical Carbon Dioxide," $J$. Supercritical Fluids 1989, 2, 30-34.

5. Giddings, J.C.; Myers, M.N.; McLaren, L.; Keller, R.A. "High Pressure Gas Chromatography of Nonvolatile Species," Science 1968, 162, 67-73.

6. Sullivan, J.J.; Quimby, B.D. Analytical Chemistry 1990, 62, 1034.

7. Eckert-Tilotta, S.E.; Hawthorne, S.B.; Miller, D.J. "Comparison of Commercially Available Atomic Emission and Chemiluminescence Detectors for Sulfur-Selective Gas Chromatographic Detection," J. Chrom. 1992, 591, 313-323. 
8. Hawthorne, S.B.; Timpe, R.C.; Miller, D.J. "Sulfur Forms in Coal," Semiannual Technical Progress Report for Jan.-Jun. 1991, Prepared for U.S. Dept. of Energy under Contract No. DE-FC21-86MC10637, EERC publication, Jul. 1991.

9. Khan, M.R. Prepr. Pap.--Am. Chem. Soc., Div. Fuel Chem. 1988, 33 (1), 253-264.

10. Kruse, C.W.; Harvey, R.D.; Rapp, D.M. In Processing and Utilization of High Sulfur Coals II; Chugh, T.P.; Caudle, R.D., Eds.; Elsevier: NY 1987 ; p 49.

11. Riley, J.T.; Ruba, G.M.; Lee, C.C. "Direct Determination of Total Organic Sulfur in Coal," In Geochemistry of Sulfur in Fossil Fuels; Orr, W.L.; White, C.M., Eds.; ACS Symposium Series 429, American Chemical Society, Washington, D.C., 1990.

12. Canfield, D.E.; Raiswell, R.; Westrich, J.T.; Reaves, C.M.; Berner, R.A. "The Use of Chromium Reduction in the Analys is of Reduced Inorganic Sulfur in Sediments and Shales," Chemical Geology 1986, 54, 149-155.

13. Hackley, K.C.; Liu, C.L.; Coleman, D.D.; Kruse, C.W. In Advances in Coal Spectroscopy; Meuzelaar, H.L.C., Ed.; Plenum Press: NY, 1992; p 91.

14. Duran, J.E.; Raymahasay, S.; Stock, L.M. Fue7 1985, 65, 1167-1168.

15. Stock, L.M.; Wolny, R. In Processing and Utilization of High Sulfur Coals II; Orr, W.L.; White, C.M., Eds.; ACS Symposium Series 429, 1990.

16. Narayan, R.; Kullerud, G.; Wood, K.V. Prepr. Pap.--Am. Chem. Soc., Div. Fuel Chem. 1988, 33 (1), 193-197.

17. Buchanan, D.H.; Coombs, K.; Murphy, P.M.; Chaven, C.; Hackley, K.C.; Kruse, C.W. In Proceedings of the Fourteenth Annual EPRI Fuel Science Conference; Electric Power Research Institute: Palo Alto, CA, 1989.

18. Schico, R.N.; Brown, S.H.; Kelly, R.M.; 01 son, G.J. Prepr. Pap.--Am. Chem. Soc., Div. Fuel Chem. 1988, 33 (4), 554-560. 

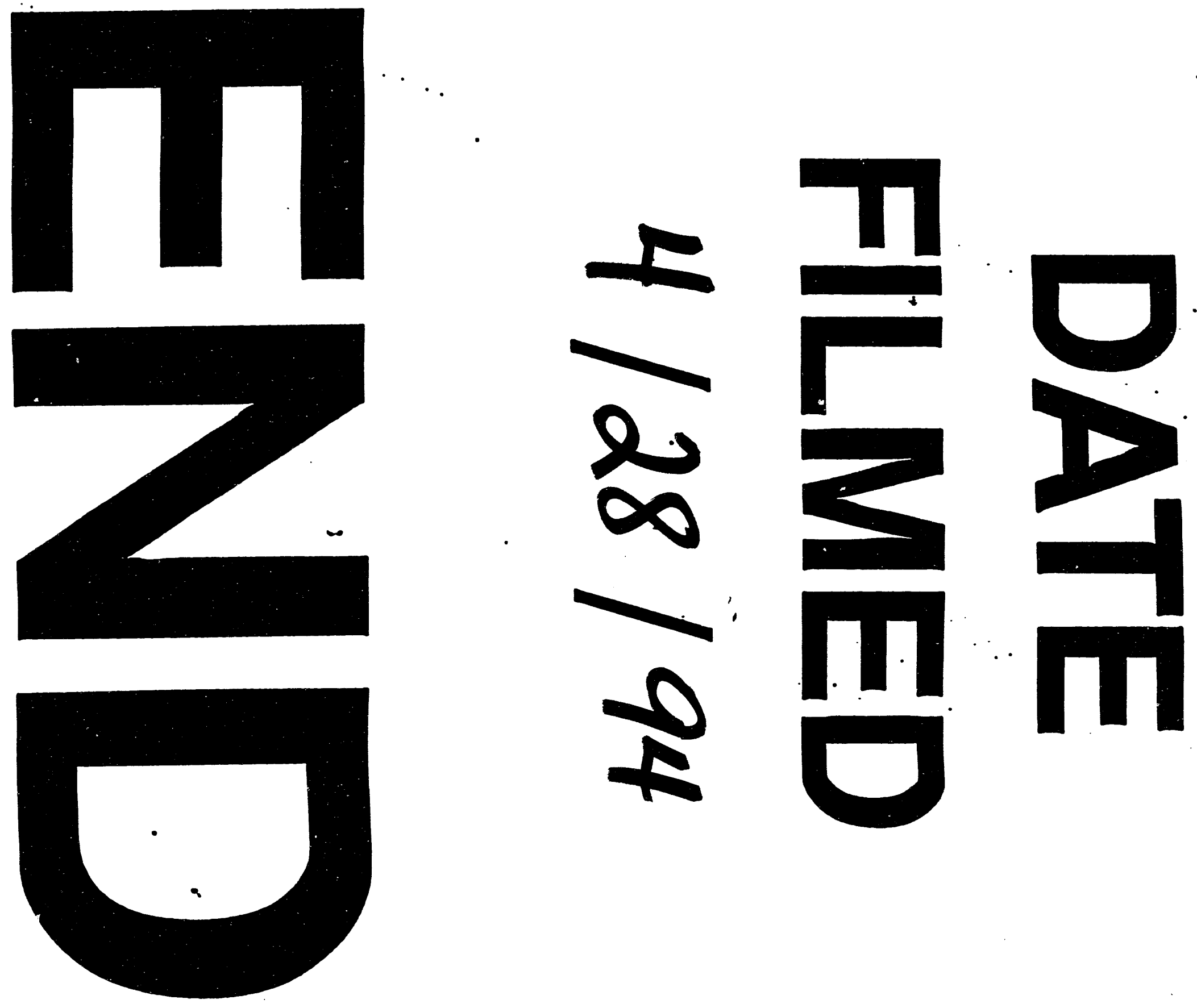
